\title{
Nationale und regionale Identität von Fernsehprogrammen. Eine Analyse der Programminhalte von ZDF, ORF 2, BR und MDR.
}

\author{
Dissertation \\ zur Erlangung des Doktorgrades \\ der Sozialwissenschaftlichen Fakultät \\ der Georg-August-Universität Göttingen \\ Vorgelegt von \\ Holger Ihle \\ geboren in Leipzig.
}

Göttingen, 2011 


\section{Betreuungsausschuss}

Erstbetreuer: $\quad$ Professor Dr. Jörg Aufermann

Weitere Betreuer: Dr. Wilfried Scharf

Professor Dr. Helmut Volpers

Tag der mündlichen Prüfung: 13. Mai 2011 


\section{Gliederung}

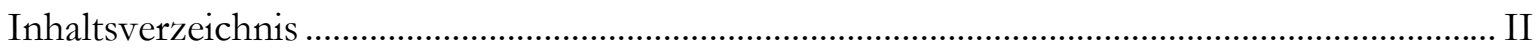

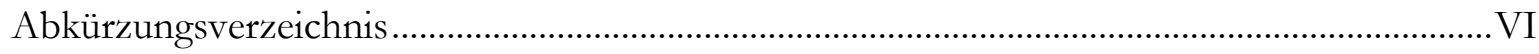

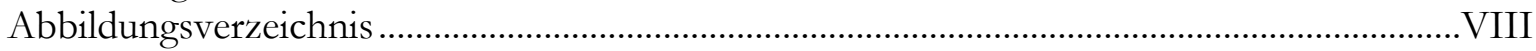

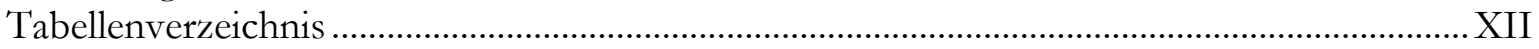

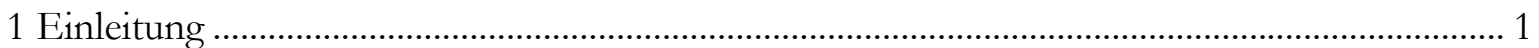

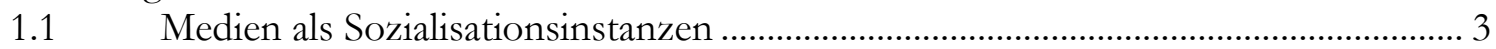

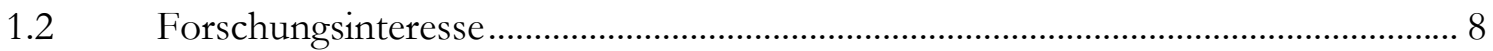

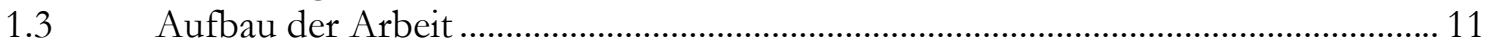

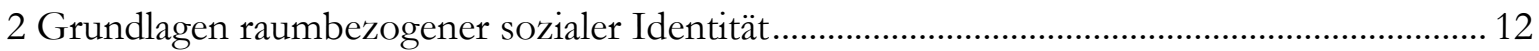

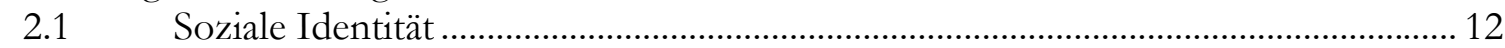

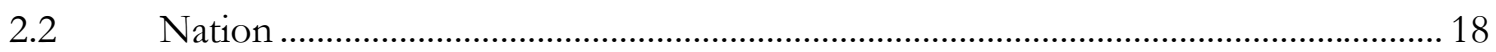

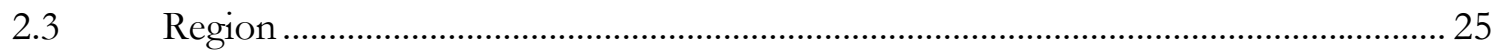

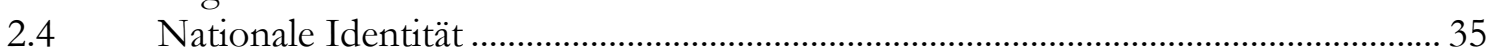

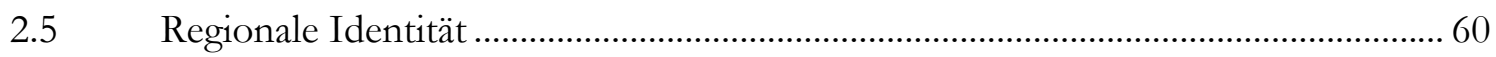

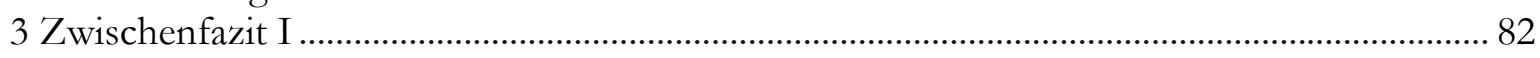

4 Die Rolle der Massenmedien bei der Konstruktion sozialer und räumlicher Identität ........... 84

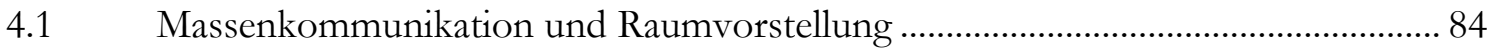

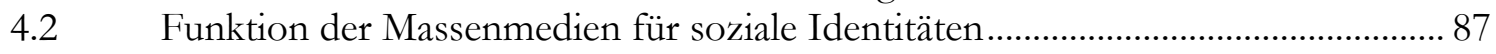

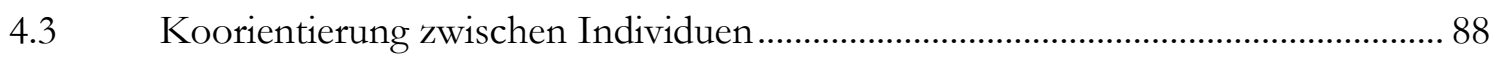

4.4 Medieninhalte als Repräsentation von Wissensstrukturen ........................................... 89

4.5 Vermittelte Koorientierung durch Massenmedien...................................................... 91

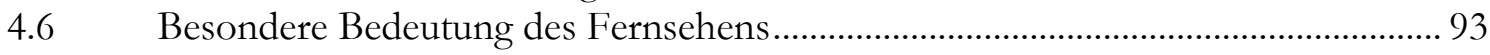

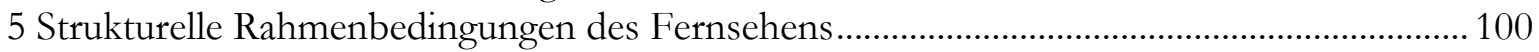

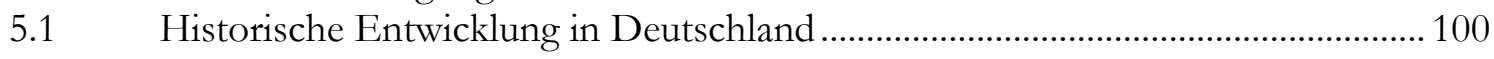

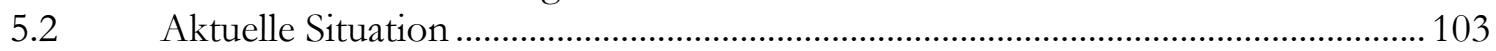

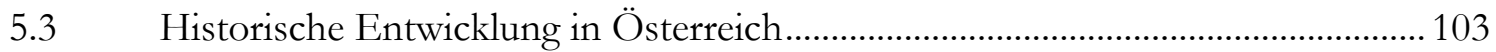

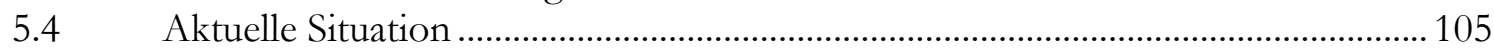

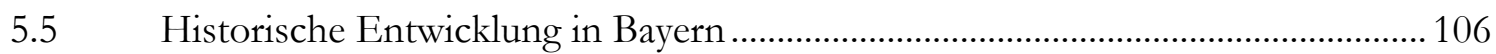

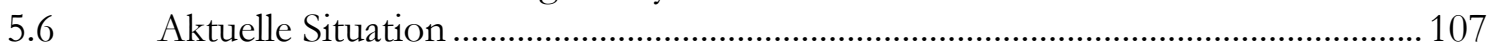

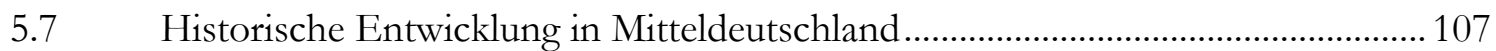

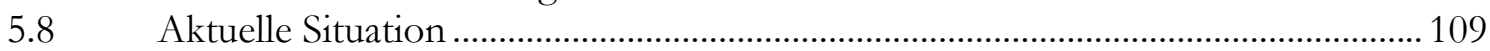

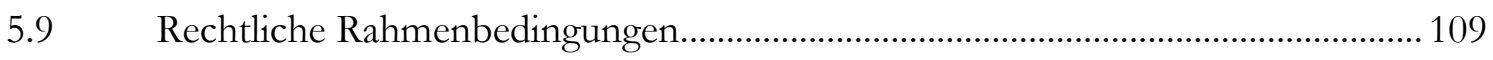

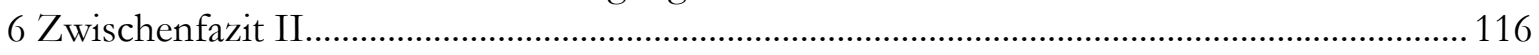

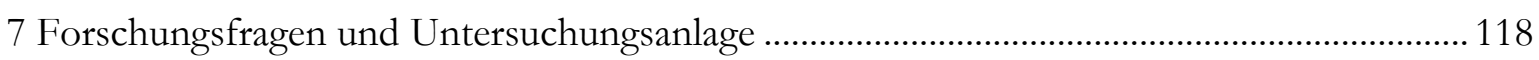

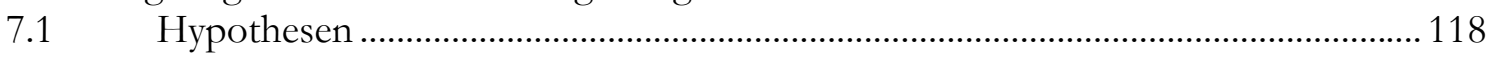

7.2 Anlage und Durchführung der Untersuchung ......................................................... 140

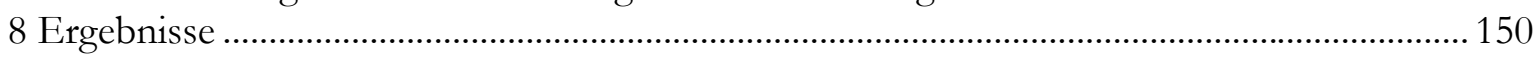

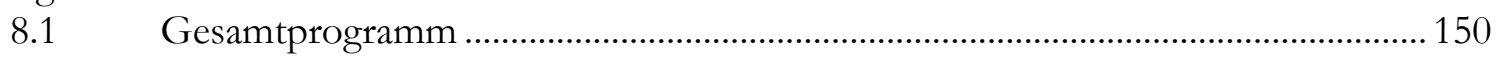

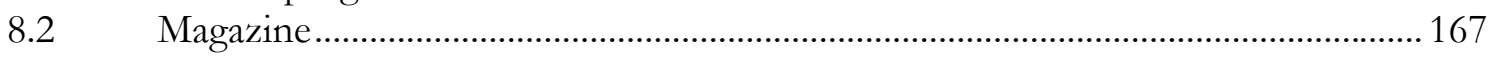

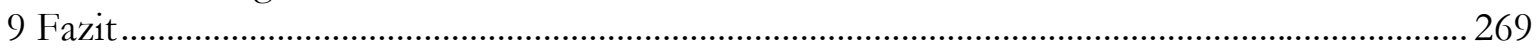

9.1 Zusammenfassung der empirischen Befunde .....................................................2. 269

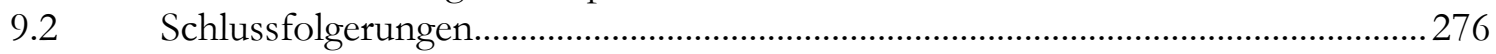

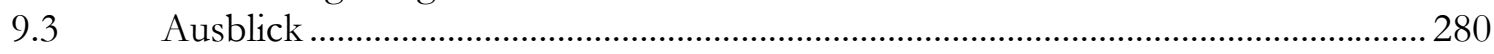

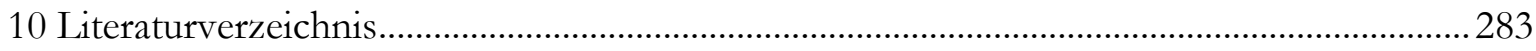

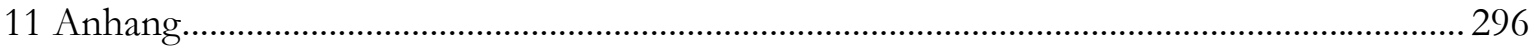




\section{Inhaltsverzeichnis}

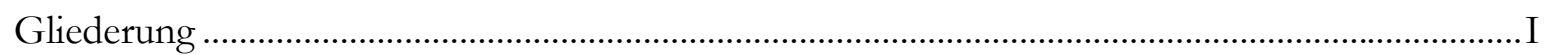

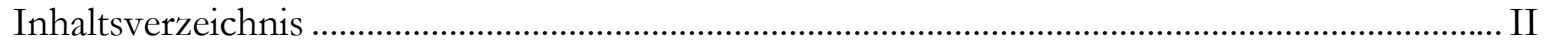

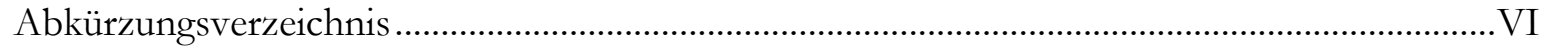

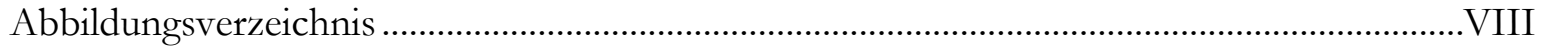

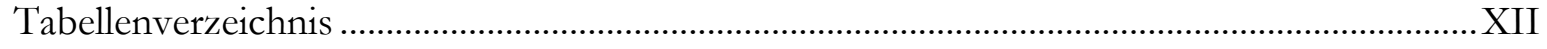

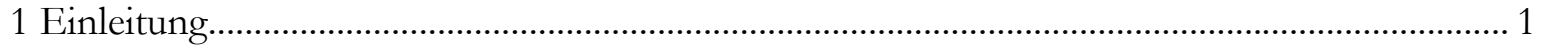

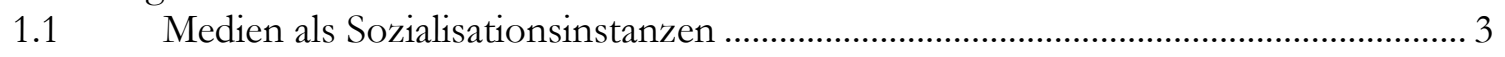

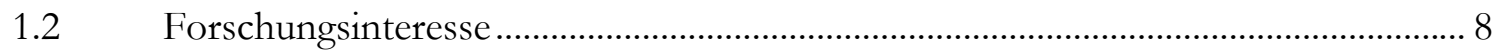

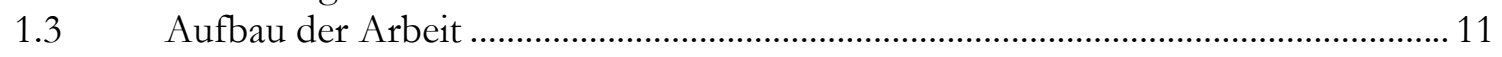

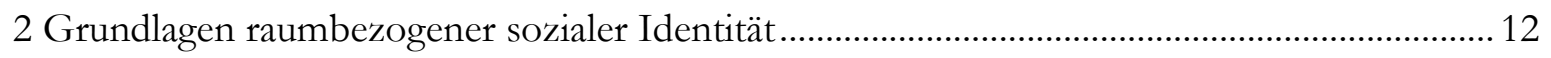

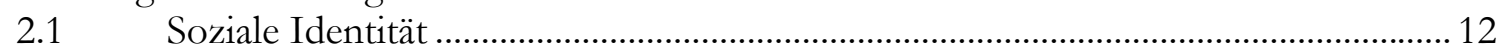

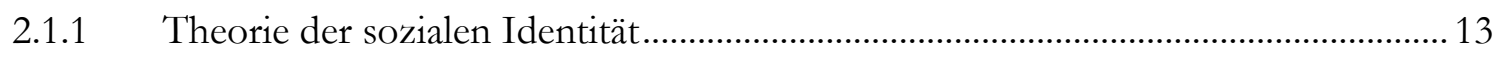

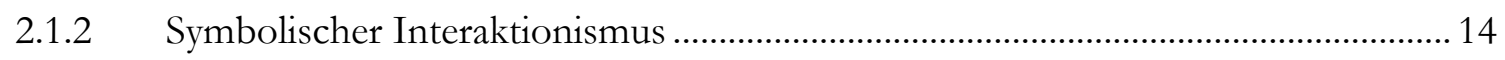

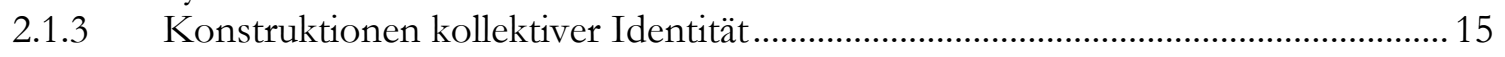

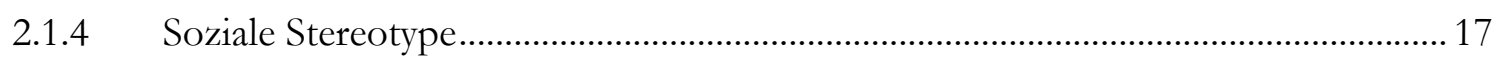

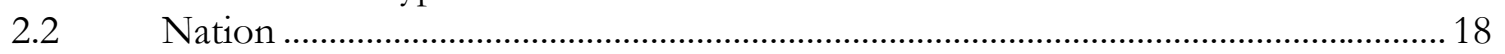

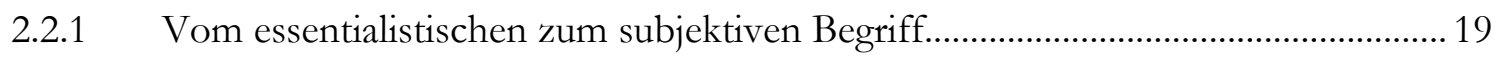

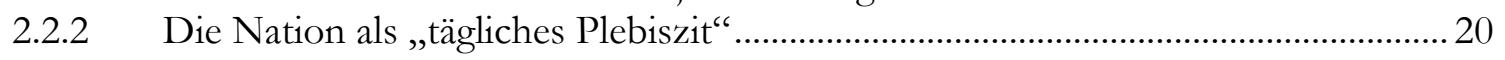

2.2.3 Die Nation als vorgestellte Gemeinschaft .................................................................. 21

2.2.4 Die Nation als historisches Doppelphänomen - der Staat und das „Wir“ „............ 22

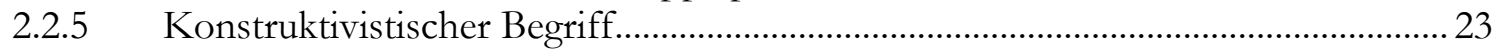

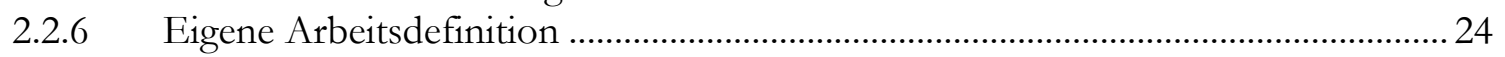

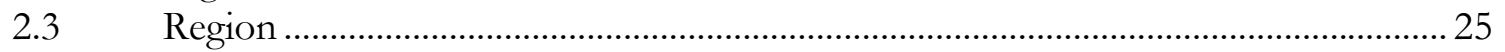

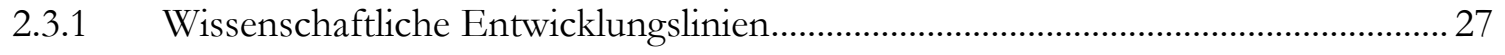

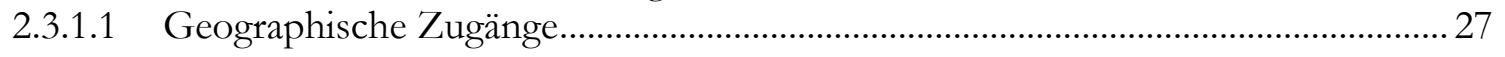

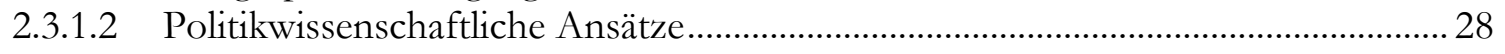

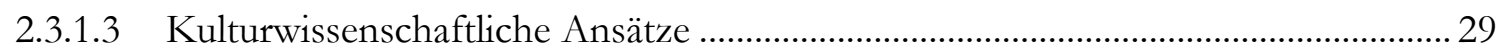

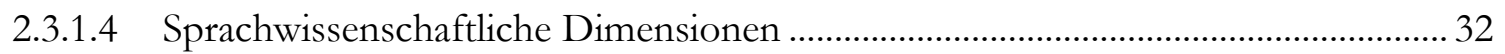

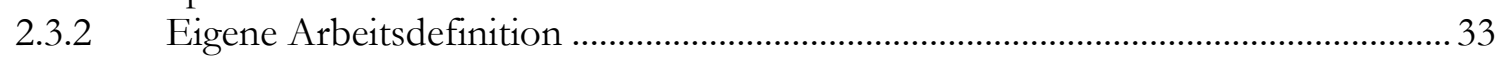

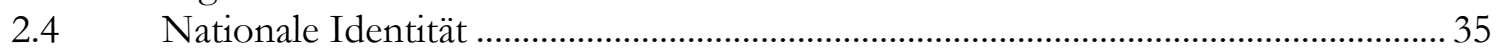

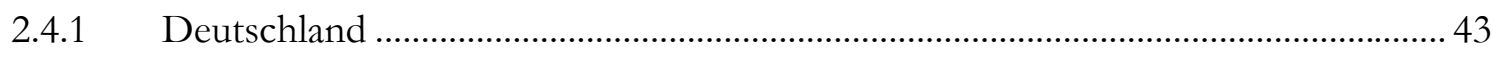

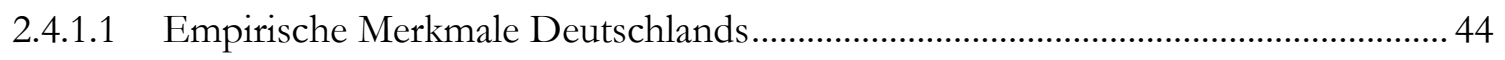

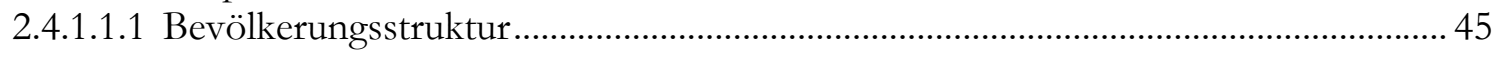

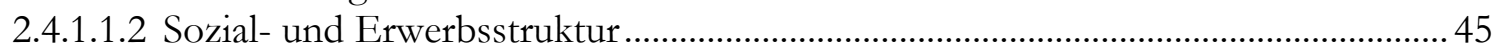

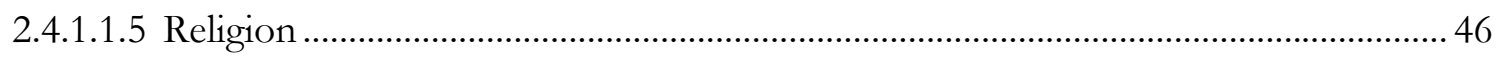

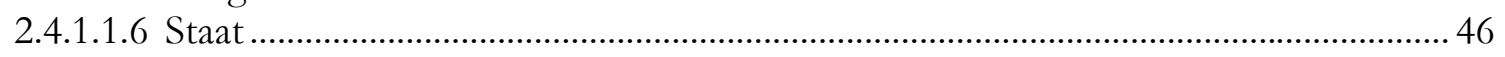

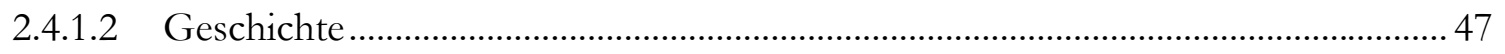

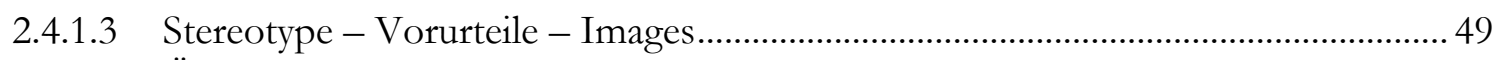

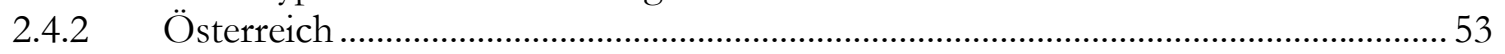

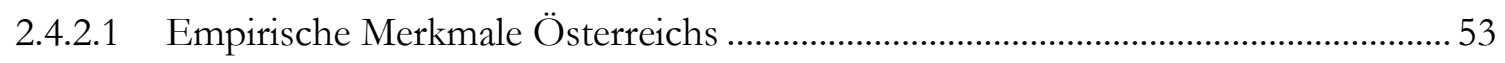

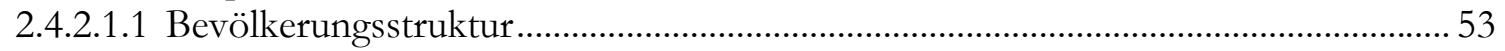

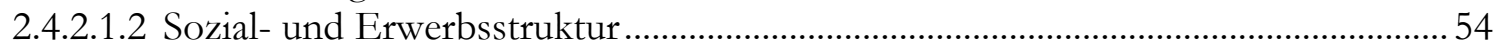

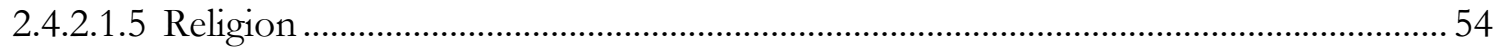

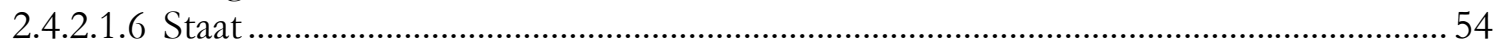

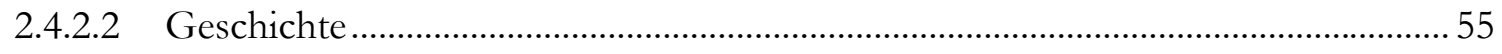

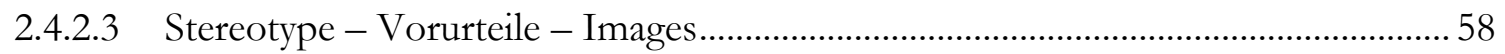




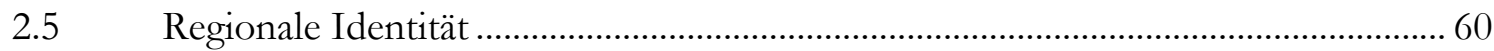

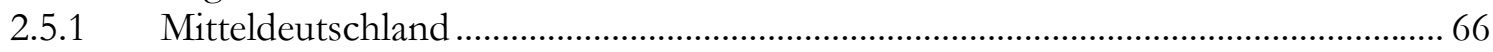

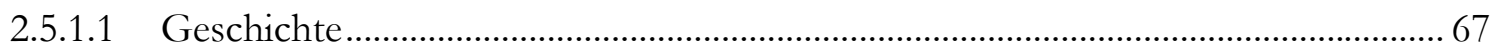

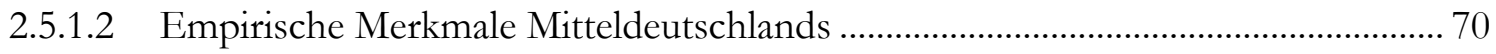

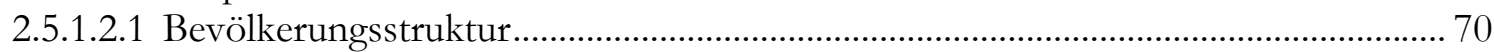

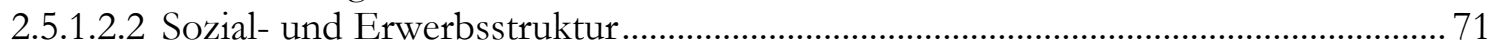

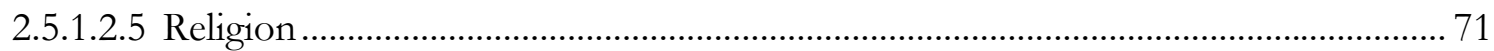

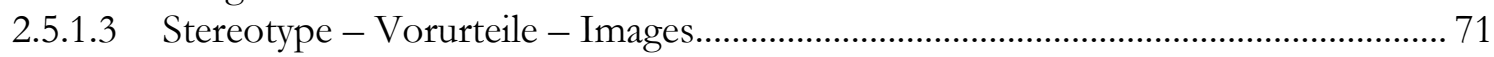

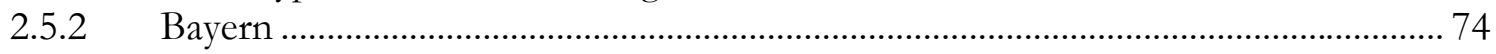

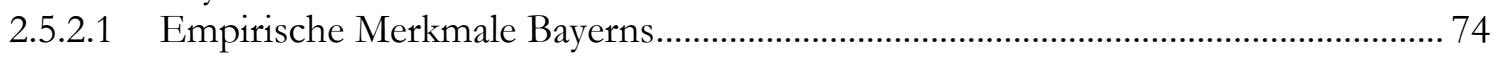

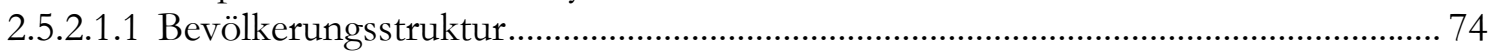

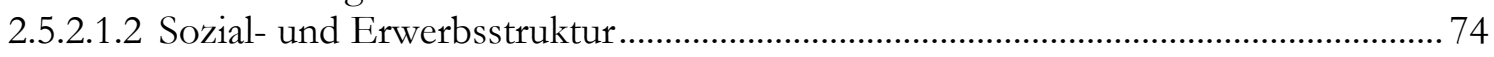

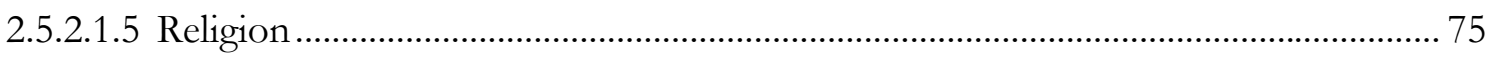

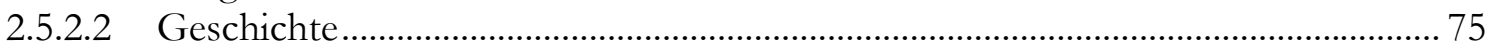

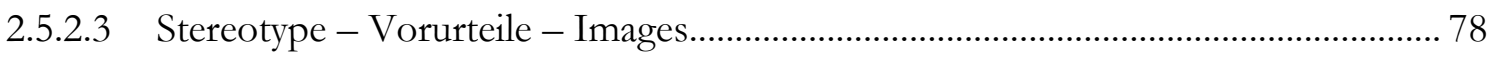

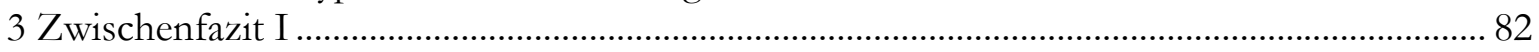

4 Die Rolle der Massenmedien bei der Konstruktion sozialer und räumlicher Identität ........... 84

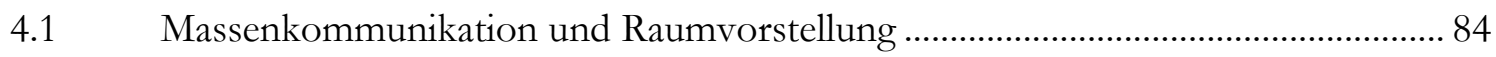

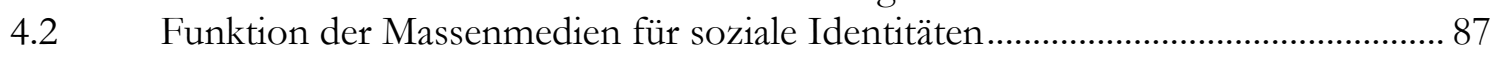

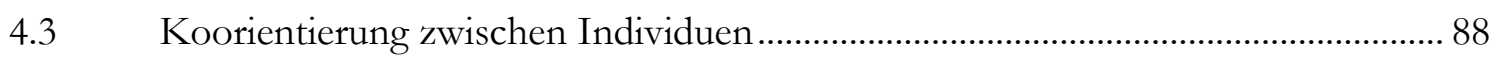

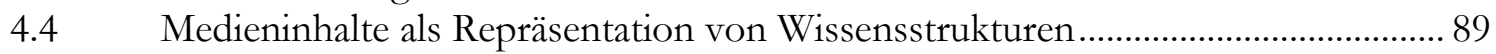

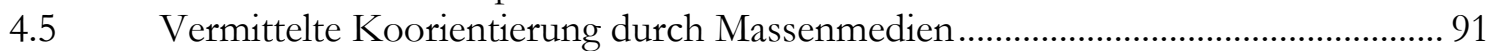

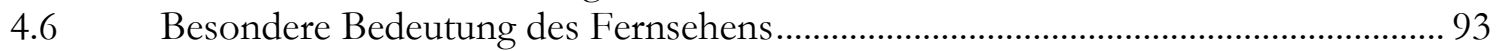

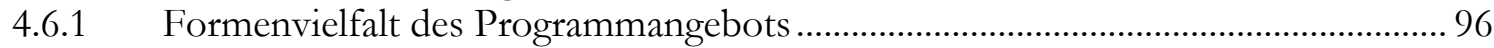

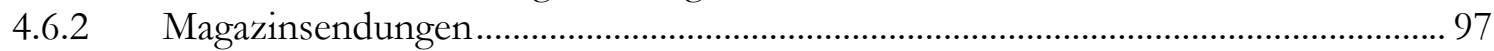

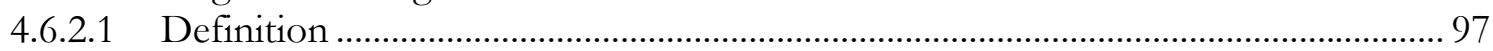

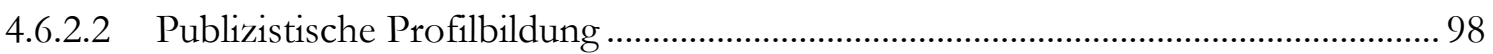

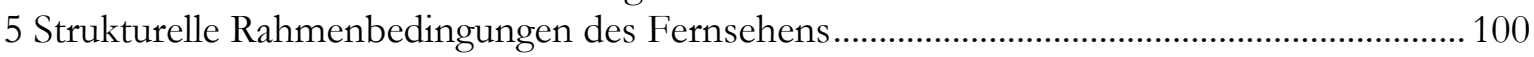

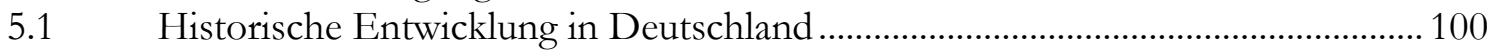

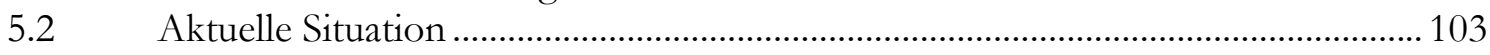

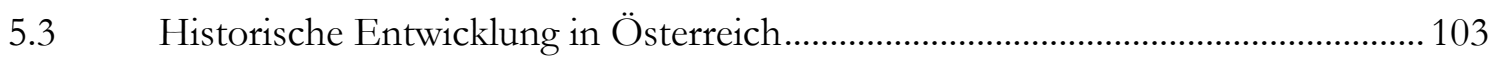

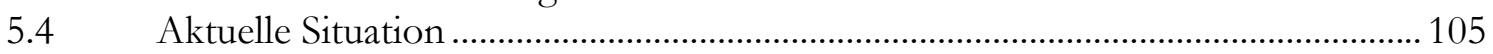

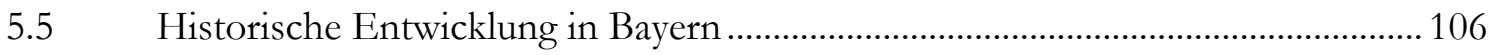

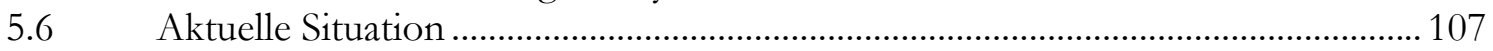

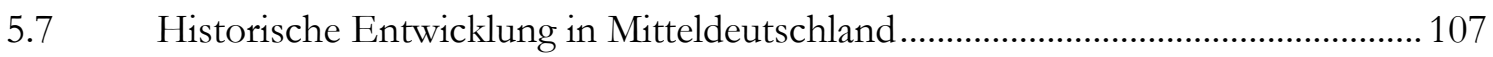

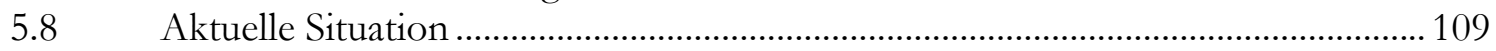

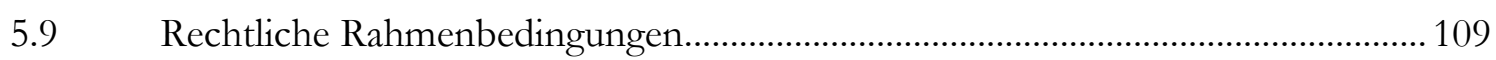

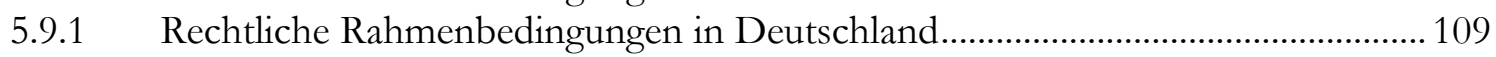

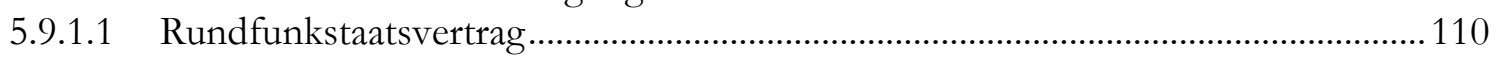

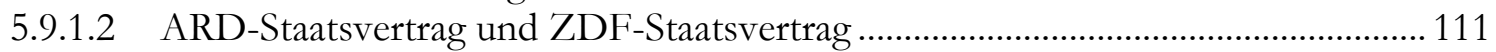

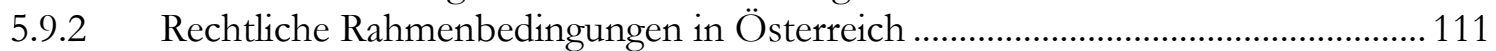

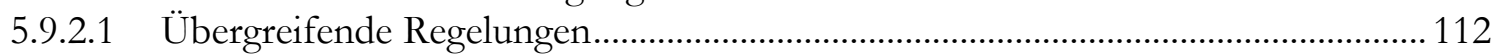

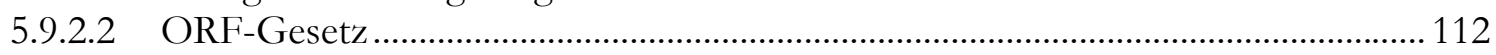

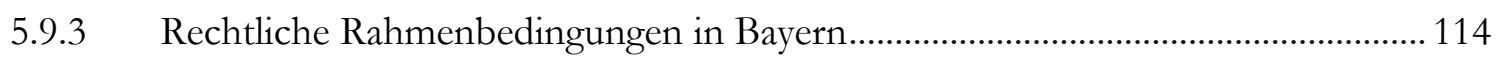

5.9.4 Rechtliche Rahmenbedingungen in Mitteldeutschland ...........................................114

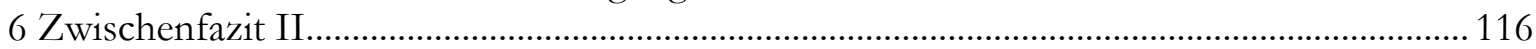

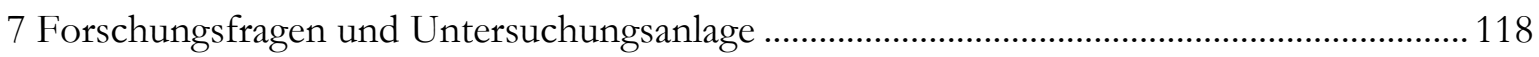

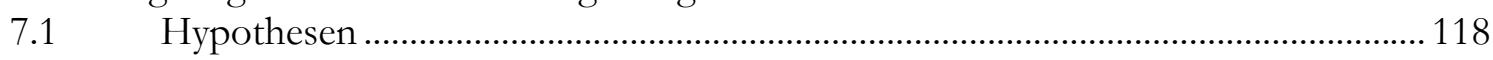

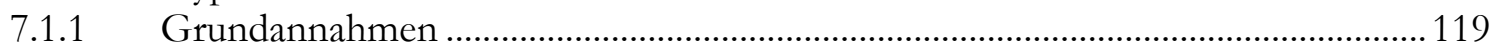

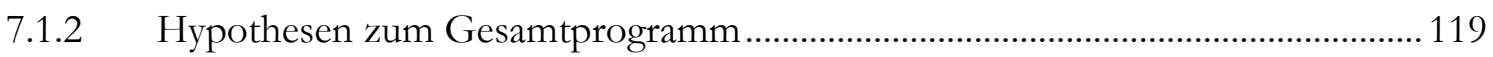

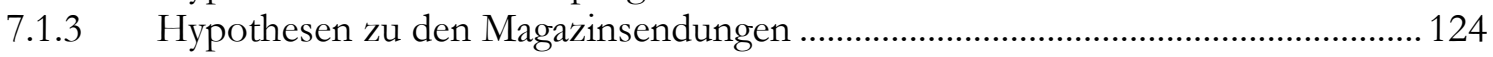

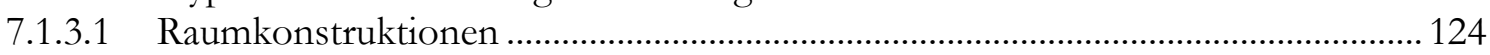




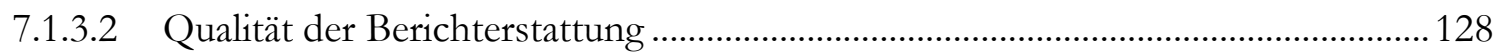

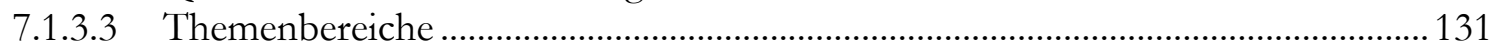

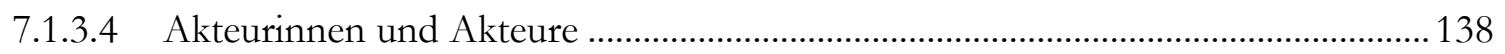

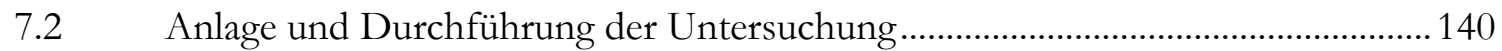

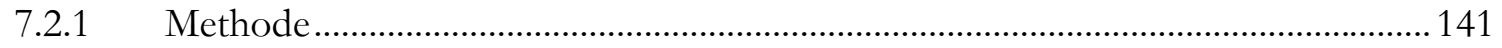

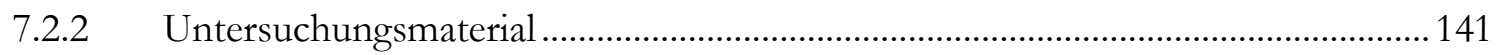

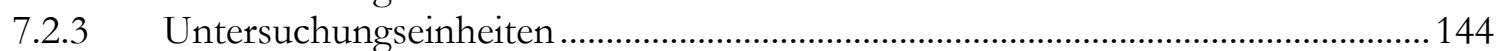

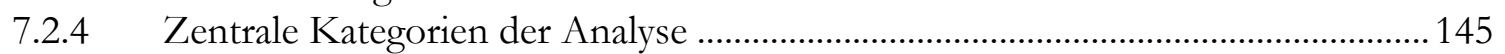

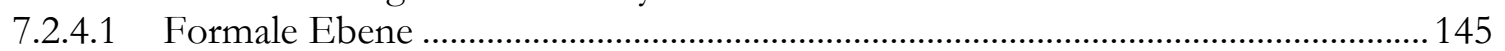

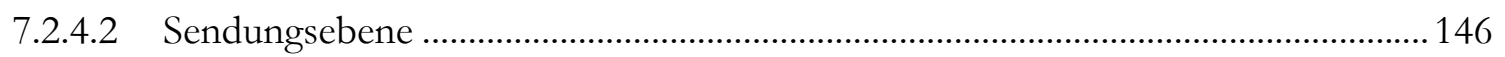

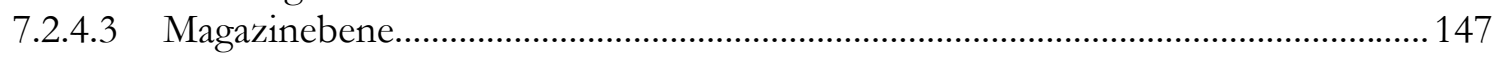

7.2.4.4 Zu Wort kommende Personen in Magazinbeiträgen................................................... 148

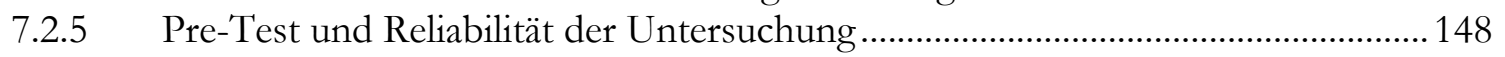

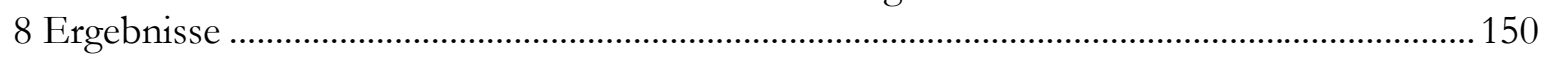

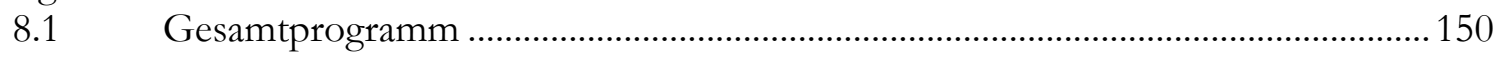

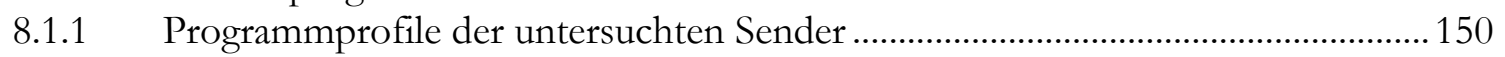

8.1.2 Programmleistung im Licht des Rundfunkstaatsvertrags ........................................158

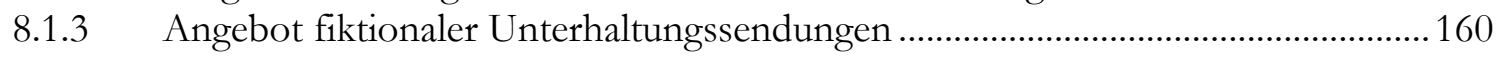

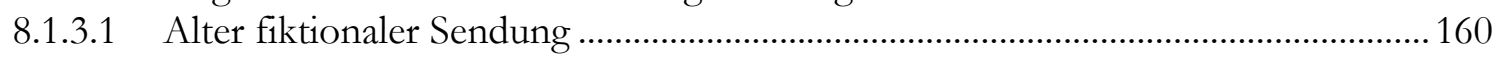

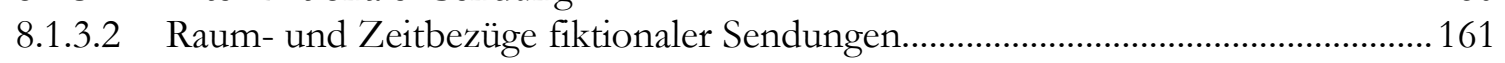

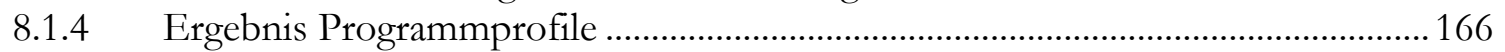

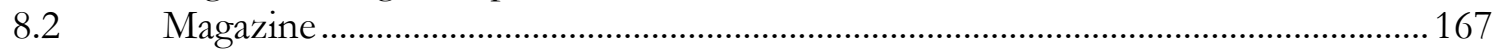

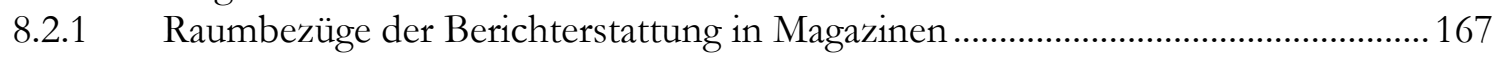

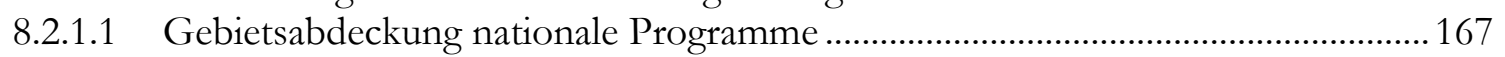

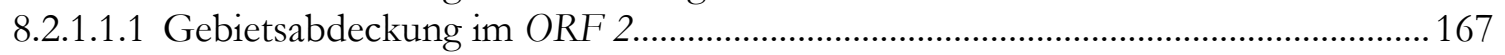

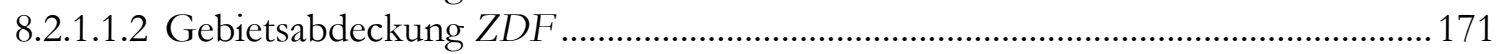

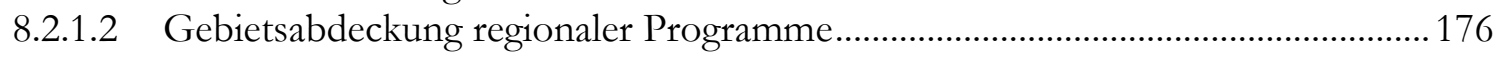

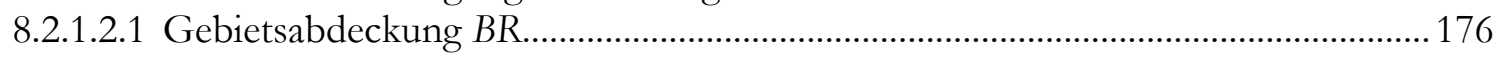

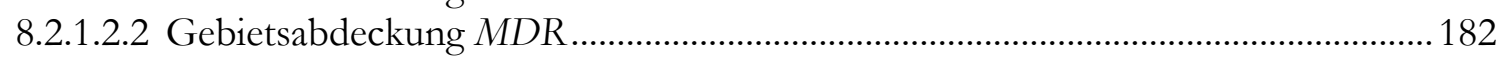

8.2.1.2.3 Verteilung des regionalen Informationsangebots im MDR auf die mittel-

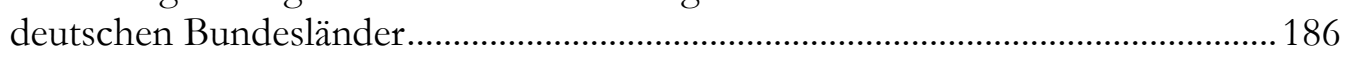

8.2.1.3 Vergleich der Verteilung der Berichterstattung auf die unterschiedlichen

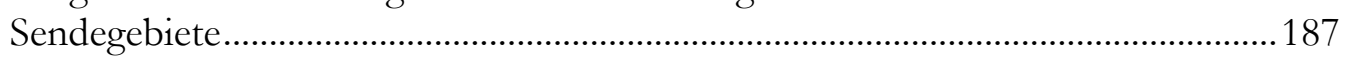

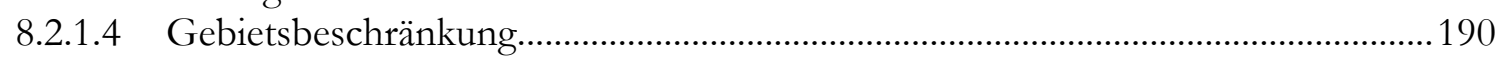

8.2.1.4.1 Gebietsbeschränkung der Berichterstattung nationaler Programme ....................... 190

8.2.1.4.2 Gebietsbeschränkung der Berichterstattung regionaler Programme ........................ 192

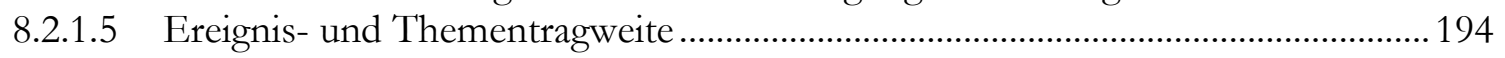

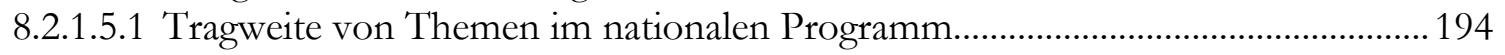

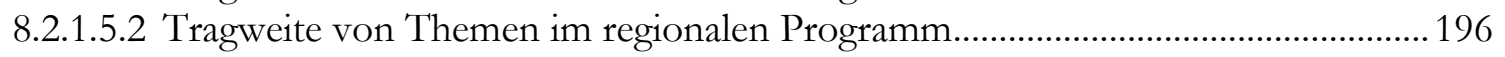

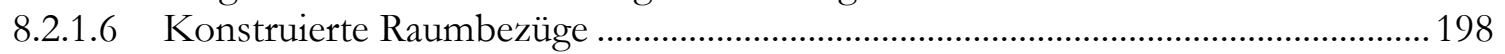

8.2.1.6.1 Anteile von Magazinbeiträgen mit künstlich hergestelltem Raumbezug in den

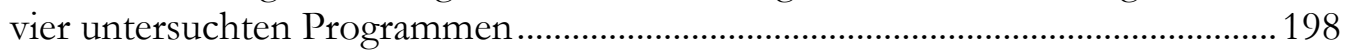

8.2.1.6.2 Künstliche Raumbezüge durch Personalisierung politischer Berichterstattung .. 199

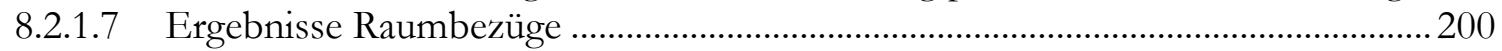

8.2.2 Dimensionen journalistischer Qualität der Berichterstattung................................ 202

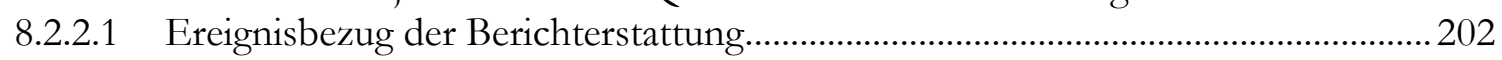

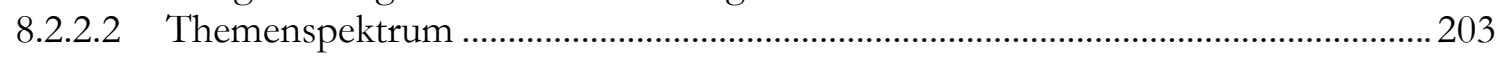

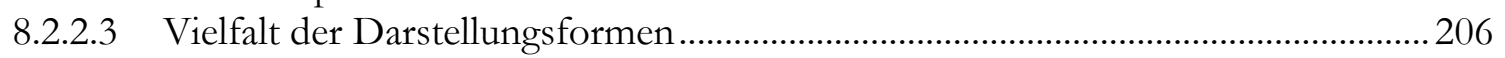

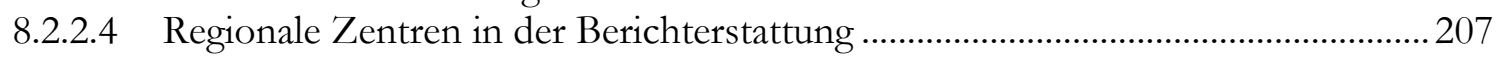

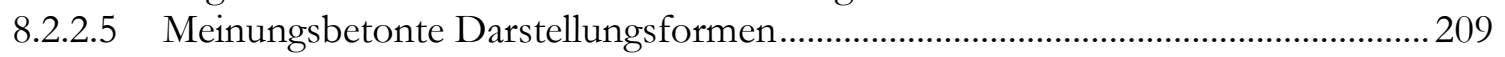

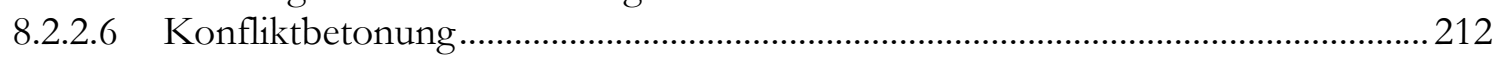

8.2.2.7 Ergebnis journalistische Qualität der Magazinbeiträge..............................................2 215 


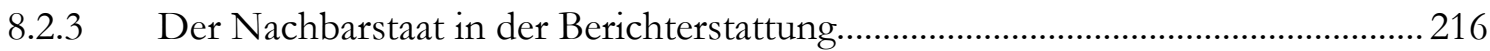

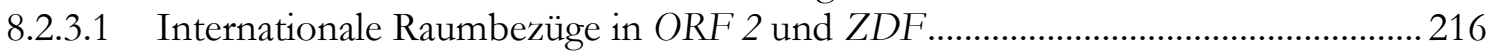

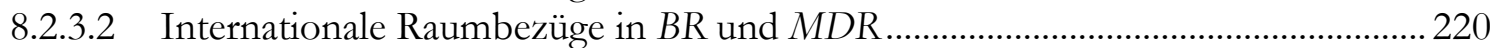

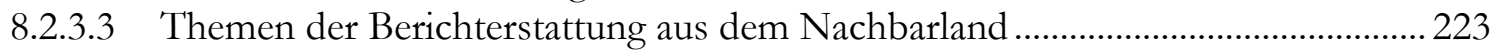

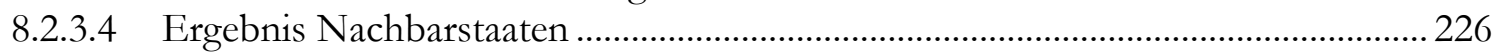

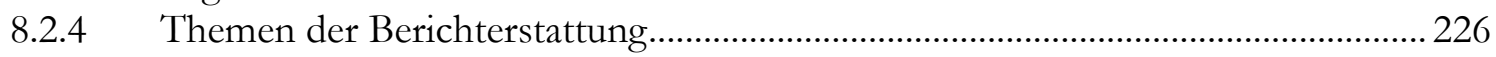

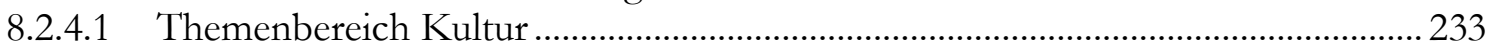

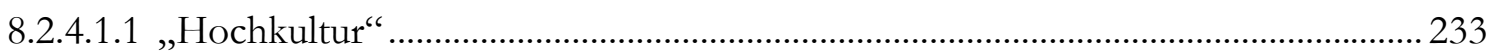

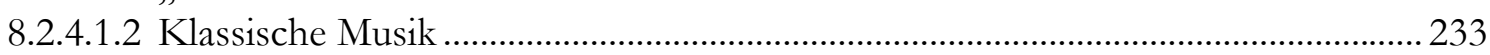

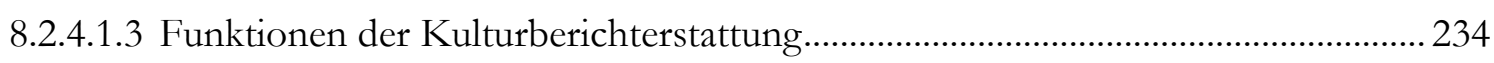

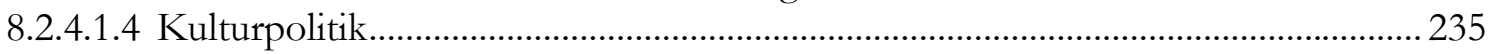

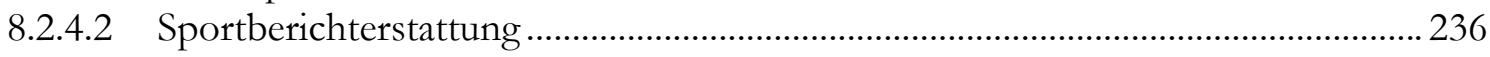

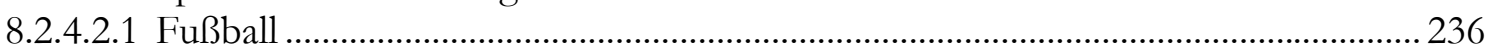

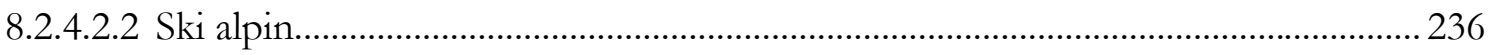

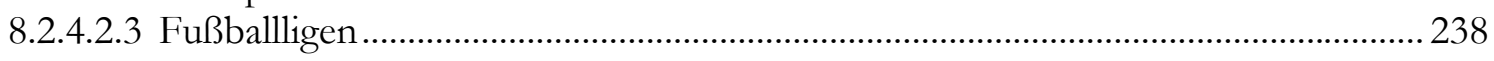

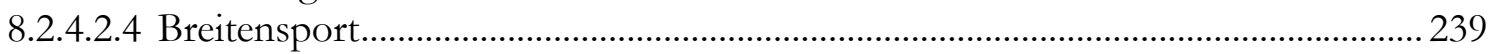

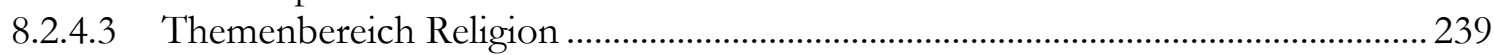

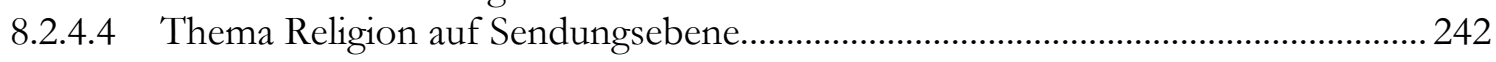

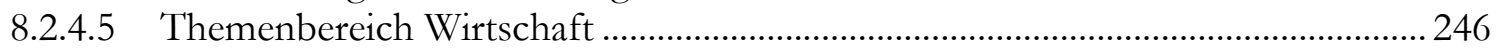

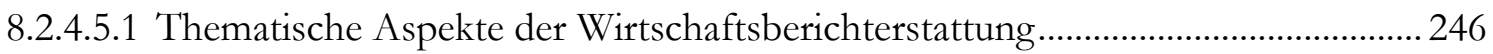

8.2.4.5.2 Berichterstattung über die einzelnen Wirtschaftssektoren...................................... 247

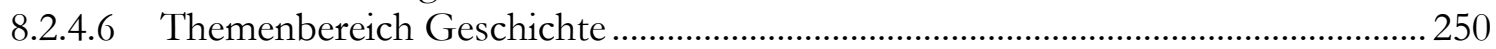

8.2.4.6.1 Anteile der am umfangreichsten berücksichtigten historischen Themen in

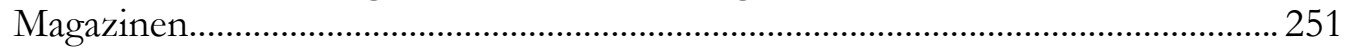

8.2.4.6.2 Alleinstehende Sendungen zu historischen Themen in BR und MDR ................ 252

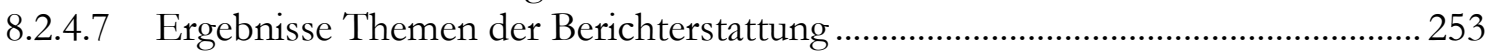

8.2.5 Zu Wort kommende Akteurinnen und Akteure der Berichterstattung................... 254

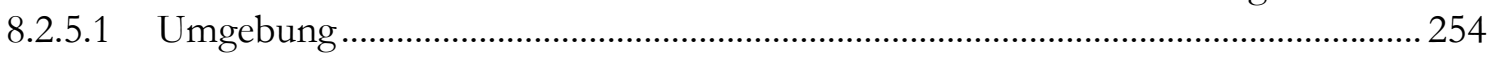

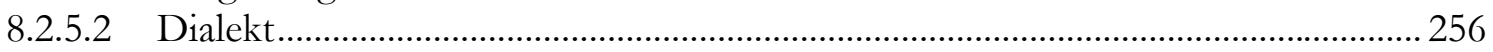

8.2.5.3 Bandbreite der gezeigten Akteurinnen und Akteure................................................ 260

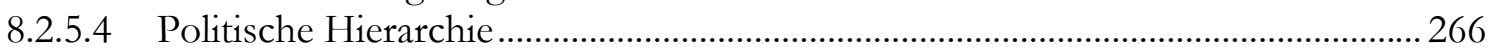

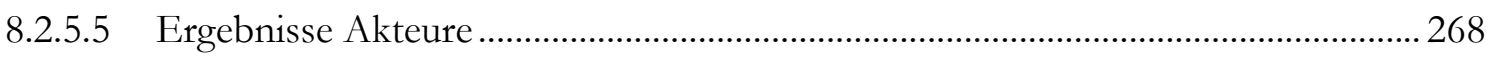

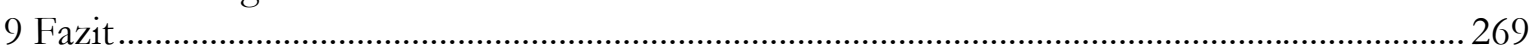

9.1 Zusammenfassung der empirischen Befunde ...........................................................2. 269

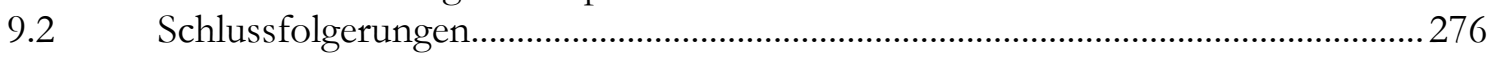

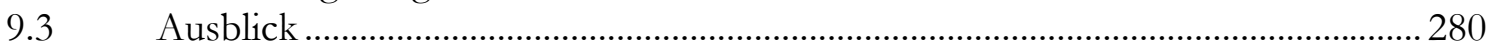

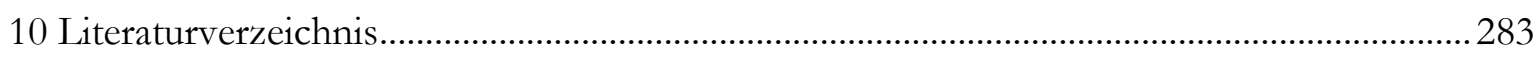

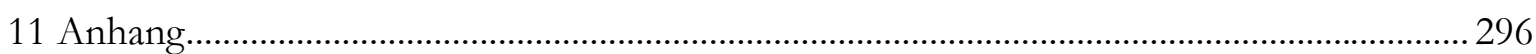

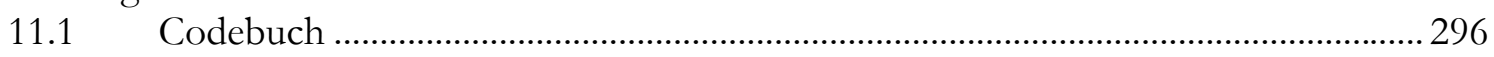

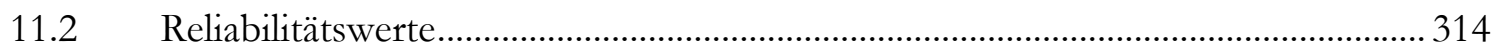

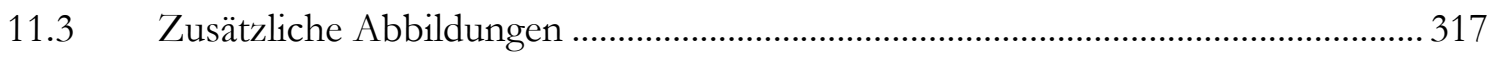

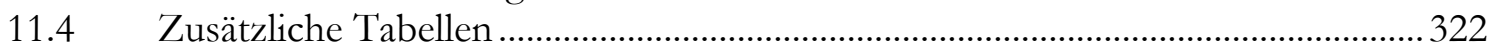




\section{Abkürzungsverzeichnis}

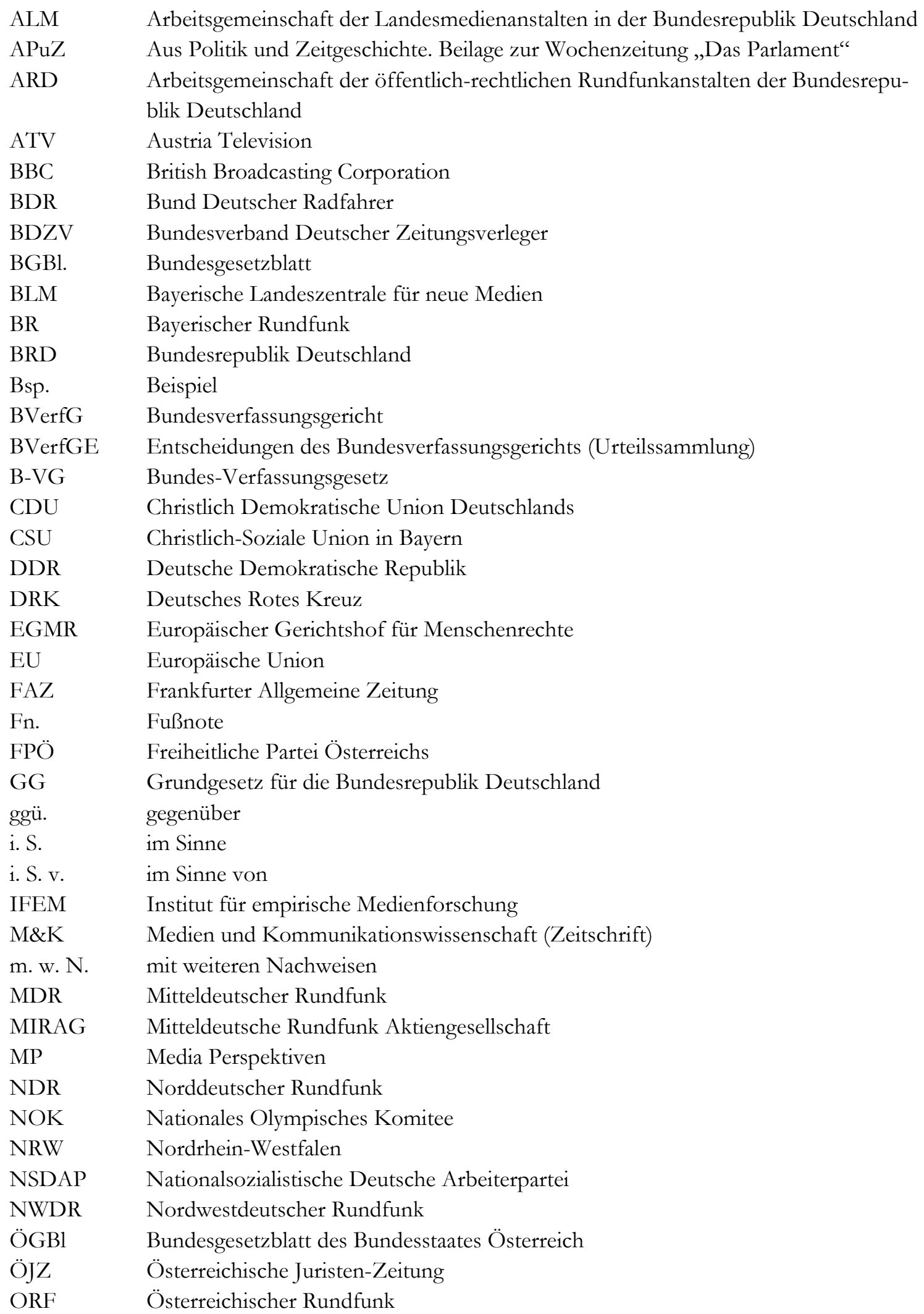


ORF-G Bundesgesetz über den Österreichischen Rundfunk

RAVAG Radio Verkehrs Aktiengesellschaft

RBB Rundfunk Berlin-Brandenburg

RRG Reichsrundfunkgesellschaft

$\mathrm{RStV} \quad$ Rundfunkstaatsvertrag

RTL Radio Télévision Luxembourg

RuF Rundfunk und Fernsehen. Forum der Medienwissenschaft und Medienpraxis (Zeitschrift)

SächsPRG Gesetz über den privaten Rundfunk und neue Medien in Sachsen

SBZ Sowjetische Besatzungszone

SFB Sender Freies Berlin

SLM Sächsische Landesanstalt für privaten Rundfunk und neue Medien

SPD Sozialdemokratische Partei Deutschlands

SPSS Statistical Package for the Social Sciences

SPVgg Spielvereinigung

SR Saarländischer Rundfunk

SZ Süddeutsche Zeitung

ThürLMG Thüringer Landesmediengesetz

TMG Tele München Gruppe

UN United Nations

VTs Veranstaltungstipps

WDR Westdeutscher Rundfunk

ZDF Zweites Deutsches Fernsehen

ZDF-StV ZDF-Staatsvertrag

$\mathrm{ZiB} \quad$ Zeit im Bild 


\section{Abbildungsverzeichnis}

Abbildung 1: Vergleichsdimensionen nationaler und regionaler Identität von

Fernsehprogramminhalten ................................................................................... 9

Abbildung 2: Grundstruktur der untersuchten Programme........................................................152

Abbildung 3: Programmleistung der einzelnen Sender...............................................................153

Abbildung 4: Zusammensetzung des Unterhaltungsprogramms der untersuchten Sender 155

Abbildung 5: Vergleich der relativen Entropiewerte für die Verteilung des

Unterhaltungsangebots auf die verschiedenen Sendeformen.............................156

Abbildung 6: Zusammensetzung des Informationsprogramms der untersuchten Sender..157

Abbildung 7: Vergleich der relativen Entropiewerte für die Verteilung des Informationsangebots auf die verschiedenen Sendeformen...............................158

Abbildung 8: Alter fiktionaler Sendungen nach Anteil der Sendezeit.........................................161

Abbildung 9: Herkunft fiktionaler Sendungen nach Anteil der Sendezeit.................................162

Abbildung 10: ORF 2 - Regionale Verteilung der Ereignisorte der Berichterstattung nach

Landkreisen - Anteil an der Sendezeit in Prozent ................................................168

Abbildung 11: ORF 2 - Prozentuale Sendezeitverteilung ..............................................................169

Abbildung 12: ORF 2 - Regionale Verteilung der Regionalberichterstattung nach

Landkreisen - Anteil an der Sendezeit in Prozent......

Abbildung 13: ORF 2 - Prozentuale Sendezeitverteilung der regionalen Berichterstattung auf die Gesamtzahl der österreichischen Landkreise ............................................171

Abbildung 14: ZDF-Regionale Verteilung der Ereignisorte der Berichterstattung nach Landkreisen - Anteil an der Sendezeit in Prozent ...............................................172

Abbildung 15: ZDF - Prozentuale Sendezeitverteilung (Ereignisorte) auf die Gesamtzahl der deutschen Landkreise..

Abbildung 16: ZDF - Regionale Verteilung der Regionalberichterstattung nach Landkreisen - Anteil an der Sendezeit in Prozent.

Abbildung 17: ZDF - Prozentuale Sendezeitverteilung der regionalen Berichterstattung auf die Gesamtzahl der deutschen Landkreise...

Abbildung 18: BR - Regionale Verteilung der Ereignisorte der Berichterstattung nach Landkreisen - Anteil an der Sendezeit in Prozent ...............................................177

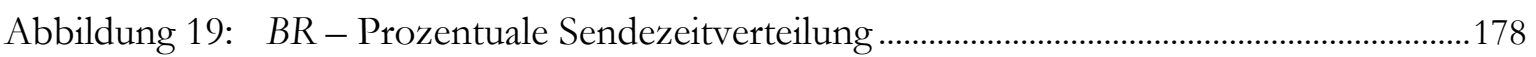

Abbildung 20: BR - Regionale Verteilung der Regionalberichterstattung nach Landkreisen - Anteil an der Sendezeit in Prozent...

Abbildung 21: BR - Prozentuale Sendezeitverteilung der regionalen Berichterstattung auf die Gesamtzahl der bayerischen Landkreise.

Abbildung 22: BR - Prozentuale Sendezeitverteilung auf die Gesamtzahl der fränkischen Landkreise.

Abbildung 23: BR - Prozentuale Sendezeitverteilung auf die Gesamtzahl der altbayerischen und schwäbischen Landkreise.

Abbildung 24: MDR - Regionale Verteilung der Ereignisorte der Berichterstattung nach Landkreisen - Anteil an der Sendezeit in Prozent.

Abbildung 25: MDR - Prozentuale Sendezeitverteilung auf die Gesamtzahl der mitteldeutschen Landkreise

Abbildung 26: MDR - Regionale Verteilung der Regionalberichterstattung nach Landkreisen - Anteil an der Sendezeit in Prozent.

Abbildung 27: $M D R$ - Prozentuale Sendezeitverteilung der regionalen Berichterstattung auf die Gesamtzahl der mitteldeutschen Landkreise. 
Abbildung 28: Verteilung der Sendezeitanteile der Magazinbeiträge mit mitteldeutschem

Ereignisort auf das Sendegebiet.

Abbildung 29: Vergleich der relativen Entropie der Sendegebietsabdeckung durch

Berichterstattung mit identifizierbaren Ereignisorten

Abbildung 30: Vergleich der relativen Entropie der Sendegebietsabdeckung durch Regionalberichterstattung.

Abbildung 31: ORF 2 - Prozentuale Verteilung der Sendezeit von Magazinbeiträgen auf Berichterstattung inner- und außerhalb des Sendegebiets.

Abbildung 32: $Z D F$ - Prozentuale Verteilung der Sendezeit von Magazinbeiträgen auf Berichterstattung inner- und außerhalb des Sendegebiets.

Abbildung 33: BR - Prozentuale Verteilung der Sendezeit von Magazinbeiträgen auf Berichterstattung inner- und außerhalb des Sendegebiets

Abbildung 34: MDR - Prozentuale Verteilung der Sendezeit von Magazinbeiträgen auf Berichterstattung inner- und außerhalb des Sendegebiets

Abbildung 35: ORF 2 - Bezugsräume der Berichterstattung in Magazinsendungen .................195

Abbildung 36: ZDF- Bezugstäume der Berichterstattung in Magazinsendungen....................196

Abbildung 37: BR - Bezugsräume der Berichterstattung in Magazinsendungen ........................197

Abbildung 38: MDR - Bezugsräume der Berichterstattung in Magazinsendungen ...................198

Abbildung 39: Anteile von Magazinbeiträgen mit regionalen Themen, nicht regionalen

Themen und künstlich regionalisierten Themen

Abbildung 40: Anteile der politischen Berichterstattung, die Zusammenhänge personalisiert am Beispiel von regional verortbaren „Normalbürgerinnen“ und „Normalbürgern“ darstellt.

Abbildung 41: Ereignisbezug der Berichterstattung......

Abbildung 42: Vergleich relative Entropie der Themenverteilung in allen Magazinen der untersuchten Sender auf Ebene aller möglichen Themen

Abbildung 43: Vergleich relative Entropie der Themenverteilung in allen Magazinen der untersuchten Sender auf Ebene aggregierter Themenbereiche.

Abbildung 44: Relative Entropie der Verteilung der Berichterstattung auf die verschiedenen journalistischen Darstellungsformen.

Abbildung 45: ORF 2 - Verteilung der Sendezeit der nicht selbstreferenziellen Magazinbestandteile auf die verschiedenen journalistischen Darstellungsformen .......210

Abbildung 46: ZDF - Verteilung der Sendezeit der nicht selbstreferenziellen Magazinbestandteile auf die verschiedenen journalistischen Darstellungsformen.......210

Abbildung 47: BR - Verteilung der Sendezeit der nicht selbstreferenziellen Magazinbestandteile auf die verschiedenen journalistischen Darstellungsformen.......211

Abbildung 48: MDR - Verteilung der Sendezeit der nicht selbstreferenziellen Magazinbestandteile auf die verschiedenen journalistischen Darstellungsformen.......211

Abbildung 49: Konfliktbetonung politischer Berichterstattung. Anteile der unterschiedlich kontroversen Magazinbeiträge mit Thema Politik am Gesamtumfang aller politischen Magazinbeiträge...

Abbildung 50: Konfliktbetonung der Berichterstattung ohne Thema Politik. Anteile der unterschiedlich kontroversen Magazinbeiträge am Gesamtumfang aller nicht politischen Magazinbeiträge .

Abbildung 51: ORF 2 - Verteilung der Ereignisorte der Berichterstattung auf In- und Ausland

Abbildung 52:

ORF 2 - Verteilung der Ereignisorte der Auslandsberichterstattung .

Abbildung 53:

$Z D F$ - Verteilung der Ereignisorte der Berichterstattung auf In- und Ausland

Abbildung 54: ZDF - Verteilung der Ereignisorte der Auslandsberichterstattung... 
Abbildung 56: BR - Verteilung der Ereignisorte der Auslandsberichterstattung .....................222

Abbildung 57: MDR - Verteilung der Ereignisorte der Berichterstattung auf In- und Ausland

Abbildung 58: MDR - Verteilung der Ereignisorte der Auslandsberichterstattung .................223

Abbildung 59: ORF 2 - Themengebiete der Berichterstattung aus Deutschland nach Sendezeitanteilen.

Abbildung 60: ZDF - Themengebiete der Berichterstattung aus Österreich nach

Sendezeitanteilen.

Abbildung 61: BR - Themengebiete der Berichterstattung aus Österreich nach Sendezeitanteilen.

Abbildung 62: Anteil der Themengebiete an untersuchter Sendezeit in Magazinen ................227

Abbildung 63: Anteil der Themengebiete an untersuchter Sendezeit in Magazinen

OHNE Nachrichtenmagazine.

Abbildung 64: ORF 2 - Thema Religion in Magazinsendungen: Verteilung der

Berichterstattung auf die Glaubensrichtungen und Konfessionen.

Abbildung 65: ZDF - Thema Religion in Magazinsendungen: Verteilung der

Berichterstattung auf die Glaubensrichtungen und Konfessionen..

Abbildung 66: BR - Thema Religion in Magazinsendungen: Verteilung der

Berichterstattung auf die Glaubensrichtungen und Konfessionen

Abbildung 67: ORF 2 - Thema Religion auf Sendungsebene, Verteilung der Sendezeit auf die Glaubensrichtungen und Konfessionen ...

Abbildung 68: ZDF - Thema Religion auf Sendungsebene, Verteilung der Sendezeit auf die Glaubensrichtungen und Konfessionen.

Abbildung 69: BR - Thema Religion auf Sendungsebene, Verteilung der Sendezeit auf die Glaubensrichtungen und Konfessionen.

Abbildung 70: $M D R$ - Thema Religion auf Sendungsebene, Verteilung der Sendezeit auf die Glaubensrichtungen und Konfessionen.

Abbildung 71: ORF 2 - Wirtschaftsberichterstattung, Anteile der einzelnen Wirtschaftssektoren an der Sendezeit

Abbildung 72: ZDF - Wirtschaftsberichterstattung, Anteile der einzelnen

Wirtschaftssektoren an der Sendezeit

Abbildung 73: BR - Wirtschaftsberichterstattung, Anteile der einzelnen

Wirtschaftssektoren an der Sendezeit

Abbildung 74: MDR - Wirtschaftsberichterstattung, Anteile der einzelnen

Wirtschaftssektoren an der Sendezeit

Abbildung 75: ORF 2 - Dialektverwendung der zu Wort kommenden Personen ...................257

Abbildung 76: ZDF-Dialektverwendung der zu Wort kommenden Personen.......................258

Abbildung 77: BR - Dialektverwendung der zu Wort kommenden Personen............................259

Abbildung 78: MDR - Dialektverwendung der zu Wort kommenden Personen......................260

Abbildung 79: Vergleich relative Entropie der zu Wort kommenden Personen nach Gruppen

Abbildung 80: Vergleich relative Entropie der zu Wort kommenden Personen nach

Gruppen, ohne Nachrichtenmagazine

Abbildung 81: Vergleich relative Entropie der zu Wort kommenden Personen nach Gruppen, außer nicht organisierten Privatpersonen.

Abbildung 82: Einordnung der zu Wort kommenden Politikerinnen und Politiker nach Hierarchieebene

Abbildung 83: Programmleistung im Informationsprogramm der einzelnen Sender ..............317

Abbildung 84: Detaillierter Ereignisbezug der Berichterstattung .................................................. 318

Abbildung 85: Vergleich relative Entropie der Themenverteilung in allen Magazinen außer Nachrichtenmagazine der untersuchten Sender auf Ebene aller möglichen Themen. 
Abbildung 86: Vergleich relative Entropie der Themenverteilung in allen Magazinen außer Nachrichtenmagazinen der untersuchten Sender auf Ebene aggregierter Themenbereiche .319

Abbildung 87: ORF 2 - Wirtschaftsberichterstattung ohne Wirtschaftspolitik, Anteile der einzelnen Wirtschaftssektoren an der Sendezeit.

Abbildung 88: ZDF - Wirtschaftsberichterstattung ohne Wirtschaftspolitik, Anteile der einzelnen Wirtschaftssektoren an der Sendezeit

Abbildung 89: BR - Wirtschaftsberichterstattung ohne Wirtschaftspolitik, Anteile der einzelnen Wirtschaftssektoren an der Sendezeit.

Abbildung 90: MDR - Wirtschaftsberichterstattung ohne Wirtschaftspolitik, Anteile der einzelnen Wirtschaftssektoren an der Sendezeit 


\section{Tabellenverzeichnis}

Tabelle 1: Wichtigkeit einzelner Lebensbereiche/Themen für das Leben in der Region....132

Tabelle 2: Produktionsländer erstmals ausgestrahlter und kurzfristig wiederholter fiktionaler Sendungen sowie alleinstehender Dokumentationen.......................159

Tabelle 3: Verteilung der Handlungsorte fiktionaler Sendungen anhand der Sendezeit...... 165

Tabelle 4: Die zehn Kreise in Bayern, aus denen im BR am umfangreichsten berichtet

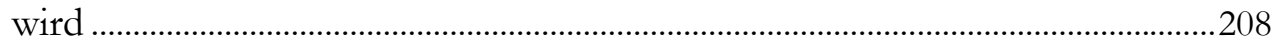

Tabelle 5: Die zehn Kreise in Mitteldeutschland, aus denen im MDR am umfangreichsten berichtet wird...............................................................................208

Tabelle 6: ORF 2 - Rangliste der zehn am umfangreichsten behandelten Themen..............230

Tabelle 7: ZDF - Rangliste der zehn am umfangreichsten behandelten Themen .................230

Tabelle 8: $\quad B R$ - Rangliste der zehn am umfangreichsten behandelten Themen......................231

Tabelle 9: $\quad$ MDR - Rangliste der zehn am umfangreichsten behandelten Themen................231

Tabelle 10: Kulturberichterstattung, Gesamtumfang, Anteil „Hochkultur“...............................233

Tabelle 11: Kulturberichterstattung, zeitliche Anteile der einzelnen Darstellungsformen.....234

Tabelle 12: Funktion von Beiträgen in der Kulturberichterstattung und ihr Anteil an der

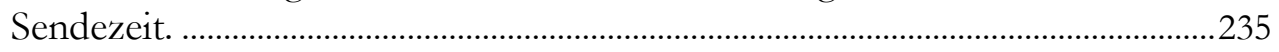

Tabelle 13: Umfang und Anteil der Sportberichterstattung an allen Magazinbeiträgen .........236

Tabelle 14: Sportberichterstattung: Anteil der einzelnen Sportarten nach Sendedauer ...........237

Tabelle 15: Verteilung der Fußballberichterstattung auf die verschiedenen Ligen...................238

Tabelle 16: Umgebung der in Magazinbeiträgen zu Wort kommenden Akteure in Beiträgen mit Bezugsraum im Sendegebiet ...........................................................25

Tabelle 17: Zu Wort kommende Akteurinnen und Akteure nach Gruppenzuordnung.........260

Tabelle 18: Zu Wort kommende Akteurinnen und Akteure nach Gruppenzuordnung.........262

Tabelle 19: Intracoderreliabilitätswerte aller Variablen der Inhaltsanalyse......................................314

Tabelle 20: Ereignisbezug der Regionalberichterstattung..............................................................322

Tabelle 21: Kulturberichterstattung in Magazinen, Umfang und Anteile.....................................323

Tabelle 22: Historische Themen in der Magazinberichterstattung, Umfang und Anteile......324

Tabelle 23: Dialektausprägung bei nicht organisierten Privatpersonen .........................................325 


\section{Einleitung}

Massenmedien sind maßgeblich an der Prägung unseres Weltbildes beteiligt. Das ist für Nachrichten über Ereignisse im Ausland sehr leicht nachvollziehbar. Je mehr aus bestimmten Gegenden der Welt berichtet wird, umso informierter glauben wir zu sein. Über bestimmte Gebiete der Welt haben wir ein relativ ausgeprägtes Wissen, während wir von anderen möglicherweise noch nie etwas gehört haben. So können sich weiße Flecken in der Nachrichtengebung auch in weißen Flecken im Wissen der Rezipienten ${ }^{1}$ niederschlagen. Wie wichtig wir zum Beispiel andere Länder einschätzen, hängt maßgeblich von der Auslandsberichterstattung ab (vgl. Wanta et al. 2004). Doch wie verhält es sich mit dem Bild, das wir von unserem eigenen Land und unserer Nation ${ }^{2}$ haben? Wie mit dem uns umgebenden Nahraum, den Regionen? Welche Bilder bekommen wir hier präsentiert? Und können wir uns als Fernsehzuschauer und Fernsehzuschauerinnen vom Programm repräsentiert fühlen? Was zeichnet unsere Nation und Region besonders aus und schlagen sich diese Besonderheiten in Fernsehinhalten nieder? Dies sind einige der Fragen, mit denen sich diese Arbeit befasst. Dabei soll vor allem untersucht werden, ob, wie und in welchem Ausmaß nationale und regionale Identitäten im Fernsehprogramm überhaupt ihren Ausdruck finden. Geht man nämlich davon aus, dass Massenmedien unser Weltbild (mit-)prägen, ist das Fernsehen für die tatsächliche gesellschaftliche Bedeutung nationaler und regionaler Identitäten von besonderer Relevanz. Die Studie bezieht sich auf die Beispiele Deutschland und Österreich auf nationaler sowie Bayern und Mitteldeutschland auf regionaler Ebene (zur Begründung dieser Auswahl vgl. S. 9).

Für das zu untersuchende Feld kommen monokausale Ursache- und Wirkungsmechanismen nicht in Betracht. Zunächst ist daher zu klären, wodurch sich nationale und regionale Identität überhaupt auszeichnen. Geht man davon aus, dass beides Phänomene gesellschaftlicher Aushandlung sind, besteht eine Aufgabe der vorliegenden Arbeit darin, das Massenmedium Fernsehen innerhalb solcher Prozesse zu verorten. Diese Verortung soll anhand der tatsächlichen Programmpraxis öffentlich-rechtlicher Programmangebote vorgenommen werden. Ein solches empiriegeleitetes Vorgehen hat den Vorzug, die theoretische Bedeutung des Fernsehens

\footnotetext{
${ }^{1}$ In dieser Arbeit werden grammatische Anzeigevarianten des Geschlechts von Personen bewusst verwendet. Wenn nur die männliche Form geschrieben steht, sind nur Männer gemeint oder vice versa Frauen. Eine Ausnahme hiervon stellen Begriffe wie „Kommunikator“ und „Rezipient“ dar. Diese werden hier als eine abstrahierende Formel verstanden, ähnlich einem mathematischen Symbol. Sie bezeichnen keine individuellen Personen, sondern deren Position innerhalb der modellhaften Beschreibung des Kommunikationsprozesses.

${ }^{2}$ Die zentralen Begriffe, um die es in dieser Arbeit geht, Nation und Region, sowie die damit zusammenhängenden Begriffe von sozialer, kultureller oder einfacher Gruppenidentität werden im Abschnitt 2 „Grundlagen raumbezogener sozialer Identität “terminologisch erörtert und präzisiert. Darauf sei an dieser Stelle stellvertretend für die gesamte Einleitung verwiesen.
} 
innerhalb der Identitätsprozesse erst über Inferenzschlüsse aus dem Programminhalt zu erschließen.

Soziale Identität kann als Identifikationsprozess von Publikumsseite aus analysiert werden (so etwa Weiß/Trebbe 2001). Dabei wird die Zuwendung zu bestimmten Medienangeboten entweder als Ausdruck sozialer Identität verstanden oder als die Begründung von - aus der Zuwendung folgenden - Medienidentitäten. ${ }^{3}$ Die Medieninhalte werden dabei vernachlässigt. Für ein solches Vorgehen spricht unter anderem, dass die Medienwirkungsforschung genügend Modelle und Befunde zusammengetragen hat, um monokausale Zusammenhänge zwischen Medieninhalten und Einstellungen der Rezipienten zu verwerfen (vgl. Maletzke 1998: 92 sowie zusammenfassend Brosius 2003: 141 und - grdsl. kritisch zum Wirkungsbegriff: Merten 2007: 340). Soziale Identitäten entstehen jedoch aus einem komplexen und fast immer zirkulären Zusammenspiel vielfältiger gesellschaftlicher und individueller Faktoren. So erscheinen Versuche, solche Einzelfaktoren auf ihren Kausalbeitrag hin zu untersuchen, als wenig aussichtsoder ertragreich. Entsprechend gibt es einige experimentelle Untersuchungen, in denen der mediale Stimulus kontrolliert wird und Auswirkungen auf die Rezeption in verschiedenen gesellschaftlichen Gruppen gemessen werden, wobei diese Gruppen sich hinsichtlich ihrer sozialen Identität unterscheiden sollen (so etwa: Coover/Godbold 1998, Richardson 2005). Es ist leicht ersichtlich, dass dieses Vorgehen (der Experimentalsituation geschuldet) an der tatsächlichen Praxis von Medieninhaltsproduktion vorbei geht. Hinzu kommt, dass auch hier Aussagen über das Publikum getroffen werden sollen (entweder in Hinsicht einer Wirkung der Inhalte oder einer Vorhersage der Zuwendungswahrscheinlichkeit). Deshalb muss bei solchen Untersuchungsdesigns die genaue Verortung der Massenkommunikation im eigentlich vorgelagerten Prozess der Generierung sozialer Identitäten unterbleiben.

Obwohl also die Rolle der Massenkommunikation für soziale Identität immer wieder betont wird, sind die Inhalte der Massenmedien nicht in dieser Hinsicht systematisch erfasst und untersucht worden. Daher liegen auf der Seite der Medieninhalte zwar Untersuchungen vor, die mittels qualitativer Methoden bestimmte Ausdrucksformen sozialer Identitäten im Medienangebot analysieren (so bspw. Marschik/Dorer 2003; Christmann 2003), jedoch keine funktionale Zuordnung dieser Inhalte leisten können. Systematisierungen von Publikumsseite aus nehmen dagegen bereits bestehende Gruppenidentitäten zum Ausgangspunkt der Untersuchung und verstehen sie als Variable für eine Hinwendung oder Bewertung bestimmter Inhalte oder umgekehrt bestimmte Inhalte als besonders attraktiv für bestimmte (Zuschauerinnen- und Zuschauer-) Gruppen (so bspw. Götz 2003). So erscheint das Publikum entweder als Ausgangs- oder Zielpunkt eines eigentlich zirkulären Vorgangs.

\footnotetext{
${ }^{3}$ Wobei beide Formen in der Folge zirkulär sein können.
} 


\subsection{Agenda-Setting-Ansatz, Kultivierungsansatz und "The Country Newspaper" - Medien als Sozialisationsinstanzen}

Gehen wir jedoch einen Schritt zurück und unterstellen zunächst einen (mono)kausalen Zusammenhang zwischen Medien und sozialer Identität. Zwei Ansätze der Medienwirkungsforschung erscheinen dann für das Interesse der vorliegenden Arbeit als einschlägig. Das sind der Agenda-Setting-Ansatz und die Kultivierungsperspektive. Beide Positionen gehen davon aus, dass sich das in den Massenmedien verbreitete Weltbild auch im Weltbild des Publikums niederschlägt. „In den Begriffen der Agenda-Setting-Metapher ist dies eine kausale Aussage dergestalt, dass die Prioritäten auf der Tagesordnung der Medien für die Prioritäten der öffentlichen Tagesordnung wichtig werden“ (McCombs 2000: 123). Im Bereich der Agenda-SettingForschung wurde dieser Effekt viele Male für Themen von öffentlichem Interesse insbesondere anhand von Nachrichten untersucht und nachgewiesen (vgl. McCombs 2000: 124 m. w. N.). Geht man davon aus, dass nationale und regionale Identität - jedenfalls zum Teil das Ergebnis von Medienrezeption sind, so könnte man stark vereinfacht annehmen, dass Massenmedien (mit-)bestimmen, über welche Themen und Aspekte des Alltags sich diese beiden sozialen Identitäten zusammensetzen. Würde also etwa das regionale Fernsehen nur noch Kochsendungen zeigen, in denen die jeweils regionale Küche gepriesen wird, so hätten die unterschiedlichen Gaumenfreuden für das jeweilige regionale Selbstverständnis eine möglicherweise sehr hohe Relevanz, regionale Politik oder Kultur dagegen eine möglicherweise sehr geringe. ${ }^{4}$

Während sich der Agenda-Setting-Ansatz allgemein auf Massenmedien bezieht, widmet sich die Kultivierungsperspektive ganz dem Fernsehen. „Dem Fernsehen kommt dabei zentrale Bedeutung zu, weil es sich aufgrund seiner allgegenwärtigen Verfügbarkeit, seiner hohen Reichweite sowie aufgrund der Gleichförmigkeit seiner Botschaften und Realitätsnähe von anderen Medien unterscheidet“ (Rossmann 2006: 145). Die Kultivierungshypothese geht davon aus, dass die TV-Darstellung bestimmter Sachverhalte das Bild beeinflusst, das sich Menschen von eben diesen Sachverhalten machen. Das prominenteste Beispiel für diesen Effekt sind die häufig überschätzten Zahlen schwerer Verbrechen wie Mord- und Totschlag. Sie kommen im Fernsehen sehr häufig vor, haben aber nur einen geringen Anteil an der tatsächlichen Kriminalität. Menschen, die sehr viel fernsehen, überschätzen diesen Anteil häufig (vgl. Gerbner et al. 1979: 190). Ausgangspunkt der Kultivierungshypothese ist die Ansicht, dass das Fernsehen „ein zentralisiertes System des Geschichtenerzählens“ sei (Gerbner 2000: 104). Es ist die ,Quelle der auf breitester Ebene allen Menschen gemeinsamen Bilder und Botschaften in der Geschichte. Es ist das führende Medium der uns allen gemeinsamen symbolischen Umwelt, in die unsere Kinder hinein geboren werden und in der wir alle unser ganzes Leben verleben werden“ (Gerbner 2000: 103, Hervorhebung im Original). Gerbner als Mitbegründer dieser

\footnotetext{
${ }^{4}$ Unabhängig von diesem hypothetischen Zusammenhang scheinen verschiedene „Esskulturen“ für nationale Identität tatsächlich konstituierend zu sein, worauf Thomas in ihrer Studie zur Konstruktion nationaler Identität hinweist (vgl. Thomas 2003b: 296).
} 
Theorie wehrt sich zu Recht dagegen, Kultivierung als unidirektionalen Prozess zu begreifen (vgl. Gerbner 2000: 107). Dennoch kann man die grundlegende Idee des Kultivierungsansatzes stark vereinfacht so ausdrücken: Wenn im Fernsehen Menschen aus Bayern sehr häufig in Trachtenkleidung auftreten, werden Menschen, die viel fernsehen, wahrscheinlich der Meinung sein, Trachten seien eine in Bayern sehr oft und gern getragene Kleidungsform - und zwar unabhängig von der tatsächlichen Verbreitung dieser Gewandung.

Insofern kann man diese beiden - im Einzelnen selbstverständlich weitaus differenzierteren Ansätze auf die einfache Formel zurückführen, dass Medien- bzw. (im Speziellen) Fernsehinhalte unser Weltbild wesentlich mitbestimmen. Im Kontext der hier relevanten Fragestellung würde das heißen, dass das Fernsehen bestimmt, was deutsch und was österreichisch oder was bayerisch und was mitteldeutsch ist. So einfach ist es aber nicht. Denn auch eine bereits bestehende soziale (sowie nationale oder regionale) Identität kann mitursächlich dafür sein, dass bestimmte Teile des Publikums bestimmte Programme einschalten. Eine unidirektionale Wirkungsrichtung gibt es also nicht.

Eine Studie zum Einfluss sozialer Identität liegt von Trepte vor (Trepte 2004). Darin wird nationale Identität (sowie Genderidentität) als Einflussfaktor auf die Wahl unterhaltender Fernsehangebote untersucht.5 Trotz der Einschränkungen, die Trepte bezüglich der Ergebnisse ihrer Studie selbst vornimmt,6 weist sie in der theoretischen Herleitung auf zentrale Aspekte des Zusammenhangs zwischen nationaler Identität und Medienwahl hin: Trotz der deutlich höheren Anteile US-amerikanischer Unterhaltungsproduktionen im deutschen Fernsehprogramm sind häufig nationale Unterhaltungsangebote erfolgreicher in der Gunst des Publikums (Trepte 2004: 235). Trepte stellt heraus, dass Inhalte mit lokalem Bezug7 Zuschauerinnen und Zuschauer in einer besonderen Weise ansprechen und bei der Identitätsbildung unterstützen. „Nur wenn Fernsehen auch nationale Interessen aufgreift und trifft, wird es erfolgreich sein. Die Zuschauer möchten bekannte Orte, Plätze, Themen und sich selbst als Teil einer Kultur wiedererkennen. Im Gegensatz zu anderen Konsumprodukten ist Fernsehunterhaltung ein Kulturprodukt“ (Trepte 2004: 235). Was als Erfolgsfaktor für unterhaltende Angebote gilt, ist für informierende Fernsehangebote eine beinahe unerlässliche Bedingung. Politische Entscheidungen können das eigene Leben unmittelbar beeinflussen, eigene Teilhabe an politischen Entscheidungen ist meist nur in lokalen, regionalen und - schon seltener - nationalen Zusammenhängen möglich. Das gleiche gilt für gesellschaftliche Prozesse und Ereignisse. Selbstverständlich ist für informierende Fernsehinhalte eine ganz andere Angebotslage gegeben als für Unterhaltungsproduktionen. Wenn aber die Präferenz für „kulturnahe“ Unterhaltungsangebote durch, ähnliche Werte, Wünsche, eine geteilte Sprache und ähnlichen

\footnotetext{
${ }^{5}$ Ergebnisse bezüglich der ebenfalls untersuchten Einflüsse von Genderidentität werden hier weggelassen, da sie den Gegenstand der vorliegenden Untersuchung nicht betreffen.

${ }^{6}$ Ein Einfluss der Nationalität auf die Medienwahl ließ sich nicht nachweisen. Dabei ist aber - wie Trepte selbst einräumt - das Herkunftsland als Indikator für nationale Identität der Befragten kritisch zu bewerten (Trepte 2004: 241). Zudem handelte es sich bei den Befragten ausschließlich um Studierende. Trepte legt selbst eine deutlich differenziertere Studie vor (Trepte (2008)). Darin geht es um den Einfluss der Faktoren Nationalität und kulturelle Nähe auf die Zuwendung zu US-amerikanischen Unterhaltungsangeboten.

${ }^{7}$ Wobei lokal hier wohl eher als Gegensatz zu international bzw. ausländisch zu verstehen ist und nicht im stärker eingegrenzten Verständnis tatsächlicher lokaler Medienangebote aus nur einer Stadt oder gar einem Stadtteil.
} 
Humor" (Trepte 2004: 235 m. w. N.) beeinflusst wird, so liegt es nahe, das auch über unterhaltende Inhalte hinaus anzunehmen. Das Fernsehen ist hier (wie die anderen Massenmedien auch) eine von vielen Sozialisationsinstanzen. Nach Schulz (Schulz 2003) werden Medien dabei von den Angehörigen einer Nation bewusst zur Entwicklung, Definition und Konservierung der eigenen Identität genutzt.8 Das schließt notwendigerweise die Kommunikatorseite mit ein, da die Produzentinnen und Produzenten der Medieninhalte ebenso Mitglieder der Nation sind wie die Rezipienten. Daher können Programminhalte eine Reihe von Hinweisen auf die Funktion" des Fernsehens als Aushandlungs- und Vermittlungsinstanz kollektiver Identitäten enthalten. Es erscheint deshalb folgerichtig, Inhalte des Fernsehens empirisch zu erfassen, um anschließend eine theoretisch-funktionale Einordnung - unter Berücksichtigung bestehender Theorien der Massenkommunikation - vorzunehmen.

Zutreffend nimmt Trepte an, dass der Herkunftsort einer TV-Sendung eine Aussage darüber enthält, „ob national geteilte Normen, gemeinsame Gebräuche, Verhaltensweisen, Humor oder kulturelles Wissen berücksichtigt werden oder nicht“ (Trepte 2004: 236). Des Weiteren nimmt die Autorin an, ,dass Rezipienten bei der Auswahl lokaler Produkte eher eine Passung der eigenen Identitätsdimensionen und der Medieninhalte erwarten“ (Trepte 2004: 236). Diese Erwartungshaltung bezieht sich dabei nicht auf eine Abwertung der out-group (also jener, die nicht Teil der eigenen sozialen Gruppe sind, genauer hierzu S. 13), sondern darauf, dass „der eigenen nationalen Identität entsprechende und auf nationale Identität bezogene Inhalte dargeboten werden und auf diese Weise eine positive soziale Distinktheit erreicht wird“ (Trepte 2004: 236). Im Zusammenhang mit dem von Trepte untersuchten Unterhaltungsangebot dürften sich diese Faktoren insbesondere darauf beziehen, dass TV-Sendungen auch Ausdruck der Kultur ihres Herkunftslandes sind. Es ist ein Mindestmaß an kultureller Passung notwendig, damit Zuschauerinnen und Zuschauer sich solchen Angeboten zuwenden. ${ }^{10}$ Daraus folgt die Notwendigkeit, dass die Medieninhalte dahingehend untersucht werden, ob sie einer solchen Erwartungshaltung überhaupt entsprechen. Für die Beantwortung der Frage, ob kollektive Identitäten Faktoren der Zuwendung zu Fernsehsendungen sind, bedarf es der Klärung, in welchem Maße solche Identitäten im Fernsehen überhaupt Ausdruck und Berücksichtigung finden.

\footnotetext{
${ }^{8}$ Nach Schulz ist das die Prämisse des funktionalen Ansatzes der Erklärung des Verhältnisses zwischen Medien und kollektiver Identität. Daneben gibt es die Prämisse des kausalen Ansatzes: „Medien prägen oder beeinflussen (verändern) die Definition kollektiver Identität.“ (Schulz 2003).

${ }_{9}^{9}$ Mit Funktionen sind hier nicht (nur) normative Aufgaben im Sinne von Zielvorgaben gemeint. Funktionen umfassen ebenso die tatsächlich erbrachten Leistungen für die Gesellschaft, unabhängig davon, ob diese gewünscht sind oder nicht (vgl.: Bonfadelli 2005b: 95). Vor diesem Hintergrund sind die Begriffe „funktionale Beschreibung“ oder „funktionale Verortung“ in dieser Arbeit so zu verstehen, dass der Frage nachgegangen wird, ob und wie sich Fernsehinhalte in eine theoretisch abgeleitete Funktion (Repräsentation, vgl. S. 89) des Fernsehens für die sozialen Gemeinschaften Nation und Region einpassen lassen.

${ }^{10}$ Dieses Mindestmaß untersuchte Trepte 2008 unter dem Begriff „kulturelle Nähe“ (vgl. Trepte 2008). Für fiktionale Sendungen kommen hier sehr vielschichtige Faktoren zusammen als Zuwendungsbedingung in Betracht. Dabei ist aber auch zu bedenken, dass kulturelle Nähe nicht nur in eine Richtung funktioniert, dann zum Beispiel stellt die Vielzahl im deutschen Fernsehen ausgestrahlter US-TV-Serien auch einen Teil dieser kulturellen Nähe erst her, die in der Folge weiterer US-amerikanischer Fernsehproduktionen hierzulande erfolgreich macht.
} 
Medien und ihre Integrationsfunktion für soziale Gemeinschaften sind bereits in den 1920er Jahren inhaltsanalytisch untersucht worden. Willey nannte seine Studie regionaler Presse von 1926 „The Country Newspaper“ im Untertitel „A study of socialization and newspaper content“". Es ging ihm dabei hauptsächlich um die Bedeutung lokaler Wochenzeitungen in ländlichen Gebieten der USA. Willey ging davon aus, dass ein direkter Einfluss der Presse auf das Sozialgefüge einer regionalen Gemeinschaft schwer zugänglich zu machen wäre. „But it was suggested that some value be had from knowing precisely how much material of various types was to be found in the columns of the papers" (Willey 1926: 108). ${ }^{11}$ Um herauszufinden, inwiefern Zeitungen eine sozialisierende Wirkung innerhalb ländlicher Kommunen darstellen, wählte er daher einen indirekten Zugang (Willey 1926: 20). Dieser basierte auf der heute relativ simpel erscheinenden Prämisse, lokale Presse habe ein Spiegel ${ }^{12}$ der lokalen Gemeinschaft zu sein. Es handelt sich dabei um eine normative Zielvorgabe, die dann erfüllt ist, wenn das lokale oder regionale gesellschaftliche Leben möglichst umfassend in der Zeitung repräsentiert ist.

„If a given paper for the period of a year fails to recount a single incident pertaining to local philanthropic activity, it can be considered that in this respect this one paper is of no importance in socialization. It has failed to make known to the community what the community is doing in one important field of human endeavor" (Willey 1926: 21).

Die Sozialisationsfunktion der Presse wird dementsprechend als eine Aufgabe innerhalb der Demokratie verstanden. Eine funktionierende Demokratie fußt nach diesem Verständnis insbesondere auf einem Gemeinschaftsbewusstsein, auf der geteilten Annahme, als Gesellschaft eine Einheit darzustellen „There can be no political democracy, much less economic or social democracy, in a group where psychological unity is lacking, for democracy in all its phases is based on mutuality“ (Willey 1926: 10). Eine Charakterisierung der Massenmedien - und speziell des Fernsehens - allein anhand solcher demokratischer Pflichten erscheint aus heutiger Sicht als zu kurz greifend. In den letzten hundert Jahren haben sich Massenmedien in einer Weise entwickelt, dass sie in nahezu allen Lebensbereichen präsent sind. So hat sich etwa das Freizeitverhalten dadurch verändert, dass im Fernsehen Unterhaltungsprogramme dargeboten werden. Die Funktionen der Massenmedien können nicht abschließend so beschrieben werden, als dienten sie der reinen Nachrichtengebung. Massenmedien sind Teil komplexer sozialer, politischer und wirtschaftlicher Gefüge. Sie sind eine Bedingung für gesellschaftliche Kommunikation, werden aber auch selbst von den Gesellschaften, in denen sie existieren stark geprägt. Dennoch hat Willeys ,indirekter Ansatz“ auch heute noch eine gewisse Berechtigung, wenn man Medien nicht als Spiegel einer Gesellschaft versteht, sondern als ihren Ausdruck. An der medialen Oberfläche drücken sich nach diesem Verständnis jene Aspekte des ( $\mathrm{Zu}-$ sammen-)Lebens aus, die eine Gesellschaft und die Menschen, die in ihr leben, umtreiben. Auf Grund der Bedeutung von Massenmedien und vor allem des Fernsehens in modernen Gesellschaften ist dieses Verständnis auch nicht einseitig zu betrachten. Denn einerseits bestehen die Medieninhalte aus Themen, die für viele Menschen interessant sind, andererseits produzieren

\footnotetext{
${ }^{11}$ Mit „,material of various types“ hebt Willey auf seine eigene Kategorisierung der abgedruckten Inhalte ab. Er unterscheidet bspw. Material von (überregionalen) Agenturen (,syndicated material“) von redaktionellen Beiträgen (vgl. Willey 1926: 39).

${ }^{12}$ Bei Willey ,a perfect mirror““ (1926: 22).
} 
Medien auch selbst Gegenstände, die das Interesse erst wecken. So wird ebenso über politische Entscheidungen einer Regierung berichtet wie über einen gecasteten „Superstar“. Beides hat auf viele Menschen Einfluss, was sich wiederum in der medialen Präsenz ausdrückt. ${ }^{13}$ Insofern verspricht eine Betrachtung der Medieninhalte - auch in der von Willey vorgemachten Weise - durchaus einigen Aufschluss über die Gesellschaft, in der diese Medieninhalte entstehen. Deshalb ist „The Country Newspaper“ als prototypisch für das Interesse der vorliegenden Arbeit anzusehen. Selbstverständlich bedarf das theoretische Fundament ebenso der Aktualisierung und Erweiterung wie der empirische Zugang.

13 Wobei mediale Präsenz hier lediglich als „Vorhandensein in den Medien“ aber noch nicht als eine quantifizierbare Größe zu verstehen ist. Denn selbstverständlich ist eine Senkung der Arbeitslosenbezüge für viel mehr Menschen von viel gravierender Bedeutung als der Ausgang einer Castingsendung. Das gilt auch, wenn letzteres die Titelseite einer Boulevardzeitung füllt und ersteres nur eine Meldung auf der letzten Seite ist. 


\subsection{Forschungsinteresse}

Das Interesse der vorliegenden Untersuchung richtet sich auf die mediale Präsenz nationaler und regionaler Identität. Beide Phänomene werden im Folgenden als Ergebnis sozialer Aushandlungsprozesse verstanden. ${ }^{14}$ Sie sind auf unterschiedliche Weise in verschiedenen Wissenschaftsdisziplinen untersucht worden (dazu im Einzelnen Kapitel 2.2 bis 2.5). Was aber bisher fehlt, ist eine vergleichende Gegenüberstellung hinsichtlich ihrer Erscheinungs- und Ausdrucksformen im Fernsehprogramm. Es wird davon ausgegangen, dass die TV-Programme inhaltliche Angebote bereithalten, die der Passung eigener Identitätsdimensionen im Publikum dienen. Daraus folgend ist anzunehmen, dass sich nationale und regionale Fernsehprogramme so unterscheiden, dass die jeweiligen Spezifika der Nation oder der Region darin deutlich werden. Darüber hinaus richtet sich das Interesse der vorliegenden Arbeit darauf, ob sich in diesen Unterschieden Strukturen erkennen lassen, die über die jeweilige Nation und Region selbst hinausgehen - ob es also spezifisch regionale und spezifisch nationale Muster im Programmangebot des Fernsehens gibt. Diese - vom zu untersuchenden Material abstrahierende - Vergleichsdimension erfordert es, auf der nationalen und regionalen Ebene jeweils mindestens zwei TV-Programme zu untersuchen. Es geht also nicht darum, die auf der jeweiligen nationalen (regionalen) Identität beruhenden Unterschiede der untersuchten Fernsehprogramme zu vergleichen, sondern dies ist nur ein Zwischenschritt. Darauf aufbauend werden die Strukturen herausgearbeitet, die die nationale bzw. regionale Identität im Fernsehprogramm tragen. Diese Strukturen sollen schließlich verglichen werden (vgl. Abbildung 1). Im Rahmen der Ergebnisinterpretation sollen dann Rückschlüsse darauf gezogen werden, wie sich nationale und regionale Identität im Fernsehprogramm zueinander verhalten (komplementär oder konträr) und für welche Lebens- und Gesellschaftsbereiche sie jeweils salient ${ }^{15}$ erscheinen.

\footnotetext{
${ }^{14}$ Die theoretischen Begründungen dafür liefert Abschnitt 2 „Grundlagen raumbezogener sozialer Identität“ (S. 12ff.).

${ }^{15}$ Der Begriff „Salienz“ ist in der Sozialpsychologie gebräuchlich. McCombs verwendet ihn innerhalb der Agenda-Setting-Theorie. Im Deutschen wird er häufig mit „Relevanz“ übersetzt. Salienz bezeichnet die kontextbezogene Wahrnehmungswahrscheinlichkeit (vgl. Fiedler/Bless 2003: 137). Die Relevanz bestimmter Sachverhalte ändert sich also mit dem Zusammenhang, in dem wir ihnen begegnen.
} 
Abbildung 1: Vergleichsdimensionen nationaler und regionaler Identität von Fernsehprogramminhalten

Nationale Ebene

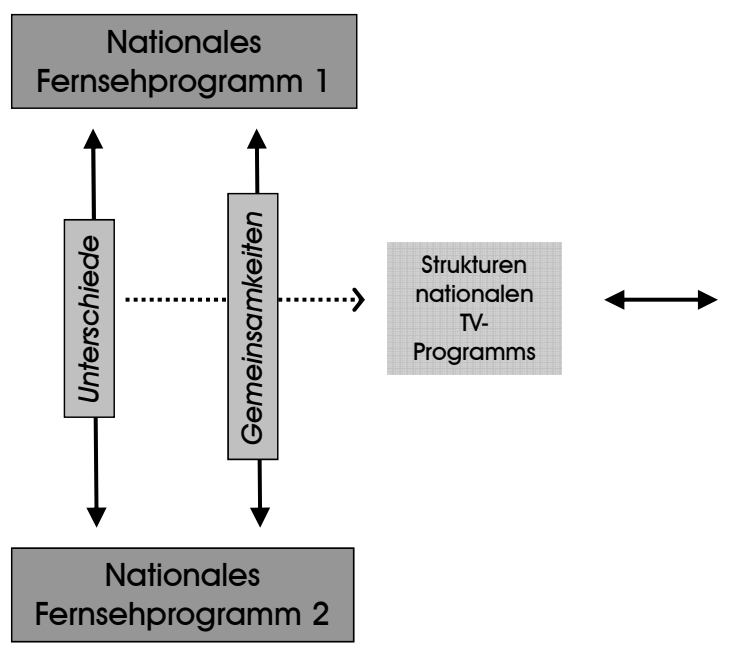

Regionale Ebene

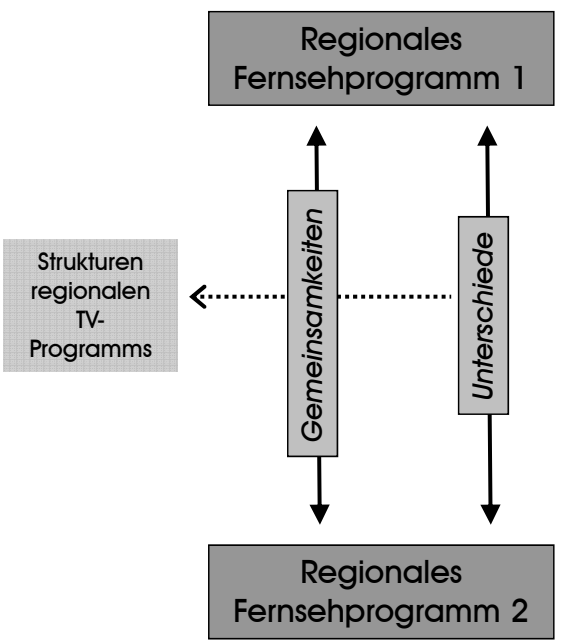

Als zu untersuchende Sender wurden das $Z D F$ und ORF 2 (nationale Ebene) sowie BRFernsehen und MDR-Fernsehen (regionale Ebene) ausgewählt. Diese Wahl ist willkürlich, folgt aber bestimmten Interessen sowie forschungslogischen und pragmatischen Überlegungen. Um auf nationaler Ebene einen Vergleich anzustellen, ist die Auswahl zweier national verbreiteter Programme zwingend notwendig. Im Rahmen international vergleichender Analysen ist man zumeist mit dem Problem der unterschiedlichen Sprachen konfrontiert. Das kann im Detail problematisch werden, sofern nicht auf muttersprachliche Sprachkenntnis zurückgegriffen werden kann. Daher fiel die Wahl auf Österreich als das Land, das Deutschland gegenübergestellt werden soll. Die Wahl der beiden nationalen Sender hat eine inhaltliche Rechtfertigung. Im Gegensatz zum Ersten Programm der $A R D$ wird das ZDF nicht als Gemeinschaftsprogramm mehrerer regionaler Sendeanstalten produziert, sondern ist auch bereits aus seiner Entstehungsgeschichte ein originär für ganz Deutschland gedachtes Programm. Auf österreichischer Seite betrifft die Wahl das Programmprofil: Während ORF 1 insbesondere auf Unterhaltungsformate in Form von Spielfilmen und TV-Serien spezialisiert ist, wird der Großteil der Informationssendungen im ORF 2 ausgestrahlt. Da informierende Angebote in der Untersuchung von besonderer Bedeutung sein sollen, war die Auswahl des ORF 2 also inhaltlich begründet. Auf regionaler Ebene wurden sowohl eine Einlandesanstalt (BR) als auch eine Mehrländeranstalt (MDR) ausgewählt. In der $A R D$ gibt es fünf Einlandesanstalten (Bayerischer Rundfunk, Hessischer Rundfunk, Radio Bremen, Saarländischer Rundfunk, Westdeutscher Rundfunk) und vier Mehrländeranstalten (Mitteldeutscher Rundfunk, Norddeutscher Rundfunk, Rundfunk BerlinBrandenburg, Südwestrundfunk). Um diese Vielfalt trotz der begrenzten Auswahl abzubilden, wurde jeweils ein Vertreter jeden Typs gewählt. Die Wahl sollte außerdem sowohl die alten als 
auch die neuen Bundesländer berücksichtigen. ${ }^{16}$ Für die Wahl des Bayerischen Rundfunks sprach schließlich auch die Annahme, dass Bayern ein besonders stark mit Stereotypen belegtes Bundesland ist. Das wirft zusätzlich die Frage auf, ob dieses Vorurteil sich an den Programminhalten des Bayerischen Rundfunks bestätigt.

Im Fokus der Untersuchung stehen Magazinsendungen. ${ }^{17}$ Das hat mehrere Gründe: Magazine stellen einen wichtigen und umfangreichen Anteil in der aktuellen Fernsehpublizistik dar. Sie sind thematisch vielgestaltiger als Nachrichtensendungen und bilden damit einen größeren Querschnitt der journalistischen Leistung eines Fernsehsenders ab. So lassen sich erste Rückschlüsse auf das publizistische Profil eines TV-Programms etwa schon aus der Anzahl von Politik-, Kultur-, Sport- und Boulevardmagazinen ziehen. Magazinsendungen gehören zu jenem Teil des Programmangebots, der von der Sendeanstalt nicht nur ausgestrahlt, sondern redaktionell gestaltet wird. ${ }^{18}$ Insofern prägen Magazine das Bild eines Fernsehsenders in einer von den Sendeverantwortlichen intendierten Weise. Die Auswahl des Spielfilmangebots dürfte sich zum allergrößten Teil an den Vorlieben des Publikum orientieren. In Magazinsendungen hingegen ist auch die publizistische Funktion des Gatekeepings ${ }^{19}$ wirksam. ${ }^{20}$ Welche Informationen werden dem Publikum übermittelt und welche nicht? Im Zusammenhang mit der hier erörterten Frage bedeutet das etwa: Welche Informationen sind lediglich für bestimmte Regionen von Interesse? Welche betreffen die ganze Nation? Wie drückt sich eine solche unterschiedliche Akzentuierung im Programm aus?

Gleichzeitig erlauben die Genrekonventionen einen praktikablen Forschungszugang. Üblicherweise sehen Magazine so aus, dass einzelne redaktionelle Beiträge innerhalb einer Sendung durch Moderationen und eine einheitliche Gestaltung zusammengehaltenen werden. So ist eine Abgrenzung der Magazine nach außen (vom sonstigen Programm) ebenso einfach nachvollziehbar wie die Abgrenzung einzelner Beiträge innerhalb der einzelnen Sendung. ${ }^{21}$ Auf diese Weise ist es möglich, große Teile eines Fernsehprogramms relativ kleinteilig zu analysie-

\footnotetext{
${ }^{16}$ Damit schieden $r b b$ und NDR aus: Der rbb sendet für Berlin und Brandenburg und sein Sendegebiet umfasst damit das frühere West-Berlin. Der NDR sendet für vier Bundesländer, von denen nur MecklenburgVorpommern auf dem Gebiet der früheren DDR liegt. Diese Integration ehemals staatlich getrennter Räume in ein Sendegebiet wäre ein ebenfalls interessantes Thema für zukünftige Forschungsarbeiten. In der vorliegenden Arbeit wurde auf diesen Aspekt bewusst verzichtet: Im Rahmen des hier gewählten Forschungsinteresse wären die sich daraus ergebenden Besonderheiten nicht im notwendigen Maße zu berücksichtigen gewesen.

${ }^{17}$ Die genaue Definition für Magazine wird im Abschnitt 4.6.2 (S. 97ff.) gegeben.

18 Tatsächlich sind die Produktionsbedingungen mittlerweile vielfältig, da es externe Produktionsfirmen gibt, die für einzelne TV-Programme Sendungen herstellen. Damit wird zwar ein Teil der redaktionellen Arbeit einer Sendeanstalt ausgelagert, nicht aber deren redaktionelle Verantwortung als Veranstalter des Programms. Ein Einfluss auf den Inhalt dürfte aber durch entsprechende vertragliche Regelungen normalerweise auch gegeben sein.

${ }^{19}$ Vgl. zur theoretischen Tragweite des Begriffs insb. Robinson 1973. Während der „Gatekeeper anfangs die Rolle der Journalistinnen und Journalisten bei der Nachrichtenauswahl bezeichnet ist er nach der später entwickelten kybernetischen Sichtweise auch geeignet, die grundsätzliche Filterfunktion, die den Massenmedien insgesamt zukommt, zu beschreiben, ohne den personellen Aspekt aufzugeben.

${ }^{20}$ Das trifft auch auf Nachrichtensendungen zu, dort aber thematisch stärker eingeschränkt. Ebenfalls trifft es auf monothematische Fernsehpublizistik zu, wie etwa einzelne Reportagen.

${ }^{21}$ Einzelne Schwierigkeiten, die sich in der tatsächlichen Operationalisierung ergeben, werden in der Vorstellung des eigentlichen empirischen Zugangs genauer problematisiert. Vgl. S. 144.
} 
ren. Es können viele verschiedene Aspekte in die Untersuchung einfließen, die bei einer groben Erfassung auf Sendungsebene keine Berücksichtigung finden könnten.

Dabei sollen Magazinsendungen aber im Kontext des Gesamtprogramms verortbar bleiben, was eine grobe Erfassung des gesamten Programms erfordert. Das ist notwendig, weil das Fernsehen insgesamt als sozialisierende Institution begriffen wird. Eine Verengung auf einzelne Sendungen könnte dem jedoch nicht gerecht werden. Insofern stellt der gewählte empirische Zugang einen Kompromiss zwischen Forschungsinteresse und Forschungsökonomie dar.

\subsection{Aufbau der Arbeit}

An die Einleitung schließt eine Präzisierung der zentralen Begriffe an, um die es in dieser Arbeit geht. Diese Präzisierung erfolgt in Auseinandersetzung mit geeigneten theoretischen Ansätzen. Daraus wird anschließend eine hypothetische Verortung des Fernsehens im Prozess nationaler und regionaler Identitätsbildung entwickelt. Da Programmrealität unter bestimmten strukturellen und institutionellen Rahmenbedingungen gestaltet wird, werden diese für die interessierenden Untersuchungsräume dargestellt. Auf Basis des theoretisch abgeleiteten Vorverständnisses des Untersuchungsgegenstandes wird das Instrumentarium entwickelt, mit dem evaluiert werden soll, wie sich die hypothetischen Funktionen des Fernsehens im sozialen Prozess nationaler und regionaler Identitätsbildung in der tatsächlichen Programmpraxis niederschlagen. Die Auswertung der empirischen Untersuchung erfolgt dann zunächst anhand eines umfangreichen Hypothesenkataloges. Dieser Betrachtung der Programminhalte folgt schließlich die übergreifende Interpretation der Ergebnisse im Hinblick auf das Forschungsinteresse dieser Arbeit. Im Resümee werden die Ergebnisse kurz zusammengefasst und ein Ausblick auf mögliche wissenschaftliche Anschlussfragen gegeben. 


\section{Grundlagen raumbezogener sozialer Identität}

In diesem Abschnitt soll zunächst ein Überblick über verschiedene Konzepte sozialer Identität gegeben werden. Daran schließt sich eine Darstellung der wissenschaftlichen Zugänge zu den Begriffen Nation und Region an. Dabei soll - unter Rückgriff auf die Erörterungen zur sozialen Identität - deren gesellschaftliche Bedingtheit herausgestellt werden. Im Anschluss werden die Konzepte nationaler und regionaler Identität auf Basis der theoretischen Vorarbeit anhand der hier relevanten Beispiele (Deutschland, Österreich, Bayern, Mitteldeutschland) dargelegt. Das Ziel der theoretischen Eingrenzung, ist die Erarbeitung eines Instrumentariums zur empirischen Erforschung nationaler und regionaler Identität von Fernsehprogramminhalten.

\subsection{Soziale Identität}

Die Auseinandersetzung mit verschiedenen Konzepten von kultureller, ${ }^{22}$ sozialer und gruppenspezifischer Identität in Zusammenhang mit Medien ist in der gegenwärtigen Sozialforschung sehr en vogue. Hepp/Thomas/Winter konstatieren gar einen Boom der Beschäftigung mit „Identität und Medien“ (2003: 7). Dementsprechend vielseitig sind auch die theoretischen Ansätze zu diesem Forschungsfeld. Im Sinne der Zielsetzung dieser Arbeit werden daher im Folgenden lediglich grundlegende Theoriekonzepte kurz dargestellt und auf ihren Nutzen für eine empirische Untersuchung von Fernsehinhalten geprüft. Im Einzelnen sind dies die Theorie der sozialen Identität nach Tajfel/Turner (Tajfel/Turner 1979), der Symbolische Interaktionismus nach G. H. Mead (Mead 2005 [1934]) sowie Giesens kulturwissenschaftliche Auseinandersetzung mit dem Phänomen kollektiver Identitäten (Giesen 1996, Giesen 1999b). Diese Ansätze sind so elaboriert, dass sie bereits das notwendige Begriffsinventar für die weitere theoretische Annäherung an den Untersuchungsgegenstand enthalten. ${ }^{23}$

\footnotetext{
${ }^{22}$ Kulturelle Identität wird im Folgenden als eine Form sozialer Identität verstanden. Kultur umfasst die Gesamtheit von Symbolen, Wissen, Wertvorstellungen und Normen, kollektiven Weltbildern und Sinnkonstrukten innerhalb eines sozialen Kontextes (so Plake 2004: 223, vgl. auch Thiele 2005: 190), beruht also auf sozialer Interaktion und Kommunikation. Kulturelle Identität bezeichnet demnach eine Gruppenidentität, die sich auf die genannten kulturkonstituierenden Konzepte bezieht. Dazu gehört aber auch ein Mindestmaß an Internalisierung der kulturell bestimmten Normen und Werte.

${ }^{23}$ Die Beschränkung auf diese Positionen ist auch auf forschungsökonomische Zwänge zurückzuführen. Gerade weil es sich um grundlegende Ansätze handelt, eignen sie sich zur Adaption für einen empirischen Zugang. Das gilt häufig nicht für Arbeiten, die sich im selben Forschungsfeld bewegen (vgl. etwa die in Hepp et al. 2003 versammelten Arbeiten). Um deren nicht minder interessanten Überlegungen nutzbar machen zu wollen, müsste man drei Schritte vor und zwei zurück gehen, da sie sich auf sehr eng umgrenzte Phänomene beziehen. Der theoretische Ertrag müsste dann erst unter Rückgriff auf weitere Ansätze rückwirkend wieder erweitert werden. Für eine in ihrem Kern empirische Arbeit wäre dieser Aufwand kaum zu rechtfertigen.
} 
Wichtig ist zunächst eine Einschränkung des Identitätsbegriffs. Als psychoanalytisch-sozialpsychologisches Konzept meint Identität zuallererst die Kontinuität des Selbsterlebens eines Individuums (Hörnig/Klima 1988: 327). Sie wird durch Übernahme sozialer Rollen und Gruppenmitgliedschaften sowie deren Anerkennung von außen ${ }^{24}$ hergestellt (Hörnig/ Klima 1988: 327, vgl. auch Giesen 1999a: 399, Giesen 1999b: 18). Im hier relevanten Kontext bezieht sich die Identität jedoch nicht auf Individuen, sondern auf Gruppen. Diese zeichnen sich ebenfalls durch eine wahrgenommene Kontinuität aus, jedoch nicht im individuellen Selbsterleben. Hier werden vielmehr verstetigte Merkmale der Gruppe wahrgenommen und zwar sowohl von den Gruppenmitgliedern als auch von Außenstehenden.

\subsubsection{Theorie der sozialen Identität}

Die Verhaltenswirksamkeit sozialer Identität haben bereits Tajfel/Turner mit ihrer Theorie der sozialen Identität herausgestellt (Tajfel/Turner 1979). Dabei gehen sie vom Minimalgruppen-Paradigma (MGP) aus, das besagt, dass bereits eine willkürliche Zuteilung von Menschen in Gruppen zur Bevorzugung der eigenen Gruppe führt. „Die einfache, ja triviale Kategorisierung in zwei soziale Gruppen reicht anscheinend aus, um diskriminierendes Verhalten gegenüber der Fremdgruppe hervorzurufen (entsprechend werden die Befunde im MGP häufig auch ,reiner Kategoriesierungseffekt" genannt)“ (Mummendey/Otten 2002: 99).

Tajfel/Turner verbinden in der Theorie der sozialen Identität vier theoretische Konzepte: soziale Kategorisierung, soziale Identität, sozialen Vergleich und soziale Distinktheit (Mummendey/Otten 2002: 100). Dabei dienen soziale Kategorisierungen der Orientierung in der Realität, indem sie die soziale Umwelt segmentieren, klassifizieren und ordnen (vgl. Tajfel/Turner 1979: 40). Die soziale Identität bestimmt sich aus der Zugehörigkeit zu einer sozialen Gruppe sowie deren Verhältnis zu anderen Gruppen. Das wichtigste Kriterium für die Gruppenmitgliedschaft eines Individuums ist, dass es sich selbst als Gruppenmitglied definiert und von anderen als Mitglied dieser Gruppe definiert wird (Tajfel/Turner 1979: 40).

Für Tajfel beruht eine Gruppe auf bis zu drei Komponenten: einer kognitiven, einer evaluativen und einer emotionalen (1982: 70). Die erste bezeichnet lediglich das Wissen, dass man zu einer Gruppe gehört. Die evaluative Komponente addiert zu der Vorstellung der Gruppenmitgliedschaft eine positive oder negative Wertkonnotation. Erst durch die emotionale Komponente können die ersten beiden auch von Emotionen bezüglich der eigenen und anderer Gruppen begleitet werden.

Die Theorie der sozialen Identität zielt vor allem auf die Erklärung der Beziehungen verschiedener Gruppen zueinander. Diese Beziehungen sind durch wahrgenommene Statusbeziehungen gekennzeichnet. Abhängig davon, ob Mitglieder die eigene Gruppe (in-group) als statusgleich, unterlegen oder überlegen sehen, ergeben sich Vergleichsergebnisse zur out-group, aus denen Informationen zur Bewertung der eigenen sozialen Identität gezogen werden können

\footnotetext{
${ }^{24}$ Im weitesten Sinne also Fremdwahrnehmung.
} 
(vgl. Mummendey/Otten 2002: 101). Im Falle eines negativen Vergleichsergebnisses streben Gruppenmitglieder danach, die Bewertung der eigenen sozialen Identität wieder positiv werden zu lassen (Mummendey/Otten 2002: 101). Dies geschieht etwa, wenn sie im Wettbewerb mit der out-group versuchen ihre Position zu verbessern und die Statusbeziehung zwischen beiden Gruppen umzukehren und dadurch ihre soziale Identität kollektiv zu verbessern (Mummendey/Otten 2002: 102; „social competition“ Tajfel/Turner 1979: 44). Zudem können die Gruppenmitglieder versuchen, die Bestandteile der Vergleichssituation zu verändern oder umzudefinieren („social creativity“ Tajfel/Turner 1979: 43). Dafür stehen ihnen nach Tajfel/Turner drei Wege zur Verfügung. Erstens können die in-group und die out-group hinsichtlich einer neuen Dimension verglichen werden. Zweitens können sie die Bewertungsrichtung umkehren, also eine Uminterpretation der bisherigen Vergleichsdimension vornehmen, und damit die bisher negativen zu positiven Vergleichsergebnissen machen. Drittens können sie die Gruppe, mit der die in-group verglichen wird, wechseln, sich also vorzugsweise mit einer statusniedrigeren Gruppe vergleichen. Wie bereits für die Konstitution der Gruppe gilt auch hier, dass die Bewertungen durch die in-group konsensual geteilt werden müssen, um im Alltag salient zu sein. Bei der Herstellung einer solchen Übereinstimmung spielen Massenmedien eine wichtige Rolle, die im Rahmen dieser Arbeit näher zu betrachten sein wird.

\subsubsection{Symbolischer Interaktionismus}

Individuelles menschliches Verhalten steht im Zentrum der Theorie des symbolischen Interaktionismus nach G. H. Mead sowie H. Blumer. Die Grundlagen werden dabei in der sozialen Interaktion gesehen. Insofern wird auch individuelle Identität als eine Folge des Zusammenlebens gesehen, denn der

„Einzelne ist das, was er ist, als bewußte und individuelle Persönlichkeit nur insoweit, als er ein Mitglied der Gesellschaft, in den gesellschaftlichen Erfahrungs- und Verhaltensprozeß eingeschaltet und dadurch in seinem Verhalten gesellschaftlich kontrolliert ist" (Mead 2005 [1934]: 302).

Im Rahmen der vorliegenden Arbeit sind die drei theoretischen Prinzipien des Symbolischen Aktionismus, wie sie von Blumer formuliert wurden, von Bedeutung. Demnach verhalten sich Menschen gegenüber Dingen ${ }^{25}$ auf der Grundlage der Bedeutung, die diese Dinge für sie haben (vgl. \{Blumer 1973 \#573: 81 /nopar). Diese Bedeutungen entstehen erst durch soziale Interaktion mit anderen Menschen, das heißt sie werden sozial ausgehandelt. Die Bedeutungen können schließlich im interpretativen Prozess der Auseinandersetzung des Individuums mit den Dingen abgeändert werden. Im hier relevanten Kontext ist vor allem die zweite Prämisse der Aushandlung von Interesse. Wird eine kollektive Identität - wie die nationale oder regionale - als eines der „Dinge“ verstanden, denen gegenüber Menschen sich verhalten, so muss sie in ihrer Bedeutung - etwa hinsichtlich räumlicher Dimensionen - ausgehandelt werden. Nur auf dieser Grundlage kann eine weitgehend übereinstimmende Übereinstimmung

\footnotetext{
${ }^{25}$ Darunter wird alles gefasst, was der Mensch in seiner Umwelt wahrnehmen kann (vgl. Blumer (1973: 81))
} 
der Bedeutung erreicht werden, zu der sich dann das einzelne Individuum interpretierend und möglicherweise abändernd verhalten kann.

Die Verbindung zwischen Mitgliedern der Gemeinschaft entsteht durch Interaktion: „eine Gesellschaft besteht aus Individuen, die miteinander interagieren“(Blumer 1973: 86). Die soziale Interaktion ,in der menschlichen Gesellschaft erfolgt charakteristischerweise und vorwiegend auf der symbolische Ebene“ (Blumer 1973: 89).

Nach Mead lösen Symbole, beim Individuum eine Reihe möglicher Reaktionen aus, wobei gewisse Reaktionsarten allen gemeinsam sind, andere von Individuum zu Individuum differieren (vgl. Mead 2005 [1934]: 111). Für die Konstruktion sozialer Gruppen wird es daher auch darauf ankommen, dass die Überschneidungen solcher Reaktionsmuster an die Gruppenzugehörigkeit und damit an die Sozialisation gebunden sind. Während für kleine Gruppen diese Sozialisation in der face-to-face-Kommunikation stattfinden kann, muss die Sozialisationsfunktion für größere Gruppen durch Repräsentationen der Symbole übernommen werden. Dies kann durch Medien, insbesondere Massenmedien erfolgen. Sie stellen in diesem Kontext einerseits einen Speicherort des Symbolvorrats dar, andererseits können sie einen Interpretationsrahmen für diese Symbole bieten. So kann etwa ein Film das Speichermedium für Symbole sein, während die Ausstrahlung des Films auf einem bestimmten Fernsehsender einen Interpretationsrahmen liefert. $^{26}$

\subsubsection{Konstruktionen kollektiver Identität}

Kollektive Identitäten sind vor allem durch Grenzkonstruktionen charakterisiert (1999a: 397). Giesen identifiziert hierfür drei Codetypen: primordiale Codes, traditionale Codes und universalistische Codes. Der erste Typus markiert die Grenze zwischen Innen und Außen einer Gemeinschaft durch unveräußerbare Merkmale. Solche Merkmale sind etwa das Geschlecht, die Abstammung oder die Ethnizität. Durch sie werden scharfe und exklusive Grenzen gezogen, die „Außenseiter nur unter ganz außergewöhnlichen Umständen passieren können“ (Giesen 1999a: 397). Dagegen basieren traditionalistische Codes auf den Selbstverständlichkeiten lokaler Lebenswelten. Die Einheitlichkeit entspringt hier der „Vertrautheit mit den implizierten Regeln einer lokalen Lebenswelt" (Giesen 1999a: 398) sowie der Annahme einer gemeinsamen Geschichte. Die Gruppe wird durch Rituale des Erinnerns zusammengehalten, die eine Kontinuität zwischen Vergangenheit und Gegenwart bewahren.

Die Grenzen universalistischer Gemeinschaften hingegen werden stetig verschoben. NichtGruppenmitglieder sollen in die Gruppe aufgenommen werden, da diese als fortschrittlich verstanden wird. Dieser Fortschritt soll auch den ,unaufgeklärten oder heidnischen Außenseitern“ (Giesen 1999a: 398) zu Gute kommen, indem sie in die Gemeinschaft integriert werden.

${ }^{26}$ Der kann mehr oder weniger offen sein, etwa abhängig von Moderationen, Ankündigungen, Themenkontexten oder auch Werbeschaltungen. 
Für den hier relevanten Kontext sind vor allem die primordialen und traditionalen Codes von Bedeutung. Erstere, weil die Konzepte der Nation und der Region ${ }^{27}$ zumindest auch auf so unveräußerliche Merkmale wie Herkunft oder Abstammung verweisen. Letztere, weil sie auf darauf basierenden ausgehandelten kulturellen Codes beruhen, die sich auf gemeinsame Traditionen berufen. Universalistische Codes kommen für beide Konzepte nur dann in Betracht, wenn Nation und Region als offene Konzepte verstanden werden, in die beliebig viele Gruppenmitglieder aufgenommen werden können. Versteht man beide vor allem auf geographische Bedingungen gegründet, erscheinen sie jedoch nicht so grundsätzlich offen, dass sie sich universalistischer Codes bedienen können. Die Offen- oder Geschlossenheit beider Konzepte wird noch zu klären sein und damit auch die Relevanz universalistischer Codes für den Untersuchungsgegenstand dieser Arbeit.

Von besonderer Bedeutung sind jedoch „symbolische Codes“. Sie sind konstitutiver Bestandteil autonomer kollektiver Subjekte. Die Gruppenangehörigen greifen damit auf Teile der Kultur zurück, in der sie sich selbst bewegen. Da diese Codes über bloße sozialstrukturelle Gruppenmerkmale hinausgehen, machen sie die Eigentümlichkeit von Identifikation und Identität aus (vgl. Giesen 1999a: 399). Die Symbolisierungen geben den Gemeinschaftsmitgliedern untereinander Auskunft über ihre Stellung zueinander innerhalb der Gemeinschaft. Darüber hinaus ermöglichen sie dem Außenstehenden, die Gemeinschaft nachzuvollziehen, weil sie (im Gegensatz zu Ritualen) auch über sie hinaus einen Verstehenshorizont eröffnen. „[S]ymbolisch vermittelte Verständigung, die von anderen geteilt werden muß, stellt [...] den elementaren Prozeß dar, aus dem Gemeinschaftlichkeit entsteht" (Giesen 1999b: 18). Eine Analyse sozialer Identität muss deshalb auf solche symbolischen Codes rekurrieren. Sie ist mithin nur aus dieser konstruktivistischen Perspektive möglich, die die Bedeutung der Codes für die Gemeinschaft analysiert und nicht auf ihre „Richtigkeit“ außerhalb eines solchen Kollektivs prüft.

Eine konstruktivistische Perspektive muss jedoch bemüht sein, jene latenten sozialen Bedingungen zu erkennen, die eine Gemeinschaft als solche zusammenhalten, ohne dass deren Bezug zu historischen, kulturellen oder sozialen Wurzeln im Einzelfall deutlich hervortritt (vgl. Giesen 1999a: 400). Der Blick wird also auf soziale Prozesse und institutionelle Formen gerichtet, „in denen Kultur hergestellt, verbreitet und aufgenommen wird“(Giesen 1999a: 399). Erst solche Institutionalisierungen und soziale Strukturen verschaffen Identitätsentwürfen Zustimmung und Plausibilität (vgl. Giesen 1999a: 401) und sind deswegen ebenso zu analysieren wie die Codes und Symbole, in denen sich kulturelle Identität manifestiert. Identität bezieht sich nicht zuletzt auf Interessen und Konflikte. „Interessen setzen immer auch Institutionen der Verteilung und Herrschaft und einen Identitätsbezug voraus, der erst Interessen generiert“ (Giesen 1999a: 401).

Die Gemeinschaftlichkeit beruht auf der Gleichförmigkeit des Handelns (im Ritual) und auf dem Bewusstsein der Einzelnen über das gleichförmige Handeln mit anderen (Giesen 1999b: 16). Dafür sei körperliche Anwesenheit von grundlegender Bedeutung. Im Kontext massen-

\footnotetext{
${ }^{27}$ Siehe zu beiden Begriffen näher unter den Abschnitten 2.2 und 2.3 (S. 18ff. bzw. S. 25ff.).
} 
medialer Kommunikation (die hier im Vordergrund steht) kann auf diese Anwesenheitspflicht indes nicht abgestellt werden. Die Konstitution eines Publikums bzw. disperser Publika ${ }^{28} \mathrm{kann}$ ebenfalls durch gleichförmiges Handeln (gleichzeitige Zuwendung zu Medieninhalt) geschehen, das unterschiedlich ausgeprägt ritualisiert sein kann. Trotz der mangelnden körperlichen Anwesenheit besteht ein mehr oder weniger stark ausgeprägtes Bewusstsein darüber, dass sich gleichzeitig viele andere demselben Inhalt zuwenden. Das ist integrativer Bestandteil von Massenkommunikation. Die (virtuelle) Gemeinschaft des Publikums kann darüber hinaus mit tatsächlichen (aktuell aber in den Hintergrund tretenden) Gemeinschaften zusammenfallen.

\subsubsection{Soziale Stereotype}

Für die Sicht auf soziale Gruppen sind insbesondere Stereotype von zentraler Bedeutung. Im Allgemeinen werden Stereotype verstanden als „eingebürgertes Vorurteil mit festen Vorstellungsklischees innerhalb einer Gruppe“ (Drosdowski et al. 2007: 996). Aus sozialpsychologischer Sicht ist jedoch die Unveränderbarkeit („festes Vorstellunsgsklischee") problematisch. Darauf weist Tajfel bereits 1981 hin (vgl. Tajfel 1982: 39) ${ }^{29}$. Er schlägt daher vor, die Definition von Oliver Stallybrass heranzuziehen. Der beschreibt das Stereotyp als „ein übervereinfachtes geistiges Bild von (normalerweise) einer Kategorie von Personen, Institutionen oder Ereignissen, das in seinen wesentlichen Merkmalen von einer großen Zahl von Personen geteilt wird“ (zit. nach Tajfel 1982: 39; Herv. i. O.). Damit wird der Stereotypbegriff dynamisiert und an soziale Prozesse innerhalb von Gruppen angebunden. Die Verwendung von Stereotypen erscheint damit offen und nicht als reine Perpetuierung festgefügter Kategorien.

Diese Offenheit muss aber nicht in beide Richtungen funktionieren, jedenfalls nicht, wenn Stereotype einen historischen Bezug haben. Die Dynamik ist damit vor allem an die stereotypverwendende Gruppe gebunden und nicht an jene, auf die sich ein Stereotyp bezieht. So kann - in den Termini der Theorie der sozialen Identität gesprochen - die in-group durch Uminterpretation (social creativity) der Qualitätsaussage von Stereotypen über sich selbst deren Bedeutung umkehren. Andererseits kann (etwa aus Motiven sozialer Erwünschtheit) ein Stereotyp bezüglich einer bestimmten Gruppe weiterhin unter anderen Vorzeichen verwendet werden. ${ }^{30}$

Die Funktion von Stereotypen besteht für Individuen in der Vereinfachung und Komplexitätsreduktion von Umweltinformationen (vgl. Tajfel 1982: 41). Sozial können Stereotype aber nur genannt werden, ,wenn sie von einer großen Zahl von Personen innerhalb sozialer Gruppen oder Entitäten ,geteilt' werden - wobei unter ,teilen' die tatsächliche Verbreitung verstanden werden muß“ (Tajfel 1982: 42).

\footnotetext{
${ }^{28}$ Vgl. Maletzke 1963: 28.

${ }^{29}$ Das Kapitel erschien bereits 1981.

${ }^{30}$ So ist etwa denkbar, dass Stereotype über Juden nach dem zweiten Weltkrieg in Deutschland weiterhin galten, aber nicht als negative, sondern positive Eigenschaften heraus gestellt wurden. Ein ähnlicher Effekt wird, oft bezogen auf Schwarze oder Farbige, als ,positiver Rassismus“ bezeichnet.
} 
Stereotype können neutrale und wertungshaltige soziale Kategorisierungen enthalten. Neutral sind solche Kategorien dann, wenn auf Grund eines sozialen Stereotyps ein Urteil bezüglich einer sozialen Gruppe gefällt werden kann, ohne dass damit ein positives oder negatives Werturteil verbunden ist (1982: 50). Durch empirische Tatsachen notwendig werdende Modifizierungen solcher Stereotype sind daher unproblematisch. Dagegen bedroht eine Modifikation stark wertungshaltiger Kategorisierungen das dahinter stehende Wertsystem, auf dem die Differenzierung zwischen den Gruppen beruht (Tajfel 1982: 50). Ein Merkmal neutraler Kategorisierung ist, dass Wertunterschiede sowohl die Akzentuierung von Unterschieden zwischen Gruppen als auch die Akzentuierung von Ähnlichkeiten innerhalb von Gruppen verstärken (Tajfel 1982: 50).

Im Falle negativ bewerteter sozialer Kategorien steht hingegen die Aufrechterhaltung des Systems sozialer Kategorien im Vordergrund. Damit sind in der sozial-kommunikativen Praxis Stereotype konstitutiver Bestandteil von Gruppenzuordnungs- und Differenzierungsverhalten.

Für den Untersuchungsgegenstand dieser Arbeit sind vor allem Stereotype, die sich auf die jeweils eigene Gruppe beziehen, von Bedeutung. Da Massenmedien bei der Gruppenzuordnung eher als affirmativ und weniger als selektiv erscheinen, dürften dabei neutrale Kategorien im Vordergrund stehen.

\subsection{Nation}

Es verwundert nicht, das Tajfel für seine Definition von Gruppen auf Emersons Definition von Nation verwiesen hat:

„Die einfachste Aussage, die man über eine Nation machen kann, besteht darin, daß sie aus einer Ansammlung von Leuten besteht, die der Ansicht sind, daß sie eine Nation darstellen; und es kann sehr gut sein, daß nach Abschluß aller detaillierten Analysen die endgültige Aussage genauso aussehen wird“ (Emerson 1960, zit. nach Tajfel 1982: 70).

Diese Definition ist sozialpsychologischen Charakters:

„Sie bezieht sich nicht auf die historischen, politischen, sozialen oder ökonomischen Ereignisse, die zu dem sozialen Konsens geführt haben, durch den jetzt definiert ist, wer ,dazugehört ${ }^{`}$ und wer nicht. Aber es besteht kein Zweifel daran, daß diese Ereignisse bei der Etablierung dieser Art von Konsens ausschlaggebend waren, und es ist ebenso richtig, daß der Konsens, der einmal besteht, die sozialpsychologischen Aspekte der sozialen Wirklichkeit repräsentiert, die mit den sozialen, politischen und ökonomischen Ereignissen interagieren, die das gegenwärtige und das zukünftige Schicksal der Gruppe und ihre Beziehungen zu anderen Gruppen bestimmt" (Tajfel 1982: 71).

Das heißt aber auch, dass diese historischen, politischen, sozialen oder ökonomischen Ereignisse den Bezugsrahmen abstecken, innerhalb dessen der Konsens über die eigene Nation sich bewegt. Es wird dabei zu klären sein, wie interpretationsbedürftig die Grenzen dieses Rahmens und damit auch wie durchlässig sie sind. Davon hängt ab, ob das Konzept der Nation als offen oder geschlossen gelten kann. 
Ziel dieses Abschnittes ist es, eine für die empirische Untersuchung brauchbare und tragfähige Definition von Nation zu erarbeiten. Dabei kann es nicht darum gehen, der Vielzahl von Versuchen, den Begriff zu fassen, einen weiteren hinzuzufügen. Vielmehr soll aus den bestehenden Ansätzen heraus ein konsistenter Begriff entwickelt werden, auf den in der weiteren Untersuchung zurückgegriffen werden kann.

\subsubsection{Vom essentialistischen zum subjektiven Begriff}

Noch zu Beginn des 20. Jahrhunderts wurde der Nation eine essentialistische Qualität zugesprochen. So formuliert etwa „Brockhaus’ Kleines Konversationslexikon“ in der Ausgabe von 1906, dass die Nation „der Gesamtheit der Staatsgenossen, die erbliche Stammes-, Sprach-, Sitten- und Kulturgemeinschaft, die bestimmten Menschenmassen ein eigentümliches Rassengepräge (Nationalcharakter) aufprägt" (Brockhaus 1906: 245). Heute deutet nur noch die Wortherkunft von lateinisch nasci ,geboren werden“ auf eine solche Essentialität des Begriffs hin. Gängige Definitionen verweisen vor allem auf seine politische Natur in Verbindung mit sozialpsychologischen Elementen wie einem gemeinsamen Bewusstsein und kollektivem Willen (vgl. etwa Stichwort „Nation“ in Zwahr 1999, Wesche et al. 2004; Wolf 2005b). Nation wird auch als Ordnungsvorstellung mit nur bedingter Verhaltensrelevanz und stets latenten Zurechnungskriterien verstanden, die nach innen Teilhabe und nach außen Abgrenzung vermitteln (Riescher 1998: 407, m. w. N.). Auch diese Herangehensweise ist sozialpsychologischer Natur. Eine sehr brauchbare Grundlage der Definition liefern Bornewasser und Wakenhut:

„Nationen sind - objektiv betrachtet - historisch gewachsene, politisch orientierte Sozialverbände, die über formale Ordnungen das solidarische Handeln ihrer Angehörigen in einem begrenzten Gebiet regeln. Nationen bilden das Ergebnis eines vom politischen Willen der Eliten oder größeren Mehrheiten getragenen Vereinheitlichungsprozesses, in dem ethnisch unterschiedlichen Bevölkerungsgruppen auf einem begrenzten Territorium eine gemeinsame Orientierung in rechtlicher und kultureller Hinsicht vermittelt wird" (Bornewasser/Wakenhut 1999: 44).

Auch wenn diese Definition von den Autoren als „objektiv“ bezeichnet wird, enthält sie doch einige sozialpsychologische Konstituenten, die deutlich auf die sozial(psychologisch)e Konstruktion des Begriffs verweisen. Gerade deshalb ist eine Nation wohl mehr als ein Staat, den Kant als „die Vereinigung einer Menge von Menschen unter Rechtsgesetzen“ (Kant 1968 [1797]: 431) definiert hat. Bei genauerer Betrachtung verweist aber auch diese Definition auf eine soziale Konstruktion, da diese Rechtsgesetze nichts anderes sein können als Ausdruck sozial geteilter Rechtsvorstellungen. Insgesamt lassen sich die Versuche, das, was Nation sei, $\mathrm{zu}$ definieren in objektivistische und subjektivistische Auffassungen sowie einige dazwischen vermittelnde Ansichten einteilen. Im ersten Fall wird die Nation als „,metaphysische Grundpotenz“, „als organische[s] Kollektiv“ verstanden, die keine Gemeinschaft des Willens ist und der sich die einzelnen Glieder nicht entziehen können (Uzarewicz/Uzarewicz 1998: 170 m. w. N.). Anders das subjektivistische Verständnis, das Nationen

„explizit als Konstrukte von bzw. als Willensgemeinschaften begreif $[t]$. Hier wird das Problem subjektivistischer Interpretationen unmittelbar deutlich: Dasjenige, das sich qua Willen als Nation konstituiert, muß als Subjekt dieses Willens schon vorausgesetzt werden. [...] Diskursive 
Kommunikation und nicht bloße rituelle Beschwörung ist das Medium, das diesen Willen zum gemeinsamen Willen aller synthetisieren soll“ (Uzarewicz/Uzarewicz 1998: 170).

Das Konstituendum existiert hier erst durch das Konstituens. Das wird aber nur dort zum Problem, wo ein kausaler Zusammenhang gesucht wird. In der Geschichtsschreibung zur Entstehung von Nationen mag dies gelegentlich der Fall sein. In der vorliegenden Arbeit kann das aber dahingestellt bleiben. Hier wird von einem zirkulären Zusammenhang ausgegangen, in welchem Nation und nationale Identität fortgeschrieben und stets aktualisiert werden. ${ }^{31}$ Zentraler Anknüpfungspunkt ist jener gesellschaftliche Diskurs (bzw. Teile davon) auf den von den referierten subjektivistischen Auffassungen abgestellt wird. Er soll anhand eines Ausschnittes öffentlicher Kommunikation bezüglich bestimmter Konstruktionsmechanismen untersucht werden.

\subsubsection{Die Nation als „tägliches Plebiszit“}

Einen der bekanntesten Versuche, den Begriff der Nation zu erfassen hat 1882 Ernest Renan in seinem Vortrag „Was ist eine Nation?“ unternommen. Eine Nation ist für ihn ein „geistiges Prinzip“ (vgl. Renan et al. 1996 [1882]: 34) verbunden mit dem „Wunsch, zusammenzuleben [und] de[m] Wille[n], das Erbe hochzuhalten [...]“ (Renan et al. 1996 [1882]: 34). Es ist deshalb „ein Plebiszit Tag für Tag“ (Renan et al. 1996 [1882]: 35).

Der historische Bezugsrahmen bezieht sich dabei nicht nur auf geschichtliche Ereignisse, die für die Entstehung von Nationen wichtig waren, sondern auch auf die Entstehung der Nationen selbst. Aus dieser Betrachtung kann Renan einige Konzepte, auf die bezüglich der Nation immer wieder verwiesen wird, verwerfen, weil sie für deren Entstehung keine Rolle spielen. Dazu zählen ethnographische Gesichtspunkte („Rasse“, vgl. 1996: 22), die Sprache (1996: 27), die Religion (1996: 29), Interessensgemeinschaft (1996: 31) sowie die Geographie (1996: 232). Dass diese Konzepte nicht die Grundlage für die Ausbildung einer Nation sind, bedeutet indes nicht, dass sie gar nichts mit ihr zu tun hätten. So gesteht Renan etwa der Geographie zu, einer der wesentlichen Faktoren der Geschichte zu sein. Bezüglich der Sprache konzediert er, dass sie zwar nicht dazu zwingt, sich als Nation zu vereinigen, aber doch immerhin dazu einlädt (vgl. Renan et al. 1996 [1882]: 27). Der Bezug zur als gemeinsam gedachten Vergangenheit besteht aber laut Renan nicht nur in der Erinnerung, sondern ebenso im Vergessen. Das Wesen der Nation beruhe daher nicht nur auf den Gemeinsamkeiten vieler Individuen, sondern auch darauf, „daß alle manche Dinge vergessen haben“ (Renan et al. 1996 [1882]: 15). Dies verdeutlicht dennoch die Wichtigkeit des Geschichtsbezugs für den Begriff der Nation. Insofern muss die Historie als einer der wichtigsten Eckpfeiler von Nationen angesehen werden,

\footnotetext{
${ }^{31}$ Dabei ist ein Bezug zur Geschichte (bzw. einer für das Phänomen verbindlichen Geschichtsschreibung) keineswegs ausgeblendet.
} 
wobei (aus konstruktivistischer Sicht) lediglich die den historischen Ereignissen zugemessene Bedeutung $^{32}$ von Belang ist und nicht die Ereignisse selbst.

\subsubsection{Die Nation als vorgestellte Gemeinschaft}

Anderson bezeichnet das „Nation-Sein“ als den „am universellsten legitimierte[n] Wert im politischen Leben unserer Zeit“(2005: 13). Als praktikable Definition für die genauere Analyse schlägt er vor: „[Die Nation] ist eine vorgestellte politische Gemeinschaft - vorgestellt als begrenzt und souverän“ (2005: 15). Vorgestellt sei diese Gemeinschaft deshalb, weil sie ohne tatsächliche Begegnung auskommt und nur darauf basiert, dass ihre Mitglieder die Vorstellung der Gemeinschaft hegen (Anderson 2005: 15). Begrenzt seien Nationen, weil sie alle in bestimmten, wenn auch variablen Grenzen leben; souverän als Folge ihrer Entstehungszeit, die mit den Gedanken von Pluralismus und Freiheit zusammenfällt (Anderson 2005: 16). Als Gemeinschaft werden Nationen imaginiert, weil sich die Gleichheit der Gemeinschaftsmitglieder lediglich auf die Angehörigkeit zu dieser Nation bezieht und anderweitige tatsächliche Unterschiede gar nicht in Betracht zieht (vgl. Anderson 2005: 17).

Es reicht aber nicht aus, dass Menschen wissen, dass es andere Menschen gibt, denen sie niemals begegnen werden. Vielmehr muss sich diese Vorstellung auch manifestieren. Anderson verdeutlicht das am Beispiel südamerikanischer lokaler Presse im 18. Jahrhundert (vgl. 2005: 68). Diese war im wesentlichen Anhängsel des jeweiligen Marktes. In der Nachrichtengebung spiegelten sich Verwaltungs- und Marktstrukturen wider, woraus eine gewisse Provinzialität resultierte. „Die Zeitung von Caracas schuf so auf ungezwungene und gerade apolitische Weise eine vorgestellte Gemeinschaft in der Leserschaft, der diese Schiffe, Bräute, Bischöfe und Preise gehörten“ (Anderson 2005: 68). An anderer Stelle verdeutlicht Anderson, dass das Lesen die vorgestellte Gemeinschaft durch Verdoppelung bestätigt, indem wir lesen, dass andere auch lesen (2005: 39). Das Lesen darüber, dass auch andere lesen, wird aber für diese Verdoppelung überflüssig: Man kann beim Lesen einer provinziellen Zeitung mitdenken, dass es auch andere provinzielle Zeitungen gibt, gerade weil nur ein Ausschnitt der globalen Realität präsentiert wird. Die vorgestellten Gemeinschaften repräsentieren sich also in der Presse und können sich je nach deren Verbreitungsgebiet auf unterschiedlich große Gruppen beziehen. Spätestens mit der Ausweitung der Presse zum Massenmedium (Massenpresse; vgl. Wilke 2002: 477) im 19. Jahrhundert wird die Presse so auch Ort der Manifestation der Nation als vorgestellter Gemeinschaft.

Ein anderer Aspekt bezieht sich auf die bereits weiter oben aufgeworfene Frage nach der Offenheit und Geschlossenheit des Konzepts der Nation. Eine Nation erweist sich ,gleichermaBen als offen und geschlossen“ (Anderson 2005: 147). Offen, weil sie sich „schon immer über die Sprache und nicht über das Blut bestimmt, d.h., man kann in die vorgestellte Gemeinschaft ,eingeladen“ werden“ (Anderson 2005: 147). Geschlossen, weil die Nation als etwas

32 Das gilt innerhalb der Gruppe derer, die sich als Nation begreifen ebenso wie außerhalb der Gruppe, wenn auf der Bedeutungszuschreibung auch die Zuschreibung zu einer bestimmten Nation von außen beruht. 
erscheint, ,an das man auf natürliche Weise gebunden ist“ (Anderson 2005: 144) und die Bindung daher nicht bewusst gewählt werden kann (vgl. Anderson 2005: 144). Für dieses Phänomen kommt auch die begriffliche Unterscheidung von Grenzen und Begrenzungen in Betracht. „Grenzen ermöglichen [...] Separation, Abgrenzung und Abschottung. Begrenzungen erzwingen jedoch keine Abgrenzung, lassen auch Offenheit zu“ (Bornewasser/Wakenhut 1999: 47). Das bedeutet, das mit dem Phänomen Nation als sozialpsychologischem Konzept zwar Nationen, Regionen oder Gruppen umschrieben sind, von denen man sich abgrenzen möchte, womit aber nicht zwangsläufig ein verengter Nationalismus oder Ethnozentrismus einhergeht (Bornewasser/Wakenhut 1999: 47). Nationen können vielmehr auch integrationsfähig erscheinen, wofür insbesondere die Mehrung positiv besetzter Zugehörigkeitsgefühle verantwortlich sein kann (Bornewasser/Wakenhut 1999: 48).

Festzuhalten bleibt, dass der Begriff Nation bei Anderson im Vergleich zu Renan um die Vorstellbarkeit erweitert wird. Das tägliche Plebiszit ist nicht voraussetzungslos, sondern basiert auf einer manifesten oder latenten Institutionalisierung der Vorstellung der Gemeinschaftlichkeit.

\subsubsection{Die Nation als historisches Doppelphänomen - der Staat und das "Wir"}

Aus Historikersicht lehnt Hobsbawm die Gleichsetzung zweier so verschiedener Phänomene wie Kollektivbewusstsein und einer angeblich darauf beruhenden Staatsform - dem Nationalstaat - ab (Hobsbawm/Rennert 2005: 7, vgl. auch im Folgenden Hobsbawm/Rennert 2005: 7). Insbesondere der deutliche zeitliche Unterschied zwischen beiden Erscheinungen spreche gegen eine solche Gleichsetzung. Wir-Gemeinschaften berufen sich erst seit ca. 150 Jahren auch (aber keineswegs ausschließlich) auf Nationen. Der darauf bezogene moderne Territorialstaat ist überhaupt erst ein Produkt des späten 19. Jahrhunderts. Die Gleichsetzung beider Phänomene kann jedoch nur in einer Richtung abgelehnt werden. Aus einer Wir-Gemeinschaft folgt nicht zwangsläufig eine nationale Gemeinschaft, eine nationale Gemeinschaft ist hingegen auf ein Kollektivbewusstsein angewiesen. Hobsbawm trägt dem auch selbst Rechnung, indem er Nationen als „Doppelphänomene“ bezeichnet, die von oben konstruiert werden, aber von unten zu analysieren sind (Hobsbawm/Rennert 2005: 21). Das folgt schon aus seiner subjektiven Definition, die auf das Bewusstsein der Gruppenmitglieder abstellt. Das ist nicht unproblematisch, da sie tautologisch ist, nur a posteriori angeben kann, was eine Nation ausmacht und ein voluntatives Element beinhaltet (Hobsbawm/Rennert 2005: 18). Dieses voluntative Element scheint dann aber das eigentlich konstituierende Merkmal zu sein, da die Konstruktion von oben auch auf einen Willen von unten stoßen muss. Das voluntative Merkmal bezieht sich dabei aber zwangsläufig auf weitere Eigenschaften, ohne die es wirkungslos bleibt.

Dadurch wird auch klar, wie objektive Beschreibungen operieren: Aus der jeweils aktuellen Verfestigung und Manifestation verschiedener Merkmale von Nationen wird unter dem Eindruck der „Macht nationaler Gefühle“ (Hobsbawm/Rennert 2005: 8) auf deren Beständigkeit 
geschlossen und sie erscheinen natürlich. Der Nationalismus alter Prägung strebte danach, jene Menschen zusammenzubinden, ,von denen man annimmt, sie hätten eine gemeinsame ethnische Herkunft, Sprache, Kultur, historische Vergangenheit usw.“ (Hobsbawm/Rennert 2005: 204). Er bringt Staaten und Nationen also erst hervor (Hobsbawm/Rennert 2005: 21).

Hobsbawms Arbeitshypothese beruht auf demselben Prinzip wie Andersons „,vorgestellte Gemeinschaft“: Er definiert als Nation ,jede ausreichend große Gemeinschaft von Menschen [...], deren Mitglieder sich als Angehörige einer ,Nation“ betrachten“ (Hobsbawm/Rennert 2005: 19). Darin tauchen die begriffsgeschichtlichen Merkmale des Schwellenprinzips (vgl. Hobsbawm/Rennert 2005: 44) sowie der Massenteilhabe bzw. Wahl (vgl. Hobsbawm/Rennert 2005: 30) auf. Damit stellt sich aber auch die Frage, wie die konsequent ausgeklammerte territoriale Begrenzung - auf die sich der Nationalstaat schließlich doch wieder bezieht - in diesen subjektivistischen Begriff Einzug hält. Am wahrscheinlichsten ist hier, dass diese Grenzen im gesellschaftlichen Aushandlungsprozess kommunikativ perpetuiert werden.

\subsubsection{Konstruktivistischer Begriff}

Reale Macht kommt Nationen vor allem durch ihre nationalstaatliche Befestigung zu (Butt 2005: 158). ${ }^{33}$ Die meisten Annäherungen an den Begriff der Nation stellen auf dessen konsequente Subjektivierung ab. Danach erwächst eine Nation daraus, dass eine Anzahl von Menschen der damit verbundenen Vorstellung vor allem Gemeinsamkeiten unterstellt. Dieser Prozess kulminiert in der Vorstellung der Gemeinsamkeit des Vorstellens selbst. Insofern handelt es sich um eine konstruktivistische Perspektive, der es um die Entstehung der offenkundigen Überschneidungen der Vorstellungen in der Gemeinschaft geht.

Eine vermittelnde Position zwischen essentialistischer bzw. objektiver und konstruktivistischer Sichtweise nimmt der Definitionsansatz von Smith ein. ${ }^{34}$ Demnach weist das westliche bzw. staatsbürgerliche Modell ${ }^{35}$

„der Nation vier Grundmerkmale auf: 1. ein geschlossenes und ziemlich klar umrissenes Gebiet, das als traditionelle Heimat oder Wiege zur fraglichen Nation gehört, 2. die Existenz von bzw. der sozial geteilte Wunsch nach einem eigenstaatlichen Vaterland im Sinne einer, Gemeinschaft von Gesetzen und Institutionen mit einem einzigen politischen Willen'. 3. Politischrechtliche Gleichheit aller Nationsangehörigen, wobei diese Gleichheit nicht nur in formellen Institutionen verankert ist, sondern auch von entsprechenden Haltungen der Beteiligten getragen wird. 4. Eine sozial geteilte, immaterielle Kultur und eine damit verbundene Staatsbürger-

\footnotetext{
${ }^{33}$ Butt nimmt darüber hinaus an, dass sich diese reale Macht auch aus der Besetzung der Vorstellung von Nation ihrer Mitglieder speist. Diese kann aber, sofern sie Übereinstimmungen erzeugen soll, nur auf einem Aushandlungsprozess beruhen, in dem sich lediglich Machtstrukturen wiederfinden lassen. Dessen Ergebnis hat einen gewissen Einfluss auf die Mitglieder und ist damit zirkulär. Macht kann dieses Ergebnis aber nur in bestimmten Manifestationen ausüben, etwa rechtlichen Regelungen oder Alltagspraxen.

${ }^{34}$ Nachgewiesen bei Estel 2002: 65.

35 Demgegenüber steht die ethnische Nationskonzeption, die hier aber nicht referiert werden soll, da sie für den Untersuchungsgegenstand dieser Arbeit keine Anwendung findet.
} 
ideologie: Nationen sind unter diesem Gesichtspunkt Kulturgemeinschaften, deren Angehörige, geeint, wenn nicht vereinheitlicht sind durch gemeinsame historische Erinnerungen, durch Mythen, durch gemeinsame Symbole und Traditionen“" (Estel 2002: 67).

Der Vorzug dieses Ansatzes besteht darin, dass die subjektivistischen Merkmale in sozial konstruierte Strukturen münden, die empirisch zugänglich sind. So sind etwa sowohl die „traditionelle Heimat“ als auch die „formellen Institutionen“ (etwa Gesetzestexte) Referenzobjekte der Nation, die einerseits aus der Vorstellung von Gemeinschaft entstanden sind und andererseits die Gemeinschaft repräsentieren.

\subsubsection{Eigene Arbeitsdefinition}

Für eine empirische Analyse wirft die Entobjektivierung des Nationsbegriffs bei dessen gleichzeitiger Bindung an subjektive Einstellungen innerhalb eines Kollektivs einige Schwierigkeiten auf. Sofern nicht die Einstellungen selbst untersucht werden, kann vorher kaum umrissen werden, was genau Gegenstand der Untersuchung ist. Insofern erscheint ein Ansatz sinnvoll, der die subjektive Komponente nicht ausblendet, sich aber stärker auf empirisch wahrnehmbare und verallgemeinerungsfähige Aspekte bezieht. Deshalb soll in dieser Arbeit der Begriff der Nation als Kombination eines voluntativen und eines realen Moments verstanden werden: Gewollt wird die Gemeinschaft von ihren Mitgliedern, die sich durch verschiedene Gemeinsamkeiten als verbunden betrachten. Sie bezieht sich dafür auf Manifestationen dieser Gemeinsamkeiten, die an den Willen rückgekoppelt sind. In ihnen kommen diese Gemeinsamkeiten zum Ausdruck und sie repräsentieren daher die Gemeinschaft bzw. die Nation. Auf diese Manifestationen soll sich die Analyse beziehen, ohne jedoch die dahinterstehenden Mechanismen aus dem Auge zu verlieren. 


\subsection{Region}

Im Gegensatz zur Nation zeichnet sich der Begriff der Region zunächst durch ein zugrunde liegendes territoriales Verständnis aus. Er ist dabei auf ein größeres Gebiet (einen Staat) bezogen und bezeichnet eine Einheit in dessen Verwaltungsgliederung (vgl. etwa Stichwort „Region" in Zwahr 1999). Dieser Unterschied zeigt sich bereits in der Etymologie der Begriffe. Während die Nation den Verweis auf die Geburt enthält (und damit zum vermeintlich natürlichen Merkmal wird), enthält das Wort Region Verweise auf Gebiet und Herrschaft (vgl. entsprechende Einträge in Alsleben/Wermke 2007).

Das erleichtert zunächst das Verständnis, weil hier scheinbar objektive Kategorien als Grundlage dienen. Hingegen verwundert es, dass im Gegensatz zur Nation eine verwaltungstechnische Regelung zur Grundlage einer gleichermaßen sozial relevanten Gruppeneinteilung verwendet werden kann.

Doch auch die administrative Grundlage des Begriffs ist nicht frei von Unschärfen, da er nicht an bestimmte geographische Maßstäbe gebunden ist (vgl. Fürst 1995: 540). So sind verschieden große Gebiete als Regionen zu bezeichnen. Zunächst bezeichnet der Begriff der Region Gebiete, die auf einer Landkarte identifiziert werden können (vgl. Mühler/Opp 2006: 19), was Staaten ebenso wie Kontinente einbezieht. Auch Sprachräume, wie sie die Sprachwissenschaft in der Dialektforschung identifiziert, können als Regionen bezeichnet werden; sie überschreiten mitunter Staatsgrenzen (vgl. etwa König/Paul 2004: 233). Zudem erhöht sich die Unschärfe, wenn die Region Grundlage eines geteilten Merkmals von Gruppenmitgliedern werden soll, da die betreffenden Personen das zugrunde liegende Territorium unterschiedlich abgrenzen und bei ihrer Zuordnung nicht zwangsläufig an die Verwaltungsgrenzen gebunden sind (vgl. Mühler et al. 2004: 12, Lilli/Diehl 1999: 103). Grundsätzlich lassen sich also voluntaristische und historische Kriterien für die Definition von Regionen unterscheiden (vgl. Fürst 1995: 540). Während ein Staatsgebiet mehrere Regionen umfasst, ist es durchaus möglich, dass auch eine Region selbst verschiedene Regionen in sich vereint. Darüber hinaus lässt der Begriff offen, auf welcher Grundlage die mögliche administrative Einteilung basiert, denn auch diese geschieht zunächst willkürlich.

Die Maßstabsdimension ist ein wichtiger Bestandteil des Regionsbegriffs, weil die Phänomene, auf die er verweist, ,irgendwo zwischen dem Örtlichen, Lokalen oder Punktuellen und dem Überregionalen, dem Kontinentalen oder gar Globalen“" angesiedelt sind (Weichhart 1996: 27). Damit wird also auf eine „mittlere Maßstabsebene“ verwiesen, auf „Teilräume innerhalb von Gesamträumen“ (Weichhart 1996: 27).

Insbesondere die spätere Operationalisierbarkeit des Begriffs macht es notwendig, ihn für die weitere Verwendung einzugrenzen. Da bereits bei der Definition des Nationsbegriffs auf ein teilweise nationalstaatliches - und damit in Teilen territoriales Verständnis - zurückgegriffen wurde, liegt es nahe, die Region als ein territoriales Gebilde innerhalb nationalstaatlicher 
Grenzen zu verstehen. Sie ist eine subnationale Einheit. Die Region ist also in jedem Falle kleinräumiger als ein Staat. Insofern können weitläufigere Definitionsansätze im Folgenden unberücksichtigt bleiben. ${ }^{36}$

Im Gegenzug ist auch eine Abgrenzung „nach unten“ notwendig. Das ergibt sich jedoch nicht aus noch kleinräumigeren Untersuchungsgebieten, die für diese Studie in Betracht kämen, sondern aus den in der Fragestellung bereits genannten Regionen Bayern und Mitteldeutschland. Diese können administrativ umgrenzt werden, was für die empirische Untersuchung von forschungspraktischem Vorteil ist. Insofern könnte man sich auf reine Verwaltungskriterien beschränken. Dennoch ist eine weitergehende Auseinandersetzung mit der Region hier notwendig, weil der Begriff Implikationen enthält, auf die sich die noch zu erörternde ,regionale Identität“ bezieht. Eine Abgrenzung „nach unten“ soll aber gerade nicht den Blick auf die verschiedenen Regionskonzepte unterhalb der (national-)staatlichen Ebene versperren und deshalb erst im Zusammenhang der eigenen Arbeitsdefinition stattfinden.

Nation und Nationalstaat sind Konzepte der Moderne, da ihre Erscheinungsformen im 19. Jahrhundert geprägt wurden. Im Gegenzug dazu handelt es sich bei der Region nicht um „ein Relikt der Vormoderne, sondern ein inhärentes strukturelles Prinzip spät- bzw. postmoderner Gesellschaften“ (Blotevogel 1996: 49, m. w. N.) In der aktuellen Auseinandersetzung mit den Erscheinungsformen von Regionalität wird oftmals betont, dass Nationalstaaten und ihnen übergeordnete institutionelle Vereinigungen (EU, UN etc.) keine große Integrationskraft mehr entfalten können. Dagegen ist es gerade die mittlere Maßstäblichkeit der Region, die sie im Alltag überschaubar erscheinen lässt. Eine auf Regionen bezogene räumliche Strukturierung des sozialen, ökonomischen und kulturellen Lebens funktioniert als symbolisches Medium der sozialen Integration (Blotevogel 1996: 49 m. w. N.) Re-Regionalisierungs- und Lokalisierungstendenzen werden demnach gerade erst durch die weitreichenden Globalisierungs- und Homogenisierungsprozesse ausgelöst (Blotevogel 1996: 49, so auch: Hock 2005: 11, Rohe 1996: 101, Matter 1998: 32). Insofern ist die Auseinandersetzung mit der Region sowohl wissenschaftlich als auch gesellschaftspolitisch von aktuellem Interesse.

\footnotetext{
${ }^{36}$ Das deckt sich auch mit dem juristischen Blick auf den Begriff: Aus EU-rechtlicher Perspektive sind die deutschen Bundesländer nicht als Regionen, sondern als Gliedstaaten zu bezeichnen (Morass 1994: 3). Diese rechtliche Unterscheidung hat innerhalb der EU Konsequenzen für Mitentscheidungsrechte der Regionen und Länder und deren Qualität als Rechtsobjekte bzw. -subjekte (vgl. Morass 1994). 2003 schuf die EU in der Verordnung Nr.1059/2003 des europäischen Parlaments und des Rates (Europarat/Europäisches Parlament 2003) eine rechtliche Grundlage für die Auswahl flächenmäßig weitgehend vergleichbarer territorialer Einheiten zu statistischen Zwecken auf Grundlage der NUTS-Nomenklatur (Nomenclature des unités territoriales pour la statistique). Die NUTS-Einteilung umfasst drei Stufen, wobei in Deutschland die Bundesländer Regionen auf der NUTS-1 Ebene darstellen, die dann weiter ausdifferenziert werden. (Eine genaue tabellarische Aufstellung enthält der Anhang der Verordnung (Europarat/Europäisches Parlament 2003), eine kartographische Übersicht der Regionen auf NUTS-2 Ebene findet sich im Anhang des Eurostat Jahrbuchs (Europäische Kommission 2007.) Die Satzung der Versammlung der Regionen Europas bestimmt hingegen auf rein administrativer Ebene als Regionen jene Gebietskörperschaften, die direkt unterhalb der zentralstaatlichen Ebene angesiedelt sind (Engel 1993: 14). Lutz betont vor allem die Notwendigkeit der je eigenen und spezifischen Profilierung von Regionen (Lutz 1998: 223).
} 


\subsubsection{Wissenschaftliche Entwicklungslinien}

\subsubsection{Geographische Zugänge}

In den letzten Jahrzehnten hat die wissenschaftliche Beschäftigung mit der Region ganz verschiedene Ansätze zu deren Definition hervorgebracht. ${ }^{37}$ Am wichtigsten dürfte dabei die Auseinandersetzung darüber sein, ob die Region als materielles oder immaterielles Raumkonzept zu verstehen ist und ob sie überhaupt räumlich zu konkretisieren ist (vgl. Hock 2005: 10, m. w. N.). Auf der einen Seite steht das traditionelle Raumverständnis, das sich auf den „physischen Raum der Erdoberfläche“ (Hock 2005: 10) bezieht. Auf der anderen Seite die Sicht, „dass Region nicht räumlich konkretisiert werden muss“, sondern das sei, „,was sich als Region versteht und artikuliert", und zwar unabhängig von politisch-administrativen Grenzen (vgl. Hock 2005: 10 m. w. N.). Die meisten modernen Ansätze sind zwischen diesen Positionen anzusiedeln. So hat etwa die Sozial- und Wirtschaftsgeographie den Raumbegriff um subjektive und gesellschaftliche Elemente erweitert und ihm nicht-materielle, politische, ökonomische und kulturelle Bedeutungsaspekte hinzugefügt (Hock 2005: 10). Darüber hinaus hat in der Humangeographie ein Wandel des Raumbegriffs hin zur Subjektivität stattgefunden, wodurch Räume und Regionen zunehmend aus der Perspektive subjektiver Aneignung und symbolischer Bedeutung der räumlichen Kategorien in der sozialen Interaktion gesehen werden (Hock 2005: 10). Insgesamt handelt es sich bei der Region um eine „funktional-differenzierte territorial gebundene gesellschaftliche Organisationsform“ (Roemheld et al. 1987: 74).

Eine Typologie der verschiedenen Regionskonzepte bietet Blotevogel (1996: 58 u. 2000: 499). Auf der ersten Ebene unterscheidet er zwischen

1. „Beschreibungs- und Analyseregionen (,Realregionen?“,

2. „Tätigkeitsregionen mit ökonomischen und politisch-administrativen Organisationen (,Aktivitätsregionen') und

3. „Wahrnehmungs- und Identitätsregionen“.

Die erste Kategorie ist in „homogene Regionen“, „funktionale Regionen“ und „komplexsystemare Regionen“ zu untergliedern. Die zweite beinhaltet „wirtschaftliche Tätigkeitsregionen“ und „politisch-administrative Regionen“. Das dritte Konzept besteht aus „Wahrnehmungsregionen“, „Identitätsregionen“ und „Regionen als Bezugsräumen eines aktiven Regionalismus“. Die „Realregionen“ sind weitgehend traditionelle geographische Konzepte, bezeichnen also physischen Raum und seine „erdräumlich eindeutig lokalisierbaren Eigenschaften“ und erst bei den ebenfalls hierunter fallenden „Funktionalregionen“ kommen auch „,rela-

\footnotetext{
${ }^{37}$ Einen zeitlichen Überblick über die geo-wissenschaftlichen Regionsbegriffe gibt Boesch, abgebildet bei Weichhart (1996: 29). Bis in die 1960er Jahre wird die Region als „real vorhandene (erd)räumliche Einheit von mittlerer Maßstäblichkeit“ verstanden und war dementsprechend ein Begriff der Geographie und Raumplanung (vgl. Blotevogel 1996: 44). In den 1970er Jahren kommt in der politischen Diskussion eine „Regionalismusdebatte“ auf, die sich zunächst auf administrative Aspekte bezog, ,die Region“ aber ab den 1980er Jahren auch in Wissenschaft, Politik und Gesellschaft zu einem Modewort werden lässt (Hock 2005: 9).
} 
tionale gesellschaftliche Raumkonzepte ins Spiel“ (Blotevogel 1996: 59). ${ }^{38}$ „Aktivitätsregionen" basieren hingegen auf Handlungen von Menschen und ihren Organisationsformen (Blotevogel 1996: 59). Als Beispiel für „wirtschaftliche Tätigkeitsregionen“ kommt etwa das Verbreitungsgebiet einer Regionalzeitung infrage. Für den hier relevanten Kontext kann demnach auch das Sendegebiet einer Rundfunkanstalt als eine solche Tätigkeitsregion genannt werden. ${ }^{39}$ Die „Wahrnehmungs- und Identitätsregionen“ werden schließlich durch soziale Kommunikation konstituiert, wobei Räume und Regionen zu deren Elementen werden (Blotevogel 1996: 60). Dennoch sind sie immer auch in einem tatsächlichen erdräumlichen Bezug zu sehen, da die Bildung raumbezogener Identität vornehmlich innerhalb des Raumes, auf den sie sich bezieht stattfindet. Darüber hinaus spielt auch die „Landschaft“ der jeweiligen Region eine wichtige Rolle „als ein Katalysator und Medium der regionalen Identitätsbildung“ (Blotevogel 1996: 60).

\subsubsection{Politikwissenschaftliche Ansätze}

Ein wichtiger Aspekt der politikwissenschaftlichen Auseinandersetzung mit dem Thema Region ist die Formierung eines Gegenbegriffs zur Globalisierung. Das schlägt sich in der Regionalismusdebatte nieder (vgl. Hock 2005: 11). Aus globalisierungskritischer Perspektive wird unter anderem argumentiert, dass durch die weltweite Vernetzung der gesellschaftlichen Akteure lokale Traditionen und Sicherheiten aufgelöst würden (vgl. Hock 2005: 11). Jedoch sind Regionalisierungstendenzen nicht ausschließlich als Gegenbewegung zur Globalisierung zu sehen, sondern sie können auch als komplementär verstanden werden (vgl. hierzu etwa Hock 2005: 11, Kohler-Koch 1998: 45, ferner zur Entwicklung des Begriffs der Regionalisierung Rohe 1996: 100).

Im politikwissenschaftlichen Verständnis des Begriffs Region besteht eine gewisse Widersprüchlichkeit. Sie besteht im räumlichen und konzeptuellen Zuschnitt von Regionen. Das Problem ist hier, dass Funktionsräume ${ }^{40}$ als nicht dauerhafte Gebilde nicht zwangsläufig auf geschichtlich überlieferten Räumen basieren. Sie setzen sich vielmehr je nach aktuellen Aufgaben und Problemen zusammen (Rohe 1996: 105). Demgegenüber steht ein Regionsverständnis, „das Regionen als historisch gewachsene Raumgebilde begreift, man mag sich dabei stärker an ,objektiven“ oder ,subjektiven“ Merkmalen orientieren“ (Rohe 1996: 105). Voraussetzung für derartige Regionen im eigentlichen Sinn ist so etwas wie regionale Identität, das heißt, dass auch hier auf die sozialpsychologischen Effekte einer Gruppenzugehörigkeit gesetzt wird, die auf den Vorstellungswelten und einer emotionalen Verbindung der Bewohner zur Region basiert (vgl. Rohe 1996: 105). Rohe merkt jedoch zutreffend an, dass trotz der historischen

\footnotetext{
$38 \mathrm{Zu}$ beachten ist aber nach Blotevogel, dass sie aus konstruktivistischer Perspektive nur als Konstrukte der Wissenschaft gelten können, die immer auch theorie- bzw. zweckgeleitet sind, auch wenn sie empirisch fundiert sind (Blotevogel 1996: 59).

${ }^{39}$ Ungeachtet der technischen Reichweite, die durch Kabelfernsehen und verschiedene Internetdienste zunehmend größer wird.

${ }^{40}$ Also etwa administrative Räume wie Landkreise oder auch Verbreitungsgebiete von Tageszeitungen, Sendegebiete von Rundfunkanstalten etc.
} 
Dauerhaftigkeit von Regionen nach diesem Verständnis historischer Wandel stattfindet, dem auch die regionale Identität unterliegt (Rohe 1996: 106). Ein Beispiel dafür ist das ehemalige Königreich Bayern: Die frühere Administrationseinheit ist heute historischer Bezugspunkt für die bayerische Identität. ${ }^{41}$ Daraus folgt, dass auch heutige Funktionsräume in Zukunft zum Ausgangspunkt regionaler Identität werden können (vgl. Rohe 1996: 106). Andererseits scheint es jedoch fraglich, ob solche Tradierungen sich erfolgreich gegen bereits bestehende Traditionen behaupten können. Allerdings besteht hier kein Verdrängungswettbewerb, sondern die verschieden begründbaren Regionen können durch die Verwender je nach Situation unterschiedlich abgerufen werden. Diese Parallelität besteht auch zwischen verschieden groBen Räumen, auf deren Teileinheiten sich ebenfalls berufen werden kann. So können sich die verschiedenen Bewohnerinnen und Bewohner Sachsens bspw. auch als Leipzigerinnen und Leipziger oder Dresdnerinnen und Dresdner verstehen, so wie einige Einwohnerinnen und Einwohner Bayerns sich als fränkisch, oberbayerisch oder schwäbisch begreifen können. Wenn Funktionsräume nur von administrativer Seite und damit großteils auch von außen bestimmt werden, ist der Faktor der regionalen Identität zu vernachlässigen. Als ideelle Ressource für erfolgreiche regionale Strukturpolitik kommt er jedoch dann in Betracht, wenn die administrativen und die sozialpsychologischen Einflussfaktoren ineinandergreifen (vgl. Rohe 1996: 106). Realistischerweise ist es aber unwahrscheinlich, dass administrative Entscheidungen Funktionsräume schaffen, die eines solchen ideellen Faktors entbehren, obwohl sie ihn benötigen. Politische Entscheidungen basieren auf sozialen Voraussetzungen und strukturellen Notwendigkeiten. Selbst eine Verordnung regionaler Identität „,von oben“ wäre immer noch jenen sozialen Prozessen, von unten“ unterworfen, die eine solche Gruppenidentität erst sozial wirksam machen.

Übertragen auf den Gegenstand der vorliegenden Untersuchung sind also die möglichen Auswirkungen des europäischen Integrationsprozesses auf die regionale Fernsehberichterstattung in Betracht zu nehmen sowie Ähnlichkeiten und Unterschiede zwischen regionaler (subnationaler) und nationaler Fernsehprogramme und darüber hinaus eventuelle Konvergenzen zwischen ihnen. Gerade die Entwicklungen auf europäischer Ebene haben nicht zuletzt zu Formulierungen in den rechtlichen Grundlagen der Rundfunkprogrammaufträge geführt, die auf die europäische Integration verweisen. ${ }^{42}$ Insofern sind entsprechende Programmangebote zu erwarten und in der Untersuchung zu berücksichtigen.

\subsubsection{Kulturwissenschaftliche Ansätze}

Kulturwissenschaftlich gesehen ist „[d]ie Region [...] eine Sinnordnung. Doch sie objektiviert sich jeweils in Strukturen, Institutionen, Mentalitäten und Artefakten“ (Siegrist 2001: 108). Die Objektivierungen werden also durch die Einteilung, auf die sie sich beziehen, erst hervorgebracht. Insofern zeigt sich auch hier, dass Regionen weder auf ihren administrativen noch auf ihren sozialen Gehalt reduziert werden können. In der Kulturwissenschaft können Regionen

\footnotetext{
${ }^{41}$ Siehe dazu auch S. 78.

42 Vgl. dazu Abschnitt 5.9 Rechtliche Rahmenbedingungen(S. 109ff.).
} 
als Zonen betrachtet werden, wobei „Zonen [Lebensbereiche sind], in denen einzelne Daseinsfunktionen separat ablaufen“ (Köck 1998: 195). Das Denken in Zonen folgt Gewöhnungen des 20. Jahrhunderts und kann sowohl als lokale Eingrenzung als auch als Wahrnehmung in Schemata der Klassifikation von Räumen in verschiedene Landschaften verstanden werden (Köck 1998: 195). Ein solches Schemadenken stellt weniger auf tatsächlich exakt bestimmbare Raumeinheiten ab, als vielmehr auf eine alltagstaugliche Verständigungsebene. Gibt etwa jemand „das Ruhrgebiet“ als seinen Herkunftsort an, so kann sein Gegenüber damit ungefähre geographische Daten assoziieren und bestimmte Vorstellungen über den Charakter des Ruhrgebiets und seiner Bewohner abrufen. Solche Denk-Schemata verstärken sich dabei durch den alltäglichen Gebrauch, weil sie nicht ständig neu ausgehandelt werden müssen, sondern kollektiver Wissensbestand sind.

Versteht man die Region als affirmative Antwort auf nivellierende ökonomische und globalisierende Tendenzen, wird die Region zur Identitätsofferte, wodurch auch eine Wirkung nach innen entfaltet wird (Lutz 1998: 223). Vereinfacht heißt das: Regionen bleiben für die Nation nur wertvoll, wenn sie sich von ihr unterscheiden.

Eine Frage, die sich über den Zusammenhang von Region und Kultur stellt, ist jene, ob erst die Kultur Region schafft oder eine Region zu einer spezifischen Ausformung von Kultur führt. Nicht zuletzt die gemeinsamen Merkmale machen eine Region erst zum in sich kohärenten Gebilde, darauf verweisen auch die Soziologie und die politische Verwaltung (vgl. Matter 1998: 36). Die Region zeichnet sich durch eine gewisse innere Homogenität und ihre Unterscheidbarkeit von benachbarten Gebieten aus (Matter 1998: 36 m. w. N.). In der gesellschaftlichen Praxis wird die innere Homogenität dadurch hergestellt, dass die zahlreichen innerregionalen Unterschiede zugunsten der Betonung der vorhandenen Gemeinsamkeiten verwischt werden (Matter 1998: 37). Die Zusammengehörigkeit der verschiedenen Gruppen einer Region wird dadurch erklärt, dass sie eine Kultur teilen (Matter 1998: 36), bzw. sich kulturelle Erscheinungsformen in einem Maße überschneiden, dass deren spezifische Ausdifferenzierungen und Unterschiede nicht ins Gewicht fallen. Die innere Kohärenz darf aber nicht auf den sozialpsychologischen Aspekt des Zusammengehörenwollens reduziert werden. Regionen sind, weil sie von Menschen gemacht sind, immer Kulturräume. Der Mechanismus der Abgrenzung nach außen basiert insofern auf der inneren Homogenität, weil die homogen gedachten Merkmale einer „bewussten Horizontverengung“ auf bestimmte Kulturausschnitte entspringen. Kulturelle Einzelheiten werden zu Besonderheiten stilisiert und eine Auswahl kultureller Erscheinungsformen wird so zum Merkmal einer bestimmten Region. „Kultur wird also segmentiert, geteilt. Sie bezieht sich nicht mehr auf die Gesamtheit von Werten, Normen und Gegenständen, sondern auf einzelne Teile, die zur Unterscheidung verwendet werden, als typisch interpretiert werden“" (Köstlin, zit. nach Matter 1998: 38).

Insbesondere die administrative Implikation wirft auch die Frage nach der Definitionsmacht über die Einteilung in Regionen auf. Die kulturwissenschaftliche Perspektive hat hier den Vorzug, dass sie nicht nur danach fragt, was eine Region ausmacht, sondern vor allem danach, wer sich wann und unter welchen Umständen auf Region bezieht (vgl. etwa Matter 1998: 39 sowie Schilling 1998: 50). 
Unter diesem Gesichtspunkt weist Schilling darauf hin, dass die Definition einer Region stets einem Interesse folgt, sei es ökonomischer, politischer oder wissenschaftlicher Natur (Schilling 1998: 50). Damit sei Region stets eine Frage der Macht (Schilling 1998: 50). Bei der Handhabung des „Entwicklungsfaktors Region durch ein Medienunternehmen“"43 sei eine Willkür in den territorialen Strategien am Werk, weshalb insbesondere die Plausibilität und Relevanz der darin behaupteten Räume zu prüfen sei (Schilling 1998: 49). Die Aufteilung etwa eines Bundeslandes in „medial zubereitete Teilstücke“ (Schilling 1998: 50) wirft dann aber auch die Frage auf, welche Chancen auf Binnen-Akzeptanz (also durch die Bewohnerinnen und Bewohner) eine solche gemachte Region hat. Diese Chancen steigen, „wenn das Konstrukt alltagsrelevant wird.“ (Schilling 1998: 51). Die Frage nach der Region als eine Frage der Macht ist auch im Zusammenhang der vorliegenden Studie relevant. Innerhalb einzelner $A R D$-Anstalten kann es zum Beispiel unterschiedliche regionale Interessen geben, die sich darauf beziehen, wie stark bestimmte Regionen innerhalb eines Programms vertreten sind. ${ }^{44}$ Dies ist deshalb brisant, weil es in den rechtlichen Grundlagen keine Regelungen darüber gibt, in welchem Umfang Teilregionen zu berücksichtigen sind. Zwar heißt es etwa im MDR-Staatsvertrag, dass die drei Bundesländer angemessen zu berücksichtigen sind - eine Ausführungsbestimmung über die tatsächliche anteilsmäßige Verteilung auf das Programm fehlt indes. ${ }^{45}$ Da mit solchen programminhaltlichen Anteilen letztlich auch die finanzielle Ausstattung bestimmter Landesfunkhäuser einhergeht, handelt es sich außerdem um eine ökonomische Machtfrage. Die Interessenverfolgung und schließlich auch Machtfrage, die Schilling anspricht, ist also eine, die sich sehr wohl programminhaltlich auswirken kann. Dadurch betrifft diese Machtfrage am Ende auch das Publikum.

Das ist umso mehr der Fall, als dass das Ziel, welches der Rundfunk mit seinen unterschiedlichen Regionalisierungsschemata verfolgt, nicht zuletzt „die Herstellung einer nachhaltigen Empfänger-Sender-Bindung“ durch die programmatische Ausbildung von Regionalbewusstsein ist (Schilling 1998: 52). Diese Regionalisierung betrifft in Schillings Beispiel des Hessischen Rundfunks lediglich den Hörfunk, ,während offenbar das Fernsehen ganz Hessen als Region versteht“ (Schilling 1998: 53). Dennoch stellt sich die Frage (für Hörfunk und Fernsehen gleichermaßen), ob die von den Sendern administrativ vorgegebenen regionalen „Zuschnitte überhaupt so etwas besitzen wie ,kulturelle Füllung, und das meint in unserem Zusammenhang auch: identitätsbildende - einschließende und ausschließende - Inhalte" (Schilling 1998: 53). Im Falle des Hessischen Rundfunks bemerkt Schilling zwei Strategien der Regionalisierung: Einerseits werden Dörfer und ländlicher Raum auf einer unteren Ebene ins Programm gehoben, während auf einer oberen Ebene die „Trademark Hessen“ als alles umschließende Klammer fungiert (vgl. Schilling 1998: 53). Daraus folgt einerseits, dass es eigentlich keine regionale Spezifität außer dem Berichtsgebiet und dem ausstrahlenden Sender gibt. Andererseits wird Regionalität mit ländlichem Idyll gleichgesetzt, das Regionale heißt dann „Stadtferne und ansehnliche Natur“ (Schilling 1998: 59). Aufbereitet werden solche Inhalte im

\footnotetext{
43 Schillings Ausführungen beziehen sich auf den Hessischen Rundfunk.

${ }^{44}$ Also etwa Beiträge aus dem fränkischen Raum im Programm des BR oder aus den drei verschiedenen Bundesländern innerhalb des Programms des MDR.

45 Siehe dazu auch Abschnitt 5.9.4, S. 114.
} 
„ereignislosen Bericht“ (Schilling 1998: 58). Regionen werden also lediglich als „operative Räume der Berichterstattung“ (Schilling 1998: 60) definiert und mit dem Namen einer übergreifenden Region als Dachmarke etikettiert. Inwiefern diese Befunde auch auf die hier zu untersuchenden Gebiete und Sender zutrifft, wird genauer zu betrachten sein. Dafür bieten sich in der Untersuchung insbesondere Kategorien an, die erfassen, ob von tatsächlichen Ereignissen berichtet wird. In der Interpretation der erhobenen Daten soll schließlich auch darauf eingegangen werden, inwieweit die Berichtsräume kulturellen Räumen entsprechen.

\subsubsection{Sprachwissenschaftliche Dimensionen}

Aus sprachwissenschaftlicher Sicht haben Regionen insbesondere hinsichtlich der Variationen gesprochener Sprache Bedeutung, etwa bezüglich Dialekten. In der Linguistik werden Regionen weniger strikt getrennt als aus administrativer Sicht. Die Grenzen zwischen Regionen erscheinen fließend und umfassen alle geographischen Gebiete, die als distinkt von anderen Gebieten erscheinen, wobei diese Distinktion durch die Menschen, die in diesen Gebieten leben, sowie durch die verschiedenen Sprachvarietäten bestimmt wird (vgl. Beal 2006: 4). Sprachgeographische Unterschiede (süddeutscher Raum vs. norddeutscher Raum: Samstag/Sonnabend; ich bin gesessen/ich habe gesessen) beschränken sich dabei nicht auf die Dialekte, sondern reichen bis in die Standardsprache hinein (Bergmann et al. 2005: 138).

Eine einfache Übersicht über die Dialekte im deutschen Sprachraum um 1900 findet sich etwa bei Bergmann et al. 2005: 141 (m. w. N.). Hier ist zu erkennen, dass die Dialektgrenzen zwar nicht mit den (heutigen) Verwaltungsgrenzen der Bundesländer zusammenfallen, aber im Kern dieser Verwaltungsgliederung grob entsprechen. Damit wird deutlich, dass die regionale Einteilung Deutschlands in die Bundesländer zwar, was die Grenzziehungen im Einzelnen betrifft, willkürlich erfolgt, aber einer historisch gewachsenen und sich in der Sprache niederschlagenden Regionalisierung nicht grundsätzlich widerspricht. Insofern erscheint es durchaus legitim, die Grenzen von Bundesländern als manifestierte Regionen zu bezeichnen.

Die Relevanz der Sprache für die Regionen zeigt sich nicht zuletzt daran, dass die Erklärung für die Unterschiede der Sprachräume auch in außersprachlichen Gegebenheiten gesucht wird. Hierfür werden etwa die Topographie, der Verkehr, wirtschaftliche Verhältnisse, territoriale Grenzen etc. herangezogen, so dass man Sprache als eine raumbildende Komponente unter vielen verstehen kann (Löffler 2003: 32). Die direkte Verbindung zwischen Raumkonstitution und räumlich orientierter Identität ist beim Phänomen Sprache besonders evident, da sie jederzeit im unmittelbaren Alltagszusammenhang der Nutzer (Sprecher) steht. Die Untersuchung von Fernsehprogrammen unter dem Gesichtspunkt von Identitätsangeboten muss daher auch auf die Sprachverwendung eingehen, auch wenn dies im Rahmen einer nicht linguistischen Arbeit nur eingeschränkt möglich ist.

Im Rahmen dieser Arbeit kann zudem gefragt werden, ob Dialekte tatsächlich eine nur geringe öffentliche Verwendung finden (so Bergmann et al. 2005: 133). Dass ihre öffentliche Verwendung geringer ausfällt als die der Standardsprache, ist schon auf Grund ihrer räumlichen Ein- 
schränkung einleuchtend, dass sie aber auf den informellen und privaten Bereich beschränkt sein soll (so ebenfalls Bergmann et al. 2005: 133), erscheint fraglich.

Für die Untersuchung der Fernsehprogramme können diese Unterschiede der Sprachverwendung nutzbar gemacht werden, weil die verwendete Sprache ein nicht zu unterschätzendes Identifikationsmedium darstellt. Hierbei ist vor allem die Verwendung von Standardsprache und Dialekt durch die zu Wort kommenden Personen von Bedeutung, wie etwa interviewte oder anderweitig gezeigte Personen im Alltag. Insbesondere von „Normalbürgerinnen“ und „Normalbürgern“ ist eine nahezu alltägliche Dialektverwendung zu erwarten. Dagegen dürften Fernsehsprecherinnen und Fernsehsprecher auf Grund ihrer Ausbildung hauptsächlich Standardsprache verwenden. Sie können daher vernachlässigt werden. ${ }^{46}$

\subsubsection{Eigene Arbeitsdefinition}

Für die eigene Definition ist zu bedenken, dass - aus konstruktivistischer Sicht - die Wissenschaftler und Wissenschaftlerinnen selbst als diejenigen mit einzubeziehen sind, deren Handeln die Region (mit-)konstruiert. Weichhardt weist zutreffend darauf hin, dass die Zuordnung von Gebieten zu Regionen auf Basis des Ähnlichkeitsprinzips bestimmter Merkmale (darauf basieren „Strukturregionen, die Zuordnung selbst bezeichnet Weichhart als „Regionalisierung") zwangsläufig Artefakte produziert, weil es für die Wahl der Bezugs- und Beobachtungseinheiten verschiedene Optionen gibt, auf die sich immer nur willkürlich bezogen werden kann (vgl. Weichhart 1996: 29). So verhält es sich auch mit den „Funktionalregionen“ und „normativen Regionen“, die methodische Konstrukte sind, die von analysetechnischen Entscheidungen abhängen oder als Ergebnis normativer Entscheidungsfindungen Ausdruck politischer Willensäußerungen darstellen (vgl. Weichhart 1996: 34). Insofern erscheint der konstruktivistische Ansatz besonders plausibel, weil er es erlaubt, den Konstruktcharakter von Regionen in verschiedenen Abstufungen zu berücksichtigen, je nach Erkenntnisinteresse des wissenschaftlichen Zusammenhangs.

Es stellt sich die Frage, ob es für die vorliegende Untersuchung sinnvoll ist, auf positivistische bzw. materielle Regionskonzepte zu verzichten und die hier betrachteten Regionen ausschließlich aus soziologischer und sozialpsychologischer Perspektive zu verstehen. Sinnvoll wäre dies hinsichtlich der Identifikationsangebote, welche die in Betracht kommenden Fernsehsender machen. Die Studie beschränkt sich jedoch auf die Seite der Medieninhalte und kann deshalb keine Aussagen über tatsächliche Wirkungen des Identifikationsangebots machen. Insofern

\footnotetext{
46 Theoretisch ist auch für Fernsehsprecherinnen und -sprecher eine abgestufte Dialektverwendung denkbar (nicht zuletzt um die Regionalität von Sendung oder Sender gezielt zu unterstreichen). Da aber in der heutigen Fernsehlandschaft die Moderatorinnen und Moderatoren keineswegs immer aus der Region stammen, in der sie moderieren (siehe etwa den „Wetterexperten“ Thomas Globig, der sowohl im MDR-Fernsehen als auch im NDR-Radio für die Wettermeldungen zuständig ist) wären hier wenig verlässliche Ergebnisse denkbar. Zudem stellt die Erfassung der Moderationsanteile einen nicht zu unterschätzendes forschungsökonomischen Aufwand dar, der angesichts der zu erwartenden Ergebnisse nicht zu rechtfertigen wäre. Darüber hinaus kann die Sprachverwendung nur ein untergeordneter Teilaspekt dieser Arbeit sein, da sie keine originär linguistischen Untersuchungsmethoden zur Anwendung bringt.
} 
bedarf es einer materiellen Vergleichsebene, auf die sich die Medieninhalte in räumlicher Hinsicht beziehen. Daraus kann abgeleitet werden, welche Gebiete überhaupt als Identitätsfaktor „angeboten“ werden. Auf administrativ-normativer Seite lässt sich daraus ableiten, wie bestimmte kommunikative Zielvorgaben durch die Fernsehanstalten ausgefüllt werden (etwa Erfüllung rechtlicher Vorgaben aus Rundfunkgesetzen). In der Nomenklatur Blotevogels kommen daher Aktivitätsregionen als Grundlage der Konstruktion von Identitätsregionen durch die Fernsehanstalten in Betracht. Es wird dabei zu fragen sein, inwiefern die Programmangebote daran mitwirken, beide Regionskonzepte in den jeweils konkreten Fällen zur Deckung zu bringen.

Insgesamt ist festzuhalten, dass die Region ein ähnlich sozial konstruiertes Phänomen ist wie die Nation, jedoch einen deutlich stärkeren Bezug zu einem konkreten geographischen Raum aufweist. In diesem räumlichen Bezug besteht ein wichtiger Unterschied zwischen der Nation und der Region, der im Fall der Region manifest, im Fall der Nation nur latent ist.

Im hier relevanten Kontext kann die Region also als Mischform der administrativen und der sozialpsychologischen Konstrukte verstanden werden. Gerade weil der Verbreitungsraum der Sendeanstalten administrativ bestimmt ist, müssen sie ihrem jeweiligen Rundfunkauftrag folgend dem sozialen Konstrukt der jeweiligen Region entsprechen und auch darüber hinausgehende Areale einbeziehen. Auf Grund der öffentlichen Verbreitung der Sendeinhalte wirken sie damit an dem sozialen Konstrukt Region mit.

Im Folgenden soll als Region ein Raumkonstrukt auf subnationaler Ebene gelten, das auf administrativer Seite durch willkürliche Grenzziehung entstanden ist. Innerhalb dieser Grenzen haben Regionen eigenständige Administrationsstrukturen, die der nationalen Ebene untergeordnet sind, jedoch nicht in allen Belangen an deren Weisungen gebunden sind. ${ }^{47}$ Innerhalb der Grenzen können sich Identitäten ausbilden, die auf den Raum und das darin stattfindende soziale Leben bezogen sind.

\footnotetext{
${ }^{47}$ Der einfache Rückgriff auf eine Definition Regionen = Bundesländer ist auf Grund des Forschungsinteresses an den Funktionen des Mitteldeutschen Rundfunks für den „Bundesländerverbund“ aus Sachsen, SachsenAnhalt und Thüringen hier nicht anwendbar. Da aber zumindest die Außengrenzen dieses Konstruktes auf denen der Bundesländer basieren, können diese Grenzen von Bundesländern aber als ein Distinktionsmerkmal von Regionen angenommen werden. Konstruktivistisch gesprochen handelt es sich bei der Ausdehnung auf mehrere Bundesländer auch dann noch um ein viables Konstrukt, wenn es sich nicht nur aus den Überlegungen des Forschers ergibt, sondern auch in anderen Zusammenhängen genutzt wird. Im Fall Mitteldeutschlands ist das durch den MDR-Staatsvertrag gegeben, der als Sendegebiet die Region aus den genannten Bundesländern vorsieht.
} 


\subsection{Nationale Identität}

Wenn von nationaler Identität gesprochen wird, so ist die nahe liegende Interpretation dieses Begriffs mit der Frage nach persönlichen und individuellen Eigenschaften verbunden, die den Angehörigen bestimmter Nationen gerade auf Grund der Zugehörigkeit zu dieser oder jener Nation zugeschrieben werden. Schnell ist dann die Rede von einem Nationalcharakter oder von Stereotypen wie deutscher Pünktlichkeit oder englischem Understatement. Dabei fällt die Identifizierung von Nationen als konkreten und unverwechselbaren Einheiten unter den Tisch, obwohl die vorgenannten Phänomene nicht zuletzt darauf beruhen. Allerdings besteht zwischen der (zugeschriebenen) Identität und der Identifizierbarkeit einer Nation kein kausaler, sondern eher ein zirkulärer Zusammenhang. Deshalb muss die das Phänomens nationaler Identität sowohl im Allgemeinen als auch in der konkreten Anwendung auf bestimmte Nationen beide Seiten betrachten - also die Identifizierung von Nation(en) und die Identifikation mit ihnen. Das gilt unabhängig davon, welchem Teil dieses Zusammenhangs sich schließlich empirisch angenähert werden soll. Hier setzt sich das Problem zwischen objektiver und subjektivistischer Auffassung fort, das schon die Nation kennzeichnet, indem auf eine gemeinsame Wahrnehmung der Zugehörigkeit verwiesen wird (vgl. Uzarewicz/Uzarewicz 1998: 201). Insbesondere die Behauptung von national begründbaren Eigenschaften der einzelnen Nationsangehörigen erscheint jedoch problematisch, insbesondere weil deren Untersuchung ein Vorwissen zum Gegenstand machen muss, das selbst infrage steht und dennoch nationale Identität als Resultat einer Praxis und Substanz von Konstruktionen begreift (Uzarewicz/Uzarewicz 1998: 201). Nach Uzarewicz und Uzarewicz sind stattdessen die Konstrukteure solcher Identitäten in den Blick zu nehmen (vgl. Uzarewicz/Uzarewicz 1998: 201). Das dürfte für die Fortschreibung und Aktualisierung einer vorgestellten Gemeinschaft im zirkulären Sinn einige Schwierigkeiten aufwerfen, die eine Überprüfung jenseits historischer Zusammenhänge bald unmöglich machen. In Hinblick auf einen empirischen Zugang ist es daher legitim, einen Ausschnitt öffentlicher Kommunikationspraxis als Ausdruck der Erzeugung nationaler Identität zu untersuchen und die Frage nach der Diskurshoheit hintanzustellen. Sie wird jedoch eine Rolle spielen, sobald es um die Funktionen dieser öffentlichen Kommunikation geht.

Da „Nationen hierarchisch gegliederte Dialoggemeinschaften [sind], die sich immer wieder neu legitimieren und anerkannt werden müssen“ (Bornewasser/Wakenhut 1999: 46), ist das Phänomen nationaler Identität insbesondere hinsichtlich seiner kommunikativen Grundlagen zu untersuchen bzw. eignet es sich gut, um innerhalb von (Massen-)Kommunikationsvorgängen analysiert zu werden. Im Folgenden soll der Rahmen erarbeitet werden, der eine Identifizierung von Nation innerhalb der kommunikativen Ausprägungen in Massenmedien erlaubt. Erst diese Grundlage erlaubt es, Aussagen über die Leistung des Fernsehens als Aushandlungsmedium der nationalen Identität zu treffen. Da Nation und nationale Identität aufeinander bezogen sind, wird auf die nationale Identität vor allem im oben zuerst genannten Sinne („Identifizierung von“) einzugehen sein. 
Da schon der Begriff der Nation von sozialpsychologischem Charakter ist, enthält er bereits eine Menge Aspekte nationaler Identität, die an dieser Stelle nicht wiederholt werden müssen. Vielmehr kommt es darauf an, aus der Vielzahl von Ausdifferenzierungen nationaler Identität jene Gesichtspunkte hervorzuheben, die für die anschließende empirische Untersuchung relevant sind. Beachtenswert ist dabei aber auch die Unterscheidung in Nationalbewusstsein und nationale Identität.

„Nationalbewußtsein und nationale Identität beschreiben Mischungen aus diesen sozialen Beziehungen [zu sozialen Gruppierungen, Nationen und Regionen], wobei die kognitiven und evaluativen Komponenten stärker das Nationalbewußtsein prägen, die affektive Komponente stärker die soziale Identität und damit auch verstärkt das Verhalten bestimmt" (Bornewasser/Wakenhut 1999: 48).

Nationalbewusstsein bezieht sich demnach hauptsächlich auf das Wissen um Eigenart und Zugehörigkeit zu einer Nation, wobei dieses Wissen eng mit Wertungen verknüpft ist (Bornewasser/Wakenhut 1999: 48). Auch wenn diese Wertungen bei den vielen Angehörigen einer Nation im Einzelnen unterschiedlich ausfallen mögen, ist die Gemeinschaft doch darauf angewiesen, einen Großteil der Wertungen abzugleichen, und sei es auch nur in Hinsicht auf die Wichtigkeit etwa eines nationalen Symbols. Ohne ein Mindestmaß an geteilten Vorstellungen und Einstellungen kann eine Nation nicht als soziale Gemeinschaft angesehen werden.

Wie bereits erwähnt, können Nationen als integrationsfähig erscheinen, wofür insbesondere die Verstärkung positiver Zugehörigkeitsgefühle verantwortlich ist. Die Integrationsfähigkeit dürfte vor allem für die hierarchische Anordnung in regionale Untergruppen ${ }^{48}$ innerhalb der Nation von Belang sein, weil die Nation hier als übergeordneter Verbund fungiert. Je enthobener solche Gemeinschaften vom Alltag der Gruppenmitglieder sind, desto wichtiger werden Symbole, auf die sich die Gemeinschaft beziehen und berufen kann. Daher ist die „Verstärkung der kollektiven Symbolsicherheit und des Nationalbewußtseins" (Bornewasser/Wakenhut 1999: 48) mitverantwortlich für die Integrationskraft einer Nation. Symbole haben den Vorteil, relativ offen für eigene Interpretationen zu sein oder ihrer gar nicht erst zu bedürfen. So lange das Symbol als eines der Nation bekannt genug ist, kann es kontextabhängig von der Betrachterin oder dem Betrachter entschlüsselt werden und die ganze Nation oder bestimmte Teile davon (in ihrer Verbindung zum Rest der Nation) repräsentieren. So ist etwa das Berliner Reichstagsgebäude oder das Wiener Parlamentsgebäude in Fernsehberichten jeweils als Symbol der Bundespolitik einsetzbar, weil es im größten Teil der Nation bekannt sein dürfte. Dieselbe Bekanntheit ist von regionalen Symbolen nicht im gleichen Maße zu erwarten. In bundesweiten TV-Programmen (mit der entsprechenden Zielgruppe) ist daher zu erwarten, dass in regionalen Zusammenhängen nur auf solche Symbole zurückgegriffen werden kann, die so bekannt sind, dass sie Ereignisorte identifizierbar machen, auch für Personen, die nicht aus der betroffenen Region stammen. Ansonsten können solche Symbole nur dann eingesetzt werden, wenn sie von überregionaler Bedeutung sind und besondere Aspekte der Nation repräsentieren. ${ }^{49}$ Hierin schlägt sich der geringere Raumbezug des Konzepts Nation im

\footnotetext{
${ }^{48}$ Von subnationalen Regionen bis hin zu Stadtvierteln.

${ }^{49}$ Hier ist beispielsweise an die Frankfurter Skyline als eine Symbolisierung des deutschen Finanzgewerbes zu denken.
} 
Vergleich zu dem der Region nieder, der zu einer größeren Offenheit dieses Konzepts führt. Zur Identifikation der Nation im Fernsehprogramm ist daher keine flächenmäßig ausgewogene Berichterstattung notwendig: Ein Fernsehprogramm richtet sich auch dann noch an eine ganze Nation, wenn es gar nicht aus allen Gebieten eines (National-)Staates berichtet, schon weil der nationale Verbund unverbindlicher ist als ein regionaler und auf einen entsprechend anderen Erwartungshorizont beim Publikum trifft.

Den Vorrat nationaler Bezugsobjekte nennt Langer „national ideology“ (Langer 1999: 153). Dabei handelt es sich um einen kollektiv geteilten Wissensspeicher, der es den Mitgliedern der Nation ermöglicht, sich als Angehörige ihrer Nation zu sehen, zu fühlen und diese Zugehörigkeit auszudrücken (Langer 1999: 153). Dieser Zeichen-, Wissens- und Bedeutungsvorrat wird dann zur nationalen Identität, wenn er im Alltag der betroffenen Personen relevant wird, weshalb erst dann von nationaler Identität zu sprechen ist, wenn sich ein großer Teil der Bevölkerung mit den Elementen der „national ideology“ identifiziert (Langer 1999: 153). Langer geht hierbei von einer Transformation aus, durch die nationale Identität in Form von Artefakten individuelle Charakteristika selbst dann noch mitbestimmt, wenn sie in der sozialen Realität schon keine Entsprechung mehr haben. Dabei ist aber zu bedenken, dass auch Geschichte oder genauer gesagt Geschichtsschreibung - zur sozialen Realität einer Nation gehört und damit ein Konstituens nationaler Identität ist. Da es sich bei der Geschichte um eine (kommunikativ ausgehandelte) Interpretation handelt, ist sie auch Bestandteil der sozialen Realität. Artefakte können also lediglich im Alltag der Mitglieder einer Nation keine Entsprechung mehr haben, die nationale Identität (insbesondere in Außenzuschreibungen) aber nach wie vor prägen.

Hieraus wird aber auch ersichtlich, dass die eigene Nationszugehörigkeit immer auch gelernt werden muss, nationale Identität also auf Nation als Wissenskonstrukt beruht. Nationale Identität basiert dabei auf nomischem Wissen, ${ }^{50}$ bringt solches Wissen aber auch hervor und bildet damit ein mögliches Raster zur Wirklichkeitsinterpretation und zur Beurteilung von Objekten aller Art (durch implizite Werten, Normen und Standards; vgl. Estel 2002: 102). Nomische Wissen existiert nicht objektiv, sondern wird innerhalb der davon getragenen Gesellschaft ausgehandelt bzw. wurde und in der Vergangenheit ausgehandelt. Dabei bilden die Elemente des nomischen Wissens ,nach ihrer Struktur, ihrem Gesamtsinn, ihrer Wertakzentuierung vergleichsweise stimmige Konfigurationen“ (Estel 2002: 103). Diese Ordnung findet sich im „Jedermannbewusstsein“ wieder, wodurch die „personale Grundfunktion, die kognitive wie emotionale Stiftung von Ordnung und Rang“ erfüllt wird (Estel 2002: 103). Deshalb meint „Kollektive Identität [...] nicht den objektiven, etwa systemischen Zusammenhang selbst, den

\footnotetext{
${ }^{50}$ Nomisches Wissen definiert Estel als einen ,von drei Grundtypen menschlichen Wissens, nämlich mythisches, religiöses, ideologisches, moralisches u.ä. Wissen [...], das den Menschen angibt, was die Dinge ,in Wirklichkeit‘, d.h. nach ihrem Wesen, ihrem eigentlichen Rang und Wert sind. [...] Nomisches Wissen belehrt die Menschen darüber, was als sinnvoll und sinnlos zu gelten hat, was zu bejahen und anzustreben, was zu verneinen und zu vermeiden ist, und besitzt also einen Doppelcharakter: Es gibt mit seinen Rastern der Wirklichkeitsinterpretation die inhaltlichen Gesichtspunkte der Beurteilung von Objekten aller Art vor und zugleich liefert es über die mit ihm verknüpften, ihm impliziten Werte, Normen und Standards Handlungsanleitungen" (Estel 2002: 101, Hervorhebungen im Original, m.w.N.).
} 
Menschen miteinander bilden, sondern seine Interpretation durch die ihm Angehörigen“" (Estel 2002: 108, Hervorhebungen im Original).

„Das Faktische, z. B. der Umgrenzung eines Territoriums, der Zwang verbindlicher Normen und Regeln oder das Sprechen einer Sprache, erfährt eine spezifische Semantisierung und wird zum Signum einer Identität, die als eine geleistete, das Produkt einer diskursiven Gesellschaft oder Gemeinschaft ist“"(Uzarewicz/Uzarewicz 1998: 202).

Bei der (historischen) Entstehung von Nationen kommt der Politik die Aufgabe zu, die Ziele der Nation zu benennen, die sich nicht in der Errichtung eines Nationalstaates erschöpfen. ${ }^{51}$ Daher ist es auch bei bestehenden Nationen eine Aufgabe der Politik, jenes ,nationale Gemeinwohl“ zu stiften, dem die vorderhand objektiven Interessen der Bevölkerung folgen, in deren Geltung jedoch immer auch nomische (mythische, religiöse, ideologische, moralische u. ä.) Gesichtspunkte erkennbar sind, die eben nicht nur an bloßer Nützlichkeit orientiert sind (vgl. Estel 2002: 147). „Und mit ihrer ideellen Bündelung zum Gemeinwohl ist eine weitere nomische Anreicherung verbunden, über deren näheren Charakter eben die kollektive Identität entscheidet“" (Estel 2002: 147).

Aus der Anordnung der einzelnen Wissenselemente und deren Interpretation ergibt sich die kollektive Identität:

„Vorhandene wie bloß vermeintliche Gemeinsamkeiten bilden grundsätzlich nur das Rohmateri-
al, aus dem in den nationalen Entwürfen ein Teil ausgewählt, so oder anders interpretiert bzw.
nomisch aufbereitet und in dieser Form zum Bau der nationalen Identität verwendet wird. Und
zwar gehören die derart aufbereiteten Gemeinsamkeiten, als der Nation eigene Qualitäten, ge-
wöhnlich zur Identitätsebene der nationalen Gegebenheiten; eine oder mehrere davon können
aber auch in den Rang des Identitätsfokus einrücken, von dem her ein solcher Entwurf die Nati-
on in erster Linie versteht. Ein einmal gewonnener Fokus ist nämlich für die Gesamtidentität in
doppelter Weise entscheidend: Die nähere Auswahl der für die Identitätskonstruktion verwen-
deten Materialen erfolgt in sinnhafter Abhängigkeit von ihm; und um ihn herum werden die aus-
gewählten Gemeinsamkeiten bzw. die Kernereignisse so organisiert, dass daraus ein umfassen-
des und in sich mehr oder minder stimmiges Wissensgebäude entsteht" (Estel 2002: 100).

Damit die nationale Identität viabel wird, benötigt sie einen mehr oder weniger öffentlichen Repräsentationsort, als der - unter den aktuellen Bedingungen - die Massenmedien gelten können. Die Begriffe „Ordnung“ und „Rang“, die sich im Bewusstsein der einzelnen Nationsangehörigen niederschlagen sollen, legen in Zusammenhang mit dem Untersuchungsfeld Massenkommunikation einen Bezug zum Agenda-Setting-Ansatz nahe. Diese Theorie der Medienwirkung besagt (vereinfacht ausgedrückt), dass in den Medien diskutierte Themen auch von den Rezipienten als wichtig eingestuft werden (Hoffmann 1998: 431), also die MedienAgenda als soziale Wirklichkeit vom Publikum übernommen wird (Bonfadelli 2005a: 360). Das betrifft auch die Einstufung der Themen in ihrer Wichtigkeit. Geht man von einem sehr weit gefassten Themenbegriff aus, können die in diesem Ansatz beschriebenen Effekte im hiesigen Zusammenhang auf einer niedrigschwelligen Ebene auftreten und zwar dann, wenn es um eher basale Elemente der kollektiven Identität geht und nicht um tagesaktuelle Bewer-

${ }^{51}$ Sonst würde die Verwirklichung von Nationen immer auch deren Ende bedeuten. 
tungen und Einordnungen politischen Geschehens. Insofern kann im Wissensrepräsentationsraum Massenmedien der (kollektive) Rahmen für nachfolgende Bewertungen bereitgestellt werden. ${ }^{52}$ Auch hier ist allerdings von Zirkularität statt Kausalität auszugehen. Die Medien ordnen die Wirklichkeit nicht gemäß nationaler oder regionaler Identität, sondern sie folgen bereits bestehenden Mustern, wodurch sie an deren Fortbestand mitwirken.

Auch die politische Einsetzung nationaler Ziele kann keineswegs willkürlich stattfinden, sondern sie muss der nationalen Identität folgen. So könnte etwa die Vorreiterrolle, die Deutschland im Umwelt- und Klimaschutz einnimmt, auf einer in der deutschen Identität besonders stark verwurzelten Nähe zu Landschaft und Natur beruhen. ${ }^{53}$

Eine Grundbedingung für die Existenz nationaler Identität ist (schon bei der Entstehung von Nationen), dass sie in der Bevölkerung für ,wahr und durch ihre Wahrheit verpflichtend gehalten“" wird (Estel 2002: 100, Hervorhebung im Original). Ohne diese Verpflichtung kann bspw. keine Alltagssolidarität entstehen. Daraus folgt aber auch ein Mindestmaß an Verbindlichkeit sowohl der ,national ideology“ als auch der Interpretation der Bezugsobjekte der nationalen Identität. ${ }^{54}$ Diese Verbindlichkeit ist es, die letztlich das Handeln (etwa politischer Akteure) im Sinne der kollektiven Identität beeinflusst. ${ }^{55}$

Praktische Bedeutung kommt der nationalen Identität im Alltag erst zu, wenn sie sich nicht nur in Wissensbeständen niederschlägt, sondern sich in irgendeiner Weise auch im alltäglichen Leben wiederfindet.

„[D]ie nationale Identität [erhält] erst durch die Institutionalisierung, insbesondere ihre Übersetzung in eine entsprechende politische Identität ihre volle praktische Bedeutung, denn es ist die Politik, in der Ziele verfolgt werden und immer wieder Entscheidungen fallen, die auch für

52 Stark vereinfacht gesehen stellt ein regionales TV-Programm einen anderen Präsentationsrahmen dar als ein nationales. Themen, die in den nationalen Nachrichten verhandelt werden, sind aus Rezipientensicht für dessen nationale Identität wichtig, andere Themen im regionalen Programm für die regionale Identität. Dabei kann die Relevanzeinordnung zwischen beiden Ebenen unterschiedlich ausfallen. Die unterschiedliche Medienagenda würde also unterschiedliche soziale Wirklichkeiten hervorrufen, die parallel existieren - und zwar nicht nur in unterschiedlichen Teilpublika. Dies ist möglich, weil die Salienz der jeweiligen sozialen Identität (national vs. regional) auch beim einzelnen Zuschauer und bei der einzelnen Zuschauerin je nach Kontext differiert. Beispielsweise wird sich jemand mit Leuten aus dem lokalen Umfeld eher über das Fernsehduell zweier Landtagswahlspitzenkandidaten unterhalten als mit Menschen im Ausland. Auf Langzeitwirkung hin gesehen käme allerdings eine weniger konkrete Themenagenda als Vorlage für die soziale Wirklichkeit der Rezipienten in Betracht. So könnte ein geringer Umfang von Politikberichterstattung im Regionalprogramm etwa zu einer geringen Bedeutsamkeitseinschätzung regionaler und kommunaler Politik führen. Das gilt aber auch für viel alltäglichere Themen. So könnte etwa ein spezielles TV-Magazin für alpines Skifahren als Freizeitvergnügen im österreichischen Fernsehen die Identität der Alpenrepublik in einer bestimmten Weise prägen - und zwar auch für Zuschauerinnen und Zuschauer, die deutlich außerhalb der klassischen Skiregionen leben.

${ }^{53}$ Dieses Beispiel dient nur der Illustration und wurde von mir weder hinsichtlich der tatsächlichen Klimaschutzpolitik Deutschlands noch hinsichtlich der Bedeutung der Natur für die deutsche Identität geprüft. Auf den ersten Blick scheint eine solche Verbindung aber nicht abwegig, wenn man etwa nur an die Bedeutung der Natur und des Waldes für die deutsche romantische Literatur denkt.

${ }^{54}$ Wobei diese Verbindlichkeit nicht zwangsläufig die zugebilligte semantische Bedeutung meint, sondern die nomische Qualität und den jeweiligen Rang der Bezugsobjekte im Gesamtkonstrukt der nationalen Identität.

${ }_{55}$ Dabei (ko-)determinieren materielle Faktoren das Verhalten eines Subjekts auf Grund ihrer unabhängig von dessen Bewusstsein und Willen bestehenden Gesetzmäßigkeiten. Das Handeln wird durch die subjektiven Bedeutungen bedingt, die dem aktuellen Wissen des Subjekts entspringen (vgl. Estel 2002: 79). 
die anderen Daseinsbereiche von großer Bedeutung sind, und in die sie auch indirekt, d. h. mehr oder minder steuernd eingreift" (Estel 2002: 114).

Insofern kommt (wie schon in der Vergangenheit bei der Durchsetzung nationaler Identitäten als Voraussetzung der Entstehung von Nationen und Nationalstaaten) der Politik eine herausragende Stellung für die Bedeutung nationaler Identität zu. Das wird bei der Analyse der Fernsehinhalte zu beachten sein, weil die Politik ihrerseits in einem gewissen Abhängigkeitsverhältnis zu den Medien steht.

Ebenso wie die Nation selbst, beruht auch die nationale Identität auf historisch gewachsenen politischen und kulturellen Strukturen (also auch: Institutionalisierungen), die in ihrer Gesamtheit die spezifische Nation unverwechselbar, identifizierbar machen. Diese Identifizierbarkeit beruht auf

1. einem Staat,

2. der für und in diesem Staat stattfindenden Politik und Administration,

3. einer Geschichte, aus der sich der aktuelle Staat mit seinen Grenzen herausgebildet hat,

4. einem spezifischen Wirtschaftsleben, das seinerseits durch die natürlichen (etwa: Rohstoffe), kulturellen und politischen Eigenheiten des Staates und seiner Geschichte geprägt ist und sie selbst (mit-)prägt,

5. einer Kultur und einem Kulturverständnis, das sich aus der Geschichte der Nation ergibt und

6. einem gesellschaftlichen Leben und sozialen Strukturen, die sich aus den vorgenannten Aspekten ergeben und diese ihrerseits tragen.

Darüber hinaus trägt auch die Sprache zu dieser Identifizierbarkeit bei, stellt aber weder ein Alleinstellungsmerkmal (die Sprache kann auch in anderen Nationen verbreitet sein) noch ein Ausschlusskriterium dar (Minderheitensprachen wie etwa Dänisch, Friesisch und Sorbisch in Deutschland oder Kroatisch, Slowenisch und Ungarisch in Österreich). Die genannten Konzepte sind ihrerseits auch Objekte der Identifikation mit einer Nation, worin sich wiederum die Zweigleisigkeit bzw. Zirkularität des Begriffs der nationalen Identität niederschlägt.

Das Konzept „Staat“ ist dabei auf den ersten Blick problematisch, da sich eine Nation nicht zwangsläufig in einem staatlichen Gebilde manifestiert. Das zeigt sich etwa an der deutschen Teilung, die zwar zwei Staaten hervorbrachte, aber keine zwei Nationen. Jedoch bleibt eine Nation auch dann noch auf einen Staat (oder mehrere) bezogen, wenn sie Staatsgrenzen ablehnt (etwa im Fall der Kurden, deren Siedlungsgebiet über mehrere Staatsgrenzen reicht) oder über diese hinausreicht (außerhalb nationalstaatlicher Grenzen lebende Minderheiten werden gerade wegen der Grenzüberschreitung und der dennoch bestehenden Verbundenheit über diese hinaus erst zur nationalen Minderheit). Insofern ist ein Staat zwar kein zwangsläufiger Bestandteil einer Nation, wohl aber ihrer Identität, ebenso wie nicht mehr bestehende Staaten Teil der nationalen Identität einer Nation sind, weil sie ihre Geschichte geprägt haben (wofür die deutsche Geschichte ebenso exemplarisch ist wie die österreichische). Wie bereits im Zusammenhang mit den Definitionsansätzen zur Nation deutlich geworden ist, geht es beim Phänomen nationaler Identität vor allem um Zuschreibungsmechanismen von innen und von 
außen sowie nach innen und nach außen. Daran wird bereits deutlich, dass Mechanismen von politischem und rechtlichem Regelungscharakter nicht ausreichen, um eine Nation zu definieren. Deshalb ist auch der Begriff der nationalen Identität zum vieldiskutierten Begriff geworden und nicht etwa der einer staatlichen Identität.

Individualpsychologische Perspektiven auf das Nationalbewusstsein sind nach Gallenmüller und Wakenhut mit verschiedenen Entwicklungsstufen des moralischen Bewusstseins verbunden (vgl. im Folgenden Bornewasser/Wakenhut 1999: 49). Sie unterscheiden daher eine eher nationalistische, eine mehr patriotische und eine verfassungspatriotische Einstellung. In der nationalistischen Ausprägung dominieren demnach Vorstellungen der Abgrenzung nach Außen und der Überlegenheit gegenüber anderen Nationen, während es in der patriotischen Einstellung eher um interne Orientierungen auf das eigene als positiv bewertete Ordnungssystem geht. Erst in der verfassungspatriotischen Einstellung werden übergreifende, universalisierbare Aspekte hervorgehoben und auch die Einbindung in supranationale Gebilde betont.

Als soziale Identität umfasst das Konzept der nationalen Identität auf der persönlichindividuellen Seite neben den Wissens- und Wertungskomponenten vor allem die Bewertung der eigenen Person in ihrer Beziehung zur eigenen Nation (Bornewasser/Wakenhut 1999: 52). Damit geht es hierbei vor allem um Aspekte der Selbstdefinition als Angehöriger der Nation und den daraus resultierenden Verhaltenserwartungen („Orientierungswissen“, vgl. Bornewasser/Wakenhut 1999: 52).

Diese individuellen Aspekte sozialer Identität für die einzelnen Gruppenmitglieder sind aber der Grund dafür, dass in der kommunikativen Repräsentation der Nation - sowohl nach innen als auch nach außen - solche Wertungen vorherrschen dürften, die dem Einzelnen die positive Besetzung der eigenen Nationszugehörigkeit erlauben. Auf personaler Ebene (also der des Selbstkonzepts) kann das Ausmaß nationaler Identifikation über „Gefühle des Stolzes oder der Peinlichkeit, Angehörige einer Nation zu sein, über die Wichtigkeit der Zugehörigkeit, über die Selbstwahrnehmung als Mitglied oder über das Wohlbefinden, das mit der Zugehörigkeit zur Nation verknüpft ist“" entscheiden (Bornewasser/Wakenhut 1999: 53).

Eine Untersuchung, die sich aber auf die nationale Identität im Sinne ihrer Differenz von anderen sozialen Entitäten und ihre kommunikative Repräsentation beziehen will - also auf möglicherweise (mit-)ursächliche Bedingungen nationaler Identität -, kann solche Bewertungen nicht im gleichen Maße untersuchen wie individualpsychologische Erhebungen. Vielmehr muss in diesem Zusammenhang das Orientierungswissen in einer seiner Vermittlungsinstanzen - den Massenmedien - in den Blick genommen werden. Hierbei sind Wertungen aber in anderer Hinsicht von Belang. Zum einen dürften sie auf Ebene der Inhaltsauswahl auf Kommunikatorseite (Gatekeeping) als Nachrichtenwertfaktoren infrage kommen. ${ }^{56}$ Damit sind sie Ausdruck nationaler Identifizierung der Journalistinnen und Journalisten. Zum zweiten können sie als explizite (Be-)Wertungen in redaktionellen Inhalten vorkommen, etwa wenn Leistungen eines deutschen Industriezweiges besonders gelobt werden. Hier erfüllen sie

${ }^{56}$ Vgl. zum Begriff Gatekeeper Beck 2006 und zum Begriff Nachrichtenwert Hagen 2006. 
allerdings eine doppelte Funktion: Ausdruck positiver Einstellung (zu einem Aspekt) auf Kommunikatorseite und Identifikationsangebot an das Publikum (sich der Meinung anzuschließen und durch die Positivbewertung spezifischer Leistungen der eigenen Nation eine Verbesserung des Selbstbildes zu erlangen, nämlich als Angehörige einer besonders leistungsfähigen Industrienation). Vor allem aber können die Medieninhalte Ausdruck dessen sein, worauf sich die Werteinstellungen der nationalen Gemeinschaft überhaupt beziehen und mithin auf die Konstituenten einer nationalen Identität im Sinne ihrer Differenz von anderen nationalen, supranationalen oder subnationalen Identitäten verweisen. Denn für die soziale Identität einer Nation dürften weniger die einzelnen Werteinstellungen von Belang sein als vielmehr die häufig mit Wertvorstellungen besetzten Lebensbereiche. Beispielsweise ist die schlichte Prominenz der alpinen Skisportarten für Österreich typischer als deren positives Identifikationspotenzial (was ebenso für den deutschen Fußball gelten kann), da die Prominenz bereits Folge der Positivbewertung sein dürfte und nach der Theorie der sozialen Identität eben zuallererst positive Einstellungen zur eigenen Gruppe gesucht werden. 


\subsubsection{Deutschland}

An dieser Stelle kann es nicht darum gehen, die Frage zu diskutieren, ob Deutschland eine Nation ist. Diese Frage ist im Rahmen dieses Forschungsvorhabens zwar nicht belanglos, würde aber auf Grund der Geschichte Deutschlands bereits ein eigenes (ganz anderes) Forschungsprojekt begründen. Ein Ziel dieses Abschnitts ist es deshalb, lediglich eine kursorische Definition der staatlichen, territorialen und historischen Rahmenbedingungen dessen zu formulieren, was wir heute unter Deutschland fassen können und worauf sich die nachfolgende empirische Untersuchung von Fernsehprogrammen beziehen kann. So wäre es etwa denkbar, dass die Berichterstattung über die Grenzen Deutschlands hinausreicht. Nur auf Grundlage einer vorherigen festgelegten (und den internationalen Grenzziehungen entsprechenden) Definition der Außengrenzen Deutschlands wäre aber eine solche „Grenzüberschreitung“ erkennbar. Darüber hinaus könnte dann erst erörtert werden, ob solche Grenzüberschreitungen bestimmten Mustern folgen. ${ }^{57}$

Zum zweiten soll hier Deutschland mit seinen empirisch bestimmbaren Charakteristika beschrieben werden, sofern sie geeignet sind, einen Beschreibungsmaßstab zu geben, mit dessen Hilfe die Darstellung Deutschlands im Fernsehen beschrieben werden kann. Das heißt nicht, dass diese Merkmale eine „objektive“ Realität darstellten und die anschließende Untersuchung des Fernsehprogramms zum Ziel hätte, dessen Abbildungs- und Annäherungsgrad an diese Realität zu messen. ${ }^{58}$ Vielmehr geben sie Aufschluss darüber, welche Aspekte des gesellschaftlichen Zusammenlebens Deutschland außerhalb der Massenmedien (mit-)prägen und der Administration, der Regierung oder der Wissenschaft als wichtig erscheinen.

Thomas stellt in ihrer Untersuchung zur Konstruktion deutscher Identität in Talkshows heraus, dass die Nationalität ein Bezugsrahmen ist, dessen Konstituenten nicht beliebig sind, die aber von unterschiedlichen Akteuren immer anders besetzt werden können. Einigkeit besteht letztlich aber immer in der Relevanz einzelner Konstituenten, die damit die Identität der Nation (mit-)bestimmen (vgl. Thomas 2003b: 297). Bezogen auf Deutschland sind dies: „[n]eben dem häufig mythologisierten Verständnis von Heimat und dem für das deutsche Selbstverständnis zentralen Nationalsozialismus [...] ein Kulturbegriff, der oft aus der Perspektive eines ethnisch bestimmten Kollektivs entwickelt wird, die nationale Diskursivierung von ,Esskulturen' sowie Sprache, gedacht als Identitätskonstituente sowie die Vorstellung eines einigenden abendländischen Christentums“ (Thomas 2003b: 296). Damit sind einige diskursive Parameter benannt, die einerseits bereits als Konstituenten von Nation und nationaler Identität herausgearbeitet wurden, andererseits wie diese in Deutschland besetzt werden. Auf Grund der „Relevanzsetzung“ im Diskurs über „deutsch sein“ ist davon auszugehen, dass sich diese Parameter

\footnotetext{
${ }^{57}$ Eine hypothetische Möglichkeit ist hier etwa, dass das Berichtsgebiet nicht an den heutigen Grenzen Deutschlands orientiert ist, sondern an Grenzen von vor 1945. Denkbar wäre dann, dass Gebiete in Polen nur dann häufiger Gegenstand der Berichterstattung sind, wenn es sich um ehemals deutsche Territorien handelt.

58 Insofern gelten hier die entsprechenden Überlegungen zur medialen Realitätsvermittlung und zum ebenso selektiven Charakter empirischer Untersuchungsergebnisse bei Früh/Hasebrink 1999: 15-18 und 24.
} 
auch in anderen Konstruktionsprozessen der vorgestellten Gemeinschaft der Deutschen wiederfinden.

\subsubsection{Empirische Merkmale Deutschlands}

Einer der Ausgangspunkte der Analyse soll die Realitätsvermittlung bzw. -konstruktion im deutschen Fernsehen sein. Ohne an dieser Stelle eine Abbildlogik von Massenkommunikation zu unterstellen, soll als Vergleichsmaßstab für die Darstellung und Identifizierung Deutschlands eine Reihe empirisch erhobener Daten aufgeführt werden, die für die Erstellung des Kategorienschemas der Inhaltsanalyse sinnvoll erscheinen. ${ }^{59}$ Hierfür kommen insbesondere solche Daten in Betracht, die Aufschluss über lebensweltliche Merkmale Deutschlands und seiner Bevölkerung geben. Darüber hinaus sind auch der Staat selbst, das politische System sowie die Geschichte und die Kultur in den Blick zu nehmen, wie aus den Ausführungen zur nationalen Identität folgt.

Die solchermaßen zusammengestellten Merkmale dienen der Identifizierbarkeit Deutschlands (und mutatis mutandis dann auch für die anderen Untersuchungsgebiete) und stellen eine Folie dar, vor der anschließend untersucht werden soll, wie identifizierbar Deutschland im Fernsehprogramm des ZDF ist. Aus der Interpretation dieser Ergebnisse sollen schließlich Schlussfolgerungen über die Rolle des Fernsehens in nationalen Identifikationsprozessen gezogen werden.

Aus dem selektiven und konstituierenden Charakter solcher statistischer Daten und weiteren Formen der Wirklichkeitskonstruktion ${ }^{60}$ ergibt sich schließlich die forschungsleitende Frage, die sich für jedes der Untersuchungsgebiete unabhängig voneinander zunächst stellt: Sie lautet mithin, ob im Fernsehprogramm Wirklichkeitskonstruktionen präsentiert werden, die sich zu anderen gesellschaftlichen Konstruktionsprozessen derselben Gegenstände konsistent verhalten. Aus der sich daran anschließenden Metaperspektive des Vergleichs der vier verschiedenen Konstruktionen (Deutschland, Österreich, Bayern, Mitteldeutschland) soll dann schließlich die Frage beantwortet werden, wie sich diese Konstruktionsprozesse im Fernsehen hinsichtlich Nation und Region unterscheiden und ob sie dabei den anderen sozialen Konstitutionsstrukturen entsprechen.

Alle folgenden statistischen Daten entstammen dem Sozialbericht der Bundeszentrale für politische Bildung (Bundeszentrale für Politische Bildung 2008) sowie dem Allbus 2006. Die teilweise (geringfügig) unterschiedlichen Berichtszeiträume und deren Abweichung vom Erhe-

\footnotetext{
${ }^{59}$ Sowohl in der Argumentation als auch hinsichtlich der Einschätzung, dass diese Daten von selektivem, fragmentarischem und konstituierendem Charakter sind, die als - nach bestimmten wissenschaftlichen Standards gewonnene - Formen der Realitätsvermittlung zu betrachten sind, ist hier Früh/Hasebrink 1999: 24 zu folgen. ${ }^{60}$ Wie etwa Stereotypisierungen, die insofern aber von doppeltem Charakter sind, weil sie sowohl Ausdruck als auch Form solcher Konstruktionen sind.
} 
bungszeitraum der vorliegenden Studie stellen kein Problem dar, da es hier nur um eine grobe Beschreibung geht, die später lediglich als ein Vergleichshorizont dienen soll. ${ }^{61}$

\subsection{Bevölkerungsstruktur}

Ende 2006 leben 82,3 Millionen Menschen in Deutschland, von denen 51 Prozent Frauen und 49 Prozent Männer sind. Die Einwohnerdichte liegt bei 231 Einwohnerinnen und Einwohnern (EW) je Quadratkilometer, wobei die Stadtstaaten Berlin, Hamburg und Bremen am dichtesten besiedelt sind und in den Flächenländern Mecklenburg-Vorpommern, Brandenburg, Sachsen-Anhalt, Thüringen und Niedersachsen die geringste Siedlungsdichte herrscht. Entsprechend den ganz unterschiedlichen Besiedlungsstrukturen sind auch die Einwohnerzahlen der Bundesländer nicht grundsätzlich von ihrer Fläche abhängig. Die meisten Menschen leben in Nordrhein-Westfalen, Bayern und Baden-Württemberg. Etwas über ein Viertel (26,7 Prozent) davon lebt in Städten, die mehr als 100.000 Einwohnerinnen und Einwohner haben, 27,4 Prozent in Städten zwischen 20.000 und 100.000 EW, 27,9 Prozent in Städten mit 5.000 bis 20.000 EW und 18,1 Prozent in Gemeinden unter 5.000 EW. Damit leben die meisten Deutschen in Klein- und Mittelstädten und die wenigsten auf dem Land.

Die Altersstruktur der deutschen Bevölkerung ist seit Jahren im Wandel begriffen, was sich insbesondere durch sinkende Geburtenzahlen und steigende Lebenserwartung zeigt. Momentan ergibt sich daraus folgende Altersverteilung: unter 20-Jährige: 20 Prozent, 20- bis 39Jährige: 26 Prozent, 40- bis 60-Jährige: 29,1 Prozent und 24,9 Prozent über 60-Jährige. Die mittlere Altersgruppe und die Alten überwiegen also die jüngeren und jungen Altersgruppen.

\subsection{Sozial- und Erwerbsstruktur}

Ein wichtiger Indikator für die Sozialstruktur sind die unterschiedlichen Einkommensverteilungen der Haushalte. Ein monatliches Haushaltsnettoeinkommen von unter 1.000 Euro haben 19,7 Prozent der Haushalte, 20,7 Prozent liegen zwischen 1.000 und 1.500 Euro, 32,4 Prozent zwischen 1.500 und 2.500 Euro und 27,1 Prozent über 2.500 Euro. Von den 43,3 Millionen Erwerbspersonen in Deutschland sind 2007 39,7 Millionen erwerbstätig und 3,6 Millionen erwerbslos. Zwischen den Geschlechtern ist die Erwerbstätigkeit unterschiedlich verteilt: Die Erwerbstätigenquote ${ }^{62}$ liegt bei den Männern bei 74,7 Prozent, bei den Frauen hingegen bei nur 64 Prozent. Die Erwerbstätigkeit ist unterschiedlich auf die verschiedenen Wirtschaftsbereiche verteilt. Im primären Sektor (Land- und Forstwirtschaft, Fischerei) arbeiten 2,2 Prozent der Erwerbstätigen, 25,5 Prozent im sekundären Bereich (produzierendes Gewerbe) und 72,3 Prozent im tertiären Sektor (Dienstleistungen). Die Erwerbstätigkeit im sekundären Sektor ist in Deutschland (altes Bundesgebiet) seit den 1970er Jahren rückläufig.

\footnotetext{
${ }^{61}$ Weder die Hypothesenbildung noch die spätere Auswertung der Untersuchung werden explizit auf hier referierten Zahlen beruhen sondern lediglich auf den in ihnen zum Ausdruck kommenden stabilen Strukturen der Wirklichkeitskonstruktion.

62 Anteil der Erwerbstätigen an der Bevölkerung im Alter von 15 bis 64 Jahren.
} 


\subsection{Religion}

Etwa ein Viertel der deutschen Bevölkerung gehört keiner Religion an, 30 Prozent sind römisch-katholisch, 34 Prozent evangelisch, knapp vier Prozent sind islamisch, jeweils knapp über zwei Prozent sind Angehörige evangelisch-freikirchlicher Gemeinden oder anderer christlicher Religionen. Knapp 106.000 Angehörige des Judentums leben Ende 2006 in Deutschland und machen damit ebenso wie Anhängerinnen und Anhänger des Buddhismus, Hinduismus und weiterer Religionen unter ein Prozent der Gesamtbevölkerung aus.

\subsection{Staat}

Die staatliche Ordnung der Bundesrepublik Deutschland gründet sich auf den verfassungsmäBigen Prinzipien, die 1949 im Grundgesetz formuliert wurden und die heute, nach der Vereinigung der bis 1990 beiden existierenden deutschen Staaten, für das gesamte Bundesgebiet Gültigkeit haben. Deutschland ist demnach ein föderaler Bundesstaat (16 Bundesländer), der auf den Prinzipien der Rechtsstaatlichkeit ${ }^{63}$ und der Volkssouveränität beruht. ${ }^{64}$ Die Regierungsform ist die einer repräsentativen - genauer parlamentarischen - Demokratie. Der Souverän ist damit das Volk (genau genommen die wahlberechtigte Bevölkerung), das die Ausübung seiner Macht an zu wählende Vertreterinnen und Vertreter delegiert. Dabei gilt das Mehrheitsprinzip (vgl. Avenarius 1997: 19).

Die staatlichen Befugnisse und Aufgaben sind auf Grund der föderalen Struktur (zweigliedriger Bundesstaat) für verschiedene Politikbereiche unterschiedlich geregelt. ${ }^{65}$ Die Verteilung der Kompetenzen ergibt sich aus dem Grundgesetz (Art. 30), wonach die Kompetenzen bei den Ländern liegen, soweit im Grundgesetz keine andere Regelung getroffen ist, dabei geht aber das vom Bund erlassene Recht dem Länderrecht vor (Avenarius 1997: 23). Dem Bund kommt im wesentlichen Gesetzgebungskompetenz zu und den Ländern die Verwaltungskompetenz (Avenarius 1997: 23). Der Bund ist zudem immer dann zuständig, wenn Interessen von Bund und Ländern in ihrer Gesamtheit betroffen sind, wie etwa hinsichtlich auswärtiger Beziehungen, Verteidigung und Schutz der Zivilbevölkerung, Post- und Telekommunikationswesen und Luftverkehr (vgl. Avenarius 1997: 23). In den Kernbereich der Länderhoheit fällt ins-

\footnotetext{
${ }^{63}$ D. h., es gilt das Primat des Rechts für die gesamte staatliche Tätigkeit, woraus sich u. a. Gesetzmäßigkeit der Verwaltung, Gerichtsschutz, Gewaltenteilung und Rechtssicherheit ergeben (vgl. Avenarius 1997: 21).

${ }^{64}$ Aus dem Prinzip der Rechtsstaatlichkeit ergeben sich u. a. spezielle Funktionen für die Massenmedien, die verkürzt - als Kontrollfunktion bezeichnet werden können. Daher rührt auch deren häufige Bezeichnung als vierte Gewalt, die jedoch lediglich auf ihre gesellschaftliche Stellung, nicht aber eine verfassungsmäßige Einordnung referiert. Sie bedeutet, dass die Massenmedien als eine außerhalb der verfassungsmäßigen Organe stehende Institution Meinungsbildung in der Öffentlichkeit ermöglichen, indem sie über politisch relevante Sachverhalte und Vorgänge informieren und dadurch eine Art Überwachung staatlicher Instanzen stattfinden kann. Die tatsächlichen Funktionsweisen der Massenmedien gehen über solche, teilweise auch rechtlich normierten, Ideale hinaus, es wäre jedoch eine eigene wissenschaftliche Untersuchung, genau zu differenzieren, inwieweit rein demokratietheoretisch und politisch gewollte Funktionen der Massenmedien und deren ebenfalls wichtigen wirtschaftlichen Funktionen sowie die ebenfalls bestehenden Wechselwirkungen zwischen Politik, Medien und Wirtschaft zusammenhängen.

${ }^{65}$ Wodurch sich möglicherweise Konsequenzen für politische Berichterstattung in deutschlandweiten Programmen im Vergleich zu regionalen Programmen ergeben.
} 
besondere die Kulturpolitik (inkl. dem Schul- und Hochschulwesen), die Ausgestaltung kommunaler Verwaltung und die Polizei- und Ordnungsverwaltung (Avenarius 1997: 24).

Insbesondere die Kulturhoheit der Länder kann als Ausdruck der besonderen Bedeutung kultureller Identität und deren Schutzes auf regionaler Ebene verstanden werden. Auch wenn an dieser Stelle nicht alle Politikbereiche mit ihren jeweiligen Zuständigkeiten aufgeführt werden sollen, so wird doch sowohl bei der Erstellung des Codeplans der Inhaltsanalyse als auch bei der Auswertung darauf zu achten sein, ob unterschiedliche staatliche Tätigkeit im Bereich von Bund und Ländern sich auf die politische Berichterstattung auswirkt.

\subsubsection{Geschichte}

In der historischen Entwicklung des Nationsbegriffs des 19. Jahrhunderts stellt Deutschland eine Besonderheit dar, indem es sich zunächst (im Bildungsbürgertum) als eine „Kulturnation“ begreift, in der Sprache, Volkstum und Dichtung zu nationalen Kriterien werden, die eine übergeordnete Verbindung des territorial zersplitterten Landes bilden (Riescher 1998: 406). Das verbindende Element anderer Nationen war eher politischer Natur, wie im Falle Frankreichs, wo es in der gesetzgebenden Versammlung bestand, welche die Gemeinschaft „Nation“ repräsentiert (Riescher 1998: 406). ${ }^{66}$ Dennoch ist es für das heutige Deutschland nicht diese Kultur allein, welche die nationale Identität bestimmt. Vielmehr sind es insbesondere historische Ereignisse, wie etwa die beiden Weltkriege im 20. Jahrhundert, die möglicherweise diese kulturell gedachte Herkunft der deutschen Nation überschatten oder sie ex post auch semantisch ganz anders aufladen (möglicherweise gerade auch politisch), als dies in der „bildungsbürgerlichen Kulturnation“ des 19. Jahrhunderts der Fall war.

Die Geschichte Deutschlands darzustellen, selbst wenn es nur schlaglichtartig oder als Abriss erfolgen sollte, würde an dieser Stelle selbstverständlich zu weit führen. Vielmehr muss es hier darum gehen, jene historischen Epochen zu identifizieren, auf die sich die aktuelle kulturelle Identität Deutschlands im besonderen Maße beruft. Daraus ergibt sich dann schon ein kleiner Teil möglicher Erklärungen für bestimmte Darstellungen historischer Ereignisse und Zusammenhänge im Fernsehprogramm. Darüber hinaus muss es dann Aufgabe der Analyse des Programms und der Interpretation bleiben, solche Darstellungen in der Identitätskonstruktion zu verorten.

Einen Anhaltspunkt für die solchermaßen sozial konstruierten Geschichtsepochen kann etwa die Einteilung eines historischen Abrisses sein, wie ihn die „Schlaglichter der deutschen Geschichte“ (Müller 2002) bieten. Hier werden bis in die Gegenwart 17 historische Abschnitte unterschieden. Die unterschiedliche Gewichtung der Abschnitte ergibt sich an diesem Beispiel bereits daraus, dass etwa der Zeit des „Dritten Reichs“ (12 Jahre Dauer) fast doppelt so viele Seiten gewidmet werden, wie dem „Hochmittelalter“ (über 300 Jahre Dauer). Dass diese Ge-

66 Wobei grundsätzlich auch Monarchien diese Repräsentationsfunktion erfüllen können, nur erscheint sie hier stärker vermittelt und als Symbol. 
wichtung zum großen Teil auch an der zeitlichen Nähe und der daraus resultierenden Quellenlage resultiert, ist sicher ein Teil der Erklärung dafür. Jedoch ergibt sich die Konstruktion der Bedeutsamkeit bestimmter historischer Abschnitte auch schon daraus, dass innerhalb kürzerer Zeitabschnitte verschiedene „Epoche machende“ Ereignisse benannt werden. Daneben ist es immer auch Ausdruck der sozialen Konstruiertheit, welche zeitlich konkurrierenden Sachverhalte (etwa bei der Benennung der Epochen) in den Vordergrund gerückt werden. ${ }^{67}$

Die oben erwähnten 17 Zeitabschnitte sind:

- „Römisch-germanische und fränkische Zeit“ (bis 843/870)

- „Hochmittelalter“ (bis 1254)

- „Spätmittelalter“ (1254 - 1500)

- „Reformation und Glaubenskriege“ (1500 - 1648)

- „Zeitalter des Absolutismus“ (1648 - 1789)

- „Napoleonische Zeit““ (1789 - 1815)

- „Restauration und Revolution“ (1815 - 1850)

- „Reaktion und Bismarckzeit“ (1850 - 1890)

- „Wilhelminische Zeit“ (1890 - 1918)

- „Weimarer Republik“ (1918 - 1933)

- „Das Dritte Reich“ (1933 - 1945)

- „Neuanfang“ (1945 - 1949)

- „Adenauerzeit“ (1949 - 1961)

- „Vom Mauerbau zum Grundlagenvertrag“ (1961 - 1972)

- „Deutsch-deutsche Verantwortung“ (1972 - 1989)

- „Die deutsche Einheit“ (ab 1989)

- „Deutschland an der Jahrtausendwende“.

Die relativ vielen Benennungen von Zeitabschnitten in der jüngsten Geschichte verweisen zunächst einmal darauf, dass es sich dabei (auch) um eine Geschichte der heutigen Bundesrepublik handelt. Da eine Vielzahl heutiger Ausformungen des Staates (insbesondere politisch bzw. rechtlich) auf Entwicklungen und Entscheidungen nach dem Zweiten Weltkrieg beruhen, ist bereits dadurch eine entsprechende Wichtigkeit im Konstitutionsprozess der als gemeinsam gedachten Geschichte gegeben. Da diese Entwicklungen durch den Zweiten Weltkrieg und das Dritte Reich bedingt waren, indem sie eine Zäsur darstellen, ist auch die Epoche des Naziregimes von großer Wichtigkeit, wobei diese selbstverständlich auch auf der (weltweiten) Tragweite der Auswirkungen der nationalsozialistischen Herrschaft und der sich daraus ergebenden historischen Verantwortung beruhen, zu der sich die spätere Bundesrepublik bekannt hat. Die Weimarer Republik ist wiederum als dem Dritten Reich vorangegangene Epoche von besonderer Bedeutung, weil sich die Bundesrepublik bei ihrer Gründung auf die Erfahrungen der Weimarer Republik und ihres Scheiterns bezog und gleichzeitig im Grundgesetz eine rechtliche Kontinuität dergestalt hergestellt wird, dass fünf Artikel (die sich auf die Religionsausübung bzw. deren Nichtausübung beziehen) der Weimarer Verfassung auch Teil des

${ }^{67}$ So wie etwa (zumindest in der neueren Geschichte) ein Vorrang politischer vor kulturellen Aspekten herrscht. 
Grundgesetzes sind. Der Weimarer Republik war ihrerseits der Erste Weltkrieg vorausgegangen, der seine Ursachen unter anderem in den Entwicklungen der „Wilhelminischen Zeit“ hatte, die eng mit der vorangegangenen „Bismarckzeit“ zusammenhing, da hierin die deutsche Vereinigung unter preußischer Vorherrschaft stattgefunden hatte. Diese Kette von Verbindungen lässt sich immer weiter zu einer vermeintlichen Kontinuität der deutschen Geschichte in die Vergangenheit zurückdenken, wobei wahrscheinlich die verbindenden Glieder in den einzelnen Zeitabschnitten immer singulärer werden, was wiederum auch daran liegt, dass die weiter zurückliegenden Epochen immer längere Zeitabschnitte umfassen. Die Bismarckzeit war eine Reaktion auf die liberalen Tendenzen der Revolutionszeit, der die Restauration als Folge der Napoleonischen Zeit vorangegangen war, die ihrerseits eine ganz Europa ergreifende Nachfolge der Französischen Revolution war, die den Absolutismus überwunden hatte. Von hier aus fällt es dem historischen Laien bereits schwerer, eine Verbindung zur Zeit der Reformation und der Glaubenskriege anhand solcher singulärer Kettenglieder herzustellen. Immerhin ist aber davon auszugehen, dass die Reformationszeit insbesondere mit Luthers Bibelübersetzung zusammenhängt, die zu einer weitgehenden Verbreitung der deutschen Sprache in Schriftform führte (nicht zuletzt auf Grund der Erfindungen Gutenbergs). Darüber hinaus ist die Wichtigkeit der Reformation sowie des Dreißigjährigen Krieges auch an der (regional unterschiedlichen) Verbreitung der verschiedenen christlichen Glaubenslehren in Deutschland abzulesen. Ohne nun in noch weiter zurückliegende geschichtliche Details einzugehen, ist thesenhaft festzuhalten, dass bei der Konstruktion eines konsistenten Geschichtsbildes für Deutschland sich derartige Kontinuitäten ausdrücken und (im populären Medium Fernsehen) dabei in besonderen Maße auf solche Schlüsselereignisse rekurriert wird.

Für die spätere Hypothesenbildung bedeutet dies, dass man entweder Schlüsselereignisse benennen kann, von denen man dann behauptet, dass sie verstärkt innerhalb historischer Zusammenhänge im Fernsehen thematisiert werden. Jedoch ist es auch möglich, zunächst historische Themen im Programm zu identifizieren und erst im Auswertungszusammenhang daraufhin zu untersuchen, ob diese solche Schlüsselereignisse darstellen. Letzterer Weg dürfte für den historischen Laien der zweckmäßigere sein.

\subsubsection{Stereotype - Vorurteile - Images}

Von besonderer Bedeutung für nationale Identität, die auch als Ausformung kultureller Identität begriffen werden kann, ist die Kultur, die eine Nation - insbesondere hinsichtlich ihres Selbstverständnisses - prägt. Dabei kommt es letztlich nicht so sehr auf bestimmte Epochen kultureller Entfaltung auf bestimmten Gebieten (etwa der Kunst) an, sondern auf deren Bedeutung für das Bild der Nation in der Gegenwart. Wie schon hinsichtlich der Geschichte kann im Zusammenhang des kurzen Problemaufrisses kein Anspruch auf Vollständigkeit erhoben werden. Da sich das Bild einer Nation nicht nur aus Selbstbildern, sondern auch aus Fremdbildern zusammensetzt, sind für diesen Bereich auch Stereotype, Images und Vorurteile von Bedeutung. Im Zusammenhang mit der Bedeutung der Massenmedien in „postmodernen Gesellschaften“ wird konstatiert, „dass Medien immer mehr an die Stelle der direkten eigenen

Erfahrung treten. Die Produktion der massenmedialen Codes und Konventionen führe zur Verbreitung dualistischer Stereotype der Wahrnehmung und Bewertung, die wie ontologische 
Wahrheiten behandelt werden (können) und gesellschaftlich auch so wirken (können)“ (Thomas 2003a: 187 m. w. N.).

Unter Stereotypen $^{68}$ sind ,vereinfachte, wenig veränderliche und weit verbreitete Vorstellungen über Gruppen von Menschen“ zu verstehen (Stierstorfer 2003: 11). Stereotype basieren auf selektiven Strategien im Wahrnehmungsprozess und erleichtern so „den Umgang mit der enormen Komplexität, der auf einen Menschen einströmenden Eindrücke. Stereotype dienen als Konstrukte, die helfen, das Bild von der Wirklichkeit zu ordnen“" (Stierstorfer 2003: 11).

Etwas variabler als Stereotype sind dagegen Bilder bzw. Images, die sehr individuell geprägt sein können (Stierstorfer 2003: 11). Im Gegensatz zu Stereotypen ist das Image aus Einzelbeobachtungen geprägt oder enthält originelle Vorstellungen über ein Land, die nicht von einer Mehrheit getragen werden müssen (Stierstorfer 2003: 12). Dabei kommt es nicht unwesentlich auf die Herkunft dessen an, der sich „ein Bild macht““ ${ }^{69}$ Denn: „Was von den eigenen, den gewohnten Verhältnissen am deutlichsten abweicht, wird zur Charakteristik des Fremden herangezogen, und dies führt selbstverständlich zu einseitigen Schlüssen“ (Bausinger 2006: 24).

Das Vorurteil wird im Unterschied zu Images und Stereotypen durch meist negative Gefühlsurteile erzeugt, „die bestimmte Eigenschaften auf eine Gruppe von Menschen projiziert“ (Stierstorfer 2003: 12). Stiersdorfer schließt daraus, dass Vorurteile einen geringeren Realitätsbezug aufweisen als Images und Stereotypen. In dem Sinne, dass alle drei Mechanismen der Komplexitätsreduktion der Umweltwahrnehmung dienen und damit direkt das Handeln von Menschen beeinflussen, sind sie allerdings gleichermaßen real und unterschieden sich allenfalls in ihrer Verbreitung und damit ihrer Wirkungsmacht.

Stereotype, Vorurteile und das Image einer Nation beziehen sich zum großen Teil auf eine Außensicht, also ein Fremdbild. Das Interesse daran dürfte vor allem aus dessen Differenz zu einem wie auch immer gearteten Selbstbild resultieren.

In Zusammenhang mit der Ausstellung „Was ist deutsch?“ des Germanischen Nationalmuseums Nürnberg wurde von der GfK eine Studie über das Image der Deutschen in Deutschland und Europa durchgeführt (Frank 2006). Interessant ist an dieser Stelle nicht so sehr, welches Bild der Deutschen im Ausland herrscht, ${ }^{70}$ sondern dass das deutsche Image überhaupt untersucht wird und auf welche Aspekte dessen Untersuchung bezogen wird. Hier bietet es sich an, eine Metabetrachtung anzustellen, um die Schnittpunkte zwischen dem bereits erwähnten Selbst- und Fremdbild zu bestimmen und damit jene Aspekte, die für die nationale Identität Deutschlands (aus der Innensicht) als besonders wichtig erscheinen.

\footnotetext{
${ }^{68}$ Siehe auch oben, Abschnitt 2.1.4 Soziale Stereotype (S. 17).

${ }^{69}$ Dafür gibt Bausinger (2006: 24) einige deutliche Beispiele, wie etwa die durchaus unterschiedliche Bewertung deutscher Altersheime durch griechische, amerikanische und japanische Studierende nach einem Deutschlandaufenthalt.

${ }^{70}$ Das Weltimage der BRD beruhte einer entsprechenden Imageerhebung zufolge 1988 auf den vier Säulen ,exzellentes Wirtschaftsimage“, „,modernes Land“, „Land mit starker Umweltverschmutzung“, „Skandale“, was Martinek anhand des Images der BRD in Österreich teilweise bestätigt sieht, wo insbesondere „Modernität“, aber auch eine Vielzahl negativer Eigenschaften assoziiert wird (Martinek 1990: 139, m. w. N.).
} 
So ist etwa weniger interessant, dass sich bestimmte Stereotype in der Selbst- und Fremdeinschätzung bestätigen, als vielmehr, in welchen Kontext sie in der Ergebnisdarstellung gerückt werden. So haben in den für die o. g. Studie befragten Ländern (Frankreich, Großbritannien, Italien, Niederlande, Österreich, Polen, Russland, Tschechien, Türkei) auf die offene Frage, was sie persönlich mit Deutschland und den darin lebenden Menschen verbinden, relativ viele Befragte Antworten aus den Wortfeldern Ordnung, gute Organisation, Akkuratesse, Fleiß und Pflichtbewusstsein, Ordnungsliebe etc. gegeben. Das veranlasst den Autor der Studie, von einer Dominanz des „Kanon[s] klassisch preußischer Tugenden“ zu sprechen (Frank 2006: 216). Damit rückt die historische Verortung eines Stereotyps in den Mittelpunkt des Interesses und überstrahlt sozusagen den realen Bezug. Derartige Verortungen finden sich denn auch nicht bei der Ergebnisdarstellung zu geäußerten negativen Assoziationen (Arroganz und Pessimismus, vgl. Frank 2006: 217). Interessant ist allerdings der Hinweis darauf, dass den niederländischen Befragten diese „,preußischen“ Tugenden an den Deutschen am wenigsten auffallen, was damit erklärt wird, dass es sich ursprünglich um „calvinistische“ Tugenden handele, die erst im 18. Jahrhundert aus den Niederlanden nach Preußen importiert wurden (vgl. Frank 2006: 217.

In der GfK-Umfrage wurde die offene Eingangsfrage durch eine Reihe von Aussagen zur Einschätzung bestimmter Eigenschaften der Deutschen ergänzt. Diese lehnten sich an fünf Persönlichkeitsdimensionen ${ }^{71}$ an, denen kulturübergreifende Gültigkeit bei Persönlichkeitsbeschreibungen zugeschrieben wird (vgl. Frank 2006: 230 m. w. N.). Dabei handelt es sich um: Extraversion, Verträglichkeit, Gewissenhaftigkeit, emotionale Stabilität und Offenheit. Darüber hinaus wurden die Faktoren Pünktlichkeit, Sparsamkeit, Sauberkeit, Zuverlässigkeit, Optimismus und Entspanntheit erhoben. Während die ersten fünf Faktoren auf verschiedenen Erkenntnissen der Umfrageforschung beruhen, dürften die letzteren Faktoren eher (Selbst-)Stereotypen geschuldet sein, da sie entweder dem Kreis der „preußischen Tugenden“ nahestehen oder einer Einschätzung von zu erwartenden Vorurteilen entsprechen. ${ }^{72}$

Die Beschäftigung mit dem eigenen Bild setzt sich also hauptsächlich aus Images (also auch auf persönlichen Erfahrungen beruhend) und Stereotypen (sowohl in neutraler Form als auch auf Vorurteile hindeutend) zusammen. ${ }^{73}$ Beide sind zum erheblichen Teil dem Bereich Wirtschaft, wirtschaftlichem Erfolg sowie seinen Grundlagen zuzuordnen. Sowohl die „preußischen Tugenden“ als auch die Assoziation der Deutschen mit Leistung und Wohlstand stehen in Zusammenhang mit der Betonung deutscher Wirtschaftsmacht oder dem Erfolgslabel „Made in Germany“. Deutsches Nationalbewusstsein wird denn auch als Wirtschaftsnationalismus bezeichnet, worin es sich etwa von Frankreich unterscheidet, dessen Nationalbewusstsein vom Modell der Staatsbürgernation geprägt ist (vgl. Bornewasser/Wakenhut 1999: 49).

\footnotetext{
${ }^{71}$ Die sogenannten „Big Five“ nach dem Fünf-Faktoren-Modell von Costa/McCrae (1992).

72 Wobei diese Erwartungshaltung ihrerseits auch bereits ein Vorurteil ist. Optimismus und Entspanntheit sollten nach dieser Erwartenshaltung eher gegenteilige Einschätzungen evozieren.

${ }^{73}$ Was wenig verwundert, da es sich bei der in-group „Nation“ auch um eine weitgehend abstrakt bleibende Größe handelt, die in ihrer Komplexität reduziert werden muss, um für den Einzelnen fassbar zu sein, auch wenn er selbst Teil dieser Größe ist.
} 
Dieses scheint in Deutschland, sieht man etwa auf Assoziationen zu gesellschaftlichstaatlichen Errungenschaften nach dem Zweiten Weltkrieg (s.u.), wenig ausgeprägt.

Besonders auffällig sind die Befunde zur Assoziation Deutschlands mit Krieg, Holocaust und Nationalsozialismus (vgl. Frank 2006: 221). Hier herrscht eine deutliche Diskrepanz zwischen Selbst- und Fremdwahrnehmung. Während 20,8 Prozent der Befragten aus den neun für die Studie berücksichtigten europäischen Staaten Ereignisse und Begriffe aus dem Zusammenhang der Naziherrschaft mit Deutschland verbinden, tun dies nur 2,5 Prozent der befragten Deutschen. Mit den in Deutschland lebenden Menschen wird dieses Themenfeld aber - ausweislich der in Frank 2006 referierten Ergebnisse - nicht verbunden, sondern mit dem Land bzw. dem Begriff „Deutschland“. Angesichts der in der Vergangenheit teilweise recht erfolgreichen Sendungen zu diesem Thema der deutschen Geschichte wird - jedenfalls bei entsprechenden Befunden - auf diesen Aspekt zurückzukommen sein.

Demgegenüber stehen nur sehr wenige Assoziationen mit Errungenschaften und Leistungen deutscher Politik der Gegenwart und jüngsten Vergangenheit. Assoziationen Deutschlands mit dem Begriffsfeld „Sozialstaat und Demokratie“ werden von Befragten in der Türkei sogar häufiger erwähnt als von den Deutschen selbst (vgl. Frank 2006: 228). Auch die deutsche Wiedervereinigung wird als herrausragendes Ereignis der deutschen Geschichte von den europäischen Nachbarn stärker wahrgenommen als von den Deutschen selbst (vgl. Frank 2006: 228). Hingegen werden wirtschaftliche, soziale und politische Probleme von den Deutschen hervorgehoben, von den Nachbarn (mit Ausnahme Österreichs) jedoch kaum wahrgenommen. Dazu konsistent sind die Antworten auf die geschlossenen Abfragen zum Aspekt „Verträglichkeit“ (bezogen auf persönlichen Umgang), wo die Deutschen selbst zu drei Vierteln der Aussage zustimmen, sie machten sich viele Sorgen, was den Wert bei den diesbezüglichen Außenzuschreibungen (29 Prozent der Befragten in den neun anderen Ländern) deutlich übertrifft (vgl. Frank 2006: 231). Weniger deutlich, aber umgekehrt, verhält es sich bei der Zustimmung zur Behauptung, die Deutschen seien optimistisch (vgl. Frank 2006: 232).

Insgesamt kann die Frage gestellt werden, ob im Fernsehen solche Themen verstärkt behandelt werden, die im Zusammenhang mit Stereotypen und Vorurteilen der Selbst- und Fremdwahrnehmung eines Landes stehen. Darüber hinaus kann mit einiger Berechtigung gefragt werden, ob bestimmte Selbsteinschätzungen Entsprechungen in der medialen Berichterstattung haben. ${ }^{74}$ Beim Einbezug von Stereotypen in die Grundlagen einer Untersuchung, die Stereotype oder Vorurteile jedoch nicht selbst als Thema hat, ist darauf zu achten, nicht selbst stereotype Muster aufzubauen. Stereotype sind selektiv und scheinen nur in der Bestätigung zu gelten. Widersprüche blenden sie aus. Deshalb ist darauf zu achten, sie nicht selbst zu Kategorien der Untersuchung zu machen. Vielmehr bieten sie sich als Folie der Interpretation von Ergebnissen im Auswertungszusammenhang an.

\footnotetext{
${ }^{74}$ So kann etwa die - von der Fremdeinschätzung gravierend unterschiedliche - Selbsteinschätzung zum Thema Deutsche „machen sich viele Sorgen“ eine Entsprechung in einem Journalismus finden, der vor allem negative Auswirkungen bestimmter Prozesse auf einzelne Verbraucher in den Mittelpunkt stellt. Eine kausale Verbindung wäre damit aber noch nicht gegeben.
} 


\subsection{2 Österreich}

\subsubsection{Empirische Merkmale Österreichs ${ }^{75}$}

\subsection{Bevölkerungsstruktur}

Anfang 2007 leben 8,3 Millionen Menschen in Österreich. 51,4 Prozent davon sind Frauen und 48,6 Prozent Männer. Die Einwohnerdichte liegt bei $99 \mathrm{EW}$ pro Quadratkilometer. Wien als einwohnerreichste Stadt (1,66 Millionen) ist dabei auch am dichtesten besiedelt (4.025 EW/ $\left./ \mathrm{km}^{2}\right)$. Während die Bevölkerungsdichte in Vorarlberg $\left(141 \mathrm{EW} / \mathrm{km}^{2}\right)$ und Oberösterreich $\left(116 \mathrm{EW} / \mathrm{km}^{2}\right)$ noch jeweils über $100 \mathrm{EW}$ pro Quadratkilometer beträgt, liegt sie in allen anderen Bundesländern unter 100, wobei Kärnten $\left(59 \mathrm{EW} / \mathrm{km}^{2}\right)$ und Tirol $\left(56 \mathrm{EW} / \mathrm{km}^{2}\right)$ die geringsten Bevölkerungsdichten aufweisen. Die insgesamt geringe Bevölkerungsdichte liegt zum großen Teil an den topographischen Bedingungen des Alpenstaates, die insbesondere in den Hochgebirgsregionen kaum dichte Besiedlungsformen zulassen. Die meisten Einwohnerinnen und Einwohner leben im kleinsten Bundesland Wien (1,66 Millionen). Im umgebenden Niederösterreich leben 1,5 Millionen Menschen. Nur in Oberösterreich und der Steiermark leben ebenfalls noch jeweils über eine Million Menschen (1,4 Millionen und 1,2 Millionen). Damit leben ca. 20 Prozent der Österreicherinnen und Österreicher in der einzigen Millionenstadt, der Bundeshauptstadt Wien, und weitere 8,5 Prozent in Städten mit mehr als 100.000 EW. 8,4 Prozent der Bevölkerung leben in Gemeinden mit 20.000 bis 100.000 EW, 19,9 Prozent in Städten mit 5.000 bis 20.000 EW und 43,2 Prozent in Gemeinden von unter 5.000 EW. Damit leben die meisten Österreicherinnen und Österreicher in Gemeinden unterhalb der Kleinstadtgröße und gleichzeitig bilden die Großstädterinnen und Großstädter den zweitgrößten Bevölkerungsteil. Die Österreicherinnen und Österreicher sind also weniger gleichmäßig auf die verschiedenen Siedlungsgrößen verteilt als die Deutschen. ${ }^{76}$

Die Altersstruktur der österreichischen Bevölkerung ist der der deutschen Bevölkerung sehr ähnlich. 21,5 Prozent der Österreicherinnen und Österreicher sind unter 20 Jahre alt, 27,4 Prozent sind in einem Alter zwischen 20 und 39 Jahren, 28,9 Prozent gehören zur Altersgruppe der 40- bis 60-jährigen und 22,2 Prozent sind über 60 Jahre alt.

Anfang 2008 leben 854.752 Ausländerinnen und Ausländer ${ }^{77}$ in Österreich, die damit 10,3 Prozent der Bevölkerung ausmachen. Rund 1,4 Millionen Einwohnerinnen und Einwoh-

\footnotetext{
${ }^{75}$ Die Daten entnehme ich Statistik Austria 2007, Statistik Austria 2008 sowie Statistik Austria 2009. Da teilweise andere Berichtsjahre zugrunde liegen, habe ich die für die jeweiligen Gebiete aktuellsten Angaben herangezogen.

${ }^{76}$ Dieser Unterschied basiert selbstverständlich auch nur auf den Festlegungen bestimmter Kennzahlgrößen und sollte nicht überbewertet werden, da solche Kennzahlen individuellen Gegebenheiten wie etwa natürlicher Topographie nicht Rechnung tragen können und Vergleichsmaßstäbe postulieren, wo diese u. U. unangemessen sein können.

77 Ohne österreichische Staatsbürgerschaft, unabhängig vom Geburtsland.
} 
ner haben einen Migrationshintergrund (selbst Zugewanderte oder Nachkommen von Zugewanderten). Den größten Anteil der ausländischen Bevölkerung stellen Zugewanderte aus Serbien und Montenegro dar (rd. 137.000), ${ }^{78}$ die zweitgrößte Gruppe sind Deutsche (rd. 114.000) und die drittgrößte Gruppe ist türkischer Herkunft (rd. 109.000). Weitere große Gruppen stammen aus Bosnien und Herzegowina sowie Kroatien. Innerhalb der EU liegt Österreich beim Ausländeranteil mit im Spitzenfeld.

\subsection{Sozial- und Erwerbsstruktur}

10 Prozent der österreichischen Haushalte verfügen monatlich über weniger als 935 Euro netto. ${ }^{79} 25$ Prozent der Haushalte verfügen über maximal 1.423 Euro monatlich ein weiteres Viertel über bis zu 2.281 Euro und 25 Prozent verfügen über bis zu 3.370 Euro im Monat. zehn Prozent der Haushalte liegen im Monat über 4.689 Euro und bilden damit das obere Ende (bzw. das oberste Dezil) der Einkommensgruppen. Von den 4,1 Millionen Erwerbspersonen in Österreich waren 2006 3,9 Millionen erwerbstätig und 195.600 arbeitslos. Auch in Österreich ist die Erwerbstätigkeit zwischen den Geschlechtern unterschiedlich verteilt. Die Erwerbstätigenquote beträgt bei den Männern 76,9 Prozent und 63,5 Prozent bei den Frauen. Bei den Verteilungen der Erwerbstätigkeit auf die unterschiedlichen Wirtschaftsbereiche ergibt sich im Vergleich zu Deutschland ein tendenziell zwar ähnliches, aber doch weniger stark ausgeprägtes Bild. Immerhin 5,5 Prozent der Erwerbstätigen sind im primären Wirtschaftssektor tätig, 28,2 Prozent im sekundären und 66,3 Prozent im tertiären Sektor.

\subsection{Religion}

Ohne religiöses Bekenntnis sind zwölf Prozent der österreichischen Bevölkerung. Der überwiegende Teil (74 Prozent) gehört der römisch-katholischen Kirche an, 4,7 Prozent der evangelischen Kirche. 4,7 Prozent der Einwohnerinnen und Einwohner sind muslimischen Glaubens. Die ca. 8.000 Angehörigen des Judentums machen weniger als 0,1 Prozent der Bevölkerung aus. ${ }^{80}$ 3,2 Prozent bekennen sich zu anderen Religionen.

\subsection{Staat}

Die Staatsordnung der Republik Österreich leitet sich aus der Verfassung ab, die mit dem Bundes-Verfassungsgesetz (B-VG) von 1920 erlassen wurde, seither aber diverse Novellierun-

\footnotetext{
${ }^{78}$ In den amtlichen Statistiken wird die Gruppe der Ausländer aus dem ehemaligen Jugoslawien zumeist zusammengefasst, was hinsichtlich der Ursachen der Zuwanderung, die u. a. in dortigen Kriegen der 1990er Jahre liegen dürften, sinnvoll erscheint. Vom Gesichtspunkt der mittlerweile strikten Trennung der Staaten des ehemaligen Jugoslawien und der daher verschiedenen Staatsangehörigkeiten ist es nicht mehr sinnvoll.

${ }^{79}$ Die amtliche Statistik weist die Einkommensgruppen nach Dezil- und Quartilswerten aus, wobei die untersten und obersten Dezilwerte sowie Quartilswerte vom arithmetischen Mittel (€ 2.626,- mtl.) angeben werden, weshalb die Einkommensstruktur hier abweichend zu der in Deutschland wiedergegeben wird.

${ }^{80}$ Laut Volkszählung von 2001. Der überwiegende Teil der jüdischen Gemeinde lebt in Wien, die Israelitische Kultusgemeinde Wien geht allerdings von rund 15.000 Juden in Österreich aus (vgl. Muzicant 2005).
} 
gen erfahren hat. ${ }^{81}$ Mit der Gründung der zweiten Republik 1945 wurde mit dem VerfassungsÜberleitungsgesetz die Verfassung von $1920^{82}$ neuerlich wirksam, nachdem sie seit 1934 mit der Zeit des Austrofaschismus und dem späteren Anschluss Österreichs an das Deutsche Reich außer Kraft gesetzt worden war. ${ }^{83}$ Im Gegensatz zum deutschen Grundgesetz enthält das österreichische Bundes-Verfassungsgesetz keinen Grundrechtekatalog. Stattdessen sind die diesbezüglichen Regelungen des von Kaiser Franz Joseph I. erlassenen „Staatsgrundgesetzes vom 21. Dezember 1867 über die allgemeinen Rechte der Staatsbürger“ Teil der Verfassung. Daneben hat in Österreich die Europäische Menschenrechtskonvention (EMRK) Verfassungsrang, aus der sich ebenfalls Grundrechte ableiten. Diese gesetzgeberischen Besonderheiten sind hier insofern interessant, als sich aus ihnen zum einen ein historischer Konnex ${ }^{84}$ zur ersten Republik sowie ein übernationales Verständnis der Grundrechte ableiten lassen.

Österreich ist ein föderaler Bundesstaat (neun Bundesländer) und basiert auf den Prinzipien der Rechtsstaatlichkeit und Demokratie. Die Regierungsform ist die der repräsentativen bzw. parlamentarischen Demokratie. Wahlberechtigt sind alle Österreicherinnen und Österreicher ab 16 Jahren. Im Vergleich zu Deutschland hat der österreichische Bundespräsident (der direkt vom Volk gewählt wird) eine theoretisch machtvollere Position als sein deutscher Amtskollege. In der realen Ausübung des Amtes spielt dies jedoch keine wesentliche Rolle, da er in diversen machtpolitischen Fragen auf Vorschläge der jeweiligen Bundesregierung angewiesen ist (insbesondere in Art. 67 B-VG normiert).

Die gesetzgeberische Kompetenzverteilung zwischen Bund und Ländern ergibt sich insbesondere aus den Artikeln 10 bis 17 B-VG. Darin ist die Zuständigkeit des Bundes katalogmäßig sehr detailliert erfasst, es wird zum Teil auch zwischen Grundsatzgesetzgebungskompetenz und der Kompetenz über Ausführungsgesetze unterschieden. Der auf den ersten Blick auffälligste Unterschied zu Deutschland besteht wohl in der Bundeszuständigkeit für Schul- und Kulturangelegenheiten. Auch der Rundfunk ist durch Bundesgesetze geregelt. ${ }^{85}$

\subsubsection{Geschichte}

Eine nicht zu unterschätzende Schwierigkeit einer (wie ausführlich auch immer betriebenen) Überblicksdarstellung der Geschichte Österreichs, besteht in der Festlegung des zugrunde

\footnotetext{
${ }^{81}$ Erstfassung: Nationalversammlung (1920)

82 In der Fassung von 1929, die bereits diverse Novellierungen enthielt.

${ }^{83}$ Formaljuristisch war die Maiverfassung von 1934 rechtswidrig, da ihr Beschluss nicht den Regeln von der seit 1920 gültigen Verfassung für eine Änderung derselben genügte. Bei der Maiverfassung des Dollfuß-Regimes handelt es sich zudem um eine oktroyierte Verfassung, die nicht das Volk als Souverän auffasste, sondern sich auf einen allmächtigen Gott berief, „,von dem alles Recht ausgeht“, in dessen Namen das österreichische Volk die Verfassung erhalte (vgl. Bundesregierung des Bundesstaates Ö̈sterreich 1934 [1934]: 1).

84 Von Kontinuität zu sprechen, wäre wohl angesichts des Ständestaates von 1934 und der späteren Angliederung an das Deutsche Reich vermessen.

${ }^{85}$ Siehe auch Abschnitt 5.9.2 (S. 111ff.).
} 
liegenden Territoriums. ${ }^{86}$ Bei der Beschränkung auf die heutige Republik bleibt zwar das betrachtete Gebiet konstant, andererseits ist diese Perspektive auf Grund der im Laufe der Jahrhunderte in viele internationale Konflikte verstrickten Habsburgermonarchie möglicherweise oft zu eng (vgl. Vocelka 2000: 10, vgl. auch Niederstätter 2007: 5). Dieses Problem berührt auch unmittelbar die Frage nach einer österreichischen Identität, da eben ein Großteil der auf die Habsburgerdynastie bezogenen Geschichtsschreibung und des daraus abzuleitenden österreichischen Selbstverständnisses weit über die Grenzen der zweiten Republik hinausgeht. Hinzu kommt, dass Österreich schon mit der ersten Republik ein Produkt des Zerfalls der Donaumonarchie nach 1918 war. Schon mit der Erklärung der Republik am 12. November 1918 war der Anschluss an Deutschland verkündet worden, der jedoch von den alliierten Siegermächten in den Pariser Friedensverträgen untersagt wurde (vgl. Vocelka 2000: 14, Zöllner 1990: 498, Niederstätter 2007: 218). Insofern handelte es sich um einen „Staat wider Willen“, der sich als Teil Deutschlands verstand und so auch zunächst keine eigene Identität entwickelte (Vocelka 2000: 14). Die Ansätze, die es zu einer eigenen Identität gab, lagen daher vor allem im Bereich des kulturellen Erbes, insbesondere der Musik, da über die Kultur so etwas wie eine Kontinuität konstituiert und darin die vergangene Größe der Monarchie konserviert werden konnte (vgl. Vocelka 2000: 14). Diese „Flucht in die Kultur“ (Vocelka 2000: 16) wurde auch nach 1945 betrieben, wobei ab diesem Zeitpunkt die Abgrenzung von Deutschland in den Vordergrund rückte. „Der oft zitierte Spruch, die Österreicher haben es verstanden, Hitler als Deutschen und Beethoven als Österreicher darzustellen, bringt das auf eine plakative, aber nicht ganz unrichtige Formel“" (Vocelka 2000: 16).

Um bei der schlaglichtartigen Beschreibung der Geschichte anhand von Einteilungen in die wichtigsten Epochen zu bleiben, soll hier zunächst Zöllners Standardwerk (Zöllner 1990) zur österreichischen Geschichte als Grundlage dienen. Darin wird auf der ersten Ebene in zehn Abschnitte unterteilt: ${ }^{87}$

- Urgeschichte

- Österreich in der Römerzeit (15 v. Chr. - Ende des 5. Jahrhunderts)

- Bairisches Stammherzogtum und fränkische Mark (6. - 10. Jahrhundert)

- Die Babenberger und das Werden der österreichischen Länder (976 - 1246)

- Das Spätmittelalter (1246 - 1526) und die Habsburgische „Herrschaft zu Österreich“

- Reformation und Gegenreformation (1526 - 1648)

- Österreichs Aufstieg zur Großmacht (1648 - 1740)

- Reform, Reaktion und Revolution (1740 - 1848)

- Die Franzisko-Josephinische Epoche und das Ende der Monarchie (1848 - 1918)

- 79 Jahre von der ersten zur zweiten Republik (1918 - 1988)

\footnotetext{
${ }^{86}$ Und ist damit auch mit der deutschen Geschichte verknüpft, da während langer Zeitperioden das „Heilige römische Reich deutscher Nation“ die Gebiete sowohl des heutigen Österreichs als auch der Bundesrepublik Deutschland umfasste (und darüber hinaus), also keine entsprechende Zweiteilung bestand.

${ }^{87}$ Sowohl Niederstätter als auch Vocelka nehmen in ihren Überblicksbänden zur österreichischen Geschichte eine feingliedrigere Einteilung vor. Das betrifft insbesondere die Zeiträume des Mittelalters, der Frühneuzeit und des 16. und 17. Jahrhunderts. In beiden Fällen kommen dabei jeweils auch kultur- und gesellschaftsgeschichtliche Abschnitte vor (vgl. Niederstätter 2007: 7, Vocelka 2000: 5).
} 
Auch wenn dies sicher dem dynastischen Blickwinkel geschuldet ist, fällt bereits hier auf, dass auf Grund der lang anhaltenden Stabilität der Habsburgerherrschaft eine große Kontinuität das Geschichtsbild Österreichs bestimmt. Das babenbergische „Ostarrichi“, das den historischen Nukleus Österreichs bildet (vgl. Niederstätter 2007: 5), wird aus der auf die Habsburgerdynastie zentrierten Sicht zum Vorläufer dieser Herrschaft. Mit der späteren Entwicklung der Monarchie zum historischen identifikatorischen Bezugspunkt Österreichs verschwinden in der allgemeinen Wahrnehmung auch die durchaus heterogenen Entwicklungen: Schon im 14. Jahrhundert kam es auf Grund von Streitigkeiten um die Herrschaft innerhalb der Familie zu einer ersten Teilung des Hauses Habsburg in eine albertinische und eine leopoldinische Linie, wobei sich letztere sogar noch weiter aufspaltete (Niederstätter 2007: 56). Das Interessante dabei ist, dass der Habsburger-Mythos inklusive seiner bis heute andauernden Verklärungen bestimmter historischer Figuren, seinen Anfang von seinem Ende her nimmt. Insbesondere die letzten Herrscher des 19. Jahrhunderts (in dem ihnen im Übrigen eine weit geringere Rolle in der Ausübung politischer Macht zukam als in vorangegangenen Jahrhunderten) wurden zum Objekt von Legendenbildung, Klischierung und Verklärung (vgl. Vocelka 2000: 252). Das prominenteste Beispiel dafür dürfte die Kaiserin Elisabeth sein, gemeinhin hauptsächlich als Sissi bekannt, wobei diese familiär-vertraute Bezeichnung die Art der Anteilnahme, die ihr bis heute öffentlich entgegengebracht wird, gut illustriert. Erst ihre Ehe mit Franz Joseph hatte auch dessen Popularität begründet (Niederstätter 2007: 183), so dass er schließlich zu der Symbolfigur des Reiches werden konnte (Vocelka 2000: 255), obwohl seine Herrschaftsausübung eher mittelmäßig zu nennen ist und seine unflexible Politik schließlich „den Grundstock für die Fehlentwicklung und das Ende der Donaumonarchie gelegt hatte“ (Vocelka 2000: 252). Wer heute die Kapuzinergruft in Wien besucht, kann anhand der Anzahl frischer Blumen und Kränze am Sarg der Kaiserin Sisi, aber auch des Kaisers Franz Joseph, (im Vergleich zu den vielen anderen Särgen der früheren Herrscherinnen und Herrscher) ermessen, wie sehr die Symbolkraft beider historischer Figuren auch heute noch zum Identifikationsobjekt der vergangenen Größe Österreichs taugt.

In Form des Images einzelner Personen der Geschichte haben denn auch die selbstgeschaffenen Mythen der Mächtigen früherer Jahrhunderte in der dynastischen und vor allem der populären Geschichtsschreibung überdauert, zumal sie „von den späteren Geschichtsschreibern meist nicht nur nicht zerstört, sondern häufig noch verstärkt" wurden, wie etwa die Beispiele von „Maximilian I, der seine sagenhaften Ahnen suchte, über die aufwändige barocke Repräsentation Leopolds I bis zur ,Mutterfigur' Maria Theresia“ zeigen (Vocelka 2000: 252). Interessanterweise steht insbesondere Franz Joseph für die neoabsolutistische Phase nach der Niederschlagung der 1848er Revolution und gleichzeitig für den Erlass eines Grundrechtskatalogs, der bis heute Bestandteil der österreichischen Verfassung darstellt. Aber er steht auch für die Ablösung Österreichs vom Deutschen Reich, da Österreichs Niederlage gegen Preußen in Königgrätz schließlich zur Verwirklichung der „kleindeutschen Lösung“ unter preußischer Vorherrschaft und unter Ausschluss Österreichs steht. Daneben wurde unter seiner Herrschaft erst die Doppelmonarchie Österreich-Ungarns geprägt, die in seiner Person als Herrscher zwei mehr oder weniger souveräne Staaten vereinigte. Damit ist das bis heute populäre 
Wort „Kakanien“68 als Anspielung auf die königlich und kaiserliche (k.u.k.) Monarchie ein Produkt der Mitte des 19. Jahrhunderts.

Daneben dürften auch der Sieg über die Türken bei der Schlacht am Kahlenberg vor Wien 1683 sowie die Erfolge der Gegenreformation von identifikatorischem Belang sein. Letztere befestigte die Vormachtstellung der katholischen Kirche in Österreich, was sich nicht zuletzt kulturell bis heute auswirkt, wenn man nur an die Vielzahl üppiger barocker Prachtbauten, Klöster und Kirchen denkt, die bis heute etwa das Erscheinungsbild Wiens mitprägen (vgl. Vocelka 2000: 118).

Letztlich mögen aber auch die für den Laien relativ unübersichtlichen Vorgänge und Entwicklungen innerhalb des Hauses Habsburg der früheren Jahrhunderte mitursächlich sein für die relativ deutliche Verengung der historischen Identifikationssymbole auf einzelne Herrscher und Perioden insbesondere ab dem 18. Jahrhundert. Dementsprechend ist es auch weniger das ehemalige Weltreich, das in seiner spanischen Linie im 16. und 17. Jahrhundert immerhin bis über den Atlantik reichte, das die vergangene „Größe“ ausmacht, die zur heutigen BezugsgröBe geworden ist, sondern vielmehr der „Glanz“ der Monarchie, der sich auch in der Kultur niederschlägt.

Insofern erscheint es folgerichtig, dass die österreichische Identität heute durchaus auf den in der Geschichtsschreibung der Habsburger-Monarchie eher wenig Raum ausmachenden deutsch-österreichischen Teil bezogen ist, der sich nach dem Ende des Kaiserreichs zunächst als Teil des größeren Deutschlands verstehen wollte und sich nach dem Zweiten Weltkrieg ganz bewusst davon abgrenzte. Es wird zu fragen sein, inwiefern sich die Geschichte Österreichs im Fernsehprogramm des $O R F$ niederschlägt, insbesondere hinsichtlich europäischer Berichterstattung. Hier wäre etwa daran zu denken, dass auf Grund der historischen Verbindungen häufig aus Ländern, die ehemals zur Monarchie gehörten, berichtet wird. Daneben dürfte interessant sein, in welchem Ausmaß über Deutschland berichtet wird und welche Schlüsse daraus auf die jeweiligen Einflüsse von außen nach Österreich sowie auf Einflüsse von Österreich über seine Grenzen hinaus geschlossen werden können.

\subsubsection{Stereotype - Vorurteile - Images}

Bei seiner Imagemessung Österreichs kommt Martinek zu dem Schluss, dass Selbst- und Fremdbild Österreichs weitgehend übereinstimmen, wenngleich das Selbstbild etwas facettenreicher erscheint (Martinek 1990: 106). Zentrale Dimensionen des österreichischen Images sind demnach „klassische Musik“, „Kunst und Kultur“ und „historische Bauwerke“ sowie „Tradition und Brauchtum“; daneben zählen „Gastronomie“, „Geselligkeit“ und „saubere Umwelt“ zu positiv besetzten Imagefaktoren (Martinek 1990: 108). Das Selbstbild wird zudem durch als Stärken bezeichnete Facetten ergänzt: „Kaffee“, „Romantik“, „Sozialstaat“ und „Asylland“ sowie „Wintersport“ (Martinek 1990: 106). Negative Aspekte bzw. Imagedefizite

\footnotetext{
${ }^{88}$ Ursprünglich geprägt von Robert Musil in dessen Roman „Der Mann ohne Eigenschaften“.
} 
ergeben sich im Selbstbild hinsichtlich der „Internationalität“, „Modernität“ und der „Wirtschaft", zudem wird Österreich verstärkt als „Land der Skandale“ bezeichnet (Martinek 1990: 107). Letztere Dimension erklärt sich in der Martinek-Studie aus der zeitlichen Nähe zur Waldheim-Affäre, dem Lucona-Prozess und dem Wein-/Glykolskandal. ${ }^{89}$ Die Skandalassoziation kann aber auch ohne neuere empirische Untersuchungen als auch heute noch präsent gelten, wenn man nur an einige international Schlagzeilen machende Vorgänge und Ereignisse der letzten Jahre denkt, wie den Doping-Skandal um das Wiener Labor „Humanplasma“ 2009, den Amstettener Inzestfall 2008, die Kampusch-Entführung 2006, die sexuellen Ausschweifungen im St. Pöltener Priesterseminar 2004 oder die international kritisierte Regierungsbeteiligung der rechtspopulistischen FPÖ nach den Nationalratswahlen 2000. ${ }^{90}$

Interessant ist auch das Bild, das Österreich bei seinen östlichen Nachbarn hat, da es seit der EU-Erweiterung 2004 schon allein geographisch von einer Rand- und Brückenlage ins Zentrum der europäischen (Ost-)Integration gerückt ist.

„Mit Österreich verbinden die Menschen in den Nachbarländern vor allem die (alpine) Landschaft und andere touristische Aspekte, Musikkultur und den Eindruck von Ordnung und Sicherheit, in hohem Ausmaß auch wirtschaftliche Erfolge. Während in der Slowakei und Polen historische Bezüge kaum angesprochen werden, ist in Ungarn und der Tschechischen Republik die gemeinsame Geschichte sehr wohl ein Thema. In beiden Ländern spielen auch nachbarschaftliche Gesichtspunkte eine erkennbare Rolle, wobei aber die Ungarn Gemeinsamkeiten hervorheben, während die Tschechen die Konflikte betonen“" (Tributsch/Ulram 2004: 21).

Darin spiegelt sich zum einen die Relevanz der Geschichte für Länderimages wider, gleichzeitig aber auch der Einfluss der Richtung, aus der ein Land betrachtet wird. Was einmal als integraler Bestandteil eines Bildes einer anderen Nation erscheint, spielt im anderen Fall möglicherweise gar keine Rolle. Entsprechend verhält es sich denn auch mit der Wahrnehmung der Nachbarn in Österreich. So glauben etwa 79 Prozent der Österreicherinnen und Österreicher, viel mit Ungarn gemeinsam zu haben (umgekehrt denken 50 Prozent der Ungarinnen und Ungarn so über Österreich) und immerhin noch 55 Prozent denken so über Tschechien (63 Prozent), aber nur 20 Prozent denken, dass viele Gemeinsamkeiten mit Polen (33 Prozent) bestehen (Tributsch/Ulram 2004: 22, m. w. N.) Die positive Wahrnehmung Ungarns in Österreich und umgekehrt zeigt sich auch in der Beschreibung der jeweiligen Charaktere, die jeweils „überwiegend positiv konnotiert" sind und vor allem jenem psychologischen Profil ähneln, „das die Österreicher von sich selbst haben“ (Tributsch/Ulram 2004: 24).

In der Außenwahrnehmung wird Österreich trotz eines immer wieder konstatierten deutschen „Kulturimperialismus“ (vgl. Tributsch/Ulram 2004: 78, m. w. N., insb. Fn. 22, S. 155f.) als

\footnotetext{
${ }^{89} \mathrm{Im}$ Selbstbild Österreichs blieb dennoch die Kategorie „Wein“ positiv besetzt, nicht aber im Fremdbild. Das könnte mit der Verbreitung der „Heurigenkultur“ zu tun haben, die ein traditioneller Bestandteil österreichischen (gastronomischen) Alltagslebens ist.

${ }^{90}$ Wobei die Skandal-Wahrnehmung auch durch Nachrichtenwertfaktoren bedingt sein kann: Da von Österreich eher wenige politisch international bedeutsame Impulse ausgehen bzw. als dafür bedeutsam bewertet werden (gemäß Nachrichtenfaktor „Bezug auf Elite-Nation“ Galtung/Ruge 1965: 68), treten in der (außerösterreichischen) Nachrichtenagenda Ereignisse von außergewöhnlicher Natur („Überraschung“ vgl. Galtung/Ruge 1965: 65) stärker hervor.
} 
durchaus eigenständiges Land wahrgenommen. In allen von Tributsch und Ulram untersuchten osteuropäischen Ländern stimmt die übergroße Mehrheit der Befragten der Behauptung zu, dass Deutsche und Österreicher zwar dieselbe Sprache sprechen, sonst aber ziemlich verschieden sind (Tributsch/Ulram 2004: 23).

Insofern kann davon ausgegangen werden, dass Bilder und Stereotype von Österreich nicht vom großen nördlichen Nachbar überlagert werden. Insbesondere die weit zurückreichende Geschichte der Habsburger-Monarchie als ehemaligem Weltreich scheint diese Eigenständigkeit mitzubegründen. Das ist insofern interessant, als dass die Habsburger über lange Strecken der Geschichte Herrscher des Deutschen Reichs (Heiliges römisches Reich deutscher Nation) waren und ihre Stammlande in der heutigen Schweiz liegen. Einen eigentlich österreichischen Staat gab es erst seit 1804. Daraus wird wiederum ersichtlich, wie sehr es sich bei historisch bedingten Bildern und Stereotypen letztlich um Projektionen handelt. Dafür bietet auch etwa der „Anfangsmythos“ der zweiten Republik von Österreich als „dem ersten Opfer des Nationalsozialismus“ ein vielsagendes Beispiel (vgl. Gries 2005: 12).

\subsection{Regionale Identität}

Das bisher dargestellte Verständnis von sozialer Identität als Kollektividentität muss für die spezifische Ausformung der regionalen Identität weiter ausdifferenziert werden. Regionale Identität ist mehr als eine Gruppenidentität im Sinne der Theorie der sozialen Identität, da ihre „Basis ein territorial begrenzter Lebensraum [ist], in dem landschaftlich-kulturelle mit sozialen Aspekten verknüpft sind“ (Lilli/Diehl 1999: 101). Das macht sie im Ergebnis zu einer Mixtur aus Attraktivität territorialer Merkmale und Zufriedenheit mit territorialen Gruppenbindungen, soweit es sich um das Selbstkonzept der davon betroffenen Individuen handelt. Allerdings ist der Begriff der regionalen Identität zunächst doppeldeutig. Zum einen beschreibt er nämlich „die ,Identität der Region“, d.h. ihre sachliche Differenz [von anderen Regionen, H. I.], und andererseits ,Regionalbewußtsein' im Sinne der regionalen Identität der Bevölkerung. “91 (Blotevogel 1996: 62, m. w. N.). Zu unterscheiden ist also zwischen kognitiven Vorstellungen über einen Raum und jenen Aspekten, die das subjektive Selbstkonzept betreffen (vgl. Weichhart 1990: 14). Die Unterscheidungskriterien sind dabei das reine Wissen über Eigenschaften und Besonderheiten sowie die Ausmaße einer Raumeinheit auf der einen Seite und eine wie auch immer geartete emotionale Bindung, ein ,aktiver Zugehörigkeitswille“ auf der anderen Seite (vgl. Weichhart 1990: 15). Als Regionalbewusstsein ist die Gesamtheit raumbezogener Einstellungen und Identifikationen, fokussiert auf eine mittlere Maßstabsebene, zu verstehen (Blotevogel et al. 1989: 68). Unter „Einstellung“ ist die erlernte, latente Bereitschaft zu verstehen, zeitlich relativ beständig auf ein bestimmtes Objekt in bestimmter Weise zu reagieren (Blotevogel et al. 1989: 71). Dem sozialpsychologischen Begriff Einstel-

\footnotetext{
${ }^{91}$ Also bezogen auf das individuelle Selbstkonzept, auf das sich kollektive Identitäten auswirken.
} 
lung $^{92}$ entsprechend, sind diese drei Dimensionen miteinander verknüpft, das heißt Wahrnehmung, Bewertung und Handeln „verhalten“ sich untereinander konsistent (Blotevogel et al. 1989: 71). Daraus ergeben sich drei Dimensionen der Strukturierung dieses Konzeptes: Die kognitive Dimension (Wahrnehmung der Region), die affektive Dimension (emotionale Einstellung zu einer Region) und die konative Dimension (tatsächliche Aktivitäten im Zusammenhang mit einer Region) (Blotevogel et al. 1989: 72).

Die Konsistenz des Begriffs „regionale Identität“ ergibt sich aus der kausalen Verbindung von „identification of“" und ,identification with“, auf der nach G. P. Stone Identität grundsätzlich beruht (vgl. Weichhart 1990: 16, m. w. N.). Das heißt nichts anderes, als dass die von Blotevogel benannte Doppeldeutigkeit der „Identität der Region“ eine kausale Verbindung beschreibt. Das „Regionalbewusstsein“ bezieht sich auf eine von der sozialen Gruppe als gleich wahrgenommene Entität, die aus der sachlichen Differenz zu anderen solchen Entitäten entsteht. Folglich basieren beide Bedeutungen auf Kommunikation: Die Außengrenzen einer Region können erst durch ihre Benennung zum Bezugspunkt darin stattfindender sozialer Identifikation werden. Diese Identifikationsprozesse können sich dann auf verschiedene Aspekte geteilter Eigenschaften beziehen, wie etwa eine gemeinsame Geschichte, ähnliche Sprache, Traditionen usw. Auch diese geteilten Eigenschaften können erst durch Kommunikation zum Teil der sozialen Identität werden.

In der Alltagssprache werden mit den Regionen bestimmte Konnotationen und Stereotype verbunden. Solche „Wahrnehmungsregionen“"93 dienen dabei als Projektionsflächen für die einzelnen Mitglieder von Gruppen sowie deren „Wir-Bewusstsein“. Dabei ist vor allem die territoriale Projektion dafür geeignet, Gruppenidentitäten zu schaffen, weil diese zu einem großen Teil auf Abgrenzung basieren (Weichhart 1996: 37). Quasi natürliche Grenzen, wie jene von alltagssprachlich konstruierten Regionen, sind dafür besonders tauglich.

Regionen erfahren in der Alltagssprache eine Umdeutung zu Gebilden, in denen die „Elemente des Naturraums und der materiellen Kultur, Sprache, Sitte, Gebräuche sowie das Gefüge sozialer Interaktionen zu einer einheitlichen Struktur verschmolzen sind" (Weichhart 1996: 36). Erst auf diesem kognitiven Konstrukt kann jedoch so etwas wie regionale Identität basieren, da bei der alltagssprachlichen Verwendung von Regionsbezeichnungen auch Konnotationen über die Bewohner von Regionen mitgedacht werden.

Wie bereits beim zugrunde liegenden Begriff der Region liegt der Hauptunterschied zur nationalen Identität in der deutlichen Anknüpfung an einen (physischen) Raum als Grundlage der Gruppenidentität. Hinzu kommt aber, dass die regionale Identität der nationalen scheinbar

\footnotetext{
${ }^{2}$ Nach Rosenberg/Hovland (1960) setzt sich das Konstrukt Einstellung aus einer affektiven, einer kognitiven und einer konativen (verhaltenswirksamen) Komponente zusammen.

${ }^{93}$ Vgl. Blotevogel (1996: 60); Weichhart (1996: 37).
} 
untergeordnet ist, das heißt, dass sie sich zum Teil auch auf die Nation bezieht. ${ }^{94}$ Dieser Bezug kann sowohl komplementär als auch oppositionell sein.

Räume und Raumausschnitte stehen im Zusammenhang mit sozialer Identität als Symbole sozialer Systeme, die sowohl aus der Außen- als auch aus der Innenperspektive klassifiziert und typisiert werden (Weichhart 1990: 18). Die Innenperspektive (um die es in dieser Arbeit vornehmlich gehen soll) ist einer Form der Identifikation mit der eigenen Umwelt, die zu einem Wir-Gefühl oder Gruppenbewusstsein der Gruppenangehörigen führt (Weichhart 1990: 19). Diese Identifikation ist aber nicht auf Personen (als Gruppe) beschränkt. Vorbilder und Bezugssysteme können darin auch historische Figuren oder Fiktionen sein (Weichhart 1990: 17). Der Raum selbst, auf den sie sich bezieht, ist dabei selbst ein symbolisches Identifikationsobjekt und seine Perpetuierung aus der immer neuen kommunikativen Herstellung dieses Raumes ist daher ebenso wichtig wie die Ausfüllung der sozialen Identität mit darin angesiedelten Bezugsobjekten. Das heißt, dass etwa die Herkunft einer historischen Person für die Identifikation mit ihr als Angehörigem der eigenen Region nur dann sinnvoll ist, wenn der Herkunftsort nicht punktuell, sondern übergreifend erscheint. Dies kann durch kommunikative Einbettung geschehen, wie sie etwa im Rahmen eines Regionalsenders gegeben ist.

Der generelle Orientierungsrahmen, den raumbezogene Identität darstellt ${ }^{95}$, ist im Alltag als implizites Wissen wirksam und stellt damit vor allem einen Erfahrungshintergrund zur Verfügung, auf dessen Basis Kommunikation und soziale Interaktion stattfindet (vgl. Weichhart 1990: 49). Zu diesem impliziten Wissen gehören nicht zuletzt Rollenerwartungen. Sie resultieren aus der Gruppenmitgliedschaft und dienen der Gruppenkohäsion, die sich

„nicht zuletzt daraus [ergibt], daß die einzelnen Mitglieder des Systems die mit der Rolle verknüpften Anforderungen der Rollensender erfüllen. Die zugeschriebene Rolle [...] beinhaltet ein Bündel an wechselseitigen Erwartungshaltungen, die vor dem Hintergrund sozialer Werthaltungen den jeweiligen Rolleninhaber zu bestimmten Verhaltensweisen und Reaktionen gleichsam nötigen. [...]“" (Weichhart 1990: 72).

Ein großer Teil dieser Rollenanforderungen innerhalb der Gruppe wird dabei sicherlich bereits durch die kindliche Erziehung geleistet. Für deren Basis und auch für die spätere Beständigkeit der Sozialisation ${ }^{96}$ als Gruppenmitglied bzw. Regionsangehöriger sind - insbesondere wenn es sich nicht um eine face-to-face agierende Gruppe handelt - Massenmedien ein besonders wichtiges Element. Insbesondere weil sich mit der räumlichen Maßstabsebene auch die Verbindlichkeit der Erwartungshaltungen verringert:

„Mit der Maßstabsebene verändern sich auch die vom Rolleninhaber eingeforderten Leistungen. Die Erwartungshaltungen werden zunehmend abstrakter und stärker entpersonalisiert und

\footnotetext{
${ }^{94}$ Das stimmt nicht grundsätzlich für alle regionalen Identitäten, wie deutlich wird, wenn man etwa an das Baskenland denkt, dass sich zum großen Teil explizit nicht auf die Nationalstaaten beruft, in denen es liegt. Für die in der vorliegenden Arbeit in Betracht kommenden Gebiete kann diese Annahme aber gelten.

${ }^{95}$ Ebenso wie andere soziale Identitäten und vor allem Gruppenzugehörigkeiten und die damit verbundenen Zuschreibungen.

${ }^{96}$ Vgl. hierzu auch Mühler (2005: 195), wo u. a. Modelllernen als wichtiger Bestandteil der Sozialisation benannt wird.
} 
beziehen sich nun vor allem auf eine undramatische Form der grundsätzlichen Solidarität mit der betreffenden symbolischen Gemeinschaft. Der Rolleninhaber weiß, daß von ihm in bestimmten Situationen erwartet wird, sich als ,Lehener', ,Salzburger', ,X-viertler/gauer ${ }^{6}$ zu fühlen. Das bedeutet, daß er unter bestimmten Umständen eine gewisse Solidarität gegenüber einem Lokalpolitiker [...], mit dem regionalen Fußball- oder Sportverein oder mit regionalen Teilorganisationen karitativer Vereinigungen demonstrieren sollte. [...] Im Rahmen dieser Rolle ist es angebracht, zumindest gelegentlich auch die jeweilige Lokalzeitung zu lesen, den Regionalfunk zu hören, Anteil zu nehmen an dem, was in der betreffenden Raumeinheit vor sich geht. Und er weiß, daß er keinerlei Sanktionen zu befürchten hat, wenn er all dies nicht tut" (Weichhart 1990: 72).

Solche Rollenerwartungen entstehen vor allem im kommunikativen Raum. Menschen in Interaktion belohnen Einstellungs- und Meinungskongruenz von Interaktionspartnern etwa mit Zuwendung, Lob und emotionaler Unterstützung, wodurch ein Anreiz zur Meinungs- und Einstellungsregulation entsteht (Mühler 2005: 197). Im Alltag kann dies schon durch das reine Wissen um bestimmte Themen, über die man sich mit den Mitmenschen austauscht, stattfinden. Hier liegt es nahe, dass Themen aus dem geographischen Nahraum größere Relevanz entwickeln als andere. Hier kann von einem Agenda-Setting-Prozess ausgegangen werden, der in zwei Richtungen weist: Einerseits wollen die Regionsbewohnerinnen und -bewohner sich gerade über ihre unmittelbare Umwelt informieren und rezipieren verstärkt regionale Medien. Andererseits bestimmen diese regionalen Medien durch die ihnen eigenen Selektionsmechanismen, welche Themen dies sind und stellen damit eine feste Bezugsgröße innerhalb der Region dar. Sozial deutlich kleinere Teilgruppen (Arbeitskollegen, Sportvereine etc.) können sich so in ihrer persönlichen Alltagskommunikation auch auf ihre regionale Verortung beziehen. Das heißt, dass regionale Massenmedien in zweierlei Hinsicht für regionale Identität relevant sind: Sie sind an der räumlichen Identitätskonstruktion beteiligt und gleichzeitig ist die Zuwendung zu ihnen bereits Teil des individuellen Identifikationsprozesses. Letzteres können sie aber nur leisten, wenn sie als spezifisches regionales Programm erkennbar, identifizierbar sind.

Um die Frage zu beantworten, wie im Fernsehprogramm regionale Identität zum Ausdruck kommen kann bzw. wie ein solches Programm als regional-spezifisch identifizierbar wird, sind gebräuchliche Charakteristika der betreffenden Regionen zu benennen. Sie bilden eine kulturell-kommunikative Basis, durch die auf diese Regionen referiert werden kann. Je stärker solche Charakteristika im Fernsehprogramm vorkommen, desto eindeutiger ist die Region darin identifizierbar. Es sei an dieser Stelle nochmals darauf verwiesen, dass es dabei nicht darum geht, eine als objektiv angenommene Realität zum Maßstab der medialen Repräsentation dieser Regionen zu machen. Vielmehr sind die Beschreibungen der Regionen in anderen Zusammenhängen Ausdruck der gleichen sozialen Konstruktionspraktiken, die auch die Identitäten der Regionen in den Medien erst hervorbringen. Der Abgleich zwischen den verschiedenen Ausdrucksformen ermöglicht es jedoch, die wirkmächtigen Konstrukte zu erkennen und die Beteiligung der Medien in diesem Prozess sichtbar zu machen. Im Sinne der oben erwähnten Konsistenz der beiden begrifflichen Aspekte regionaler Identität sind aus dem Angebot der Massenmedien Rückschlüsse auf das Selbstverständnis der Regionsbewohnerinnen und -bewohner möglich. In dem Maße, in dem ein regionales Medienangebot als für eine bestimmte Region spezifisches Angebot identifizierbar ist, drückt sich darin zwangsläufig auch das Regionalbewusstsein aus, da beide Seiten in einem wechselseitigen bzw. zirkulären Zusammenhang stehen. Das liegt nicht zuletzt auch an den Produktionsbedingungen der Medien- 
inhalte - sie werden für ein als regional gedachtes Publikum produziert von (jedenfalls zum Teil) in der Region lebenden und arbeitenden Kommunikatoren. Zu diesen Produktionsbedingungen zählen auch Rahmenbedingungen wie rechtliche Regulierungen der Anforderungen an das Programm oder wirtschaftliche und institutionelle Rahmenbedingungen. ${ }^{97}$

Spätestens im regionalen Bereich stößt die institutionelle Betrachtung des Programmangebots als Ausdruck gesellschaftlicher Rahmenbedingungen, wie Köster sie für verschiedene europäische Nationen vornimmt (Köster 2008), an ihre Grenzen. Was auf europäischer und nationaler Ebene noch überzeugt, kann auf der regionalen Ebene schnell zu wissenschaftlichen Artefakten führen. Köster versteht eine Vielzahl empfangbarer Fernsehprogramme etwa als Ausdruck unterschiedlicher Individualisierungsgrade innerhalb verschiedener Länder (vgl. im Einzelnen Köster 2008: 588). Diese Unterschiede basieren demnach unter anderem auf soziokulturellen Einflussfaktoren, wie etwa dem wirtschaftlichen Wohlstand. Diese Einflussfaktoren werden aber auf regionaler Ebene von administrativen Strukturen fast vollständig verdrängt, wie schon die Unterschiede der (privaten) Fernsehangebotsstrukturen innerhalb Mitteldeutschlands zeigen. ${ }^{98}$ Gerade deshalb bieten sich hier inhaltliche Vergleiche in bestimmten Teilen des Gesamtprogrammangebots eher an als institutionelle Vergleiche.

Die Identität einer Region - im Sinne der „identification of“ - setzt sich zusammen aus

1. dem zugrunde liegenden Raum,

2. für diesen Raum gültige Administration und Politik,

3. in diesem Raum stattfindendes gesellschaftliches Leben,

4. einer regionalen Wirtschaft,

5. einer für diesen Raum typischen Kultur und

6. einem historischen Verständnis dieses Raumes, auf den sich die vorgenannten Merkmale mehr oder weniger stark beziehen.

Diese Merkmale bilden für Regionen jeweils typische Strukturen und Erscheinungsweisen aus. Es ist anzunehmen, dass sie sich in den Massenmedien einer Region niederschlagen. Damit ist es die Aufgabe dieser Arbeit, diese Strukturen in Fernsehprogrammen aufzufinden, zu beschreiben und schließlich ihre möglichen Funktionen zu erörtern.

Nitschke kommt durch einen Vergleich auf europäischer Ebene zu fünf Voraussetzungen, die zur besonders starken Ausprägung regionaler Identität führen:

„[R]egionale Identität ist vor allem da stark zu verorten, wo

I) ein regional verankertes politisches Establishment konkret vorhanden ist und sich entsprechend engagiert sowie auch institutionell einigermaßen gesichert ist;

II) dieses Establishment über ein spezielles soziokulturelles Umfeld verfügt - mit anderen Wor-

\footnotetext{
${ }_{97}$ Vergleiche hierzu Abschnitt 5 Strukturelle Rahmenbedingungen (S. 100ff.).

${ }_{98}$ Insbesondere die eklatanten Unterschiede angebotener Lokalsender in Sachsen im Vergleich zu deren Anzahl in Sachsen-Anhalt und Thüringen (siehe hierzu genauer S. 109) dürfte kaum aus unterschiedlichen soziokulturellen Bedingungen in diesen Bundesländern erwachsen sein, sondern beruht vielmehr auf unterschiedlicher Rundfunkpolitik.
} 
ten: innerhalb einer eigenständigen politischen Kultur agieren kann, die von der nationalen differiert;

III) diese Kultur über spezifische historische Erfahrungsbilder tradiert wird;

IV) die Kultur mittels einer mehr oder weniger noch lebendigen Sprache in der Bevölkerung vermittelt ist;

V) die Funktion und/oder Notwendigkeit einer Front- bzw. Vermittlungsstelle zwischen divergierenden kulturpolitischen Großsystemen besteht“"(Nitschke 1996: 298).

Diese Voraussetzungen finden theoretisch Ausprägungen im Fernsehen, da sie entweder auf kommunikative Vermittlung angewiesen sind oder in den Bereich fallen, über den zu berichten Aufgabe des Rundfunks ist. 


\subsubsection{Mitteldeutschland}

Auf den ersten Blick erscheint der Begriff Mitteldeutschland heute manchen Menschen unangebracht und politisch irgendwie verdächtig. Zu dieser Einschätzung kann aber nur kommen, wer die historischen und inhaltlichen Implikationen des Begriffs Mitteldeutschland nicht kennt. Das Unbehagen an dem Begriff scheint vor allem aus dem bundesdeutschen Sprachgebrauch der Zeit des Kalten Krieges zu stammen. Damals wurde häufig von der gesamten DDR als „Mitteldeutschland“ gesprochen, womit durchaus auch ein Blick auf die früheren Ostgebiete des Deutschen Reichs und eine Vorläufigkeit der deutschen Ostgrenzen impliziert war (vgl. John 2001c: 11, John 2001b: 19-20, 64-66, Schönfelder 2001: 165, König/Paul 2004: 123) ${ }^{99}$. Jedoch darf diese unangemessene Politisierung des Begriffs nicht von seiner tatsächlich weiter zurückreichenden Begriffsgeschichte ablenken, die - bei allen inhaltlich möglichen Widersprüchen - im Kern ,immer mehr oder weniger deckungsgleich mit dem obersächsischthüringischen Raum ,in der Mitte Deutschlands“ verknüpft war“" (Schönfelder 2001: 165). Sprachwissenschaftlich bezeichnet der Begriff „Mitteldeutschland“ das gesamte Gebiet, das den oberdeutschen vom niederdeutschen Sprachraum in Ost- West-Ausdehnung teilt und reicht in der weitesten Deutung (nach Adelung von 1782) von Straßburg und Köln im Westen bis nach Schlesien im Osten. Im engeren Sinn (etwa Gottsched 1748) wird mit dem Begriff ein Raum, der hauptsächlich Thüringen und den Süden Sachsens umschließt bezeichnet. Wieder andere Definitionen verorten den Raum etwa von Dresden im Osten bis weit ins Hessische hinein (vgl. König/Paul 2004: 122). Als geographischer Begriff wurde „Mitteldeutschland" für wechselnd große Gebiete verwendet, wobei es insbesondere die landeskundlichen und wirtschaftsgeographischen Einteilungen sind, die sich hauptsächlich um den genannten mitteldeutschen Kern herum wiederfinden, während die eher physisch-geographisch orientierten Einteilungen mehr der sehr weiten Verwendung des sprachgeographischen Raums entsprechen (vgl. Abbildung bei König/Paul 2004: 122). Die heute gängige Verwendung für das Gebiet der drei Bundesländer Sachsen, Sachsen-Anhalt und Thüringen dürfte hingegen vor allem auf Verwaltungsgliederungsabsichten in den 1920er/1930er Jahren zurückgehen. Die damals beabsichtigte Reichsreform brachte auch die Frage nach einer Wirtschaftsprovinz „Mitteldeutschland“ auf die Tagesordnung. Damit sollten die Territorien Sachsens, der preuBischen Provinz Sachsen, Braunschweigs, Thüringens und Anhalts ganz oder teilweise neu geordnet werden (vgl. Schönfelder 2001: 162, Schönfelder 2001: 166, John 2001c: 14). Hierfür gab es unterschiedlich weitgehende Vorschläge, die von „kleinmitteldeutschen“, „teilmitteldeutschen“ bis zur "großmitteldeutschen“ Gliederung reichten. Die Zusammenfassung der heutigen drei Bundesländer Sachsen, Sachsen-Anhalt und Thüringen entspricht dabei dem großmitteldeutschen Vorschlag (Schönfelder 2001: 162). Auf diese Ansätze der 1920er und 1930er Jahre beriefen sich denn auch die Bestrebungen zur Einrichtung eines Bundeslandes Mitteldeutschland nach der deutschen Einheit zu Beginn der 1990er Jahre. Auch wenn ein

\footnotetext{
${ }^{99}$ Die Verwendung des Begriffs „Mitteldeutschland“ als Bezeichnung für die DDR in überregionalen Tageszeitungen war zeitlich begrenzt und lag nicht über der Häufigkeit anderer Synonyme wie König/Paul 2004: 124 für SZ, FAZ und Welt zeigen.
} 
solches Bundesland politisch nicht realisiert wurde, gab es doch auch zahlreiche Initiativen auf wirtschaftlicher Seite, die sich ebenfalls auf den Mitteldeutschlandgedanken beriefen (vgl. Schönfelder 2001: 162).

„Heute sollte der geographische Begriff wieder unbefangen verwendet werden können. Steht er doch für einen charakteristischen Raumausschnitt aus der Geosphäre mit einer bestimmten, arteigenen naturräumlichen Ausstattung, ähnlicher sprachlich-kultureller Entwicklung und spezifischer Wirtschaftsstruktur, der als Einheit dieses Raumes, als einmalige individuelle geographische Region, begriffen werden kann, obwohl er im scharfen Gegensatz dazu, bis heute nicht als territoriale Einheit gesehen wird, sondern mehr oder weniger durch historisch bedingte Zersplitterung bis in die Gegenwart gekennzeichnet ist" (Schönfelder 2001: 166).

Von diesen Argumentationslinien ausgehend ist es möglich, von Mitteldeutschland als Konstrukt einerseits und Identifikationsraum andererseits zu sprechen. Das Programm des Mitteldeutschen Rundfunks steht damit - qua Programmauftrag - in einer Doppelfunktion: Es soll die mitteldeutsche Identität abbilden und befördern, muss sie zu diesem Zweck aber selbst erst in einem gewissen Maße stiften. Dieser Aufgabe kam das MDR-Fernsehen in der Vergangenheit unter anderem mit der Sendereihe „Geschichte Mitteldeutschlands“ nach. ${ }^{100}$ Daneben spiegelt sich dieser Anspruch auch im Markenauftritt des Senders wider, der 2003 überarbeitet wurde und im Corporate Design konsequent auf eine Visualisierung der „Trinität“ Mitteldeutschlands setzt, indem etwa das Programmlogo dreigeteilt wurde und drei Linien ins Design von Programmtrailern, Plakaten, etc. eingeführt wurden (vgl. dazu im Einzelnen Markuse 2006: 346). ${ }^{101}$ Die Analyse muss nicht zuletzt daran interessiert sein, wie gut die Erfüllung dieser programmlichen Aufgabe in den Sendungen des MDR umgesetzt wird. Dabei wird insbesondere darauf zu achten sein, ob im Kern „mitteldeutsche“ Themen tatsächlich in der Programmrealität vorkommen, nur behauptet werden oder ob eher die Vielfalt betont wird, indem etwa zu bestimmten Themen die unterschiedlichen regionalen Aspekte innerhalb des Sendegebiets herausgestellt werden.

\subsubsection{Geschichte}

Davon ausgehend, dass mit dem geographischen Begriff eine individuelle erdräumliche Einheit beschrieben wird, spielt für deren kulturelle Identität nicht zuletzt ihre Geschichte eine herausragende Rolle. Dabei kann es, da es sich bei Mitteldeutschland um einen Ausschnitt der geographisch größeren Einheit Deutschland handelt, nur um solche Ereignisse und Prozesse der Vergangenheit gehen, die mit der Individualität der Region zusammenhängen, also um historische Alleinstellungsmerkmale, die hauptsächlich diese Region betreffen oder in ihr bestimmte Ausprägungen erfahren haben. Dass die historischen Ereignisse der umliegenden bzw. größeren Raumeinheiten die Geschichte ebenfalls (wahrscheinlich sogar in mindestens gleichem Maße) geprägt haben, ist dabei mitzudenken, ebenso wie es umgekehrt nicht darum

${ }^{100}$ Die bereits Gegenstand wissenschaftlicher Auseinandersetzung hinsichtlich der Stiftung regionaler und symbolischer Identifikationsräume war: Felgenhauer (2007), Felgenhauer/Schlottmann (2007).

${ }^{101}$ Ein interessanter Randaspekt zum Logo des MDR: Dieses war nach dessen Gründung zunächst in schwarzrot-gold (verteilt auf die drei Buchstaben) gehalten, verwies also explizit auf die Nation (vgl. Artikel 22 GG). 
gehen kann, solche weitergreifenden historischen Prozesse auf ihre jeweils regionalen Auswirkungen und Ausprägungen in jedem Fall nachzuvollziehen.

Dabei ist insbesondere an Phasen (teilweiser) staatlicher Souveränität (einzelner Teile des heutigen Mitteldeutschlands) bis etwa zum Ende des 19. Jahrhunderts zu denken sowie an die Zeit der DDR. ${ }^{102}$ Hier ist jedoch darauf zu achten, nicht zugunsten der Behauptung einer mitteldeutschen territorial-administrativ begründbaren Geschichte, historische Kontinuitäten zu konstruieren, wo es sie gar nicht gibt. „Von einer historisch gewachsenen ,Einheit Mitteldeutschlands‘ ausgehende Großraumkonzepte können sich kaum positiv auf dauerhaftgemeinsame territoriale und administrative Strukturen berufen“ (John 2001a: 229). In (historisch) so heterogen strukturierten Regionen prägen sich daher häufig Deutungsmuster aus, die ein Streben nach der Überwindung der Kleinteiligkeit oder eine Einheit in der Vielfalt als konstitutiv behaupten (vgl. John 2001a: 229).

„Doch gerät der Versuch, aus solchen Wirkungszusammenhängen gemeinschaftsbildende Traditionen der heutigen Bundesländer herauszufiltern, zum fragwürdigen Konstrukt. Kleinstaatenfülle und Polyzentralität kann man als prägende Phänomene, als fördernde oder hemmende Faktoren der jeweiligen Geschichts- und Kulturlandschaft beschreiben, aber kaum auf heutige Landesidentiät hochrechnen“" (John 2001a: 230).103

Diese Einschränkungen sind daher mitzudenken, wenn im Folgenden einzelne Epochen benannt werden, die für eine mitteldeutsche Identität als (mit-)konstitutiv gelten sollen. Entsprechend den Feststellungen Johns ist es dabei durchaus üblich, sehr weit in die Geschichte zurückzugehen, auch wenn ,,vorstaatlich-mittelalterlich Strukturen keinen Bestand hatten, zerfielen oder in anderen territorialstaatlichen und administrativen Zusammenhängen aufgingen“" (John 2001a: 230). Dabei greifen die Verfechter einer politischen Einheit Mitteldeutschlands bis in die Völkerwanderungszeit zurück, da sich auf Grund dünner Quellenlage einerseits und archäologisch belegbaren sehr weiten Siedlungsraumes diese Epoche gut als Projektionsfläche eignet (John 2001a: 234). ${ }^{104}$

„Allerdings ergaben sich seit jener Zeit [seit der Völkerwanderung] nur zwei Perioden, in welchen die Region Mitteldeutschland von einer dynastischen Macht mehr oder weniger deutlich dominiert worden ist. Dies war einerseits zur Zeit des Thüringer Reiches der Fall, als es noch keine Territorialherrschaft im späteren Sinne gab, welches durch die Franken mit Unterstützung durch die Sachsen nach der Schlacht im Jahre 531 in der Nähe der unteren Unstrut, bei Burgscheidungen (?), unterging. Andererseits gab es in weiten Teilen Mitteldeutschlands eine

\footnotetext{
102 Wenngleich die DDR-Zeit kein Alleinstellungsmerkmal Mitteldeutschlands darstellt, da diese auch die Bundesländer Berlin, Brandenburg und Mecklenburg-Vorpommern betrifft. Immerhin unterscheidet Mitteldeutschland dieser Teil der Vergangenheit aber doch vom größten Teil des restlichen Deutschlands und dürfte bis heute (wenn auch mit anderen Ostbundesländern geteilte) spezifische Nachwirkungen in vielen Lebensbereichen haben.

103 An Thüringen und Sachsen-Anhalt zeigt John auch, wie zugunsten einer konsistenten Landesidentität solche Epochen in den Vordergrund gerückt werden, die heutige Regionen als wirtschaftliche, kulturelle und eben auch historische Einheiten erscheinen lassen (vgl. John 2001a: 230). Lediglich Sachsen erscheint vor diesem Hintergrund als im Kern ungebrochenes territorialstaatliches Konstrukt, das daher ein „identitätspolitisch relativ unproblematisches Land“" ist (John 2001a: 233).

104 Wenngleich sich diese Epoche keineswegs so einheitlich darstellt, dass sie als begründend für eine eigene mitteldeutsche Identität gelten kann (vgl. hierzu insb. John 2001a: 236).
} 
relativ einheitliche Entscheidungsgewalt durch die Herrschaft des Hauses Wettin zwischen 1247 (Tod des Thüringer Landgrafen Heinrich Raspe) und 1815 (Wiener Kongreß)“ (Schönfelder 2001: 174). ${ }^{105}$

Ein weiteres historisches Schlüsselmoment mitteldeutscher Geschichtsschreibung stellt die Reformation mit Beginn des 16. Jahrhunderts dar. Sie hat mit Luthers Wirkungsstätten einen örtlich fixierbaren Ursprung im mitteldeutschen Raum und wirkte von dort ausgehend auch so weit darüber hinaus (räumlich, zeitlich und geistesgeschichtlich), dass sie als identifikatorischer Bezugspunkt dienen kann.

Spätere Zeiträume sind dagegen nur mit höherem argumentativen Aufwand als derartige „,mitteldeutsche" Identifikationspunkte auszumachen. Zu deutlich werden sie entweder von räumlich größeren Zusammenhängen geprägt oder beziehen sich eindeutig nur auf Teile des heutigen Mitteldeutschlands. Dies betrifft etwa die Geschichte des Königreichs und früheren Kurfürstentums Sachsen, das ,zu den einflußreichsten frühneuzeitlichen Staaten und Konkurrenten Brandenburg-Preußens“ gehörte (John 2001a: 233) und im 19. Jahrhundert ,als industrielle Pionierregion und bis 1866 in mittelstaatlichen Versuchen, ein an Österreich angelehntes ,drittes Deutschland“ zu formieren, eine wichtige Rolle“ spielte (John 2001a: 233). Im Rahmen von für mitteldeutsche Identität konstitutiven Argumentationslinien wird Sachsen denn „häufig auch als ausbaufähiger Kern eines administrativen mitteldeutschen Großraumes mit dem wettinischen Territorialstaat des 15. Jahrhunderts als Vorläufer“ (John 2001a: 233) gesehen. Darin ist ein Negativbild Preußens impliziert, dessen Provinzen - die große Teile des heutigen Sachsen-Anhalts ausmachen - als zu vereinnahmende „Aufteilmasse für ein künftiges Großland ,Mitteldeutschland““(John 2001a: 233) gelten. Die entsprechende Bewertung der Geschichte der Region wurde insbesondere in den Dienst der Mitteldeutschlandpläne der 1920er/1930er Jahre gestellt. Nach deren Scheitern gab es denn auch keine Zeitabschnitte mehr, in denen die Region als politische Einheit bestanden hätte und auf die sich die neuerlichen Pläne, nach der Deutschen Einheit ein Bundesland Mitteldeutschland zu etablieren, hätten beziehen können. Allerdings war noch 1954 ein Plan zur Neugliederung Mitteldeutschlands für den Fall der Wiedervereinigung entwickelt worden (vgl. Rutz 2001: 450-451, 458 m. w. N.). Auf diesen wurde aber nicht zurückgegriffen, als 1989 und 1990 Entwürfe erarbeitet wurden, die das Gebiet der DDR administrativ-territorial neu gliedern sollten (vgl. Rutz 2001: 450. Obwohl es mehrere Vorschläge zur Einrichtung eines mitteldeutschen Bundeslandes gab, ${ }^{106}$ wurde schließlich zugunsten einer Neugründung der Bundesländer, wie sie in der Sowjetischen Besatzungszone 1945 - 1952 existiert hatten, darauf verzichtet.

Unabhängig von dieser Ideengeschichte Mitteldeutschlands dürfte für das dafür eigene historisch-kulturelle Bild die Zeit der DDR eine herausragende Rolle spielen. Nicht zuletzt hat die übergroße Mehrheit der mitteldeutschen Bevölkerung den Großteil ihres Lebens im „Arbeiter- und Bauernstaat“ bzw. „ersten sozialistischen Staat auf deutschem Boden“ verbracht. Auch wenn es an dieser Stelle zu weit führte, die sich daraus ergebenden besonderen Prägungen von Biographien und des Geisteslebens zu erörtern, ist doch davon auszugehen, dass ein

\footnotetext{
105 Vgl. auch John (2001a: 234)

106 Siehe hierzu insb. Rutz (2001).
} 
Fernsehprogramm für Mitteldeutschland vor diesem Hintergrund besonders Rechnung tragen wird. In welchem Umfang und mit welchen Mitteln das geschieht, wird eine der Fragen der Programmanalyse sein.

\subsubsection{Empirische Merkmale Mitteldeutschlands}

\subsection{Bevölkerungsstruktur ${ }^{107}$}

In Mitteldeutschland leben zum Ende des Jahres 2007 8,9 Millionen Menschen, die Verteilung auf die beiden Geschlechter entspricht der der deutschen Gesamtbevölkerung. Die Einwohnerinnen und Einwohner leben zu 47 Prozent in Sachsen, 27 Prozent leben in Sachsen-Anhalt und 26 Prozent in Thüringen. Die Bevölkerungsdichte liegt bei 162 EW je Quadratkilometer. ${ }^{108} 23$ Prozent der Bevölkerung in Mitteldeutschland wohnen in Städten mit einer Einwohnerzahl zwischen 100.000 und 500.000, elf Prozent in Städten zwischen 20.000 und 100.000 EW, 17,3 Prozent in Städten mit 5.000 bis 20.000 EW und 49 Prozent in Gemeinden unter 5.000 EW. ${ }^{109}$ Diese Verteilung unterscheidet sich ziemlich deutlich von der Gemeindegrößenklassenverteilung Gesamtdeutschlands. In Mitteldeutschland lebt fast die Hälfte der Bürgerinnen und Bürger in Kleinstädten und Landstädten, aber immerhin auch fast ein Viertel in Großstädten.

Bei der Altersverteilung ergibt sich für Mitteldeutschland ebenfalls ein von Gesamtdeutschland abweichendes Bild: Die unter 20-Jährigen machen 15,5 Prozent der Bevölkerung aus, 20bis 39-Jährige 24,5 Prozent, 40- bis 60-Jährige 31,3 Prozent und die über 60-Jährigen 28,7 Prozent. Die Abweichung von der deutschen Gesamtbevölkerung betrifft damit insbesondere die jüngste Altersgruppe, deren Anteil fünf Prozentpunkte niedriger liegt und die Gruppe der Ältesten, die fast vier Prozentpunkte über dem Wert in der deutschen Gesamtbevölkerung liegt. Ende 2007 leben ca. 211.000 Ausländerinnen und Ausländer in Mitteldeutschland, ihr Anteil an der Bevölkerung beträgt damit 2,4 Prozent und liegt so deutlich unter dem Ausländeranteil in Gesamtdeutschland.

\footnotetext{
${ }^{107}$ Die folgenden Daten entnehme ich den Statistiken der statistischen Landesämter Sachsens, Sachsen-Anhalts und Thüringens sowie dem Allbus 2006. Die teilweise unterschiedlichen Berichtszeiträume für einige Daten sowie die zeitliche Abweichung vom Untersuchungszeitraum dieser Studie sind insofern unschädlich, als dass nur die grobe Beschreibung des Raumes im Vordergrund steht, nicht aber ein eventueller statistischer Zusammenhang zwischen diesen Daten und den späteren Ergebnissen meiner Studie.

108 Wobei die Einwohnerdichte in den einzelnen Bundesländern sehr unterschiedlich ausfällt: Während in Sachsen durchschnittlich 228 Einwohner auf einem Quadratkilometer leben, sind es in Thüringen 141 und in Sachsen-Anhalt nur 117. Im Folgenden sollen die Unterschiede zwischen diesen drei Ländern jedoch nicht gesondert ausgewiesen werden, da es hier ja gerade um eine als gemeinsam gedachte mitteldeutsche Identität geht.

109 Wobei insgesamt nur $16 \%$ in kleinen Gemeinden unter 2.000 Einwohnern leben.
} 


\subsection{Sozial- und Erwerbsstruktur}

Ein monatliches Nettoeinkommen von unter 1.000 Euro haben 27,3 Prozent der mitteldeutschen Haushalte, 25,5 Prozent haben ein Einkommen zwischen 1.000 und 1.500 Euro, mit 31 Prozent machen Haushaltseinkommen zwischen 1.500 und 2.500 Euro die größte Gruppe aus und 16,2 Prozent der Haushalte haben monatlich über 2.500 Euro zur Verfügung.

4,1 Millionen Mitteldeutsche sind erwerbstätig, das entspricht einer Erwerbstätigenquote ${ }^{110}$ von 68 Prozent, die damit fast sieben Prozentpunkte unter dem Bundesdurchschnitt liegt. Im primären Wirtschaftssektor arbeiten 2,5 Prozent der mitteldeutschen Erwerbstätigen, 26,4 Prozent im sekundären und 71,1 Prozent im tertiären Sektor. Hier liegt Mitteldeutschland annähernd im Bundesdurchschnitt und weist weder in der Tendenz noch in der Grundstruktur deutliche Abweichungen auf.

\subsection{Religion}

Zwei Drittel der im Allbus befragten Mitteldeutschen gehören keiner Religion an, 4,1 Prozent sind römisch-katholisch, 26,1 Prozent evangelisch, 2,2 Prozent sind Angehörige einer evangelischen Freikirche, 0,7 Prozent sind Angehörige einer anderen christlichen Religion. Alle anderen Religionen machen jeweils unter ein Prozent aus.

\subsubsection{Stereotype - Vorurteile - Images}

Wie bereits in den Ausführungen zur Geschichte Mitteldeutschlands angedeutet wurde, dürfte die Periode der DDR sowohl für ein mitteldeutsches Selbstverständnis als auch für dessen Außenwahrnehmung von besonderer Bedeutung sein. Auf die Gegenwart übertragen bedeutet das eine speziell darauf bezogene Wahrnehmung von Unterschieden zwischen Ost- und Westdeutschland. Für Bilder über Mitteldeutschland und die Mitteldeutschen ergibt sich das Problem, dass ostdeutsche Stereotypien über Mitteldeutschland hinausgreifen, spezifisch sächsische, sachsen-anhaltinische und thüringische jedoch nur einen Teil Mitteldeutschlands betreffen. Dagegen kann eingewendet werden, dass Stereotypien ihrer Natur nach immer Verkürzungen darstellen. Das heißt aber nicht, dass sie daher beliebig projizierbar sind. Das wird etwa deutlich, wenn man das stereotype Bild vom ,gemütlichen Kaffeesachsen“ aufruft. Unabhängig davon, ob es in der Selbst- und Fremdwahrnehmung der Sachsen Unterschiede in dessen Bewertung gibt, ist es nicht auf Thüringer oder Sachsen-Anhaltiner erweiterbar, weil die Bezeichnung kulturhistorische Ursprünge hat, die auf das kursächsische Kernland verwei$\operatorname{sen}^{111}$ und der dort bereits früh im deutschen Raum verbreiteten Kaffeekultur. ${ }^{112}$ Daran wird

\footnotetext{
110 Anteil der Erwerbstätigen an der Bevölkerung zwischen 15 und 65 Jahren, Stand: Ende 2006.

111 Wie etwa die erste deutsche Kaffeehausordnung von 1697 oder das älteste Kaffeehaus Deutschlands „Zum arabischen Coffe Baum“ (1711) in Leipzig (vgl. Stadtgeschichtliches Museum Leipzig 2008). Ausführlich dokumentiert in Heise (1994).
} 
deutlich, dass es sich bei Bildern von und über Mitteldeutschland nicht einfach um die Agglomeration von Images seiner Einzelteile handeln kann. Das bedeutet aber auch nicht, dass die Wahrnehmung Mitteldeutschlands nicht dennoch von ihnen mitgeprägt wird. Eine deutlichere und alle Teile Mitteldeutschlands umfassendere Wahrnehmungsprägung dürfte aber von ostdeutschen Stereotypen ausgehen. Auf diese sei hier daher kurz eingegangen.

Spezifisch ostdeutsche Eigenarten wurden im medialen und öffentlichen Diskurs insbesondere im Hinblick auf Unterschiede geführt. Wissenschaftliche Untersuchungen zu diesen Unterschieden wiesen teilweise weitaus geringere Abweichungen von ost- und westdeutschen Eigenschaften aus, wurden aber bei weitem nicht so in die Öffentlichkeit kolportiert, wo stattdessen - den Bedingungen der Massenkommunikation folgend - die anders gelagerten Erwartungen des Publikums bedient wurden (vgl. Ahbe 2004: 17). Diese Zuschreibungen sind in erster Linie negativ besetzt, die Ostdeutschen erscheinen darin als den Westdeutschen gegenüber defizitär (vgl. Ahbe 2004: 17). Das liegt unter anderem daran, dass mit dem Verlauf des politisch-gesellschaftlichen Umbruchs im Osten Deutschlands Anpassungsleistungen von der Bevölkerung gefordert waren, die in vielerlei Hinsicht zu einem asymmetrischen Verhältnis zwischen Ost- und Westdeutschen geführt haben, da die Ostdeutschen die Lernenden und die Verwalteten waren, während die Westdeutschen als Kapitaleigner und Ausbilder erschienen (Ahbe 2004: 13). Unterschiede in den Wert- und Sinnvorstellungen wurden immer wieder auf Effekte der DDR-Sozialisation geschoben. Wissenschaftliche Untersuchungen zeigen jedoch, dass Einstellungen so unterschiedlich gar nicht sind und sich innerhalb von wenigen Jahren stark anglichen (vgl. Ahbe 2004: 13). ${ }^{113}$ Auch die häufig öffentlich gemachte These von der Beförderung fremdenfeindlicher und rechtsextremistischer Einstellungen durch die DDRSozialisation wurde durch ihre häufige Wiederholung nicht richtig: Wissenschaftlich belegbar ist sie nicht (vgl. Friedrich 2001). Die eigentlichen Unterschiede zeigen sich vielmehr im Bereich der Selbsteinschätzung und den darin zum Ausdruck kommenden Werthaltungen. So zeigt die Frage nach der subjektiven Schichteinstufung deutliche (und zeitlich relativ stabile) Unterschiede zwischen Ost- und Westdeutschen: Während 61 Prozent der Ostdeutschen sich der Unter- und Arbeiterschicht zuordnen und nur 37 Prozent der Mittelschicht, verorten sich 57 Prozent der Westdeutschen in der Mittel- und nur 29 Prozent der Unter- und Arbeiterschicht. Allerdings unterscheidet sich die reale soziale Schichtung nicht im gleichen Maße, wie es die Wahrnehmung der Befragten offenkundig tut (Ahbe 2004: 15, m. w. N.). Die Ursache für diese Unterschiede liegt denn auch sehr wahrscheinlich tatsächlich in der unterschiedlichen Sozialisation, da sowohl Ost- als auch Westdeutsche sich vornehmlich mit den Schichten identifizieren, die in ihren (früheren) Gesellschaften als maßgeblich und stilbildend galten (Ahbe 2004: 15). Hinzu kommen Unterschiede in den Anforderungen an die Politik und den Staat: „Das Demokratieverständnis der Ostdeutschen schließt neben politischen Rechten auch soziale mit ein [...]. Insbesondere schreiben die Ostdeutschen dem (Sozial-)Staat größere Verantwortlichkeit für soziale Gerechtigkeit und Absicherung der Menschen zu“ (Ahbe 2004: 14).

\footnotetext{
112 Ähnlich dürfte es sich auch mit regionalspezifischen Speisen wie der Thüringer Bratwurst verhalten. Hieran wird andererseits auch deutlich, welchen Stellenwert die Diskursivierung von Esskulturen nicht nur im Kontext nationaler Identität haben dürfte, wie Thomas gezeigt hat (vgl. Thomas 2003b: 296).

113 Untersucht von Thomas Gensicke anhand speyerischer Wertetypen über mehrere Jahre hinweg seit 1990, Nachweis bei Ahbe (2004: 13).
} 
Entsprechend verhält es sich mit der Zufriedenheit mit dem politischen System der Bundesrepublik, das in Deutschlands Osten eine abnehmende Zustimmung erfährt, ${ }^{114}$ während es in Westdeutschland gleichbleibend anerkannt wird (Ahbe 2004: 14).

Eher im Alltagshandeln relevante Stereotype haben ihre Ursachen schon deutlicher vermittelt in unterschiedlichen Sozialisationen:

„In Alltagsgesprächen oder bei einem Smalltalk neigen Ostdeutsche beispielsweise stärker dazu, über Mängel, Missstände oder auch eigene Probleme zu reden, während Westdeutsche lieber mit der Thematisierung von leichten und nichtigen Dingen das Gespräch eröffnen. In ihren jeweils eigenen Kulturen funktioniert das gut. Im Osten erzeugt man durch die ostdeutsche Art zu kommunizieren ,Nähe und Solidarität', man nimmt das Gegenüber als ,offen und leutselig ${ }^{6}$ wahr. Die Westdeutschen erzeugen auf ihre Art nicht minder entspannende ,positive Stimmung', die es erlaubt, sich gegenseitig als ,geistreich und diskret ${ }^{6}$ wahrzunehmen und zu inszenieren. Erst wenn Ost- und Westdeutsche gemeinsam auf die Anforderungen der Kommunikationssituation mit den jeweils in ihren eigenen Kulturen angemessenen Kommunikationsstilen reagieren wollen, kommt es zu Friktionen. Ostdeutsche beschweren sich über Westdeutsche, die ,oberflächlich und abweisend' seien, und diese wiederum nennen die Ostdeutschen, larmoyant und unersättlich““ (Ahbe 2004: 16, m. w. N.).

Den Verbreitungsmechanismen von Stereotypen einerseits und der Marktlogik der Massenmedien andererseits folgend, sind es schließlich bestimmte Eigenarten, die das Bild der Ostdeutschen bestimmen und in vielerlei Hinsicht von einer westdeutschen Sicht geprägt sind. ${ }^{115}$ „Demgemäß wird der ostdeutsche Habitus als steif, altmodisch, verklemmt, naiv, konfliktscheu, opportunistisch, larmoyant und immobil konstruiert“" (Ahbe 2004: 17, m. w. N.).

Im Rahmen dieser Studie kann es nicht darum gehen, die Unterschiede in der Ost-Westwahrnehmung herausgehoben zu thematisieren. Angesichts der hier wiedergegebenen deutlichen Befunde zur Präsenz ostdeutscher Stereotype im öffentlichen Diskurs kann aber auch nicht darüber hinweggegangen werden. $\mathrm{Da}$ es in dieser Arbeit aber vor allem um die medialen Grundlagen regionaler Gruppen-Konstruktionen geht (und nicht um ihre Wahrnehmung oder Wirkung), wird sich die entsprechende Fragestellung eher darauf konzentrieren, inwieweit DDR- und Ostdeutschland-spezifische Identifikationsangebote im Fernsehprogramm des MDR vorkommen und damit den Stereotypisierungen aus der Innensicht Nahrung geben.

\footnotetext{
${ }^{114}$ Von 1990 aus gesehen, als noch 77 Prozent damit zufrieden waren.

115 Was allerdings nicht verwundert, da Stereotype zum Großteil der sozialen Produktion „der Anderen“ geschuldet sind, die so die eigene Position festigen sollen.
} 


\subsubsection{Bayern}

\subsubsection{Empirische Merkmale Bayerns}

\subsection{Bevölkerungsstruktur ${ }^{116}$}

In Bayern leben Ende 2007 12,5 Millionen Menschen. Die prozentuale Verteilung auf Frauen und Männer entspricht der der deutschen Gesamtbevölkerung. Die Einwohnerdichte liegt bei 177,5 EW je Quadratkilometer. Sechs Prozent der Bayern leben in Städten mit über 500.000 Einwohnern und Einwohnerinnen und 11,8 Prozent in Städten mit 100.000 bis 500.000 EW. 22,1 Prozent bewohnen Städte mit 20.000 bis 100.000 EW, 32,2 Prozent solche mit 5.000 bis 20.000 EW und 27,7 Prozent leben in Gemeinden mit weniger als 5.000 EW. Damit wohnen in Bayern anteilsmäßig deutlich mehr Menschen in Landstädten als in Gesamtdeutschland, aber deutlich weniger (21 Prozentpunkte) als in Mitteldeutschland. Über die Hälfte der Bevölkerung lebt in Klein- und Mittelstädten, was in etwa der Verteilung in Gesamtdeutschland entspricht. In Großstädten leben dagegen anteilsmäßig weniger Einwohnerinnen und Einwohner als in Gesamtdeutschland und auch weniger als in Mitteldeutschland. Damit ergibt sich ein wenig eindeutiges Bild: Bezogen auf die kleinsten Gemeindegrößen hat Bayern ein weniger ausgeprägtes ländliches Profil als Mitteldeutschland und entspricht damit möglicherweise nicht einem verbreiteten Klischee. Andererseits widerspricht der im Vergleich zu Bayern größere Anteil mitteldeutscher Großstadtbewohnerinnen und Großstadtbewohner einer dahingehend eindeutigen Charakterisierung.

Hinsichtlich der Altersstruktur entspricht Bayern ziemlich genau dem gesamtdeutschen Bild: 20,3 Prozent unter 20-Jährige, 25,6 Prozent 20- bis 39-Jährige, 29,9 Prozent 40- bis 60-Jährige und 24,3 Prozent über 60-Jährige. Der Ausländeranteil liegt mit 9,5 Prozent geringfügig über dem Bundesdurchschnitt.

\subsection{Sozial- und Erwerbsstruktur}

Ein monatliches Haushaltsnettoeinkommen von unter 1.000 Euro haben 16,8 Prozent der bayerischen Haushalte, 17,4 Prozent liegen zwischen 1.000 und 1.500 Euro, 35,4 Prozent zwischen 1.500 und 2.500 Euro und 30,4 Prozent über 2.500 Euro. Damit unterscheiden sich die Einkommensstrukturen in den hier untersuchten Regionen teilweise deutlich: Während die mittlere Einkommensklasse von 1.500 bis 2.500 Euro sowohl in Bayern als auch in Mittel-

\footnotetext{
116 Die folgenden Daten entnehme ich den Statistiken des statistischen Landesamts Bayern sowie dem Allbus 2006. Die teilweise unterschiedlichen Berichtszeiträume für einige Daten sowie die zeitliche Abweichung vom Untersuchungszeitraum dieser Studie sind insofern unschädlich, als dass nur die grobe Beschreibung des Raumes im Vordergrund steht, nicht aber ein eventueller statistischer Zusammenhang zwischen diesen Daten und den späteren Ergebnissen meiner Studie.
} 
deutschland die größte Gruppe der Haushalte ausmacht, ist das Verhältnis bezüglich der höchsten und niedrigsten Einkommensklassen genau umgekehrt: In Bayern bildet die höchste Einkommensklasse den zweitgrößten Anteil der Haushalte, in Mitteldeutschland die niedrigste.

Rund 6,5 Millionen Bayern sind erwerbstätig, was einer Erwerbstätigenquote ${ }^{117}$ von 79 Prozent entspricht. Damit liegt Bayern hinsichtlich der Erwerbstätigenquote über dem Bundesdurchschnitt. Auf die einzelnen Wirtschaftsbereiche verteilt, sind 2,9 Prozent der erwerbstätigen Bayern im primären Wirtschaftssektor beschäftigt, 28,9 Prozent im sekundären und 68,2 Prozent im tertiären Wirtschaftssektor. Die Abweichungen vom Bundesdurchschnitt sind gering: Anteilsmäßig arbeiten etwas weniger Bayern im tertiären Sektor als im Bundesdurchschnitt (4,1 Prozentpunkte) und wenige mehr im sekundären Sektor (3,4 Prozentpunkte).

\subsection{Religion}

14,9 Prozent der Bayern gehören keiner Religion an, 58,6 Prozent sind römisch-katholisch, 16,2 Prozent evangelisch, vier Prozent sind islamisch, 2,3 Prozent gehören einer evangelischfreikirchlichen und 5,6 Prozent einer anderen christlichen Religion an. Die Angehörigen weiterer Religionen sind jeweils mit weniger als ein Prozent in der bayerischen Bevölkerung vertreten.

\subsubsection{Geschichte}

Der Name Bayerns ${ }^{118}$ geht zurück auf den germanischen Stamm der Bajuwaren, der erstmals in Quellen des 6. Jahrhunderts erwähnt wird, also eher am Ende der Völkerwanderungszeit (Kraus 1983: 13). Ansässig war der Stamm zwischen Donau und Alpen (vgl. Hartmann 1989: 42, März 2008: 59), welches Gebiet demnach als der eigentliche Kern historisch-bayerischer Identität angesehen werden kann (und, wie noch zu zeigen sein wird, das Bild bis heute maßgeblich prägt, vgl. auch Prinz 1997: 274, Hartmann 1989: 42). „Das Königreich Bayern umfasste drei große historische Integrationszonen: die fränkische (die späteren Regierungsbezirke Ober-, Mittel-, und Unterfranken), die schwäbische (der heutige Regierungsbezirk Schwaben) und die altbayerische (in den Grenzen der heutigen Regierungsbezirke Ober- und Niederbayern sowie Oberpfalz)“ (Stoll 2001: 23). In seiner heutigen Gestalt ist Bayern ein Produkt der Umgestaltungen der deutschen Territorien durch Napoleon zu Beginn des 19. Jahrhunderts (Prinz 1997: 13). Dieses territoriale Produkt war nach dem Wiener Kongress, der einige der territorialen napoleonischen Veränderungen wieder revidierte, die damalige Summe des bayerischen Kernlandes und der Bistümer Passau, Eichstätt, Würzburg und Bamberg, die Fürsten-

\footnotetext{
117 Anteil der Erwerbstätigen an der Bevölkerung zwischen 15 und 65 Jahren.

118 Die Schreibweise mit „y“ wurde erst 1825 durch Ludwig I. von Bayern eingeführt und illustriert dessen Verehrung für das alte Griechenland. Da sie heute die gebräuchliche Schreibweise ist, wird sie im Folgenden auch für davor liegende zeitliche Abschnitte benutzt, als die Bayern noch Baiern waren. Eine Ausnahme bildet die linguistische Bezeichnung des Dialekts, der „Bairisch“ heißt.
} 
tümer Ansbach und Bayreuth, sowie einer Anzahl freier Reichsstädte mit teilweise erheblichen umliegenden Territorien (Nürnberg, Augsburg, Regensburg, Kempten im Allgäu, Kaufbeuren, Lindau, Memmingen, Dinkelsbühl, Nördlingen, Rothenburg ob der Tauber, Schweinfurt) sowie eine Anzahl kleinerer Städte und Territorien zwischen Lech und Iller (vgl. Prinz 1997: 275,März 2008: 69). Damals wurden nicht nur bis dahin nicht zu Bayern gehörende „Stammesgebiete“ (Franken, Pfalz, Schwaben) integriert, ${ }^{119}$ sondern auch Gebiete, die seit der Reformation und dem Dreißigjährigen Krieg eine konfessionell zum bayerischen Stammland andere Entwicklung genommen hatten (vgl. März 2008: 60). Insbesondere weite Teile Frankens waren seither evangelisch. Die nach dem Dreißigjährigen Krieg mit dem Westfälischen Frieden von 1648 gezogenen Grenzen innerhalb des Deutschen Reichs hatten diese konfessionellen Grenzen befestigt (Kraus 1983: 252). Sie lagen damals jedoch noch außerhalb des Gebietes ds späteren Königreichs Bayern. ${ }^{120}$

In den verschiedenen historischen Überblicken fällt auf, dass sowohl dem Mittelalter als auch der Zeit bis zur Begründung des Königreichs Bayern relativ viel Raum gegeben wird. Darin spielen verschiedene dynastische Entwicklungen eine große Rolle sowie kirchliche Entwicklungen, da es mit den Hochstiften mit ihren Fürstbischöfen eine Anzahl kleinerer Territorien gab, in denen das kirchliche Amt auch weltliche Herrschaft bedeutete.

1818 wurde eine bayerische Verfassung frühkonstitutionellen Typs erlassen, die eine gesamtbayerische Integrationsleistung insbesondere im Hinblick auf die fränkischen und pfälzischen Landes- und Bevölkerungsteile hin leisten sollte (März 2008: 71). Unter König Ludwig I. wurde in Bayern eine dezidiert eigenstaatliche Politik verfolgt. Sie setzte stark auf antifranzösisches Nationalbewusstsein und wollte unter anderem durch eine sehr kostspielige Kunstpolitik eigene bayerische Akzente setzen, indem München zu einer gegenüber Berlin konkurrenzfähigen Metropole ausgebaut wurde (März 2008: 72). Dies wird nicht zuletzt als Kompensation des fehlenden Großmachtstatus gegenüber Österreich im Süden und Preußen im Norden gewertet (März 2008: 72). Bayerns Sonderstellung in der weiteren deutschen Entwicklung ergab sich schließlich wohl aus wechselnder Parteinahme zwischen Österreich und Preußen hinsichtlich der klein- und großdeutschen Lösung. Nach Ludwigs Abdankung im Zuge der 1848er Revolution war unter den Nachfolgern Max II. und ab 1864 unter Ludwig II. Bayerns Politik bis in die Gründungsphase des Deutschen Reichs 1870/71 durch eine größere Nähe zu Österreich geprägt. Es wurde eine großdeutsche Lösung eher konföderalen Charakters verfolgt, wobei Bayern aber eine durchaus exponierte Stellung zwischen den beiden Großmächten anstrebte (März 2008: 74). Mit dem Ende des Deutschen Bundes 1866 durch den Sieg Preußens über Österreich (an dessen Seite Bayern gegen Preußen gekämpft hatte) war Bayern durch ein Bündnis sowohl militärisch als auch ökonomisch an Preußen gebunden. Mit dem Versailler Hauptvertrag von 1870 trat Bayern schließlich nach dem deutsch-französischen Krieg in das 1871 proklamierte deutsche Kaiserreich ein (März 2008: 74, vgl. Bosl 1980: 173).

\footnotetext{
${ }^{119}$ Deren bis dahin in der Geschichtswissenschaft als eigenständig zu betrachtende Entwicklung illustriert etwa die Gliederung von Hartmann (1989), der bis zum Beginn der Phase des Königreichs Bayern um 1800 alle Zeitabschnitte für den bayerischen, ostschwäbischen und fränkischen Raum gesondert betrachtet.

${ }^{120}$ Maximilian I. war als einziger deutscher Fürst mit territorialen Gewinnen für das Kurfürstentum Bayern aus dem Krieg hervorgegangen (Kraus 1983: 253).
} 
Dessen Konstruktion gewährte Bayern zahlreiche Sonderrechte hinsichtlich des kulturellen Eigenlebens, gewährte zudem den Fortbestand einer eigenen Armee ${ }^{121}$ und beließ Post- und Eisenbahnwesen in bayerischer Eigenverantwortlichkeit (März 2008: 75).

In dieser historisch relativ kurz zurückliegenden Entwicklung, welche die entscheidende territorial-integrative Entwicklung Bayerns als souveränem Staat sowie die kulturelle Behauptung dieser Selbstständigkeit gegenüber dem bzw. innerhalb des Deutschen Kaiserreichs enthält, mag man die Ursprünge der bis heute immer wieder betonten bayerischen Eigenständigkeit erblicken. Diese zeigte sich jedoch auch schon in der Weimarer Republik: Anfang der 1920er Jahre stand Bayern für eine rechtsgerichtete föderal-reaktionäre Politik, die sich gegen den demokratischen Staat von Weimar richtete, und eine Vielzahl noch weiter rechts stehender Gruppierungen bildete schließlich den Nährboden für den Hitler-Ludendorff-Putsch 1923 (vgl. März 2008: 79). Die weiteren Jahre der Weimarer Republik standen im Zeichen einer bürgerlich-konservativen Politik, die um die Rückgewinnung von noch im Kaiserreich verbürgten föderalen Positionen bemüht war sowie die Nähe zur katholischen Kirche suchte und betonte (März 2008: 80). Auf Parteienebene war die bayerische Sonderrolle in der Bayerischen Volkspartei manifest, die sich 1918 vom unitaristischer eingestellten Zentrum gelöst hatte, für eine föderale Politik stand und auf Reichsebene als Schwesterpartei des Zentrums agierte, freilich unter Betonung bayerischer Eigeninteressen (vgl. März 2008: 80). Diese deutliche Parallele zur heutigen deutschen Parteienlandschaft ist sicher kein Zufall.

Im Dritten Reich wurden Bayerns politische Privilegien beseitigt und das Land stand unter dem politisch wie kulturell gleichgeschalteten Einfluss der Nazidiktatur, wobei in Bayern insbesondere ideologisch-rituelle Funktionen des totalitär-pseudoreligiösen Selbstverständnisses der Nationalsozialisten Platz griffen (März 2008: 84). Nürnberg war die Stadt der Reichsparteitage wie auch der Rassengesetze, München beherbergte den administrativen Parteiapparat der NSDAP und diente auch der Darstellung des nationalsozialistischen Kunst- und Kulturverständnisses (März 2008: 84). ${ }^{122}$

Nach dem Zweiten Weltkrieg zeigte sich die Beharrlichkeit Bayerns hinsichtlich des eigenständigen Sonderverständnisses bereits im Entwurf der bayerischen Verfassung 1946. Darin fanden sich die etatistischen Traditionen unter anderem darin wieder, dass ein sich selbst genügendes Staatswesen etabliert werden sollte, das in der Institution eines bayerischen Staatspräsidenten gipfelte, die Zugehörigkeit zu einem künftigen deutschen Bundesstaat fakultativ gemacht hätte und eine bayerische Staatsangehörigkeit schaffen wollte. Die amerikanische Besatzungsmacht strich die beiden letzteren Forderungen. Die Einführung des Staatspräsidentenamts wurde dagegen durch die verfassungsgebende Versammlung (wenn auch knapp) abgelehnt (vgl. März 2008: 88, Bosl 1980: 193).

${ }^{121}$ Noch im Ersten Weltkrieg traten letztmals eigene bayerische Streitkräfte in eigener geschlossener Formation in Erscheinung (März 2008: 76).

122 Siehe „Haus der Deutschen Kunst“, das mit der Ausstellung „Entartete Kunst“ eröffnet wurde sowie dem zur Kultstätte nationalsozialistischer „Heldenverehrung“ umgestalteten Königsplatz. 
„Während andere Länder der späteren Bundesrepublik 1945/46 besatzungspolitische Neubildungen waren und vor neuen Integrationsproblemen standen, konnte im zweiten Freistaat Bayern auf einem breiten und tief verankerten historischen Fundament mit dem Wiederaufbau und der Errichtung einer demokratischen Republik begonnen werden. Die weitgehende territoriale Kontinuität über die Zäsur des ,Dritten Reiches' hinweg bildete das entscheidende Fundament für ein ungebrochenes bayerisches Staatsbewusstsein, das sich vor allem in der Betonung der bayerischen Eigenstaatlichkeit und einer Führungsrolle bei der Artikulation föderalistischer Positionen innerhalb Deutschlands manifestierte“ (Stoll 2001: 21).

Insofern erscheint insbesondere die relativ kurze und kurz zurück liegende Geschichte des Königreichs Bayern mit seiner Integrationspolitik für die verschiedenen Landesteile als prägend für die bayerische Identität, die, im Bewusstsein einer gewissen Eigenständigkeit stehend, auch immer selbstbewusst nach außen vermittelt wird.

In der weiteren (politischen) Geschichte der Bundesrepublik nahm Bayern immer wieder eine herausgehobene Position ein, ${ }^{123}$ wobei es sich spätestens ab den 1970er Jahren auch auf eine wirtschaftlich deutlich erstarkte Stellung berufen konnte (März 2008: 94).

Insgesamt ist vereinfachend anzunehmen: Alle zwischen stammesgeschichtlich unterschiedlich begründeten Gebieten bestehenden „innerbayerischen“ Abgrenzungsbemühungen (wie etwa Betonungen fränkischer Besonderheit und Eigenständigkeit) leiten sich aus der Zeit vor 1800 ab. Die integrierenden Bemühungen lassen sich dagegen auf das Königreich Bayern sowie auf dessen Sonderstellung im Deutschen Kaiserreich beziehen. Das betrifft vor allem die heute nach außen hin als bayerische Sonderstellung innerhalb der Bundesrepublik wahrgenommenen Tendenzen (etwa manifestiert in der Bezeichnung „Freistaat“, die wenigstens bis 1990 in der BRD singulär war, wenngleich sich daraus keine rechtliche Sonderstellung begründet).

\subsubsection{Stereotypen - Vorurteile - Images}

Bayern ist, wie wahrscheinlich kein anderes Bundesland bzw. keine andere deutsche Region, mit einer Vielzahl stereotyper Zuschreibungen, Bilder und Vorstellungen einer reichhaltigen Ikonographie verbunden. ${ }^{124}$ Ohne an dieser Stelle entscheiden zu können, ob Fremdzuschreibungen oder Selbstklischierungen daran den größeren Anteil haben, ist doch auffällig, dass Heterostereotype auf eine ausgeprägte Selbstinszenierung bayerischer Identitätssymbolik treffen, die in Deutschland ihresgleichen vergeblich sucht. Insbesondere folkloristische Inszenierungen bayerischer Lebensart erscheinen hierfür als auffälliges Beispiel, etwa wenn beim Oktoberfest „mit dem traditionsreichen Wies'n-Einzug der Festwirte, mit Trachtengruppen und Blasmusik vor Tausenden von Zuschauern auf der Straße und Hunderttausenden vor den

\footnotetext{
${ }^{123}$ Wofür insbesondere Franz Josef Strauß als exemplarisch gelten kann, der es einerseits 1976 im Kreuther Trennungsbeschluss über die Bundestagsfraktionsgemeinschaft der Schwesternparteien CDU und CSU auf einen (verlorenen) Machtkampf ankommen ließ oder als CSU-Vorsitzender eine Verfassungsklage der bayerischen Landesregierung gegen den Grundlagenvertrag der BRD mit der DDR initiierte (ebenfalls erfolglos).

${ }^{124} \mathrm{Zu}$ diesem Schluss kommt auch Gockerell (1974: 303), die eine erstaunliche Konstanz der Wahrnehmung einer „Andersartigkeit“ der Bayern v. a. in der Reiseliteratur feststellt.
} 
Fernsehbildschirmen Heimatgefühl und Verwurzelung [demonstriert]“ werden (Stoll 2001: 20). ${ }^{125}$

Derartige Selbstdarstellung hat in Bayern durchaus Tradition und ist auch politisch gewollt. Die staatsbayerische Identität als kollektives Landesbewusstsein wurde insbesondere nach 1945 von bayerischer Regierungsseite zu festigen gesucht, unter anderem, weil sie sich in den ersten Nachkriegsjahren auch partikularistischen Strömungen in Franken und Schwaben gegenüber sah (Stoll 2001: 37). So wurden in der Vergangenheit etwa eigene staatliche Hoheitszeichen etabliert und durchgesetzt, wie das Staatswappen, der bayerische Verdienstorden oder die Bayernhymne ${ }^{126}$ (vgl. hierzu ausführlich Stoll 2001: 34).

Der Fundus folkloristischer und traditioneller Symbole ist in verschiedenen auch alltäglichen Lebensbereichen fest verankert: „Kleidung (Tracht), Nahrung (Weißwurst, Bier), Unterhaltung (Blasmusik, Oktoberfest), Sprache (Dialekt), Herrschaft (Landesfarben, Ludwig II., Strauß), Sehenswürdigkeiten (Neuschwanstein), Natur (grüne Wiesen, weiß-blauer Himmel, Kühe, Starnberger See) [...]“ (Wolf 2005a: 130). Wobei Wolf diese Aufzählung einer bewusst auf bayerische Stereotype abzielenden Grafik aus dem SZ-Jugendmagazin „Jetzt“ entnimmt. Dabei entspricht es dem Wesen von stereotyper Verkürzung, dass diese Aufzählung sowohl vollständig als auch offen erscheint: Die (durchaus auch klischeehaften) Wahrnehmungsstrukturen bayerischer Identität sind symbolhaft und verdichtet zusammengestellt und gleichzeitig sind die Symbolfelder noch offen für Ergänzungen (z. B. Nahrung: Brezn; Sehenswürdigkeiten: Wallfahrtskapelle St. Bartholomä, Münchner Frauenkirche, Walhalla; Natur: Königssee, Zugspitze, Watzmann, Unterhaltung: Schuhplatteln, Jodeln usf.). Es handelt sich daher um eine stereotype Zusammenstellung von Images. ${ }^{127}$

Derartige stereotype Stilisierungen betreffen sowohl Bayern als Land bzw. Region als auch seine Bewohner in Form von Typisierungen. Insbesondere in Reiseberichten und Literatur des 19. Jahrhunderts trifft man auf DEN Bayern als Summe zugeschriebener Charaktereigenschaften hauptsächlich archaischer und urtümlicher Couleur (vgl. Moser 1999: 106 mit Beispielen).

„Dabei fällt der Abstand dieses Bayernbildes von der viel differenzierteren Wirklichkeit nur deshalb nicht ins Auge, weil die Selbstdarstellung ,bayerischen Wesens' bei Gelegenheiten wie dem Münchner Oktoberfest oder bei offiziellen Anlässen gerade durch den Rückgriff auf jene Klischees erfolgt, die Einzelphänomene verschiedener Entwicklungsstadien und landschaftlicher Gegebenheiten zu einem stereotypen Gesamtbild vereinigt haben, mit dem man sich in trotziger ,Mir-san-mir'-Haltung zu identifizieren sucht. Was die Reisebeschreibungen des frühen 19. Jahrhunderts als Charakterzug ,des' und ,der' Bayern hervorkehren - das Naturmenschen- und Kraftprotzentum, das heitere Temperament, das sich durch Singen und Jodeln bei der Arbeit erweise, das naive und ungenierte Geschlechtsleben, der Bierdurst und die Rauflust

\footnotetext{
${ }^{125}$ Eine ähnlich stark ausgeprägte Betonung eines saisonalen traditionsbehafteten Volksfestes wie dem Oktoberfest mag man im Kölner oder rheinischen Karneval erblicken. Inwieweit dieser ähnlich stark symbolisch aufgeladen ist, vermag ich nicht zu entscheiden. Meiner Meinung nach handelt es sich aber eher um eine Inszenierung einer bestimmten (regional verwurzelt gedachten) Charaktereigenschaft (Frohsinn) und weniger um eine umfassende stereotyp verdichtete Ausstellung von Lebensart, Tradition und saisonal nicht begrenzter Brauchtumspflege.

${ }^{126}$ Die anders als die erst genannten jedoch nicht in die Verfassung verankert ist.

${ }^{127}$ Siehe auch Abschnitt 2.4.1.3 Stereotype - Vorurteile - Images (S. 49ff.).
} 
-, wird von manchen Bayern bis zur Gegenwart als Abbild der Wirklichkeit betrachtet, gepflegt und schon den Kindern als Idealvorstellung eingeprägt. Der Tourismus zeigt hier seine langfristigen Auswirkungen“ (Moser 1999: 106).

Doch nicht nur der Fremdenverkehr profitiert von diesem Image. Klischeebilder werden auch von politischer Seite instrumentalisiert, um eine besondere Verwurzelung bayerischer Parteien oder Landespolitikerinnen und Landespolitiker zu demonstrieren. Sie werden „auch verwendet, wenn über ,Lebensart' und ,Mentalität‘ seiner [Bayerns, Anm. H. I.] Bevölkerung oder über die ,besondere Lebensqualität ${ }^{`}$ in diesem natürlich-geographischen Raum und politischhistorischen Territorium berichtet wird [durch die Presse, hier: SZ, Anm. H. I.]“ (Wolf 2005a: 130). Besonders interessant ist hierbei, dass in der Vergangenheit gerade die Bezugnahme auf bayerische Tradition, Verwurzelung und Eigenständigkeit mit landespolitischen Erfolgsgeschichten verknüpft ist. Bei der Landtagswahl 1950 konnte die damals neue Bayernpartei ${ }^{128}$ im ersten Anlauf 17,9 Prozent erringen. Die jahrelang erfolgreiche Strategie der CSU mit weißblauer Symbolik und der Stärkung eines integrativen gesamtbayerischen Bewusstseins wurde zur Landtagswahl 1978 von der SPD ${ }^{129}$ kopiert, die damit ein weiteres Absinken des eigenen Stimmanteils verhindern und eine kleine Trendwende zu ihren Gunsten als Teilerfolg verbuchen konnte (vgl. Stoll 2001: 31 m. w. N.). Die erfolgreiche Besetzung des Bayerngedankens war der CSU selbst erst in den 1950er/1960er Jahren gelungen (Stoll 2001: 29). ${ }^{130}$

Hierin zeigt sich die Mehrdimensionalität und Zirkularität kollektiver Identitätszuschreibungen: Die starke Identifikation mit dem und die Besetzung des Bayerngedankens ist ein wichtiges Fundament der traditionellen Stärke der CSU in Bayern. Weil die starke Betonung des „Bayerischen“ durch die CSU zu ihrem lang anhaltenden politischen Erfolg beigetragen hat, wird sie auf Bundesebene als genuin bayerische Interessenvertretung wahrgenommen. Ihre Inszenierungsstrategien bestärken dabei stereotype Wahrnehmungen. Diese Wahrnehmung bestärkt ihrerseits den Eigenständigkeits- bzw. Besonderheitsgedanken bayerischer Staatsidentität, den es zu verteidigen gilt und dessen Berücksichtigung im politischen Programm so zum wichtigen Erfolgsfaktor wird.

In der Entwicklung bayerischer Stereotype (sowohl Hetero- als auch Autostereotype) fällt auf, dass sie relativ deutliche Gegenbilder zu Vorstellungen von preußischen bzw. norddeutschen Eigenschaften und Images sind. Das zeigen etwa entsprechende Reiseberichte aus dem 19. Jahrhundert (aber auch deutlich früherer Zeit), in denen das bayerische Naturmenschentum und die agrarische Verwurzelung, aber auch der Katholizismus betont werden, die dem preuBischen Sittenkodex, von Handel geprägter Wirtschaft und dem Protestantismus gegenüber-

\footnotetext{
${ }^{128}$ Die Bayernpartei hat etwa den politischen Aschermittwoch ins Leben gerufen, der heute eine fixe Institution im politischen Leben nicht nur Bayerns, sondern ganz Deutschlands ist.

${ }^{129}$ Die SPD hatte in der Vergangenheit sogar partikularistischen Interessen in Franken und Schwaben nahe gestanden (vgl. Stoll 2001: 25). Interessant ist dabei auch, dass noch zu Landtagswahlen der 1950er und 1960er Jahre die Wahlgeographie stark an die alten dynastisch-territorialen Räume erinnerte, da es der CSU erst in den 1970ern gelang, in den fränkisch-protestantischen Raum vorzudringen (Stoll 2001: 30, m.w.N.).

${ }^{130}$ Während die Bayernpartei aber zunächst für eine tatsächliche Eigenstaatlichkeit eingetreten war, bemühte sich die CSU stärker um den Föderalismusgedanken in der Bundesrepublik, der die Eigenständigkeit Bayerns als Teil Deutschlands zum Maßstab hatte.
} 
stehen (Beispiele mit weiteren Nachweisen bei Moser 1999: 101). Stark vereinfacht handelt es sich dabei um ein Gegensatzpaar (preußischer) Verstandes- und (bayerischer) Gefühlskultur (vgl. Moser 1999: 103). Teilweise beruhen die Heterostereotype in der Vergangenheit auch auf romantischen Verklärungen, die eine natürliche Urwüchsigkeit bayerischer Landschaften nicht nur als Gegenbild, sondern als bereichernde Ergänzung zum städtisch geprägten Preußen begreifen (vgl. Moser 1999: 104). ${ }^{131}$ Gemäß den Entwicklungslogiken von Vorurteilen und Stereotypen ist deshalb auch heute noch das Image Bayerns nicht unwesentlich von seiner Naturlandschaft geprägt, ganz im Gegensatz etwa zu Berlin und Brandenburg (die man heute wohl am ehesten als Nachfolger Preußens ansehen mag) oder Mitteldeutschland, die weder deutlich als Industrie- noch als Naturräume ${ }^{132}$ wahrgenommen werden. Auch in der Beständigkeit dieses Bildes mag sich die touristische Vermarktung Bayerns als Urlaubsregion niederschlagen. Wie sich das Fernsehen affirmativ an der Gestaltung solcher Stereotype beteiligt, wird in der Studie zu klären sein.

Für die Analyse des Fernsehprogramms des Bayerischen Rundfunks ${ }^{133}$ ergibt sich die Frage, wie autostereotype Darstellungen oder zumindest dafür förderliche Inhalte zu berücksichtigen sind. Da es nicht darum geht, diese auf interpretativem Weg aus einzelnen Darstellungen abzuleiten, kommt dafür vor allem eine themenzentrierte Kategorisierung infrage. Das bedeutet aber gleichzeitig, dass nicht mit einer einfachen Abfrage „Beitrag ist stereotyp: ja/nein“ operiert werden kann. Vielmehr soll erst im Rahmen der Ergebnis-Interpretation auf möglicherweise stereotype Programminhalte eingegangen werden. So wird auch vermieden, mittels einer Kategorisierung, die gezielt nach Stereotypien „fahndet“, Artefakte zu produzieren.

\footnotetext{
${ }^{131}$ Nicht ganz unwesentlich für diese Entwicklung mag auch sein, dass die preußische Alpen- und Bayernbegeisterung im 19. Jahrhundert von der „Bildungsschicht“ ausgegangen war, wofür Moser zahlreiche Belege zusammenstellt, die nicht zuletzt in die Literatur der deutschen Klassik zurückreichen (Moser 1999: 110).

132 Bliebe als dritte Alternative noch der Begriff „Kulturraum“, der mir in diesem Zusammenhang jedoch zu unspezifisch erscheint. Dass insbesondere Mitteldeutschland ein vor allem kulturräumlich zu verstehendes Konstrukt ist, dürfte aus den obigen Ausführungen deutlich werden.

133 Und vice versa auch für alle anderen zu untersuchenden Programme, da hier jeweils die gleichen Kategorien anzulegen sind.
} 


\section{Zwischenfazit I}

Nation und Region lassen sich als Erscheinungsformen sozialer Identität beschreiben. Das heißt, sie sind nicht naturgegeben, sondern entstehen erst durch gesellschaftliche Aushandlungsprozesse. Sie gewinnen deshalb ihre Relevanz erst durch das Ausmaß, in dem sich auf sie berufen wird, um das Zusammenleben zu organisieren. Sie unterscheiden sich dabei nicht nur in ihrem jeweiligen Ausmaß, sondern auch hinsichtlich der Aspekte, auf die sie sich beziehen und aus denen sie erwachsen. Das betrifft zum Beispiel die Geschichte. Sie ist für beide eine gleichermaßen relevante Bezugsgröße. Der Unterschied betrifft aber die konkrete Relevanz der zeitlichen Abschnitte, auf die eine jeweilige soziale Identität verweist. Deshalb kommen für subnationale Räume (Regionen) teilweise andere historische Epochen als Bezugszeiträume in Betracht als für die Nation als Ganzes. Für Deutschland ist der Zeitraum von ca. 1920 bis 1950 von besonderer Bedeutung. Auch wenn dies für das heutige Österreich ebenfalls zutrifft, so ist dies nicht die Zeitepoche, auf die sich für das nationale Selbstverständnis hauptsächlich berufen wird. ${ }^{134}$ Das trifft eher auf die Zeit der k.u.k-Monarchie zu. Die bayerische Identität bezieht sich inhaltlich vor allem auf das Königreich Bayern, da dieses erst jene räumliche Integration des Gebiets herstellte, die sich zum Teil im heutigen Bundesland widerspiegelt. Für Mitteldeutschland ist die Benennung einer entsprechenden Epoche, auf die sich eine genuin mitteldeutsche Identität berufen könnte, deutlich schwieriger. Hier kommen eher solche Zeitabschnitte in Betracht, die für das heutige Gebiet der drei Bundesländer eine größere gemeinsame Bedeutung haben, als für die Mehrzahl der anderen deutschen Regionen. Das trifft in der jüngeren Vergangenheit auf die DDR-Zeit zu. In der weiter zurückliegenden Historie auf die Zeit der Reformation und zwar in dem Sinne, dass in Mitteldeutschland die Hauptwirkungsstätten Martin Luthers liegen (Wittenberg, Eisenach, Eisleben etc.).

Auch die Sprache ist in concreto von unterschiedlicher Bedeutung für regionale und nationale Identität. In der Ausformung als Dialekt verweist sie nach innen und damit auf subnationale Größen, also Regionen. Sie kann je nach Kontext sowohl Abgrenzung bedeuten als auch Ausdruck einer Vielfalt sein, die zusammengehört, solange es sich um dieselbe Sprache handelt.

Die aufgeworfene Frage nach der Offenheit der Konzepte von Nation und Region - und damit der Relevanz universalistischer Codes ${ }^{135}$ - lässt sich kurz so zusammenfassen: Die Region ist ein weniger offenes Konzept als die Nation, weil sie unverbrüchlich mit einem geographischen Raum assoziiert ist. Für Nationen ist das heute nur insofern der Fall, als dass sie sich

\footnotetext{
134 Wobei klarstellend anzumerken ist, dass bezüglich Deutschlands ein „sich Berufen“ auf die Zeit zwischen 1933 bis 1945 nicht im Sinne historischer Kontinuität zu verstehen ist. Doch auch in besonders deutlicher Distanzierung von Sachverhalten liegt letztlich eine enge inhaltliche Verbindung, wenn auch „mit umgekehrten Vorzeichen".
}

135 Vgl. S. 16. 
seit spätestens dem 19. Jahrhundert in Staaten, die ein Territorium aufweisen, manifestieren. Sie beruhen aber nicht auf dieser spezifischen erdräumlichen Ausformung. Für diese Arbeit heißt das, dass universalistische Codes nicht in das Untersuchungsdesign einfließen können, da sie - wenn überhaupt - nur für die Aspekte der Nation, aber nicht die Region in Betracht kommen. Eine systematische Ungleichbehandlung der Untersuchungsgegenstände würde aber Unterschiede bereits vorwegnehmen und damit vielleicht erst in den Ergebnissen hervorbringen.

Sowohl nationale als auch regionale Identität ist begrifflich nicht ausschließlich auf den sozialpsychologischen Bedeutungshorizont beschränkt. Vielmehr spielt auch der Aspekt der Identifizierbarkeit eine Rolle, also genauer gesagt der Differenz von anderen Nationen und Regionen. Aus dieser Bedeutung des Begriffs ergibt sich für die Arbeit die simple Frage: Ist die Nation bzw. Region in einem nationalen bzw. regionalen Programm erkennbar? Die weniger simple Frage lautet: Wodurch wird sie darin erkennbar? Hierfür dürften empirische Merkmale eine Rolle spielen, da eine Bevölkerungsstruktur dann nicht im Programm wieder erkennbar wäre, wenn darin zum Beispiel ausschließlich Politikerinnen und Politiker zu Wort kämen. Dann übernähme das Fernsehen lediglich politische Repräsentationsmechanismen. 


\section{Die Rolle der Massenmedien bei der Konstruktion sozialer und räumlicher Identität}

Im bisherigen Gang der Darstellung wurde stillschweigend davon ausgegangen, dass Massenmedien bzw. speziell das Fernsehen für die sozialen Konstruktionen von Nation und Region eine zumindest (mit-)prägende Bedeutung haben. Dieser Aspekt soll im Folgenden vertieft werden. Daran anschließend wird die Möglichkeit fokussiert, dieser Bedeutung anhand der Medien- bzw. speziell TV-Programminhalte nachzugehen. Hier ist es zunächst notwendig, ein grundlegendes theoretisches Verständnis der gesellschaftlichen Rolle der Massenmedien zu entwickeln, vor dessen Folie die inhaltlichen Leistungen der zu untersuchenden Medien später analysiert werden können.

\subsection{Massenkommunikation und Raumvorstellung}

Die Rolle der Massenmedien ist schon in historischer Hinsicht eng an die Entstehung von Nationalstaaten geknüpft. Diese Beziehung betrifft vor allem räumliche Vorstellungen sowie die Verbundenheit mit anderen Menschen über den lokalen und selbsterfahrbaren Rahmen hinaus. Massenmedien ermöglichen darüber hinaus eine Synchronisierung der Interessen, auf denen die Nation beruht.

\footnotetext{
„Mit ihrer Hilfe [der Massenmedien, H. I.] konnten Ideologien für die Massen einerseits standardisiert, homogenisiert und umgeformt und andererseits natürlich von Privatinteressen und Regierungen für die Zwecke einer gezielten Propaganda eingesetzt werden. [...] Dennoch war eine gezielte Propaganda zweifellos weniger ausschlaggebend als die Fähigkeit der Massenmedien, letztlich nationale Symbole zu einem Bestandteil des Lebens jedes einzelnen zu machen und auf diese Weise die Trennung zwischen dem Privatbereich und der lokalen Sphäre, in der die meisten Bürger normalerweise lebten, einerseits und der öffentlichen und nationalen Sphäre andererseits aufzuheben“ (Hobsbawm/Rennert 2005: 167).
}

Massenkommunikation schafft also einen öffentlichen Raum, der für die Menschen nur auf Grund der Vorstellung relevant wird, dass auch andere Menschen die darin vorkommenden Inhalte wahrnehmen. Aus den vorstehenden Darlegungen ergibt sich somit auch eine begriffliche Nähe zur Nation. Im Fall der Region wurde expliziert, dass sie begrifflich stärker an einen auch physisch vorhandenen Raum bzw. eine Vorstellung davon gebunden ist. Zwischen Massenkommunikation und Raumvorstellungen bestehen wechselseitige funktionale Beziehungen. Diese sind nach Ronneberger unter verschiedene Gesichtspunkte zu unterteilen: 
„1. Kulturräume ${ }^{136}$ als Resultanten einer Vielzahl von strukturellen Gegebenheiten und kulturprägenden Handlungen und Verhaltensformen erweisen sich als Stifter und Stabilisatoren der öffentlichen Medienkommunikation.

2. Die Verbreitungsgebiete von Medienkommunikaten korrespondieren mit Kulturräumen.

3. Die Medien, insbesondere die Tagespresse und der Rundfunk, konstituieren je eigene Kommunikationsräume.“ (Ronneberger 1990: 261). ${ }^{137}$

Diese Punkte verweisen im Grunde auf denselben Aspekt. Zwischen einer möglichen Wirkung der Massenmedien auf sozial geteilte Raumvorstellungen und bereits bestehenden sozial konstituierten Räumen herrscht ein zirkulärer und weniger ein kausaler Zusammenhang. Es gibt jedoch Beispiele, die eine Kausalverbindung mal in die eine, mal in die andere Richtung nahezulegen scheinen. Stuiber hat pressestatistische Typenbildungen mit raumstrukturellen Gegebenheiten verglichen (Stuiber 1979). Dabei zeigte sich, dass „die Verbreitungsräume der verschiedenen Tageszeitungen in aller Regel den Strukturen funktional integrierter Räume entsprechen“, jedoch diese Räume ,in den seltensten Fällen den politischen Grenzen auf Gemeinde-, Kreis-, Regierungsbezirks- oder Landesebene folgen“ (Stuiber 1979: 304). Dass die „Aktivitätsregion“ eines Zeitungsverbreitungsgebiets auch über Jahrzehnte hinaus raumintegrierend wirken kann, zeigt sich für Ronneberger am Beispiel der Frankenpost:

„Das Verbreitungsgebiet der in Hof erscheinenden ,Frankenpost‘ umfaßte vor 1945 einen größeren Kulturraum, der auch das thüringisch-sächsische Vogtland einschloß. Durch die Abgrenzung zur DDR verlor die Zeitung dieses Teilgebiet ihres Verbreitungsraumes. Sie musste sich nach Süden und Westen hin neu orientieren. So entstand in einigen Jahrzehnten ein neuer Verbreitungsraum, der Ansätze zu einer neuen Integration hervorbrachte, wie sich in einer eingehenden empirischen Untersuchung nachweisen ließ.138 Als sich Ende 1989 die Grenze wieder öffnete, erwies sich die Kontinuität des älteren Kulturraums von überraschender Durchschlagskraft: Der ,Frankenpost' fiel das frühere Verbreitungsgebiet gewissermaßen wie von selbst wieder zu“" (Ronneberger 1990: 263).

Diese Darstellung übergeht allerdings die ökonomischen Interessen der erneuten verlegerischen Betätigung des Frankenpost-Verlags. Dass dem Verlag ein Verbreitungsgebiet „wie von selbst“ zugefallen sei, kann man wohl kaum ernsthaft annehmen. Zumal aus heutiger Sicht (aus allerdings deutlicher zeitlicher Distanz) sich der vormalige Kulturraum als weit weniger tragend erwies als Ronneberger 1990 noch annahm. Der Frankenpost-Verlag ist heute nicht mehr im thüringisch-sächsischen Raum aktiv. Aus wirtschaftlichen sowie in der Folge kartellrechtlichen Gründen wurde der vom Verlag bis dahin herausgegebene Vogtland-Anzeiger

136 Als Kulturräume versteht Ronneberger Territorien, in denen „übereinstimmende kulturelle Formen in größerer Anzahl vorkommen, wobei es sich im Wesentlichen um gesellschaftliche Verhaltensformen handelt, die durch Symbole über Generationen hinweg übermittelt werden [...] und in Wertvorstellungen und Ideen bewusst werden“" (Ronneberger 1990: 262).

${ }^{137}$ Darüber hinaus noch: „4. Der Raumüberwindung durch die modernen Verkehrsmittel entspricht die Ausdehnung der Kommunikationsräume.

5. Die Spaltung des Raumbewußtseins der Medienrezipienten in primär erlebbare und sekundär vermittelte Räume vertieft sich.

6. Der Erlebbarkeit von medienvermittelten Raumvorstellungen sind soziale und psychische Grenzen gesetzt. 7. Die Besonderheiten der Medienrealität erweisen sich auch beim Raumbezug der öffentlichen Medienkommunikation“ (Ronneberger 1990: 261). Diese Aspekte werden jedoch vom Erkenntnisinteresse der vorliegenden Arbeit nicht umfasst.

138 Meister (1984). 
2004 an die WVD-Mediengruppe verkauft (BDZV 2004). Die anderen im ehemaligen Verbreitungsgebiet zwischenzeitlich von der Frankenpost herausgegebenen Zeitungen ${ }^{139}$ wurden noch früher wieder eingestellt (vgl. Cicero-Media GmbH 2009).

Diese Aspekte beziehen sich lediglich auf Strukturen der Verbreitung von Medien, wogegen die verbreiteten Inhalte unbeachtet bleiben. Diesen kommt aber entscheidende Bedeutung zu, wenn es darum geht, die „Aktivitätsregion“ von Medien mit einer auf den jeweiligen Kulturraum bezogenen Bedeutung zu versehen. Eine Region lässt sich jedoch „,nicht allein durch die Existenz eines bestimmten erdräumlich abgrenzbaren Gebiets definieren und konstituieren [...] Das ausschlaggebende Moment ist das durch Kommunikation zustande kommende Sozialbewußtsein, wonach Menschen unter jeweils von der Umwelt abgrenzbaren Bedingungen zusammenleben und zusammengehören“ (Ronneberger 1990: 266). Deshalb soll die Funktion der Massenmedien für die nationale und regionale Identität im Folgenden aus ihrem inhaltlichen Aspekt abgeleitet werden. ${ }^{140}$

139 Thüringenpost und Sachsenpost bzw. später (Umbenennung) Zwickauer Tageblatt.

${ }^{140}$ Dabei kann freilich die äußere Struktur nicht außer Acht gelassen werden, die sich unter anderem aus der Einseitigkeit (Kommunikator-Rezipienten-Beziehung) der Massenkommunikation ergibt. 


\subsection{Funktion der Massenmedien für soziale Identitäten}

Im Sinne der Theorie der sozialen Identität können Massenmedien mehrere Funktionen erfüllen. Zunächst gehen von Massenmedien Kategorisierungseffekte aus. Im Rahmen dieser Arbeit ist dabei vor allem an räumliche Zuordnungen zu denken. Diese finden etwa durch regionalisierte Programmangebote statt. So werden Zuschauerinnen und Zuschauer des MDRFernsehens dann als Thüringerinnen und Thüringer kategorisiert, wenn sie das Fensterprogramm $^{141}$ für Thüringen (,Thüringen-Journal“) empfangen und zu diesem Ausstrahlungszeitpunkt nicht „Sachsen-Anhalt heute“ oder den „Sachsenspiegel“ sehen können. Das ist keine willkürliche Setzung und sie geht auch nicht auf die Sendeanstalt zurück. Auch sie orientiert sich bei der Festlegung der Ausstrahlungsgebiete ihrer Unterprogramme an bereits bestehenden räumlichen Aufteilungen. Letztlich werden diese bestehenden Einteilungen so aber perpetuiert. Dieses Beispiel verbleibt freilich noch auf rein struktureller Ebene. Die Titel der genannten Sendungen verweisen aber bereits auf eine anzunehmende inhaltliche Füllung.

Im Prozess der Bewertung der sozialen Identität bieten Massenmedien als Kommunikationsinstrumente Möglichkeiten für den sozialen Vergleich. Um beim Beispiel regionalisierter Programmangebote zu bleiben, so wird daran deutlich, dass hier für die Zuschauerinnen und Zuschauer nicht nur in-groups erzeugt werden können, sondern auch entsprechende, nämlich geografisch anders verortete, out-groups. Der Vergleich muss in der massenmedialen Kommunikation nicht zwangsläufig auf Seiten des Individuums im Publikum stattfinden. Es besteht ebenso die Möglichkeit, dass bereits das Kommunikationsangebot durch solche Vergleiche gekennzeichnet ist. Allerdings wäre dieser Schritt lediglich auf Kommunikatorebene vorgenommen worden und insofern nicht weniger individuell als auf Rezipientenebene. Es kann auch nicht davon ausgegangen werden, dass Kommunikatoren den Schritt des sozialen Vergleichs antizipieren können. Die Zusammenhänge zwischen Medienangebot und Medienwirkung sind dafür längst als zu komplex erkannt worden. Deutlich wird hier aber, dass Kommunikatoren bei der Erzeugung von in-groups und out-groups nicht in der Position von Versuchsleiterinnen und Versuchsleitern stehen, die, wie in den Experimenten von Tajfel/Turner, willkürlich Gruppen erzeugen. Vielmehr gehören sie im komplexen Geflecht regionalisierter Kollektivierungen selbst Gruppen an und orientieren sich an ihrer sozialen Identität.

Da für Entstehung und Bestehen sozialer Kollektive immer auch ein gewisser Konsens über die geteilten Merkmale und deren Bewertungen nötig ist (vgl. etwa Nohlen et al. 1998: 324; Mummendey/Otten 2002: 98; Tajfel/Turner 1979: 40), kommt den Massenmedien in diesem Zusammenhang auch die Funktion der Konsenserzeugung und Vermittlung zu. Dies gilt besonders für sehr heterogene Gruppen und solche, die sich fast ausschließlich durch Repräsentationen und Selbstzuschreibungen definieren, die aber wenig oder keine face-to-faceKommunikation pflegen.

141 Zeitlich begrenzte Ausdifferenzierung eines Fernsehprogramms in diverse regionale oder lokale Einzelangebote auf einer Frequenz (vgl. Lünenborg 2006a: 63). 
Diese Funktionsweisen können hier nur vereinfacht dargestellt werden. Es liegt auf der Hand, dass die Strukturen tatsächlich komplexer sind, da es eine große Zahl von Mischformen dieser Erscheinungen gibt und die Funktionen selbst auch durch zahlreiche Rückkopplungen und Wechselbezüge gekennzeichnet sind. Vor diesem Horizont wird die Funktion der Massenmedien hier als Re-Präsentation verstanden, was im Folgenden näher expliziert werden soll.

\subsection{Koorientierung zwischen Individuen}

Nationale und regionale Identität als spezielle Formen sozialer Identitäten beruhen nicht nur auf dem Bewusstsein der Gruppenzugehörigkeit, sondern auch auf einer von den Gruppenmitgliedern geteilten Vorstellung davon, was aus dieser Gruppenzugehörigkeit folgt. Dieses Teilen der Vorstellungsinhalte entsteht in Form von sozialen Aushandlungsprozessen wie Interaktion und Kommunikation sowie Koorientierung.

Der Begriff Koorientierung ist in der Kommunikationswissenschaft vor allem im Zusammenhang mit Medienwirkungsannahmen bezüglich Einstellungsänderungen bzw. -beeinflussungen geläufig. Dabei kommen in der „klassischen“ Medienwirkungsforschung vor allem Effekte von Kommunikation auf Individuen in Betracht. ${ }^{142}$ Das ABX-Modell von Newcomb bezieht sich auf face-to-face-Kommunikation, in der zwei Personen (A und B) auf Grundlage ihrer Einstellungen zueinander sowie ihrer Einstellung zu einem Sachverhalt (X) miteinander kommunizieren. Die Angleichung der Einstellungen (Bewertungen) gegenüber X ist zwischen A und B umso größer, je positiver die Einstellung zum Kommunikationspartner und je enger ihre Beziehung zueinander ist (vgl. Newcomb 1953: 397.). Ein wichtiger Aspekt, auf den Newcomb hinweist, ist der der Selbstvergewisserung über die eigene Einstellung des Individuums, ,the advantage of validation of one's own orientation toward X; the more similar A's and B's orientations, either cognitive or cathectic [...] the more confident each of them can be of his own cognitive and evaluative orientations" (Newcomb 1953: 395). Insofern ist davon auszugehen, dass Kommunikation von Mitgliedern einer sozialen Gruppe auch der Bestätigung von den in dieser Gruppe gültigen Normen dient. Hat A also eine aus den Gruppennormen abgeleitete Einstellung zu X, deren Gültigkeit durch B bestätigt wird, dann leitet B seine Einstellung zu X ebenfalls aus der Gruppenzugehörigkeit ab und sieht sich darin seinerseits durch A bestätigt.

Im Feld der Massenkommunikation spielen noch weitere Faktoren eine Rolle. Hier wirkt sich nicht nur die bereits bestehende Einstellung des Rezipienten zum Kommunikator aus, son-

\footnotetext{
142 Deutlich ist dies etwa im Westley/MacLean-Modell (Westley/MacLean 1957: 35), das eine Adaption des ABX-Modells von Newcomb (Newcomb 1953: 394) für die Massenkommunikation darstellt (Schenk 2002: 16). Westleys und MacLeans Modell schaltet gemäß dem vermittelt stattfindenden Massenkommunikationsprozess den Kanal C zwischen A und B und die Rückkoppelungsmöglichkeiten von B zu A fallen vergleichsweise gering aus(Schenk 2002: 16). X ist bei Westley/MacLean einer von unendlich vielen Sachverhalten $\left(\mathrm{X}_{1}-\mathrm{X}_{\infty}\right)$, der von $A$ ausgewählt und entsprechend seiner Einstellungen mit der Absicht der Beeinflussung über $\mathrm{C}$ an $\mathrm{B}$ vermittelt wird. Dabei wird X bei B im Sinne seiner eigenen Vorstellung dadurch verändert, dass B aus einer großen Anzahl von Cs eine Auswahl trifft (Schenk 2002: 17). Zu den Einschränkungen des Westley/MacLean-Modells hinsichtlich seiner idealisierenden und harmonisierenden Sichtweise vgl. insb. Schenk (2002: 17).
} 
dern auch die Einstellung zum Medium, über welches die Aussagen (Medieninhalte) empfangen werden.

\subsection{Medieninhalte als Repräsentation von Wissensstrukturen}

Die eigene soziale Identität - die also nicht zuletzt auf bereits bestehender Gruppenzugehörigkeit beruht - ist ein Faktor, der sowohl die Zuwendung zu bestimmten Medien beeinflusst als auch die Bewertung der darin vorkommenden Inhalte. Insofern wirken hier interpersonale Aspekte mit, und umgekehrt werden sie auch von der Zuwendung zu Massenmedien beeinflusst.

„Mass media content determines, perhaps to a much greater extent than we realize, what things we will argue or agree about with others. In turn - and even less obviously - this interpersonal context plays a major role in shaping the content of the mass media“" (Chaffee 1972: 95).

Das ist insbesondere deshalb der Fall, weil bereits die individuelle Entscheidung, sich einem bestimmten Medieninhalt zuzuwenden, auf einer Bewertung basiert, die mit den anderen Publikumsmitgliedern geteilt wird, nämlich, dass es sich dabei um einen beachtenswerten Inhalt handelt. Hinzu kommt: Je wichtiger der oder die Einzelne glaubt, dass diese Inhalte für die anderen Mitglieder der eigenen Gruppe sind, desto mehr Wichtigkeit wird er oder sie selbst ihnen beimessen, abhängig von der momentanen individuellen Salienz der Gruppenidentität. Ebenso wichtig ist aber - wie Chaffee verdeutlicht - dass auch die Produktion der Medieninhalte durch soziale Identitäten geprägt ist. Das bezieht sich jedoch nicht nur auf die Identität des gesellschaftlichen Subsystems „Journalismus“, sondern auch auf nationale und regionale Identitäten, denen Journalistinnen und Journalisten und andere Medienakteurinnen und -akteure ebenso angehören wie die Rezipienten. Medieninhalte stellen eine Referenz für Wissensstrukturen dar, an denen sich Mitglieder sozialer Systeme orientieren (vgl. Hanitzsch 2004: 218). Indem Medien geteiltes Wissen bereitstellen und die Einzelnen an den sozialen Wertekanon anschließen, machen sie als „Gedächtnis der Gesellschaft“ soziale Beziehungen sichtbar und möglich (Hanitzsch 2004: 219). Öffentliche Kommunikation stellt im Sinne der Koorientierung ein reflexives Korrektiv zur zunehmenden Ausdifferenzierung der Gesellschaft dar (Hanitzsch 2004: 231), weil sie einzelnen Rezipienten die Wahrnehmung vieler verschiedener gesellschaftlicher Systeme und Subsysteme ermöglicht. Massenmedien stehen dabei als institutionalisierte kollektive Regelsysteme in einer Repräsentationsfunktion (vgl. Jarren 2008: 337, 332). Jarren stellt in seiner theoretischen Einordnung von Massenmedien als Intermediäre implizit vor allem auf die Funktionen im Rahmen politischer und gesellschaftlicher Teilhabe des Publikums ab, es geht ihm insbesondere um Informations- und Wissensvermittlung. Der Aspekt der Koorientierung kann sich aber auch auf weniger explizite Wissensbestände beziehen als mit dezidierter Informationsaufnahme verbunden sind, da sich auch basale Wissens- 
strukturen in Massenmedien widerspiegeln. ${ }^{143}$ Im Zusammenhang mit kollektiven Identitäten dürfte das etwa auf den Umfang und die Tragweite von Identitätsmerkmalen zutreffen. Anders gesagt: Ein Bericht über die Entscheidung einer Bürgermeisterin oder eines Bürgermeisters einer kleinen Landgemeinde ist per se als von regional begrenzter Tragweite identifizierbar, ohne dass explizit darauf hingewiesen werden müsste. Gleichzeitig transportiert ein solcher Bericht aber Eigenschaften der Region, in der er angesiedelt ist, mit - und sei es auch nur die ganz grundlegende, dass ein Ort XY in der Region $\mathrm{Z}$ angesiedelt ist (also deren räumlichen Umfang mitbestimmt). Die basale Information Raumumfang bzw. Raumgehalt wird im TVBericht repräsentiert, weil sie affirmativ beim Rezipienten wirken kann, indem sie im Kontext regionaler Berichterstattung auftaucht. ${ }^{144}$ Gleichzeitig ist sie aber Voraussetzung für das Auftauchen in dieser Berichterstattung, da aus dem Ort nur berichtet wird, weil er innerhalb der „Zuständigkeit“ des regionalen Fernsehsenders liegt. Wissensstrukturen sind also Voraussetzung und Wirkung von medialer Berichterstattung zugleich. Insofern ist die Repräsentativität als Doppelfunktion der Massenmedien zu verstehen: Massenmedien dienen nicht nur der Aushandlung über die Strukturen der kollektiven Identitäten, sondern auch deren jeweils aktueller Manifestation.

\footnotetext{
${ }^{143} \mathrm{Da}$ ich mich hier vor allem auf solche basalen Wissensbestände beziehe, lasse ich Einwände gegen eine Überbetonung einer Integrationsfunktion von Journalismus für die Gesellschaft außer Acht. Diese Einwände zeigt Hanitzsch (2004) mit umfangreichen Literaturangaben auf. Sie beziehen sich vor allem darauf, dass öffentliche Kommunikation als integraler Bestandteil der modernen Gesellschaft auf deren zunehmende Ausdifferenzierung nur mit einem Mehr an Eigenkomplexität reagieren kann, was einer Integration tendenziell zuwider läuft (Hanitzsch 2004: 220). Hanitzsch zeigt aber auch auf, dass die Funktion des gesellschaftlichen Subsystems Journalismus aus systemtheoretischer Sicht gar nicht mit einem Integrationsbegriff beschrieben wird, sondern sich an Marcinkowskis Funktionsbeschreibung der „Ermöglichung von Selbstbeobachtung der Gesellschaft“ orientiert (Hanitzsch 2004: 221). Für die mediale Bereitstellung basaler Wissensstrukturen, auf denen kollektive Identitäten (auch) beruhen, kann eine solche Integrationsfunktion daher unbeachtlich bleiben, da sie ohnehin nicht intentional geschieht.

144 Wobei nach der Schema-Theorie davon auszugehen ist, dass durch diese Kontextualisierung das Schema „Region“ beim Rezipienten aktiviert ist und die kognitive Einordnung dementsprechend vollzogen wird (vgl. etwa Schenk 2002: 274 m. w. N.).
} 


\subsection{Vermittelte Koorientierung durch Massenmedien}

Der Aspekt, dass einzelne Rezipienten wissen, dass sie Teil eines größeren Publikums sind, macht bestimmte Wirkungsannahmen möglich. Aus der beschriebenen Repräsentationsfunktion ergibt sich insbesondere die Möglichkeit der Koorientierung am Gesamtpublikum bzw. an der Zielgruppe von TV-Sendungen. Dabei sind die Wissensstrukturen und Einstellungen der in-group „Publikum“, an denen die einzelne Zuseherin und der einzelne Zuseher sich orientiert, scheinbar im Programminhalt manifestiert: Die eigenen Bewertungen der Kollektividentität, die zum Einschalten eines bestimmten Programms führen, können als gleichermaßen wirksame Entscheidungsgrundlage auf das restliche Publikum projiziert werden. ${ }^{145}$ Werden durch das Programmangebot diese Einstellungen bestätigt, ${ }^{146}$ kann sich die Bewertung der kollektiven Identität verstärken. ${ }^{147}$ Die Produktion und Auswahl des Programmangebots auf Kommunikatorseite findet nicht selbst innerhalb sozialer Strukturen statt. Die Programmmacher sind meist selbst Teil der regionalen oder nationalen Gruppe, für die sie produzieren oder sie tun dies zumindest im Bewusstsein, für diese jeweilige Gruppe zu produzieren. ${ }^{148}$ Deshalb

\footnotetext{
145 Was auch das Publikum aus jeweils individueller Sicht zu einer vorgestellten Gemeinschaft macht. Insofern erscheint es legitim, über den Umweg eines regional konzipierten Publikums - auf Grund der technischen Verbreitungsmöglichkeiten ist es nicht tatsächlich begrenzt - die Region ebenso wie die Nation als eine vorgestellte Gemeinschaft im Sinne Andersons aufzufassen.
}

146 Hinzu kommt, dass gemäß den Erkenntnissen der Kognitionspsychologie solche Inhalte besser wahrgenommen werden, die auf bereits vorhandene kognitive Strukturen beim Rezipienten treffen (vgl. Schenk 2002: 270 m. w. N.). Diese selektive Informationsverarbeitung beim Rezipienten kann dabei auch von der jeweiligen aktuellen Salienz der infrage kommenden sozialen Identität abhängen.

147 Grundsätzlich ist es auch möglich, dass der ,internen Theorie“ des Rezipienten über die Struktur der Kollektividentität widersprochen wird, was dann eine Einstellungsänderung nach sich ziehen kann (vgl. insb. das Informationsprozessmodell nach Donohew/Tipton erläutert in Schenk 2002: 167). Eine solche Anpassung geschieht vor allem bei Informationen, die den bestehenden kognitiven Mustern beim Rezipienten nur in mittlerem Ausmaß widersprechen. Die hier betrachteten Kollektividentitäten Nation und Region gelten aber als relativ beständige Konzepte. Das schließt sozialen Wandel innerhalb dieser Gruppen zwar nicht aus, weist aber darauf hin, dass sich Änderungen hierin eher graduell als abrupt vollziehen. Vor diesem Hintergrund lässt sich zum Teil auch ein Phänomen wie die deutsche Fußballbegeisterung während der Weltmeisterschaft der Männer 2006 nachvollziehen: Fußball gilt in Deutschland als Sportart Nummer eins, was auch von jenen Deutschen wahrgenommen wird, die sich eher wenig für diesen Sport interessieren. Im Rahmen der Austragung der WM im eigenen Land und der damit verbundenen hohen Anzahl ausländischer Besucher steigt die aktuelle Salienz des Konzepts der eigenen Nationalität an, da die Besucher als different (also nicht deutsch) wahrgenommen werden. Gleichzeitig wird im persönlichen wie im medialen Alltag verstärkt auf das Ereignis Fußball-WM referiert, wodurch die Wichtigkeit der Sportart für eine große Zahl der Deutschen verstärkt wahrnehmbar ist. Im Rahmen der Orientierung an der in-group „Deutsche“ gewinnt das Konzept „Fußball“ größere Bedeutung, wodurch auch sonst weniger an Fußball Interessierte das Turnier verfolgen und die sonst eher latente Relevanz des Fußballsports für die nationale Identität der Deutschen sich mehr und mehr im Alltag manifestiert. Die starke Identifikation mit der eigenen Mannschaft, die sich im Fußball üblicherweise auch durch Verwendung von etablierten Mannschaftssymbolen bei den Fans äußert (Schals, Trikots, Fahnen etc.), wird dann im Rahmen eines Nationenturniers zur Verwendung entsprechender nationaler Symbole, die aber stärker aufgeladen sind (historisch etwa) als Clubsymbole von Bundesligavereinen. Dadurch verstärkt sich wiederum die aktuelle Salienz des Konzepts „Nation“. Das hat in der Folge wohl die öffentliche Debatte um den neuen und „entspannten“ Umgang mit der eigenen Nationalität mit befördert. Daneben spielen selbstverständlich auch ganz andere Aspekte eine Rolle für das „Sommermärchen“ von 2006; diese Überlegungen sind nur Teil eines weitaus komplexeren Zusammenspiels vieler Faktoren.

148 Im Feldschema der Massenkommunikation nach Maletzke ist dieser Aspekt mit dem Begriff „Bild des Kommunikators vom Rezipienten“ beschrieben (vgl. Maletzke 1963: 41). 
ist davon auszugehen, dass die Programminhalte den basalen Strukturen, auf denen die sozialen Identitäten fußen, nicht grundsätzlich zuwiderlaufen. Koorientierung ist darüber hinaus auch an Akteurinnen und Akteuren im Fernsehen möglich. Soweit es aber um Kollektividentitäten geht, dürfte das hauptsächlich in Form von Pars-pro-toto-Wahrnehmungen von Einzelakteurinnen und Einzelakteuren ${ }^{149}$ oder in Form der Orientierung an herausragenden Persönlichkeiten, die als Integrationsfiguren gelten, eine Rolle spielen. Die Koorientierung an der im Publikum versammelten in-group „Nation“ oder „Region“ kann also als doppelt indirekter Prozess verstanden werden: Er ist indirekt, weil er durch das Medium Fernsehen vermittelt ist und weil er auf Projektionen beruht, die durch das Vorwissen über die in-group gesteuert werden.

Hinsichtlich räumlich (mit-)definierter Kollektividentitäten sind die Wirkungsannahmen ebenfalls noch differenzierbar. Der Rezipient weiß nämlich nicht nur um seine Stellung innerhalb des Publikums, sondern auch um Merkmale des Mediums, wie etwa der regionalen Verortung eines Fernsehprogrammanbieters. Das heißt, er wird Informationen eines Regionalprogramms, das er außerhalb dessen „Kernregion“ etwa per Kabelanschluss empfängt, anders einordnen als Informationen des Regionalprogramms, in dessen Sendegebiet er selbst wohnt. Auch Informationen in einem nicht regionalen oder internationalen Programm wird er entsprechend anders einordnen. Oder beispielhaft verdeutlicht: Bayerische Bewohnerinnen und Bewohner der deutsch-österreichischen Grenzregion, die Nachrichten im ORF anschauen, werden Berichte über Entscheidungen der österreichischen Regierung für die eigene Betroffenheit anders bewerten als Nachrichten in der $A R D$-Tagesschau über Entscheidungen der deutschen Bundesregierung, obwohl anzunehmen ist, dass weder im ORF- noch im $A R D$ Bericht das Merkmal der Nationalität der jeweiligen Regierung hervorgehoben wird. In Maletzkes Feldschema der Massenkommunikation ist dieser Aspekt als das „Bild des Rezipienten vom Medium“ bezeichnet (vgl. Maletzke 1963: 41). In diesem Sinne stimuliert das Image eines TV-Senders unterschiedliche Schemata, wie etwa „Nation“ oder „Region“, wodurch dann die weitere Informationsverarbeitung beim Rezipienten gemäß dessen Ausprägung dieser Schemata beeinflusst wird.

Aus der theoretischen gesellschaftlichen Verortung der Medien ergibt sich, dass die jeweils aktuellen Bedeutungen und Wissensstrukturen nationaler und regionaler Identitäten an Medieninhalten ablesbar sind, sowohl hinsichtlich ihrer spezifischen Ausformungen als auch ihrer Wichtigkeit für verschiedene Aspekte menschlichen Zusammenlebens. Der Vorteil einer Analyse von Fernsehprogramminhalten liegt deshalb darin, den Mittelpunkt des Aushandlungsprozesses der Kollektividentitäten in den Blick zu nehmen. Dabei geht es weder um die tatsächliche Identifikation der Rezipientenseite ${ }^{150}$ mit dem gesamten Begriffsumfang der betrachteten sozialen Identität noch um (wahrscheinlich vage bleibende) direkte Intentionen der Kommunikatorseite für ein Identifikationsangebot. Von den postulierten Annahmen ausge-

\footnotetext{
${ }^{149}$ So wird etwa ein Milchbauer oder eine Milchbäuerin, welche die Milchpreispolitik der EU beklagen, als Vertreter oder Vertreterin der gesamten Zunft wahrgenommen, ohne dass er bzw. sie hierfür Funktionsträger bzw. Funktionsträgerin sein muss und damit durch ein Amt dazu berechtigt wird, für alle Milchbauern und bäuerinnen zu sprechen.

${ }^{150}$ Die letztlich sehr individuell ausfallen kann und wohl nur durch Befragung messbar ist.
} 
hend soll deshalb im Folgenden das Analyseinstrumentarium entwickelt werden, mit dem die Fernsehprogramminhalte auf den Repräsentationsfundus nationaler und regionaler Identitäten hin untersucht werden können. Im Auswertungszusammenhang wird darauf einzugehen sein, ob die obigen Postulate zutreffen oder modifizierende Einschränkungen vorzunehmen sind. Zunächst müssen dafür noch das Fernsehen sowie Magazinsendungen als eigentlicher Gegenstand der Untersuchung genauer in den Blick genommen werden.

\subsection{Besondere Bedeutung des Fernsehens}

Im bisherigen Verlauf der Darstellung wurde allgemein von der Rolle der Massenmedien im Zusammenhang mit den Prozessen nationaler und regionaler Identität gesprochen. Das Erkenntnisinteresse der vorliegenden Arbeit richtet sich speziell auf das Fernsehen als Ort sozialer Aushandlung der Inhalte sozialer Identitäten. Dem wurde dadurch Rechnung getragen, dass insbesondere hinsichtlich illustrierender Beispiele auf das Fernsehen bzw. das besondere Interesse dieser Arbeit verwiesen wurde. Die besondere Bedeutung des Fernsehens für gesellschaftliche Prozesse und seine besondere Stellung im Mediensystem Deutschlands und Österreichs hervorzuheben, mutet ein wenig an, wie Eulen nach Athen zu tragen. Die Stellen, an denen ähnliches in kommunikations- und publizistikwissenschaftlichen Arbeiten bis heute getan wurde, sind Legion (vgl. stellvertretend die Beiträge in Hickethier 1992) und das „Leitmedium Fernsehen“ längst sprichwörtlich. Am Zutreffen dieser Einordnung auch am Ende des ersten Jahrzehnts des zweiten Jahrtausends kann angesichts der Reichweiten und Einschaltzeiten kaum Zweifel herrschen (vgl. auch Schwotzer/Weiß 2009 sowie Maurer 2009). Nach einem geringfügigen Rückgang der durchschnittlichen täglichen Sehdauer im Jahr 2008 auf 207 Minuten täglich, verbrachten die durchschnittlichen Zuschauerinnen und Zuschauer ab drei Jahren im Jahr 2009212 Minuten pro Tag mit Fernsehen (vgl. Zubayr/Gerhard 2010: 107).

„Ein Vergleich dieser drei Stunden und 32 Minuten mit der Fernsehzeit in den vergangenen 17 Jahren macht deutlich, dass nur im Jahr 2006 der Fernsehkonsum einen gleich hohen Umfang aufwies. Bekanntermaßen war das Jahr 2006 aber von den Olympischen Winterspielen und der Fußball-Weltmeisterschaft geprägt - zwei Sportgroßereignissen, die das Zuschauerinteresse atypisch erhöhten. Im vergangenen Jahr [2009, H. I.] fehlten Ereignisse vergleichbarer GröBenordnung, so dass auf Basis dieser Messergebnisse ein nachhaltig hohes Bevölkerungsinteresse am Fernsehen konstatiert werden kann, das nur schwer mit manchen Prognosen zu vereinbaren ist, die bereits seit einigen Jahren ein rückläufiges Interesse zu erkennen glauben“ (Zubayr/Gerhard 2010: 107).

Auch in einem ausdifferenzierten Mediensystem nimmt das Fernsehen also eine herausgehobene Position ein. Deshalb sollen im Folgenden nur einige grundsätzliche Überlegungen zu den Besonderheiten dieses Massenmediums angestellt werden, sofern sie seine gesellschaftliche Rolle betreffen.

Die Bedeutung des Fernsehens ergibt sich nicht zuletzt aus dessen Vielgestaltigkeit. Diese ist durchaus mehrdimensional: Auf Wahrnehmungsebene betrifft sie zum Beispiel die angesprochenen Reize von Seh- und Hörsinn ebenso wie die variierende Inanspruchnahme von Kogni- 
tion und Emotion. Kognitive Verarbeitung (Lernen) von dargebotenen Stimuli scheint abhängig von der investierten mentalen Anstrengung zu sein (vgl. Salomon 1984: 649, m.w.N.). Empirische Studien legen nahe, dass TV-Rezeption weniger mentale Anforderungen stellt als etwa Zeitungslesen oder Radiohören (vgl. Salomon 1984: 650). Jedoch ist die Bandbreite von Darbietungsmöglichkeiten im Fernsehen ungleich höher als in Printmedien. Daraus folgt, dass es nicht nur Darstellungsformen gibt, die zum ,geistigen Zurücklehnen“ anregen, sondern auch solche, die intellektuelle Aufmerksamkeit erfordern. Das heißt, die kognitive Beeinflussung durch Fernsehkonsum kann vielgestaltiger erfolgen als durch andere Einzelmedien - und wird so in der Bandbreite wichtiger. Allerdings scheinen audiovisuelle Medien vor allem verstärkend hinsichtlich bereits bekannter Informationen zu wirken (Salomon 1984: 647). In Hinsicht der vorliegenden Studie ist das deshalb interessant, weil die Konzepte nationaler und regionaler Identität den Rezipienten nicht als neu erreichen können, weil er bereits mit ihnen sozialisiert ist. Fernsehen kann hier aber (bezogen auf Inhalt und Umfang der Konzepte) insbesondere perpetuierend und im geringen Umfang variierend wirken.

„Das Fernsehen unterscheidet sich von anderen Medien auch in Bezug auf seine zentralisierte Massenproduktion eines kohärenten Satzes von Bildern und Botschaften, die für allumfassende (breite) Populationen (Publika) produziert wurden, sowie bezogen auf eine relativ nonselektive, fast schon ritualistische Verwendung durch die Mehrheit der Nutzer“ (Gerbner 2000: 104).

Damit dürfte vor allem die Nutzung als Nebenbei-Medium gemeint sein. Angesichts der oben genannten Zahlen zur durchschnittlichen täglichen Fernsehdauer in Deutschland ist jedoch nicht davon auszugehen, dass diese Nutzungsweise in unseren Breiten die derzeit dominierende ist. ${ }^{151}$ Die Produktion kohärenter Bilder kann sich aber auch auf die Formenvielfalt des Fernsehens beziehen. Unabhängig davon, ob es sich um eine Unterhaltungs- oder Informationssendung handelt, bleibt der Rezeptionsrahmen im Sinne der Tätigkeit „Fernsehen“ gleich. Rein äußerlich besteht damit kein Unterschied zwischen dem inszenierten Tod eines Serienhelden und dem in den Nachrichten gezeigten Tod von Soldatinnen und Soldaten in einem Krieg. Der fiktionale Tod kann den Zuschauer oder die Zuschauerin gelegentlich sogar emotional stärker betreffen als der „echte“. Die herausragende Bedeutung des Fernsehens ist also nicht nur durch hohe Nutzungszahlen bedingt, sondern auch durch eine „Nutzungsbreite“. Das Fernsehen offeriert eine deutlich größere Zahl von Nutzungsmöglichkeiten als etwa Zeitungen. Der Konsum letzterer dürfte im Regelfall von einem Informations- und weniger einem Unterhaltungsbedürfnis geleitet sein. Die Leserin oder der Leser kann nicht im gleichen Maße „abschalten“ wie es die Fernsehzuschauerin oder der Fernsehzuschauer kann. Gleichzeitig steht letzteren immer die aufmerksame Nutzung offen, bis hin zum Nebenbei-Medium. Ähnliches gilt für den Hörfunk, hier fehlt aber der visuelle Reiz, womit die Bandbreite der Sinnesansprache eingeschränkt ist. Für die Nutzung des Webs dürfte hingegen - hinsichtlich der notwendigen Aufmerksamkeitsschwelle - ähnliches wie für die Zeitung gelten, da hier der

\footnotetext{
${ }^{151}$ Gerbner geht von einer „typischen nordamerikanischen Familie“ aus, in der das Fernsehgerät „täglich mehr als sieben Stunden“ eingeschaltet ist. Dabei betrage die tatsächliche Sehdauer „durchschnittlich drei Stunden pro Tag“ Gerbner (2000: 104).
} 
Rezipient (etwa um eine bestimmte Website aufzurufen) per se aktiver (und damit aufmerksamer) agieren muss als dies für die Fernsehnutzung gilt.

Die Nutzungsmöglichkeiten des Fernsehens können damit als sowohl horizontal wie auch vertikal sehr stark ausdifferenziert bezeichnet werden. Dabei meint „horizontal“ die inhaltliche Ebene, ,vertikal“ bezieht sich auf das emotionale und kognitive Involvement auf Rezipientenseite. Darin besteht die Massenattraktivität dieses Mediums. Aus ihr folgt schließlich auch die hohe Bedeutung, die dem Fernsehen durch die verschiedensten gesellschaftlichen Gruppen zugeschrieben wird. Indem dieser Zuschreibung gemäß gehandelt wird, verstärkt sich die Wichtigkeit des Mediums noch. So wie es für die einen wichtig ist, im Fernsehen präsent zu sein, wird es für die anderen wichtig, diese Präsentation wahrzunehmen. Umgekehrt erwächst so aber auch eine (wahrgenommene) Relevanz des im Fernsehen Gezeigten. In letzter Konsequenz bedeutet es aber in jedem Fall, dass Gesellschaft auch im Fernsehen ,stattfindet“. Deshalb verwundert es nicht, dass sowohl von politischer als auch rechtlicher Seite immer wieder Anforderungen an das Fernsehen formuliert und durchgesetzt wurden.

In seinem zweiten Fernsehurteil schreibt das Bundesverfassungsgericht dem (öffentlichrechtlichen) Rundfunk eine das Staatsganze integrierende Funktion zu (vgl. BVerfG 1971: 314). Diese Formulierung ist nicht als Forderung zu lesen, sondern als Feststellung (vgl. Scharf 1981: 202 m. w. N.). Integration bedeutet in diesem Zusammenhang nicht Hinführung der Bürger zu einem bestimmten Zielzustand, sondern sie ist ein „dynamisch-dialektischer Prozeß“ (Schwarzkopf 1978: 2). Schwarzkopf folgend ist der Rundfunk wie kein anderes Medium geeignet, den Staat als Gemeinschaft der Bürgerinnen und Bürger in der realen Verfassung zu vermitteln (vgl. Schwarzkopf 1978: 2, vgl. auch Scharf 1981: 203). Gewiss sind diese Formulierungen und auch die daraus folgenden strukturellen und inhaltlichen Anforderungen an das öffentlich-rechtliche Fernsehen vor dem Hintergrund des zweiten Fernsehurteils und der dahinter stehenden politischen Debatte zu lesen. Sie enthalten aber auch einen Verweis auf die Struktur des dispersen Publikums, das als solches nicht grundsätzlich eine Gemeinschaft von Staatsbürgerinnen und Staatsbürgern sein muss. Im konkreten Programmerlebnis wird statt einer Genese von Staatsbürgerlichkeit vielmehr die Salienz der nationalen (oder regionalen) Identität von Belang sein. Das beginnt in der verwendeten Sprache, es betrifft aber auch die gezeigten Bilder. Landschaften und symbolische Orte sind davon ebenso umfasst wie gezeigte Personen, die in verschiedenen gesellschaftlichen Zusammenhängen als Teil der sozialen Gemeinschaft sichtbar werden, zu der auch das Publikum gehört. Darüber hinaus spielen auch die behandelten Themen (v. a. in Informationssendungen) eine Rolle. Diese können per se von unterschiedlicher Tragweite sein oder in unterschiedlich weitreichenden Auswirkungen dargestellt werden. Damit kann die Bedeutung zum Beispiel für unterschiedliche Regionen innerhalb Deutschlands durchaus variieren. Das geschieht entweder durch vom Programm (im Sinne der Institution) unterschiedliche aufgerufene Rahmen (also den unterschiedlichen Erwartenshorizont des Rezipienten gegenüber dem Bayerischen und dem Norddeutschen Rundfunk) oder durch inhaltliche Gestaltung von Beiträgen. Beide Aspekte können sich dabei gegenseitig bedingen - und zwar noch auf Kommunikatorseite. Dieses Bedingungsgeflecht wirkt sich folgerichtig auf inhaltlicher Ebene aus. Deshalb sollen hier Fernsehprogramminhalte untersucht werden. 


\subsubsection{Formenvielfalt des Programmangebots}

Wie bereits angedeutet, gibt es in inhaltlicher und formaler Hinsicht viele verschiedene Darbietungsformen im Fernsehprogramm. Die Hauptunterscheidungslinie liegt hier zwischen fiktionalen und nicht fiktionalen Angeboten. Eine ebenfalls wichtige Unterscheidung ist die zwischen Unterhaltung und Information. Sie ist nicht deckungsgleich zur ersten, wie am Beispiel nicht fiktionaler Unterhaltungssendungen (also etwa Quizsendungen) deutlich wird. Gewiss ist die Dichotomie zwischen Information und Unterhaltung problematisch, vor allem weil sie eine inhaltliche Unterscheidung vornimmt, die per se gar nicht besteht, sondern erst im Erleben der Zuschauerin oder des Zuschauers stattfindet. Aus pragmatischen Erwägungen sowie in Hinblick auf die gängige Forschungspraxis kann sie aber hingenommen werden, soweit dieses Problem das eigentliche Forschungsinteresse nicht berührt. In den alljährlichen Programmprofilen in Media Perspektiven (etwa Krüger/Zapf-Schramm 2007, Krüger/ZapfSchramm 2008, Krüger/Zapf-Schramm 2009) wird nach „Sparten“ unterschieden: „1. Information (ohne Sport), 2. Sport, 3. nonfiktionale Unterhaltung, 4. Musik, 5. Kinder/Jugendprogramm, 6. Fiction (ohne Kinderprogramm), 7. Sonstiges und 8. kommerzielle Werbung“(Krüger/Zapf-Schramm 2009: 222). Ganz ähnlich sieht die Kategorisierung in der regelmäßigen ALM-Programmanalyse aus (vgl. etwa: Trebbe 2010). Hier werden die Kategorien „Fernsehpublizistik, Fiktionale Unterhaltung, Nonfiktionale Unterhaltung, Restliches Programm, Werbung und Sponsoring“" unterschieden (vgl. Trebbe 2010: 47). Diese Unterscheidungen werden nicht aus einem gemessenen Unterhaltungserleben bei den Zuschauern und Zuschauerinnen abgeleitet - vielmehr dürfte auf eine der jeweiligen Sendung inhärente gleichwohl unterstellte - Absicht des Kommunikators abgestellt werden. Jedoch zeigt allein die Problematik dieser Einteilung, wie vielgestaltig das Fernsehprogramm insgesamt ist. Unter den Begriff „Infotainment“"152 können sowohl unterhaltend aufbereitete dokumentarische Inhalte fallen als auch fiktionale Inhalte, die in Form einer Dokumentation dargeboten werden. Deshalb kann dem Forschungsinteresse der vorliegenden Arbeit nicht nachgegangen werden, wenn lediglich Programmteile untersucht werden. Es ist vielmehr notwendig, das Fernsehprogramm möglichst breit zu erfassen. Für die gesellschaftliche Aushandlung von Inhalt und Bedeutung sozialer Identitäten dürften Informationssendungen von besonderer Bedeutung sein. Ihre Einbettung in den Gesamtkontext der Programmangebote ist aber dennoch notwendig. Der Fokus der Arbeit wird auf Magazinsendungen liegen. Dieses Genre ist sehr stark ausdifferenziert und steht teilweise an der Schnittstelle zwischen Information und Unterhaltung. Das ergibt sich insbesondere aus Themen-Magazinen, die sich zum Beispiel auf Boulevard- oder Politikthemen spezialisieren. Magazine stellen deshalb - in Verbindung mit einer Betrachtung auch des restlichen Programms - ein ebenso in die Breite wie in die Tiefe gehendes Untersuchungsmaterial dar.

152 „Der Begriff zielt vor allem auf Medienprodukte, bei denen in Inhalt und Form Merkmale von Informationsund Unterhaltungsformaten kombiniert werden“" (Vowe 2006: 100). 


\subsubsection{Magazinsendungen}

\subsubsection{Definition}

Der Begriff „Magazin“ findet sich in den Massenmedien sowohl im Print- als auch im Hörfunk- und Fernsehjournalismus. Von der Wortbedeutung her verweist der Begriff bereits auf formale Charakteristika: Abgeleitet von der ursprünglichen Bezeichnung eines Vorrats- oder Lagerhauses wird das Wort Magazin seit dem 18. Jahrhundert als Titel periodisch erscheinender Zeitschriften verwendet im Sinne einer „Sammelstelle von Neuigkeiten usw.“ (Alsleben/Wermke 2007).

Im bundesdeutschen Fernsehen hat sich das Magazin-Format seit den 1960er Jahren etabliert. Es lässt sich definieren als „eine Programmform [...], bei der mittels Moderation thematisch und formal heterogene Einzelbeiträge additiv verbunden werden“ (Lünenborg 2006b: 157). Wegener formuliert folgende formale Elemente, die für Magazine als Form konstitutiv sind Wegener 2001: 54:

- Periodirität: regelmäßig wiederkehrende Erscheinungsweise

- Baukastenprin₹ip: verschiedene, voneinander unabhängige Beiträge bestimmen die innere Struktur einer Magazinsendung

- Moderation: verbindende Komponente zwischen den Einzelbeiträgen

Darüber hinaus haben Fernsehmagazine einige Besonderheiten, die sich sowohl auf ihre Stellung im Programm als auch auf ihre Rezeption auswirken.

„Die offene Struktur des M[agazin]s, der damit verbundene beständige Themenwechsel und die vergleichsweise kurze Dauer der Einzelbeiträge tragen zu einer partialisierten und fragmentarisierten Rezeption von Wirklichkeitsdarstellungen bei. Mit der Entwicklung und Etablierung von Infotainment- oder Boulevard-M[agazin]en im kommerziellen, später auch im öffentlichrechtlichen Fernsehen findet eine tendenzielle Auflösung der bisherigen thematischen Struktur statt. Eine Veränderung von Themenauswahl (human-interest-stories) und Präsentationsstil (schnellere Schnittfolge, intensiverer Einsatz von Spannungselementen, dynamischere Moderation) zielt vor allem auf die Sehgewohnheiten eines jüngeren Publikums ab" (Lünenborg 2006b: 157).

Die Partialisierung von Darstellungen ist damit sowohl hinsichtlich der Vielzahl von Themenbereichs-Magazinen gegeben als auch sendungsimmanent. Im Zusammenhang mit dem Interesse der vorliegenden Arbeit bedeutet das aber auch, dass gerade Magazine die größtmögliche inhaltliche Bandbreite präsentieren können, auf die sich die Aufmerksamkeit des Publikums richtet. Mit anderen Worten ist diese Sendeform - in ihrer ursprünglichen Wortbedeutung ein gut gefülltes Magazin von Wissensvorräten der Gesellschaft, auf die es inhaltlich referiert. 


\subsubsection{Publizistische Profilbildung}

Magazinsendungen im Fernsehen prägen das publizistische Profil des ausstrahlenden Senders in besonderer Weise mit. Das hat mehrere Gründe: Im Gegensatz zu Nachrichtensendungen sind Magazine weniger stark den teilweise ritualisierten Nachrichtenselektionsmechanismen des tagesaktuellen Journalismus unterworfen. Tagesaktualität ist für Magazine kein bestimmendes Gestaltungsmerkmal sondern sie folgen häufig mittelfristig latent aktuellen Themen (Wegener 2001: 54, m. w. N.). Dadurch bleibt den Redakteurinnen und Redakteuren mehr Zeit für die Recherche und Aufbereitung der Themen, insbesondere Hintergrundinformationen können so gesammelt und schließlich vermittelt werden (vgl. Wegener 2001: 55). Mit der teilweisen Unabhängigkeit von eigentlich nachrichtlichem Journalismus, der wohl auch weitgehend durch die Nachrichtenagenturen als Gatekeeper geprägt sein dürfte, erhalten die Magazinredaktionen die Möglichkeit, durch Themenwahl, Aufbereitung und Darbietung, ein mehr oder weniger deutlich sichtbares Profil für das Magazin zu entwickeln, das sich wiederum als journalistisches Aushängeschild der ausstrahlenden Anstalt etablieren kann. Hierfür ist nicht zuletzt die im Vergleich zu reinen Nachrichtensendungen ausgeprägtere Meinungsbetonung in den Darstellungsformen verantwortlich.

„Die politischen M[agazin]e ermöglichen - stärker als Nachrichtensendungen - eine politische Profilierung der Sender, da sie in der Person des Moderators sowie der Themenauswahl und Aufbereitung bewusst vom Neutralitätsgrundsatz abweichen. Thematisch bieten diese M[agazin]e im Vergleich zur Nachrichtensendung Vertiefung und Ergänzung der tagesaktuellen Information“ (Lünenborg 2006b: 157).

Ebenso wie sich im Kommentar der Tageszeitung deren politisch-publizistisches Profil offenbart, kann das publizistische Profil von Fernsehsendern mit den Magazinsendungen assoziiert werden. ${ }^{153}$ Ein solches (politisches) Senderprofil ${ }^{154}$ bezieht seine Bestandteile dann aus der Gesamtheit aller sendereigenen Magazine, während das Profil des Einzelmagazins sich eher im Sinne eines Markenimages manifestieren dürfte - wer „Monitor“ im Ersten einschaltet, erwartet keinen unkritischen Journalismus, der konservative politische Positionen verficht.

Darüber hinaus prägt aber auch das grundlegende Programmprofil eines Senders das Magazinangebot mit. Das betrifft insbesondere die Regionalprogramme. „Regionale Informationssendungen gehören zu den Kernangeboten der Dritten Fernsehprogramme der $A R D$ und sind die Programmangebote, die am stärksten nachgefragt werden“ (Simon et al. 2009: 60). Umge-

\footnotetext{
${ }^{153}$ Neben dem häufig bereits über das Unterhaltungsangebot bestehende Image des Senders hinaus, das ein solches publizistisches Profil aber überlagern kann. So wird etwa der Sender Pro Sieben vor allem als Spielfilmsender wahrgenommen, während das werktägliche Magazin „Galileo“ aber keine ausreichende Relevanz entwickelt, um dieses reine Unterhaltungsimage des Senders in anderer Richtung zu beeinflussen.

${ }_{154}$ Wobei der Begriff des politischen Profils nicht mit (partei-)politischen Präferenzen verwechselt werden darf. Auch ein Programm, in dem alle politischen und gesellschaftlichen Gruppen vorkommen, hat ein politisches Profil, indem bestimmte Themen fokussiert werden usw. In diesem Sinne hat letztlich auch ein Sender, in dem gar keine Politik vorkommt, ein politisches Profil - dann im Sinne der vollständigen Marginalisierung von Politik.
} 
kehrt dürften auf nationaler Ebene Magazine, die sich ausschließlich mit Themen aus einer bestimmten Region beschäftigen, nicht vorkommen. ${ }^{155}$

Magazinsendungen stellen also einen besonders wichtigen Teil der Fernsehprogramminhalte dar. Aus den dargestellten wechselseitigen Beziehungen zwischen Inhalt, Form und publizistischer Bedeutung ergibt sich ihre Relevanz für das Forschungsinteresse der vorliegenden Arbeit.

${ }^{155}$ Eine Ausnahme stellen die Regionalfenster im Programm von RTL und Sat.1 dar. Deren Ausstrahlung beruht auf besonderen rechtlichen Vorgaben für Privatfernsehen. Siehe hierzu Abschnitt 5.9.1.1

RundfunkstaatsvertragTPF (S. 110f.). 


\section{Strukturelle Rahmenbedingungen des Fernsehens}

Nachdem die Bedeutung des Fernsehens herausgestellt wurde, sollen im Folgenden die strukturellen Rahmenbedingungen des Fernsehens in Deutschland, Österreich, Bayern und Mitteldeutschland dargestellt werden. Für den Vergleich verschiedener nationaler und regionaler Identitäten von Fernsehprogrammen sind die institutionellen Rahmenbedingungen wichtig, weil „das Programmangebot seiner Struktur nach den Rahmenbedingungen der institutionellen Gegebenheiten folgt“ (Köster 2008: 587). Bevor Medieninhalte im Kontext kollektiver Identität untersucht werden, lohnt sich also ein Blick auf die Entwicklung und Struktur der Mediensysteme in den betrachteten Gebieten. Dabei soll auch die historische Entwicklung abrissartig dargestellt werden, weil sich die räumliche Neuordnung Deutschlands nach 1945 in der Struktur des öffentlich-rechtlichen Rundfunks widerspiegelt. Die Unterschiede in den verschiedenen Gebieten sind anschließend mitzudenken, wenn es darum geht die Fernsehprogramminhalte in zwei Nationen zu vergleichen.

\subsection{Historische Entwicklung in Deutschland}

Zum Beginn seiner Geschichte ist der Rundfunk in Deutschland regional ausdifferenziert. Der technische Grund dafür war die zu Beginn der 1920er Jahre noch geringe Sendereichweite. Der politische Grund waren die Kompetenzen der Länder. Insgesamt wurden im Deutschen Reich bis 1924 neun regionale Rundfunkgesellschaften gegründet. Eine rechtliche Regelung für den Rundfunk erfolgte erst 1926 mit den „Richtlinien über die Regelung des Rundfunks“. 1932 wurden unter Reichskanzler von Papen die „Richtlinien zur Neuordnung des Rundfunks“ erlassen, mit denen der Rundfunk zentralisiert und die Stellung der Reichsrundfunkegesellschaft (RRG) gestärkt wurde. So war es den Nationalsozialisten ab 1933 ein Leichtes, den Rundfunk unter ihre Kontrolle zu bringen und unter Führung des Reichsministeriums für Volksaufklärung und Propaganda zum Instrument ihrer Politik zu machen. ${ }^{156}$

Nach Kriegsende wurde der deutsche Rundfunk unter alliierter Kontrolle grundlegend neu geordnet (vgl. im Folgenden Mathes/Donsbach 2002). Durch Verabschiedung von Landesrundfunkgesetzen wurden bis 1948 der Bayerische Rundfunk, der Hessische Rundfunk, Radio Bremen, der Süddeutsche Rundfunk und der Südwestfunk ${ }^{157}$ gegründet. Der Nordwestdeutsche Rundfunk. (NWDR) ging bereits 1947 in deutsche Hände über. Auf Grund der sehr heterogenen Struktur

\footnotetext{
156 Übersichtsdarstellung bei Kaiser (1998a), Kaiser (1998b), detaillierter etwa Mathes/Donsbach (2002: $550 \mathrm{ff}$.$) .$

${ }^{157}$ Der Staatsvertrag über den Südwestfunk, wurde erst 1951 unterzeichnet, der Sendebetrieb war aber bereits 1948 aufgenommen worden.
} 
des Sendegebiets (das von Flensburg bis Aachen reichte und daneben auch noch Berlin umfasste) wurde der NWDR 1954 in den Westdeutschen (WDR) und den Norddeutschen Rundfunk (NDR) aufgeteilt und der Sender Freies Berlin (SFB) gegründet. 1956 folgte, nach der Eingliederung des Saarlandes in die Bundesrepublik, der Saarländische Rundfunk (SR).

Die bis dahin gegründeten Landesrundfunkanstalten schlossen sich 1950 zur Arbeitsgemeinschaft öffentlich-rechtlicher Rundfunkanstalten der Bundesrepublik Deutschland (ARD) zusammen. 1954 beginnt die $A R D$ mit der Ausstrahlung des Deutschen Fernsehens. Mit der Unterzeichnung des ZDF-Staatsvertrags 1962 wurde das Zweite Deutsche Fernsehen als gemeinsame öffentlichrechtliche Rundfunkanstalt aller Bundesländer eingerichtet. ${ }^{158}$ Das ZDF nimmt 1963 seinen Sendebetrieb auf. ${ }^{159}$ Nachdem die $A R D$ bis zur Einrichtung des ZDF von 1961 bis 1963 bereits versuchsweise ein zweites Fernsehprogramm ausgestrahlt hatte, bestand seitens einzelner ARD-Anstalten der Wunsch, das eigene Programmangebot durch regionale Fernsehprogramme auszudifferenzieren (Hickethier/Hoff 1998: 140). Ihr Schwerpunkt lag zunächst auf der Bildung und Kultur. Heute bieten sie durchgehend Vollprogramme an, wie die nationalen Fernsehprogramme auch, haben aber starke regionale Schwerpunkte.

1978 wurden von den Ministerpräsidenten vier zeitlich befristete Kabelpilotprojekte beschlossen, in deren Rahmen 1985 Sat.1 und RTLplus auf Sendung gingen (vgl. im Einzelnen Mathes/Donsbach 2002, vor allem aber Steinmetz 1999: 179). Mit dem vierten Rundfunkurteil des Bundesverfassungsgerichts (BVerfG 1986) wurde das „duale Rundfunksystem“, das sich bereits ausbildete, auch rechtlich anerkannt und die „Grundversorgung“ als unerlässliche Aufgabe dem öffentlich-rechtlichen Rundfunk zuerkannt. ${ }^{160}$

Während private Hörfunksender ganz überwiegend regional und lokal ausgerichtet sind, bedienen die großen privaten Fernsehstationen hauptsächlich den gesamtdeutschen Markt. Die Programmkontrolle findet jedoch durch die Landesmedienanstalten statt, also auf föderaler Ebene. Die beiden reichweitenstärksten privaten Fernsehprogramme sind nach $\int 25 \mathrm{RStV}$ verpflichtet, regionale Fenster „zur aktuellen und authentischen Darstellung der Ereignisse des

\footnotetext{
158 Zuvor war mit dem ersten Fernsehurteil BVerfG (1961) höchstrichterlich entschieden worden, dass dem Bund keine Gesetzgebungskompetenz hinsichtlich des Rundfunks als kulturellem Phänomen zukommt BVerfG (1961: 229), sondern lediglich hinsichtlich des sendetechnischen Betriebs BVerfG (1961: 230).

${ }^{159}$ Eine Verpflichtung des ZDF, regionale Programmfenster der ARD in sein Programm aufzunehmen, wurde durch den rheinland-pfälzischen Ministerpräsidenten Peter Altmeier - zugleich Vorsitzender des ZDF-

Verwaltungsrats - verhindert. „Die Ausstrahlung der Münchner ,Abendschau' hatte Altmeier mit dem Argument abgewehrt, die finanzielle Ausstattung des $Z D F$ sei mangelhaft. Es müsse aus den laufenden Einnahmen den institutionellen Aufbau finanzieren und sei deshalb besonders auf die Werbeeinnahmen und damit auf die Sendezeit vor 20.00 Uhr angewiesen“ (Hickethier/Hoff 1998: 209). Gleichzeitig wurde so aber die Stellung des ZDF als Anstalt aller Bundesländer gefestigt, dessen Programm für Deutschland in seiner Gesamtheit gedacht ist (vgl. auch $\int 5 \mathrm{ZDF}-\mathrm{StV}$ ).

${ }^{160}$ Die Grundversorgung durch den öffentlich-rechtlichen Rundfunk ist dabei die Voraussetzung dafür, dass an den privaten Rundfunk hinsichtlich der Breite des Programmangebots und der Sicherung gleichgewichtiger Vielfalt „nicht gleich hohe Anforderungen zu stellen wie im öffentlich-rechtlichen Rundfunk“ (BVerfG 1986: 118). Das gilt, „,solange und soweit“ durch den öffentlich-rechtlichen Rundfunk insbesondere „der klassische Auftrag des Rundfunks erfüllt wird, der neben seiner Rolle für die Meinungs- und politische Willensbildung, neben Unterhaltung und über laufende Berichterstattung hinausgehender Information seine kulturelle Verantwortung umfaßt.“ (BVerfG 1986: 158).
} 
politischen, wirtschaftlichen, sozialen und kulturellen Lebens in dem jeweiligen Land aufzunehmen“ ( $\int 25 \mathrm{IV}$, S. 1).

Das Bundesverfassungsgericht bestärkte 1987 die Stellung der öffentlich-rechtlichen Rundfunkanstalten im regionalen Bereich. Mit der 5. Rundfunkentscheidung wurde es dem Gesetzgeber untersagt, die Landesrundfunkanstalten ,,von der Veranstaltung regionaler und lokaler Rundfunkprogramme“ auszuschließen (BVerfG 1987: 298). ${ }^{161}$ Insofern bestehen auch im regionalen und lokalen Bereich die vollständigen Voraussetzungen für das Nebeneinander von privatem und öffentlich-rechtlichem Rundfunk. Seit Anfang der 1990er formierten sich mehr und mehr private regional und lokal verbreitete Fernsehsender, insbesondere in den neuen Bundesländern und Berlin. Heute gibt es bundesweit 234 solcher privater lokaler Fernsehstationen (vgl. Übersicht in Kors et al. 2007: 261).

161 Wobei hier vor allem lokale und subregionale gemeint sind. Die Landesregierung von Baden-Württemberg sah in ihrem Gesetz den öffentlich-rechtlichen Rundfunk lediglich für landesweite Programme vor und wollte subregionale und lokale Programme privaten Anbietern vorbehalten (vgl. im Einzelnen BVerfG 1987). 


\subsection{Aktuelle Situation in Deutschland ${ }^{162}$}

Der Fernsehmarkt ist durch eine immer stärkere Ausdifferenzierung geprägt. Mit den digitalen Verbreitungswegen drängen immer mehr Spartenkanäle auf den Markt (vgl. Schwotzer/Weiß 2009: 24). Daneben existieren aber die seit Jahren etablierten Vollprogramme ${ }^{163}$, die zusammen noch immer 83 Prozent der Zuschauermarktanteile auf sich vereinigen (vgl. Zubayr/Gerhard 2009: 103). Die Bedeutung der Vollprogramme ist damit nach wie vor gegeben, auch wenn die Vielzahl der Sparten- und Special-Interest-Kanäle zwischenzeitlich ihre Anzahl übersteigt.

Zwischen den öffentlich-rechtlichen und den privaten Fernsehanbietern ist der Zuschauermarkt einigermaßen ausgeglichen aufgeteilt. Hier entfallen rund 44 Prozent auf die öffentlichrechtlichen Fernsehsender und rund 47 Prozent auf die privaten (vgl. Zubayr/Gerhard 2009: $\left.103^{164}\right)$. Sehr viel ungleichmäßiger sind die inhaltlichen Ausrichtungen der Sender verteilt. Laut kontinuierlicher Programmbeobachtung der ALM führen Das Erste und das ZDF im Bereich der Fernsehpublizistik ${ }^{165}$. Im ZDF entfallen 56 Prozent der Sendezeit, im Ersten 44 Prozent auf die Fernsehpublizistik, dagegen 41 Prozent des RTL- und nur 22 Prozent des Sat.1Programms (vgl. Weiß/Trebbe 2008: Tab. 11.1). Insbesondere bei den Magazinformaten führt das ZDF das Feld deutlich an: 26 Prozent der Sendezeit entfallen auf Magazinsendungen. Das Erste folgt mit 20 Prozent, RTL mit 14 Prozent und Sat.1 mit zwölf Prozent (vgl. Weiß/Trebbe 2008: Tab. 11.1). Anders sieht die Verteilung hinsichtlich unterhaltender Formate aus: Hier führt Sat.1 mit 57 Prozent Anteil unterhaltender Sendungen an der Gesamtsendezeit, gefolgt vom Ersten mit 42 Prozent sowie ZDF mit 33 und RTL mit 32 Prozent (fiktionale und nonfiktionale Unterhaltung zusammengenommen, auf ganze Prozent gerundet, vgl. Weiß/Trebbe 2008: Tab. 11.1). ${ }^{166}$

162 Zur Beschreibung der aktuellen Situation werden die Zahlen für 2008 herangezogen, weil auch der Untersuchungszeitraum in dieses Jahr fällt.

${ }_{163}$ Das Erste, ZDF, Dritte Programme der ARD, RTL, Sat.1, Pro 7, VOX, RTL II, Kabel 1, 3sat, arte. Der Einfachheit halber wurden die Dritten Programme hier mit einbezogen, auch wenn sie streng genommen wohl keine Vollprogramme darstellen (siehe hierzu auch unten, S. 130 und S. 229). Ohne die Dritten reduziert sich der Anteil auf 70 Prozent. Ähnliches gilt für 3 sat und arte, die sich mit ihrer thematischen Schwerpunksetzung auf Kultur im Bereich der Spartenprogramme bewegen könnten. Dagegen spricht allerdings das doch recht ausdifferenzierte Programmangebot. Beide zusammen haben 2008 1,7 Prozent Marktanteil erreicht. Somit ist der grundsätzliche Befund der herausgehobenen Stellung der Vollprogramme auch mit den vorgenommenen Einschränkungen richtig.

164 Ohne Berücksichtigung der dort unter „Restliche Sender“ fallenden Programme (8,8 \%).

165 Zusammengesetzt aus den Formen Nachrichtensendungen (Universelle Nachrichten, Spezifische Nachrichten), Tagesmagazine (Frühstücksfernsehen, Tageszeitmagazine, Regionalmagazine, Boulevardmagazine, Sonstige Tagesmagazine), Sonstige Magazine, Reportagen, Dokumentationen, Tägliche Interview- und Talkformate, Sonstige Interview- und Talkformate, Sondersendungen, Sonstige Formate (Weiß/Trebbe 2006: T19).

166 Dass die öffentlich-rechtlichen Sender sowohl hinsichtlich der Fernsehpublizistik als auch hinsichtlich der Unterhaltung die meiste Sendezeit zur Verfügung haben, liegt aber nicht zuletzt daran, dass bei beiden hier betrachteten Privatsendern jeweils über 20 Prozent der Sendezeit auf die Werbung entfallen, bei den öffentlichrechtlichen jedoch nur jeweils knapp über ein Prozent (vgl. Weiß/Trebbe 2006: T11). 


\subsection{Historische Entwicklung in Österreich}

Der österreichische Rundfunk ist bereits zu Beginn seiner Geschichte durch zentrale Organisation und Nähe zum Staat gekennzeichnet. Die Wiener Radio-Verkehrs-AG (RAVAG) ,war als Monopolunternehmen in ,Staatsnähe“" (Steinmaurer 2002: 31) gegründet worden und nahm 1924 den Betrieb eines Radiosenders auf. Während des Bürgerkrieges 1934 wurde er als Propagandainstrument genutzt und war deswegen zwischen den Bürgerkriegsparteien umkämpft. 1938 wurde die RAVAG im Zuge des Anschlusses an das Dritte Reich durch Aktienkauf in die Reichsrundfunkgesellschaft eingegliedert und als „Deutsch-österreichischer Rundfunk" weiter betrieben (Steinmaurer 2002: 34).

Nach dem Krieg wurde der österreichische Rundfunk in vier Sendergruppen aufgeteilt, die sich aus den vier Besatzungszonen der Alliierten ergaben. Doch anders als in Deutschland kam es zum Ende der Besatzungszeit 1954, zu einer Rezentralisierung des Rundfunks, der damit zu einer Bundessache wurde. 1957 wurde das damalige „österreichische Rundspruchwesen“ durch Ministerratsbeschluss in die Österreichische Rundfunk Ges.m.b.H. integriert (Steinmaurer 2002: 32). 1964 strengten parteiunabhängige Tages- und Wochenzeitungen erfolgreich ein Volksbegehren an, das eine Reformierung des österreichischen Rundfunks zum Ziel hatte. In dessen Folge trat 1967 ein neues Rundfunkgesetz (Bundesgesetz über die Aufgaben und die Einrichtung der österreichischen Rundfunk Gesellschaft m.b.H., Rundfunkgesetz, BGBl. Nr. 195/1966) in Kraft. 1974 wurde mit der zweiten Rundfunkreform die GmbH in eine Anstalt öffentlichen Rechts umgewandelt.

Im Vergleich mit anderen europäischen Staaten fand diese Liberalisierung des österreichischen Rundfunkmarktes sehr spät statt. Erst 1993 beschloss der Nationalrat ein Gesetz, das zehn privaten Hörfunkanbietern eine Sendelizenz versprach. Zwei davon konnten im Herbst 1995 auf Sendung gehen. Der Fernsehmarkt wurde in Österreich sogar erst auf Entscheidungen des Europäischen Gerichtshofs hin liberalisiert. ${ }^{167}$ Die rechtliche Neuregelung hin zu einer dualen Rundfunkordnung verzögerte sich noch bis ins Jahr 2001. ${ }^{168}$ Eine Lizenz für bundesweites terrestrisches Privatfernsehen erhielt Anfang 2002 die ATV Privatfernseh-GmbH, die im Juni 2003 mit ATV plus auf Sendung ging. Daneben sind mehrere Lizenzen für lokales und regionales Privatfernsehen vergeben worden. Mit Puls 4 ging im Januar 2008 ein zweites bundesweites privates Fernsehprogramm auf Sendung.

\footnotetext{
167 EGMR 1993; EGMR 2000; EGMR 2000.

${ }^{168}$ Im Zuge einer umfassenden Reformierung des ORF wurde im Nationalrat auch das „Bundesgesetz, mit dem Bestimmungen für privates Fernsehen erlassen werden“, verabschiedet, in das auch das bis dahin geltende Kabelund Satellitenrundfunkgesetz integriert wurden Steinmaurer (2002: 56).
} 


\subsection{Aktuelle Situation in Österreich ${ }^{169}$}

Der österreichische Fernsehmarkt wird heute durch den ORF mit seinen beiden TVProgrammen dominiert (41\% durchschnittlicher Tagesmarktanteil an allen Zuschauerinnen und Zuschauern ab zwölf Jahren im Frühjahr 2009, ATV: 4 \%, Puls 4: 2 \%. Vgl. Woelke 2010: 22. Die übrigen Anteile verteilen sich auf einstrahlende ausländische - hauptsächlich deutsche - Fernsehsender.). Die beiden Programme des ORF sind unterschiedlich ausgerichtet. ORF 1 ist der Unterhaltungssender, ORF 2 dient eher der Information und Bildung. Entsprechend hoch sind im ORF 1 die Anteile fiktionaler Sendungen und Sportübertragungen (vgl. Woelke 2010: 64). Im zweiten Programm dominieren dagegen Informations-, Magazin- und Kultursendungen (Woelke 2010: 64). Seit April 2007 wird auf die zeitgleiche Ausstrahlung der Hauptnachrichtensendung Zeit im Bild in beiden Programmen um 19.30 Uhr verzichtet. Diese wird nur noch im ORF 2 gezeigt. Im ersten Programm wird stattdessen um 20 Uhr die Kurznachrichtensendung ZiB 20 ausgestrahlt. Die Informationskompetenz ist damit (den Sportbereich ausgenommen) hauptsächlich auf den $O R F 2$ verlagert.

Das Programm von $A T V$ zeichnet sich ebenfalls durch hohe Anteile von Unterhaltungssendungen aus (vgl. Woelke 2010: 65). Dazu zählen vor allem US-amerikanische Serien, aber auch eigenproduzierte Dokusoaps und Infotainmentangebote. Aktuelle Informationsangebote beschränken sich bei $A T V$ auf die Nachrichtensendung ATV aktuell und den ATV Sport.

${ }^{169}$ Die Zahlen zur aktuellen Lage des Fernsehens in Österreich sind Woelke (2010) entnommen. Diese beziehen sich auf das Jahr 2009 und liegen damit nach dem Untersuchungszeitraum der vorliegenden Studie. Der nächstfrühere verfügbare Berichtszeitraum wurde erst 2008 bezogen auf das Jahr 2007 vorgelegt. Die Entscheidung für die neueren Zahlen fußt darauf, dass sich mit dem bundesweiten Programmstart des Senders Puls 4 ein weiteres Vollprogramm am österreichischen Fernsehmarkt etabliert hat (hervorgegangen aus dem Wiener Lokalsender Puls TV. 


\subsection{Historische Entwicklung in Bayern}

Der Rundfunk ging in Bayern erstmals am 30. März 1924 auf Sendung. Die Deutsche Stunde aus Bayern war - im Gegensatz zu den anderen regionalen Rundfunkgesellschaften in Deutschland - keine Aktiengesellschaft sondern lediglich eine regionale Filiale der Berliner Deutschen Stunde in Form einer GmbH (Hasselbring 1999: 53). Die Betonung der bayrischen Eigenständigkeit zeigte sich aber daran, dass sie als einzige deutsche Sendegesellschaft 1925 nicht der Reichsrundfunkgesellschaft (RRG) beitrat. Ab 1931 firmierte der Rundfunk in Bayern unter dem Namen Bayerische Rundfunk GmbH. Aufgrund der Nicht-Mitgliedschaft in der RRG konnte in Bayern der Rundfunk seine organisatorische Unabhängigkeit nach der Machtübernahme der Nationalsozialisten noch bis zum März 1934 bewahren, als die bayrische Staatsregierung ihre Anteile an der Bayerischen Rundfunk GmbH an die RRG verkaufte.

In der Bundesrepublik produziert der Bayerische Rundfunk seit 1954 Fernsehsendungen für das Gemeinschaftsprogramm der $\mathrm{ARD}^{170}$, wobei aus Bayern zunächst vor allem Unterhaltungsformate beigesteuert wurden (Fuchs 1999: 94; Hickethier/Hoff 1998: 136). Der BR ist die erste Landesrundfunkanstalt, die mit der Ausstrahlung eines Regionalprogramms zwischen 19 und $20 \mathrm{Uhr}$ als Vorlauf zum Gemeinschaftsprogramm der $A R D$ begann. 1956 führte der BR Werbung im Vorabendprogramm ein (Fuchs 1999: 94). 1964 begann der BR mit der Ausstrahlung seines „Studienprogramms“"171 und ist damit der erste deutsche Sender, der ein regelmäBiges Drittes Fernsehprogramm anbietet. 1978 trat schließlich ein eigenes bayrisches Vollprogramm an die Stelle des Studienfernsehens. Seit 1979 strahlt das Bayerische Fernsehen mehrmals täglich die selbstproduzierte Nachrichtensendung „Rundschau“ aus und bietet immer stärker regional orientierte Berichterstattung mit eigens entwickelten Sendungsformaten an (Fuchs 1999: 96). Als erste Landesrundfunkanstalt strahlt der BR ab 1978 RegionalfensterSendungen für die unterschiedlichen Regionen des Sendegebiets aus (Fuchs 1999: 97).

\footnotetext{
170 Zunächst veranstaltet der BR vor allem Hörfunkprogramme. Diese Entwicklung wird hier übersprungen. Näher dazu vor allem Gruber 1999.

${ }^{171}$ Dieses Studienprogramm gewann vor allem deshalb ein eigenes Gewicht, weil mit dem darin ausgestrahlten „Telekolleg“ die von der bayerischen Staatsregierung anerkannte Fachhochschulreife erworben werden konnte Hickethier (1993: 212).
} 


\subsection{Aktuelle Situation in Bayern}

Das heutige bayerische Rundfunksystem ist gekennzeichnet durch eine Vielzahl privater lokaler und regionaler Rundfunkanbieter auf der einen Seite und den Bayerischen Rundfunk als öffentlich-rechtlicher Anstalt auf der anderen Seite. Landesweiter (terrestrischer ${ }^{172}$ ) privater Hörfunk ist auf privater Seite bisher die Ausnahme geblieben und wird nur von Antenne Bayern angeboten. Daneben gibt es rund $40^{173}$ private lokale und regionale Radiosender (vgl. BLM 2007).

Landesweites Fernsehen ist die Domäne des Bayerischen Rundfunks. Private Anbieter (17:30 Live für Bayern; Bayern Journal) produzieren lediglich bayernweite Fensterprogramme, die zu bestimmten Zeiten auf den Frequenzen von Sat.1 und RTL ausgestrahlt werden. ${ }^{174}$ Daneben gibt es rund 20 private lokale und regionale Fernsehsender. Hinzu kommen etwa gleich viele nur in lokalen Breitbandkabelnetzen oder digital verbreitete Sender (vgl. BLM 2007: 12). Fünfzehn private Lokalsender sind unter der Dachgesellschaft TV Bayern zusammengeschlossen, über die sie sowohl Programminhalte teilen als auch Werbezeiten vermarkten.

Neben dem Hauptprogramm des Bayerischen Fernsehens bietet der BR seit Januar 1998 den „Bildungskanal“ ${ }^{175} B R$ alpha an, der vor allem Weiterbildungs- und Wissenschaftssendungen ausstrahlt. Gemessen an den Zuschaueranteilen belegt das Bayerische Fernsehen in Bayern - hinter ZDF, Das Erste, RTL und Sat.1 - mit 7,8 Prozent TV-Marktanteil den fünften Gesamtrang. Die privaten bayerischen Lokal- und Regionalprogramme kommen dagegen nur auf 2,2 Prozent Anteil an der Gesamtzahl bayerischer Zuseherinnen und Zuseher (vgl. TNS Infratest MediaResearch 2007).

Das Bayerische Fernsehen versteht sich als ein ,auf den Freistaat konzentriertes Vollprogramm“ (BR 2007). Laut Eigencharakterisierung des TV-Programms des BR fallen rund ,zwei Drittel der Sendungen im Bayerischen Fernsehen [...] unter die Kategorie Information. Der Schwerpunkt liegt in der regionalen Berichterstattung und auf gesellschaftspolitisch und kulturell orientierten Sendungen“ (BR 2007).

\footnotetext{
${ }^{172}$ Im digitalen Radio senden drei Anbieter (Fantasy Bayern, Radio Galaxy, Rock Antenne) bayernweit.

173 Insgesamt listet die BLM allein 104 UKW-Hörfunkprogramme auf (BLM 2007: 2). Davon entfallen aber 45 auf so genannte Spartenanbieter, die nur einzelne Sendungen anderen Hörfunkanbietern zuliefern. Hinzu kommt eine Anzahl von Sendern, die unter demselben Namen an verschiedenen Standorten Radioprogramme ausstrahlen, also eher als Netzwerk anzusehen sind und daher nicht zwangsläufig für jeden Standort einzeln zu zählen sind.

${ }^{174}$ Dabei handelt es sich vornehmlich um Magazine, die innerhalb von 30 bis 60 Minuten aktuelle und regionale Themen aufbereiten (vgl. etwa Volpers et al. 2000: 250. „17:30 - Live für Bayern“ wird von der Sat.1 Privatfernsehen in Bayern GmbH \& Co. KG, das „Bayern Journal“ von C.A.M.P. TV Fernsehgesellschaft mbH produziert.

175 Eigenbezeichnung des $B R$.
} 


\subsection{Historische Entwicklung in Mitteldeutschland}

Der heutige Zuschnitt des Sendegebites des Mitteldeutschen Rundfunks ist historisch keine Neuheit sondern fußt auf der Tradition der MIRAG, der Mitteldeutsche Rundfunk-A.-G., Gesellschaft für Unterbaltung und Belehrung (MIRAG), die im Januar 1924 gegründet und im März desselben Jahres auf Sendung gegangen war (vgl. Unger/Lieberwirth 2002: 9). Zum mitteldeutschen Sendegebiet gehörte damals das Gebiet der damaligen Freistaaten Sachsen, Thüringen und Anhalt, die preußische Provinz Sachsen und Teile der Regierungsbezirke Magdeburg und Braunschweig (Pfau/Lieberwirth 2000: 17). Damit entsprach die Sendephilosophie bereits in den 1920er Jahren dem „Dreiländergedanken“, der auch heute den Mitteldeutschen Rundfunk prägt (Pfau/Lieberwirth 2000: 45). Nach dem Ende der NS-Herrschaft ${ }^{176}$ wurde im November die Mitteldeutsche Rundfunkgesellschaft gegründet und damit für kurze Zeit der Gedanke eines integrierenden Sendegebiets kurzzeitig wiederbelebt. Dieser Zuschnitt endete aber 1952 mit Auflösung der Bundesländer in der DDR. Der Rundfunk wurde stattdessen zentralisiert und unter Kontrolle des „Staatlichen Komitees für Rundfunk beim Ministerrat der DDR“ zentral von Berlin aus geleitet (Unger/Lieberwirth 2002: 14). Im Fernsehen der DDR spielte regionalisierte Berichterstattung keine Rolle und wurde erst mit der politischen Wende 1990 etabliert (vgl. etwa Unger/Lieberwirth 2002: 156). Mit der Wiedervereinigung wurden schließlich in Landesrundfunkanstalten nach bundesdeutschem Vorbild gegründet. Hierbei wird der Mitteldeutschland-Gedanke wieder aufgegriffen und im Mai 1991 der Staatsvertrag über die Gründung des Mitteldeutschen Rundfunks durch Vertreter der Bundesländer Sachsen, SachsenAnhalt und Thüringen unterzeichnet. Am 1. Januar 1992 ging der Mitteldeutsche Rundfunk auf Sendung.

${ }^{176}$ Die MIRAG bestand bis 1932. Noch vor der Machtübernahme der Nationalsozialisten wurde - mit der „Neuregelung für den Rundfunk“ unter der Regierung von Papen - der Rundfunk nach und nach zentralisiert und verstaatlicht (Mathes/Donsbach 2002: 551). Der Sendebetrieb wurde in Leipzig 1942 eingestellt und erst unter der kurzen Zeit amerikanischer Besatzung 1945 als Radio Leipzig wieder aufgenommen (Unger/Lieberwirth 2002: 13). 


\subsection{Aktuelle Situation in Mitteldeutschland}

Gemessen an der Akzeptanz im jeweiligen Sendegebiet ist das MDR-Fernsehen das erfolgreichste Dritte Programm (Zubayr/Gerhard 2009: 104). Der durchschnittliche Zuschauermarktanteil liegt hier bei 8,9 Prozent. Auch innerhalb der fünf neuen Bundesländer zusammengenommen führt der MDR die Dritten Programme an. Hier liegt der Marktanteil bei 6,6 Prozent, einem Wert, den die beiden anderen in den neuen Bundesländern sitzenden Dritten (NDR für Mecklenburg-Vorpommern, RBB für Berlin und Brandenburg) auch zusammengenommen nicht erreichen (jeweils 2,5 Prozent). Privat-kommerzielle Wettbewerber, die sich auf sein Sendegebiet beziehen, hat der MDR nicht. Lediglich eine Vielzahl lokaler Rundfunkanstalten findet sich hier, die aber in den drei Bundesländern höchst unterschiedlich verteilt sind. So hat die Sächsische Landesmedienzentrale 60 private Fernsehveranstalter lizenziert, die Thüringische aber lediglich 17 und die Medienanstalt Sachsen-Anhalt nur 13 (Stand 08/2007 laut Homepages der drei genannten Medienanstalten: www.slm-online.de, www.tlm.de und www.lra.de). Von diesen 90 Programmen wird aber keines landesweit ausgestrahlt, so dass auch hier keine ausgeglichene Konkurrenzsituation besteht. Zudem sind die Reichweiten dieser Sender höchst unterschiedlich und reichen von wenigen Hundert bis zu 250.000 erreichbaren Haushalten.

Das Programm des MDR-Fernsehens will „regionale Kompetenz und die Mischung aus Information, Lebenshilfe und Unterhaltung“ (MDR 2007) bieten. Der MDR sieht sich als „Verbunden mit der Region und ihrer Geschichte“(MDR 2007). Dafür hat man laut eigener Aussage ,eine Vielzahl von Sendeformaten entwickelt, die auf eine moderne Weise gesellschaftliche, kulturelle und politische Themen aus Mitteldeutschland aufgreifen und den Zuschauern Identität und regionale Verbundenheit vermitteln“ (MDR 2007).

\subsection{Rechtliche Rahmenbedingungen}

Im Folgenden werden rechtliche Rahmenbedingungen des Rundfunks in den zu untersuchenden Gebieten umrissen, soweit sie die inhaltliche Ausgestaltung des Rundfunkprogramms betreffen. Auf die organisatorische Struktur und rechtliche Stellung wird lediglich am Rande eingegangen.

\subsubsection{Rechtliche Rahmenbedingungen in Deutschland}

Bestimmungen für den national verbreiteten Rundfunk in Deutschland sind vor allem auf staatsvertraglicher Ebene geregelt, da der Rundfunk Ländersache ist. Einschlägig ist hier zunächst der Staatsvertrag für Rundfunk und Telemedien (RStV). Er enthält sowohl Bestimmungen für den öffentlich-rechtlichen als auch den privaten Rundfunk. 


\subsubsection{Rundfunkstaatsvertrag ${ }^{177}$}

In $\int 3 \mathrm{RStV}$ werden für alle bundesweit verbreiteten Fernsehprogramme allgemeine Programmgrundsätze aufgestellt, die vor allem die Achtung und den Schutz von Grundrechten vorschreibt. In \4 wird die Fernsehausstrahlung ,,von Ereignissen von erheblicher gesellschaftlicher Bedeutung“" geregelt. ${ }^{178}$ Auf Grund der Definition bestimmter Ereignisse als „,von erheblicher gesellschaftlicher Bedeutung“" wird hier aber auch etwas über die Gesellschaft gesagt, für die solche „Großereignisse“ von besonderer Bedeutung sein sollen. Bei der abschlieBenden (Altes 2003: 115) Aufzählung dieser Ereignisse handelt es sich ausschließlich um Sportveranstaltungen, von denen nur eines (Olympische Spiele) kein Fußballspiel ist. Der Europäische Gerichtshof wie auch das Bundesverfassungsgericht haben den „Gemeinwohlbezug“" und die besondere gesellschaftliche Bedeutung des Sports (insbesondere des Fußballs) vor allem auf Grund kollektiver Identifikationsmöglichkeiten anerkannt (Altes 2003: 7). Da die Regelung auf Artikel 3a der EG-Fernsehrichtlinie basiert, sind vergleichbare Regelungen auch in anderen Staaten der Europäischen Union getroffen worden. Zwar zielte der europäische Gesetzgeber mit dieser Regelung auf sportliche Ereignisse, jedoch haben etwa Italien, Österreich und der flämische Teil Belgiens auch kulturelle Ereignisse in ihren jeweiligen Regelungen aufgelistet (Altes 2003: 114). Insofern drückt sich im Inhalt der Liste der Großereignisse zumindest auch eine Annahme des Gesetzgebers über identitätsstiftende Ereignisse aus.

$\int 6$ trifft Regelungen zur Darstellung der kulturellen Vielfalt in Deutschland und Europa. Der Hauptteil der Sendezeit für Spielfilme, Fernsehspiele, Serien und Dokumentarsendungen soll demnach europäischen Werken vorbehalten sein. ${ }^{179}$ Nach \6 III RStV sollen Fernsehvollprogramme einen wesentlichen Anteil Eigenproduktionen sowie Auftrags- und Gemeinschaftsproduktionen aus dem deutschsprachigen oder europäischen Raum enthalten. Für Spartenprogramme gilt diese Regelung nur eingeschränkt. Ein Vollprogramm ist laut $\ 2$ II, Nr. 2 $\mathrm{RStV}$ ein Rundfunkprogramm „mit vielfältigen Inhalten, in welchem Information, Bildung, Beratung und Unterhaltung einen wesentlichen Teil des Gesamtprogramms bilden. “ Unklar ist hier jedoch die genaue Auslegung des Begriffs „,wesentlicher Teil“. In der rechtswissenschaftlichen Literatur wird davon ausgegangen, dass jeder der Bereiche Information, Bildung, Beratung und Unterhaltung einen Mindestanteil von zehn Prozent des Gesamtprogramms ausmachen muss (vgl. Schulz 2008: 63, m.w.N.).

\footnotetext{
177 In der Fassung vom 31.08.1991, zuletzt geändert durch Artikel 1 des dreizehnten Staatsvertrags zur Änderung rundfunkrechtlicher Staatsverträge vom 10.03.2010, in Kraft getreten am 01.04.2010.

178 Sinn dieser Vorschrift ist die Sicherstellung darüber, dass solche Ereignisse nicht ausschließlich über verschlüsselte Kanäle gesendet werden.

179 Als europäische Werke gelten - in Anlehnung an \6 der EG Richtlinie vom 3.10.1989 zur Koordinierung bestimmter Rechts- und Verwaltungsvorschriften der Mitgliedstaaten über die Ausübung der Fernsehtätigkeit solche aus Mitgliedsstaaten der EU, aus Vertragspartnerstaaten des europäischen Übereinkommens über grenzüberschreitendes Fernsehen des Europarats und Werke aus anderen europäischen Ländern (Hartstein et al. 1995: 662).
} 


\subsubsection{ARD-Staatsvertrag und ZDF-Staatsvertrag}

Der ARD-Staatsvertrag enthält keine Regelungen für die inhaltliche Ausgestaltung des Programms. Lediglich in $\int 1$ ARD-StV wird normiert, dass das von allen in der $A R D$ zusammengeschlossenen Landesrundfunkanstalten veranstaltete Fernsehprogramm ein Vollprogramm ist. Die inhaltliche Verantwortung liegt bei den einzelnen Anstalten, die ihrerseits an die für sie einschlägigen Landesgesetze und Staatsverträge gebunden sind. ${ }^{180}$

Hingegen enthält der ZDF-Staatsvertrag im II. Abschnitt $\int 5$ ZDF-StV Vorgaben für die inhaltliche Gestaltung der Sendungen. ${ }^{181}$ Danach sollen Sendungen des ZDF einen „objektive[n] Überblick über das Weltgeschehen, insbesondere ein umfassendes Bild der deutschen Wirklichkeit“ vermitteln und „eine freie individuelle und öffentliche Meinungsbildung fördern“. Im Programm sollen sowohl das Geschehen in den einzelnen Ländern als auch die kulturelle Vielfalt Deutschlands angemessen dargestellt werden ( $\$ 5$ II ZDF-StV). Neben der Achtung der Grund- und Menschenrechte sollen die Sendungen des ZDF „,vor allem die Zusammengehörigkeit im vereinten Deutschland fördern sowie der gesamtgesellschaftlichen Integration in Frieden und Freiheit und der Verständigung unter den Völkern dienen und auf ein diskriminierungsfreies Miteinander hinwirken“" ( 5 III ZDF-StV). Aus dem Wortlaut dieser Normen lässt sich eine besondere Bedeutung des (gesamt-)deutschen Geschehens für die Sendungen des $Z D F$ ableiten, da dieses nicht nur von der Berichterstattung zu berücksichtigen, sondern explizit zu fördern ist. Nicht zuletzt besteht ein qualitativer Unterschied zwischen der Darstellung des „Geschehens in den einzelnen Ländern“ und der Darstellung der kulturellen Vielfalt Deutschlands. Während ersteres sich auf nachrichtliche Faktenlagen bezieht, umschreibt letzteres eher Grundlagen gesellschaftlichen Zusammenlebens. Insofern ist davon auszugehen, dass sich das Programm des ZDF eher auf Deutschland insgesamt beziehen soll als auf regionale oder lokale Aspekte. Damit wird ihm auch eine Integrationsfunktion zugeschrieben, die sich auch auf die Annahme einer deutschen Identität beziehen kann.

\subsubsection{Rechtliche Rahmenbedingungen in Österreich}

Die Bestimmungen für den Rundfunk in Österreich finden sich vor allem in zwei Bundesgesetzen. Der öffentlich-rechtliche Rundfunk wird durch das ORF-Gesetz (ORF-G) ${ }^{182}$ geregelt, der privat-kommerzielle Rundfunk durch das Privatfernsehgesetz (PrTV-G) ${ }^{183}$. Im Gegensatz zu Deutschland ist der Rundfunk keine Länder-, sondern Bundesangelegenheit.

\footnotetext{
180 Siehe hierzu auch Abschnitt 5.9.3, S. 114. und Abschnitt 5.9.4, S. 114f. als Beispiele für Bayern, Sachsen, Sachsen-Anhalt und Thüringen.

${ }^{181}$ Inhaltliche Auswirkungen können daneben auch von $\int S$ 10, 11 ZDF-StV (Verlautbarungsrecht der Bundesund Landesregierungen, Wahlwerbung, Bereitstellung von Sendezeit für Religionsgemeinschaften) ausgehen.

182 Hier bezogen auf die Fassung des Bundesgesetzblattes I Nr. 159/2005.

${ }^{183}$ Hier bezogen auf die Fassung des Bundesgesetzblattes I Nr. 66/2006.
} 


\subsubsection{1 Übergreifende Regelungen}

Auch im österreichischen Rundfunkrecht gibt es Regelungen für die Übertragung von „Ereignissen von erheblicher gesellschaftlicher Bedeutung“". Für den ORF ist hier $\int 12$ ORF-G einschlägig; eine übergreifende Regelung für öffentlich-rechtlichen und privaten Rundfunk findet sich jedoch im Fernseh-Exklusivrechtegesetz (FERG). ${ }^{184}$ Dort wird auch eine Definition solcher Ereignisse gegeben ( $\int 4$ I, Nr. 1 - 4 FERG). Im Gegensatz zum deutschen Gesetzgeber wird dafür kein Katalog der infrage kommenden Ereignisse, sondern eine auslegungsbedürftige Voraussetzungsliste veranschlagt. Ereignisse von erheblicher gesellschaftlicher Bedeutung sind demnach solche, auf die mindestens zwei von vier Eigenschaften zutreffen: Sie finden in der österreichischen Bevölkerung breite Beachtung (Nr. 1). Es handelt sich um Sportereignisse, die durch die Teilnahme österreichischer Spitzensportler von besonderer nationaler Bedeutung sind, oder um Sportereignisse, die auf Grund ihrer internationalen Bedeutung breite Beachtung in Österreich finden (Nr. 3). Zudem sollen sie schon in der Vergangenheit im frei zugänglichen Fernsehen ausgestrahlt worden sein (Nr. 4). Die Ereignisse sollen „Ausdruck der kulturellen, künstlerischen und sozialen Identität Österreichs“ sein (Nr. 2). Im Gegensatz zur deutschen Regelung, wird hier explizit auf die Bedeutung des Ereignisses für Österreich verwiesen. Die „Identität Österreichs“ wird auf drei mögliche Felder gesellschaftlichen Zusammenlebens bezogen, in denen diese zum Ausdruck kommen kann, bleibt darüber hinaus aber unbestimmt.

\subsubsection{ORF-Gesetz}

Der $O R F$ ist seit seiner umfassenden Neuordnung durch die Gesetzesreform vom Juli 2001 als eine Stiftung öffentlichen Rechts organisiert, deren Zweck die Erfüllung des öffentlichrechtlichen Auftrags des Österreichischen Rundfunks ist (\$1 II, S. 1 ORF-G). Dieser Auftrag umfasst den Versorgungsauftrag ${ }^{185}$ und den Programmauftrag ( $(1$ II, S. 2 ORF-G). Die Stiftung ist nicht auf Gewinn gerichtet ( $\int 1$ IV ORF-G), als Begünstigter der Stiftung gilt die Allgemeinheit.

Der Programmauftrag ( $\int 4$ ORF-G) bezieht sich auf die inhaltliche Ausgestaltung des Gesamtprogramms. So soll der Österreichische Rundfunk insgesamt ein differenziertes Programm von Information, Kultur, Unterhaltung und Sport anbieten, wobei die Interessen aller Zuhörerinnen, Zuhörer, Zuschauerinnen und Zuschauer ausgewogen berücksichtigt werden sollen ( $\S$ 4, II ORF-G).

An Sendungen aus den Bereichen Information, Kultur und Wissenschaft werden nach $\int 4$, IV ORF-G besonders hohe Qualitätsmaßstäbe angesetzt. Daneben habe der Österreichische Rundfunk auf „die kulturelle Eigenart, die Geschichte und die politische und kulturelle Eigenstän-

\footnotetext{
184 85. Bundesgesetz über die Ausübung exklusiver Fernsehübertragungsrechte.

185 Der Versorgungsauftrag ( $\int 3$ ORF-G) bezieht sich hauptsächlich auf technische Voraussetzungen und umfasst die Ausstrahlung und Sicherstellung der Programm- und Empfangsqualität dreier österreichweiter und neun bundeslandweit empfangbarer Hörfunkprogramme sowie zweier bundesweit empfangbarer Fernsehprogramme.
} 
digkeit Österreichs sowie auf den föderalistischen Aufbau der Republik besonders Bedacht zu nehmen“ (\$ 4, IV, S. 2 ORF-G). Kritisch ist hier anzumerken, dass die Begriffe in der gesetzlichen Regelung des Programmauftrages eine solche Unbestimmtheit aufweisen, dass die Einhaltung kaum überprüft werden kann. ${ }^{186}$

Deutlicher macht der Gesetzgeber seine Vorschriften mit einer Aufzählung von 18 Aufgaben des $O R F$ in $\ 4$, I, Nr. 1-18 ORF-G. Hier finden sich allgemeine Regelungen zur umfassenden Information, Förderung von Kunst und Kultur, dem Auftrag zur Unterhaltung und der angemessenen Berücksichtigung bestimmter Bevölkerungsgruppen. Daneben aber auch die Verpflichtung zur „Förderung der österreichischen Identität im Blickwinkel der europäischen Geschichte und Integration“ ( $\int 4$, I, Nr. 3 ORF-G). ${ }^{187}$ Diese Aufgabe steht in enger Verbindung mit der zur „Förderung des Verständnisses für die europäische Integration“ ( $(4, \mathrm{I}, \mathrm{Nr} .4$ ORF-G) und der Verpflichtung zur „Information über die Bedeutung, Funktion und Aufgaben des Bundesstaates sowie die Förderung der regionalen Identität der Bundesländer“ ( $(\mathbb{4}$, I, Nr. 16 ORF-G).

Im Gegensatz zu den deutschen Regelungen wird hier die Sorge für nationale und regionale Identität explizit in die Verantwortung des Rundfunks gelegt. Für die vorliegende Arbeit sind diese Regelungen von besonderer Bedeutung. Mit der Untersuchung der Rolle des Rundfunks bei der Erzeugung und Perpetuierung dieser Identitäten können en passant Aussagen über die Erfüllung dieser gesetzlich geregelten Aufgabe getroffen werden. ${ }^{188}$

In den Programmgrundsätzen sind zum einen eher allgemeine journalistische Qualitätskriterien aufgezählt, welche die Rolle des Rundfunks in der Demokratie widerspiegeln. Zum anderen wird dem $O R F$ als „Kultursender“ aber auch aufgegeben, „Forum österreichischer Kreativität und Gegenwartskunst“ zu sein ( $(10$ VIII ORF-G). Dieser Aufgabe soll er vor allem durch Eigenproduktionen und entsprechende Auftragsvergabe gerecht werden. Die weiteren Regelungen im ORF-G beziehen sich vor allem auf seine Organisationsstruktur. Weitere Regelungen zu Programminhalten betreffen nur solche des Jugendschutzes und des Werberechts.

\footnotetext{
${ }^{186}$ So wäre eine Überprüfung von \4, III S. 3 ORF-G mit den Mitteln der Inhaltanalyse und aus der Perspektive der Konvergenzthese (vgl. Schatz 1994; Bruns/Marcinkowski 1996; Krüger 2001) denkbar. Jedoch bleibt vollkommen unklar, wodurch sich eine solche „Unverwechselbarkeit“ ergeben soll. Zudem ist auf sie nur ,zu achten“, was einer strikten Auslegung widerspricht.

187 Ähnliche Anforderungen werden auch an den privaten Rundfunk gestellt, für den im Privatfernsehgesetz reguliert ist, ,dass in das Programm österreichbezogene Beiträge, die beispielsweise eine Darstellung des kulturellen, künstlerischen, politischen und sozialen Lebens, des österreichischen Sports oder sonstiger, die Charakteristik Österreichs vermittelnder Elemente beinhalten, einbezogen werden“ ( $\int 7, \mathrm{Nr} .4$ PrTV-G).

188 Wobei einschränkend anzumerken ist, dass sich die Regelung auf die „Gesamtheit der Programme“ bezieht, in dieser Arbeit aber nur Teile davon untersucht werden. Dennoch soll zumindest ein Analyseinstrumentarium zur Verfügung gestellt werden, das mutatis mutandis auch auf das Gesamtprogramm anwendbar ist.
} 


\subsubsection{Rechtliche Rahmenbedingungen in Bayern}

In Bayern enthält das „Gesetz über die Entwicklung, Förderung und Veranstaltung privater Rundfunkangebote und anderer Mediendienste in Bayern“ (Bayerisches Mediengesetz BayMG) die Regelungen für den privaten Rundfunk. Für den öffentlich-rechtlichen Rundfunk (namentlich der Bayerische Rundfunk, BR) werden im „Gesetz über die Errichtung und die Aufgaben einer Anstalt des öffentlichen Rechts ,Der Bayerische Rundfunk“" (Bayerisches Rundfunkgesetz - BayRG) Regelungen getroffen.

Das BayRG regelt in Art. 4 I, dass die Sendungen des Bayerischen Rundfunks nicht nur der Bildung, Unterrichtung und Unterhaltung dienen sollen, sondern darüber hinaus von demokratischer Gesinnung, kulturellem Verantwortungsbewusstsein, Menschlichkeit und Objektivität getragen sein und der Eigenart Bayerns gerecht werden sollen. Der Bayerische Rundfunk soll dabei einen objektiven und umfassenden Überblick über das internationale, nationale und das bayerische Geschehen in allen Lebensbereichen geben. Worin die Eigenart Bayerns besteht, ist nicht näher umschrieben. Jedoch ist davon auszugehen, dass dem Rundfunk hier - zumindest auch - eine integrative und identifikatorische Rolle zugeschrieben wird, die sich auf Bayern bezieht. Da hier nur Bayern insgesamt genannt ist und die einzelnen bayerischen Regionen keine besondere Erwähnung finden, ist anzunehmen, dass Gesamtbayern dabei als übergeordnete Klammer anzusehen ist. Das schließt die Berücksichtigung der einzelnen Regionen nicht aus. Sie sind dann aber als ein Teil Bayerns zu verstehen, der zur bayerischen Eigenart zwar beiträgt, sie jedoch nicht allein ausmacht.

\subsubsection{Rechtliche Rahmenbedingungen in Mitteldeutschland}

Die rechtlichen Vorgaben für den Rundfunk in Sachsen, Sachsen-Anhalt und Thüringen sind für den privaten Rundfunk in den jeweiligen Landesmediengesetzen ${ }^{189}$ festgelegt. Der öffentlich-rechtliche Rundfunk (namentlich der Mitteldeutsche Rundfunk, MDR) ist im „Staatsvertrag über den Mitteldeutschen Rundfunk“ (MDR-StV) reguliert. Der private Rundfunk ist damit jeweils auf Landesebene geregelt, während für den öffentlich-rechtlichen Rundfunk eine länderübergreifende Regelung getroffen wurde.

Im Staatsvertrag über den Mitteldeutschen Rundfunk wird dessen regionale Gliederung festgeschrieben, die Landesfunkhäuser in Dresden, Magdeburg und Erfurt vorsieht ( $\int 2$ I MDR$\mathrm{StV}$. Gemeinsame und überregionale Aufgaben sind hingegen vom Sitz des MDR in Leipzig aus zu erledigen, wobei Teile dieser zentralen Organisation auch in Halle und Erfurt anzusiedeln sind. In dieser staatsvertraglichen Regelung ist das Bestreben zu erkennen, keinem der drei am MDR beteiligten Länder ein Übergewicht in der Programmgestaltung zukommen zu lassen. Auf Grund des Hauptsitzes der Anstalt in Leipzig ist jedoch zu überprüfen, ob sich im

\footnotetext{
189 „Gesetz über den privaten Rundfunk und neue Medien in Sachsen“ (Sächsisches Privatrundfunkgesetz SächsPRG, Fassung vom 21.02.2004), „Mediengesetz des Landes Sachsen-Anhalt“ (MedienG LSA, Fassung vom 8.2.2007), „Thüringer Landesmediengesetz“ (ThürLMG, Fassung vom 5.3.2003).
} 
tatsächlichen Programm des MDR eine Dominanz Sachsens und insbesondere des Raums Leipzig feststellen lässt. Im gemeinsamen Fernsehprogramm des MDR sollen Beiträge aus allen Landesfunkhäusern enthalten sein, zusätzlich wird die Möglichkeit auseinandergeschalteter Landesprogramme eingeräumt ( $\int 3$ II, S. 3 MDR-StV). ${ }^{190}$ Eine anteilsmäßige Anforderung an die Beteiligung der Landesfunkhäuser wird jedoch nicht getroffen. Im Programmauftrag wird jedoch eine angemessene Berücksichtigung der Gliederung des Sendegebiets in Länder gefordert ( $\int 6$ II MDR-StV). Der MDR hat demnach die Funktion einer integrativen Klammer für die drei Bundesländer, die dabei aber ein ausgeprägtes Eigengewicht behalten sollen.

${ }^{190}$ Die Landesprogramme sind nach \4 I MDR-StV ausschließlich für die jeweiligen Länder bestimmt. Ihnen kommt also per se keine integrative Funktion für das Sendegebiet als Gesamtheit zu. 


\section{Zwischenfazit II}

Zwischen Massenkommunikation und Raumvorstellungen bestehen wechselseitige funktionale Beziehungen. Das begriffliche Konzept eines dispersen Publikums weist einige Parallelen zu Nation und Region auf. Letztere basieren beide auf der geteilten Vorstellung darüber, dass eine gewisse Anzahl anderer Menschen sich in ihrem Selbstverständnis auf die gleiche Vorstellung davon berufen, worin die jeweiligen Eigenarten und Besonderheiten einer Nation oder einer Region bestehen. Das Publikum ist an sich ein flüchtiges Konstrukt, das sich nur für die Zeitdauer einer Zuwendung zu bestimmten Medieninhalten konstituiert. Die Nation und die Region sind dagegen relativ dauerhafte Konzepte. In einem Regionalprogramm zum Beispiel können jedoch bestimmte Vorstellungen darüber zum Ausdruck kommen, wie eine spezifische Region beschaffen ist (territoriales Ausmaß, heimischer Dialekt, historische Besonderheiten etc.). Dadurch können entsprechende Wissensstrukturen perpetuiert werden und den einzelnen Mitgliedern des Publikums kann ein über das „Publikumsdasein“ hinausgehendes Selbstverständnis vermittelt werden. Die Beziehung bleibt aber in jedem Fall wechselseitig, das heißt, niemand wird durch Ansehen eines entsprechenden Fernsehprogramms bayerisch oder sächsisch.

Mit anderen Worten: In den Inhalten der Massenkommunikation kann sich lediglich das Wissen manifestieren, auf dem sich soziale Identitäten (mit-)begründen. Die besondere Bedeutung der Massenmedien besteht aber darin, dass sie dafür sorgen, dass es sich dabei um allgemein geteiltes Wissen handelt. Nur in der Vorstellung darüber, dass andere eine zumindest ähnliche Vorstellung darüber haben, was eine bestimmte soziale Identität ausmacht, entsteht diese schließlich erst. Da Nation und Region beide über den persönlich erfahrbaren Lebensraum hinausgehen, wird die Massenkommunikation zu einer Art Ankerpunkt dieser ,vorgestellten Gemeinschaften“. Die besondere Bedeutung des Fernsehens besteht nicht nur darin, „Leitmedium“ zu sein, sondern auch darin, in seinen Inhalten universell zu sein. Es gibt nicht nur Unterhaltung und nicht nur Information, nicht nur politische Nachrichten, sondern auch Spielfilme und Serien.

Die historischen Bedingungen unter denen der Rundfunk in Deutschland und Österreich nach dem zweiten Weltkrieg neu geordnet wurde, wirken sich auf seine Organisationsstruktur bis heute aus. Für Deutschland fasst dies ein Zitat von Leo Flamm gut zusammen:

„Entscheidender Faktor bei der Ausbildung der Rundfunktopographie in Deutschland waren in erster Linie die politischen Verwaltungsräume, denen kommunikationsräumliche Argumente untergeordnet wurden; diese fanden erst in den zeitgenössischen Regionalisierungsdebatten wieder Beachtung. Die ,Rundfunklandschaft ${ }^{\circ}$ im Nachkriegsdeutschland wurde jedenfalls in besonderem Maße von den administrativen Grenzen dominiert" (Flamm 1993: 29). 
Insbesondere für die föderale Rundfunkordnung in Deutschland bedeutet das, dass administrative Gegebenheiten sich auf das Rundfunkwesen teilweise stärker ausgewirkt haben als kulturell gewachsene Räume. Gerade der Begriff der Region beinhaltet die Verbindung von Kultur und Verwaltungsgliederung. Insofern scheint es in der historisch gewachsenen deutschen Rundfunklandschaft eine Aufgabe der Landesrundfunkanstalten zu sein, für die administrativ bestimmten Sendegebiete eine kulturelle Klammer zu bilden. Eine solche Klammer kann nur Bestand haben, wenn sie den kulturellen Grundlagen nicht zuwiderläuft, dabei aber die rein politisch bestimmten Räume dennoch mit kulturellem Leben füllt.

In Österreich stellt sich die Situation anders dar. Hier herrscht ein zentralisiertes Rundfunksystem vor. Der ORF hat schon von gesetzgeberischer Seite die Aufgabe, der österreichischen Identität Ausdruck zu verleihen. Auch das lässt sich nicht zuletzt auf historische Bedingungen zurückführen. So kann diese diese Aufgabe als Betonung nationalstaatlicher Souveränität verstanden werden. Insofern bestünde darin möglicherweise eine bewusste Abgrenzung zum großen Nachbarn Deutschland und könnte als Folge des Anschlusses Österreichs an das Deutsche Reich 1938 verstanden werden. Zum anderen stellt Österreich in seiner heutigen Form und Größe nur noch ein Bruchteil der einstigen Donaumonarchie dar, die sich als Vielvölkerstaat verstand. Unter diesem Aspekt ist die gesetzliche Identitäts-Aufgabe an den österreichischen Rundfunk auch als eine nationalstaatliche identitätsbildendende Aufgabe zu verstehen.

Das Medienangebot und die dahinterliegende Organisationsstruktur sind nicht nur Organe der Gesellschaft, sondern selbst sozial bedingt. Das zeigt sich an unterschiedlichen rechtlichen Rahmenbedingungen ebenso wie an der der wirtschaftlichen Bedeutung und an den historischen Entwicklungslinien (die zur jeweiligen heutigen Gestalt beigetragen haben). 


\section{Forschungsfragen und Untersuchungsanlage}

In den folgenden Abschnitten sollen aus den bisherigen Überlegungen das allgemeine Forschungsinteresse in geeignete Forschungsfragen überführt werden. Die starke Ausdifferenzierung des Forschungsinteresses in jeweils sehr spezifische Einzelhypothesen strukturiert dabei die Datenauswertung vor. Im Anschluss an die Formulierung des Hypothesenkatalogs werden die bisher theoretisch betrachteten Begriffe und Konzepte für die Untersuchung im Medium Fernsehen operationalisiert. Daraus wird schließlich das Analyseinstrumentarium entwickelt und vorgestellt. Bevor die einzelnen Hypothesen und Fragen hergeleitet werden, seien hier nochmals die Hauptfragen der vorliegenden Arbeit genannt:

- Wie ist das Fernsehen im Prozess der Generierung nationaler und regionaler Identität funktional zu verorten? Diese Frage bezieht sich auf die tatsächlichen Programminhalte. Es geht also um die Überprüfung der in Abschnitt 4 (Die Rolle der Massenmedien bei der Konstruktion sozialer und räumlicher Identität) hergeleiteten theoretischen Annahmen.

- Werden im Fernsehprogramm Wirklichkeitskonstruktionen präsentiert, die sich zu anderen gesellschaftlichen Konstruktionsprozessen von Nation und Region konsistent verhalten?

Diese beiden Fragen basieren auf der grundlegenderen Frage:

- Schlagen sich Kennzeichen nationaler und regionaler Identität im Fernsehprogramm überhaupt nieder? Und wenn ja: Wie manifestieren sie sich? Diese Frage unterstreicht den explorativen Charakter der Studie.

\subsection{Hypothesen}

Die im Folgenden formulierten Hypothesen dienen vor allem der Strukturierung der Untersuchungsanlage und der Ergebnisdarstellung. Es handelt sich explizit nicht um - im strengen Sinne - nomologische Hypothesen (vgl. Diekmann 2010: 124). Aus ihrer jeweiligen Annahme oder Ablehnung folgt somit nicht zwangsläufig eine Aussage über bestimmte Zusammenhänge. Vielmehr dienen die hier formulierten Annahmen der Lenkung der deskriptiven Beschreibung. Insofern folgt aus der Anzahl von zutreffenden oder nicht zutreffenden hypothetischen Aussagen keine Bestätigung oder Ablehnung des theoretischen Rahmens. Die Rückbindung erfolgt vielmehr erst im Rahmen der Interpretation der deskriptiven Befunde. Das ist dem explorativen Charakter der Studie geschuldet. Es geht darum, herauszufinden, ob Nation und Region überhaupt Konzepte sind, welche die Programminhalte von Fernsehsendern maßgeblich beeinflussen. 


\subsubsection{Grundannahmen}

Die Untersuchung geht zunächst grundsätzlich davon aus, dass nationale Programme untereinander mehr inhaltlich-strukturelle Ähnlichkeiten aufweisen als mit regionalen Programmen, die sich ihrerseits stärker untereinander ähneln als sie Gemeinsamkeiten mit nationalen Programmen aufweisen. Dieser Annahme liegen die Unterschiede der Konzepte Nation und Region zu Grunde, die sich - wie gezeigt wurde - in mehr Punkten als nur ihrer erdräumlichen Ausdehnung unterscheiden. Aus der oben dargstellten Position der Region als affirmative Antwort auf die Nation (vgl. S. 30) folgt auch, dass sich regionale Fernsehprogramme von national verbreiteten Fernsehprogrammen durch ein jeweils spezifisches Profil unterscheiden sollten. Nur so sind sie im Sinne einer Profilierung der jeweiligen Region als Gegenstück zur Nation von Nutzen.

H1 Nationale und regionale Programme unterscheiden sich so, dass sich auf der einen Seite nationale und auf der anderen Seite regionale Programme in ihrer inhaltlichen Struktur ähneln.

Die weitere Hypothesenbildung basiert auf der Annahme, dass diese Hypothese zutrifft. Sollte sich aber herausstellen, dass dies nicht der Fall ist, wird der Erkenntnisgewinn der Untersuchung nicht geschmälert. Vielmehr können dann auf Grundlage weitgehend deskriptiver Aussagen über die untersuchten Sender Aussagen darüber getroffen werden, worin sich deren Inhalte tatsächlich unterscheiden. Damit werden Rückschlüsse auf die dann in allen vier Einzelfällen unterschiedlichen Konstruktionsgrundlagen nationaler und regionaler Gemeinschaften möglich.

\subsubsection{Hypothesen zum Gesamtprogramm}

Das Profil der untersuchten Fernsehprogramme kann sich nicht in den Magazinsendungen allein niederschlagen. Vielmehr sind die Magazinsendungen in das Gesamtangebot integriert, was deren Image beim Publikum mitbedingt. Ein Sender, dessen Programmprofil keinerlei regionale Spezifität aufweist, wird sich also schwer tun, als kompetente Instanz für regionale Informationen wahrgenommen zu werden. Dasselbe gilt umgekehrt für nationale Sender. Als Beispiel stelle man sich ein Unterhaltungsprogramm vor, das ausschließlich plattdeutsche Mundartsendungen präsentiert. In einem solchen Programmumfeld würde eine Informationssendung zu nationalen Themen im Süden Deutschlands nur sehr begrenzt wahrgenommen. 
Insofern stellt sich die Frage, durch welche Programmprofile ${ }^{191}$ sich die untersuchten Sender auszeichnen.

F1 Welche Programmprofile kennzeichnen die nationalen Sender ORF 2 und ZDF, welche die regionalen Sender BR und MDR?

F2 Welche Strukturen weisen die Programmprofile hinsichtlich des Anteils von fiktionalen und nonfiktionalen unterhaltenden Sendungen sowie Informationssendungen auf? ${ }^{192}$

In der hypothetischen Grundannahme (H1), die der Vergleichsmatrix (vgl. Abbildung 1, S.9) folgt, wird davon ausgegangen, dass sich die regionalen Programme untereinander stärker ähneln als den nationalen Programmen (und vice versa). Daraus ergeben sich in Verbindung mit der Frage nach der Programmstruktur auch die entsprechenden Hypothesen über die Ähnlichkeiten der Programmstrukturen (Anteile von inhaltlichen Angeboten).

H2 Die Ähnlichkeit der Programmstrukturen (Anteile unterhaltender und informierender Sendungen) entspricht der Gegenüberstellung von nationalen Sendern auf der einen und regionalen Sendern auf der anderen Seite.

H2a Die Programmstruktur des ORF 2 ähnelt der des ZDF stärker als der von $B R$ und $M D R$.

H2b Die Programmstruktur des ZDF ähnelt der des ORF 2 stärker als der von $B R$ und MDR.

H2c Die Programmstruktur des BR ähnelt der des MDR stärker als der von $O R F 2$ und $Z D F$.

H2d Die Programmstruktur des $M D R$ ähnelt der des BR stärker als der von ORF 2 und ZDF.

Wie aus der ALM-Fernsehprogrammanalyse hervorgeht, weist das ZDF mit 55 Prozent gegenüber dem Ersten Programm der $A R D$ mit 43,8 Prozent einen leicht erhöhten Informationsanteil auf (vgl. Weiß/Trebbe 2006: T11, einen etwas geringeren Unterschied konstatieren

\footnotetext{
191 Inhaltsprofile des deutschen Fernsehens werden kontinuierlich im Rahmen der Programmforschung der ALM erhoben (vgl. Weiß 2008, Weiß 2009). Daneben werden Programmstrukturen im Auftrag der MediaPerspektiven erhoben (vgl. Krüger/Zapf-Schramm 2008, Krüger/Zapf-Schramm 2009). Seit 2006 liegen zudem Daten aus Österreich vor (Woelke 2007, Woelke 2008b). Diese sind zumindest mit der ALM-Studie gut vergleichbar, da dort weitgehend mit denselben Kategorien gearbeitet wird. Allerdings fehlt es an entsprechenden regelmäßigen Erhebungen zu den Dritten Programmen (zuletzt Krüger/Zapf-Schramm 2000 für die Jahre 1997 - 1999). Deshalb werden in der vorliegenden Studie auch die strukturellen Daten der untersuchten Sender erhoben. Auf diese Weise wird die Vergleichbarkeit (durch einheitliche Kategorien) sichergestellt. Zudem muss bei der Entwicklung des Kategorienschemas der vorliegenden Arbeit keine Rücksicht auf die verfügbaren Studien genommen werden. Schließlich ist es auch in Hinblick auf die Interpretation der Befunde sinnvoll, auf eigens erhobene Programmprofile zurückzugreifen, weil so die inhaltlichen Befunde aus derselben Stichprobe wie die Strukturdaten stammen.

192 Der Begriff der Unterhaltung wird hier als Genrebegriff verwendet, unabhängig davon, dass auch Informationssendungen „unterhaltsam“ sein können. Vgl. hierzu insb. Dehm (1984a), Dehm (1984b), ferner Bernhard (2008: 31).
} 
die MP-Basisdaten Reitze 2007: 24). Ähnliche Anteilswerte erzielt das Programm des ORF 2: Hier entfallen 46 Prozent auf die Fernsehpublizistik (vgl. Woelke 2008a: 32). Hingegen liegt der Informationsanteil bei den Dritten Programmen deutlich höher als im Ersten oder dem ZDF, nämlich durchgehend bei über 60 Prozent (vgl. ARD 2007: 409). Geht man davon aus, dass die Dritten Programme komplementär zum nationalen Fernsehprogrammangebot sind, stellt sich allerdings die Frage, wie der erhöhte Informationsanteil zustande kommt. Denkbar wäre hier, dass im nationalen Programm hinsichtlich gesendeter Informationen andere Relevanzkriterien gelten, die auf einem kleineren gemeinsamen Nenner beruhen, als es im Regionalprogramm der Fall ist. Insofern ist nicht nur zu prüfen, ob die vorliegenden Zahlen auch auf den für diese Arbeit gewählten Untersuchungszeitraum zutreffen, sondern auch, wie sich diese Informationsanteile im Einzelnen zusammensetzen. Das wird in der vorliegenden Arbeit am Beispiel der Magazinsendungen erfolgen.

\section{H3 Der Informationsanteil im Regionalprogramm ist höher als im nationalen Pro- gramm.}

Bezüglich der Zusammensetzung der Information stellt sich die Frage, ob der wahrscheinlich höhere Informationsanteil der Regionalprogramme verstärkt durch Übernahmen (aus anderen $A R D$-Programmen), Wiederholungen sowie im Kern nicht regionale Informationen zustande kommt. Insbesondere letzteres spräche gegen eine tatsächlich komplementäre Informationsleistung, da es sich dann weitgehend um eine Dopplung nationaler und internationaler Themen handelte, zu der sich die regionale Information lediglich hinzuaddiert.

\section{F3 Ist der hohe Informationsanteil der Regionalprogramme deren regionaler Iden-} tität geschuldet?

Wie schon erwähnt, ist für das Image eines Fernsehsenders das gesamte Programmangebot maßgeblich, weshalb auch die unterhaltenden Angebote in die Untersuchung miteinbezogen werden. Insbesondere den Regionalprogrammen wird häufig ein eher altmodisches Programmangebot unterstellt, wenn es um fiktionale Unterhaltung geht. Nicht nur, dass hier häufig Produktionen wiederholt werden, die bereits im Ersten ausgestrahlt wurden, sondern vor allem, dass es sich dabei häufig auch um Filme und Serien älteren Datums handelt, trägt zu diesem Image bei. Das liegt sicher nicht zuletzt an den Bedingungen des Rechtehandels, an dem sich im Wettbewerb mit den Privaten das Erste und das ZDF zwar beteiligen, wenn es zum Beispiel um internationale Kinoproduktionen (z. B. sogenannte „Blockbuster") geht, nicht aber die Dritten Programm der $A R D$, die aber auf das Filmarchiv der $A R D$ zurückgreifen können. Daraus lässt sich zunächst die Hypothese ableiten, dass im Regionalprogramm weniger neue fiktionale Unterhaltungsproduktionen ausgestrahlt werden als im nationalen Programm.

\section{H4 Das Angebot fiktionaler Unterhaltung im Regionalprogramm beinhaltet mehr alte Produktionen als das nationale Programm.}

Zusätzlich stellt sich die Frage, ob auch die Auswahl fiktionaler Unterhaltung in den Dritten besonderen programmplanerischen Linien folgt, die aus regionaler Verwurzelung, Traditionen 
und besonderen Gegebenheiten folgen. Dem lässt sich insbesondere durch die Erhebung von Raum- und Zeitbezügen (Produktionsland, Produktionsjahr, Handlungsorte) für Angebote fiktionaler Unterhaltung nachgehen. Da für die Senderimages insbesondere stereotype Wahrnehmungen verantwortlich sein dürften, bietet es sich daher an, dem Zutreffen solcher Stereotype nachzugehen. Für den Bayerischen Rundfunk kommen etwa sogenannte Heimatfilme mit Handlungsort Alpenraum als stereotypgerechtes Unterhaltungsangebot in Betracht. Darin wird häufig auf eine Landschaftsidylle referiert, die als „typisch bayerisch“ wahrgenommen wird. ${ }^{193}$ Ein Großteil dieser Filme stammt aus den 1950er Jahren, die zum Teil als Inbegriff konservativer Normen und traditionalistischer Ansichten gelten, beides Begriffe, die in Stereotypisierungen Bayerns ebenfalls oft zu finden sind.

Das Programm des MDR hingegen steht im Ruf, einer DDR-Nostalgie Vorschub zu leisten. Nicht nur, dass hier etwa häufig Personen auftreten, die über die ehemalige DDR hinaus kaum Prominenz erlangt haben, sondern auch Filme und Fernsehserien aus DDR-Produktion prägen dieses Bild. Vor allem solche Serien, die in einem hohen Maße Alltagskultur abbilden zumal eine Alltagskultur, die dem westdeutschen Publikum fremdartig erscheint -, können ein entsprechendes Senderimage prägen. Gleichzeitig konservieren sie aber auch ein Stück biographischer Identität des größten Teils der Bevölkerung Mitteldeutschlands. Unabhängig von politischen Implikationen einer solchen Programmgestaltung oder der Frage, ob man sie den Senderverantwortlichen vorwerfen dürfte, kann daran der Charakter des Fernsehens als kulturelles Speichermedium deutlich werden, weil es die Erinnerung an gelebten Alltag fokussieren kann. Die Serien und Filme bilden den vergangenen Alltag nicht nur ab, sondern waren als Teil des DDR-Fernsehprogramms früher selbst Teil dieses Alltags.

Für beide angerissenen Untersuchungsfelder liegt es auf der Hand, Raum- und Zeitbezug gesondert zu erheben. Zum einen, weil keineswegs alle deutschen Filme der 1950er Jahre „Heimatfilme" waren und zum anderen, weil nicht alle fiktionalen DDR-Produktionen den DDRAlltag behandelten oder überhaupt in der DDR spielten. ${ }^{194}$

\section{H5 Raum- und Zeitbezüge fiktionaler Unterhaltung}

H5a Das fiktionale Unterhaltungsangebot im Fernsehprogramm des Mitteldeutschen Rundfunks enthält zum großen Teil Produktionen des DDRFernsehens.

H5b Das fiktionale Unterhaltungsangebot des Bayerischen Rundfunks enthält zum großen Teil bundesdeutsche Produktionen aus den 1950er Jahren.

H5c Ein großer Teil der Handlungsorte fiktionaler Sendungen im MDRFernsehen liegt im Gebiet der ehemaligen DDR.

\footnotetext{
193 Vgl. insbesondere Höfig (1973: 400). Von den acht dort aufgeführten Landschaftstypen fallen allein fünf in den Donau-Alpen-Raum.

194 Wenngleich auch ein Historienfilm aus DDR-Produktion immer noch die Implikation hat, selbst Teil der früheren DDR-Alltagskultur zu sein.
} 
H5d Ein großer Teil der Handlungsorte fiktionaler Sendungen im BR liegt im Alpenraum.

Als Gegenposition zur hypothetisch formulierten und erwarteten Anmutung des Regionalprogramms ließe sich die einfache Umkehrung formulieren, das nationale Programm beinhalte vornehmlich Produktionen neueren Datums und sei weniger eindeutig positioniert, was die raum-zeitliche Verortbarkeit fiktionaler Unterhaltungsangebote betrifft. Da insofern jedoch ein eher uncharakteristisches Bild zu erwarten ist, bietet sich hier eine offene Frage von explorativem Charakter an. Ziel ihrer Beantwortung ist dabei eine Profilbeschreibung des fiktionalen Unterhaltungsangebots von ORF 2 und ZDF (sowohl im Vergleich zueinander als auch im Vergleich zu den Regionalprogrammen).

F4 Wie lässt sich das fiktionale Unterhaltungsangebot der nationalen TV-Sender ZDF und ORF 2 charakterisieren?

Über den Anteil des fiktionalen Unterhaltungsprogramms an regionalen oder nationalen Raumkonstruktionen lassen sich - über die in obigen Hypothesen bereits eingegrenzten Handlungsorte hinaus - Aussagen treffen, indem die Produktions- und (Haupt-)Handlungsorte erhoben und ausgewertet werden. Hierbei interessiert dann auch wieder der Vergleich zwischen nationalen und regionalen Programmen.

\section{F5 Lassen sich zwischen den Raumbezügen fiktionaler Unterhaltungsangebote regionaler und nationaler Sender Unterschiede ausmachen, die auf dem jewei- ligen Sendegebiet beruhen?}

Auch wenn das nicht fiktionale Unterhaltungsangebot ebenfalls einen großen Einfluss auf das Image eines TV-Senders hat und darüber hinaus für nationale und regionale Identität relevant sein kann, soll es im Rahmen dieser Untersuchung lediglich anteilsmäßig berücksichtigt werden. Dasselbe gilt für jene Informationsanteile des Programms, die außerhalb von Magazinsendungen platziert sind. Hierfür soll lediglich der Raumbezug zusätzlich zum zeitlichen Umfang erfasst werden, etwa wenn es sich um eine Reportage handelt. Da der Fokus der Untersuchung auf Magazinsendungen liegt, ist diese forschungsökonomische Einschränkung nötig. ${ }^{195}$

195 Zumal eine zu kleinteilige Erfassung des Gesamtprogramms hauptsächlich dessen struktureller Deskription dienen würde, die im Hinblick auf den Gegenstand der Untersuchung nur ein geringes Plus an Erkenntnis brächte. 


\subsubsection{Hypothesen zu den Magazinsendungen}

\subsubsection{Raumkonstruktionen}

Wie aus den Ausführungen zu den Konzepten Nation und Region deutlich geworden ist, enthalten beide Begriffe auch (unterschiedlich geartete) geographisch-erdräumliche Dimensionen. Daraus ergibt sich die Frage, inwieweit diese Räume durch die Berichterstattung abgedeckt werden. Für das fiktionale Unterhaltungsangebot werden die Bezugsgrößen von Handlungsorten und Produktionsland erhoben (vgl. oben, S. 122). Im Bereich der Magazine lautet die nahe liegende Frage, die an das Untersuchungsmaterial zu stellen ist: Von wo wird berichtet? Obwohl diese Frage sehr einfach erscheint, ist sie nur auf den ersten Blick ebenso einfach zu beantworten. Für die Untersuchung journalistischer Darstellungen innerhalb der zu untersuchenden Magazinsendungen reicht eine einfache Ortsmarkierung - wie im Fall der Handlungsorte fiktionaler Sendungen - zur Beantwortung der Frage nach dem Raumbezug nicht aus. Entscheidungen, die an einem Ort getroffen werden, können sich auf andere Orte und ganze Regionen auswirken. Entwicklungen, die ein ganzes Land betreffen, können anhand von Einzelfällen dargestellt werden, die zwar an einem bestimmten Ort angesiedelt sind, aber journalistisch „pars pro toto“ eingesetzt werden. Der Raumbezug ist daher zu differenzieren. Dafür bietet sich zunächst auf Ebene der berichteten Ereignisse ${ }^{196}$ an zu unterscheiden, ob ein vorhandener Raumbezug konstruiert wurde oder das Ereignis tatsächlich am Berichtsort stattgefunden hat. Daneben ist zu erfassen, ob ein berichtetes Geschehen nur für den Ort, aus dem berichtet wird, relevant ist oder Auswirkungen darüber hinaus hat. Das ist etwa regelmäBig bei Regierungsentscheidungen der Fall, die zwar zumeist am Regierungssitz getroffen und von dort berichtet werden, räumlich aber im gesamten der jeweiligen Regierung unterstellten Hoheits- bzw. Verwaltungsgebiet gelten.

Im nationalen Rahmen ist davon auszugehen, dass weniger partikular-relevante Themen aufgegriffen werden, als das im Regionalprogramm der Fall ist. Für den regionalen Journalismus wird es als originäre Aufgabe angesehen, nah am Alltag des Publikums zu sein und auch von solchen von Ereignissen zu berichten, die eine lokal und regional begrenzte Bedeutung haben. Auf nationaler Ebene geht es hingegen eher um übergeordnete und weitgreifende Themen, welche die große Mehrzahl der Menschen gleichermaßen betreffen. Das folgt schon aus der (bereits begrifflich erörterten) stärkeren symbolischen „Vermitteltheit“ der Nation gegenüber der Region, zumal aus den Begriffen eben auch die weniger starke Raumorientierung der Nation folgt. Daher ist in Bezug auf die räumliche Abdeckung des Sendegebiets zu erwarten, dass lokal begrenzte Sachverhalte und Themen im nationalen Programm seltener vorkommen als im regionalen. Daraus folgt, dass aus dem Staatsgebiet auf nationaler Ebene nur punktuell berichtet wird, wenn kein übergreifendes Thema aufgegriffen wird. Im Regionalprogramm ist dagegen zu erwarten, dass vermehrt Themen lokal und regional begrenzter Bedeutsamkeit aufgegriffen werden und sich aus den Ortsmarken der Berichterstattung das Sendegebiet mo-

196 Der Übersichtlichkeit halber wird hier zunächst nur der Terminus „Ereignis“ verwendet. Magazinbeiträge berichten aber nicht zwangsläufig nur über Ereignisse im engeren Sinn. 
saikartig zu einem Ganzen zusammensetzt. Im Verhältnis dürften damit im Regionalprogramm auch weniger häufig Beiträge vorkommen, deren Thema übergreifend die gesamte Region gleichermaßen betrifft.

\section{H6 Gebietsabdeckung.}

H6a Die Berichterstattung in Magazinen des nationalen Programms deckt den Raum nur punktuell ab.

H6b Die Berichterstattung in Magazinen des Regionalprogramms deckt das Sendegebiet in der gesamten Fläche ab.

Hinsichtlich der Konstruktion des Raumes ist auch eine normative Sichtweise möglich, die danach fragt, ob berichtete Ereignisse und Themen in ihrem Kern tatsächlich die Region betreffen. Normativ ist diese Sichtweise deshalb zu nennen, weil in den gesetzlichen und staatsvertraglichen Grundlagen der Regionalprogramme Anforderungen an das Programm gestellt werden (siehe Abschnitt 5.9). So bestimmt das Bayerische Rundfunkgesetz ebenso wie der MDR-Staatsvertrag, dass die Programme über das internationale, nationale sowie das länderbezogene ${ }^{197}$ Geschehen einen umfassenden und objektiven Überblick geben sollen. Konkretisierungen über die Anteile dieser Informationen werden nicht getroffen, was eine Überführung in eine messbare Anforderung erschwert. Davon ausgehend, dass ein Regionalprogramm einen spezifischen regionalen Informationsmehrwert gegenüber national verbreiteten Programmen bieten sollte, erscheint auf Grund der Dreiteilung in die Bereiche, aus denen informiert werden soll, eine Mindestforderung von einem Drittel regionaler Information bezogen auf den Gesamtinformationsanteil angemessen. Bedenkt man zusätzlich, dass internationale Themen wahrscheinlich weniger stark berücksichtigt werden als in einem nationalen Programm, ist dieser Anteil auch keineswegs unerfüllbar. Im MDR ist bei der Anforderung zusätzlich die Berücksichtigung der Aufteilung des Sendegebiets in drei Bundesländer zu beachten, die auch rechtlich gefordert wird. Fraglich ist hier, ob einer Unterteilung in drei Bundesländer ebenfalls eine Drittel-Anteilsforderung folgen muss oder ob eine solche Anteilsforderung eher an den Bevölkerungsanteilen zu bemessen wäre. Diese Frage kann hier indes dahingestellt bleiben und vielmehr explorativ in dem Sinne angegangen werden, dass diese Anteile festgestellt werden und schließlich zusammen mit der Themenverteilung beschrieben werden können. In der Auswertung kann dann vor dem Hintergrund dieser Verteilungen darauf eingegangen werden, inwieweit der normierte Auftrag erfüllt wird.

Welchen Anteil haben regionale Informationen in Magazinen der Regionalsender?

F7 Wie verteilt sich das regionale Informationsangebot des MDR auf die drei Bundesländer des Sendegebiets?

\footnotetext{
${ }^{197}$ Die Formulierung „länderbezogen“ entstammt dem MDR-StV, der eine neutrale Formulierung wählt, damit alle drei Länder gleichermaßen gemeint sind, im Bayerischen Rundfunkgesetz ist vom bayerischen Geschehen die Rede.
} 
Eine gewissermaßen umgekehrte Folge aus dieser Annahme ist, dass die Berichterstattung im Regionalprogramm auf den Raum des Sendegebiets beschränkt bleibt, während die Staatsgrenzen keine räumliche Einschränkung des nationalen Programms darstellen. Am einfachsten ist dies am übergreifenden Thema „Außenpolitik“ nachvollziehbar. Es betrifft im Regelfall die Nation insgesamt gleichermaßen und ist nicht an lokale Besonderheiten geknüpft.

\section{H7 Gebietsbeschränkung.}

H7a Die Berichterstattung in den Magazinen des nationalen Programms ist nicht auf das Staatsgebiet der Nation beschränkt.

H7b Die Berichterstattung in den Magazinen des Regionalprogramms ist auf das Sendegebiet beschränkt.

Wie bereits erwähnt, sind einfache Ortsmarkierungen kein hinreichender Indikator für die tatsächliche (räumliche) Tragweite des Themas eines einzelnen Berichts und damit die räumliche Abdeckung des Sendegebiets. Insofern sind die Hypothesen H6 und H7 noch hinsichtlich der Bedeutsamkeit berichteter Ereignisse und Themen zu spezifizieren. Die erwähnte „mosaikartige“ Zusammensetzung der Region aus Einzelthemen ist nur für die Gesamtheit der Beiträge messbar, deren Berichtsanlass lokal begrenzte Auswirkung und Bedeutung hat. Gleichzeitig ist zu erwarten, dass weniger Themen berichtet werden, die im Kern die gesamte Nation und nicht nur die Region betreffen. Im nationalen Programm ist umgekehrt eine entsprechende gesamtnationale Bedeutsamkeit der berichteten Themen und Ereignisse zu erwarten.

\section{H8 Ereignis- bzw. Thementragweite.}

H8a Die Berichterstattung in Magazinen des nationalen Programms betrifft das gesamte Staatsgebiet gleichermaßen.

H8b Die Berichterstattung in Magazinen des Regionalprogramms bezieht sich in ihrer Mehrzahl auf subregionale Räume.

Regionale Berichterstattung ist in der Regel aufwändig und kostenintensiv (vgl. Volpers 2005: 4). Möglicherweise ist deshalb vereinzelt zu beobachten, dass im Kern überregionale Themen durch eine regionalisierende Aufmachung ,heruntergebrochen“ werden, ${ }^{198}$ um als regionale Information zu erscheinen. Auf das Herunterbrechen von Berichtsanlässen sind verschiedene Sichtweisen möglich. Sie können einerseits als Service für das Publikum interpretiert werden, wenn komplexe politische Sachverhalte auf ihre unmittelbaren Auswirkungen auf die „Normalbürgerin“ und den „Normalbürger“ reduziert und so vermittelt werden. Eine Regionalisierung der Thematik findet dann jedoch ausschließlich über Akteurinnen und Akteure (die beispielhaften „Normalpersonen“) statt, die jedoch austauschbar sein können. Das trifft insbesondere dann zu, wenn die Auswirkung auf jede andere „Durchschnittsperson“ in einer vergleichbaren sozialen Lage in allen Regionen Deutschlands gleich ausfällt. In diesem Fall handelte es sich um eine im Kern nicht regionale Information. Der höhere Rechercheaufwand für

${ }^{198}$ Ein Beispiel hierfür wäre etwa, wenn das eigentlich überregionale Thema „Verkündung von Arbeitslosenzahlen“ zum Anlass für einen Bericht über einen Langzeitarbeitslosen aus einem Ort in der Region genommen wird. 
die Entdeckung von Berichtsanlässen macht es wahrscheinlich, dass im Regionalprogramm häufiger so verfahren wird als im nationalen Programm. Unter negativen Vorzeichen betrachtet kann bei dem geschilderten Vorgehen von künstlich konstruiertem Raumbezug gesprochen werden.

Ebenfalls ist aber der Fall denkbar, dass nationale oder internationale politische Entscheidungen sich in einer Region spezifisch auswirken. ${ }^{199}$ Hier wäre das Herunterbrechen keine künstliche Regionalisierung, sondern durch das Thema selbst bedingt. Bei der Analyse der verschiedenen Informationsanteile wird daher darauf zu achten sein, wie viel regionale Berichte auch tatsächlich über Regionales berichten. Dabei handelt es sich nicht zuletzt um eine Frage der Informationsqualität. Davon ausgehend, dass für überregionale Themen insbesondere die Nachrichtensendungen die Hauptinformationsquelle sind, kann daher an Magazinsendungen die Anforderung gestellt werden, aus der Region zu berichten, für die der Sender „zuständig ist“. Diese Forderung geht mit der Annahme einher, dass Regionalberichterstattung komplementär zum nationalen und internationalen Informationsangebot ist. Eine regionale Berichterstattung, die sich etwa darauf beschränkte, Auswirkungen bundespolitischer Entscheidungen am individualisierten Beispiel regionaler Akteurinnen und Akteure zu zeigen, würde ihren Zweck also verfehlen. Das leuchtet unmittelbar ein, wenn man sich als Gegenprobe vorstellt, dass bundesweite Nachrichten sich auf die Auswirkungen internationaler Politik auf die Bundesrepublik beschränken würden und so das Handeln deutscher Politikerinnen und Politiker ausblendeten. Hiergegen kann eingewandt werden, verschiedene Politikfelder beträfen Regionen auf ganz andere Weise als die Nation und umgekehrt. Gerade diese Ausdifferenzierung erfordert aber letztlich ein ebenso differenziertes Informationsangebot, da es beispielsweise nicht Aufgabe der regionalen Berichterstattung sein sollte, vermehrt über Außenpolitik zu berichten, sofern dadurch Informationen etwa aus dem Bereich der Kulturpolitik vernachlässigt werden.

H9 Konstruierte Raumbezüge.

H9a In Magazinbeiträgen des Regionalprogramms werden überregionale Ereignisse am Beispiel regionaler Sachverhalte dargestellt (Themen werden regional „heruntergebrochen“).

H9b In Magazinbeiträgen des nationalen Programms werden überregionale Ereignisse nicht auf Einzelregionen „heruntergebrochen“.

H10 Künstliche Herstellung von Raumbezügen durch das „Herunterbrechen“ politischer Entscheidungen und/oder Sachverhalte findet im Regionalprogramm vor allem durch die Darstellung unmittelbarer Auswirkungen im Alltag (regionaler) Normalbürgerinnen und Normalbürger statt.

Ein weiterer Aspekt des Raumes besteht in den Beziehungen der beiden hier untersuchten Länder Deutschland und Österreich zueinander. Diese ist insbesondere durch die geographi-

${ }^{199}$ So dürfte etwa von einer EU-weiten Krabbenfangregulierung Schleswig-Holstein anders betroffen sein als Bayern und Sachsen. 
sche und historische Nähe geprägt. Es wurde festgestellt, dass in der österreichischen Nachrichtengebung Deutschland eine besonders herausgehobene Stellung einnimmt, was sich nur zum Teil aus dem Nachrichtenfaktor Nähe und daneben mit dem „Next-Door-GiantEffekt “200 sowie der gemeinsamen Sprache und Regionalismus erklären lässt (Hagen 1998: 153). Da Magazinsendungen anderen journalistischen Produktionsbedingungen unterliegen als tagesaktuelle Nachrichtensendungen, kann angenommen werden, dass sich die Nähe Deutschlands hier nicht im selben Maße inhaltlich auswirkt. Andererseits ist unklar, ob sich der NextDoor-Giant-Effekt auf bestimmte Themenbereiche konzentriert. Das kann insbesondere für die Themen Politik und Wirtschaft zutreffen. Politik wegen der herausgehobenen Rolle Deutschlands innerhalb der EU, ${ }^{201}$ Wirtschaft auf Grund der vielfältigen unternehmerischen Tätigkeiten deutscher Firmen in Österreich bzw. auch der hohen Importquote. ${ }^{202}$ Auf Grund der deskriptiven Zielrichtung dieses Problemkomplexes sei das hierauf bezogene Interesse als Fragekomplex formuliert.

F8 Wie hoch ist der Anteil der Berichterstattung über Deutschland in österreichischen Magazinen? Wie fällt dieser Anteil im Vergleich mit anderen (Nachbar-) Staaten aus? Wie groß ist umgekehrt die Beachtungsquote Österreichs in deutschen Magazinbeiträgen? Auf welche Themengebiete bezieht sich die österreichische Deutschlandberichterstattung hauptsächlich?

\subsubsection{Qualität der Berichterstattung}

Die künstliche Herstellung von Ortsbezügen steht an der Schnittstelle der Medienfunktion der Raumkonstruktion und den Anforderungen an journalistische Qualität. Hinsichtlich der Güte regionaler Informationen bestehen kaum rechtliche Regulierungen. Lediglich für die landesweiten Regionalfenster (nach $\int 25 \mathrm{RStV}$ ) von RTL und Sat.1 sind in der dazugehörigen Ausführungsbestimmung, der Fernsehfensterrichtlinie, Ansprüche formuliert, die neben einem zeitlichen auch einen inhaltlichen Aspekt haben. Dort heißt es, die

\footnotetext{
200 Schenk 1987 nutzt den Begriff des „,next door giant neighbours“ für einen Nachbarstaaten, über den - trotz unterschiedlicher Bündniszugehörigkeit oder wirtschaftlicher Strukturen - häufig und umfangreich berichtet wird, „,wenn dieser aufgrund seiner Stärke und Machtposition eine Bedrohung darstellen kann“ (Schenk 1987: 40) Als Beispiel wird hier China als „,next door giant neighbour“ von Taiwan angeführt. An gleicher Stelle spricht Schenk auch vom „,next door giant“ und vom ,giant neighbour“. Mittlerweile hat sich der Begriff „Next-DoorGiant" für (meist große) statushohe Nachbarstaaten kleinerer Länder etabliert - unabhängig von unterschiedlichen politischen oder wirtschaftlichen Strukturen. Der größere Staat hat für den kleinen Nachbarn wirtschaftlich, politisch und kulturell eine herausragende Bedeutung. Es konnte nachgewiesen werden, dass in den Medien des kleineren Staates besonders umfangreich und detailliert über den großen Nachbarn - den „Next-door-giant“ berichtet wird (und zwar stärker als in den Medien anderer Staaten, die dem statushohen „Giant“ zwar politisch und kulturell ebenfalls „nah“ sind, aber nicht an ihn angrenzen). Das wird als „Next-door-giant-Effekt“ bezeichnet wird (vgl. Hagen 1998: 153).

${ }^{201}$ Zudem kann der Nachrichtenfaktor „Bezug auf Elite-Nation“ hier eine Rolle spielen, wenn man aus österreichischer Sicht die vergleichsweise große außenpolitische Bedeutung Deutschlands in Betracht zieht.

202 Vgl. Statistik Austria (2007: 113): 41 Prozent aller nach Österreich importierten Waren stammen aus Deutschland, gleichzeitig werden 30 Prozent aller von Österreich exportierten Waren nach Deutschland ausgeführt.
} 
„danach verbleibende Nettosendezeit muss mindestens 20 Minuten redaktionell gestaltete Inhalte zur authentischen Darstellung der Ereignisse des politischen, wirtschaftlichen, sozialen und kulturellen Lebens aus der Region, für die das Regionalprogramm bestimmt ist, enthalten. Davon müssen im Durchschnitt einer Woche mindestens 10 Minuten aktuelle und ereignisbezogene Inhalte sein“ (ALM 2005: Punkt 1. II, 5-6).

Als im weitesten Sinne qualitative Anforderung kann hier die Formulierung ,aktuell und ereignisbezogen“ verstanden werden. ${ }^{203}$ Dabei dürfte es angesichts etwa der Feststellungen Schillings über die Qualität des Regionalprogramms und seiner Beschreibung des „ereignislosen Berichts“ (Schilling 1998: 58, vgl. S. 31) vor allem auf den Ereignisbezug ankommen, um diese qualitative Mindestforderung zu erfüllen. ${ }^{204} \mathrm{Im}$ Grunde genommen wäre ein mangelnder Ereignisbezug auch eine Auswirkung des erhöhten Rechercheaufwands im regionalen Bereich. Hier ist insbesondere an selbstreferentielle Berichte zu denken, etwa über Aktionen und Veranstaltungen, die ein Sender veranstaltet oder tatsächlich selbst inszenierte Ereignisse. ${ }^{205}$

\section{H11 Ereignislose Berichte kommen im Regionalprogramm häufiger vor als im nati- onalen Programm.}

$\mathrm{Zu}$ fragen ist darüber hinaus nach spezifischen inhaltlichen Ansprüchen an regionale und nationale Berichterstattung, die über rechtliche Regulierungen hinausgehen. Dafür kommen quasi-normative Anforderungen infrage, die sich aus den gesellschaftlichen und politischen Funktionen der Massenmedien ergeben. Auf die (politische) Berichterstattung im regionalen Rahmen bezogen, macht Teichert verschiedene Leistungsdefizite der Medien aus (Teichert 1982: 25). Speziell für das Regionalfernsehen sind demnach vor allem folgende Defizite zu beklagen: ${ }^{206}$

1. zu große Nähe zur lokalen und regionalen Politik

2. mangelnde Vielfalt

3. vermittelnde statt kritische Berichterstattung

4. mangelnde Recherche

5. Protokoll- bzw. Terminjournalismus

6. geringe Flexibilität in den Darstellungsformen

\footnotetext{
203 Auch wenn sich die Fernsehfensterrichtlinie nicht auf das hier zu untersuchende Programmangebot bezieht, gibt sie doch ein Beispiel für die Möglichkeit auch inhaltlicher Anspruchsnormen an Fernsehprogramme. Die äußerlich-formalen Aspekte hinsichtlich durchschnittlicher Sendezeit sind hier unbeachtlich.

204 An dieser Stelle sei darauf hingewiesen, dass hier nur auf einige wenige inhaltliche Qualitätsdimensionen eingegangen wird und die Dimensionen der Nachrichten- bzw. Informationsaufbereitung unberücksichtigt bleibt. Die Untersuchung dieser Qualitätsaspekte im regionalen und nationalen Programm im Vergleich wäre bereits eine eigene Studie, angesichts der mittlerweile zahlreichen und differenzierten kommunikationswissenschaftlichen Ansätze zur Messung journalistischer Qualität (vgl. nur Hagen 1995, Bucher 2003, Rager 1994).

${ }^{205}$ Dafür kann etwa die im privaten Rundfunk beobachtbare publizistische Begleitung von Doku-Soaps gelten: Besonders herausragende Fälle werden in Magazinsendungen des Senders in eigenen Berichten vor und nach der Ausstrahlung einer Episode der entsprechenden Doku-Soap zusätzlich aufbereitet, ein tatsächliches Ereignis liegt aber nicht vor, da es sich um Alltagsgeschehen handelt, das nur durch die Sendung in die öffentliche Wahrnehmung rückt.

${ }^{206}$ Hier sind verschiedene von Teichert angeführte Punkte zusammengefasst, die sich teilweise auch auf die Presse beziehen. Grundlage für Teicherts Aufstellung ist eine systematisierende Sichtung damals aktueller empirischer Befunde zum Regional- und Lokaljournalismus.
} 
7. metropolen-zentrierte Programmangebote ${ }^{207}$

Für die vorliegende Arbeit ergibt sich durch die vergleichende Anlage der Studie die Möglichkeit, das regionale Programmangebot daraufhin zu untersuchen, ob es sich gegenüber der nationalen Berichterstattung tatsächlich als defizitär ${ }^{208}$ charakterisieren lässt. Damit ist jedoch nicht die Annahme verbunden, auf die Nation bezogene Berichterstattung sei per se nicht defizitär oder auch nur ein Qualitätsmaßstab. Es kann lediglich verglichen werden, ob etwa auf nationaler Ebene eine größere Flexibilität der Darstellungsformen oder mehr Themenvielfalt herrschen.

Von den bei Teichert aufgelisteten Befunden sind mit der Anlage dieser Untersuchung insbesondere die Punkte 2, 3, 6 und 7 gut zu untersuchen. (Die anderen Punkte entziehen sich zwar nicht der (quantifizierenden) Analyse, würden aber einen verhältnismäßig hohen Aufwand an zusätzlicher Operationalisierungs- und vor allem Kodierarbeit erfordern, der eher im Rahmen einer eigenen Studie vertretbar wäre.) Wie schon erwähnt, soll nicht davon ausgegangen werden, dass die Berichterstattung auf nationaler Ebene ein Vergleichsmaßstab ist, sondern es kann lediglich ein mögliches Vorhandensein entsprechender Unterschiede aufgezeigt werden. Hinsichtlich Teicherts Kritik am geringeren Themenspektrum des Regionalprogramms lässt die theoretische Erörterung der Begriffe Nation und Region aber auch einen gegenteiligen Schluss zu: Weil die Region die kleinere soziale Gemeinschaft als die Nation ist, ist die Schnittmenge geteilter Bezugseigenschaften größer. Im Vergleich dazu, bezieht sich die Nation auf einen kleineren gemeinsamen Nenner von alle Beteiligten gleichermaßen betreffenden Themen. Möglich ist hier etwa vor allem eine Verengung auf das Politische. Daher wird hier die entsprechende Hypothese (H12) als gegenteilige Erwartung zu Teicherts Feststellungen formuliert, die übrigen jedoch in Teicherts Sinne.

\section{H12 Das Themenspektrum der Magazinsendungen im Regionalprogramm ist brei- ter als in nationalen Fernsehprogrammen.}

\section{H13 Magazine des Regionalprogramms zeichnen sich durch geringere Vielfalt der Darstellungsformen aus.}

\footnotetext{
${ }^{207}$ Darüber hinaus kritisiert Teichert, dass „,die föderale Struktur der Rundfunkanstalten in der Bundesrepublik [...] über Jahre die regionalen Programmaufgaben vornehmlich in Richtung umfassender Länderprogramme“ festgelegt habe (Teichert 1982: 28). Länderzentrierte Programmpolitik entspreche dabei aber insbesondere den Öffentlichkeitsansprüchen regionaler Parteien, Verbänden und Institutionen. Teicherts Untersuchung basiert jedoch auf einem enger gefassten Regionenbegriff (vgl. Teichert 1982: 87. Es ist davon auszugehen, dass auch unterhalb der Länderebene Parteien, Verbände und Institutionen weitgehend entlang bestehender Verwaltungsstrukturen (etwa Landkreise) organisiert sind. Da die Daten der folgenden Inhaltsanalyse schon aus forschungsökonomischen Gründen nur auf Basis der bestehenden Verwaltungsstrukturen aggregiert werden können, würde es die Untersuchung überfordern, einen Abgleich der organisatorischen Strukturen mit denen der Berichterstattung in geographischer Form vorzunehmen.

208 Wobei zu klären sein wird, worin ein Defizit bestehen kann, da an Regionalprogramme möglicherweise andere Anforderungen hinsichtlich der Angebotsbreite zu stellen sind als an ein „klassisches“ Fernsehvollprogramm. Darin könnte aber auch gerade ein Problem bestehen, da die Dritten Programme der $A R D$ sich in den letzten Jahren weitgehend zu Vollprogrammen entwickelt haben (so Lünenborg 2006c: 244). Das wäre nur dann unproblematisch, wenn sich die damit verbundene Angebotsvielfalt dennoch als im Kern der Regionalität verpflichtet charakterisieren lässt.
} 
H14 Die Berichterstattung der Magazine des Regionalprogramms konzentriert sich auf regionale Zentren. ${ }^{209}$

Für die Untersuchung eines etwaigen Mangels an kritischer Berichterstattung kann auf die Darstellung von Konflikten zwischen verschiedenen Interessen abgestellt werden. Dabei geht es nicht darum, ob einer Seite grundsätzlich mehr Raum zur eigenen Interessendarstellung eingeräumt wird als einer anderen, sondern ob die Widersprüche zwischen zwei Seiten in der Berichterstattung dargestellt werden. Dies kann über eine meinungsbetonte Form erfolgen, wobei die vom Journalisten vertretene Meinung eine von zwei Seiten wäre, wenn etwa in einem Kommentar eine politische Entscheidung bewertet wird. Aber auch in sachbetonten Darstellungsformen kann ein politisch ausgetragener Konflikt betont und damit der Meinungsbildungsfunktion der Medien entsprochen werden. Auch das von Teichert benannte Problem des Protokoll- und Terminjournalismus verweis implizit auf eine Glättung politischer und gesellschaftlicher Kontroversen in der regionalen Berichterstattung. Insofern ist sowohl die Darstellungsform als auch die Aufbereitung hierfür relevant. Die Darstellungsformen werden bereits für die Hypothese H13 erfasst. Hieran ist dann anzuschließen mit der Frage nach der Häufigkeit meinungsbetonter Darstellungsformen.

\section{H15 In Magazinen des Regionalfernsehens kommen meinungsbetonte Darstel- lungsformen seltener vor als im nationalen Programm.}

Daneben ist zu untersuchen, ob unkritische Berichterstattung im Regionalfernsehen auch in verminderter Konfliktbetonung zum Ausdruck kommt.

\section{H16 Konfliktbetonung.}

H16a Magazinbeiträge im nationalen Programm sind stark konfliktbetont.

H16b Magazinbeiträge im Regionalprogramm sind kaum konfliktbetont.

\subsubsection{Themenbereiche}

Der Erhebung der Themen der Berichterstattung kommt eine zentrale Bedeutung in der Untersuchung zu. Das geht schon aus einigen der bisher formulierten Hypothesen hervor. An dieser Stelle sollen Fragen und Hypothesen formuliert werden, die sich auf einige ausgesuchte Themenbereiche beziehen. Damit soll ermöglicht werden, Vergleichsmaßstäbe zu den oben (Abschnitte 2.4.1.1, 2.4.2.1, 2.5.1.2, 2.5.2.1) dargestellten Daten über die vier Untersuchungsgebiete herzustellen.

Für regionale Informationsangebote lassen sich eine Reihe als besonders wichtig empfundener Themen benennen, die im Zuge einer Studie über „Regionale Interessen und Heimatver-

\footnotetext{
${ }^{209}$ Diese Hypothese ist die Gegenformulierung zur Hypothese H6b, wonach die regionale Berichterstattung in die Fläche gehen soll. Da aber neben einer flächigen Berichterstattung immer noch ein Vorherrschen von Berichten aus einzelnen Zentren möglich ist, sei diese Hypothese hier zusätzlich formuliert.
} 
ständnis“ am Beispiel Nordrhein-Westfalens und des WDR-Fernsehens gewonnen wurden (Simon et al. 2009). Im Rahmen einer dafür unternommenen Repräsentativbefragung wurden jene Themenbereiche identifiziert, die für die Bevölkerung einen hohen Stellenwert für ihre Heimatregion $^{210}$ besitzen. Daraus ergibt sich, dass für das Leben in der Region vor allem die Nähe zu Freundinnen und Freunden und zur Verwandtschaft sowie die Arbeitsplätze als wichtig erachtet werden (Simon et al. 2009: 61). Darauf folgen die Themenbereiche ein spezifisches „Lebensgefühl“, Landschaft und Natur sowie Freizeitmöglichkeiten (vgl. Tabelle 1).

Tabelle 1: Wichtigkeit einzelner Lebensbereiche/Themen für das Leben in der Region.

\begin{tabular}{|c|c|c|}
\hline & Sehr wichtig & $\begin{array}{r}\text { Sehr wichtig/ } \\
\text { wichtig }\end{array}$ \\
\hline Nähe von Freunden bzw. Verwandten & $74 \%$ & $92 \%$ \\
\hline Arbeitsplätze & $73 \%$ & $91 \%$ \\
\hline Lebensgefühl & $67 \%$ & $90 \%$ \\
\hline Landschaft bzw. Natur & $65 \%$ & $90 \%$ \\
\hline Freizeitmöglichkeiten & $59 \%$ & $90 \%$ \\
\hline Mentalität der Menschen, die hier leben & $51 \%$ & $84 \%$ \\
\hline Unternehmen und Firmen & $51 \%$ & $81 \%$ \\
\hline Universitäten bzw. Bildungseinrichtungen & $47 \%$ & $78 \%$ \\
\hline Kino, Theater- bzw. Musikveranstaltungen & $41 \%$ & $74 \%$ \\
\hline Sport & $35 \%$ & $73 \%$ \\
\hline Gastronomie bzw. Kneipen und Cafés & $35 \%$ & $66 \%$ \\
\hline Sitten und Gebräuche & $31 \%$ & $64 \%$ \\
\hline Kunst und Kultur & $30 \%$ & $64 \%$ \\
\hline kommunale Politik & $30 \%$ & $63 \%$ \\
\hline regionale Küche & $27 \%$ & $63 \%$ \\
\hline Basis $(=100 \%)$ & 8.617 & 8.617 \\
\hline
\end{tabular}

Quelle: (Simon et al. 2009: 61): „Repräsentative Befragung ,Regionale Interessen und Heimatverständnis‘, $n=8600$ Befragte ab 14 Jahren in NRW, TNS EMNID.“ Mehrfachnennungen möglich.

Laut den Autoren der Studie ergeben sich drei regionale Grundorientierungen. Dabei wird die Relevanz verschiedener Themenbereiche besonders häufig zusammen genannt: Die erste und wichtigste Grundorientierung setzt sich demnach aus Mentalität, Sitten und Gebräuchen, Lebensgefühl, Landschaft und Natur sowie regionaler Küche zusammen. Die zweite Grundorientierung umfasst die Faktoren Arbeitsplätze, Bildung und Unternehmen in der Region, die dritte Grundorientierung bezieht sich vor allem auf Freizeitmöglichkeiten, Gastronomie, Ki-

${ }^{210}$ Der darin verwendete Regionsbegriff unterscheidet sich allerdings vom in dieser Studie zugrunde gelegten Regionsbegriff, da auf Gebiete unterhalb der Bundeslandgrenze referiert wird, also insbesondere auch auf die kommunale Ebene. Dies erklärt sich daraus, dass die Studie, die im Auftrag der WDR-Sendung „Lokalzeit“ durchgeführt wurde, die täglich in elf Regionalfenster auseinandergeschaltet aus den verschiedenen Gebieten Nordrhein-Westfalens berichtet. 
no, Theater und Musik sowie ferner Kultur und Kunst (Simon et al. 2009: 61). In den verschiedenen Regionen NRWs, wo die Befragung stattgefunden hat, sind die Relevanzeinschätzungen unterschiedlich ausgeprägt. Darüber hinaus weisen die Autoren darauf hin, dass insbesondere die erste Grundorientierung mit einer hohen regionalen Verbundenheit korreliert, wohl auch, weil die anderen Themen (Arbeitsplatz, Bildung etc.) die Menschen auch unabhängig von der jeweiligen Region stark beschäftigen.

Angesichts dieser Befunde kommt der Themenidentifizierung und -klassifizierung eine besonders wichtige Rolle zu. Mit ihr kann geklärt werden, ob im Regionalprogramm tatsächlich andere Themen als im nationalen Programm behandelt werden und ob diese mit den Faktoren für die Identifikation übereinstimmen. Daraus ergibt sich die offen zu formulierende Forschungsfrage:

F9 Welche Themengebiete bestimmen das Regionalprogramm und welche das nationale Fernsehen?

Aus der Vergleichsperspektive der Arbeit sowie der Grundsatzhypothese H1 ergibt sich zudem die Frage nach der daraus möglichen Typologisierung der Programmprofile:

\section{F10 Entsprechen die thematischen Profile der untersuchten Magazinsendungen im nationalen und regionalen Programm der Unterscheidung in regionales und nationales Fernsehen?}

Die fünfzehn wichtigsten Themengebiete, die Simon et al. identifiziert haben, werden allesamt von über 50 Prozent der Befragten als mindestens ,,wichtig“ für das Leben in der Region erachtet. In der Bewertung als „sehr wichtig“ sind die Unterschiede klarer, jedoch möglicherweise relativ deutlich an das Bundesland NRW gekoppelt. So bewerten zum Beispiel nur 27 Prozent der Befragten die regionale Küche als besonders relevanten Themenbereich. Jedoch gibt es relativ wenige besonders charakteristische nordrheinwestfälische Spezialitäten, die in stereotyper Manier mit der Region verbunden sind. ${ }^{211}$

Eine besondere Herausforderung dürfte hier allerdings die teilweise geringe Spezifität einiger Themenbereiche darstellen, die in einer quantifizierenden Untersuchung Unschärfen produzieren kann. So ist es zwar grundsätzlich möglich, so etwas wie das Vorkommen regionaler Mentalitäten oder eines Lebensgefühls im Fernsehen zu erfassen, dies erforderte aber einen entweder dezidiert qualitativen Zugang oder einen - für die vorliegende Studie nicht zu leistenden - Codieraufwand mit entsprechend hohen Anforderungen an den Coder und sehr umfangreiche, ständige Reliabilitätstests.

\footnotetext{
${ }^{211}$ Wie es etwa in Thüringen mit Klößen und Bratwurst oder Weißwurst und Brezn in Bayern der Fall ist.
} 
Auffällig niedrige Werte bei der regionalen Relevanzeinschätzung erreicht neben der kommunalen Politik und dem Sport die Kunst und Kultur. ${ }^{212}$ Das kann ein Hinweis darauf sein, dass der Bereich der „Hochkultur“ (siehe dazu näher S. 134) eher für die Nation als die Region für relevant erachtet wird. Insofern verspricht die vergleichende und detaillierte Berücksichtigung dieses Themenbereichs für die untersuchten Sender einigen Aufschluss.

Hinsichtlich stereotyper Images Österreichs wurde die herausgehobene Stellung der Bereiche Kultur und insbesondere der klassischen Musik festgestellt. Daraus kann die Vermutung abgeleitet werden, dass diese Themenbereiche im österreichischen Fernsehen häufiger vorkommen als im deutschen Fernsehprogramm. Entsprechend des Stereotyps sind die Begriffe Kultur und klassische Musik einzugrenzen. „Klassische Musik“ bezieht sich weitgehend auf ein alltägliches Verständnis des Begriffs und nicht auf die musiktheoretische Epochenbezeichnung. Hier ist insbesondere die Unterscheidung zwischen U- und E-Musik ausschlaggebend. Der Begriff Kultur ist in diesem Zusammenhang stark einzugrenzen und bezieht sich hier auf künstlerische Darbietungen oder Ausstellungen sowie Literatur ebenfalls aus dem ernsten („Hochkultur`) und nicht dem hauptsächlich populären Bereich.

Bei diesen Annahmen ist zu beachten, dass in Deutschland und Österreich das öffentlichrechtliche Fernsehen unterschiedlich strukturiert ist. ${ }^{213}$ Während die beiden Fernsehsender ORF 1 und 2 eher komplementäre Inhalte anbieten, sind das ZDF und Das Erste weitestgehend unabhängig voneinander, auch was die Programmplanung und Inhalte betrifft. ${ }^{214}$ ORF 1 wendet sich eher an eine jüngere Zielgruppe mit unterhaltungsbetonten Programmpräferenzen als der ORF 2. Daraus folgt aber auch, dass die beschriebenen Gegenstände aus dem Bereich der Kultur eher im ORF 2 ihren Platz finden. In Deutschland ist das öffentlich-rechtliche Fernsehen etwas stärker ausdifferenziert, so dass solche kulturbetonten Inhalte teilweise in Spartenprogrammen ausgestrahlt werden. Da aber das ZDF an das Gebot der Grundversorgung gebunden ist und sich vornehmlich an eine ähnliche Zielgruppe wendet wie der ORF 2, kann von einer grundsätzlichen Vergleichbarkeit beider Programme ausgegangen werden. Das enthebt selbstverständlich nicht von der Notwendigkeit, die hier geschilderten Bedingungen bei der Auswertung und Dateninterpretation zu berücksichtigen.

\section{H17 Im ORF 2 wird umfangreicher über Ereignisse und Themen aus dem Bereich „Hochkultur“ berichtet als in den anderen untersuchten Sendern.}

\footnotetext{
212 Wobei die Einteilung in Kunst und Kultur sowie Kino, Theater- und Musikdarbietungen in meinen Augen durchaus angreifbar ist, da hier nicht zwischen Populär- (Kino, Rock- und Popkonzerte) und „Hochkultur“ unterschieden wird, was möglicherweise andere Zustimmungswerte erzeugt hätte. Dafür spricht etwa das Gefälle in den Altersgruppen: Während 42 Prozent der über 50-Jährigen Kunst und Kultur als „sehr wichtig“ einstufen, aber nur 19 bzw. 23 Prozent der 14 - 29-Jährigen bzw. 30 - 49-Jährigen, gibt es dieses Gefälle für den Themenbereich „Kino, Theater- bzw. Musikveranstaltungen“ nicht.

213 Vgl. Abschnitt 5 Strukturelle Rahmenbedingungen (S. 100ff.).

214 Abgesehen etwa von Übertragungen sportlicher Großereignisse, die beide Sender in Kooperation gestalten sowie den eher marktregulatorischen Berücksichtigungen der jeweils anderen Programmplanung (so wird etwa Das Erste im Normalfall zu Terminen der ZDF-Sendung „Wetten, dass...?“ selbst keine konkurrierende Unterhaltungsshow ausstrahlen).
} 


\section{H18 Im österreichischen Programm bildet innerhalb der Kulturberichterstattung die „klassische Musik“ einen besonderen Schwerpunkt.}

Der deutsche Gesetzgeber legt die Kultur weitestgehend in die Kompetenz der Bundesländer. Neben der Bildungspolitik dürfte diese Kompetenzverteilung unter dem Schlagwort „Kulturhoheit der Länder“ einer der bekanntesten Aspekte gesetzgeberischer Kompetenzverteilung nach föderalem Prinzip sein. Diese Verteilung ist Ausdruck und Mitursache der besonderen Rolle von Kultur in den und für die Regionen. Daraus können für Programminhalte aus dem Bereich Kultur verschiedene Folgen resultieren. So kann man zum Beispiel davon ausgehen, dass in Regionalprogrammen mehr aus dem Bereich der Kultur (wiederum i. S. v. „Hochkultur") berichtet wird als im nationalen Programm. Verdeutlicht sei dies am Beispiel Theater: Hier ist denkbar, dass von lokalen Theatern, die keinen herausragenden Ruf über die Region hinaus genießen, berichtet wird, während im nationalen Programm insbesondere große und etablierte Bühnen von internationalem Rang berücksichtigt werden. Gleichzeitig kann der Fokus auf andere Aspekte gelegt werden: Im nationalen Programm könnte die Auseinandersetzung mit künstlerischen Aspekten, schauspielerischen und inszenatorischen Leistungen im Vordergrund stehen. Im Regionalprogramm könnte stattdessen der wirtschaftliche Aspekt hervorgehoben werden, da der Kulturetat von kleineren Kommunen häufig zur politischen Disposition steht, wenn die öffentliche Hand sparen muss. Hier würde dann auch Teicherts Kritik am Regionaljournalismus relevant: Statt inhaltlicher Auseinandersetzung mit den Theaterinszenierungen werden möglicherweise nur Aufführungstermine als Serviceleistung bekannt gemacht (,vermittelnde statt kritische Berichterstattung“, „,mangelnde Recherche“6215).

\section{H19 In der Kulturberichterstattung des Regionalprogramms dominiert hinweisende Berichterstattung gegenüber kritischen Formen.}

\section{H20 Kulturpolitik ${ }^{216}$ kommt im Regionalprogramm häufiger vor als im nationalen Programm.}

Auch der Sport wird nur von knapp über einem Drittel der Befragten der WDR-Studie als „sehr wichtig“ eingeschätzt. ${ }^{217}$ Unabhängig davon gilt der Sport jedoch als fixe Größe regionaler aber auch nationaler Identifikation. ${ }^{218}$ Dabei ist er teilweise auch stereotyp besetzt, wie sich etwa an der immer wiederholten Rede von den „deutschen Tugenden“ (Kampf, Siegeswillen, Einsatzbereitschaft, Durchsetzungsvermögen etc.) im Fußball zeigt. Dies kann zwar - analog zum Bereich „Hochkultur“ - auch als Ausdruck höherer Wichtigkeit im Bereich der Nation angesehen werden, dieser Vermutung widerspräche jedoch die teilweise noch immer deutliche regionale Verankerung vieler Sportvereine, insbesondere wenn man an Ballspielsportarten denkt. Eine unterschiedliche Gewichtung nach Sportarten hat bei der WDR-Umfrage leider

\footnotetext{
${ }^{215}$ Davon ausgehend, dass fundierte Theaterkritik entsprechendes Hintergrundwissen voraussetzt.

216 Auf den hier gemeinten Bereich der Kultur beschränkt, ohne Bildungspolitik, auch wenn die gemeinhin in den Aufgabenbereich der Kultusministerien fällt.

217 Aber von immerhin zehn Prozent mehr als mindestens „,wichtig“ als Kunst/Kultur und Kommunalpolitik.

218 Das wird schon aus den oben genannten Regelungen zu gesellschaftlichen Großereignissen deutlich.

Vgl. S. 110.
} 
nicht stattgefunden, es kann aber davon ausgegangen werden, dass sich hier ein differenzierteres Bild hätte zeichnen lassen. Denkt man nämlich an andere Sportarten als Hand- und Fußball, kann man schnell zur Einschätzung gelangen, dass sie eher auf nationaler Ebene ein Identifikationspotenzial entwickeln als in der Region. Als Beispiel könnte etwa der „DeutschlandAchter“ im Rudern oder der „Deutsche Vierer“ im Bahnradsport dienen. Noch weiter in den Hintergrund scheint die Region in Individualsportarten zu treten. ${ }^{219}$

Erhebungen über den Umfang und die Struktur der Sportberichterstattung sind etwa mit Rühle 2003 verfügbar. Darin ist eine relativ klare Dominanz des Fußballs im deutschen Fernsehen erkennbar (vgl. Rühle 2003: 224). ${ }^{220}$ Ohne in dieser Arbeit den gleichen Erhebungsaufwand betreiben zu wollen, wie er für eine genuine Sportstudie geleistet werden kann, sollen doch diesbezügliche Fragen untersucht werden. Damit soll das Sportangebot im Rahmen der regionalen oder nationalen Identitätsfunktionen des Fernsehens näher beleuchtet werden. Dies ist sinnvoll, weil Sport in Spartenmagazinen vorkommen und damit einen thematischen Schwerpunkt bilden kann. Zudem können sich entlang der regionalen und nationalen Unterscheidungslinie relativ deutliche Unterschiede ergeben, die nationalen Stereotypen und regionalen Besonderheiten geschuldet sein können. Insbesondere die erwartbare Dominanz alpiner Skisportarten im österreichischen Fernsehen wäre hier zu nennen aber auch die wahrscheinlich verschiedenen regionalen Einflussgrößen. In Mitteldeutschland spielte zum Zeitpunkt der Stichprobenziehung kein Fußballverein in der ersten oder zweiten Fußballbundesliga, ${ }^{221}$ in Bayern aber allein sechs Mannschaften. ${ }^{222}$ Das lässt erwarten, dass bei gleich bleibender sozialer Funktion des Fußballs im regionalen Bereich, unabhängig von der sportlichen Klasse, unterschiedliche Anteile auf die Berichterstattung aus den unterschiedlichen Ligen entfallen. Dabei ist im Falle Bayerns zusätzlich interessant, wie stark sich der sportliche Erfolg auf die Medienpräsenz auswirkt, was nicht zuletzt eine (medien-)sportpolitische Frage ist.

Bei diesen Überlegungen ist zwischen (semi-)professionellem Wettkampfsport und Breitensport zu unterscheiden. Letzterer dürfte - wenn überhaupt - wohl nur im Regionalfernsehen vorkommen, da er insbesondere lokal verankerte Strukturen aufweist. ${ }^{223}$

\section{H21 Unterschiede in der Sportberichterstattung.}

\section{H21a Im ZDF dominiert Fußball die Sportberichterstattung.}

\footnotetext{
${ }^{219}$ Vgl. hier etwa Befunde zur Berichterstattung über die Tour de France, Ihle 2008: 66.

${ }^{220}$ Jedenfalls anhand der Gesamtzahlen für alle Sender. Die unterschiedlichen Ausdifferenzierungen bei einzelnen Sendern sind unterschiedlichen Rechteverteilungen (etwa an Bundesliga etc.) geschuldet oder auch bestimmten größeren Sportereignissen wie Olympischen Spielen oder Weltmeisterschaften.

221 Vier Mitteldeutsche Vereine spielten hingegen in der 2008/09 neu geschaffenen 3. Liga: Dynamo Dresden, Rot-Weiß Erfurt, Erzgebirge Aue, Carl-Zeiss Jena; bayerische Vereine in dieser Liga: SpVgg Unterhaching, FC Bayern München II, SSV Jahn Regensburg, SV Wacker Burghausen.

222 1. Liga: FC Bayern München, 2. Liga: 1. FC Nürnberg, SpVgg Greuther Fürth, FC Augsburg, 1860 München, FC Ingolstadt 04.

${ }^{223}$ Wobei hier aber vom eher individualisierten Fitnesssport zu unterscheiden ist, der keine derartigen Strukturen aufweist, aber auch kaum auf Wettkampf ausgerichtet ist. Auf Grund der vorrangigen Zielrichtung der Gesundheitspflege dürfte dieses Thema auch nicht in der Sportberichterstattung im engeren Sinne vorkommen, sondern eher im Rahmen von Gesundheits- und Ratgeberthemen.
} 
H21b Im ORF 2 dominiert alpiner Skisport die Sportberichterstattung.

H21c Im MDR dominiert Fußball auf Regional- und Drittligaebene die Sportberichterstattung.

H21d Im BR dominiert Erst- und Zweitligafußball die Sportberichterstattung. H22 Über Breitensport wird nur im Regionalfernsehen berichtet.

In der WDR-Studie kommt Religion als für wichtig befundenes regionales Thema gar nicht vor. Es ist nicht davon auszugehen, dass dieses Thema auf nationaler Ebene eine größere Wichtigkeit erlangte, sondern vielmehr als eher im privaten Bereich belangvoll erachtet wird. Für die Untersuchung eignet es sich hier dennoch, da - wie oben dargestellt (S. 46, S. 54, S. 71 u. S. 75) - die Unterschiede zwischen den Regionen aber auch den beiden untersuchten Nationen bezüglich der Verteilung der Konfessionszugehörigkeit relativ deutlich sind. Wenn das TV-Programm diesen Gegebenheiten inhaltlich folgt, ergeben sich daraus folgende Erwartungen:

H23 Unterschiede im Themenbereich Religion/Kirche.

H23a Im Bayerischen Rundfunk dominiert die katholische Kirche den Themenbereich Religion.

H23b Im Mitteldeutschen Rundfunk kommen religiöse Themen nur im marginalen Umfang vor.

H23c Im ZDF verteilt sich die Behandlung religiöser Belange relativ gleichmäßig auf evangelische und katholische Kirchen, während andere Religionen nur vereinzelt behandelt werden.

H23d Im ORF 2 dominiert die katholische Kirche den Themenbereich Religion.

Für den Bereich der Wirtschaftsberichterstattung bietet sich ebenfalls ein Vergleich mit den regional und national unterschiedlichen Gegebenheiten an. Hier ist etwa an die unterschiedlichen Ausprägungen bestimmter Industrie- und Dienstleistungszweige zu denken. Auf Grund der sehr starken Ausdifferenzierung der Wirtschaft ist hier eine offene Fragestellung zu bevorzugen. Sie ermöglicht es, die Struktur der Wirtschaftsberichterstattung mit den - oben bereits referierten - Wirtschaftsdaten der beiden Staaten und Regionen zu vergleichen. Dies enthebt zudem von der Unterstellung einer Abbildungsfunktion von Realität, die im Bereich der Wirtschaft mit ihren vielfältigen Einflussmöglichkeiten auf die Medienproduktion ohnehin fragwürdig wäre.

F11 Über welche wirtschaftlichen Themen und aus welchen Wirtschaftsbereichen wird in den vier Untersuchungsgebieten berichtet? Welche Unterschiede lassen sich dabei ausmachen?

In enger Verbindung mit der Wirtschaftsberichterstattung steht auch der Bereich des Berufslebens. Diese Kategorie ist eine individuelle, die sich anhand gezeigter Personen erschließt, sofern diese als berufstätig in einem bestimmten Bereich kenntlich gemacht werden. Solche 
Individualkategorien sollen auf Ebene von Akteurinnen und Akteuren untersucht werden. Das ist insofern wichtig, weil die rein thematische Unterscheidung zwischen Alltagsinformation und anderweitiger Informationen keinen Aufschluss darüber gibt, welche Personen im Programm zu Wort kommen und damit auch als Repräsentantinnen und Repräsentanten und/oder Identifikationsfiguren der Region oder Nation fungieren (siehe hierzu, Seite 139).

Da sich nationale und regionale Identität insbesondere auch über die als gemeinsam gedachte Geschichte konstituiert, kommt historischen Themen und Bezugnahmen besondere Bedeutung zu. Wie oben (in Abschnitt 2.4.1.2 Geschichte, S. 47ff.) bereits ausgeführt, ist es für diesen Themenbereich sinnvoll, zunächst zu erfassen, welche historischen Themen in welcher Häufigkeit und in welchem Umfang vorkommen. Anschließend wird dann zu überprüfen sein, ob sich daraus für alle Untersuchungsgebiete unterschiedliche „Geschichtsprofile“ ergeben, die sich auf deren regionale oder nationale Identität beziehen lassen. Aus den Erörterungen zur jeweiligen Geschichte ergibt sich aber die Möglichkeit, Erwartungen an diesen Themenbereich zu formulieren. So ist davon auszugehen, dass im MDR häufig auf die DDR-Geschichte Bezug genommen wird, im ORF hingegen auf die k.u.k-Monarchie, während im ZDF eher mit häufiger Behandlung der Zeit von 1933-45 und der unmittelbaren Nachkriegszeit zu rechnen ist und im Bayerischen Fernsehen die Geschichte des Königreichs Bayern eine herausgehobene Rolle spielen könnte. Die Besonderheit bei der Erfassung geschichtlicher Themen dürfte in der bestehenden Verbindung zeitlicher und räumlicher Aspekte liegen.

\section{H24 Unterschiede im Themenbereich Geschichte.}

H24a Im Themenbereich Geschichte wird im MDR die DDR häufiger behandelt als andere historische Themen.

H24b Im Themenbereich Geschichte wird im ZDF die nationalsozialistische Herrschaft in Deutschland häufiger behandelt als andere historische Themen.

H24c Im Themenbereich Geschichte wird im ORF 2 die k.u.k-Monarchie häufiger behandelt als andere historische Themen.

H24d Im Themenbereich Geschichte wird im BR das Königreich Bayern des 19. Jahrhunderts häufiger behandelt als andere historische Themen.

\subsubsection{Akteurinnen und Akteure}

In der fortgesetzten Programmanalyse des IFEM speziell für die Dritten Programme der $A R D$ (Krüger/Zapf-Schramm 2000) wurde der hohe Anteil und damit die besondere Bedeutung des Berichterstattungsbereichs „Alltagsinformation“ herausgestellt. Dafür werden in der Programmbeobachtung vor allem auf Sendungsebene ermittelte Informationsanteile verantwortlich gemacht. Das heißt, dass vor allem Ratgebersendungen und auf bestimmte Themen fokussierte Dokumentationen für diesen Befund herangezogen werden (vgl. Krüger/ZapfSchramm 2000: 537). Für das Erkenntnisinteresse dieser Arbeit ist das Vorgehen nicht differenziert genug, da der Themenbereich „Alltag“ sowohl einer ist, der sich in darauf bezogenen 
Themen darstellt als auch in der Präsentation von Akteuren und Akteurinnen und auf dieser Ebene sehr unterschiedliche Ausprägungen möglich sind. Das heißt, dass unabhängig vom Thema eines Beitrags Menschen in einer bestimmten Kulisse zu Wort kommen können. Sie können in einem beruflichen oder freizeitlichen Ambiente gezeigt werden, das jeweils noch weiter ausdifferenziert werden kann. Wird eine Person im geschlossenen Raum seines Büros gezeigt oder in der freien Natur? Handelt es sich bei der Lokalität um einen freizeitlich oder beruflich konnotierten Raum? Aus der Erfassung dieser verschiedenen Kulissen ergibt sich ein Bild des im Fernsehen repräsentierten „Alltags“ von Menschen in den Untersuchungsgebieten. Hieran lässt sich ablesen, durch welche Lebensbereiche die unterschiedlichen Untersuchungsgebiete in ihrer Darstellung hautsächlich geprägt werden. So können auch Themenbereiche wie Landschaft und Natur ${ }^{224}$, die sehr stark durch Bildsprache vermittelt werden und nicht ausschließlich als Themen der Berichterstattung erfassbar sind, der Untersuchung zugänglich gemacht werden.

\section{F12 In welchen Umgebungen werden Akteurinnen und Akteure der Berichterstat- tung gezeigt? Lassen sich dabei Unterschiede erkennen, die sich aus den Un- terschieden der Untersuchungsgebiete bzw. ihrer unterschiedlichen Images er- klären lassen?}

Ein zumindest für Regionen wichtiger Aspekt hinsichtlich ihrer individuellen Merkmale sind Dialekte. Auf Grund ihrer meist nur regional begrenzten Verbreitung ist ihre Verwendung ein wichtiger Träger regionaler Identität. Da regionales Programm sich damit grundsätzlich an ein Publikum richtet, dem ein Verständnis des jeweiligen Dialekts unterstellt werden kann, ist davon auszugehen, dass im Regionalfernsehen häufiger Dialektsprecher und -sprecherinnen vorkommen als im nationalen Programm. ${ }^{225}$

\section{H25 Akteurinnen und Akteure in Magazinbeiträgen des Regionalprogramms spre- chen häufiger Dialekt als solche im nationalen Programm.}

Auch in der Auswahl der zu Wort kommenden Akteurinnen und Akteure selbst liegt aus Perspektive der Repräsentationsfunktion der Medien eine Mitgestaltung der Wahrnehmung von Nation und Region, die sich ja als soziale Gemeinschaften konstituieren. Geht man davon aus, dass die Region als lebens- und alltagsnäher empfunden wird als die Nation, kann das im Fernsehen auf verschiedene Weisen zum Ausdruck kommen. So ist anzunehmen, dass Akteure und Akteurinnen im nationalen Programm vor allem auf Grund statushoher Funktionen zu Wort kommen, die ihrerseits bereits eine Repräsentationsfunktion beinhaltet. Das ist etwa für gewählte politische Vertreterinnen und Vertreter der Fall, gilt aber etwa auch für Wirtschaftsvertreterinnen und -vertreter, da sie ihr Unternehmen repräsentieren. Da im nationalen Pro-

\footnotetext{
${ }^{224}$ Die in der Wichtigkeitseinschätzung für das Leben in der Region an vierter Stelle stehen, vgl. Tabelle 1.

225 Grundsätzlich ist bei Zutreffen dieses Befundes als Ursache auch möglich, dass im nationalen Programm statushöhere Personen vorkommen als im regionalen Programm. Zudem könnten Dialektsprecher vor einer Fernsehkamera des nationalen Senders sich eher aufgefordert fühlen, Hochdeutsch zu sprechen als vor der Kamera des eigenen Regionalsenders. Jedoch ändern diese Ursachen nichts an der daraus folgenden Repräsentation im Fernsehen, die hier erfasst werden soll.
} 
gramm auf Grund der theoretisch größeren Verbreitung der gemeinsame Nenner des anzusprechenden Publikums kleiner ist, kann angenommen werden, dass rang- oder statushohe Vertreter- bzw. Symbolfiguren häufiger zu Wort kommen. Statt Landesvorsitzenden einer Gewerkschaft werden eher Amtsträgerinnen und Amtsträger auf Bundesebene zu Wort kommen, wenn das berichtete Thema nicht regional begrenzt ist - was angenommenerweise im nationalen Programm seltener als im Regionalfernsehen der Fall ist. Da die in Amt oder Funktion integrierte Repräsentationsfunktion insbesondere aber bei politischen Mandatsträgern und Mandatsträgerinnen vorkommt und die Politik auf Bundesebene in den meisten Fällen Themen generiert, die das gesamte Staatsgebiet gleichmäßig betreffen, ist mit einer Mehrzahl politischer Akteurinnen und Akteure im nationalen Fernsehen zu rechnen.

Darüber hinaus stellt sich die Frage, wie sich die politische Hierarchie von Länder- und Bundesebene im TV-Programm niederschlägt. Die größere Lebensnähe der Region könnte sich etwa darin zeigen, dass im politischen Bereich rangniedrigere Vertreterinnen und Vertreter zu Wort kommen als im nationalen Fernsehen. Während Bundestagsabgeordnete ihren Wahlkreis in Berlin vertreten und damit die durch sie vertretenen Bürgerinnen und Bürger schon räumlich entfernt agieren, sind Ortsvorsteherinnen und -vorsteher ebenfalls gewählte Repräsentantinnen und Repräsentanten, aber erscheinen im Alltag präsent, schon weil ihre Entscheidungen häufig unmittelbar nachvollzogen werden können.

\section{H26 Bandbreite von Akteuren.}

H26a Die Mehrzahl der Akteure im nationalen Programm sind politische Akteure.

H26b Im Regionalprogramm sind die Akteure relativ gleichmäßig auf verschiedene gesellschaftliche Interessengruppen verteilt.

H27 Politische Akteure in Magazinbeiträgen des Regionalprogramms sind in der politischen Hierarchie niedriger angesiedelt als solche im nationalen Programm.

\subsection{Anlage und Durchführung der Untersuchung}

In den folgenden Abschnitten wird das Analyseinstrument vorgestellt, mit dem die bisher dargestellten Fragen und Hypothesen beantwortet und überprüft werden sollen. Hier werden vor allem die zentralen Untersuchungseinheiten bestimmt und die wichtigsten Analysekategorien erörtert. Zuvor wird die Auswahl des Untersuchungsmaterials begründet. 


\subsubsection{Methode}

In der vorliegenden Arbeit geht es vor allem um die formal-inhaltlichen und thematischen Strukturen im Fernsehprogramm. Ihnen wird mittels standardisierter Inhaltsanalyse ${ }^{226}$ nachgegangen. Die Wahl der Methode ergibt sich bereits aus der Zielrichtung der Studie. Es geht darum, herauszufinden, ob sich bestimmte Fernsehprogramme in ihren Inhalten auf spezifische Weise voneinander unterscheiden. Dazu müssen diese Inhalte sinnvoll und kontrolliert erfasst werden. Hierfür ist die Inhaltsanalyse das geeignete Instrument. Sie dient dazu, inhaltliche und formale Merkmale von Mitteilungen systematisch und intersubjektiv-nachvollziehbar zu beschreiben (vgl. Früh 2007: 27). Ziel dieses Vorgehens ist eine auf die gewonnenen Daten gestützte interpretative Schlussfolgerung auf Sachverhalte, die über die Mitteilung hinausgehen (vgl. Früh 2007: 27). Es soll also „,von Merkmalen eines manifesten Textes auf Merkmale eines nicht-manifesten Kontextes geschlossen“" werden (Merten 1983: 16). In der vorliegenden Arbeit ist dieser Kontext ein gesellschaftlicher - es sollen Rückschlüsse über die wechselseitigen Beziehungen zwischen Fernsehen und nationaler bzw. regionaler Identität ermöglicht werden. Das betrifft insbesondere den Aspekt der Identifizierbarkeit des jeweiligen Programms. In der Folge betrifft es aber auch die darin zum Ausdruck kommende Relevanz dieser sozialen Konstrukte für das Fernsehen. Die Systematik der Untersuchung wird dadurch gewährleistet, dass das gesamte Untersuchungsmaterial mit denselben Maßstäben analysiert wird. Im Klartext gibt es also für alle vier zu untersuchenden Sender nur ein Kategorienschema und nicht vier verschiedene.

Die Inhaltsanalyse ist in der Kommunikationswissenschaft hinreichend bekannt, definiert und erprobt. Auf weitergehende theoretische und methodologische Erörterungen wird deshalb an dieser Stelle verzichtet. Stattdessen wird das tatsächliche Vorgehen im Rahmen der vorliegenden Studie dargelegt.

\subsubsection{Untersuchungsmaterial}

Die Auswahl des Untersuchungsmaterials ergibt sich zum Teil bereits aus der Fragestellung und dem Forschungsinteresse der Studie (siehe S. 9). Da die vier Sender (ORF 2, ZDF, BR und $M D R$ ) durch die Fragestellung und theoretische Vorüberlegungen bestimmt sind, gehört deren Auswahl noch in den Bereich der Definition der Grundgesamtheit und nicht der Stichprobe (vgl. Kops 1977: 29, Jandura et al. 2005: 72).

Als Untersuchungsmaterial wurde eine natürliche Woche im Herbst 2008 bestimmt (27. Oktober bis 02. November). Innerhalb dieser Woche wurden täglich 16 Stunden Pro-

\footnotetext{
${ }^{226}$ Den Terminus „,standardisierte Inhaltsanalyse“ schlägt Rössler zur Vermeidung der missverständlichen Begriffe „quantitativer“ und „qualitativer“" Methode vor (vgl. Rössler 2005: 16). Die mangelnde Präzision dieser Unterscheidung ergibt sich schon daraus, dass die Inhaltsanalyse „die Häufigkeit ,qualitativer ${ }^{\circ}$ Merkmale an einer Vielzahl von Texten ermittelt [...]. Insofern ist sie also in der Regel zwar eine quantifizierende Methode, die aber die ,qualitative“ Analyse voraussetzt“ (Früh 2007: 39). Oder kurz gesagt handelt es sich um „eine Methode, die zwei qualitative Analyseschritte durch einen quantifizierenden verbindet“" (Früh 2007: 67).
} 
gramm ( 9 bis 1 Uhr) der vier Sender aufgezeichnet. Die aufzuzeichnende Woche wurde so ausgewählt, dass sie möglichst frei ist von erwartbaren Großereignissen (wie etwa bestimmte Sportveranstaltungen oder politische und gesellschaftliche Begebenheiten), auf die eventuell von den Senderverantwortlichen mit Änderungen der Programmroutinen reagiert worden wäre. So soll eine möglichst typische Abbildung der regelmäßigen Programmrealität im Untersuchungsmaterial erreicht werden. Die Auswahl solcher „Normalzeiten“ dient vor allem der Vermeidung der Dominanz von bestimmten Ereignissen in der Berichterstattung (vgl. Wolling 2005: 148). Dennoch gibt es üblicherweise Themen und Ereignisse, die in der Berichterstattung besonders präsent sind, auch über den eigentlichen Ereigniszeitpunkt hinaus. Das ist allerdings nicht zwangsläufig problematisch, denn es erscheint letzten Endes ohnehin „fragwürdig, eine ereignisarme Zeit per Definition als normal zu betrachten. Zum anderen sind viele Zeiten, die auf den ersten Blick als Normalzeiten bezeichnet werden könnten, vermutlich weniger normal als der Name es vermuten lässt, denn herausragende Themen gibt es fast immer“ (Wolling 2005: 148, Hervorhebung im Original). In der vorliegenden Untersuchungswoche waren dies die zurückliegenden Parlamentswahlen in Österreich und Bayern (jeweils 28. September) und deren Folgen (Regierungsbildung etc.) sowie die bevorstehende Wahl des USPräsidenten (4. November).

Der Zeitraum einer Woche entspricht den Bedingungen des Fernsehprogramms, das in seiner Struktur normalerweise dem siebentägigen Rhythmus folgt. ${ }^{227}$ Methodologisch gesehen handelt es sich bei diesem Ausschnitt also um eine „Auswahl typischer Fälle“ (vgl. hierzu insb. Kops 1977: 179). Mit der Entscheidung für eine natürliche Woche als Untersuchungsmaterial geht eine Einschränkung der Aussagekraft der zu erzielenden Ergebnisse einher, was ihre Verallgemeinerbarkeit auf größere Zeiträume als die tatsächlich analysierte Woche betrifft. Entsprechende Aussagen sind also lediglich auf Plausibilitätsebene möglich. Diese Einschränkung ist aber durch den explorativen Charakter der vorliegenden Arbeit gerechtfertigt. ${ }^{228}$

Es versteht sich daher von selbst, dass diese Selektion aus dem Fernsehangebot nicht als repräsentativ für etwa das gesamte TV-Programm gelten kann. Das ergibt sich schon aus der Beschränkung auf öffentlich-rechtliche Sender. ${ }^{229}$ Deshalb wird hier darauf verzichtet, einen exakten, über die untersuchte Woche hinausgehenden Untersuchungszeitraum anzugeben, für

\footnotetext{
${ }^{227}$ So gibt es wöchentlich wiederkehrende Plätze für bestimmte Sendungen, tägliche Serien werden nur montags bis freitags ausgestrahlt $u$. ä.

228 Tatsächlich wäre eine auf einem Zufalls- oder Quotenverfahren basierende Auswahl des Untersuchungsmaterials, diesem explorativen Charakter sogar weniger gerecht geworden. Eine solche Stichprobe hätte einer auch zeitlichen Definition der Grundgesamtheit (etwa eines Jahres) bedurft. Damit wäre aber kein Mehrwert für die Aussagekraft der Studie verbunden, sondern vielmehr eine Beschränkung. Die zu beantwortende Frage hätte dann gelautet: Wie hat sich regionale oder nationale Identität im Fernsehprogramm der vier Sender im Jahr 2008 gezeigt? Die interessierenden Fragen lauten aber: Schlagen sich nationale und regionale Identität im Fernsehprogramm überhaupt nieder? Und wenn ja: Wie manifestieren sie sich?

${ }^{229}$ Diese Beschränkung ist aber inhaltlich gerechtfertigt, da es auf der regionalen Ebene kein vergleichbar ausdifferenziertes Programmangebot von privaten Veranstaltern gibt.
} 
den die Ergebnisse gültig sein sollen. ${ }^{230}$ Es ist jedoch plausibel, anzunehmen, dass die zu entdeckenden Strukturen und inhaltlichen Merkmale sich so oder zumindest sehr ähnlich auch in anderen als der untersuchten Woche wiederfinden, allerdings mit Einschränkungen, die sich aus fernsehsystemimmanenten Produktionsbedingungen ergeben. Inhaltliche Strukturen des TV-Angebots sind einem mehr oder weniger stetigen Wandel unterworfen, Programmplätze werden ausgetauscht, veränderten Sehgewohnheiten angepasst oder wegen mangelnder Einschaltzahlen werden Sendungen aus dem Programm genommen. Andere Inhalte sind dagegen seit Jahrzehnten konstant und längst Teil einer über das eigentliche Angebot hinausgehenden Fernsehkultur. ${ }^{231}$ Insofern handelt es sich beim untersuchten Material um eine typische Woche im Fernsehprogramm der zweiten Jahreshälfte 2008. Für die Plausibilität dieser Überlegungen sprechen vor allem die Ergebnisse der kontinuierlichen Programmanalysen des deutschen Fernsehens - zum einen im Auftrag von $A R D$ und ZDF (etwa Krüger/Zapf-Schramm 2007, Krüger/Zapf-Schramm 2008, Krüger/Zapf-Schramm 2009) und zum anderen im Auftrag der ALM (etwa Weiß/Trebbe 2008, Maurer et al. 2009, Trebbe 2010) - sowie die methodologischen Überlegungen zu deren Stichprobenziehung (vgl. insbesondere Trebbe 2005) ${ }^{232}$.

Zuletzt soll nicht verschwiegen werden, dass auch (forschungs-)ökonomische Gründe für die Begrenzung der Untersuchung auf den Zeitraum einer Woche sprechen: Eine zufällige Auswahl von Tagen im Verlauf eines Jahres zum Beispiel hätte den Zeitraum der Materialgewinnung deutlich in die Länge gezogen. Gleichzeitig hätten dann die technischen Einrichtungen zur parallelen digitalen Aufzeichnung ${ }^{233}$ des Programms vierer Sender sehr lange bereitgehalten werden müssen, statt für einen kurzen Zeitraum. ${ }^{234}$

\footnotetext{
${ }^{230}$ Auf Grund der nicht zufälligen Auswahl des Untersuchungsmaterials wären ohnehin keine Aussagen über die entsprechende statistische Genauigkeit von Vermutungen über die eigentliche Stichprobe hinaus möglich (etwa Konfidenzintervalle). Aus demselben Grund verbieten sich im Übrigen auch statistische Tests, z. B. der Überzufälligkeit von Ergebnissen.

231 So etwa die tägliche „Tagesschau“ im Ersten oder der „Tatort“ an (fast) jedem Sonntagabend.

232 Wobei Trebbe nachvollziehbar argumentiert, dass es sich beim Stichprobenkonzept der als typisch bestimmten natürlichen Woche um „Vollerhebungen zum jeweiligen Zeitpunkt T“ (Trebbe 2005: 135) handelt. Deren Ergebnisse sind auf Grund der Kontinuität der Erhebung im Zeitverlauf vergleichbar. In der hier vorliegenden Untersuchung sollen Entwicklungstendenzen in den Programmen gar nicht aufgezeigt werden. Entsprechende Überlegungen erübrigen sich also. Die Plausibilitätsüberlegungen stellen aber eine dem Untersuchungsziel angemessene Grundlage für die Gültigkeit der zu erzielenden Aussagen über den Untersuchungsgegenstand dar.

233 Sowie der Überwachung der Aufzeichnung, da gerade die computergestützte Aufnahme fehleranfällig ist. Die Aufzeichnung auf Band kam wegen des großen Sendevolumens gar nicht infrage.

234 Zumal eine zusätzliche Schwierigkeit darin besteht, dass der ORF 2 in Deutschland nur verschlüsselt empfangen werden kann und über einen Decoder zusammen mit einer Freischaltkarte entschlüsselt werden muss. Diese Karten haben aber eine begrenzte Gültigkeitsdauer.
} 


\subsubsection{Untersuchungseinheiten}

Die Auswahleinheit der Inhaltsanalyse ist das zwischen 9 und $1 \mathrm{Uhr}$ ausgestrahlte Fernsehprogramm der TV-Sender ORF 2, ZDF, BR und $M D R^{235}$ der einzelnen Tage der zuvor festgelegten Untersuchungswoche (27.10. - 02.11.2008). Die Auswahleinheit ist zeitlich durch Beginn und Ende festgelegt, ob zu diesen Zeitpunkten einzelne Sendungen beginnen oder enden, spielt keine Rolle. Innerhalb der Auswahleinheiten gibt es drei Formen von Analyseeinheiten, abhängig davon, ob es sich bei der jeweils zu analysierenden Sendung um eine Magazinsendung handelt oder nicht. Die Analyseeinheiten der ersten Ebene sind die einzelnen Programmbestandteile (Sendungen). Als Sendung gelten alle in Präsentationsform und Inhalt jeweils voneinander abgrenzbaren Bestandteile des Programms. ${ }^{236}$

Auf der zweiten Ebene, innerhalb von Magazinsendungen, handelt es sich bei den Analyseeinheiten um die einzelnen inhaltlich-formal voneinander getrennten Bestandteile des jeweiligen Magazins (Beiträge). Als Magazinsendung gilt jede einzelne Sendung, die mehrere redaktionelle Beiträge enthält, die innerhalb einer formalen und inhaltlichen Klammer (Gestaltung und Moderation) präsentiert werden. Die Beiträge müssen journalistisch aufbereitet sein und hauptsächlich der Information dienen. Eine Zusammenstellung rein unterhaltender Beiträge (etwa verschiedene Aufzeichnungen von Musikdarbietungen), die in einer Sendung präsentiert werden, erfüllt den Magazincharakter nicht. Die Sendung muss zudem in regelmäßiger zeitlicher Folge (mindestens monatlich) in neuer Ausgabe ausgestrahlt werden. Nachrichtensendungen, die diese formalen Kriterien auch erfüllen, gelten nur dann als Magazine, wenn sie Präsentationsformen aufweisen, die über bloße Meldungen und Nachrichtenfilme hinausgehen sowie von Seite des ausstrahlenden Senders als Magazin bezeichnet werden. ${ }^{237}$ Die Abgrenzung eines Beitrags folgt formalen und inhaltlichen Kriterien. Auf formaler Ebene werden entsprechende Signale in der Moderation zur Identifikation von Beginn und Ende herangezogen. Daneben kommen auch optisch-akustische Signale infrage (etwa bestimmte Tonfolgen am Ende eines Beitrags oder Texttafeln mit Informationen zu den verantwortlichen Redakteurinnen oder Redakteuren).

235 ORF 2, BR und MDR strahlen auf verschiedenen Frequenzen unterschiedliche Programme aus, die sich in der Kennung unterscheiden (erkennbar z. B. bei Digitalempfang über Satellit). Inhaltlich wirkt sich das lediglich in den regionalen Auseinanderschaltungen aus, also jenen Sendefenstern, in denen Sendungen ausgestrahlt werden, die nur für bestimmte Teile des Sendegebiets gedacht sind (ORF 2 und MDR für die jeweiligen Bundesländer, $B R$ für Franken und den Süden Bayerns). Aufgezeichnet wurde jeweils nur eines der zur Verfügung stehenden Programme. Da die regionalen Auseinanderschaltungen nicht in die Analyse eingeflossen sind (es wurde nur die Zeitdauer der regionalen Auseinanderschaltung erfasst), hat diese Auswahl keinen Einfluss auf die Ergebnisse der Untersuchung. Im Falle des BR wurde das Programm mit der Kennung „Bayerisches FS Süd“ aufgezeichnet. Vom $M D R$ das mit der Kennung ,MDR S-Anhalt“ versehene Programm. Da es beim Empfang von ORF 2 technische Probleme gab, wurde während der ersten zwei Tage das Wiener Programm aufgezeichnet („ORF 2 W“), die folgenden Tage das Programm aus Niederösterreich („ORF 2 NOE“). Ähnlich wie im Fall der Regionalprogramme, unterscheidet sich das Programm ausschließlich in den zeitgleich ausgestrahlten Regionalfenstern. Da diese nicht in die thematische Untersuchung einfließen, ergeben sich daraus keine Konsequenzen für die Untersuchungsergebnisse.

236 Die exakten Codieranweisungen sind dem Codebuch im Anhang (S. 296) zu entnehmen.

237 Die Bezeichnung muss nicht zwangsläufig im Titel der Sendung zum Ausdruck kommen. Es gelten auch entsprechende Selbstdarstellungen, etwa in Programminformationen auf der Internet-Homepage des Senders. 
Innerhalb der Magazinbeiträge vorkommende Personen, die im Bild und im Originalton zu Wort kommen, bilden die dritte Form von Analyseeinheiten. Die Analyse beschränkt sich dabei auf die ersten vier Personen pro Beitrag. ${ }^{238}$ Journalistinnen und Journalisten, die den Beitrag erstellt haben und eventuell selbst darin zu Wort kommen, fließen in diese Untersuchung nicht mit ein. Das gilt ebenfalls für Moderatorinnen oder Moderatoren, die diesen Beitrag anmoderieren.

Die Unterteilung in die Analyseeinheiten stellt forschungslogisch kein Problem dar, weil die Magazin-Analyseeinheiten als Untereinheiten der Analyseeinheiten auf Sendungsebene anzusehen sind. Das gilt auch für die Erhebung zu Wort kommender Personen. Die Ebenen werden in der Auswertung getrennt behandelt. Die Analyseeinheiten folgen in ihrer Aufteilung der Forschungslogik, die sowohl die Magazinbeiträge untersuchen will, dabei aber das Gesamtprogramm (als Rahmen) nicht unberücksichtigt lässt. Die in den Magazinbeiträgen zu Wort kommenden Personen sind nur als eigene Analyseeinheit sinnvoll zu erfassen, da sie jeweils eigene Merkmale mitbringen, die nicht Merkmale des Beitrags selbst sind (etwa: Dialektausprägung, Funktion, Alter, u. ä.).

\subsubsection{Zentrale Kategorien der Analyse}

Die Kategorien der Inhaltsanalyse ergeben sich neben eher formalen Kriterien vor allem aus dem Forschungsinteresse der Arbeit sowie den konkretisierenden Hypothesen. Im Folgenden sollen einige Kategorien erläutert werden und der Bezug zu den dahinterstehenden Fragen hergestellt werden. Die exakten Codieranweisungen sind dem Codebuch im Anhang zu entnehmen, deshalb beschränkt sich die Darstellung an dieser Stelle auf die zentralen inhaltlichen Kategorien.

\subsubsection{Formale Ebene}

Ausstrablung: Mit der Art der Ausstrahlung wird unterschieden, ob es sich um eine Erstsendung, eine kurz- oder langfristige Wiederholung oder eine Übernahme (direkt oder zeitlich versetzt) aus einem anderen Programm handelt. Hiermit soll vor allem die eigentliche Programmleistung gemessen werden. Der Umfang wiederholter oder übernommener Sendungen ist zudem ein Indikator für den Status eines Senders innerhalb des Rundfunksystems. Das ist hinsichtlich der strukturellen Einordnung und Bewertung der Sender vor dem Hintergrund rechtlicher Regelungen von Bedeutung.

\footnotetext{
238 Die Beschränkung auf vier Personen folgt dabei den Beobachtungen des Pre-Tests. Hier lag der Mittelwert der Anzahl zu Wort kommender Personen pro Beitrag bei 1,81. Die Standardabweichung hatte den Wert 2,478. Das bedeutet, in der übergroßen Mehrzahl der Beiträge kommen nicht mehr als vier Personen zu Wort. Insofern stellt die Beschränkung auf vier Personen einen forschungsökonomischen Kompromiss dar. Die wenigen Beiträge, in denen mehr als vier Personen vorkommen, würden den Kodierprozess über Gebühr verlangsamen (im Regelfall muss der Mitschnitt für die Kodierung der Personenmerkmale angehalten werden), ohne dass dies einen substanziellen Mehrwert für die Ergebnisse hätte.
} 


\subsubsection{Sendungsebene}

Programmfläche: Auf Sendungsebene wird zunächst unterschieden, ob es sich um Werbung, Sponsoring oder selbstreferenzielle Programmflächen (Programmhinweise u. ä.) handelt oder um eine fiktionale oder nicht fiktionale Sendung. Diese Unterscheidung ist zusammen mit den entsprechenden weiteren Kategorien wichtig zur Ermittlung des Informations- und Unterhaltungsanteils im Programm der Sender.

Fiktionale Sendeform: Die fiktionale Unterhaltung wird danach klassifiziert, ob es sich um Spielfilme, Serien, Theater bzw. Opernmittschnitte oder Animationsfilme handelt. Hier ist insbesondere die Unterscheidung nach Spielfilmen (singulär) und Serien (regelmäßig) zur Charakterisierung der einzelnen Sender von Bedeutung. Das bezieht sich vor allem auf die Annahme, dass Serien ein Programm viel stärker bezüglich seiner Wiedererkennbarkeit prägen als dies bei Spielfilmen mit immer wechselnden Protagonisten und Handlungsorten der Fall ist. Insbesondere eigenproduzierte Serien prägen das Bild eines Senders als „Marke“ mit (bspw. „Tatort“ im Ersten oder die „Soko“-Reihe im ZDF).

Nationalität Protagonist, Geschehensort, Charakterisierung Geschehensort, Geschehenszeit: Mit den Kategorien zur räumlichen und zeitlichen Verortung fiktionaler Handlungen soll vor allem der Frage nachgegangen werden, inwiefern sich das Sendegebiet auch im Rahmen inszenierten Geschehens niederschlägt. Darüber hinaus können die damit erfassten Daten auch zur Charakterisierung bestimmter Filme dienen (so zeichnen sich beispielsweise prototypische Heimatfilme durch die Kombination von Handlungsort „Alpenraum“, Produktionszeitraum 1950er Jahre aus, vgl. S. 122).

Nicht fiktionale Sendungsformen: Die Klassifizierung der nicht fiktionalen Sendungsformen soll zum einen Unterhaltungssendungen (etwa: Quizshows) von Informationsangeboten trennen. Gleichzeitig sollen diese Informationsangebote nach ihrer Form kategorisiert werden (Nachrichten, Dokumentarfilme, Magazinsendung usw.).

Thema der Sendung ${ }^{239}$ : Zentrale Bedeutung kommt der Identifizierung der Themen von nicht fiktionalen, informierenden Sendungen zu. Erfasst wird dieses Thema durch Vergabe von maximal zwei numerischen Codes, die auf jeweils ein (im Codebuch konkretisiertes) Thema verweisen. Es wurden insgesamt 254 Themen unterschieden, die sich auf die vier Oberkategorien „Politik“, „Wirtschaft“, „Gesellschaft“, „Kriminalität“, „Unglück“, „Sport“, „Private Lebenswelt“, „Kunst und Kultur“ sowie „Geschichte“ verteilen. Die Ausdifferenzierung ermöglicht die relativ genaue Erfassung der Themen. Die Einordnung in Oberthemenbereiche erleichtert die Aggregierung der Daten. Die Doppelcodierung bedeutet dabei keine Themenrangfolge. Im Rahmen der Auswertung werden beide vergebenen Themencodes gleichwertig behandelt. Das heißt konkret, dass jeweils die Hälfte der Sendezeit der jeweiligen Sendung einem der zwei Themen zugeschlagen wird. Entsprechend entfällt die volle Sendezeit auf ein

239 Wird nicht für Magazinsendungen vercodet, hier werden die Themen auf Beitragsebene erfasst. 
Thema, wenn nur eines identifiziert wurde. Zusätzlich wird das Thema der Sendung offen (stichwortartig) formuliert.

Produktionsland, Produktionsjabr. Die Erfassung von Herkunft und Alter ist insbesondere auf nationaler Ebene von Interesse, um zu unterscheiden, ob hauptsächlich einheimische oder ausländische Filme und Serien gezeigt werden. Vor dem Hintergrund des Rundfunkstaatsvertrags (bzw. des ORF-Gesetzes) ist auch der Anteil von Produktionen aus Europa von Interesse. Das Alter von Filmen ist ein zusätzlicher Indikator für den Stellenwert eines Senders im Fernsehsystem. (Werden viele „Konserven“ aus den Filmarchiven gesendet oder hauptsächlich neue Produktionen?) Darüber können sich im Alter von Filmen in Verbindung mit ihrer Herkunft Bezüge zu bestimmten historischen Zeitabschnitten ablesen lassen (so wären z. B. DDR-Produktionen im MDR bei gehäuftem Auftreten ein Hinweis darauf, dass die DDRVergangenheit wesentlicher Bestandteil des Selbstverständnisses von Mitteldeutschland ist, vgl. dazu auch S. 122).

\subsubsection{Magazinebene}

Magazinbestandteile, Darstellungsform: Eine Magazinsendung besteht nicht nur aus den einzelnen Beiträgen, sondern enthält im Regelfall auch selbstreferenzielle Flächen (wie etwa Vor- und Abspann oder Hinweise auf einzelne Beiträge oder die nächste Sendung) sowie gegebenenfalls Sponsorenhinweise (wenn einzelne Rubriken gesponsert werden). In die Untersuchung fließen nur die redaktionellen Beiträge ein. Diese werden nach journalistischer Darstellungsform unterschieden. Das ermöglicht zum Beispiel Aussagen darüber, wie abwechslungsreich Magazine gestaltet sind bzw. den redaktionellen Aufwand, der in der Themenaufbereitung betrieben wird.

Ereignisraum, Bezugsraum: Mit den Kategorien Ereignis- und Bezugsraum wird erfasst, wo berichtete Ereignisse faktisch stattfinden und auf welche Orte sie sich beziehen. Die Unterscheidung ist notwendig, weil beispielsweise Sitzungen des Deutschen Bundestags regulär in Berlin stattfinden, sich aber auf ganz Deutschland beziehen. Die Verortung der Berichterstattung ist eine zentrale Kategorie, weil hiermit ersichtlich wird, wie sich das jeweilige Sendegebiet in der Berichterstattung abzeichnet und wie vollständig oder lückenhaft es abgedeckt wird. Die Einordnung folgt verschiedenen Abstufungen, je nachdem ob es sich um Berichterstattung aus dem In- oder Ausland handelt. Die kleinstmögliche erfassbare Einheit sind konkrete Orte. Davon werden pro Beitrag bis zu sechs erfasst (falls mehr als ein Handlungsort vorhanden ist).

Regionalität, Ereignisbequg, Konfliktbetonung: Mit der Kategorie Regionalität wird gemessen, ob berichtete Sachverhalte regionalspezifisch sind oder nicht. Das geht über die Unterscheidung von Ereignis- und Bezugsraum hinaus, weil hiermit erfasst werden kann, ob in der Berichterstattung Regionalität „,künstlich“ hergestellt wird. Der Ereignisbezug gibt an, ob dem Beitrag ein tatsächliches externes (vom ausstrahlenden Sender unabhängiges) Geschehen zugrunde liegt. Das ist ein Indikator für journalistische Qualität. Die Konfliktbetonung der Berichterstattung gehört ebenfalls zu den Qualitätsindikatoren der Berichterstattung. In dieser Katego- 
rie wird erfasst, wie stark widerstreitende Meinungen und Ansichten innerhalb eines Beitrags zum Ausdruck gebracht werden. Dies ist ein Indikator für den Aufwand der journalistischen Aufbereitung von Themen (Verlautbarungsjournalismus vs. Hintergrundinformation).

\subsubsection{Zu Wort kommende Personen in Magazinbeiträgen}

Von allen in einem Beitrag zu Wort kommenden Akteurinnen und Akteuren werden die jeweils vier ersten (in Reihenfolge ihres Auftretens) einer weitergehenden Kategorisierung unterzogen. Alle weiteren zu Wort kommenden Personen werden lediglich gezählt (zur Begründung vgl. Fn. 238).

Personen-Orts-Bequg: Es wird bestimmt, auf welcher Stufe innerhalb der (politischen) Hierarchie eine zu Wort kommende Person steht. Dies erfolgt anhand der Klassifizierung ihres Einflussbereichs (von „international“ bis „lokal oder kommunal“ oder „keine Reichweite über persönliches Umfeld hinaus"). Diese Kategorie dient der Beantwortung der Frage, ob zu Wort kommende Politikerinnen und Politiker im Regionalprogramm eher aus der Kommunalpolitik stammen und im nationalen Programm eher aus der Bundespolitik.

Bereich: Die Personen werden nach Tätigkeitsfeldern bzw. beruflichen oder sozialen Funktionen klassifiziert. Das ermöglicht die Beantwortung der Frage, welche gesellschaftlichen Gruppen im Programm vertreten sind und in welchem Ausmaß. Diese Kategorien sind ein Indikator für die Ausgewogenheit der Berichterstattung, die zum Beispiel nicht gegeben wäre, wenn ausschließlich Vertreterinnen und Vertreter der Wirtschaft in den Beiträgen vorkämen.

Berufliche Umgebung: Auch für die Personen wird - immer wenn sie in beruflicher Umgebung gezeigt werden - erfasst, zu welchem Wirtschaftssektor der Arbeitshintergrund gehört (also eine Bäuerin auf ihrem Hof gehört zum primären Sektor, ein Kassierer an der Supermarktkasse zum tertiären). Diese Kategorisierung ist eine Ergänzung zur Erfassung der Sektoren in der Wirtschaftsberichterstattung. Hiermit kann analysiert werden, welches Bild der Berufswelt themenübergreifend in der Berichterstattung gezeichnet wird.

Dialektausprägung: Die Ausprägung des gesprochenen Dialekts der zu Wort kommenden Personen erfolgt nach Stärke der Abweichung vom Hochdeutschen. Damit soll der Frage nachgegangen werden, ob das wichtige Merkmal der sprachlichen Verschiedenheit - insbesondere im Regionalprogramm - sich in der Berichterstattung widerspiegelt. Der Dialekt selbst (oberbayerisch, unterfränkisch, sächsisch, vogtländisch) wird nicht erfasst. Stattdessen wird zu jeder Dialekt sprechenden Person codiert, ob der gesprochene Dialekt zu der Region, aus der jeweils berichtet wird, gehört.

\subsubsection{Pre-Test und Reliabilität der Untersuchung}

Das Erhebungsinstrument wurde einem Pre-Test unterzogen, nachdem die Einheiten der Analyse festgelegt und das Kategoriensystem erstellt worden war. Die Probecodierung erfolgte 
mit extra dafür aufgezeichnetem Material (je Sender vier Stunden Programm von Tagen auBerhalb der Untersuchungswoche). Wo nötig, wurde das Kategorienschema ergänzt, einzelne Codieranweisungen wurden präzisiert.

Während der gesamten Codierphase wurde die Intracoderreliabilität überwacht. Dazu wurde im Abstand von maximal vier Tagen eine Stunde bereits codierten Untersuchungsmaterials nach dem Zufallsprinzip zur erneuten Codierung bestimmt. Die Abweichungen von der Erstcodierung hielten sich über die gesamte Datenerhebungsphase in engen Grenzen. ${ }^{240}$ Die Reliabilität der Untersuchung ist damit gegeben. Nachdem die Daten eingegeben und bereinigt waren, erfolgte die Datenanalyse mit SPSS für Windows.

240 Der durchschnittliche Reliabilitätswert lag bei .983 (Holsti-Koeffizient). Der niedrigste Wert lag bei .75 und betraf nur eine Variable. Der höchste Wert lag bei 1 (19 mal von insgesamt 56 Variablen). Die Reliabilitätswerte sind in Tabelle 19 (S. 314) im Anhang für alle Variablen einzeln ausgewiesen. 


\section{Ergebnisse}

Im folgenden Kapitel werden die Ergebnisse der Untersuchung vorgestellt. Die Darstellung erfolgt anhand der in Abschnitt 7.1 aufgestellten Hypothesen. Wie dort bereits dargelegt, dienen diese Hypothesen hauptsächlich der Strukturierung der Auswertung. Da die Ergebnisse an einigen Stellen interpretationsbedürftig sind, erfolgt die Einordnung und Bewertung zusammen mit ihrer Darstellung. Deshalb reicht dieser Abschnitt über die bloße Bestätigung oder Ablehnung von Hypothesen hinaus.

Einige der Annahmen erwiesen sich im Licht der Untersuchungsergebnisse als zu kurzgreifend. In diesen Fällen wird mit einer umfassenden Ergebnisinterpretation Abhilfe geschaffen. Der Übersichtlichkeit halber sind aber am Ende der jeweiligen Themenkomplexe die Hypothesen zusammenfassend hinsichtlich ihres Zutreffens oder Nichtzutreffens aufgelistet.

\subsection{Gesamtprogramm}

\subsubsection{Programmprofile der untersuchten Sender}

Betrachtet man die rein formal-inhaltlichen Unterschiede zwischen den untersuchten Sendern, so ist der Unterschied zwischen nationalen Programmen auf der einen und regionalen Programmen auf der anderen Seite relativ eindeutig (vgl. Abbildung 2). Die beiden Hauptbestandteile bilden jeweils Information und Unterhaltung. Diese sind jedoch sehr unterschiedlich verteilt. In den beiden Dritten Programmen BR und MDR ist der Informationsanteil mit 63 bzw. 59 Prozent der untersuchten Sendezeit sehr hoch. In ZDF und ORF 2 liegt er jeweils bei rund 50 Prozent. Dagegen ist der Anteil der Unterhaltungsangebote in den nationalen Programmen mit 37 Prozent (ORF 2) bzw. 45 Prozent ( $Z D F)$ deutlich höher als in den Regionalprogrammen, wo er bei 31 Prozent (BR) bzw. 33 Prozent (MDR) liegt. Der Anteil von (expliziten ${ }^{241}$ ) Werbe- und Sponsoringformen ist im nationalen Programm deutlich höher als in $B R$ und MDR. Das liegt an den gesetzlichen Grundlagen, die Werbung in den Dritten Programmen untersagen. Der marginale hier vorhandene Anteil entspringt daher ausschließlich Formen von Sponsoring („Das Wetter wird Ihnen präsentiert von ..."). Dass der Anteil von Werbung im $Z D F$ niedriger als im ORF 2, erklärt sich ebenfalls aus gesetzlichen Unterschieden bzw. solchen des Mediensystems beider Länder. Das ZDF unterliegt anderen Restriktionen hinsicht-

${ }^{241}$ Programmintegrierte Formen - die zum Teil unzulässig sein können - sind damit nicht erfasst. Einen Überblick zur aktuellen Werbepraxis im deutschen Fernsehen bietet Volpers et al. (2008). 
lich der Werbung als der ORF 2 und darf zum Beispiel nach 20 Uhr keine Werbung mehr ausstrahlen, was für den ORF 2 nicht gilt. Regionale Auseinanderschaltungen ${ }^{242}$ kommen dagegen im ZDF gar nicht vor, sehr wohl aber im ORF 2 sowie im BR und MDR. Auch das ist leicht zu erklären: Da es in Österreich anders als in Deutschland keine regionalen öffentlichrechtlichen Fernsehprogramme gibt, werden stattdessen im ORF 2 Regionalfenster ausgestrahlt. Das heißt, zu einer bestimmten Sendezeit wird in den verschiedenen Bundesländern ein spezifisches Landesprogramm gesendet. Die regionalen Auseinanderschaltungen im BR und MDR sind ähnlich zu erklären. Im BR wird ein Teil der „Abendschau“ als Regionalprogramm entweder für den fränkischen Raum oder für das südliche Bayern ausgestrahlt („Abendschau Franken“, „Abendschau Der Süden“). ${ }^{243}$ Im MDR gibt es Regionalfenster für die drei Bundesländer des Sendegebiets („Sachsenspiegel“, „Sachsen-Anhalt heute“, „Thüringenjournal"). ${ }^{244}$ Schließlich fällt auf, dass der Anteil der selbstreferenziellen Programmflächen im ORF 2 und ZDF etwas höher ausfällt als im BR und MDR. Das bedeutet, dass in beiden nationalen Programmen mehr Eigenwerbung insbesondere in Form von Programmhinweisen betrieben wird als in den Dritten.

\footnotetext{
${ }^{242}$ Die Regionalen Auseinanderschaltungen stellen im Regelfall Informationsprogramme dar. Sie wurden in der Untersuchung aber nicht analysiert. Das hat zum einen technische Gründe - es ist nicht möglich, gleichzeitig mehrere Regionalfenster an einem Standort zu empfangen und aufzuzeichnen. Daneben ist es auch inhaltlich gerechtfertigt, da hier keine sub-regionalen Programmleistungen untersucht werden sollen.

243 Wobei die Auseinanderschaltung für das südbayerische Publikum weniger auffällig ist, als für das fränkische. Während im Süden die Sendung nahezu nahtlos im Anschluss an den Wetterbericht mit der selben Moderatorin weiterläuft (dann allerdings ohne den Zusatz „Der Süden“ im Sendungstitel), ist für das fränkische Publikum der Unterschied schon durch den Moderatorenwechsel deutlich. Mittlerweile wurde diese Praxis aber verändert, so dass die Abendschau ab 18 Uhr eine eigenständige Sendung darstellt und direkt im Anschluss an die Regionalprogramme „Frankenschau aktuell“ und „Schwaben \& Altbayern aktuell“ ausgestrahlt wird.

244 Außerhalb des Sendegebiets wird auf diesem Sendeplatz die Sendung „Länderzeit“ ausgestrahlt, die Beiträge aus allen drei Regionalfenstern enthält.
} 
Abbildung 2: Grundstruktur der untersuchten Programme

Basis: 112 Stunden Programm je Sender

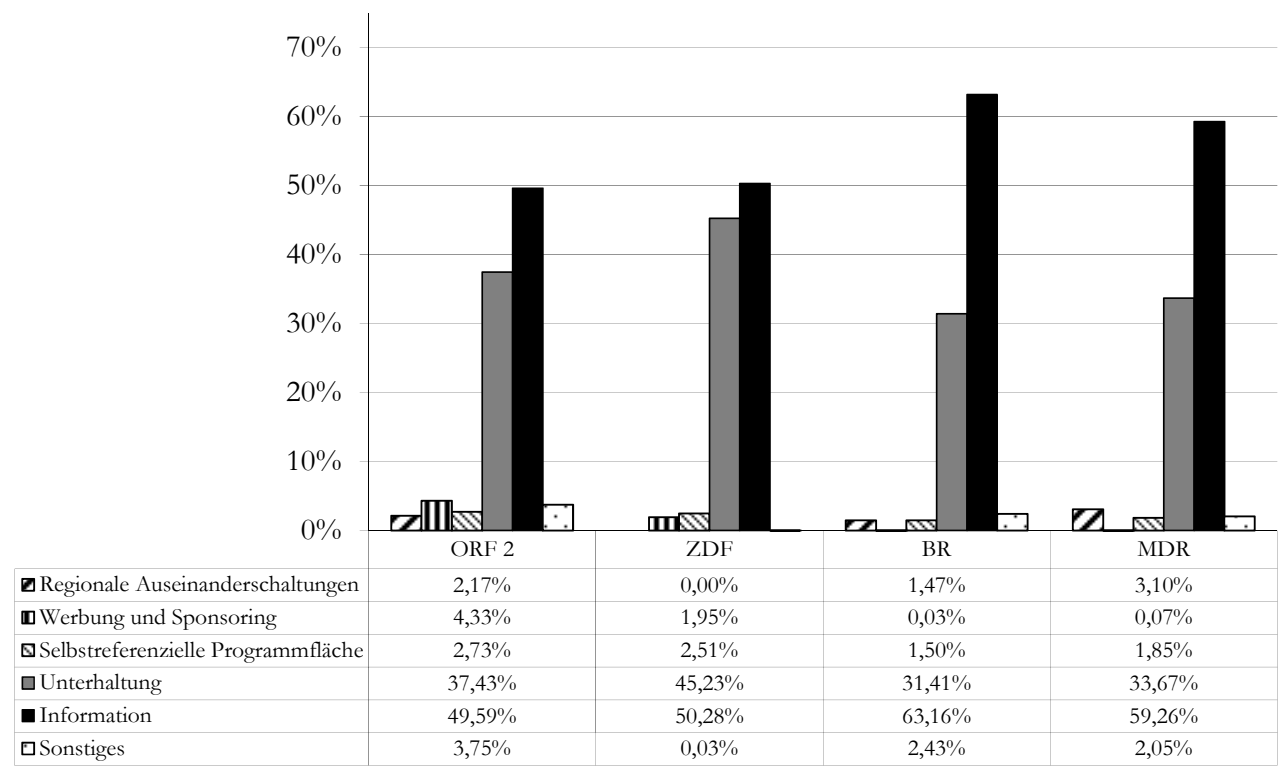

Auch hinsichtlich der erbrachten Programmleistungen ergeben sich Unterschiede zwischen nationalen und regionalen Programmen. So liegt der Anteil des tatsächlich eigenen Programms ohne Wiederholungen und Übernahmen bei $B R$ und $M D R$ deutlich unter den Werten von ORF 2 und ZDF (vgl. Abbildung 3). In beiden Regionalprogrammen machen Wiederholungen circa ein Drittel der Sendezeit aus. Dieser hohe Umfang von Sendungen ,aus der Konserve“ betrifft auch das Informationsprogramm in den Dritten Programmen. Im BR sind das insgesamt 21 Prozent der Sendezeit, die auf Information entfällt, im MDR 17 Prozent. In den nationalen Sendern ist der Wiederholungsanteil innerhalb der Fernsehpublizistik deutlich geringer (ORF 2: sieben Prozent, im ZDF gibt es hier keine Wiederholungen ${ }^{245}$ ).

${ }^{245}$ Dass es gar keine wiederholten Informationssendungen im ZDF gibt, ist damit aber nicht gesagt. Es gibt sie nicht in der Untersuchungswoche innerhalb der untersuchten Sendezeit von 9 Uhr morgens bis 1 Uhr nachts. Dass im Nachtprogramm einzelne Sendungen z. B. vom Vortag wiederholt werden, ist nicht ausgeschlossen. 
Abbildung 3: Programmleistung der einzelnen Sender.

Basis: Programm ohne Werbung, Sponsoring, selbstreferenzielle Flächen und Regionalfenster in hh:mm:ss ORF 2: 101:22:53, ZDF: 107:00:23, BR: 108:38:25, MDR: 105:45:47

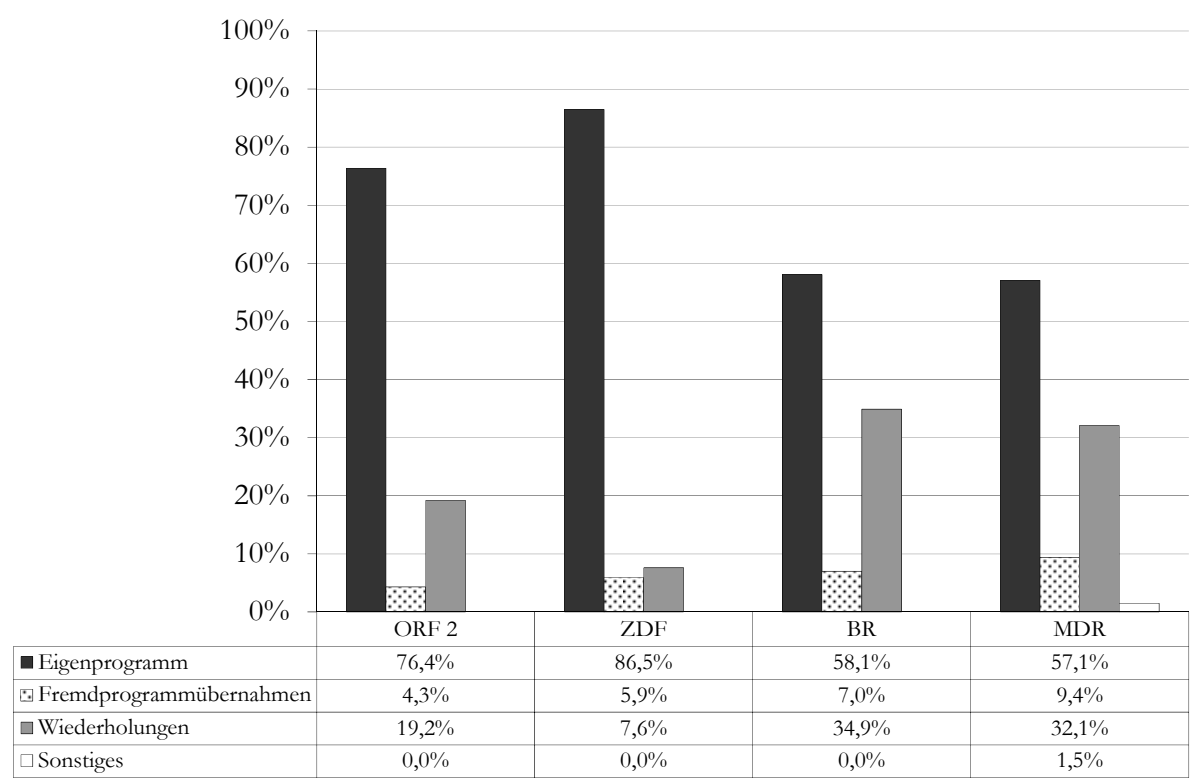

Auf der rein formalen Ebene scheint sich die Annahme eines strukturellen Unterschieds von nationalem und regionalem Fernsehprogramm zu bestätigen. Dies darf aber nicht darüber hinwegtäuschen, dass es sich dabei lediglich um solche Unterschiede handelt, die sich aus der jeweiligen Stellung der TV-Programme im jeweiligen Gesamtfernsehsystem ergeben. Im Falle Deutschlands ist dieses - jedenfalls zum Teil - föderalistisch ${ }^{246}$ organisiert. Der Status der Dritten Programme ergibt sich nicht zuletzt aus der spezifischen deutschen Rundfunkgeschichte. Die Regionalsender bieten lediglich ein zusätzliches Porgrammangebot. ${ }^{247}$ Das spiegelt sich programminhaltlich darin wider, dass die Dritten hohe Anteile von Wiederholungen sowie einen (absolut nicht sehr hohen, im Vergleich zu den beiden nationalen Programmen aber etwas umfangreicheren) Anteil von Fremdprogrammübernahmen aufweisen.

246 Die Landesrundfunkanstalten sind in $\operatorname{der} A R D$ organisatorisch verbunden.

${ }^{247}$ Die Befunde legen zumindest die Überlegung nahe, ob es sich bei den hier untersuchten Dritten überhaupt um Vollprogramme im Sinne des $\int 2$ II, Nr. 2 RStV i. V. m. \6 III RStV handeln kann, wie oben noch vermutet (siehe S. 130). Im Allgemeinen wird davon ausgegangen, dass die Dritten mittlerweile Vollprogramme darstellen: „Mittlerweile haben sich alle Dritten Programme zu Vollprogrammen entwickelt, die sich nicht auf quotenschwache Bildungsprogramme beschränken wollen“ (Lünenborg 2006c: 244). Dafür spricht, dass auch die Regionalprogramme in einem wesentlichen Teil des Gesamtprogramms solche Inhalte bieten, die laut $\ 2$ II, Nr. 2 RStV der Information, Bildung, Beratung und Unterhaltung dienen. Dagegen spricht aber, dass die zusätzlichen Anforderungen aus $\ 6$ III RStV nicht erfüllt werden. Dies ist jedenfalls dann nicht der Fall, wenn man die Regelungsabsicht ernst nimmt. Diese besteht in der Sicherung der heimischen und europäischen Film- und Fernsehproduktion als Kulturgut (so Kröber 2003: 46-48). Eine solche Förderung ist aber nicht gegeben, wenn der wesentliche Anteil der fiktionalen Inhalte aus Wiederholungen und Übernahmen besteht. 
Im Rahmen der rein formalen Beurteilung der Programmleistung stellt sich auch die Frage, ob der hohe Informationsanteil in den Regionalsendern auch auf einer Eigenleistung beruht und damit überhaupt zur Beurteilung deren regionaler Identität herangezogen werden kann (Frage F3). Das Informationsprogramm enthält nur zu einem geringen Anteil Fremdprogrammübernahmen (3,4 Prozent der Sendezeit im BR und 8,7 Prozent im MDR, vgl. Abbildung 83 im Anhang, S.317). Insofern ist von der formalen Zuordnung her nicht zu erwarten, dass das Informationsprogramm hauptsächlich Themen aus anderen Regionalprogrammen enthält, die dann hier fälschlicherweise als regionalspezifisch deklariert werden. ${ }^{248}$

Es sollte aber nicht der Fehler gemacht werden, den hohen Anteil an Informationssendungen in den Dritten allein aus deren spezifischer geschichtlichen Entwicklung im deutschen Rundfunksystem zu erklären. Die Regionalprogramme gingen schließlich in erster Linie als „Bildungsfernsehen“ auf Sendung. Nun wäre es leicht, in der heutigen Programmstruktur eine Fortsetzung regionaler Fernsehtraditionen zu erkennen - wenn nicht der hier untersuchte MDR gar nicht aus dieser Tradition käme. Dass auch der MDR hohe Informationsanteile aufweist, spricht aber dafür, dass er innerhalb des deutschen Fernsehsystems eine ähnliche Stellung einnimmt, wie alle $A R D$-Dritten. Das dürfte aber eher der Rundfunkorganisation insgesamt geschuldet sein, wenngleich sich diese aus historischen Gegebenheiten heraus entwickelt hat.

Die Unterschiede ergeben sich nicht zwangsläufig aus der Unterscheidung in nationale und regionale Programme. Eine entsprechende Einteilung in Voll- und Spartenprogramme erbrächte möglicherweise ähnliche Ergebnisse. Es gilt daher, die Frage zu beantworten, ob die strukturellen Unterschiede sich auch auf inhaltlicher Ebene aus der Kategorisierung in nationale und regionale Programme ergeben.

Da Unterhaltung und Information die beiden Hauptbestandteile der Fernsehprogramminhalte darstellen, sollen diese jeweils noch gesondert en detail betrachtet werden. ${ }^{249}$ Hier geht es wieder darum, ob sich die regionalen Programme untereinander stärker ähneln als den nationalen.

Im Bereich der Unterhaltung lassen sich relativ deutlich Differenzen erkennen (vgl. Abbildung 4). So liegt zum Beispiel der Anteil der Fernsehserien im MDR bei unter 20 Prozent, in allen anderen Sendern über 40 Prozent (im ZDF über 50 Prozent). Dagegen ist im MDR der Anteil nicht-fiktionaler Unterhaltungssendungen sowie von Spielfilmen höher als in den drei anderen Sendern. Theater- bzw. Opernmitschnitte werden dagegen nur im BR ausgestrahlt.

\footnotetext{
${ }^{248}$ Das beträfe aber ohnehin nur jene monothematischen Sendungen, denen im Rahmen der Themen „Geschichte“ und „Religion“ Bedeutung zugemessen wird. In den Magazinsendungen wird ohnehin der tatsächliche Raumbezug erfasst.

${ }^{249}$ Wobei die regionalen Auseinanderschaltungen im Regelfall Informationsprogramme darstellen.
} 
Abbildung 4: Zusammensetzung des Unterhaltungsprogramms der untersuchten Sender Basis: Umfang des Unterhaltungsprogramms in hh:mm:ss - ORF 2: 41:55:36, ZDF: 50:39:14, BR: 35:10:31, MDR: 37:42:38.

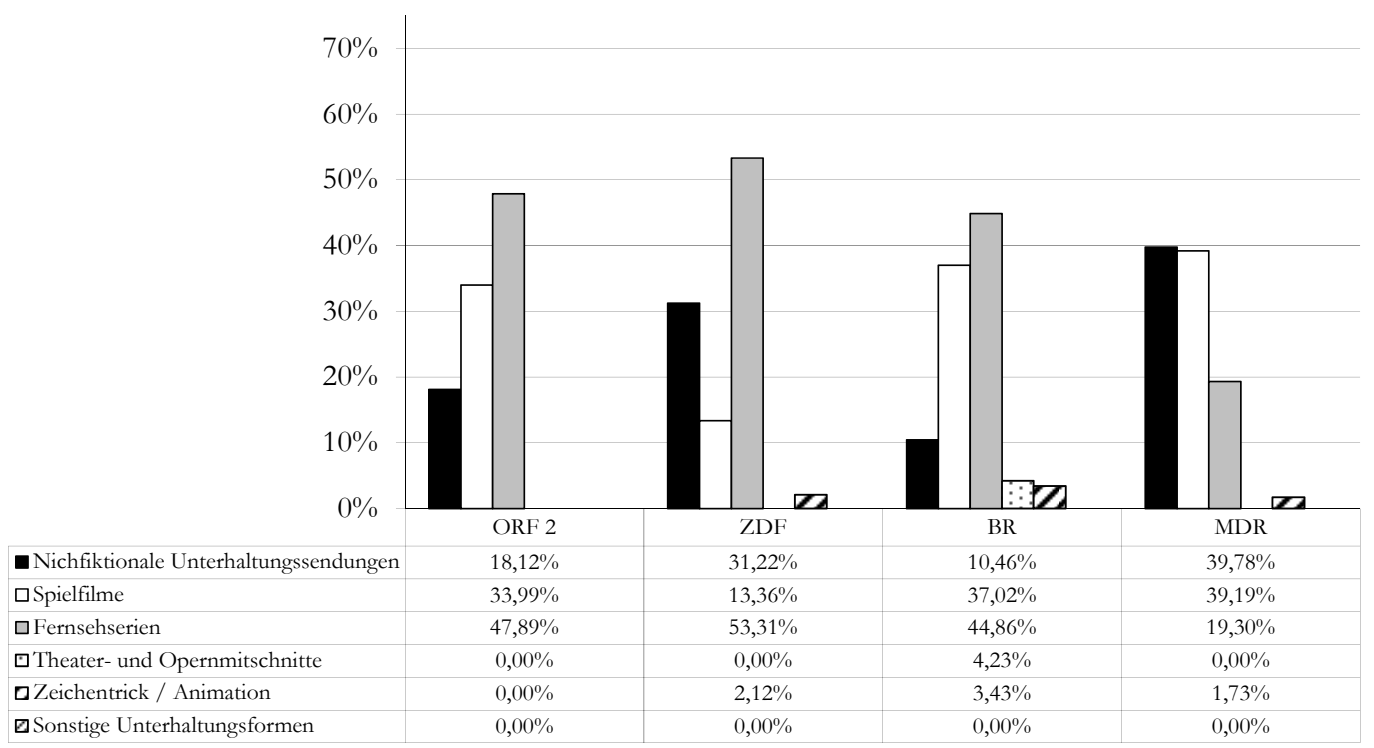

Die Verteilung des gesamten Unterhaltungsangebots auf die verschiedenen Programmformen lässt sich anhand des relativen Entropiewerts $\mathrm{H}^{250}$ für diese Verteilung gut vergleichen (vgl. Abbildung 5). Im hier interessierenden Zusammenhang bedeutet ein Wert von $\mathrm{H}=1$, dass die gesamte Sendezeit des jeweiligen Unterhaltungsangebots sich auf die verschiedenen Formen (Nicht fiktionale Unterhaltung, Serien, Filme, usw.) vollkommen gleichmäßig verteilt. Bestünde dagegen das gesamte Unterhaltungsprogramm eines Senders nur aus Spielfilmen, wäre die Verteilung die geringstmögliche und $\mathrm{H}=0$. Mutatis mutandis gilt dies auch für die anderen im Folgenden noch vorkommenden Auswertungen zur Vielfalt von Programmformen und -inhalten.

Im $B R$ ist das Unterhaltungsangebot gleichmäßiger auf die möglichen Formen verteilt als in den drei anderen Sendern. Dagegen liegen die Werte von ORF 2, ZDF und MDR eng beieinander. Sie sind aber alle niedriger als der relative Entropiewert für das Unterhaltungsangebot des BR. Hinsichtlich der Verteilung der Unterhaltung auf die verschiedenen Formen, ähneln

\footnotetext{
${ }^{250}$ Das Maß der relativen Entropie basiert auf dem von Shannon entwickelten Index H für die Verteilung einer Informationsmenge. Als Diversitätsmaß zeigt $\mathrm{H}$ an, wie bestimmte Informationen auf eine Anzahl von Kategorien verteilt sind. Der Wert der relativen Entropie ergibt sich aus der Division von H durch den von der Anzahl der Kategorien abhängigen Maximalwert $\mathrm{H}_{\max }$. Dadurch werden die Vergleiche von Verteilungen über verschieden große Kategoriemengen ermöglicht. Das Maß der relativen Entropie hat sich gegenüber methodischen Verzerrungen, die sich aus der Anzahl von Kategorien ergeben können, als stabiler als andere Verteilungsmaße erwiesen (vgl. Kambara 1992: 205, Stark 2008: 202, Mcdonald/Dimmick 2003: 76) und wird deshalb in dieser Arbeit für Verteilungsangaben herangezogen.
} 
sich die beiden nationalen Programme. Allerdings hat jeder der vier untersuchten Sender ein relativ spezifisches Unterhaltungsprofil, das sich wohl nicht aus dem Charakter als nationales oder regionales Programm ergibt. Das zeigt sich schon daran, dass die Differenz des H-Werts für das MDR-Unterhaltungsangebot zu den entsprechenden Werten des ZDF geringer ist als zum entsprechenden H-Wert des BR. Die Differenz zum H-Wert des ORF 2 ist nahezu gleich groß.

\section{Abbildung 5: Vergleich der relativen Entropiewerte für die Verteilung des Unterhaltungsange- bots auf die verschiedenen Sendeformen}

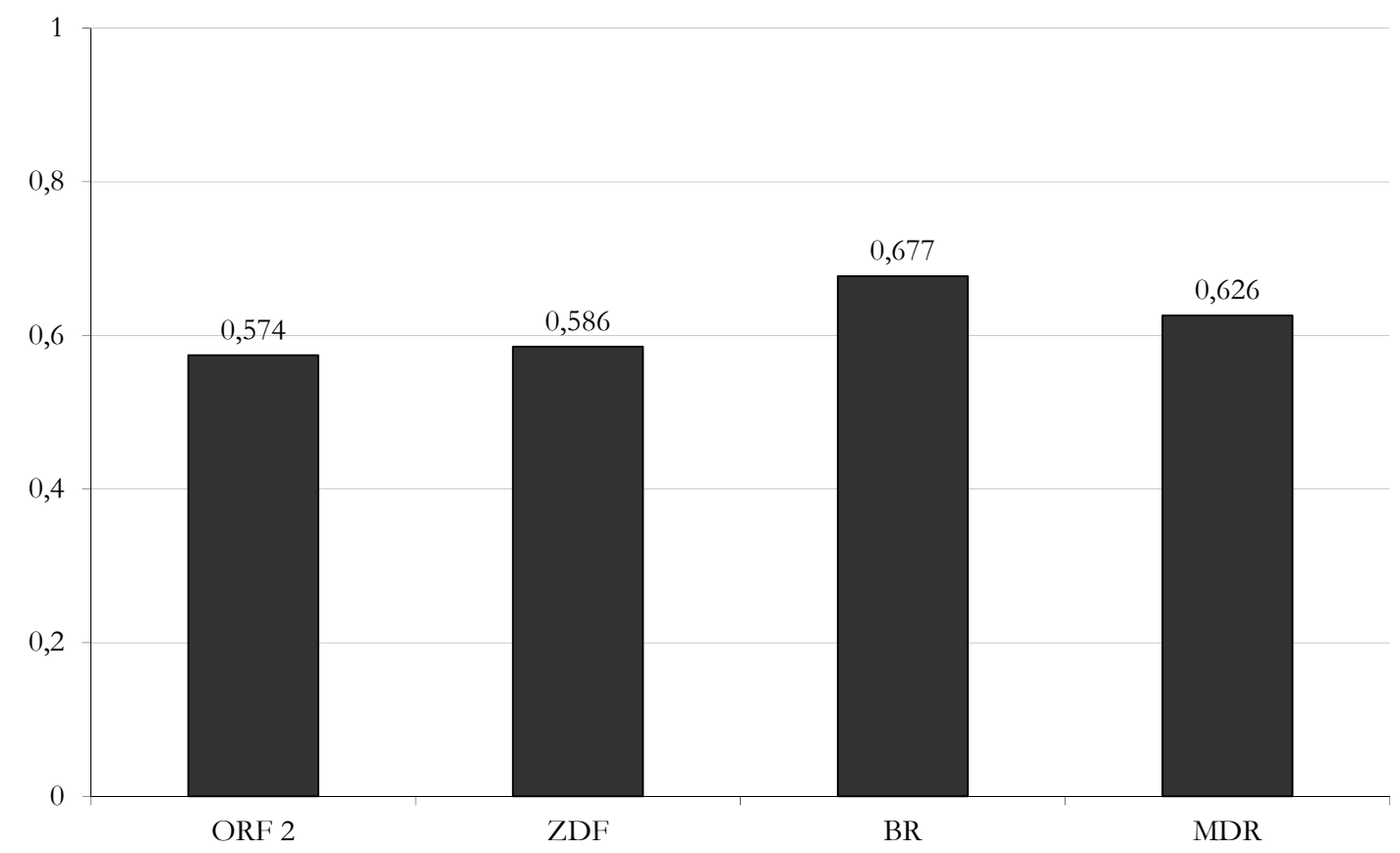

Auch im Bereich der Informationsprogramme sind senderspezifische Profile erkennbar, die nicht der Unterscheidung in nationale und regionale Sender entsprechen (vgl. Abbildung 6). Für den Anteil alleingestellter Reportagen und Dokumentationen lässt sich eine Ähnlichkeit zwischen BR und MDR ausmachen. Ihr Anteil liegt in den beiden Regionalsendern bei über 30 Prozent, während er in ZDF und ORF 2 bei 14 bzw. 20 Prozent liegt. Der Anteil der Nachrichtensendungen liegt dagegen in den nationalen Programmen über dem in den Regionalsendern. ${ }^{251}$ Die anderen Formen informierender Sendungen weisen keine Gemeinsamkeiten zwischen $O R F 2$ und $Z D F$ einerseits und $B R$ und $M D R$ andererseits auf.

Die relativen Entropiewerte für die Verteilung der entsprechenden Sendezeit auf die Formen der Information zeigt, dass sich die Regionalsender untereinander ähnlicher sind als die nationalen Programme (vgl. Abbildung 7). Gleichzeitig liegt aber der Entropiewert des BR näher an dem des ORF 2 als dem des MDR. Die Dichotomie zwischen Regionalprogrammen und nati-

${ }^{251}$ Wobei Nachrichtenmagazine hier nicht dazugehören. Diese wurden den Magazinsendungen zugerechnet. 
onalem Programmangebot spiegelt sich also in der jeweiligen Angebotsstruktur nicht wider. Vielmehr zeichnen sich individuelle bzw. sehr spezifische Strukturen der vier untersuchten Sender ab. Das allein bedeutet aber nicht, dass die jeweilige Programmzusammensetzung nicht regional oder national induziert ist. Es gibt lediglich nicht „das regionale“ und „das nationale“ Senderprofil. ${ }^{252}$

\section{Abbildung 6: Zusammensetzung des Informationsprogramms der untersuchten Sender}

Basis: Umfang des Informationsprogramms in hh:mm:ss - ORF 2: 59:27:17, ZDF: 56:21:09, BR: 73:27:54, MDR: 68:03:09.

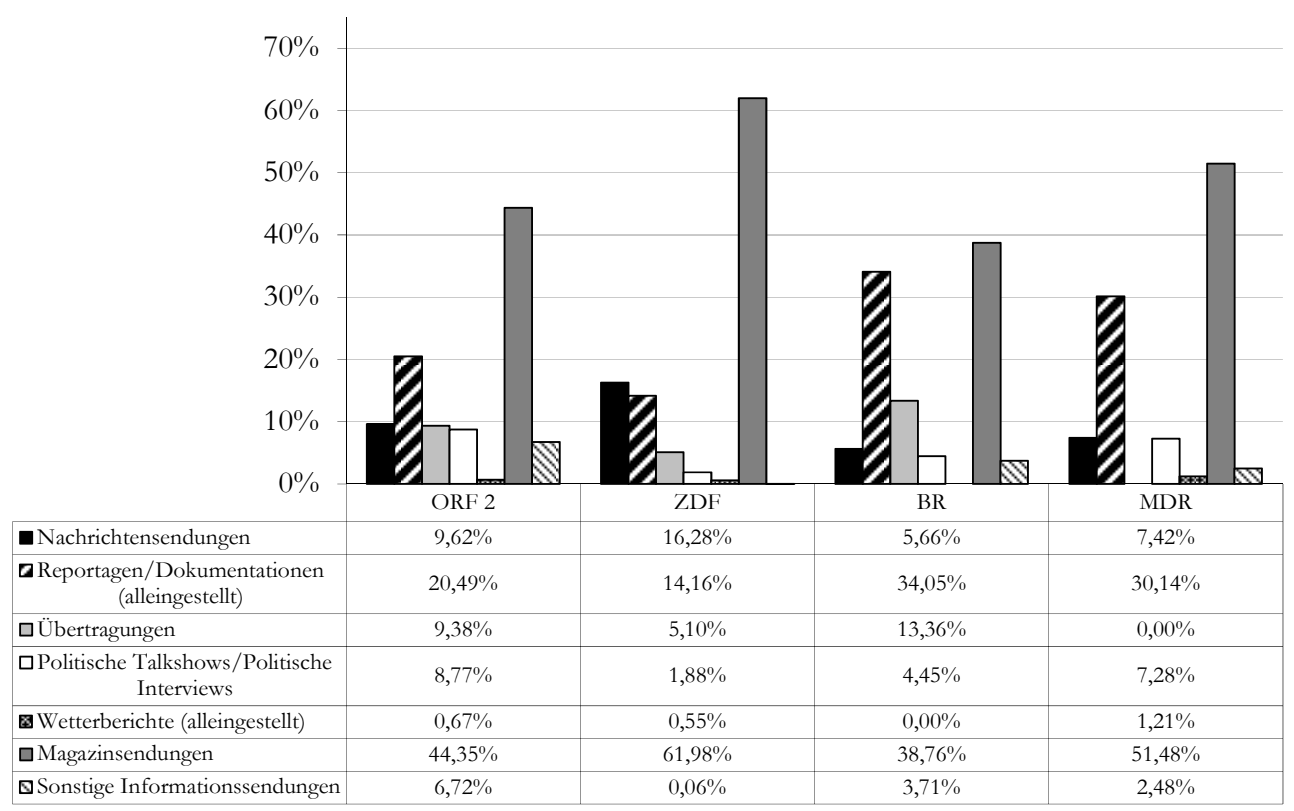

${ }^{252}$ Insofern dürfte es unzulässig sein, anhand der rein formalen und inhaltlichen Programmstruktur zu bestimmen, ob es sich um ein regionales oder nationales Programm handelt. Andererseits ist es ebenfalls nicht möglich zu sagen, es gäbe beispielsweise ein spezifisch bayerisches Programmprofil, auch weil der BR das einzige bayerische Regionalprogramm (in dieser Größenordnung) ist. Der Mangel dieses Vergleichsmaßstabs bedeutet aber gerade nicht, dass der individuelle Charakter des BR sich nicht (zumindest auch) daraus ergibt, dass er ein Programm für Bayern ist. Entsprechendes gilt für die anderen Sender. 
Abbildung 7: Vergleich der relativen Entropiewerte für die Verteilung des Informationsangebots auf die verschiedenen Sendeformen

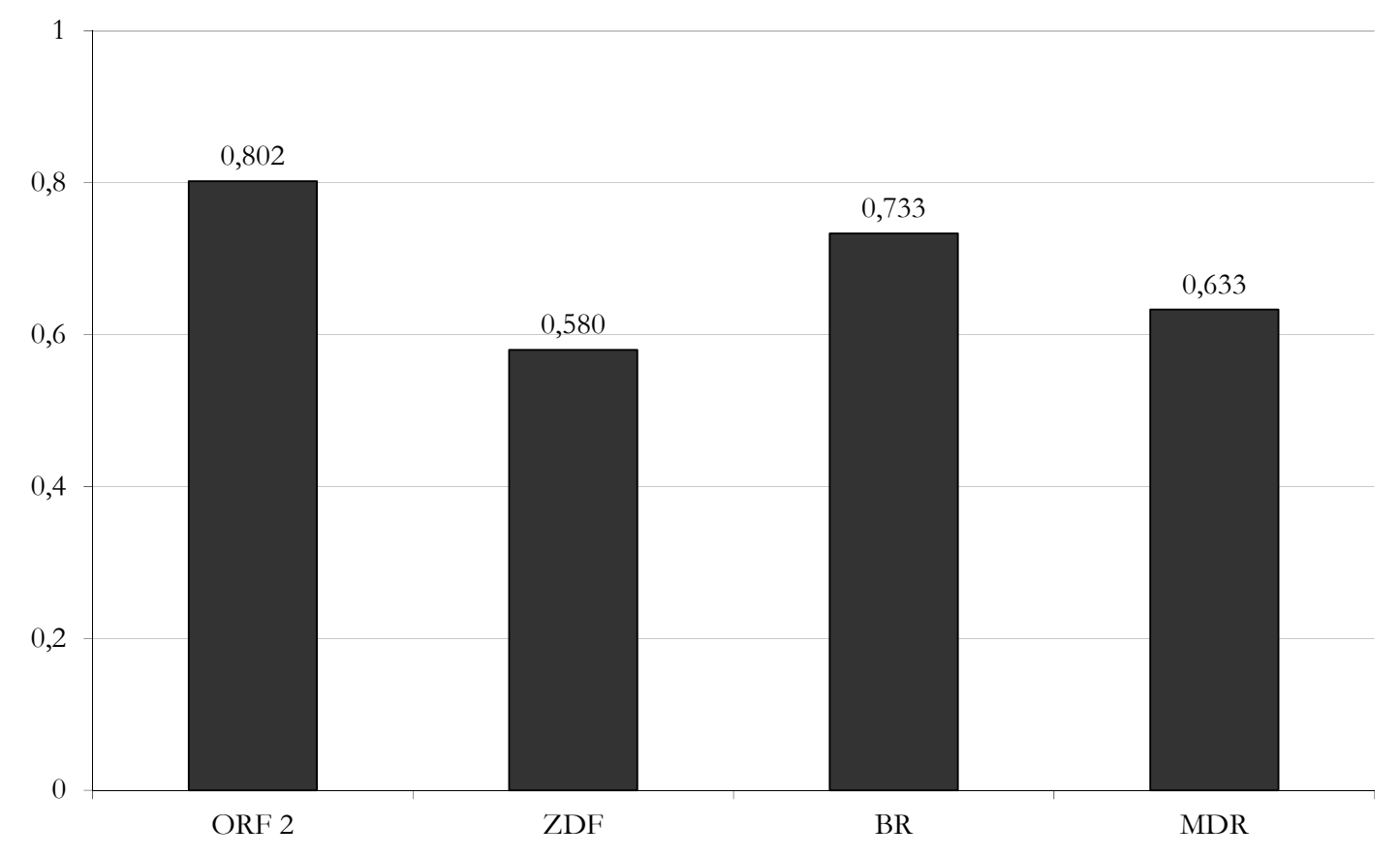

\subsubsection{Programmleistung im Licht des Rundfunkstaatsvertrags}

Der Rundfunkstaatsvertrag trifft Regelungen (vgl. S. 110) darüber, wie sich die kulturelle Vielfalt Deutschlands und Europas im Programm niederschlagen soll. Demnach soll der Hauptteil der Sendezeit für Spielfilme (Kino- und Fernsehfilme), Serien und (alleingestellte) Dokumentationen deutschen und europäischen Werken vorbehalten sein. Ob diese Anforderungen im Verlauf der Untersuchungswoche erfüllt wurden, lässt sich anhand der erhobenen Produktionsländer für die infrage kommenden Sendungen ablesen (vgl. Tabelle 2). Dafür werden hier nur Erstausstrahlungen und kurzfristige Wiederholungen berücksichtigt. Zwar macht der Rundfunkstaatsvertrag bezüglich der Berücksichtigung von nicht erstmals ausgestrahlten Sendungen keine Angaben, es scheint jedoch nicht im Sinne der Regelung zu sein, diese mitzuberücksichtigen. Das ergibt sich aus dem Zweck der Vorschrift, die europäische Produktionen besonders fördern will, was wirtschaftlich nur dann sinnvoll möglich ist, wenn nicht ein- und dieselben Filme oder Serien immer wieder aufs Neue ausgestrahlt werden. 
Tabelle 2: Produktionsländer erstmals ausgestrahlter und kurzfristig wiederholter fiktionaler Sendungen sowie alleinstehender Dokumentationen

\begin{tabular}{l|c|c|c|c|c|c|c|c} 
& \multicolumn{2}{|c|}{ ORF 2 } & \multicolumn{2}{c|}{ ZDF } & \multicolumn{2}{c}{ BR } & \multicolumn{2}{c}{ MDR } \\
\hline & $\begin{array}{l}\text { Umfang in } \\
\text { hh:mm:ss }\end{array}$ & Anteil & $\begin{array}{c}\text { Umfang in } \\
\text { hh:mm:ss }\end{array}$ & Anteil & $\begin{array}{c}\text { Umfang in } \\
\text { hh:mm:ss }\end{array}$ & $\begin{array}{c}\text { Umfang in } \\
\text { hh:mm:ss }\end{array}$ & $\begin{array}{c}\text { Umfang in } \\
\text { hh:mm:ss }\end{array}$ & Anteil \\
\hline Dänemark & $00: 00: 00$ & $0,00 \%$ & $01: 49: 28$ & $5,26 \%$ & $00: 00: 00$ & $0,00 \%$ & $00: 00: 00$ & $0,00 \%$ \\
\hline $\begin{array}{l}\text { Deutsch- } \\
\text { land }\end{array}$ & $11: 26: 13$ & $47,53 \%$ & $04: 56: 51$ & $83,46 \%$ & $19: 01: 35$ & $100,00 \%$ & $08: 01: 45$ & $100,00 \%$ \\
\hline England & $02: 53: 22$ & $12,01 \%$ & $00: 00: 00$ & $0,00 \%$ & $00: 00: 00$ & $0,00 \%$ & $00: 00: 00$ & $0,00 \%$ \\
\hline Österreich & $09: 44: 17$ & $40,47 \%$ & $00: 43: 15$ & $2,08 \%$ & $00: 00: 00$ & $0,00 \%$ & $00: 00: 00$ & $0,00 \%$ \\
\hline USA & $00: 00: 00$ & $0,00 \%$ & $03: 11: 31$ & $9,20 \%$ & $00: 00: 00$ & $0,00 \%$ & $00: 00: 00$ & $0,00 \%$ \\
\hline Gesamt & $\mathbf{2 4 : 0 3 : 5 2}$ & $\mathbf{1 0 0 , 0 0 \%}$ & $\mathbf{3 4 : 4 1 : 0 5}$ & $\mathbf{1 0 0 , 0 0 \%}$ & $\mathbf{1 9 : 0 1 : 3 5}$ & $\mathbf{1 0 0 , 0 0 \%}$ & $\mathbf{8 : 0 1 : 4 5}$ & $\mathbf{1 0 0 , 0 0 \%}$
\end{tabular}

Es zeigt sich, dass der absolute Umfang infrage kommender Sendungen in MDR und BR deutlich geringer ist als in den beiden Nationalprogrammen. Das dürfte sich aus der dort festgestellten generell hohen Anzahl von Wiederholungen ergeben. Darüber hinaus werden hier ausschließlich deutsche Produktionen ausgestrahlt. Allerdings weist auch das ZDF innerhalb des Untersuchungszeitraums nur einen geringen Anteil europäischer nicht deutscher Produktionen auf. Hierauf entfallen lediglich sieben Prozent der hier berücksichtigten Sendezeit. Mehr Sendezeit wird mit US-amerikanischen Inhalten gefüllt.

Im ORF 2 hingegen (für den die Vorgaben des Rundfunkstaatsvertrags allerdings nicht gelten) zeigt sich, dass der größte Teil nicht wiederholter Filme, Serien und Dokumentationen aus Deutschland stammt. Hinzu kommen zwölf Prozent Sendezeit aus England. Der Anteil nicht österreichischer Produktionen liegt dabei bei fast 60 Prozent. Vor dem Hintergrund der Regelungen des ORF-Gesetzes erscheint das problematisch, da der ORF seine Aufgabe, Forum österreichischer Kultur zu sein, insbesondere durch Eigen- und Auftragsproduktionen erfüllen soll. Gleichwohl ist der Anteil heimischer Produktionen auch im ORF 2 relativ hoch. Angesichts der Rahmenbedingungen, die das österreichische Mediensystem vorgibt (Größe, ökonomische Leistungsfähigkeit etc.), dürften höhere Anteile auch nur schwer möglich sein. Jedenfalls ist ein Unterschied zu den deutschen Programmen deutlich zu erkennen, der wohl auch österreich-spezifisch sein dürfte.

In allen Fällen ist zu bedenken, dass den Gesetzesgrundlagen keine Regelungen hinsichtlich der tatsächlich eingeforderten Anteile deutscher und europäischer Produktionen zu entnehmen sind. Darüber hinaus gibt es keine Bestimmung darüber, in welchem Zeitraum diese An- 
teile zu erbringen sind ( $\mathrm{bb}$ also die Anteile im Programmverlauf einer Woche, eines Monats oder des ganzen Jahres heranzuziehen sind). ${ }^{253}$

\subsubsection{Angebot fiktionaler Unterhaltungssendungen}

\subsubsection{Alter fiktionaler Sendung}

Anhand des Alters der in den untersuchten Sendern ausgestrahlten fiktionalen Sendungen (also hauptsächlich Serien und Spielfilme) zeigt sich erneut, dass insbesondere in den Dritten Programmen viele Wiederholungen ausgestrahlt werden. Während in ORF 2 und ZDF 44 bzw. 65 Prozent (Anteil an Sendezeit des fiktionalen Programms) auf aktuelle Produktionen entfallen, sind dies im BR 29 Prozent und im MDR nur 21 Prozent (vgl. Abbildung 8). Dagegen entfällt in den beiden Regionalsendern ein relativ hoher Anteil auf Sendungen aus den 1990er Jahren. Dementsprechend werden hier also nicht - im Sinne einer Ansprache eines betagten Zielgruppenpublikums - Filme ,aus der guten alten Zeit“ gesendet, sondern vielmehr relativ junge Produktionen, die aber doch alt genug sind, dass für sie keine zusätzlichen Kosten für die Ausstrahlung mehr anfallen (sofern es sich um solche aus dem $A R D$-Bestand handelt). Insgesamt beträgt der Anteil ,alter“ Produktionen (als die hier solche von vor 2000 gelten sollen) im MDR 54 Prozent, im BR 45 Prozent. Im ORF 2 liegt er dagegen bei 28 Prozent und im ZDF bei 16 Prozent. Besondere Präferenzen für bestimmte vergangene Jahrzehnte lassen sich aber anhand der Ergebnisse nicht belegen. Selbst wenn sich hier infrage kommende nationale oder regionale Identitäten also inhaltlich auf bestimmte Jahrzehnte des 20. Jahrhunderts beziehen würden, spiegelte sich das im Alter der Filmproduktionen nicht wider.

\footnotetext{
${ }^{253}$ Die Regelungen zu den Regionalfenstern im Privatfernsehen (siehe auch S. Fehler! Textmarke nicht definiert.) beziehen sich jedoch auf den Zeitraum einer Woche, was immerhin dafür spricht, dass es sich aus rechtlicher Perspektive dabei um einen gängigen Beurteilungszeitraum handelt. Legt man diesen Maßstab auch hier an, sind die in den Ergebnissen dargestellten Verteilungen als jedenfalls problematisch zu bezeichnen. Dagegen ist allerdings zu beachten, dass die Menge von Filmen, die innerhalb einer Woche gezeigt werden können, gering ist und sich die Regionalfenstervorgaben auf kleinteiligere Einheiten beziehen. Insofern sollten die vorliegenden Befunde nicht überbewertet werden.
} 
Abbildung 8: Alter fiktionaler Sendungen nach Anteil der Sendezeit

Basis: Gesamtdauer fiktionaler Sendungen in hh:mm:ss - ORF 2: 34:19:42, ZDF: 34:50:32, BR: 17:26:34, MDR: 10:28:36.

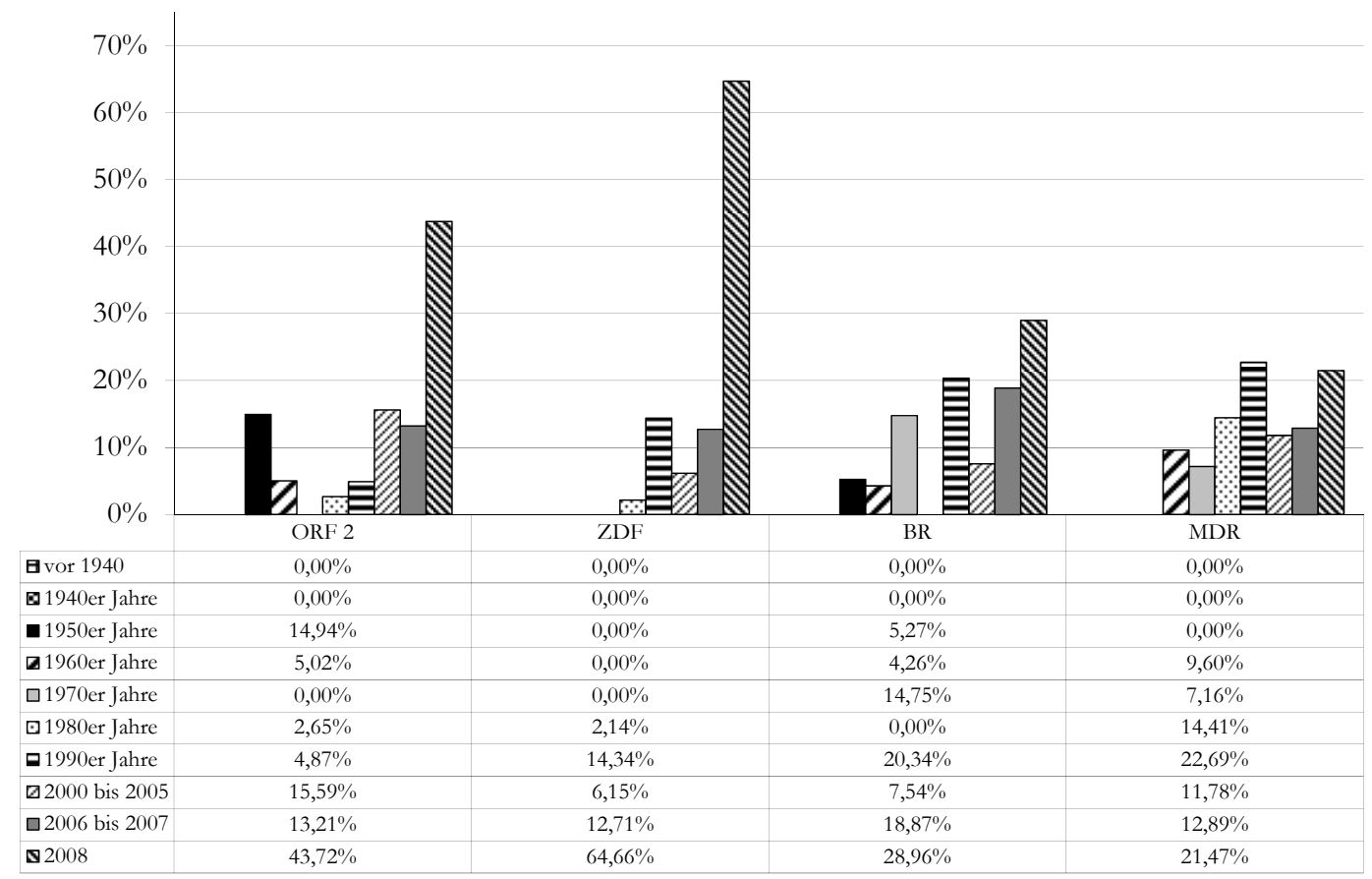

\subsubsection{Raum- und Zeitbezüge fiktionaler Sendungen}

Filme und Fernsehserien lassen sich nicht nur anhand ihres Alters, sondern auch nach ihrer Herkunft klassifizieren (vgl. Abbildung 9). Das ist insofern von Interesse, als dass sich hieraus kulturelle Unterschiede ergeben können oder andererseits hegemoniale Entwicklungen möglich sind (etwa wenn das Angebot von amerikanischen Serien dominiert wird). 
Abbildung 9: Herkunft fiktionaler Sendungen nach Anteil der Sendezeit

Basis: Gesamtdauer fiktionaler Sendungen in hh:mm:ss - ORF 2: 34:19:42, ZDF: 34:50:32, BR: 17:26:34, MDR: $10: 28: 36$

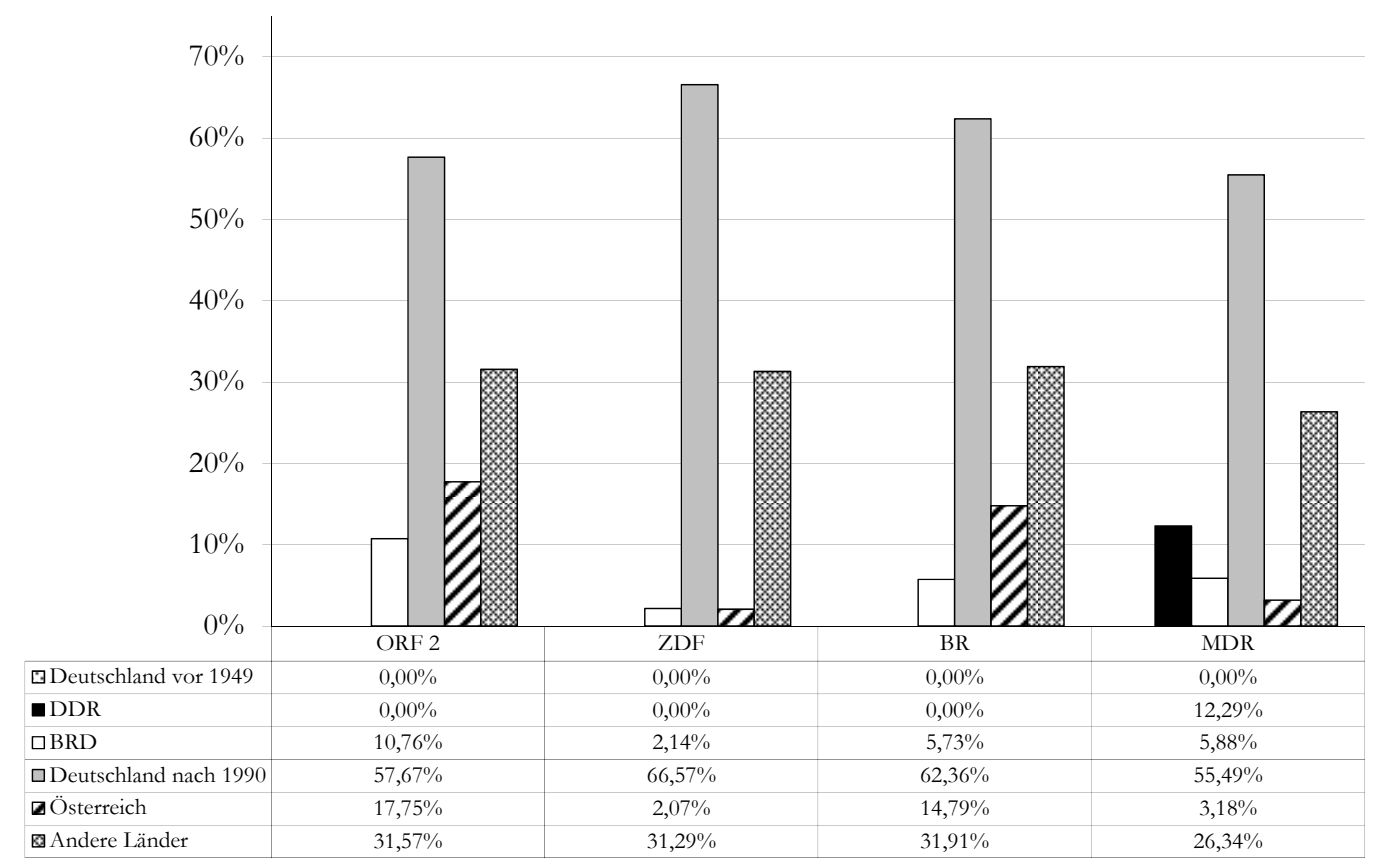

Eine Dominanz US-amerikanischer Produktionen ist in keinem der untersuchten Sender festzustellen. Der Anteil solcher Sendungen am fiktionalen Programm liegt außer im ZDF (20 Prozent) bei max. zehn Prozent. ${ }^{254}$ DDR-Produktionen werden ausschließlich im MDR ausgestrahlt, wo sie zwölf Prozent des fiktionalen Angebots ausmachen. In allen untersuchten Sendern bilden bundesdeutsche Produktionen (von nach 1990) den Hauptanteil der Filme und Serien. Das gilt auch für den ORF 2. Der Anteil österreichischer Sendungen liegt hier bei nur 18 Prozent. Das sind nur drei Prozentpunkte mehr als im BR. Damit dürfte sich im ORF 2 die insgesamt geringe Bedeutung der österreichischen Film- und Fernsehproduktion niederschlagen. Auf Grund des relativ kleinen österreichischen Gesamtpublikums sind die Produktionskosten im Vergleich zu den Einnahmemöglichkeiten zu hoch, als dass die österreichische Filmindustrie einen hohen Output erreichen könnte. Der hohe Anteil deutscher Sendungen am Fernsehprogramm der Alpenrepublik ist die logische Folge: Hierfür fallen keine zusätzlichen Kosten für Synchronisation oder Untertitelung an. Allerdings stellt sich schon die Frage, ob angesichts der Empfangsmöglichkeiten deutscher Fernsehprogramme via Kabel und Satellit diese Programmzusammensetzung noch zeitgemäß ist.

Die deutschen Filme und Serien im BR sind in ihrer Mehrzahl aus der Zeit nach 1990. Lediglich sechs Prozent entfallen während der Untersuchungswoche auf ältere bundesdeutsche 
Produktionen. Diese stammen sämtlich aus den 1970er Jahren. Aus den 1950er Jahren wird hier lediglich ein österreichischer Heimatfilm ausgestrahlt („Bruder Martin“). Umgekehrt machen aber im ORF 2 fiktionale bundesdeutsche Filme aus den 1950er Jahren immerhin acht Prozent des fiktionalen Unterhaltungsprogramms aus.

Dass das MDR-Programm als kulturelles Speichermedium fungiere, in dem besonders viele DDR-Produktionen gezeigt werden, lässt sich nur teilweise bestätigen. Solche Sendungen werden überhaupt nur im MDR ausgestrahlt. Insofern können eventuelle „,nostalgische Bedürfnisse“ hier - aber eben auch nur hier - befriedigt werden. Jedoch ist der Umfang von Filmen aus der DDR nicht so groß, als dass im MDR der Nostalgie Vorschub geleistet würde. Vor allem fanden sich im Programm gar keine Fernsehserien aus dem ehemaligen sozialistischen Staat, das heißt, eine nachträgliche Perpetuierung des DDR-Alltags (durch dessen Zeigen in der Serie, bzw. dessen Wiederholung durch Ansehen einer solchen, vgl. S. 122) wird durch den $M D R$ nicht ermöglicht. Dieses Untersuchungsergebnis heißt nicht, dass im MDR gar keine solchen Fernsehserien ausgestrahlt werden. Dass dies aber jedenfalls während der Untersuchungswoche nicht der Fall war, zeigt, dass sie kein fester Bestandteil des Programms sind.

Auch im BR werden nostalgische Bedürfnisse, die sich auf die heile Welt des Heimatfilms beziehen könnten, nicht bzw. in nur sehr geringem Umfang bedient. Insofern handelt es sich bei den diesbezüglichen hypothetisch formulierten Vermutungen um ein Klischee, das sich nicht bestätigt. Im Zusammenhang mit den weiter unten ausformulierten Ergebnissen zur Themenrangfolge in den Magazinen des BR (umfangreichstes Thema: „Brauchtum und Tradition“, siehe S. 231) bedeutet das auch, dass sich Traditionsverbundenheit und Brauchtumspflege nicht nur im Umfeld rückwärtsgewandter Vergangenheitsbetrachtung entfalten können. Jedenfalls käme ein solches Traditionsverständnis nicht im Fernsehprogramm des Bayerischen Rundfunks zum Ausdruck.

Insgesamt weisen die vier untersuchten Sender hinsichtlich der Herkunft der gezeigten fiktionalen Sendungen keine derart deutlichen Unterschiede auf, als dass sich ein spezifisches und interpretationsfähiges Profil daraus ableiten ließe. Hinsichtlich des ORF 2 ist das allerdings bemerkenswert, da dessen Spielfilm- und Serienangebot in dieser Form wohl auch in einem deutschen Programm laufen könnte. Auch wenn das - wie schon gesagt - eher Folge der österreichischen Medienwirtschaftsstruktur sein dürfte, so kann doch festgehalten werden, dass der ORF 2 auf dieser Betrachtungsebene jedenfalls nicht als österreichisches Programm erkennbar wird.

Neben ihrer räumlichen und zeitlichen Herkunft weisen Filme und Serien auch durch den jeweiligen Ort der gezeigten Handlung einen Raumbezug auf. In den untersuchten deutschen Programmen zeigen sich tatsächlich Unterschiede bezüglich der Handlungsorte (vgl. Tabelle 3). So spielen die Geschichten in Filmen und Serien, die im MDR ausgestrahlt werden, zu einem Drittel in Mitteldeutschland. Hinzu kommen noch 6,5 Prozent Sendezeit, die auf Orte auf dem Gebiet der ehemaligen DDR entfallen, aber zu Mitteldeutschland gehören. Dieser letztgenannte Wert ist aber nicht höher als im ZDF und kann damit nicht als Ausdruck besonders ausgeprägten Ostdeutschlandbezugs gesehen werden. Der Fokus liegt ein- 
deutig auf dem angestammten Sendegebiet. Im BR ist das eigene Bundesland zu 46 Prozent der Zeit Schauplatz der gezeigten Handlungen. Wobei der Großteil davon auf die Gebirgsregionen entfällt, die Bayern landschaftlich besonders charakterisieren. Im ZDF liegen die Orte des fiktiven Geschehens zu zwei Dritteln innerhalb Deutschlands. ${ }^{255}$ Entsprechend dem hohen Anteil deutscher Sendungen im ORF 2 liegen allerdings auch hier die Handlungsorte sehr häufig in Deutschland (zu 65 Prozent und damit häufiger als im ZDF). Österreich bildet dagegen nur in 17 Prozent der Zeit den Hintergrund fiktiver Handlungen. Insofern scheint zwar viel für einen Zusammenhang zwischen Sendegebiet und bevorzugt gezeigten Handlungsorten zu bestehen. Der ist aber nicht zwangsläufig unabhängig von äußeren (z. B. wirtschaftlichen) Einflüssen. Auf die untersuchten deutschen Programme begrenzt, zeigt sich deutlich, dass das eigene Sendegebiet auch der bevorzugte Handlungsort fiktionaler Sendungen ist. Im Bayerischen Rundfunk ist diese Vorliebe zur Heimatregion am deutlichsten ausgeprägt. Es ist allerdings anzumerken, dass diese Häufung des Freistaats als Filmkulisse wenigstens zum Teil auf Sendungen aus dem Ersten Programm der $A R D$ zurückzuführen ist, die jeweils am Folgetag in den Dritten wiederholt werden (im Untersuchungszeitraum die Telenovela „Sturm der Liebe“). Allerdings strahlt der BR auch eine eigene Daily Soap mit explizitem Bayern-Bezug aus („Dahoam is Dahoam“), die von keinem anderen Programm übernommen wird. Insofern erscheint eher der mit zehn Prozent relativ hohe Sendezeitanteil mit bayerischen Schauplätzen im MDR als (allerdings strukturbedingter ${ }^{256}$ ) „Ausreißer“ als der insgesamt hohe Bayernanteil im BR. Im ZDF, BR und MDR ist das Sendegebiet auch im fiktionalen Programm ,abgebil$\operatorname{det}^{\prime}$. Als filmische Kulisse werden diese Programme damit als spezifisch national bzw. regional erkennbar. Vor allem für die beiden Dritten dürfte dies auch von Seiten der Programmverantwortlichen intendiert sein. Gerade weil hier besonders häufig auf ältere Filme und Wiederholungen zurückgegriffen wird, ist es wahrscheinlich, dass die räumliche Nähe eines der Auswahlkriterien darstellt. Im ZDF dagegen dürfte sich eher der hohe Anteil an (neuen) Eigenproduktionen niederschlagen (etwa die verschiedenen Serienableger der „SOKO“-KrimiReihe, deren Handlungsorte mit deutlich erkennbaren Regionalbezügen über Deutschland verteilt liegen).

\footnotetext{
${ }^{255}$ Hier mit den gesondert erfassten deutschen Regionen zusammengefasst, da diese auch im ZDF-Sendegebiet liegen.

${ }^{256}$ Die Ausstrahlung der Serie „Sturm der Liebe“ dürfte von Seiten der $A R D$ vorgegeben sein. Gleichzeitig ist der zeitliche Umfang fiktionaler Sendungen im MDR insgesamt geringer, so dass diese Telenovela mit ihrem täglichen Senderhythmus stärker ins Gewicht fällt.
} 
Tabelle 3: Verteilung der Handlungsorte fiktionaler Sendungen anhand der Sendezeit.

Der jeweils höchste Anteilswert pro Sender ist hervorgehoben.

\begin{tabular}{|c|c|c|c|c|}
\hline & ORF 2 & ZDF & BR & MDR \\
\hline USA/Nordamerika & $7,54 \%$ & $20,09 \%$ & $0,00 \%$ & $10,13 \%$ \\
\hline Mittel-/Südamerika & $0,00 \%$ & $0,00 \%$ & $0,00 \%$ & $2,37 \%$ \\
\hline Afrika & $0,70 \%$ & $0,00 \%$ & $0,00 \%$ & $0,00 \%$ \\
\hline Westeuropa & $9,72 \%$ & $8,11 \%$ & $4,26 \%$ & $4,81 \%$ \\
\hline Osteuropa & $0,00 \%$ & $0,00 \%$ & $9,02 \%$ & $0,00 \%$ \\
\hline $\begin{array}{l}\text { Deutschland allg. (ohne unten genannte dt. } \\
\text { Regionen) }\end{array}$ & $32,56 \%$ & $42,67 \%$ & $15,92 \%$ & $12,37 \%$ \\
\hline $\begin{array}{l}\text { Österreich allg. (ohne unten genannte österr. } \\
\text { Regionen) }\end{array}$ & $9,33 \%$ & $2,07 \%$ & $14,79 \%$ & $3,18 \%$ \\
\hline $\begin{array}{l}\text { Ostdeutschland (außerhalb Mitteldeutsch- } \\
\text { lands) }\end{array}$ & $0,00 \%$ & $15,34 \%$ & $0,00 \%$ & $6,52 \%$ \\
\hline Mitteldeutschland & $6,80 \%$ & $2,08 \%$ & $5,84 \%$ & $33,28 \%$ \\
\hline Bayern allg. & $4,26 \%$ & $4,52 \%$ & $14,13 \%$ & $2,12 \%$ \\
\hline Bayerische Gebirgsregionen & $20,96 \%$ & $2,05 \%$ & $32,20 \%$ & $10,10 \%$ \\
\hline Österreichische Alpenregionen & $8,12 \%$ & $0,00 \%$ & $0,00 \%$ & $6,40 \%$ \\
\hline Sonstige & $0,00 \%$ & $3,08 \%$ & $3,83 \%$ & $8,72 \%$ \\
\hline Gesamt & $100,00 \%$ & $100,00 \%$ & $100,00 \%$ & $100,00 \%$ \\
\hline$=\mathrm{hh}: \mathrm{mm}: \mathrm{ss}$ & $=34: 19: 42$ & $=34: 50: 32$ & $=31: 29: 50$ & $=22: 42: 40$ \\
\hline
\end{tabular}

Auf formaler Ebene setzt sich das Angebot fiktionaler Unterhaltung in den nationalen Programmen etwas anders zusammen als in den Regionalprogrammen. Im ORF 2 und ZDF machen Serien den größten Anteil aus, wobei er im deutschen Sender mit 78 Prozent der auf fiktionale Sendungen entfallenden Zeit deutlich höher liegt als beim ORF 2, wo der Wert bei 59 Prozent liegt. Das heißt, dass wiederkehrende Elemente das Programm stark prägen. Auf Spielfilme entfallen im ZDF 19 Prozent, im ORF 242 Prozent der Zeit. Zeichentrick- bzw. Animationsfilme kommen im ORF 2 gar nicht, im ZDF nur in geringem Umfang (drei Prozent) vor. Während im ZDF immerhin zwei Drittel der fiktionalen Sendungen Erstausstrahlungen sind, ist dies im ORF 2 nur zu etwas über einem Drittel der Fall. ${ }^{257}$ Kurzfristige Wiederholungen (also erneute Ausstrahlung innerhalb von 48 Stunden) machen im ZDF zehn, im ORF 218 Prozent aus. Der Anteil langfristiger Wiederholungen liegt im ZDF bei 23 Prozent und im ORF 2 bei 45 Prozent. Deutlich unterschiedlich ist dagegen das fiktionale Unterhaltungsprogramm der Regionalsender zu charakterisieren. Im MDR gibt es im Untersuchungszeitraum gar keine Erstausstrahlungen, im BR sind es nur neun Prozent. Langfristige Wiederholungen machen im MDR 82 Prozent aus, im BR immerhin noch 69 Prozent. Kurzfristig zeitversetzte Programmübernahmen aus anderen Sendern umfassen in beiden Sendern

${ }^{257}$ Wobei im ORF 2 hier die vorkommenden Direktübernahmen mitgezählt wurden. Das sind Sendungen, die zeitgleich auch in einem anderen Programm ausgestrahlt werden. Das waren in der Untersuchungswoche knapp vier Stunden aus dem Programm des Ersten Deutschen Fernsehens (Telenovela „Sturm der Liebe“). Ohne diese Übernahmen liegt der Anteil von Erstausstrahlungen fiktionaler Sendungen im ORF 2 bei nur einem Viertel. 
ca. 13 Prozent. Diese speisen sich jeweils zum größten Teil aus der Ausstrahlung der jeweiligen Vortagsfolge der Telenovela „Sturm der Liebe“ aus dem Ersten Programm der $A R D$.

\subsubsection{Ergebnis Programmprofile}

Hinsichtlich der formal-inhaltlichen Struktur der Programme lässt sich die Grundannahme (Hypothese H1) über die Unterschiede zwischen nationalen und Regionalprogrammen nur zum Teil bestätigen. Es gibt einige Ähnlichkeiten zwischen BR und MDR sowie ORF 2 und $Z D F$. Diese betreffen vor allem einzelne Sendezeitanteile bestimmter Sendeformen (Information vs. Unterhaltung, Anteil Erstausstrahlungen vs. Wiederholungen). Je differenzierter die Programmstrukturen (auch inhaltlich) betrachtet werden, umso deutlicher werden individuelle Charakteristika der untersuchten Programme sichtbar, die aber nicht durchweg der Gegenüberstellung von national und regional entsprechen.

Hypothese H2 (H2a bis H2d) wird abgelehnt. Die Programmstrukturen unterscheiden sich nicht auf eine Weise, die der Zweiteilung in nationale Programmw auf der einen und regionale Programme auf der anderen Seite entspräche.

Hypothese H3 wird angenommen. Der Informationsanteil liegt in den Regionalprogrammen höher als bei den nationalen Sendern.

Hypothese H4 wird abgelehnt. Der Anteil alter Produktionen im fiktionalen Programm der beiden Regionalsender ist sehr hoch. Er liegt aber nur im Fall des MDR bei über 50 Prozent.

Hypothese H5a wird angenommen. Der Anteil von DDR-Produktionen ist im MDRFernsehen höher als in allen drei anderen untersuchten Sendern.

Hypothese H5b wird abgelehnt. Während des Untersuchungszeitraums wurden im BR gar keine BRD-Filme oder -Serien aus den 1950ern ausgestrahlt.

Hypothese H5c wird angenommen. Fast 40 Prozent der Handlungsorte fiktiver Sendungen im MDR liegen auf dem Gebiet der ehemaligen DDR. Davon entfällt allerdings die übergroße Mehrheit auf das Sendegebiet Mitteldeutschland.

Hypothese H5d wird angenommen. Fast zu einem Drittel spielt sich das Geschehen fiktionaler Sendungen im BR vor der Kulisse der bayerischen Gebirgswelt ab. 


\subsection{Magazine}

\subsubsection{Raumbezüge der Berichterstattung in Magazinen}

Um der Frage nachzugehen, in welchem Ausmaß die Berichterstattung die verschiedenen Gebiete berücksichtigt, sind mehrere Dimensionen der Betrachtung möglich. Zunächst zeigt sich die Gebietsabdeckung in den Orten, aus denen berichtet wurde (Ereignisorte). Orte, an denen sich ein Geschehen abspielt, sind aber nicht zwangsläufig identisch mit den Orten, auf die sich eine Handlung bezieht (etwa bei Regierungshandeln, dass sich meist am Regierungssitz abspielt, sich aber auf das gesamte Land bezieht). Das ist etwa regelmäßig der Fall, wenn eine Bundes- oder Landesregierung Entscheidungen trifft und bekannt gibt. Aus diesem Grunde wurden auch die Bezugsorte erhoben. Eine Verbindung der Dimensionen „Ereignis- und Bezugsort" sowie der Variable „Regionalität“ macht demgegenüber die eigentliche Regionalberichterstattung erkennbar. Entsprechend ist der zeitliche Gesamtanteil des Programms, der auf die verschiedenen Ereignisorte entfällt, immer höher als der Anteil der Regionalberichterstattung. Für die folgende Darstellung der Gebietsbezüge heißt das, dass die verschiedenen Bedeutungsdimensionen für alle vier Sendegebiete jeweils nacheinander ausgewiesen werden.

Die wichtigste Dimension ist die der Ereignisorte, denn hieraus wird am unmittelbarsten ersichtlich, wie sich das Gebiet, aus dem in einem Programm berichtet wird, zusammensetzt. Die Mehrzahl der Untersuchungseinheiten weist mindestens einen solchen Ereignisort auf. ${ }^{258}$ Die Ausweisung der im Kern regionalen Berichterstattung verweist dagegen zwar auch auf das tatsächliche Berichtsgebiet, bezieht sich aber inhaltlich bereits auf erwartete Unterschiede zwischen regionalen und nationalen Programmen. Von letzteren wird weniger regionale Berichterstattung erwartet als von ersteren.

\subsubsection{Gebietsabdeckung nationale Programme}

\subsection{Gebietsabdeckung im ORF 2}

Die Abdeckung Österreichs durch die Berichterstattung in Magazinsendungen des ORF 2 stellt sich je nach inhaltlicher Bedeutungsweite der Untersuchungseinheiten unterschiedlich dar. Bei bloßer Betrachtung der genannten Ereignisorte (ohne Berücksichtigung von Bezugsraum oder Regionalität des Themas) wird aus fast zwei Dritteln der österreichischen Landkreise berichtet (vgl. Abbildung 11). Auf Wien entfallen dabei mit 39 Prozent als einzigem Kreis über zehn Prozent der Sendezeit aller Magazinbeiträge (Abbildung 10). Das heißt, dass trotz

\footnotetext{
${ }^{258}$ Gemessen an der Sendezeit weisen 62 Prozent der redaktionellen Magazinbeiträge mindestens einen Ereignisort auf. Gemessen an der Anzahl 56 Prozent.
} 
dieser sehr starken Konzentration auf die Hauptstadt, die Mehrzahl der österreichischen Kreise berücksichtigt wird. Es werden alle zehn Bundesländer berücksichtigt, wenn auch unterschiedlich stark. Damit fällt die Abdeckung des österreichischen Staatsgebiets insgesamt höher aus als erwartet. Es kann nicht von einer rein punktuellen Berichterstattung gesprochen werden, wenn zwei Drittel aller Kreise sowie alle Bundesländer vorkommen. Insofern lassen sich die entsprechenden hypothetischen Vorannahmen hier nicht bestätigen.

Abbildung 10: ORF 2 - Regionale Verteilung der Ereignisorte der Berichterstattung nach Landkreisen - Anteil an der Sendezeit in Prozent

Basis: ORF 2-Magazinsendungsbestandteile mit identifizierbaren Ereignisorten in Österreich in hh:mm:ss = 18:27:05. Da einzelne Untersuchungseinheiten mehr als einen Ereignisort enthalten können, ist die ausgewiesene Sendezeit hier erhöht.

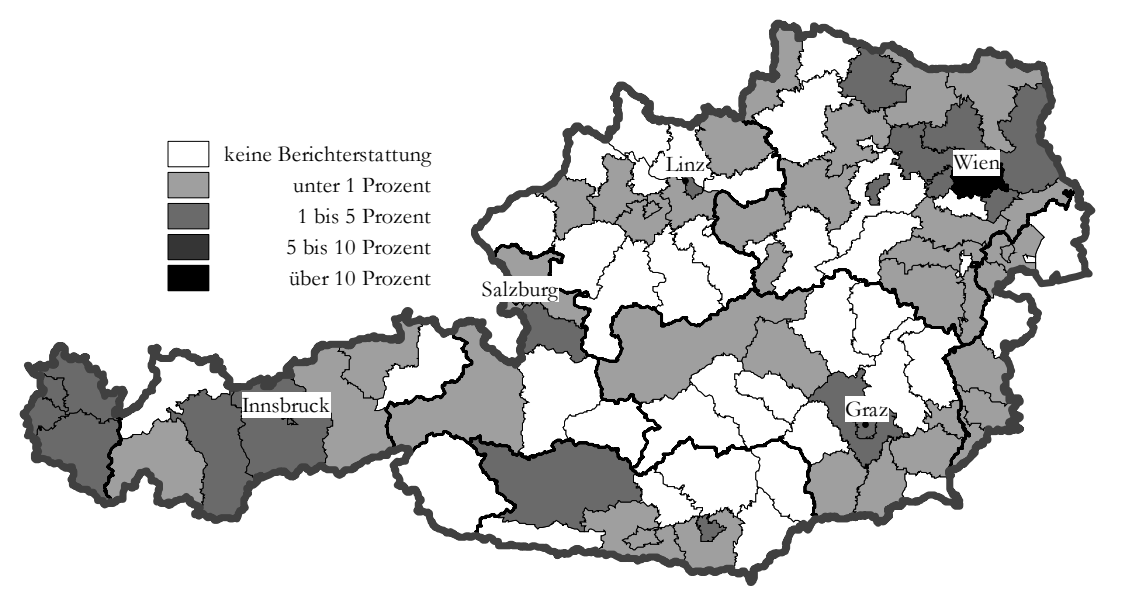


Abbildung 11: ORF 2 - Prozentuale Sendezeitverteilung

(UEs mit Ereignisort in Österreich) auf die Gesamtzahl der österreichischen Landkreise (Basis: 121 Landkreise)

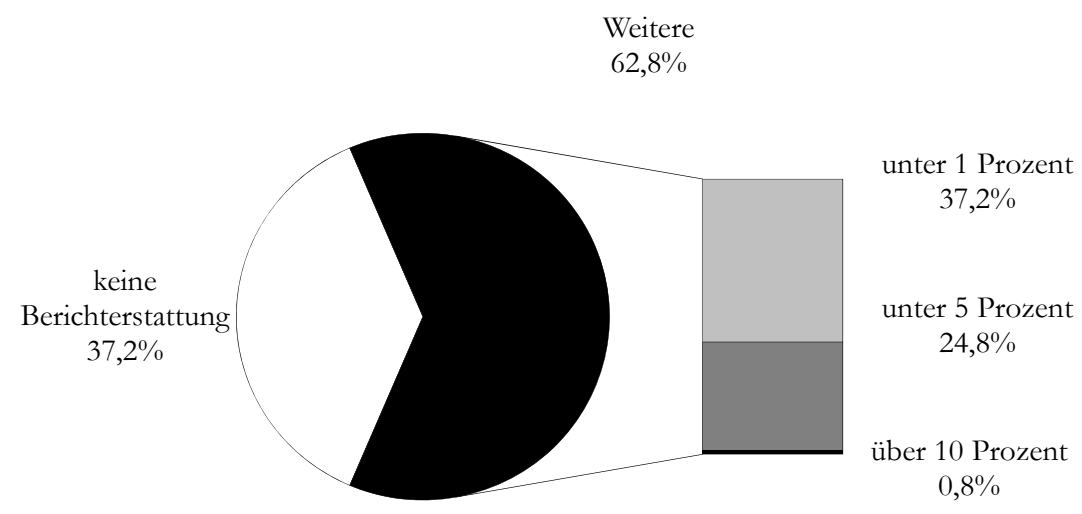

Betrachtet man dagegen nur die Regionalberichterstattung ${ }^{259}$ (vgl. Abbildung 12 und Abbildung 13), reduziert sich die Zahl der berücksichtigten Kreise auf 50 Prozent. Auch das bedeutet, dass in den Magazinen des ORF 2 das Staatsgebiet nicht nur punktuell berücksichtigt wird. Die eigentliche Regionalberichterstattung findet immerhin auch für die Hälfte aller Landkreise statt. Davon wiederum wird gut die Hälfte ausführlicher berücksichtigt (über fünf Prozent der Sendezeit) als andere Kreise, auf die jeweils weniger als ein Prozent der Berichterstattung entfällt. Auch im Rahmen der Regionalberichterstattung bleibt allerdings die Fokussierung auf Wien erhalten. Das heißt, dass sich auch deutlich über zehn Prozent der im Kern regionalen Berichterstattung auf die Hauptstadt beziehen.

Einschränkend ist hier zu beachten, dass der Untersuchungszeitraum nur eine Woche umfasst. Die vorliegenden Zahlen bedeuten also nicht, dass im ORF 2 grundsätzlich zwei Drittel (bzw. die Hälfte) der Landkreise berücksichtigt werden. Die Ergebnisse bedeuten aber sehr wohl, dass man als Österreicherin oder Österreicher mit Wohnsitz außerhalb Wiens, möglicherweise eine Woche lang im Fernsehen nichts aus der eigenen näheren Umgebung erfährt, insbesondere dann nicht, wenn man tatsächlich regional relevante Informationen sucht. ${ }^{260}$ Insofern dürfte die wider Erwarten hohe Gebietsabdeckungsrate aus Publikumssicht wenig relevant

${ }^{259}$ Entsprechend der oben gemachten Eingrenzung: Als Regionalberichterstattung gelten jene Untersuchungseinheiten, deren Ereignis- und Bezugsort übereinstimmen und die zudem in der Variable „Regionalität“ als mindestens „durch zahlreiche Bezüge regionalisiert“ ausgewiesen sind, vgl. S. 167 sowie Codebuch, S. 301.

${ }^{260}$ Dies mit der Einschränkung, dass Regionalfenster, die es im Programm des ORF 2 gibt, nicht berücksichtigt wurden. 
sein. Denn ein TV-Programm, das in nur 50 Prozent seiner Magazinbeiträge aus dem eigenen Umfeld berichtet, dürfte kaum die bevorzugte Quelle für regionale Informationen sein. Insofern sind die informativen Inhalte des ORF 2 ein auf nationale Maßstäbe ausgelegtes Medienangebot.

\section{Abbildung 12: ORF 2 - Regionale Verteilung der Regionalberichterstattung nach Landkreisen -} Anteil an der Sendezeit in Prozent

Basis: ORF 2-Magazinsendungsbestandteile mit Regionalberichterstattung in hh:mm:ss = 07:09:47. Da einzelne Untersuchungseinheiten mehr als einen Ereignisort enthalten können, ist die ausgewiesene Sendezeit hier erhöht.

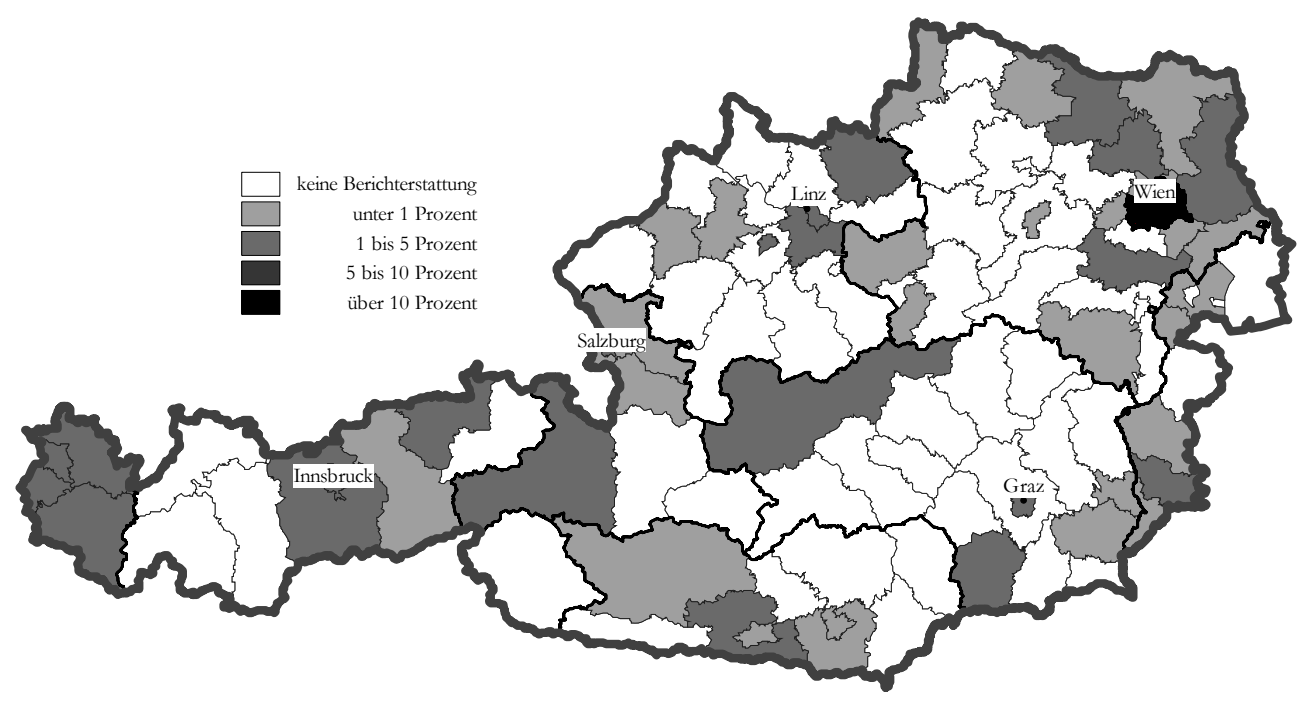


Abbildung 13: ORF 2 - Prozentuale Sendezeitverteilung der regionalen Berichterstattung auf die Gesamtzahl der österreichischen Landkreise

Basis: 121 Landkreise

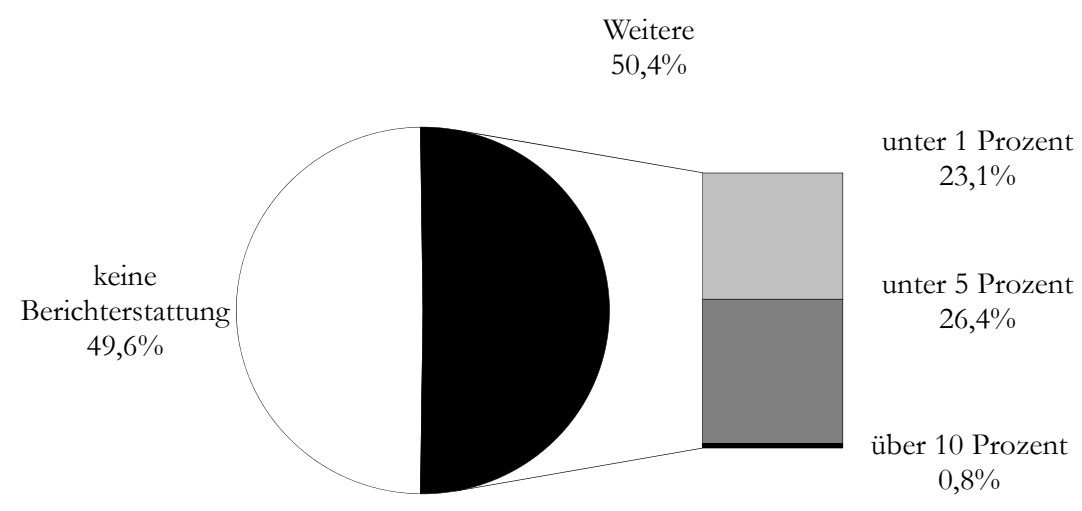

\subsection{Gebietsabdeckung ZDF}

Auch im Programm des ZDF bestehen Unterschiede in der Berücksichtigung verschiedener Orte des Sendegebiets - je nachdem ob es sich um bloße Ereignisorte handelt oder ob aus den betreffenden Gebieten Regionalberichterstattung erfolgt. Betrachtet man lediglich die Ereignisorte, die während der Untersuchungswoche berücksichtigt wurden, so wurde knapp ein Drittel der deutschen Landkreise berücksichtigt (vgl. Abbildung 15). Auf Berlin entfallen mit zwölf Prozent als einzigem Ort über zehn Prozent der Sendezeit aller Magazinbeiträge (vgl. Abbildung 14). Im Vergleich zum ORF 2, als dem zweiten untersuchten nationalen Programm, heißt das, dass die Berichterstattung zwar auch auf die Hauptstadt konzentriert ist, jedoch weniger stark. Gleichzeitig wird aber - im Gegensatz zum österreichischen Programm - aus einem deutlich geringeren Anteil der Kreise des Sendegebiets berichtet. 
Abbildung 14: ZDF - Regionale Verteilung der Ereignisorte der Berichterstattung nach Landkreisen - Anteil an der Sendezeit in Prozent

Basis: ZDF-Magazinsendungsbestandteile mit identifizierbaren deutschen Ereignisorten in hh:mm:ss = 25:57:22.

Da einzelne Untersuchungseinheiten mehr als einen Ereignisort enthalten können, ist die ausgewiesene Sendezeit hier erhöht.

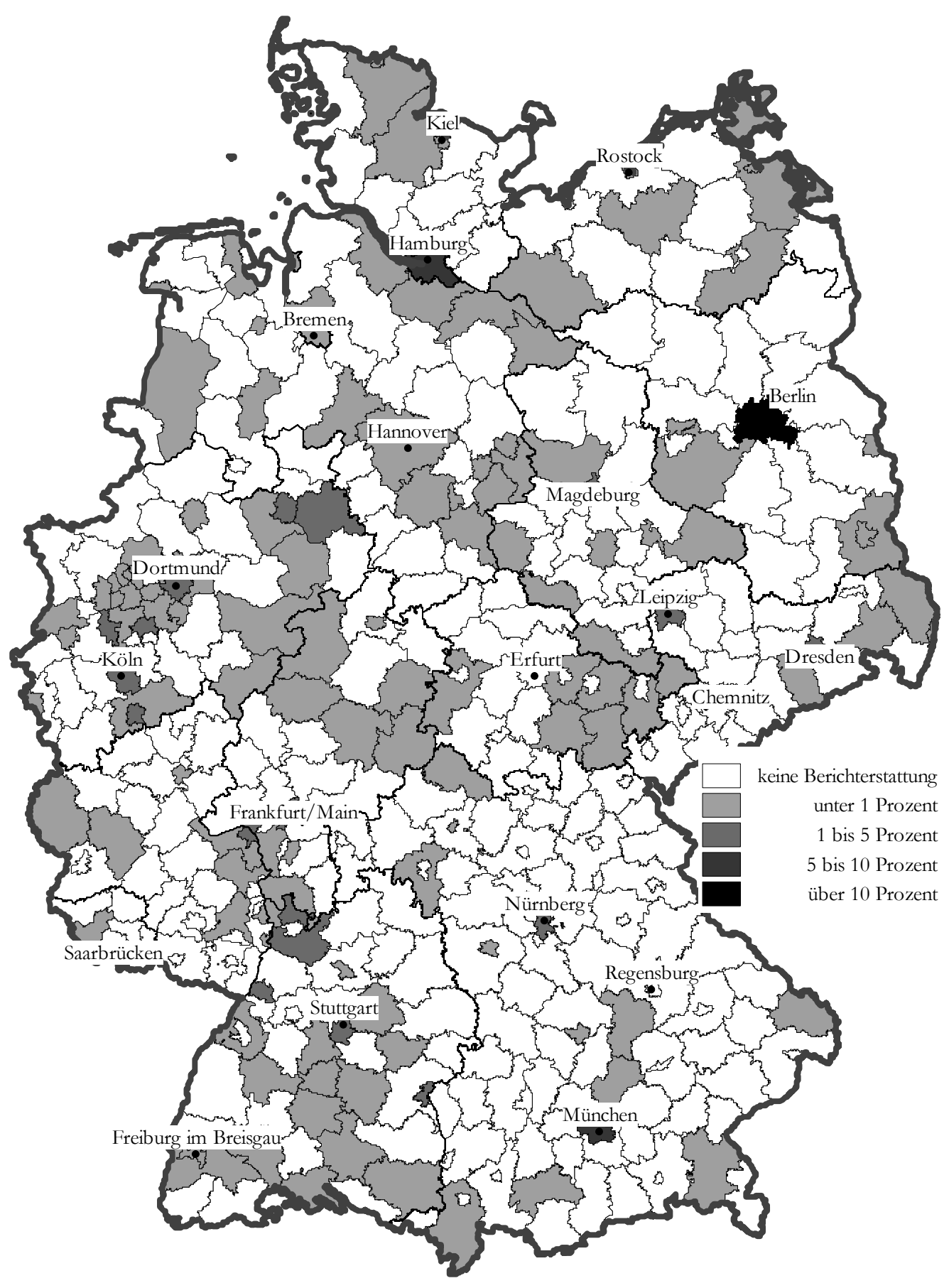


Abbildung 15: ZDF - Prozentuale Sendezeitverteilung (Ereignisorte) auf die Gesamtzahl der deutschen Landkreise

Basis: 273 Landkreise

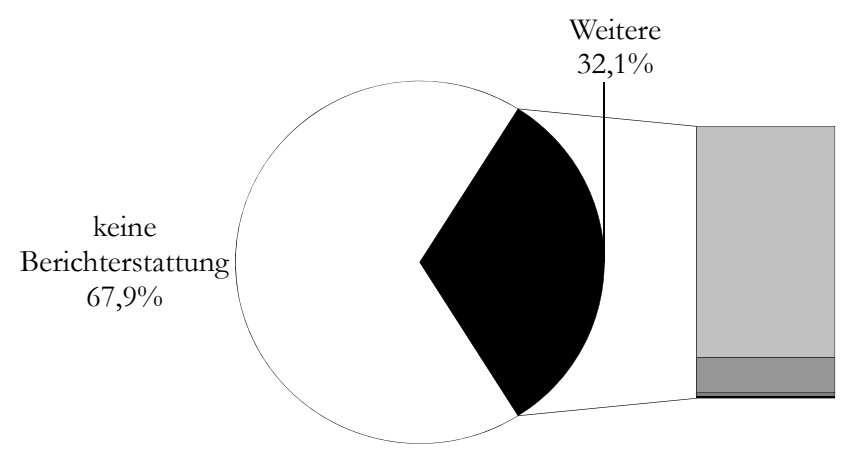

unter 1 Prozent

$$
27,3 \%
$$

1 bis 5 Prozent

$4,1 \%$

5 bis 10 Prozent

$0,5 \%$

über 10 Prozent

$0,2 \%$ 
Abbildung 16: ZDF - Regionale Verteilung der Regionalberichterstattung nach Landkreisen Anteil an der Sendezeit in Prozent

Basis: ZDF-Magazinsendungsbestandteile mit regionaler Berichterstattung in hh:mm:ss = 13:27:45. Da einzelne

Untersuchungseinheiten mehr als einen Ereignisort enthalten können, ist die ausgewiesene Sendezeit hier erhöht.

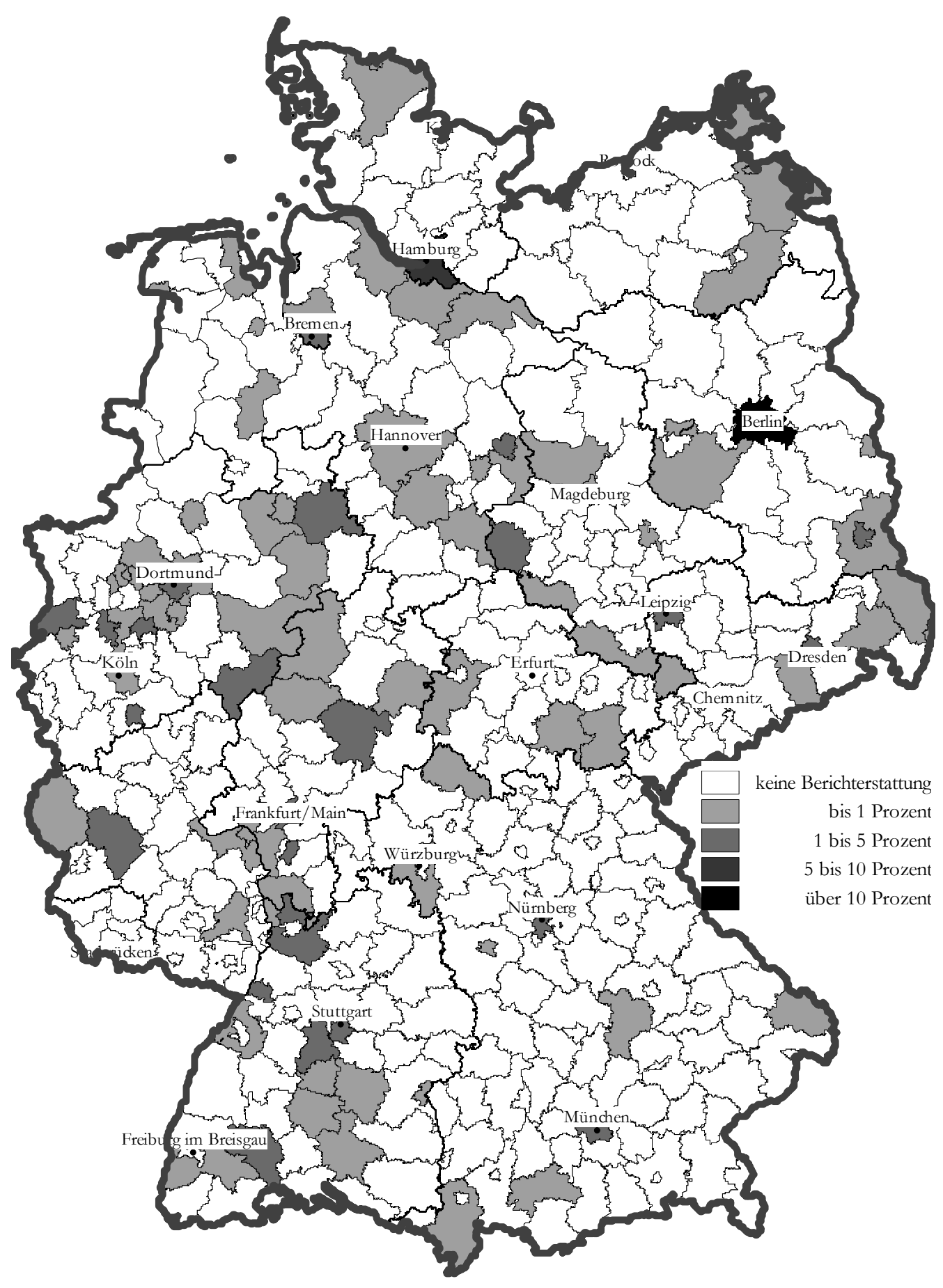


Abbildung 17: ZDF - Prozentuale Sendezeitverteilung der regionalen Berichterstattung auf die Gesamtzahl der deutschen Landkreise

Basis: 273 Landkreise

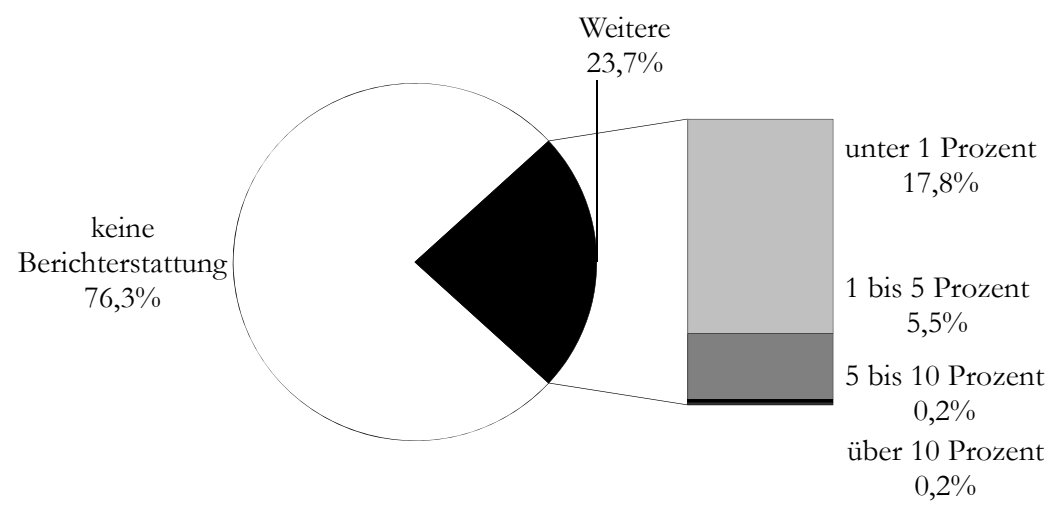

Noch deutlicher fällt der Unterschied zwischen ZDF und ORF 2 bei der Regionalberichterstattung aus. Im ZDF wird nur ein Viertel der deutschen Kreise berücksichtigt (vgl. Abbildung 17). Hier wäre es also absolut berechtigt, von einer nur punktuellen Berichterstattung zu sprechen. Allerdings ist dabei zu bedenken, dass es in Deutschland mehr Landkreise als in Österreich gibt. Bei gleichbleibendem Untersuchungszeitraum ist also die Chance jedes einzelnen Landkreises, in der Berichterstattung vorzukommen, ohnehin geringer wenngleich im $Z D F$ achteinhalb Stunden mehr Sendezeit auf Magazinsendungen entfallen als im ORF 2, was diesen Unterschied ein wenig relativiert. In absoluten Zahlen gesehen, wurden innerhalb der untersuchten Woche im ZDF 134 Landkreise berücksichtigt, im ORF 2 waren es 57.

Auch hier gilt die Einschränkung, dass die Ergebnisse nur die Momentaufnahme einer Woche darstellen. Dennoch ist es für eine Zuschauerin oder einen Zuschauer des ZDF-Programms insgesamt im Verlauf einer Woche unwahrscheinlicher, Informationen aus der eigenen Nahumgebung zu erhalten, als dies für österreichische Zuseherinnen und Zuseher der Fall ist. Der Schwerpunkt der ZDF-Magazine liegt eindeutig nicht in der Regionalberichterstattung. Es sind alle 16 Bundesländer in der Berichterstattung vertreten, wenngleich unterschiedlich häufig und umfangreich. Der punktuelle Charakter der Gebietsabdeckung ist aber im Gegensatz zum ORF 2 deutlich erkennbar. Für die dargelegten Befunde dürfte eine Mischung aus der tatsächlichen Ereignislage, auf die journalistisch reagiert wird, und dem Bemühen, regional ausgewogen zu berichten, verantwortlich sein. 


\subsubsection{Gebietsabdeckung regionaler Programme}

\subsection{Gebietsabdeckung $B R$}

Im Bayerischen Rundfunk fallen die Unterschiede der Gebietsabdeckung zwischen ortsbezogener und regionaler Berichterstattung geringer aus als in den beiden untersuchten nationalen Programmen (vgl. Abbildung 19 und Abbildung 21). Das heißt, dass die ortsbezogene Berichterstattung häufiger tatsächlich regionale Berichterstattung darstellt als dies in den nationalen Programmen der Fall ist. Fast 60 Prozent der Kreise im Sendegebiet des BR kommen in der Berichterstattung mindestens in Form einer Erwähnung vor. Das ist mehr als im ZDF, aber weniger als im ORF 2. Auch hier zeigt sich, dass sich die Gegenüberstellung von nationalem und regionalem Programm inhaltlich nicht auf allen programm-inhaltlichen Ebenen auswirkt. Was die reinen Ereignisorte betrifft, zeigt sich auch, dass im BR kaum über den Freistaat hinaus berichtet wird. Die Verteilung der Orte außerhalb Bayerns, aus denen Magazinbeiträge stammen, erscheint relativ willkürlich. Es zeigt sich zum Beispiel auch keine hervorstechende Berücksichtigung benachbarter Landkreise etwa aus Baden-Württemberg oder Thüringen. 
Abbildung 18: BR - Regionale Verteilung der Ereignisorte der Berichterstattung nach Landkreisen - Anteil an der Sendezeit in Prozent

Basis: BR-Magazinsendungsbestandteile mit identifizierbaren deutschen Ereignisorten in hh:mm:ss = 24:55:08. Da einzelne Untersuchungseinheiten mehr als einen Ereignisort enthalten können, ist die ausgewiesene Sendezeit hier erhöht. Das Sendegebiet ist durch Umrandung hervorgehoben.

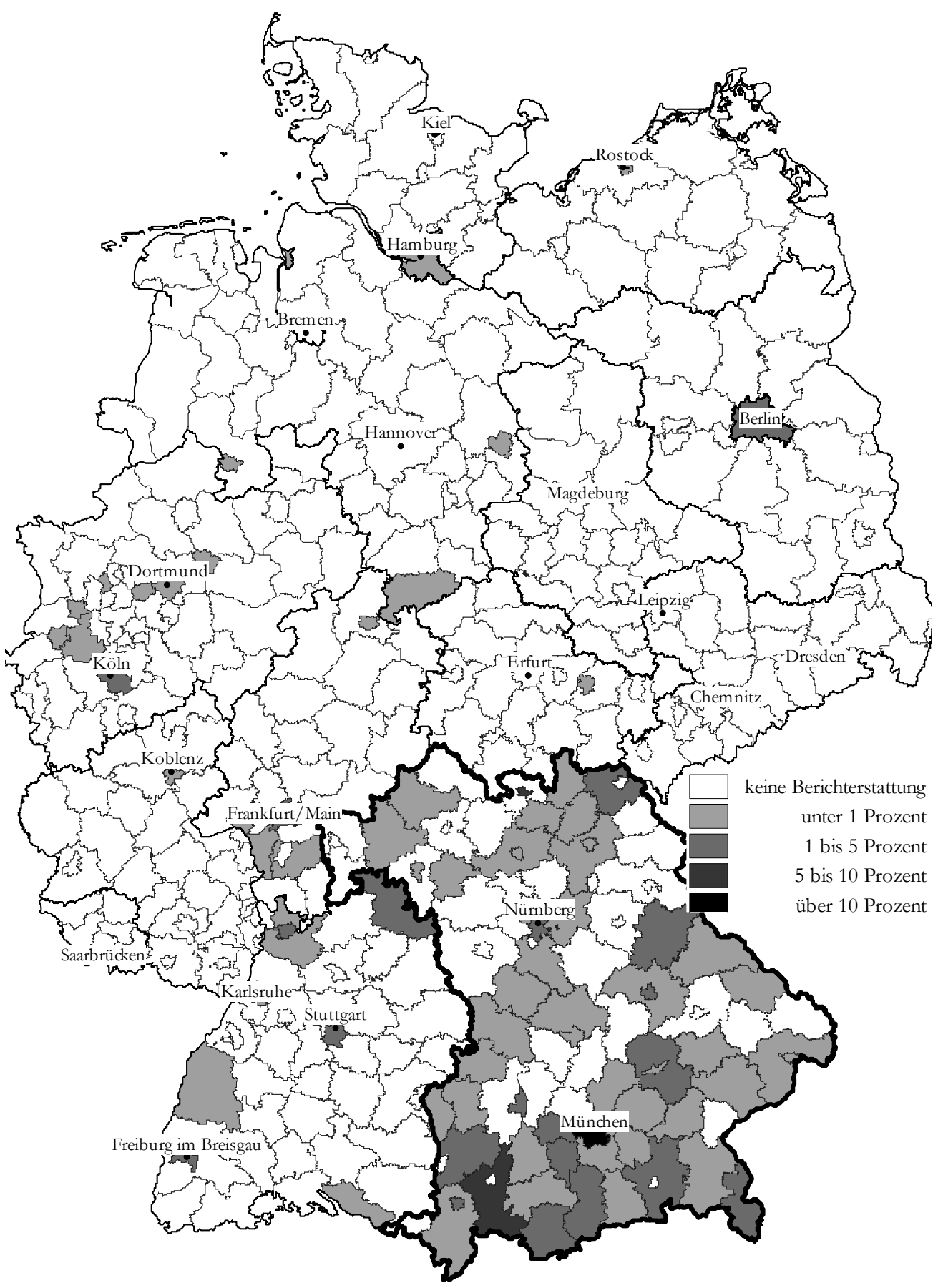


Abbildung 19: BR - Prozentuale Sendezeitverteilung (Ereignisorte) auf die Gesamtzahl der bayerischen Landkreise

Basis: 96 Landkreise

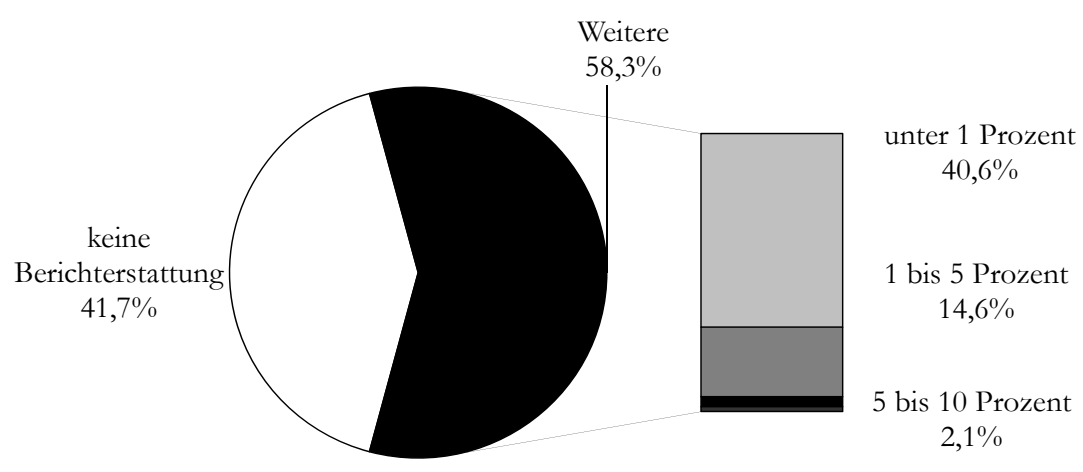

über 10 Prozent $1,0 \%$ 
Abbildung 20: BR - Regionale Verteilung der Regionalberichterstattung nach Landkreisen Anteil an der Sendezeit in Prozent

Basis: BR-Magazinsendungsbestandteile mit regionaler Berichterstattung in hh:mm:ss $=12: 03: 32$. Da einzelne Untersuchungseinheiten mehr als einen Ereignisort enthalten können, ist die ausgewiesene Sendezeit hier erhöht. Das Sendegebiet ist durch Umrandung hervorgehoben.

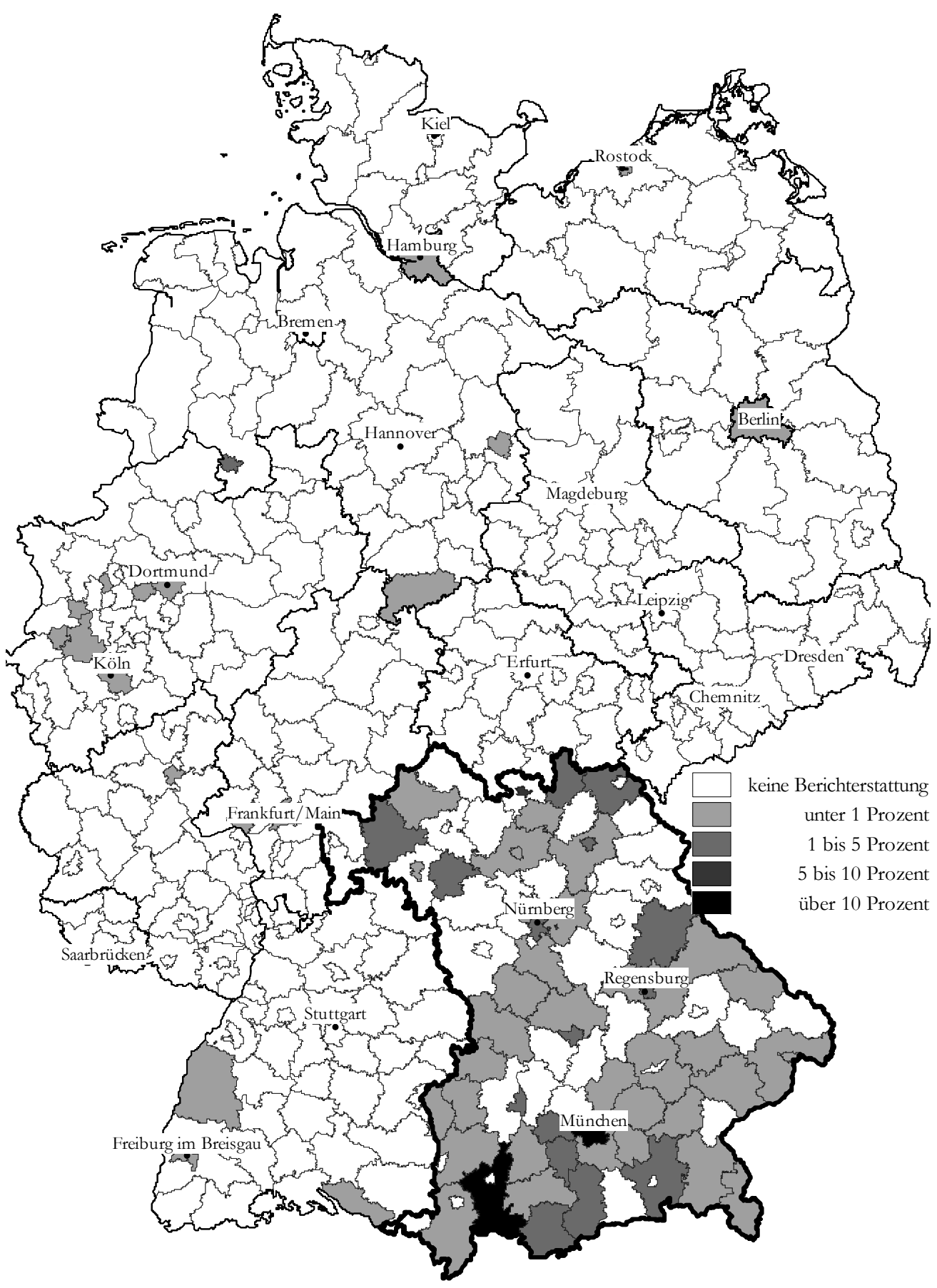


Abbildung 21: BR - Prozentuale Sendezeitverteilung der regionalen Berichterstattung auf die Gesamtzahl der bayerischen Landkreise

Basis: 96 Landkreise

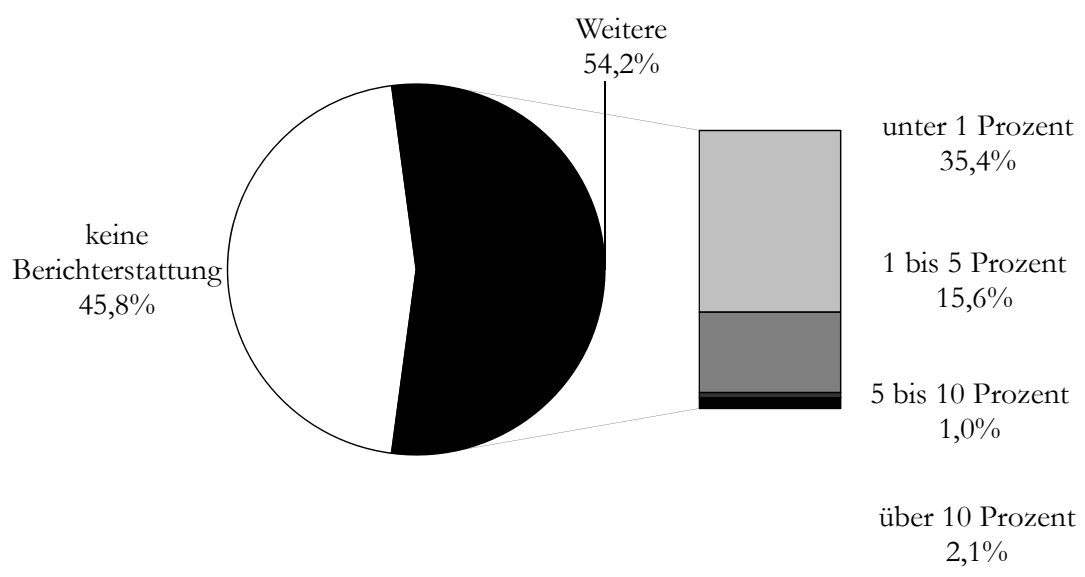

Betrachtet man nur die Regionalberichterstattung, so werden aus 54 Prozent der Kreise Informationen ausgestrahlt. Ähnlich wie in den beiden nationalen Programmen, wird die Landeshauptstadt besonders stark berücksichtigt (vgl. Abbildung 21 und Abbildung 20). Diese Hauptstadtorientierung ist aber deutlich ausgeprägter: Sowohl bei der nur ortsbezogenen als auch der eigentlich regionalen Berichterstattung entfallen über 20 Prozent der redaktionellen Sendezeit aller Magazinbeiträge auf München. Des Weiteren fällt auf, dass die südlichen Kreise des Bundeslandes beinahe ausnahmslos von der Berichterstattung erfasst werden, aber in den nördlichen Landesteilen einige Gebiete unbeachtet bleiben. Um wiederum die Zuschauerbzw. Zuschauerinnensicht zu bemühen, heißt das: Bewohnerinnen und Bewohner des bayerischen Voralpen- und Alpenraums haben beim Einschalten des BR-Programms eine höhere Chance, Informationen aus ihrem Umfeld zu erhalten als (außerhalb von Nürnberg wohnende) fränkische Einwohnerinnen und Einwohner.

Hier ist eine Konzentration auf das historische bayerische Kernland zu erkennen. Betrachtet man nämlich die drei fränkischen Regierungsbezirke (Ober-, Mittel- und Unterfranken) getrennt vom historisch älteren Territorialbestand Bayerns (Ober- und Niederbayern, Schwaben und Oberpfalz), so offenbart sich ein Ungleichgewicht zu Ungunsten Frankens. Zwar lebt etwa ein Drittel der Einwohner und Einwohnerinnen Bayerns in Franken, aber nur zu einem Viertel der Sendezeit von Magazinbeiträgen im BR-Fernsehen wird auch aus Franken berichtet. Darüber hinaus ist die Sendegebietsabdeckung im fränkischen Landesteil deutlich geringer: Nur 49 Prozent der dortigen Landkreise kommen in der Berichterstattung vor (vgl. Abbildung 22). Von den bayerischen Kernlanden werden dagegen 64 Prozent der Land- 
kreise von der Berichterstattung berücksichtigt (vgl. Abbildung 23). Oben wurde bereits festgestellt, dass sich die bayerische Identität zum großen Teil auf die „urbayerischen“ Territorien bezieht (vgl. S. 75). Insofern manifestiert sich die bayerische Identität hier inhaltlich auf der Ebene der Raumabdeckung. Das ist - und darauf sei hier noch einmal ausdrücklich hingewiesen - kein kausaler Zusammenhang. Indem aber aus den entsprechenden Landesteilen umfangreicher berichtet wird, wird auch der assoziierbare Raumbezug zu diesen verstärkt. Mit anderen Worten: Das Bild, das sich die Zuschauerinnen und Zuschauer des BR von Bayern machen können, wird durch das historische Kernland stärker geprägt als durch Franken. Je nach Häufigkeit zu Wort kommender Dialektsprecherinnen und -sprecher im Programm kann das zum Beispiel bedeuten, dass die fränkische Mundart viel weniger mit Bayern in Verbindung gebracht wird als die Dialektformen aus Oberpfalz, Schwaben, Ober- und Niederbayern. Gleichzeitig wird durch die angebotenen Möglichkeiten der Wahrnehmung Bayerns auch das entsprechende (auf den Süden bezogene) Bild perpetuiert. Dieses Bild beeinflusst dann umgekehrt auch die Redakteurinnen und Redakteure des BR, wenn sie aus ihrer Heimat berichten. Sendeplätze, die besonders identitätsstiftenden Inhalten (etwa Brauchtumspflege, Geschichte u. ä.) vorbehalten sind, werden dann möglicherweise eher mit Inhalten gefüllt, die auch wieder aus Ober- oder Niederbayern, Schwaben und der Oberpfalz stammen. Bayern wird also auf der Ebene der Raumabdeckung sowohl extensiv als auch intensiv erkennbar. Ersteres, indem die Mehrzahl der Kreise des gesamten Bundeslandes in der Berichterstattung berücksichtigt wird. Letzteres, indem Territorien, die für die bayerische Identität historisch bedeutsamer sind, ausführlicher vorkommen als andere.

Abbildung 22: BR - Prozentuale Sendezeitverteilung (Ereignisorte) auf die Gesamtzahl der fränkischen Landkreise (37 Landkreise)

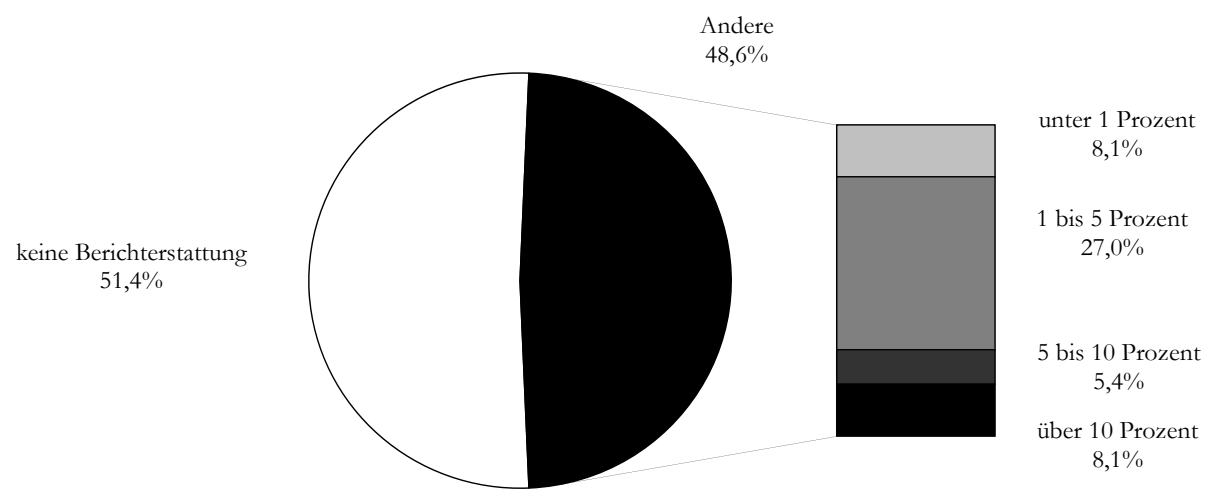


Abbildung 23: BR - Prozentuale Sendezeitverteilung (Ereignisorte) auf die Gesamtzahl der altbayerischen und schwäbischen Landkreise (59 Landkreise)

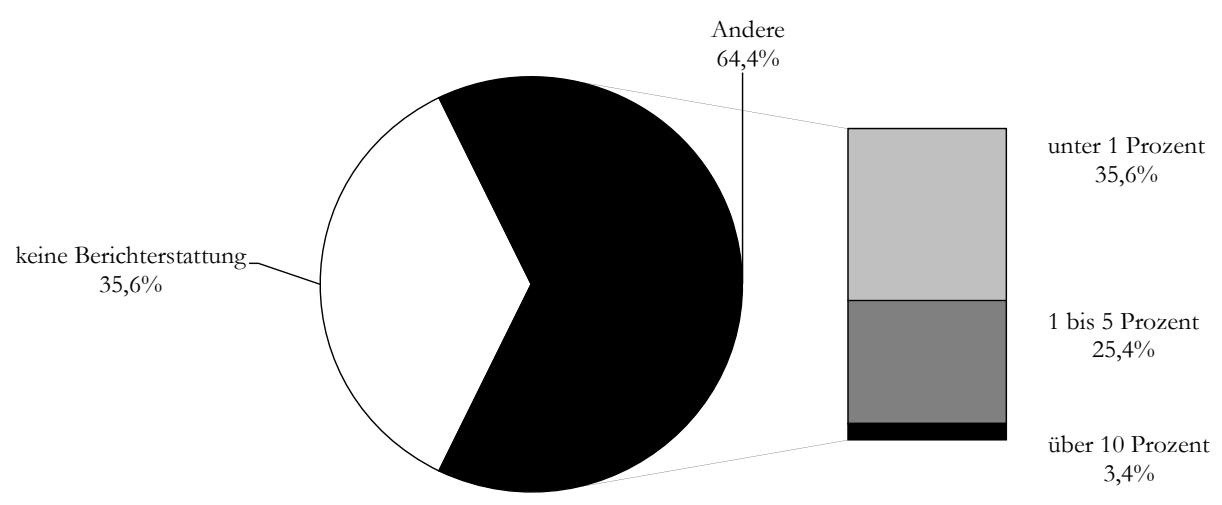

\subsection{Gebietsabdeckung MDR}

Die Berichterstattung in den Magazinen des MDR-Fernsehens berücksichtigt fast 90 Prozent der mitteldeutschen Landkreise (Abbildung 25). Damit ist fast das gesamte Sendegebiet in der Berichterstattung präsent (vgl. Abbildung 24). Mit regionaler Berichterstattung werden immerhin noch 80 Prozent der Kreise bedacht (Abbildung 27). Eine Hauptstadtkonzentration der Berichterstattung ist nicht im selben Ausmaß wie bei allen anderen untersuchten Sendern festzustellen. Im Falle Mitteldeutschlands müsste sich eine solche Fokussierung auf Dresden, Erfurt und Magdeburg beziehen. Auf keinen dieser Orte entfallen jedoch mehr als zehn Prozent der Berichterstattung. ${ }^{261}$ Stattdessen wird während 17 Prozent der Sendezeit der Magazinbeiträge aus Leipzig berichtet. Dies mag daran liegen, dass der MDR hier seinen Hauptsitz hat. Diese herausgehobene Stellung Leipzigs spiegelt sich aber im Bereich der regionalen Berichterstattung nicht im gleichen Maße wider (vgl. Abbildung 26). Hier bildet Leipzig zwar immer noch einen Schwerpunkt, es beziehen sich aber nur sieben Prozent der regionalen Berichterstattung darauf. Auf Dresden entfallen sechs Prozent und auf Erfurt und Magdeburg jeweils drei Prozent.

${ }^{261}$ Dresden: 7 Prozent, Magdeburg: 5 Prozent, Erfurt: 3 Prozent der Berichterstattung mit Ereignisorten. 
Abbildung 24: MDR - Regionale Verteilung der Ereignisorte der Berichterstattung nach Landkreisen - Anteil an der Sendezeit in Prozent

Basis: MDR-Magazinsendungsbestandteile mit identifizierbaren deutschen Ereignisorten in hh:mm:ss = 39:05:57. Da einzelne Untersuchungseinheiten mehr als einen Ereignisort enthalten können, ist die ausgewiesene Sendezeit hier erhöht. Das Sendegebiet ist durch Umrandung hervorgehoben.

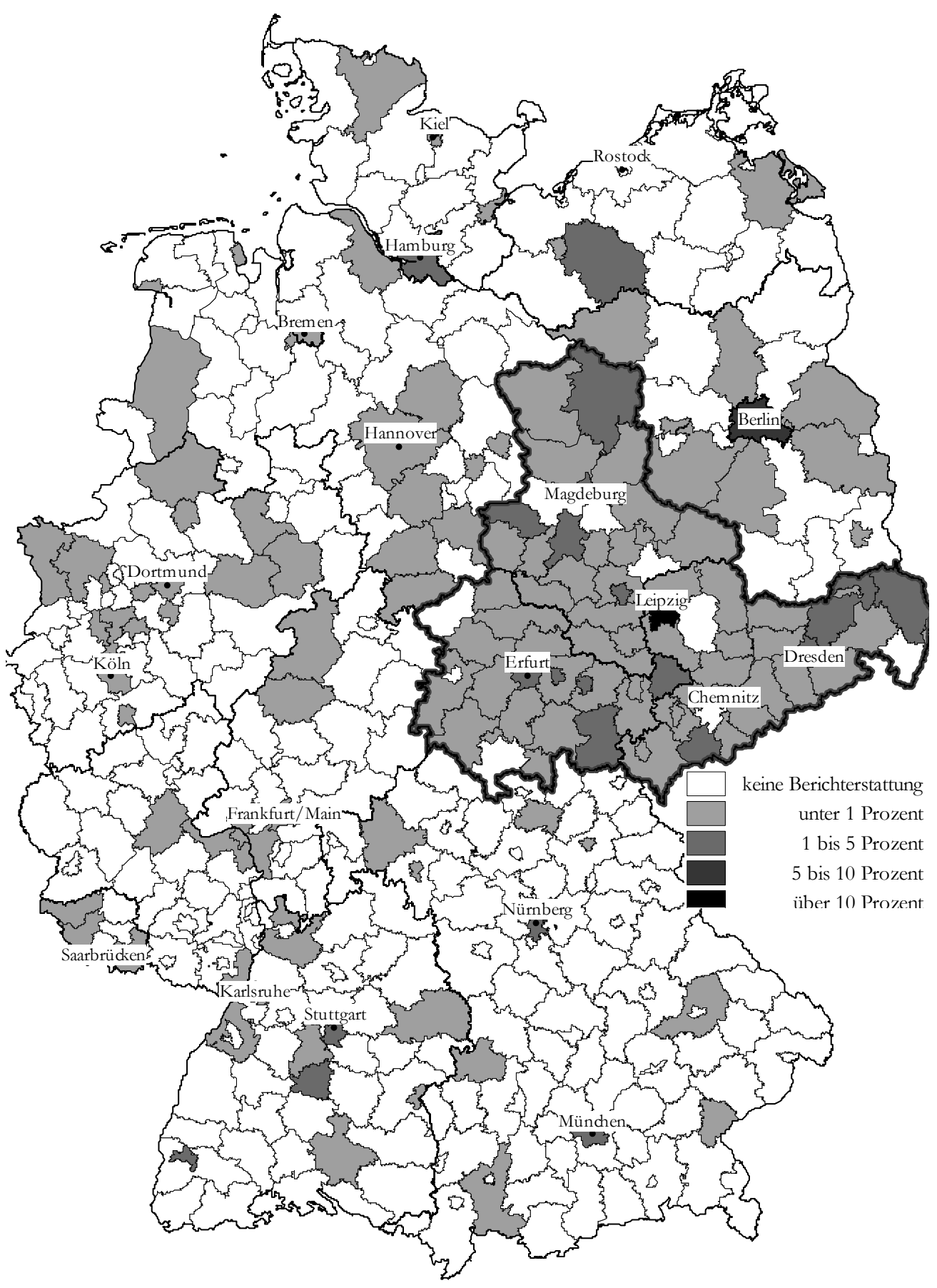


Abbildung 25: MDR - Prozentuale Sendezeitverteilung (Ereignisorte) auf die Gesamtzahl der mitteldeutschen Landkreise

Basis: 76 Landkreise
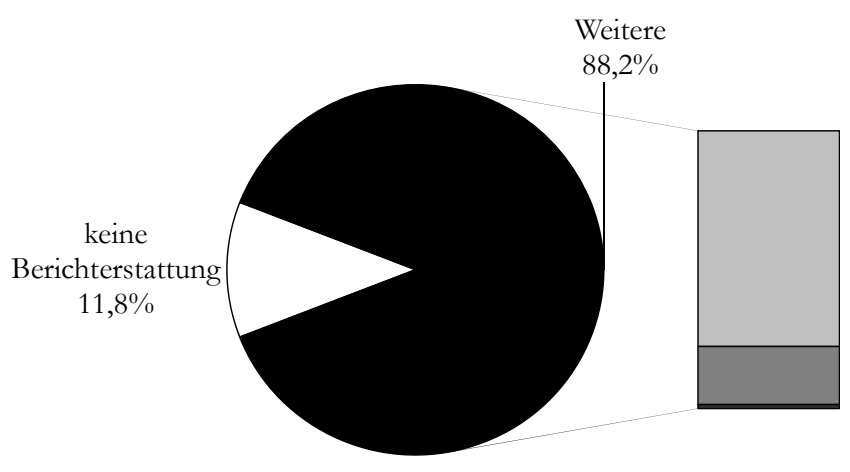

unter 1 Prozent $68,4 \%$

1 bis 5 Prozent $18,4 \%$

5 bis 10 Prozent $0,0 \%$

über 10 Prozent $1,3 \%$ 
Abbildung 26: MDR - Regionale Verteilung der Regionalberichterstattung nach Landkreisen Anteil an der Sendezeit in Prozent

Basis: MDR-Magazinsendungsbestandteile mit regionaler Berichterstattung in hh:mm:ss $=18: 52: 41$. Da einzelne Untersuchungseinheiten mehr als einen Ereignisort enthalten können, ist die ausgewiesene Sendezeit hier erhöht. Das Sendegebiet ist durch Umrandung hervorgehoben.

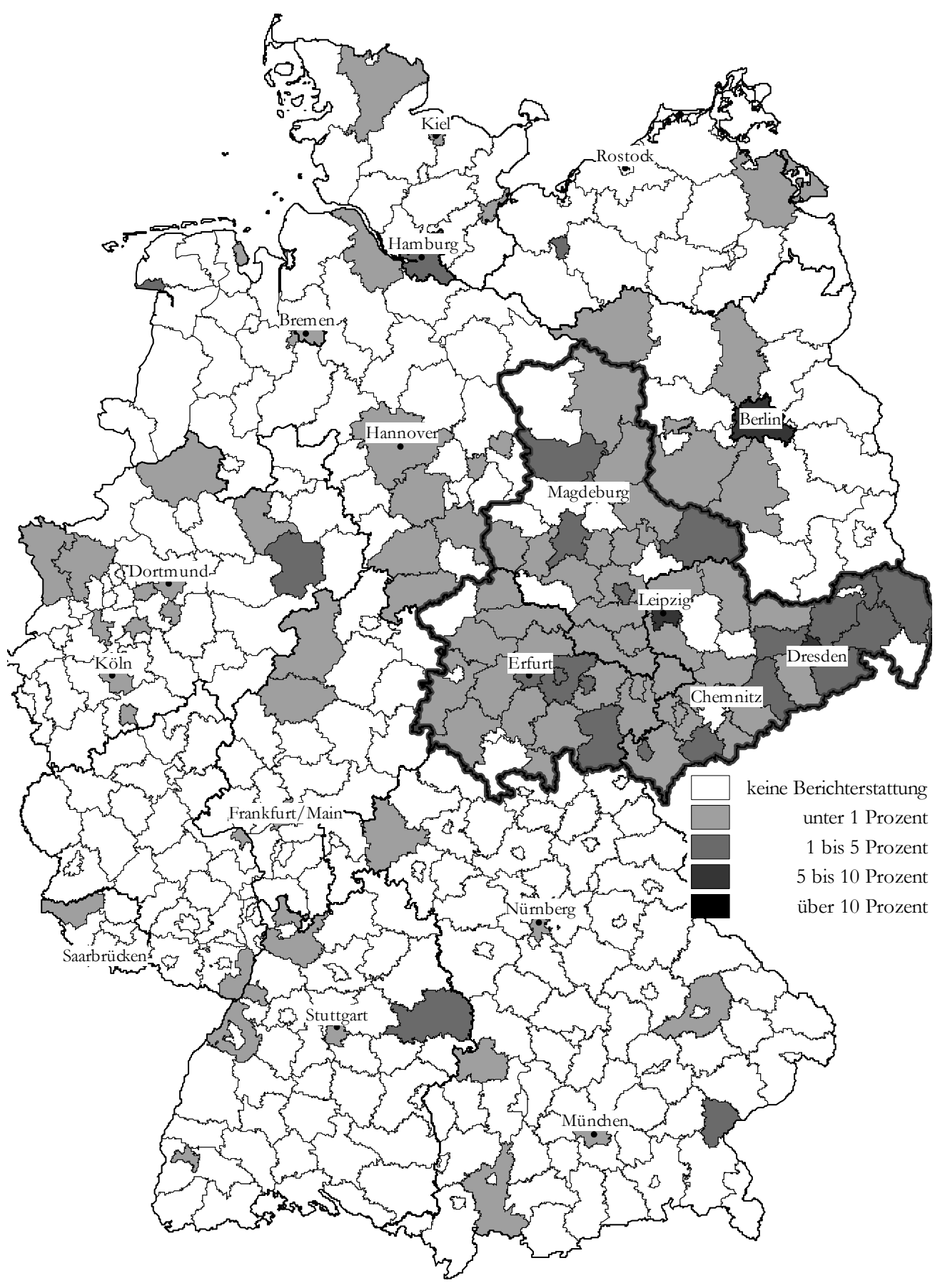


Abbildung 27: MDR - Prozentuale Sendezeitverteilung der regionalen Berichterstattung auf die Gesamtzahl der mitteldeutschen Landkreise

Basis: 76 Landkreise

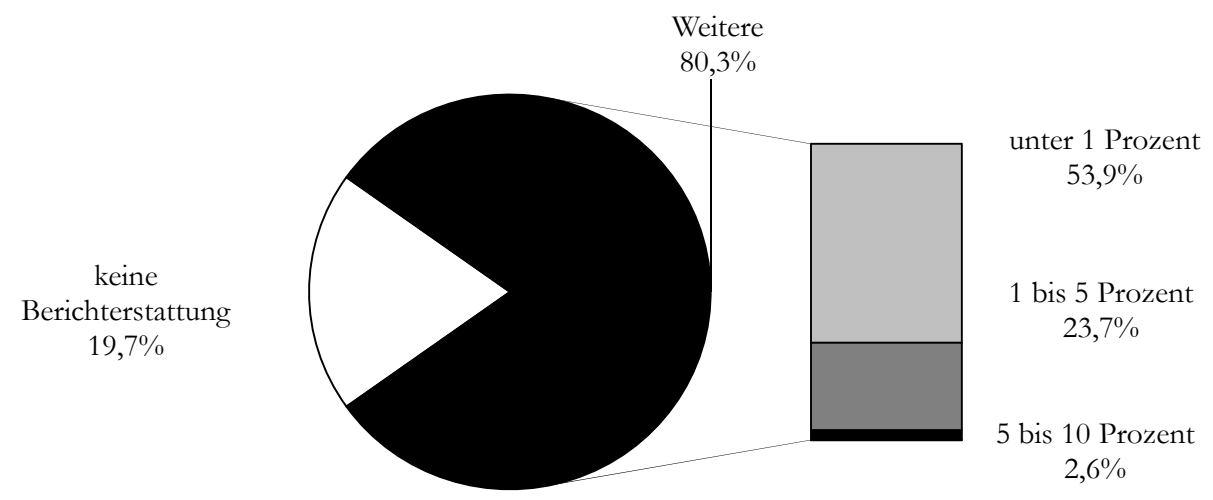

Es fällt auf, dass im $M D R$ - im Vergleich zum $B R$ - auch aus relativ vielen Kreisen von auBerhalb des Sendegebiets berichtet wird (siehe S. 193). Dabei lässt sich aber weder eine eindeutige Präferenz von angrenzenden Kreisen noch eine besondere Berücksichtigung des Gebiets der fünf neuen Bundesländer erkennen. Allerdings wird aus Berlin auch relativ umfangreich - und zwar im Kern regional - berichtet. Da im MDR Politikberichterstattung eine nur marginale Rolle spielt, ${ }^{262}$ handelt es sich dabei aber wohl nicht um eine Auswirkung des Status als Zentrum der Bundespolitik.

\subsection{Verteilung des regionalen Informationsangebots im MDR auf die mit- teldeutschen Bundes/änder}

Für den MDR ist von zusätzlicher Bedeutung, wie sich das Informationsangebot auf die drei Bundesländer verteilt. Das ergibt sich aus den normativen Anforderungen, dass sich die Gliederung des Sendegebiets in die drei Bundesländer im gemeinsamen Programm niederschlagen soll ( $\int 6$ II MDR-StV).

${ }^{262}$ Vgl. hierzu Abbildung 62, S.227. 
Abbildung 28: Verteilung der Sendezeitanteile der Magazinbeiträge mit mitteldeutschem Ereignisort auf das Sendegebiet.

Da ein Beitrag mehr als einen Ereignisort enthalten kann und damit auch Ereignisorte auf mehrere Bundesländer verteilt sein können, ist die zugrunde liegende Sendezeitbasis (52:09:55) hier erhöht. D. h., in den Anteil für jedes der drei Bundesländer fließt jeweils die gesamte Sendezeit eines Beitrages ein, der mindestens einen im jeweiligen Bundesland liegenden Ereignisort aufweist.

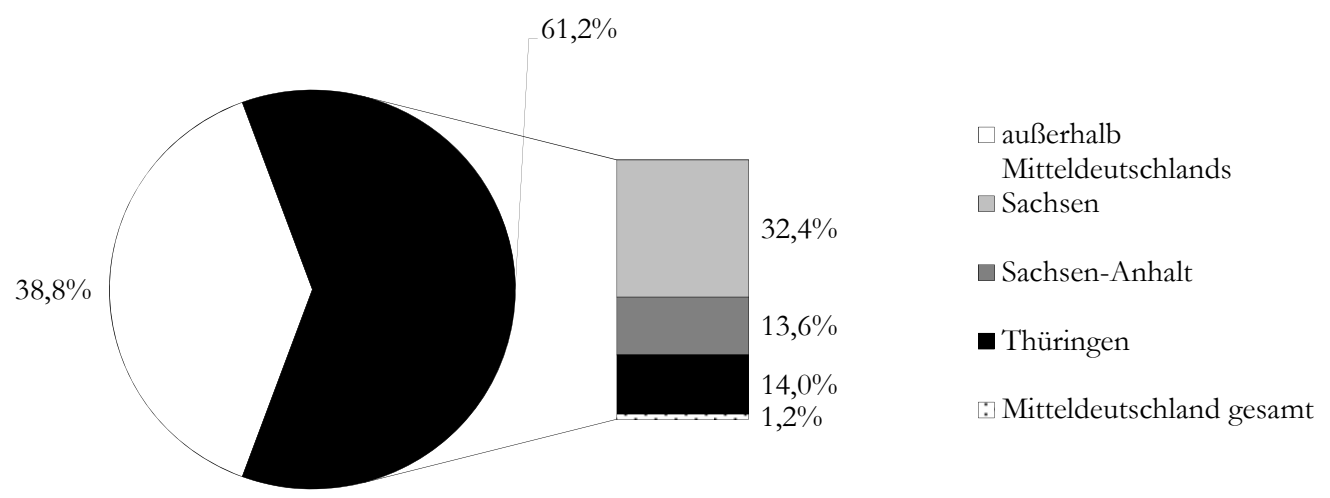

Die Mehrzahl der Magazinbeiträge bringt Informationen aus Sachsen. Thüringen und Sachsen-Anhalt sind jeweils in etwa gleich stark in der Berichterstattung berücksichtigt. Auch wenn diese Verteilung auf den ersten Blick ungleichmäßig erscheint, entspricht sie letztlich doch der Forderung des MDR-Staatsvertrags, das Sendegebiet in seiner Aufteilung auf die Länder abzubilden. Die Einwohnerzahlen der drei Bundesländer unterscheiden sich beträchtlich (vgl. S. 70). Die Sendezeitverteilung entspricht nicht der bloßen Dreiteilung in die Länder, sondern ähnelt vielmehr der Bevölkerungsverteilung auf die Länder. Sachsen ist dieser Verteilung gegenüber im Programm leicht überrepräsentiert, während die Rangfolge von Sachsen-Anhalt und Thüringen den Bevölkerungsanteilen widerspricht. Dieser Unterschied ist jedoch zu vernachlässigen. Die Aufteilung des Sendegebiets spiegelt sich in der Berichterstattung also recht klar wider.

\subsubsection{Vergleich der Verteilung der Berichterstattung auf die unterschied- lichen Sendegebiete}

Da sich die Sendegebiete der vier untersuchten Programme erheblich unterscheiden, wurde zur Überprüfung der Hypothesen auf die prozentualen Anteile der Sendezeit der Magazinbeiträge zurückgegriffen, die auf die einzelnen Kreise entfallen. Dabei wurde auch berücksichtigt, dass auf manche Kreise mehr Sendezeit entfällt als auf andere. Die Unterschiede betreffen 
also zwei Dimensionen: 1. Die unterschiedliche Zusammensetzung der Sendegebiete. 2. Die unterschiedliche Verteilung der Sendezeitanteile auf die verschiedenen Kreise. Für einen Vergleich der Sendegebietsabdeckung aller vier Programme unter Berücksichtigung dieser beiden Dimensionen bietet sich daher auch hier das Maß der relativen Entropie an. Bei Gleichverteilung der Sendezeit auf alle Kreise im Sendegebiet läge der Wert von H bei 1. Bei Einfachbesetzung (gesamte Sendezeit entfällt auf einen Kreis) läge er bei 0. Das heißt, je höher der Wert von $\mathrm{H}$ liegt, desto gleichmäßiger ist die Sendezeit auf die Kreise verteilt.

\section{Abbildung 29: Vergleich der relativen Entropie der Sendegebietsabdeckung durch Berichter- stattung mit identifizierbaren Ereignisorten}

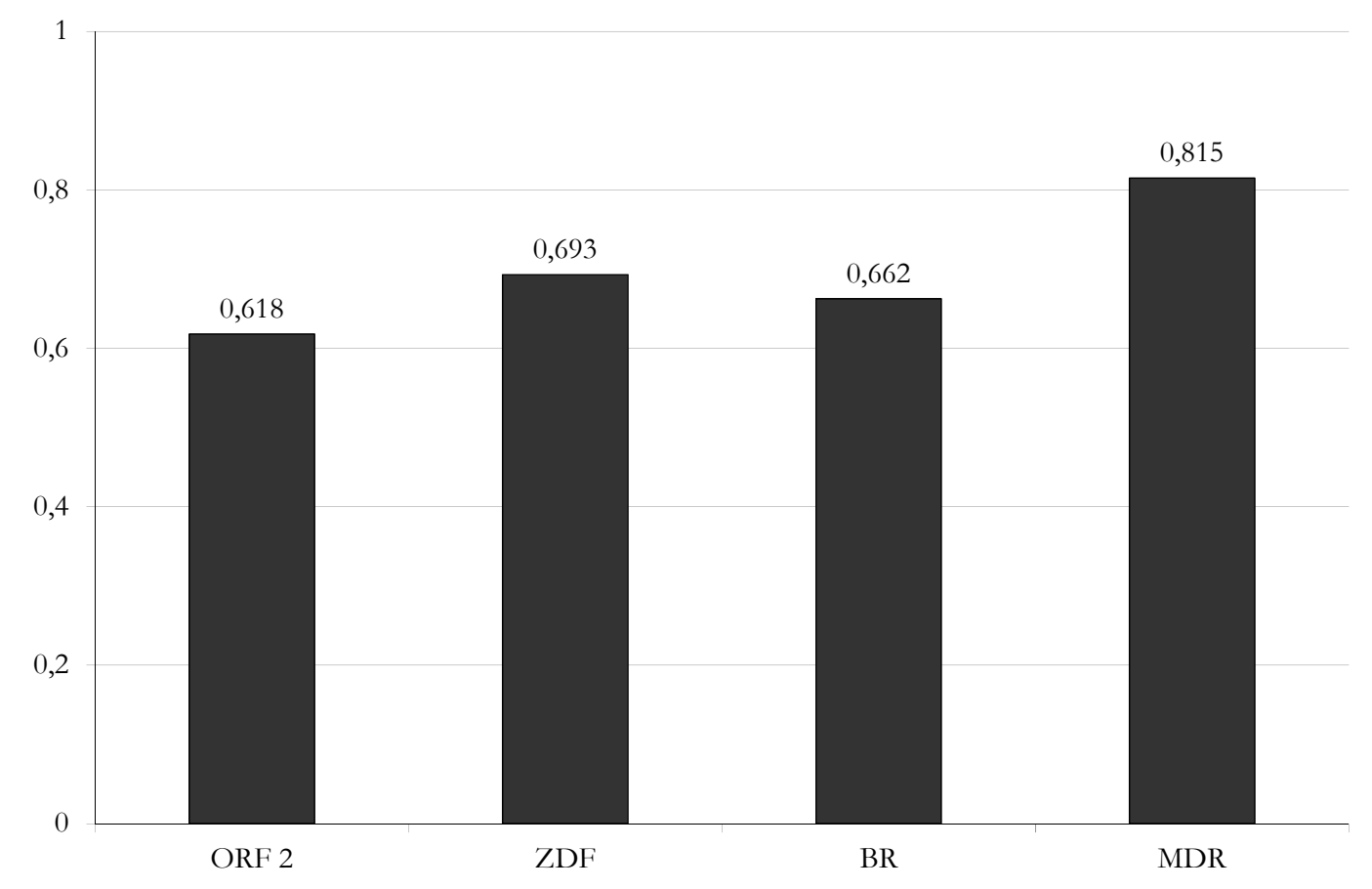

Der Vergleich des relativen Entropiewertes für die Berichterstattung mit genannten Ereignisorten zeigt, dass die Berichterstattung des MDR von allen vier Sendern am gleichmäßigsten auf das Sendegebiet verteilt ist (vgl. Abbildung 29). Hier ist also die Wahrscheinlichkeit, dass ein bestimmter Kreis innerhalb der berücksichtigten Sendezeit vorkommt, höher als in den anderen Sendern. Das ist insbesondere aus Publikumssicht relevant, da ein Zuschauer oder eine Zuschauerin im Regelfall in einem bestimmten Ort wohnt und möglicherweise gern über dortige Ereignisse informiert werden möchte. Der geringste Wert ist für den ORF 2 festzustellen. Angesichts der im Vergleich zum ZDF höheren Sendegebietsabdeckung überrascht das zunächst. In dem niedrigen H-Wert spiegelt sich aber die besonders starke Konzentration auf die Hauptstadt Wien wider. Obwohl also zwei Drittel der Kreise Österreichs von der Berichterstattung erfasst werden, ist die Verteilung der Sendezeit auf die Kreise sehr ungleichmäßig. Die Fokussierung auf die Hauptstadt fällt im ZDF wesentlich geringer aus. Deshalb ist die Verteilung der Sendezeit auf die Kreise hier gleichmäßiger - trotz insgesamt geringer ausfallender Abdeckungsquote. Der H-Wert ist für den BR, trotz relativ hoher Gesamtabdeckung 
(58 Prozent, vgl. Abbildung 19), ebenfalls niedrig. Auch hier spiegelt sich die hohe Konzentration auf die Landeshauptstadt München (22 Prozent der Sendezeit aller Magazinbeiträge) wider.

\section{Abbildung 30: Vergleich der relativen Entropie der Sendegebietsabdeckung durch Regional- berichterstattung}

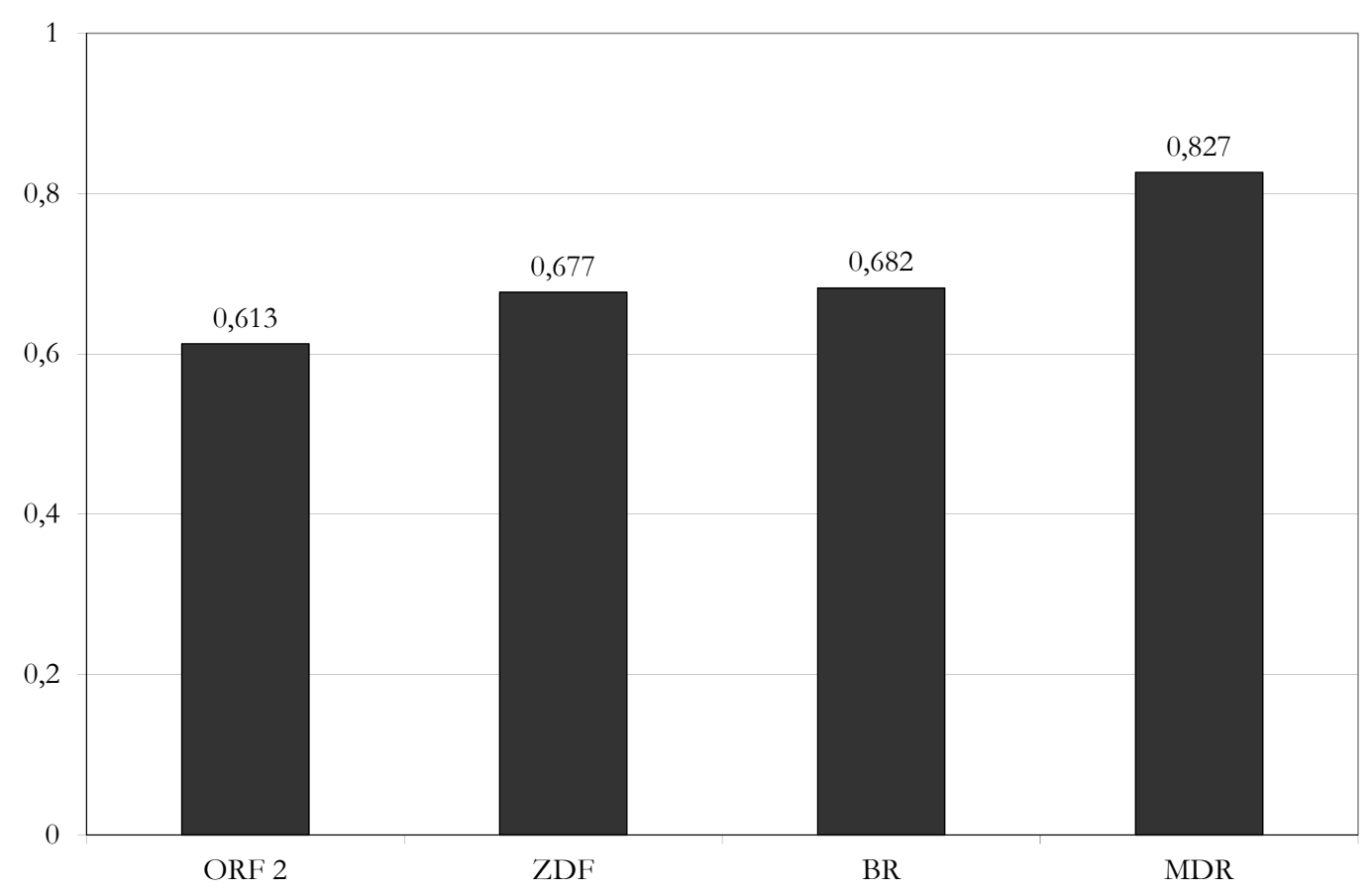

Für die Regionalberichterstattung ergibt sich ein ganz ähnliches Bild (Abbildung 30). Die Unterschiede zur nicht ausschließlich regionalen Berichterstattung sind marginal. Was sich hierin widerspiegelt ist, dass sich die Hauptstadtzentrierung in ORF 2, BR und (in insgesamt geringerem Ausmaß) im $Z D F$ auch bei der Regionalberichterstattung wiederfindet. Die Fokussierung ergibt sich also nicht allein aus dem Hauptstadtstatus als Ort von Regierungshandeln und ähnlichem.

Warum aus den Hauptstädten auch ohne überregionale Bedeutung von Ereignissen verstärkt berichtet wird, lässt sich mit den Mitteln der Inhaltsanalyse nicht bestimmen. Es kann gut sein, dass sich hier fernsehtypische Produktionsbedingungen niederschlagen. Dafür spricht, dass die Hauptstadtkonzentration in ORF 2 und BR besonders hoch ist - den beiden Sendern, die ihren Sitz jeweils in der Kapitale haben. Dagegen spricht, dass das ZDF seinen Sitz nicht in Berlin hat und dennoch von dort oft über regionale Gegebenheiten berichtet. Gleichzeitig ist nicht erkennbar, dass im ZDF verstärkt vom Senderstandort Mainz berichtet würde. Ein wieder anderes Bild zeigt sich beim $M D R$, der seinen Sitz in Leipzig hat und von dort häufiger berichtet als aus anderen Orten - was sich aber in der Regionalberichterstattung kaum auswirkt, zumal aus den drei eigentlichen Hauptstädten des Sendegebiets jeweils ähnlich umfangreich - regional wie überregional - berichtet wird. So scheint sich in der Berücksichtigung der 
Hauptstädte (zumindest auch) ihre symbolische Bedeutung zu manifestieren. Selbst wenn man das nicht als tatsächliche Ursache sehen will, ${ }^{263}$ wird durch das Faktum der Konzentration selbst, der besondere Status der Hauptstädte dennoch hervorgehoben. Lediglich im MDR, dessen Sendegebiet als Ganzes keine einzelne Hauptstadt hat, findet sich auch keine Konzentration darauf. ${ }^{264}$

Insgesamt lässt sich als Modifizierung und Ergänzung der oben gemachten Aussagen über das Zutreffen der Hypothesen H6a und H6b festhalten: Eine Tendenz zu eher punktueller Berücksichtigung des jeweiligen Sendegebiets ist in den Programmen von ORF 2, ZDF und BR feststellbar. Eine eher flächige Berichterstattung findet im MDR statt. Insofern bestätigt sich hier die angenommene Vergleichsmatrix zwischen nationalen und regionalen Programmen ebenfalls nicht.

\subsubsection{Gebietsbeschränkung}

Die Betrachtung der möglichen Beschränkung der Berichterstattung auf das Sendegebiet erfolgt, anders als bei der Gebietsabdeckung, nicht nur anhand der Berichterstattung mit identifizierbaren Ereignisorten, sondern anhand aller Magazinbeiträge. Das bedeutet, dass eine großflächige Abdeckung sich nicht zwangsläufig auch in einer Beschränkung auf das Sendegebiet widerspiegeln muss, da hier auch die über die jeweiligen Grenzen hinausweisende Berichterstattung berücksichtigt wird. Untersuchungseinheiten, die Ereignisorte von außerhalb des Sendegebiets aufweisen, zählen als „Berichterstattung über Sendegebiet hinaus“. Nur solche Untersuchungseinheiten, die auch bei mehr als einem Ereignisort keine Gebiete außerhalb des Sendegebiets aufweisen, gelten als „Berichterstattung nur aus dem Sendegebiet“"

\subsection{Gebietsbeschränkung der Berichterstattung nationaler Programme}

\subsection{Gebietsbeschränkung der Berichterstattung im ORF 2}

Der größte Teil der Berichterstattung in den Magazinen des ORF 2 entfällt auf Informationen aus Österreich (vgl. Abbildung 31). Weniger als ein Viertel der Sendezeit der Magazinbeiträge dreht sich um Geschehnisse außerhalb der Alpenrepublik. Für sechs Prozent der hier eingeflossenen Sendezeit konnte kein Raumbezug identifiziert werden. Insofern zeigt sich hier ein

\footnotetext{
${ }^{263}$ Gegen die Vermutung eines kausalen Zusammenhangs spricht schon die Menge möglicher weiterer Ursachen, wie etwa die Größe der Hauptstädte, die eine regionale Berichterstattung ebenfalls wahrscheinlicher werden lässt, da viele Menschen davon betroffen sein können. Gleichzeitig steigert die Menge der darin lebenden Leute auch die Wahrscheinlichkeit des Vorkommens berichtenswerter Ereignisse usw. Alle diese möglichen Ursachen sind aber letztlich mitverantwortlich für den erhöhten Symbolwert einer Hauptstadt für eine Region oder Nation. Aus dieser Perspektive heraus wäre es allerdings historisch interessant zu untersuchen, ob in der Zeit vor der deutschen Einheit Bonn für die BRD eine ähnliche Bedeutung innehatte wie heute Berlin.

${ }^{264}$ Die Konzentration auf Leipzig zeigt sich nur bei den Ereignisorten und fällt im Fall der echten Regionalberichterstattung deutlich geringer aus als es bei den drei anderen Sendern bzgl. Wien, Berlin und München der Fall ist (vgl. auch Tabelle 5, S. 208).
} 
ganz klar auf das eigene Land bezogenes Informationsprofil des Senders. Gleichwohl wird auch von außerhalb Österreichs in nennenswertem Umfang berichtet.

Abbildung 31: ORF 2 - Prozentuale Verteilung der Sendezeit von Magazinbeiträgen auf Berichterstattung inner- und außerhalb des Sendegebiets

Basis: alle Magazinbeiträge in hh:mm:ss = 25:02:33

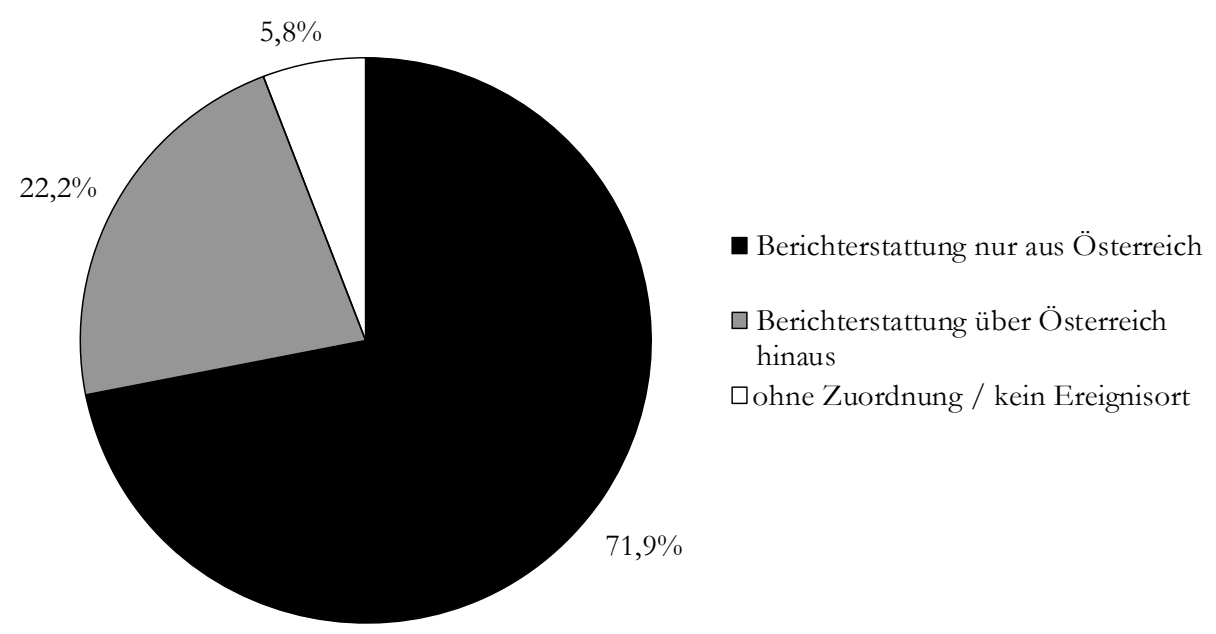

\subsection{Gebietsbeschränkung der Berichterstattung im ZDF}

Für das $Z D F$ zeigt sich eine noch stärkere Fokussierung der Berichterstattung auf das eigene Land (vgl. Abbildung 32). Über drei Viertel der untersuchten Berichterstattung bezieht sich auf Deutschland. 15 Prozent auf Themen und Ereignisse außerhalb Deutschlands. Auch für das $Z D F$ ist damit ein auf das eigene Land bezogenes Informationsprofil festzustellen. 
Abbildung 32: ZDF - Prozentuale Verteilung der Sendezeit von Magazinbeiträgen auf Berichterstattung inner- und außerhalb des Sendegebiets

Basis: alle Magazinbeiträge in hh:mm:ss = 33:36:49

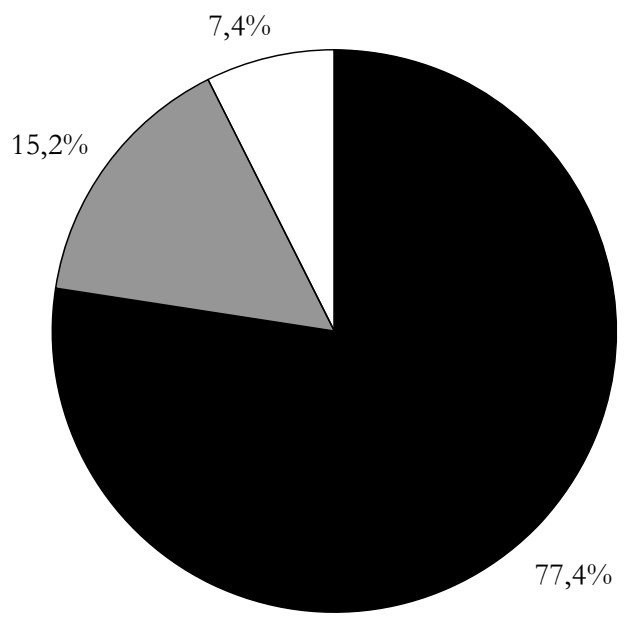

- Berichterstattung nur aus Deutschland

$\square$ Berichterstattung über Deutschland hinaus

$\square$ ohne Zuordnung / kein Ereignisort

\subsection{Gebietsbeschränkung der Berichterstattung regionaler Programme}

\subsection{Gebietsbeschränkung der Berichterstattung im $B R$}

Die Berichterstattung im BR findet zu fast zwei Dritteln der untersuchten Sendezeit der Magazinbeiträge aus Bayern statt. Etwas weniger als ein Drittel entfällt auf außerbayerische Themen und Ereignisse. Damit ist die Fokussierung auf das Sendegebiet ebenfalls sehr stark, aber doch weniger ausgeprägt als bei beiden untersuchten nationalen Programmen. Das Informationsprofil des BR ist klar regional ausgerichtet. 
Abbildung 33: BR - Prozentuale Verteilung der Sendezeit von Magazinbeiträgen auf Berichterstattung inner- und außerhalb des Sendegebiets

Basis: alle Magazinbeiträge in hh:mm:ss = 25:54:25

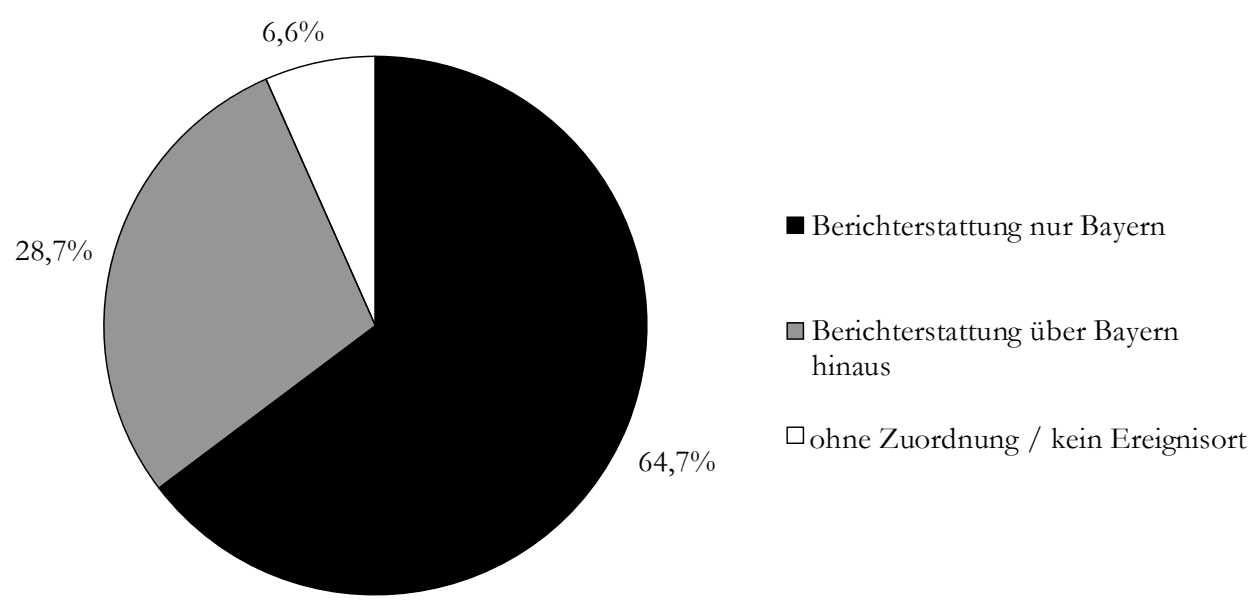

\subsection{Gebietsbeschränkung der Berichterstattung im MDR}

Ein ganz anderes Bild zeigt sich für den MDR (Abbildung 34). Hier wird zu über der Hälfte der Sendezeit der Magazine von außerhalb des Sendegebiets berichtet, 38 Prozent dagegen aus Mitteldeutschland. Damit ist die eigene Region zwar durchaus stark vertreten und berücksichtigt, stellt aber nicht den Schwerpunkt des Informationsangebots dar. Das überrascht nicht, wenn man sich die Verteilung der Ereignisorte der Berichterstattung betrachtet (Abbildung 24). Schon hier fällt auf, dass auch aus vielen Kreisen Deutschlands berichtet wird, die nicht zum originären Einzugsgebiet des MDR gehören. Hinzu kommt noch die Auslandsberichterstattung. Die Mehrzahl der Informationen im MDR stammt also von außerhalb des Sendegebiets und stellt damit keine regionalspezifische Berichterstattung dar. Besonders überraschend ist dies deshalb, weil der MDR im Vergleich zu den anderen Sendern die bei weitem höchste Abdeckungsrate des Sendegebiets aufweist. Eine klare regionale Ausrichtung und Verankerung der Berichterstattung bedeutet demnach nicht gleichzeitig eine regionale Beschränkung. Es ist allerdings zu beachten, dass der MDR im Vergleich zum BR einen größeren Gesamtumfang von Magazinen aufweist. Es steht insgesamt mehr Sendezeit zur Verfügung und diese kann eben auch für überregionale oder internationale Berichterstattung genutzt werden.

Immerhin bedenkenswert ist aber folgender Aspekt: Der BR hat - gemessen an der Bevölkerungszahl Bayerns im Vergleich zu der Mitteldeutschlands - eine größere Menge von Menschen mit Informationen zu versorgen. Das muss selbstverständlich nicht in Form von Maga- 
zinen erfolgen. Wenn es aber innerhalb deren Sendezeit nicht gelingt, das gesamte Sendegebiet „abzubilden“, ist es doch erstaunlich, dass hierfür nicht mehr Sendezeit aufgewandt wird, insbesondere wenn man bedenkt, dass der „kleinere“ (bezogen auf die Bevölkerung) MDR nicht nur das eigene Sendegebiet nahezu vollständig berücksichtigt, sondern darüber hinaus noch in erhöhtem Maße überregionale Berichterstattung betreibt.

Abbildung 34: MDR - Prozentuale Verteilung der Sendezeit von Magazinbeiträgen auf Berichterstattung inner- und außerhalb des Sendegebiets

Basis: alle Magazinbeiträge in hh:mm:ss = 32:31:20

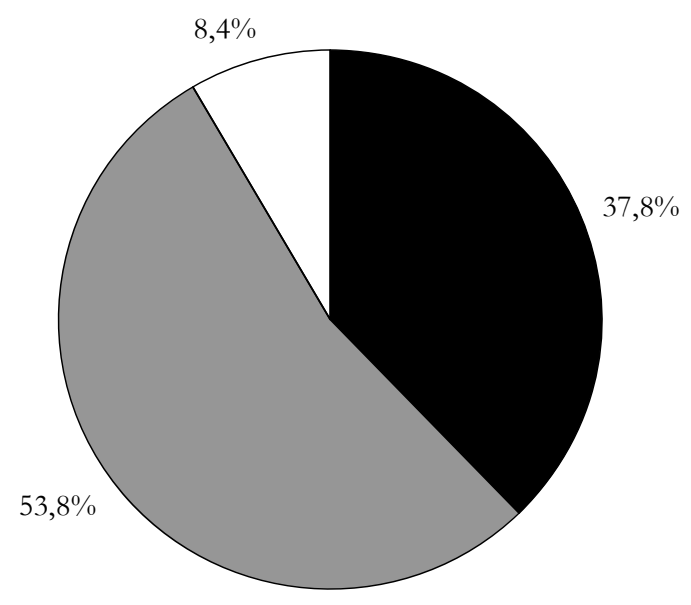

- Berichterstattung nur aus

Mitteldeutschland

$\square$ Berichterstattung über

Mitteldeutschland hinaus

$\square$ ohne Zuordnung / kein Ereignisort

\subsubsection{Ereignis- und Thementragweite}

\subsection{Tragweite von Themen im nationalen Programm}

Um die räumliche Tragweite der Berichterstattung zu ermitteln, wird der Bezugsort bzw. Bezugsraum zugrunde gelegt, der für alle Magazinbeiträge ermittelt wurde. Die Anteile ergeben sich aus der Sendezeit der jeweiligen Untersuchungseinheiten.

\subsection{Thementragweite im ORF 2}

Die bereits in Zusammenhang mit der Überprüfung der Gebietsbeschränkung gemachten Befunde spiegeln sich hier wider (vgl. Abbildung 35). 70 Prozent der Berichterstattung beziehen sich auf Österreich, 21 Prozent auf das Ausland. Innerhalb der Österreichberichterstattung entfallen rund 43 Prozent auf Lokalberichterstattung, also auf Themen, die sich im Wesentlichen auf einen oder wenige Orte beziehen, ohne in größeren Zusammenhängen zu ste- 
hen. Vier Prozent der Berichterstattung insgesamt erfolgt auf Ebene einzelner Bundesländer. Hierzu zählen etwa landespolitische Vorgänge. 36 Prozent der Informationsgebung bezieht sich auf Österreich insgesamt. Das können bundespolitische Entscheidungen ebenso sein wie gesamtwirtschaftliche Prozesse. ${ }^{265}$

\title{
Abbildung 35: ORF 2 - Bezugsräume der Berichterstattung in Magazinsendungen
}

Basis: alle Magazinbeiträge in hh:mm:ss = 25:02:33

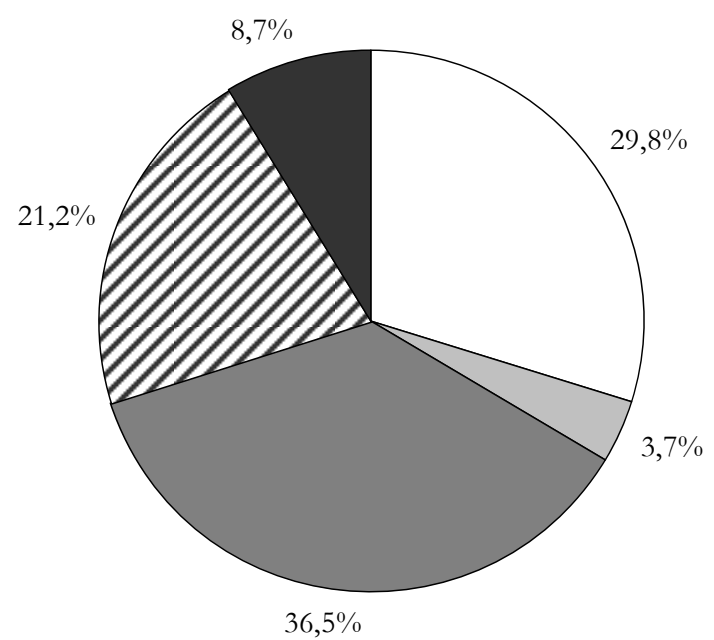

\author{
$\square$ Lokalberichterstattung aus \\ Österreich \\ $\square$ Berichterstattung, die sich auf \\ österr. Bundesländer bezieht \\ $\square$ Berichterstattung, die sich auf \\ ganz Österreich bezieht \\ $\square$ Auslandsberichterstattung
}

口 ohne Raumbezug/ keine Zuordnung

\subsection{Thementragweite im ZDF}

Auch für das ZDF entsprechen die Befunde zu den Bezugsräumen der Berichterstattung im Wesentlichen denen zur Gebietsbeschränkung. Die 75 Prozent der auf Deutschland bezogenen Berichterstattung verteilen sich $\mathrm{zu}$ fast gleichen Teilen auf lokale Informationen (38 Prozent aller untersuchten Magazinbestandteile, vgl. Abbildung 36) und Themen von gesamtnationaler Bedeutung (35 Prozent). Themen auf Länderebene spielen mit drei Prozent eine untergeordnete Rolle. Der Auslandsberichterstattung fallen 17 Prozent der Magazinbeiträge zu.

265 Die neun Prozent der Sendezeit ohne erkennbaren Raumbezug entfallen insbesondere auf solche Themen, die zwar durch die Berichterstattung möglicherweise einen benennbaren Ereignisort haben, sich aber themenbedingt nicht auf lokalisierbare Territorien beziehen. Hierfür sind etwa Gesundheits- oder Wissenschaftsthemen prägnante Beispiele: Durch eine personalisierte Darstellung gibt es einen Ereignisort des dargestellten Geschehens, dieses ist jedoch nur illustrativ für ein eher abstraktes oder omnivalentes Thema, so dass es keinen Raumbezug geben kann. 
Abbildung 36: ZDF - Bezugsräume der Berichterstattung in Magazinsendungen

Basis: alle Magazinbeiträge in hh:mm:ss = 33:36:49

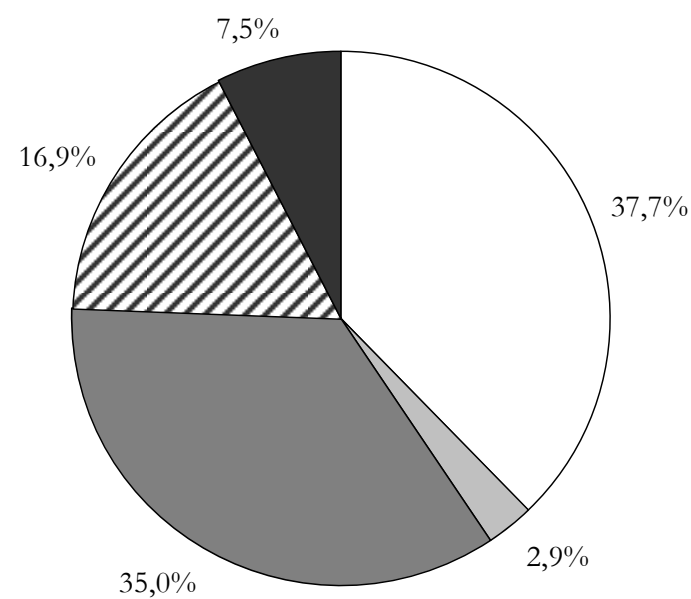

$\square$ Lokalberichterstattung aus

Deutschland

$\square$ Berichterstattung, die sich auf deutsche Bundesländer bezieht

$\square$ Berichterstattung, die sich auf ganz Deutschland bezieht

Auslandsberichterstattung

ohne Raumbezug/

keine Zuordnung

\subsection{Tragweite von Themen im regionalen Programm}

Für die Ermittlung der Thementragweite regionaler Programme kommen die Dimensionen der Regional- und Lokalberichterstattung von außerhalb des eigenen Sendegebiets hinzu. Diese werden hier mit ausgewiesen, da sie sich nicht auf Gesamtdeutschland beziehen, sondern in kleinräumigem Zusammenhang stehen, ohne die eigene Region des Senders zu betreffen. Im MDR gibt es zudem Regionalberichterstattung, die sich auf ein Bundesland im Sendegebiet bezieht und solche, die sich auf das ganze Sendegebiet bezieht.

\subsection{Thementragweite im $B R$}

Der überwiegende Teil (45 Prozent) der bayerischen Informationen bezieht sich auf lokale Themen (vgl. Abbildung 37). Berichterstattung auf Landesebene macht zwölf Prozent der Magazinbeiträge aus. Auf dieser Ebene findet jedoch keine Berichterstattung von außerhalb Bayerns statt, sehr wohl aber auf lokaler Ebene - im Umfang von acht Prozent. Etwa doppelt so ausführlich werden Themen von nationaler Tragweite behandelt. 
Abbildung 37: BR - Bezugsräume der Berichterstattung in Magazinsendungen

Basis: alle Magazinbeiträge in hh:mm:ss = 25:54:25

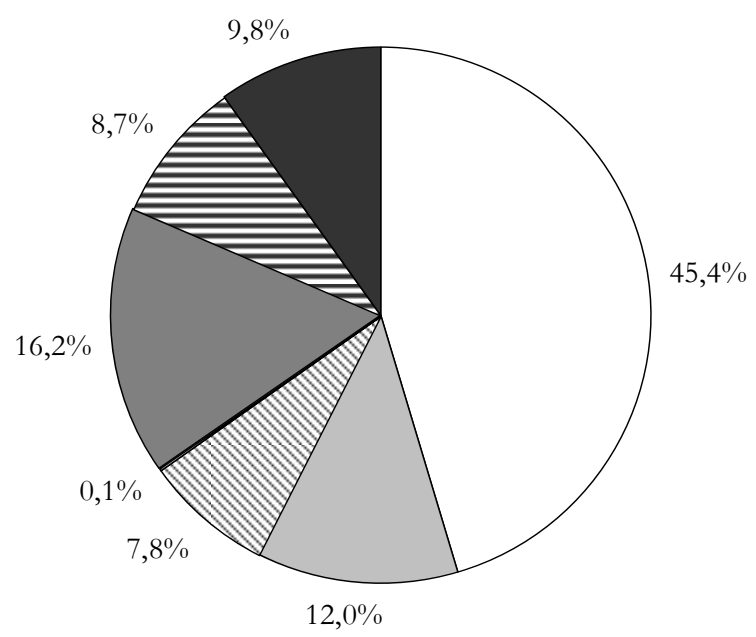

$\square$ bayrische Lokalberichterstattung

$\square$ Berichterstattung, die sich auf ganz Bayern bezieht

Q außerbayrische

Lokalberichterstattung

$\square$ außerbayrische

Regionalberichterstattung

$\square$ Berichterstattung, die sich auf ganz

Deutschland bezieht

曰Auslandsberichterstattung

ahne Raumbezug/

keine Zuordnung

\subsection{Thementragweite im MDR}

Im MDR zeigt sich bei der Aufschlüsselung nach Bezugsräumen (Abbildung 38) ein abweichendes Bild gegenüber der reinen Betrachtung der Ereignisorte. Während 38 Prozent der Berichterstattung zwar Ereignisorte innerhalb des Sendegebiets aufweisen, beziehen sich die Themen nur zu 32 Prozent auf das Sendegebiet. Dabei ist der Großteil Lokalberichterstattung. Weniger als ein Prozent der Berichterstattung bezieht sich auf einzelne Bundesländer des Sendegebiets. Zwei Prozent betreffen Mitteldeutschland insgesamt. Lokalberichterstattung von außerhalb des Sendegebiets macht 19 Prozent aus und 25 Prozent der Berichterstattung betreffen die nationale Ebene.

Für die beiden Regionalsender wurde festgestellt, dass in deren gesetzlichen Grundlagen (Bayerisches Rundfunkgesetz und MDR-Staatsvertrag) Anforderungen dahingehend gestellt wurden, dass über das internationale, nationale und länderbezogene Geschehen informiert werden solle. Die Dreiteilung wurde dahingehend interpretiert, dass sich wenigstens ein Drittel der Informationen auf die Region des Sendegebiets beziehen sollten, um dem spezifischen Charakter eines Regionalprogramms gerecht zu werden (vgl. S. 125). Diese Anforderung wird in beiden Regionalprogrammen (jedenfalls im Rahmen der Magazine) erfüllt, im BR allerdings viel deutlicher als im Mitteldeutschen Rundfunk. Da aber - wie bereits festgestellt - die Magazine des MDR insgesamt umfangreicher sind, ist dieser Unterschied aus normativer Sicht nicht zu kritisieren. 
Abbildung 38: MDR - Bezugsräume der Berichterstattung in Magazinsendungen
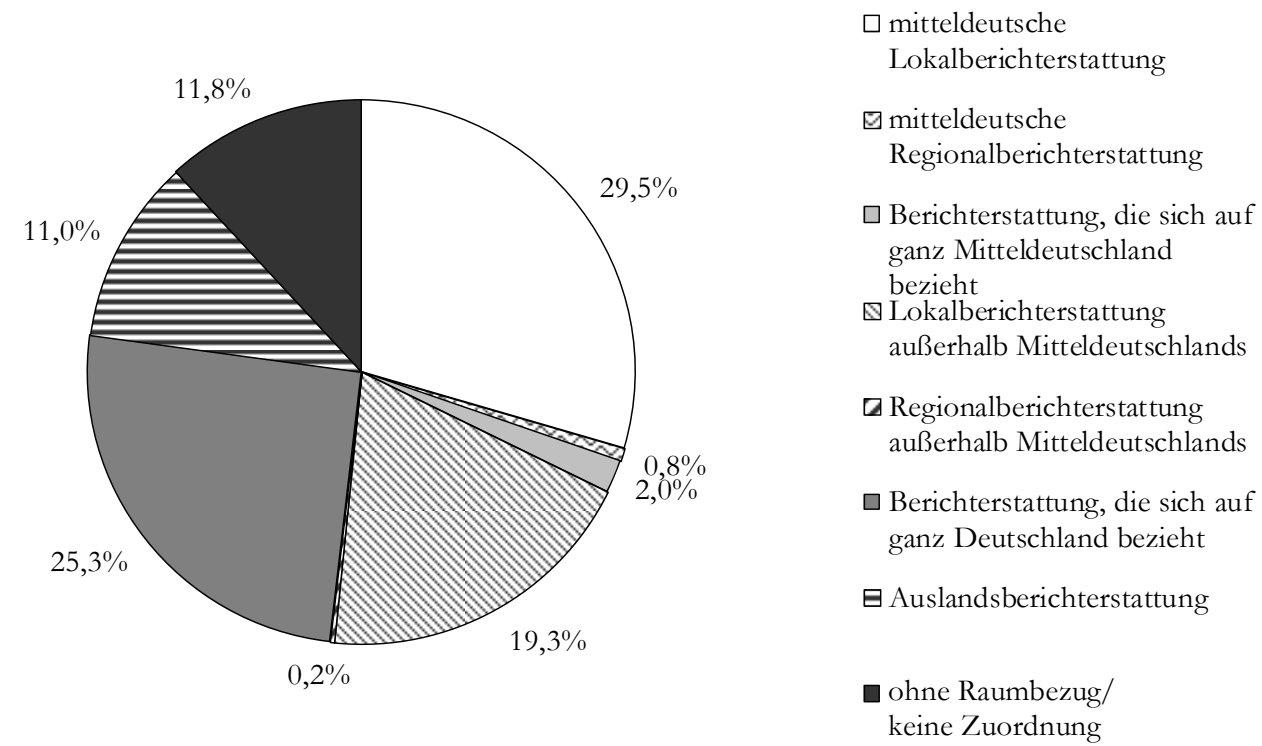

\subsubsection{Konstruierte Raumbezüge}

\subsection{Anteile von Magazinbeiträgen mit künstlich hergestelltem Raumbe- zug in den vier untersuchten Programmen}

Die künstliche Herstellung von Raumbezügen (vgl. S. 127) steht in analytischer Hinsicht an der Schnittstelle zwischen der Konstruktion sozialer Räume (Nationen und Regionen) und journalistischer Qualität. Der Sendegebietsbezug des Programms selbst bedingt, dass in Redaktionen teilweise so verfahren wird, Beiträge „künstlich“ zu regionalisieren. Im Hinblick auf die kollektive Raumpassung auf Seite des Publikums, ist ein solches Vorgehen weder positiv noch negativ zu bewerten, sondern kann rein funktional betrachtet werden. Eine journalistische Beurteilung steht dagegen sehr wohl vor der Frage nach der Notwendigkeit einer solchen Praxis. Das ist leicht zu erkennen, wenn man bedenkt, dass so der Nachrichtenwertfaktor „Nähe“ simuliert wird und dem Publikum somit eine Relevanz suggeriert, die möglicherweise nicht vorhanden ist.

In beiden untersuchten Regionalprogrammen haben künstlich regionalisierte Themen etwa gleichviel Anteil an der Sendezeit der Magazinbeiträge (jeweils 24 Prozent). Gleichzeitig bilden aber tatsächlich regionalspezifische Themen auch den jeweils größten Teil aller Themen, im BR zur Hälfte, im MDR zu immerhin 40 Prozent (vgl. Abbildung 39). Auf der anderen Seite haben in den nationalen Programmen künstlich regionalisierte Themen ebenfalls etwa gleichgroße Anteile an den Magazinbeiträgen (14 bzw. 13 Prozent). Nicht-regionale Themen beherr- 
schen aber mit jeweils über 50 Prozent die Berichterstattung. Insofern kann gesagt werden, dass die künstliche Herstellung regionaler Raumbezüge zwar kein alleiniges Spezifikum regionaler Programme ist, dort aber häufiger - und zwar zu vergleichbar großen Teilen - vorkommt. In nationalen Programmen werden nicht-regionale Ereignisse auch künstlich auf Einzelregionen heruntergebrochen, jedoch in geringerem Umfang. Es ist anzumerken, dass diese Befunde keine Einschränkung der Ergebnisse zur Raumabdeckung durch Regionalberichterstattung darstellen, da dort künstlich regionalisierte Beiträge nicht eingeflossen sind.

Abbildung 39: Anteile von Magazinbeiträgen mit regionalen Themen, nicht regionalen Themen und künstlich regionalisierten Themen

Basis: alle Magazinbeiträge in hh:mm:ss - ORF 2: 25:02:33, ZDF: 33:36:49, BR: 25:54:25, MDR: 32:31:20

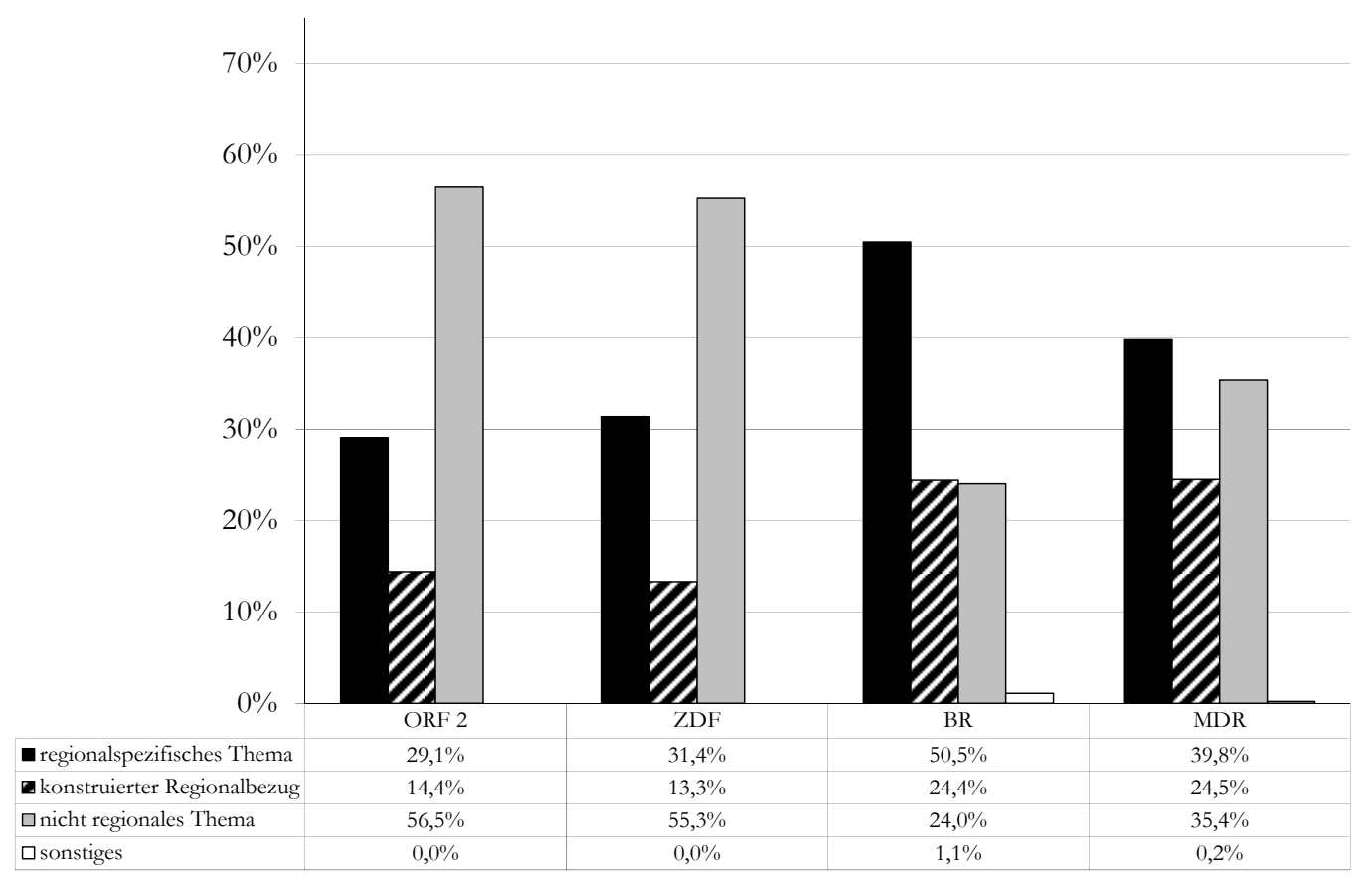

\subsection{Künstliche Raumbezüge durch Personalisierung politischer Berichter- stattung}

In engem Zusammenhang mit der künstlichen Regionalisierung von Themen steht deren Personalisierung. Es wurde vermutet, dass dies insbesondere im Regionalprogramm der Fall sei, wo politische Entscheidungen und Sachverhalte in ihren Auswirkungen an persönlichen Beispielen aufgezeigt würden. Das bestätigt sich nicht. Um dies zu zeigen, wurden zunächst alle Beiträge, die politische Themen behandeln, extrahiert und anschließend daraufhin untersucht, ob sie sowohl das Merkmal der personalisierten Darstellung aufweisen als auch über einen lediglich konstruierten Regionalbezug verfügen. Anschließend wird nur noch unterschieden, ob diese Merkmalskombination auf die (politische) Berichterstattung zutrifft oder nicht.

Zwar finden sich derartige Darstellungen in beiden regionalen Programmen häufiger als in den nationalen Programmen (vgl. Abbildung 40), insgesamt ist diese Form der Darstellung jedoch 
nicht umfangreich genug, um hier eine zuverlässige Aussage zu treffen. Es fällt lediglich auf, dass im MDR diese Form der Darstellung häufiger ist als in allen anderen drei Sendern. Da politische Berichterstattung in Magazinen des MDR aber eher eine Ausnahmeerscheinung ist (vgl. S. 228), wirken sich hier bereits wenige personalisierte Berichte auf das Ergebnis aus.

Abbildung 40: Anteile der politischen Berichterstattung, die Zusammenhänge personalisiert am Beispiel von regional verortbaren „Normalbürgerinnen“ und „Normalbürgern“ darstellt

Basis: Dauer der Magazinbeiträge mit Thema „Politik“" in hh:mm:ss - ORF 2: 06:51:23, ZDF: 07:51:54, BR: 04:57:43, MDR: 02:15:17.

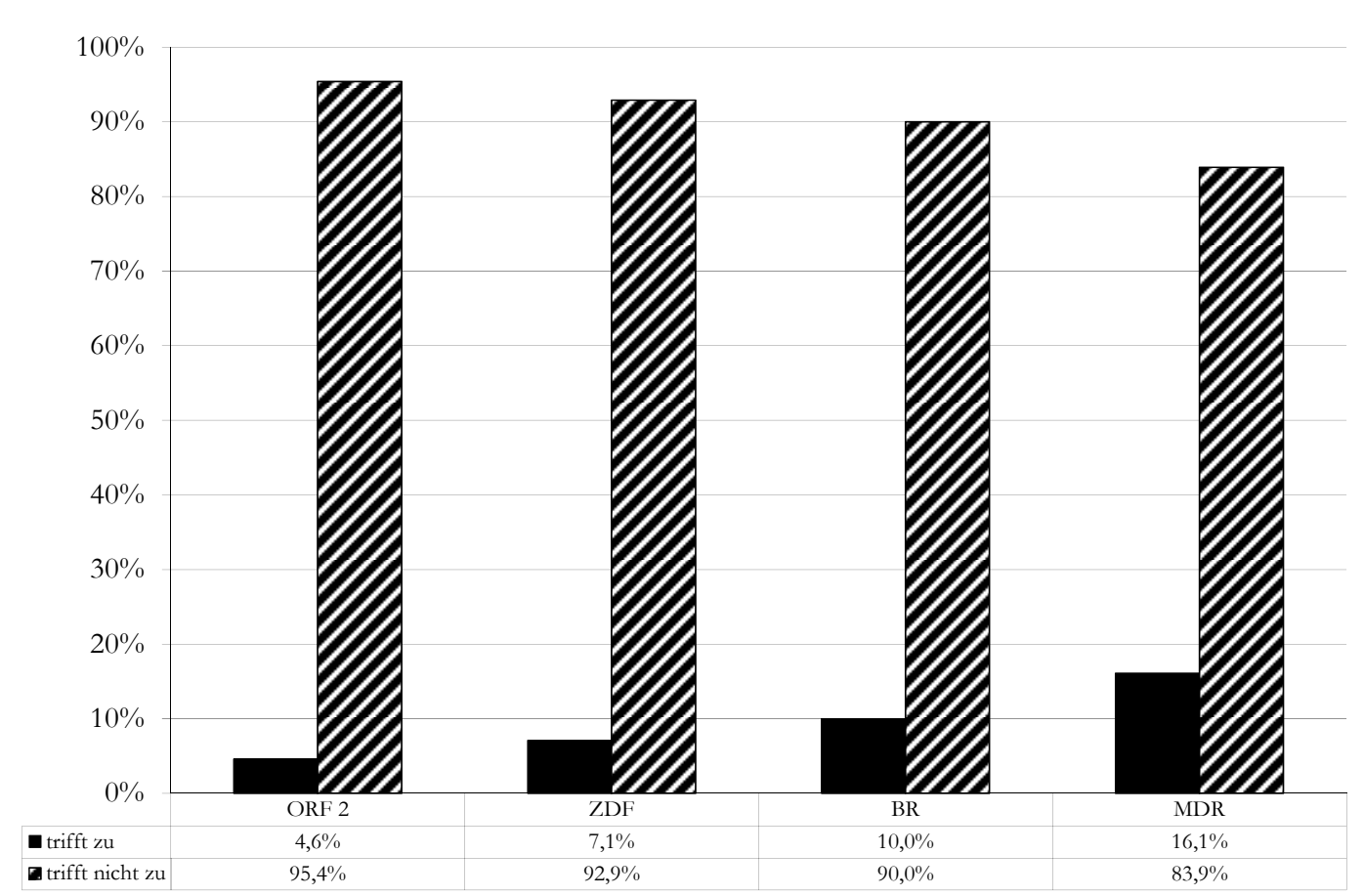

\subsubsection{Ergebnisse Raumbezüge}

Die Hypothese H6a wird abgelehnt. Die Formulierung der Hypothese ging von einer grundsätzlich bestehenden Ähnlichkeit der nationalen Programme aus. Sie wäre deshalb nur bestätigt gewesen, wenn für beide untersuchten Sender eine wenigstens in der Tendenz ähnliche Breite der ortsbezogenen und regionalen Berichterstattung feststellbar wäre. Das ist nicht der Fall, sondern die Raumabdeckung des ORF 2 geht ,in die Fläche“, während sie im ZDF - der hypothetischen Annahme entsprechend - punktuell ist.

Hypothese H6b wird abgelehnt. In beiden untersuchten Regionalprogrammen gibt es Landkreise, die durch Magazinbeiträge nicht berücksichtigt werden. Deshalb kann nicht davon gesprochen werden, dass tatsächlich die gesamte Fläche abgedeckt wird. Gleichzeitig ist auch ein relativ großer Unterschied in der Abdeckungsrate beider Sendegebiete feststellbar. Hier ähnelt der BR eher dem ORF 2 als dem MDR. Deshalb kann die Hypothese H6b schon unter der Maßgabe, dass sie zur Bestätigung von $B R$ und $M D R$ gleichermaßen erfüllt sein müsste, nicht angenommen werden. 
Hypothese $\mathrm{H} 7 \mathrm{a}$ wird bestätigt. Es ist jedoch anzumerken, dass die Formulierung (auch in Bezug auf Hypothese H7b) auf der Vermutung basierte, dass die nationalen Programme sehr viel Auslandsberichterstattung aufweisen würden. Auch wenn dies (in durchaus beachtlichem Umfang) der Fall ist, so überwiegt die Inlandsberichterstattung doch eindeutig.

Hypothese H7b wird abgelehnt. Sie trifft weder in ihrer strikten Formulierung noch hinsichtlich der Aussagetendenz zu, dass Regionalprogramme ganz überwiegend aus der eigenen Region berichten. Vielmehr ist die in-group-Fokussierung weniger ausgeprägt als bei den nationalen Programmen.

Hypothese H8a wird abgelehnt. In beiden untersuchten nationalen Programmen betreffen die inländischen Themen in etwa zur Hälfte das gesamte Sendegebiet gleichermaßen, sind also von nationaler Tragweite. Das heißt aber gleichzeitig, dass ein ebenso großer Teil der Berichterstattung nur von begrenzter Bedeutungsreichweite ist. Die subnationalen Themen spielen sich in erster Linie auf lokaler Ebene ab. Damit spiegelt sich aber gerade nicht die föderale Struktur der beiden hier untersuchten Staaten in der Berichterstattung der nationalen Programme wider. Prozesse auf Landesebene spielen nur eine untergeordnete Rolle. Die Annahme, dass die Mehrzahl der Themen die Nation als Ganzes beträfe, bestätigt sich damit nicht.

Hypothese H8b wird abgelehnt. In beiden Regionalprogrammen machen lokale Themen (also solche von subregionaler Reichweite) aus dem Sendegebiet nicht die Mehrheit der Berichterstattung aus. Die Berichterstattung ist zudem in beiden untersuchten Sendern durchaus unterschiedlich. Schon deshalb kann die Annahme, dass Themen in Magazinen des Regionalprogramms sich in ihrer Mehrheit auf subregionale Räume beziehen, nicht bestätigt werden. Hier wurde von einer grundlegenden Ähnlichkeit beider Sender ausgegangen, die sich nicht bestätigt. Zwar stellt in beiden Sendern die sendegebietsinterne Lokalberichterstattung den größten einzelnen Teil dar, das trifft aber auch auf das ZDF zu. Im MDR ist der Anteil von Lokalberichterstattung sogar geringer als im ORF 2.

Hypothese $\mathrm{H} 9 \mathrm{a}$ wird angenommen. In beiden regionalen Programmen findet ein Herunterbrechen überregionaler Themen in vergleichbar hohem Umfang statt.

Hypothese H9b wird abgelehnt. Auch in beiden nationalen Programmen finden sich Beiträge mit konstruierten Raumbezügen. Der Umfang ist im Vergleich zu den regionalen Programmen gleichwohl geringer.

Hypothese H10 wird abgelehnt. In allen untersuchten Sendern machen regionalpersonalisierte Berichte mit politischem Thema nur einen geringen Umfang der Berichterstattung aus. Ein diesbezüglicher systematischer Unterschied zwischen nationalen und regionalen Programmen lässt sich auf Grund teilweise geringer Gesamtzahlen nicht belegen. 


\subsubsection{Dimensionen journalistischer Qualität der Berichterstattung}

\subsubsection{Ereignisbezug der Berichterstattung}

Bezüglich der journalistischen Qualität der Inhalte wurde oben der „ereignislose Bericht“ als besonders eklatantes Beispiel von Fehlentwicklungen genannt (vgl. S. 31 u. 129). Dieser wurde insbesondere von Schilling als ein systematischer Mangel des regionalen Rundfunks erkannt. Zur Überprüfung der Frage, wie häufig dieses Phänomen in den untersuchten Sendern auftaucht, wurde zu jeder Untersuchungseinheit erfasst, ob sie auf ein tatsächliches Geschehen rekurriert. ${ }^{266}$ Die Annahme, dass solche Berichterstattung, die kein Ereignis zum Anlass hat, im Regionalfernsehen häufiger vorkommt als im nationalen Programm, bestätigt sich. In beiden untersuchten Dritten Programmen hat ereignislose Berichterstattung einen Anteil von 43 Prozent (vgl. Abbildung 41). ${ }^{267} \mathrm{Im} Z D F$ und ORF 2 liegt der Anteil dagegen bei rund einem Viertel.

\section{Abbildung 41: Ereignisbezug der Berichterstattung}

Basis: alle Magazinbeiträge in hh:mm:ss - ORF 2: 25:02:33, ZDF: 33:36:49, BR: 25:54:25, MDR: 32:31:20

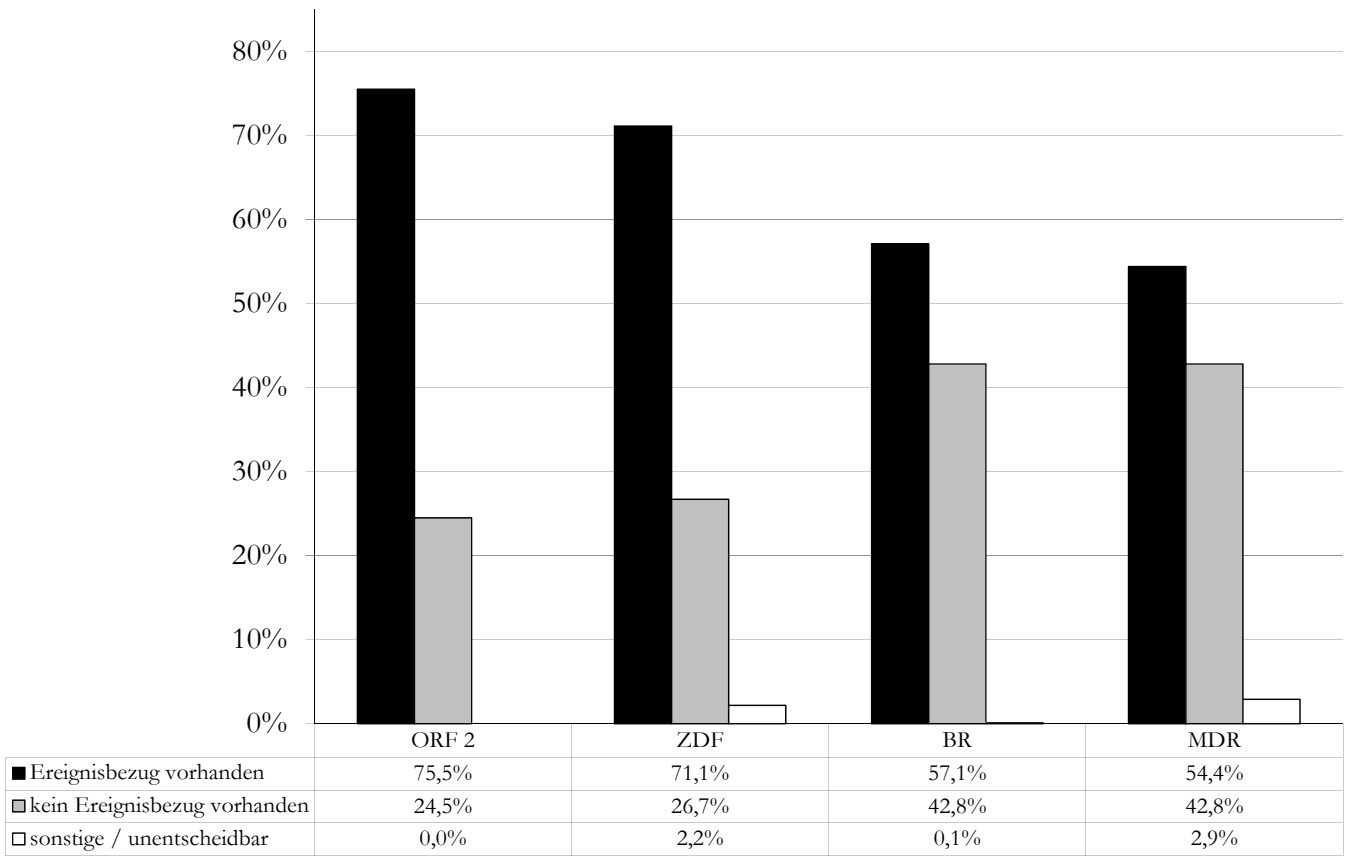

Die Ergebnisse können zunächst so verstanden werden, dass Schillings entsprechende Befunde zum regionalen Rundfunk aus dem Jahr 1998 nicht an Aktualität eingebüßt haben. Schilling

\footnotetext{
266 Zur genauen Definition siehe Codeplan (S. 301).

${ }^{267}$ Für den Ereignisbezug auf Ebene der Vercodung (genauere Abstufung von Ereignis vs. Nichtereignis) vgl. Abbildung 84 im Anhang, S. 318.
} 
hat gezeigt, dass eine Berichterstattung, die eigentlich nicht über tatsächliche Vorkommnisse informiert, insofern problematisch ist, als dass sie dafür steht, dass Regionen gegebenenfalls gar nicht inhaltlich ausgefüllte Konstrukte sind, sondern lediglich journalistisch-operative Räume. Mit anderen Worten: Es ist nicht wichtig, was von wo berichtet wird, sondern nur dass von überall (aus der Region) berichtet wird. In dieser Schärfe lassen sich die vorliegenden Ergebnisse bei genauerer Betrachtung aber nicht bewerten. Die ereignislosen Berichte entfallen nämlich zum größten Teil gar nicht auf die Regionalberichterstattung ${ }^{268}$ sondern vor allem auf jene Beiträge, die gar keine regionalen Themen behandeln oder (zum kleineren Teil) auf solche Beiträge, die künstlich regionalisiert sind. Insofern wird der insgesamt hohe Regionalbezug von $M D R$ und $B R$ nicht grundsätzlich durch ereignislose Berichte erkauft. Als problematisch erscheinen insofern vor allem jene Sendezeitanteile, in denen ein Regionalbezug künstlich hergestellt wird und denen es gleichzeitig an einer berichtenswerten Tatsache fehlt. Diese machen (gemessen am Gesamtumfang der Berichterstattung in Magazinen) im BR 15 und im MDR elf Prozent aus. ${ }^{269}$ Damit erscheinen Schillings Befunde (vgl. S. 31) - jedenfalls für die hier untersuchten Sender - weniger brisant. Schließlich ist es gerade nicht die jeweils eigene Region, die im Regionalprogramm ereignislos und damit inhaltsleer erscheint. Demnach ist der ereignislose Bericht zwar ein Kennzeichen des Regionalprogramms. In diesem Programm betrifft er aber nur in geringem Ausmaß die Region. Deshalb stellt er auch kein rundfunkpolitisches Problem dar, wie es Schilling noch nahelegte (vgl. S. 31). Es handelt sich insofern um eine bloße Frage journalistischer Qualitätsansprüche. Diese erscheinen dann (jedenfalls in diesem Teilaspekt) im Regionalfernsehen allerdings niedriger als im nationalen Programm.

\subsubsection{Themenspektrum}

Das Themenspektrum wird hier zunächst verstanden als Themenvielfalt. ${ }^{270} \mathrm{Zu}$ deren Bestimmung wird wiederum auf das Maß der relativen Entropie zurückgegriffen. Die hier ermittelte Breite behandelter Themen berücksichtigt also sowohl den anteiligen Umfang, den Themen in der Berichterstattung einnehmen, als auch die Menge der überhaupt vorkommenden Themen. Die der Auswertung zugrunde liegenden Werte relativer Entropie beziehen sich dabei lediglich auf die Verteilung im Codeplan vorkommender Themen (bzw. Aggregationen davon). Es handelt sich also nicht um ein „objektives“ Maß des Informationsgehalts der untersuchten Programme, sondern lediglich um ein Maß dafür, wie gleichmäßig oder ungleichmäßig sich die (untersuchte) Sendezeit auf die vorher festgelegten Themen verteilt. Als Indikator für journalistische Qualität ist es daher in dem Sinne geeignet, als dass gesagt werden kann, dass in einem Sender das Themenspektrum breiter ist als in einem anderen. Das relative Entropiemaß bewegt sich auch hier grundsätzlich zwischen 0 und 1, wobei 0 bedeuten würde, dass die ge-

\footnotetext{
268 Hiervon machen ereignislose Berichte im BR 28,9 Prozent der Magazinbeitragsdauer aus, im MDR 27,9 Prozent. Dabei ist die im Kern regionale Berichterstattung in beiden Sendern ähnlich umfangreich (vgl. Tabelle $20 \mathrm{im}$ Anhang, S. 322).

${ }^{269} \mathrm{Da}$ die künstliche Regionalisierung ereignisloser Berichte im nationalen Programm keine besondere Brisanz besitzt, werden die entsprechenden Zahlen hier nicht zum Vergleich herangezogen.

${ }^{270} \mathrm{Zu}$ den eigentlichen Themen der Berichterstattung in inhaltlichem Verständnis siehe S. 226.
} 
samte Sendezeit auf nur ein Thema entfällt, während 1 bedeuten würde, dass alle Themen in genau gleichem Umfang berücksichtigt werden. ${ }^{271}$

Für die Auswertung bestehen mehrere Möglichkeiten bei der Berücksichtigung des untersuchten Materials. Es kann zunächst die Verteilung über alle bei der Kodierung möglichen Themen berücksichtigt werden. Daneben kann aber auch eine Aggregierung dieser Themen nach übergeordneten Themenkategorien erfolgen und die Verteilung darüber zur Grundlage der Berechnung genommen werden. ${ }^{272}$

\section{Abbildung 42: Vergleich relative Entropie der Themenverteilung in allen Magazinen der unter- suchten Sender auf Ebene aller möglichen Themen}

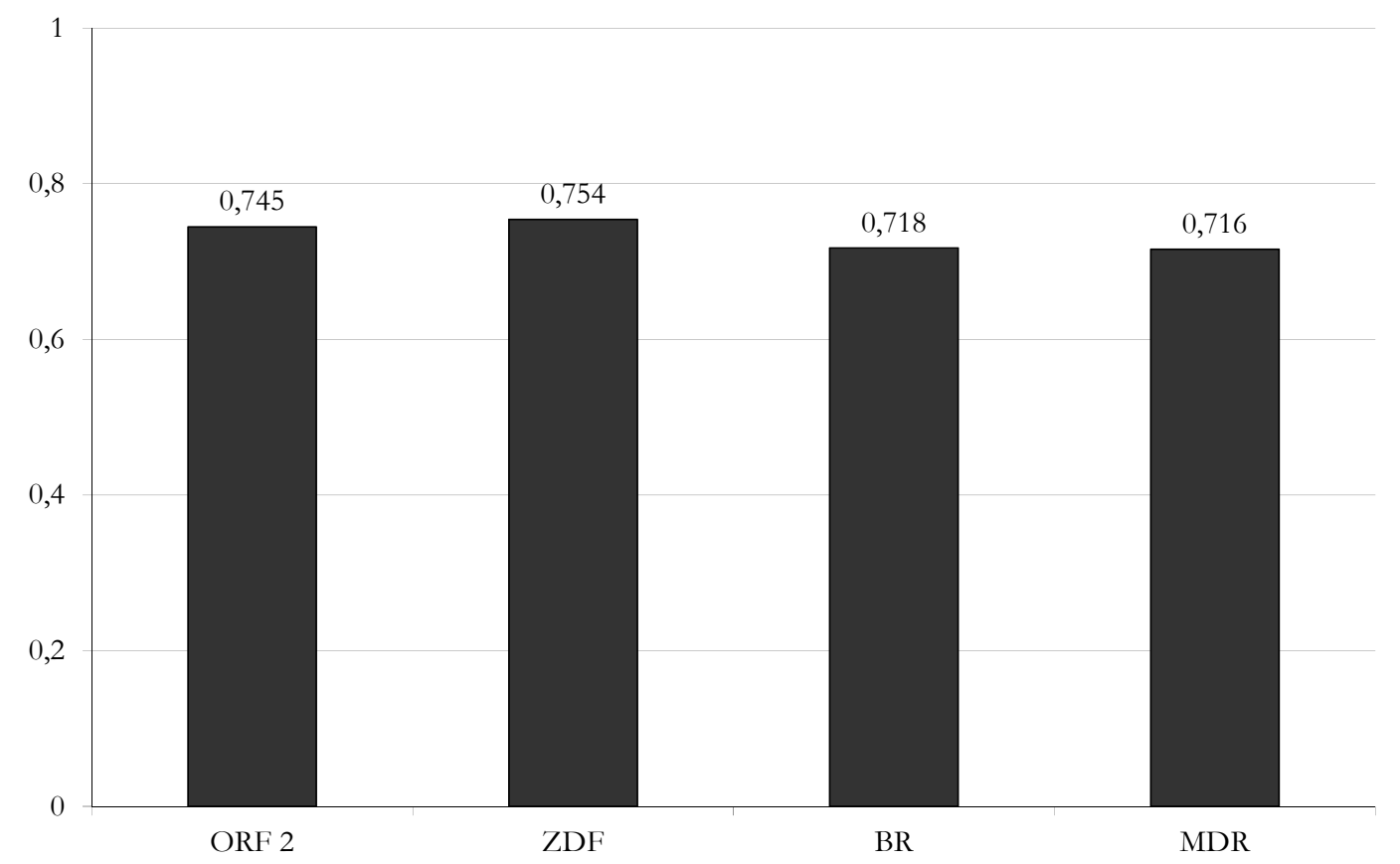

${ }^{271}$ Wobei der Wert 1 hinsichtlich journalistischer Qualitätsmaßstäbe auch fragwürdig erschiene, da er ein Indikator für mangelhaftes Relevanzbewusstsein bei den Journalisten und Journalistinnen wäre. Zu deren Aufgabe gehört es schließlich, wichtige von unwichtigen Nachrichten zu unterscheiden und entsprechend umfangreich darüber zu berichten.

${ }^{272} \mathrm{Da}$ im MDR keine Nachrichtenmagazine ausgestrahlt werden, ist zudem das Themenspektrum ohne Berücksichtigung dieser Form von Nachrichten aufzuzeigen. Der dahinter stehende Gedanke ist der, dass Nachrichtenmagazine insbesondere über politische Themen berichten und darüber hinaus weitere gesellschaftlich relevante Themen berücksichtigen. Vergleicht man nun aber einen Sender, der zwar Nachrichten ausstrahlt, aber eben nicht in Magazinform, mit Sendern, die genau das tun, würde man erstgenannten Sender ,benachteiligen“jedenfalls, wenn man das Verteilungsmaß über die Themen als einen Indikator für journalistische Qualität versteht. 


\section{Abbildung 43: Vergleich relative Entropie der Themenverteilung in allen Magazinen der unter-} suchten Sender auf Ebene aggregierter Themenbereiche

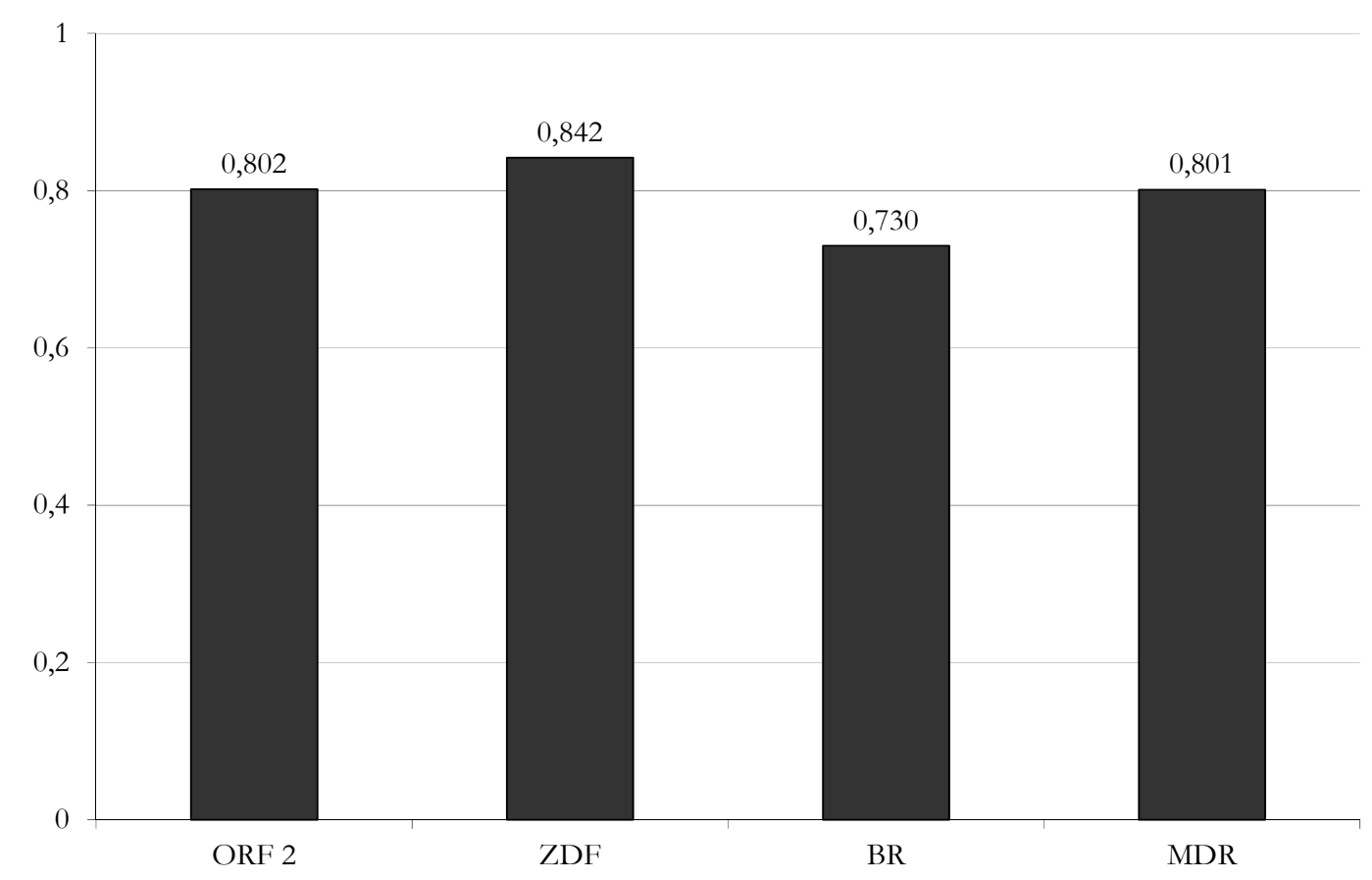

Beim Vergleich über alle Einzelthemen in allen Magazinen zeigt sich, dass der relative Entropiewert bei allen vier Sendern nah beieinander liegt, in den regionalen Programmen ist er gleich nahezu groß (vgl. Abbildung 42). Dass bedeutet, dass die Themenverteilung jeweils ähnlich breit gestreut ist. Eine Aussage über Themenschwerpunktsetzungen ist damit aber nicht möglich. Ein systematischer und gleichzeitig bedeutsamer Unterschied in der Vielfalt behandelter Themen ist jedenfalls nicht erkennbar. Dieses Bild ändert sich, wenn die Auswertung nur noch auf Grundlage zusammengefasster Themenoberkategorien ${ }^{273}$ stattfindet. Dann liegt der Wert für den Bayerischen Rundfunk mit 0,73 am niedrigsten, während ORF 2, ZDF und $M D R$ Werte von 0,8 und darüber erreichen (vgl. Abbildung 43). Das bedeutet, dass zwar grundsätzlich in allen Sendern vergleichbar viele Themen behandelt werden, diese im $B R$ aber weniger breit über die Hauptthemengebiete verteilt sind (vgl. Abschnitt 8.2.4). Das heißt, bei ähnlicher Streuung über die Einzelthemen, stammen diese im BR aus weniger Oberkategorien als in den anderen Sendern. Insofern ist hier die Themenvielfalt doch etwas geringer. Dennoch ist auch im Hinblick auf die Verteilung der Berichterstattung auf die thematischen Oberkategorien kein nennenswerter und systematischer Unterschied zwischen nationalen und regionalen Programmen zu erkennen.

273 Politik, Wirtschaft, Gesellschaft, Kriminalität, Unglück, Sport, Private Lebenswelt/Service/Verbraucher, Kunst/Kultur, Geschichte. 
Der MDR strahlt als einziges der untersuchten Programme kein Nachrichtenmagazin ${ }^{274}$ aus. $\mathrm{Da}$ in solchen Sendungen aber möglicherweise eine besonders große Bandbreite von Themen vorkommt (insbesondere im Vergleich etwa zu Ressortmagazinen), könnte es theoretisch sein, dass die hohe Themenstreuung in den anderen Sendern aus diesem Umstand resultiert. Diesbezüglich lässt sich jedoch feststellen, dass sich keine großen Unterschiede bei der (rein quantitativen) Themenverteilung ergeben. Zwar liegen alle Werte nur geringfügig niedriger, unterscheiden sich aber in der Tendenz (Unterschiede zwischen den Sendern) kaum. ${ }^{275}$

\subsubsection{Vielfalt der Darstellungsformen}

Auch hinsichtlich der Vielfalt der verschiedenen Darstellungsformen wird auf das Maß der relativen Entropie zurückgegriffen. Hierbei sei betont, dass eine besonders starke Variabilität der Darstellungsformen nicht per se für hohe journalistische Qualität steht. Es liegt in der Natur der Sache (oder besser: an den Produktionsbedingungen von Fernsehmagazinen), dass manche Formen sehr viel häufiger vorkommen als andere (etwa Bericht vs. Reportage). Eine vollständig gleiche Verteilung der Berichterstattung hieße schließlich, dass Nachrichten ebenso häufig und umfangreich wären wie Kommentare - das spräche eher gegen einen sachverständigen Einsatz der verschiedenen journalistischen Mittel. Die relative Entropie dient hier also ausschließlich dem Vergleich der Verteilungen und ist kein Maßstab für journalistische Güte des Programms.

\footnotetext{
274 Wohl aber ,gewöhnliche“ Nachrichtensendungen.

275 Einzelthemen: ORF 2: 0,74, ZDF: 0,71, BR: 0,71, MDR: 0,72; aggregierte Themen: ORF 2: 0,80, ZDF: 0,82, BR: 0,72, MDR: 0,80 (vgl. auch Grafiken im Anhang, Abbildung 85, S. 319 und Abbildung 86, S 319).
} 
Abbildung 44: Relative Entropie der Verteilung der Berichterstattung auf die verschiedenen journalistischen Darstellungsformen (nach Dauer)

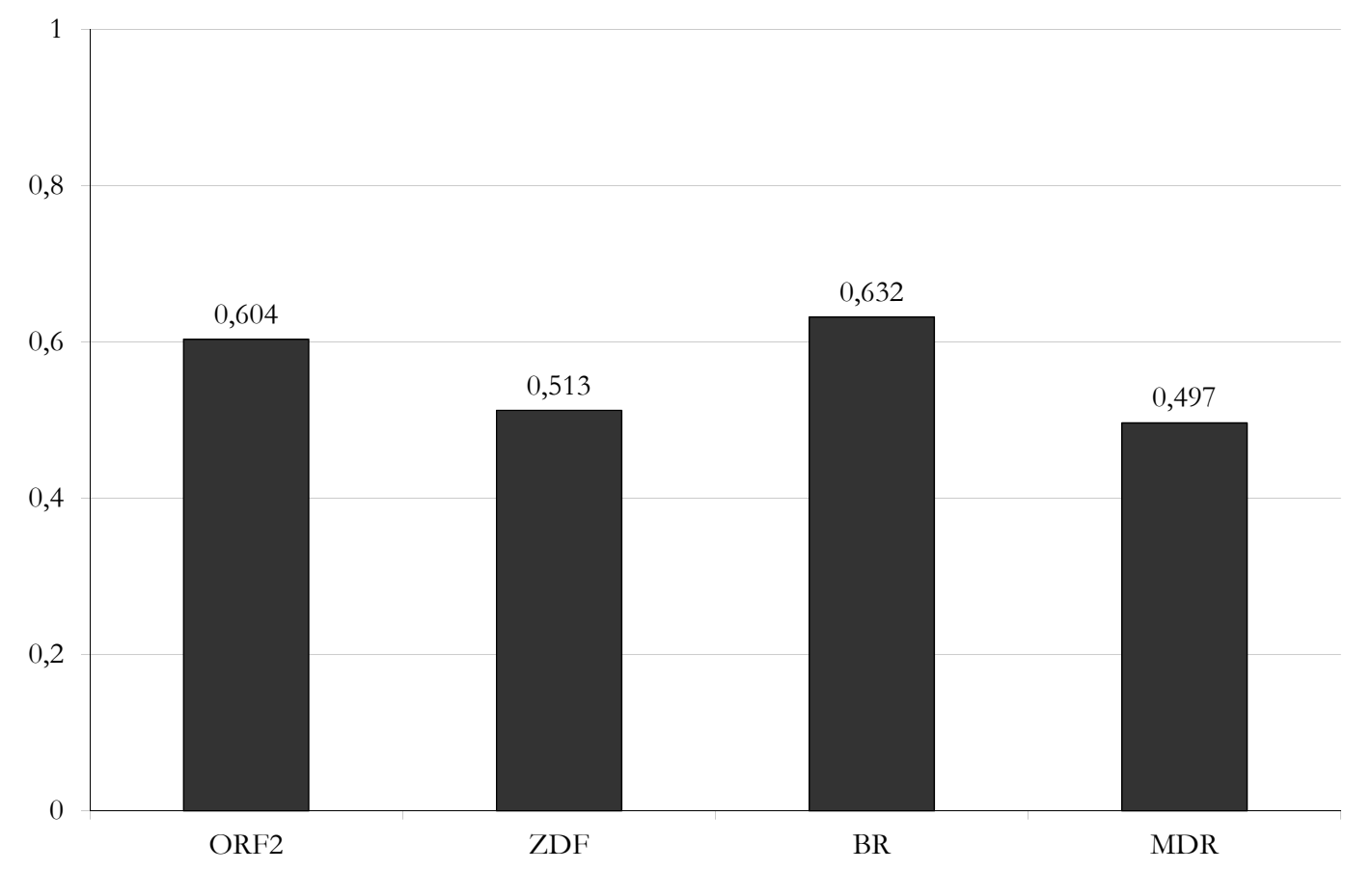

Der Vergleich ergibt, dass sich hinsichtlich des Vorkommens der verschiedenen Darstellungsformen auf der einen Seite ORF 2 und BR ähneln, auf der anderen Seite ZDF und MDR. Insgesamt ist der Entropiewert für alle vier Programme erwartbar niedrig und weist jeweils auf eine mittlere Streuung der Zeitanteile über die Kategorien (Darstellungsformen) hin. Das dürfte an der in allen Programmen von vornherein zu erwartenden Dominanz von Filmberichten liegen (vgl. Abschnitt 8.2.2.3). In ORF 2 und BR, wo deren Anteil jeweils deutlich niedriger als in den anderen beiden Sendern ist, spiegelt sich das in einem entsprechend höheren Wert der Verteilung wider (vgl. Abbildung 44). Auch hier zeigt sich, dass sich die Zusammensetzung der redaktionellen Inhalte bezüglich der verwendeten Darstellungsformen nicht systematisch zwischen regionalen und nationalen Programmen unterscheidet.

\subsubsection{Regionale Zentren in der Berichterstattung}

Wie bereits im Zusammenhang der Gebietsabdeckung festgestellt, gibt es Kreise, aus denen besonders häufig bzw. umfangreich berichtet wird. Im Falle des BR entfallen auf einen einzigen Kreis (Stadtkreis München) über 30 Prozent der Berichterstattung (Zeitumfang von Untersuchungseinheiten mit Ereignisort München). Im MDR wird dagegen der Stadtkreis Leipzig mit einem Anteil von ca. 17 Prozent berücksichtigt (vgl. S. 189).

Es stellt sich die Frage, ob sich auch die restlichen Anteile der Berichterstattung auf solche Kreise beziehen, die regionale Zentren darstellen, also in irgendeiner Weise (Größe, politische oder wirtschaftliche Bedeutung) gegenüber anderen Kreisen herausgehoben sind. Hierfür bie- 
tet sich ein Blick auf die „Top Ten“ der Berichterstattung (bezogen auf Ereignisorte) an (vgl. Tabelle 4 und Tabelle 5).

Tabelle 4: Die zehn Kreise in Bayern, aus denen im BR am umfangreichsten berichtet wird

\begin{tabular}{l|r|r} 
Kreis & $\begin{array}{l}\text { Umfang der } \\
\text { Berichterstattung } \\
\text { (hh:mm:ss) }\end{array}$ & \multicolumn{2}{|l}{$\begin{array}{l}\text { Anteil an allen } \\
\text { Magazinbeiträgen }\end{array}$} \\
\hline SK München & $5: 38: 20$ & $30,11 \%$ \\
\hline LK Ostallgäu & $1: 33: 14$ & $8,30 \%$ \\
\hline SK Coburg & $1: 16: 11$ & $6,78 \%$ \\
\hline LK Hof & $0: 53: 32$ & $4,76 \%$ \\
\hline SK Nürnberg & $0: 41: 21$ & $3,68 \%$ \\
\hline LK Schwandorf & $0: 38: 00$ & $3,38 \%$ \\
\hline LK Garmisch-Partenkirchen & $0: 36: 50$ & $3,28 \%$ \\
\hline LK Rosenheim & $0: 35: 31$ & $3,16 \%$ \\
\hline LK Bad Tölz-Wolfratshausen & $0: 29: 30$ & $2,63 \%$ \\
\hline LK Starnberg & $0: 26: 51$ & $2,39 \%$
\end{tabular}

Tabelle 5: Die zehn Kreise in Mitteldeutschland, aus denen im MDR am umfangreichsten berichtet wird

\begin{tabular}{l|r|r} 
Kreis & $\begin{array}{l}\text { Umfang der } \\
\text { Berichterstattung } \\
\text { (hh:mm:ss) }\end{array}$ & \multicolumn{2}{|l}{$\begin{array}{l}\text { Anteil an allen } \\
\text { Magazinbeiträgen }\end{array}$} \\
\hline SK Leipzig & $4: 06: 34$ & $17,46 \%$ \\
\hline SK Dresden & $1: 45: 01$ & $7,44 \%$ \\
\hline SK Magdeburg & $1: 11: 38$ & $5,07 \%$ \\
\hline LK Niederschles. Oberlausitzkreis & $0: 54: 51$ & $3,88 \%$ \\
\hline SK Weimar & $0: 51: 47$ & $3,67 \%$ \\
\hline LK Altenburger Land & $0: 49: 25$ & $3,50 \%$ \\
\hline SK Halle (Saale) & $0: 48: 46$ & $3,45 \%$ \\
\hline LK Halberstadt & $0: 44: 23$ & $3,14 \%$ \\
\hline SK Erfurt & $0: 44: 00$ & $3,12 \%$ \\
\hline LK Kamenz & $0: 43: 16$ & $3,06 \%$
\end{tabular}

Im Fall des BR zeigt sich keine eindeutige Präferenz regionaler Zentren, außer München. Zwar kommen hier etwa Nürnberg und Hof vor, die als solche Zentren gelten können, in größerem Umfang wird aber zum Beispiel auch aus dem Landkreis Ostallgäu berichtet, der eine eher ländliche Region darstellt. Die besonders herausgehobene Stellung Münchens stellt aber in jedem Fall eine Konzentration der Berichterstattung auf ein regionales Zentrum dar. 
Anders ist das Bild beim MDR. Hier sind die ersten drei Plätze durch regionale Zentren besetzt. Dabei handelt es sich um Leipzig, Dresden und Magdeburg. Beide letztgenannte Städte sind Landeshauptstädte, Leipzig kann in jedem Fall als wirtschaftlich bedeutende Stadt gelten, die zudem den Hauptsitz des MDR beherbergt. Auffällig ist lediglich, dass Erfurt als Landeshauptstadt Thüringens in deutlich geringerem Maße Eingang in die Berichterstattung findet als das sächsische und anhaltinische Pendant. Daneben finden sich in den „Top Ten“ weitere wichtige Städte wie Halle, Weimar und Halberstadt. Hier spiegeln sich die bereits referierten Befunde zur Verteilung der Berichterstattung auf die Sendegebiete wider (vgl. S. 189). Insbesondere die starke München-Konzentration im BR ließ sich unter dem Aspekt der sozialen Konstruktion der Region „Bayern“ zumindest plausibel machen. Aus dem Blickwinkel journalistischer Qualität ist eine solche Häufung der Berichterstattung aber eher fragwürdig. Selbst unter Bedachtnahme des „Hauptstadtbonus“ erscheint eine so deutliche Übergewichtung einer einzelnen Stadt kaum gerechtfertigt. Es ist nicht anzunehmen, dass sich fast ein Drittel des Geschehens in Bayern in München abspielt. Mit Abstrichen ist diese Kritik auch gegenüber dem MDR angebracht, insbesondere, weil hier die Konzentration mit Leipzig auf eine Stadt entfällt, deren Bonus lediglich im Senderstandort liegen dürfte. Wie bereits oben ausgeführt, fällt die Konzentration auf Leipzig deutlich geringer aus, wenn die eigentliche Regionalberichterstattung in den Blick genommen wird. Insofern dürften hier wohl produktionsökonomische Einflüsse den Ausschlag für die Häufigkeit geben. Hinsichtlich der Bewertung der journalistischen Qualität bleibt der Anteil aber auch dann immerhin fragwürdig.

\subsubsection{Meinungsbetonte Darstellungsformen}

Um zu überprüfen, ob in den untersuchten Regionalprogrammen weniger meinungsbetonte Darstellungsformen vorkommen als in den nationalen Programmen (wie es in Hypothese H15 vermutet wird), bietet sich ein Blick darauf an, welche Darstellungsformen überhaupt vorkommen und in welchem Umfang. Es sei darauf hingewiesen, dass meinungsbetonte Darstellungsformen bzw. ihr Vorkommen nicht grundsätzlich für mehr oder weniger Meinungsfreude im Programm stehen müssen. Meinungsbetonte Elemente können auch außerhalb von ausgwiesenen Kommentaren (,jenseits der Nachricht“) vorkommen, wenn Journalistinnen und Journalisten - wider die redaktionellen Gepflogenheiten - ihre Meinungen in Berichten und Nachrichten zum Ausdruck bringen oder umgekehrt in Kommentaren keine Stellung beziehen. Der Rekurs auf die äußere Form ist aber ein guter Indikator für das redaktionelle Selbstverständnis der Programmverantwortlichen, da er zeigt, wie viel Platz man von vornherein einer neutralen Berichterstattung einräumt und wie viel der Meinungsverbreitung. 
Abbildung 45: ORF 2 - Verteilung der Sendezeit der nicht selbstreferenziellen Magazinbestandteile auf die verschiedenen journalistischen Darstellungsformen

(Basis: alle Magazinbeiträge in hh:mm:ss $=25: 02: 33$

$\square$ Moderation

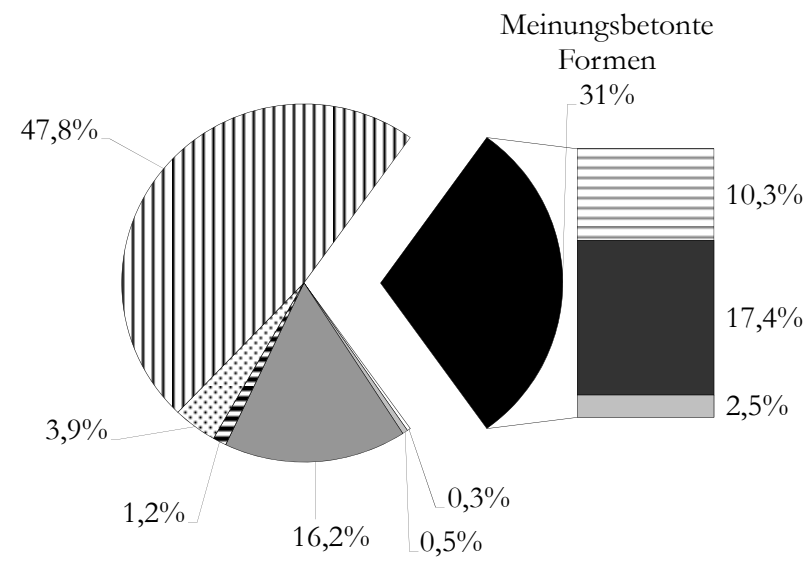

$\square$ Sprechermeldung

$\square$ Interview/Gesprächsrunde

E Nachrichtenfilm

Service-/Hinweisform

П Filmbericht

$\boxminus$ Korrespondentenbericht

- Reportage

$\square$ Kritik/Rezension/

Besprechung

Abbildung 46: ZDF - Verteilung der Sendezeit der nicht selbstreferenziellen Magazinbestandteile auf die verschiedenen journalistischen Darstellungsformen

Basis: alle Magazinbeiträge in hh:mm:ss = 33:36:49

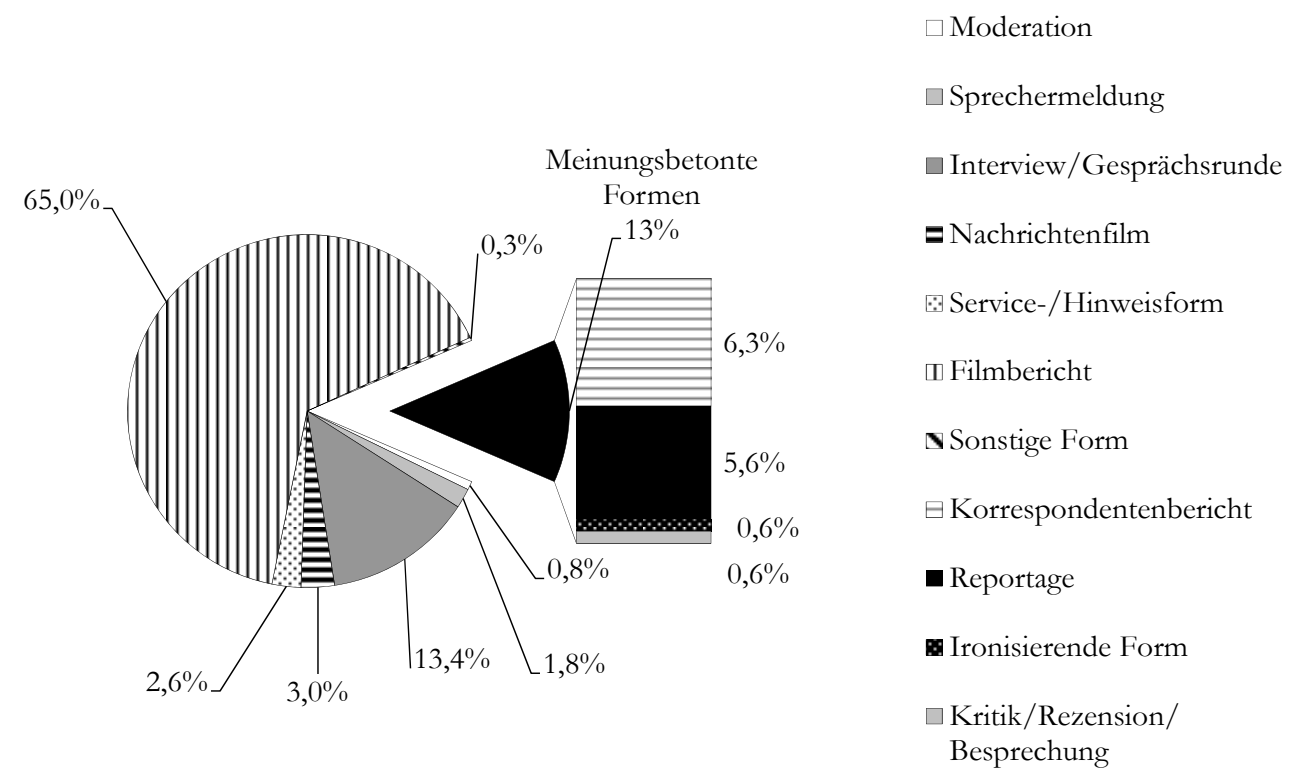


Abbildung 47: BR - Verteilung der Sendezeit der nicht selbstreferenziellen Magazinbestandteile auf die verschiedenen journalistischen Darstellungsformen

Basis: alle Magazinbeiträge in hh:mm:ss $=25: 54: 25$

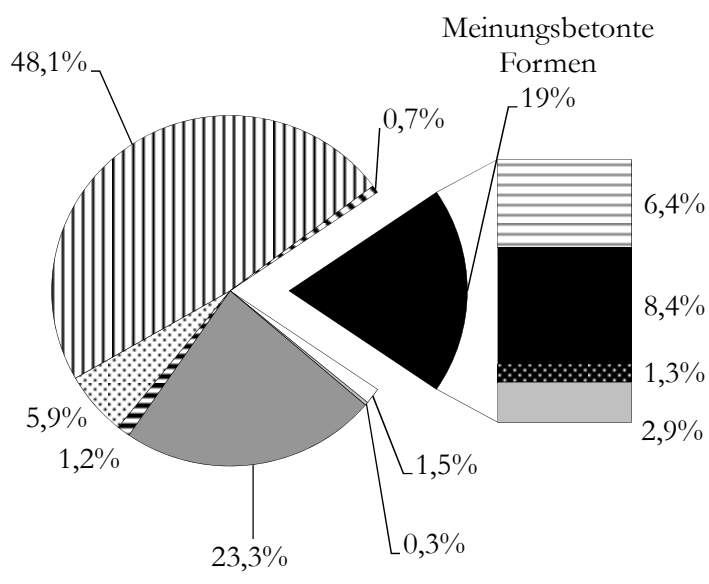

$\square$ Moderation

$\square$ Sprechermeldung

$\square$ Interview/Gesprächsrunde

= Nachrichtenfilm

(9) Service-/Hinweisform

Ш Filmbericht

s Sonstige Form

$\boxminus$ Korrespondentenbericht

- Reportage

Ironisierende Form

$\square$ Kritik/Rezension/

Besprechung

Abbildung 48: MDR - Verteilung der Sendezeit der nicht selbstreferenziellen Magazinbestandteile auf die verschiedenen journalistischen Darstellungsformen

Basis: alle Magazinbeiträge in hh:mm:ss = 32:31:20

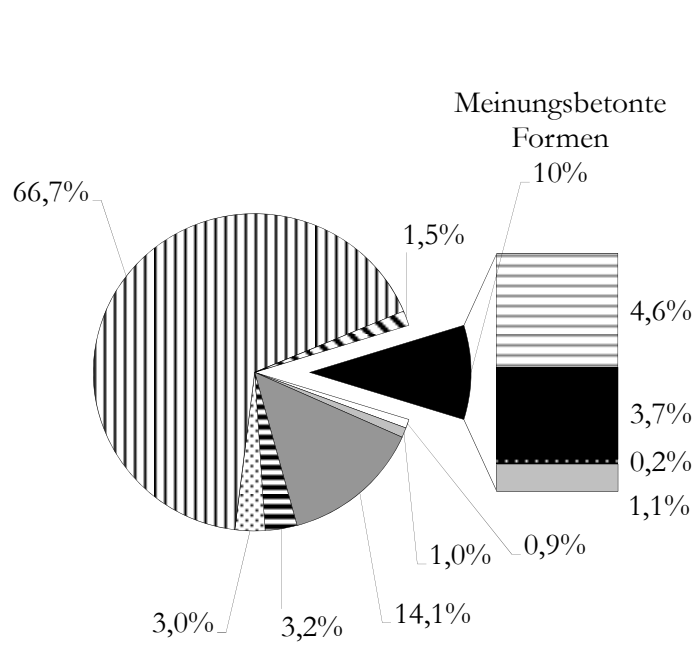

$\square$ Moderation

$\square$ Sprechermeldung

$\square$ Interview/Gesprächsrunde

ENachrichtenfilm

Q Service-/Hinweisform

[1] Filmbericht

s Sonstige Form

$\boxminus$ Korrespondentenbericht

- Reportage

Ironisierende Form

$\square$ Kritik/Rezension/

Besprechung 
In allen untersuchten Programmen ist der Filmbericht die dominierende Form. Im ZDF und MDR macht er zwei Drittel der Sendezeit innerhalb der Magazinsendungen aus. Im ORF 2 und BR jeweils 48 Prozent. Daneben spielen in allen vier Sendern Interviews eine große Rolle, wenn auch erstens deutlich weniger als Filmberichte und zweitens mit unterschiedlichen Anteilen.

Die meinungsbetonten Formen sind im ORF 2 deutlich stärker vertreten als in den deutschen Programmen. Das betrifft vor allem die beiden hier relevanten Formen des Korrespondentenberichts und der Reportage. Dabei ist zu bedenken, dass insbesondere bei letzterer auch eine geringe Fallzahl zu einem hohen Anteil führen kann, da Reportagen grundsätzlich eine gewisse Dauer aufweisen. In den deutschen Programmen machen die meinungsbetonten Formen insgesamt wie auch im Einzelnen deutlich weniger Sendezeit als im ORF 2 aus. Am geringsten fällt der Anteil meinungsbetonter Formen im MDR aus (10 Prozent). Im ZDF ist er mit 13 Prozent ebenfalls klein. ${ }^{276}$

Ein übergreifender Unterschied zwischen nationalen und regionalen Programmen lässt sich auch hier nicht ausmachen. Insofern ist nicht davon auszugehen, dass etwa im Bereich der öffentlichen Meinungsbildung die Dritten Programme lediglich eine Komplementärfunktion erfüllen würden. Vielmehr liegt das Hauptaugenmerk in allen Sendern auf der bloßen Tatsacheninformation, die durch meinungsbetonte Formen ergänzt wird. Im ORF 2 ist dieser ,Zusatznutzen" besonders ausgeprägt.

\subsubsection{Konfliktbetonung}

Die Frage nach der Konfliktbetonung der Berichterstattung steht im engen Zusammenhang mit der nach der Meinungsfreude. Eine nur vermittelnde Berichterstattung dürfte weniger der Darstellung und Betonung bestehender widerstreitender Interessen dienen als eine kritische. Dazu gehört aber auch, bestehende Konflikte darzustellen und sie nicht nur en passant zu berücksichtigen, indem etwa an einem Tag über eine Erklärung der Regierung berichtet wird und am nächsten über die Reaktionen der Opposition. ${ }^{277}$

Es ist zu erwarten, dass politische Berichterstattung häufiger Konflikte betont als die sonstige Berichterstattung. Deshalb werden Beiträge zu politischen Themen hinsichtlich ihrer Konfliktbetonung gesondert ausgewiesen.

\footnotetext{
276 Diese Unterschiede bestehen auch bei den absoluten Zahlen, sind also nicht ein bloßes Ergebnis der rein anteilsmäßigen Betrachtung. (In hh:mm:ss: ORF 2: 07:32:22, ZDF: 04:24:07, BR: 04:55:58, MDR: 03:05:48.)

${ }^{277}$ Dasselbe gilt aber auch für andere als politische Themen, wenn etwa die Kritik an der Unzulänglichkeit einer medizinischen Studie nicht im Bericht über deren Ergebnisse enthalten ist.
} 
Abbildung 49: Konfliktbetonung politischer Berichterstattung. Anteile der unterschiedlich kontroversen Magazinbeiträge mit Thema Politik am Gesamtumfang aller politischen Magazinbeiträge

Basis: Umfang aller Magazinbeiträge mit Thema Politik in hh:mm:ss - ORF 2: 06: :51:24, ZDF: 07:51:53, BR: 04:57:42, MDR: 02:15:17

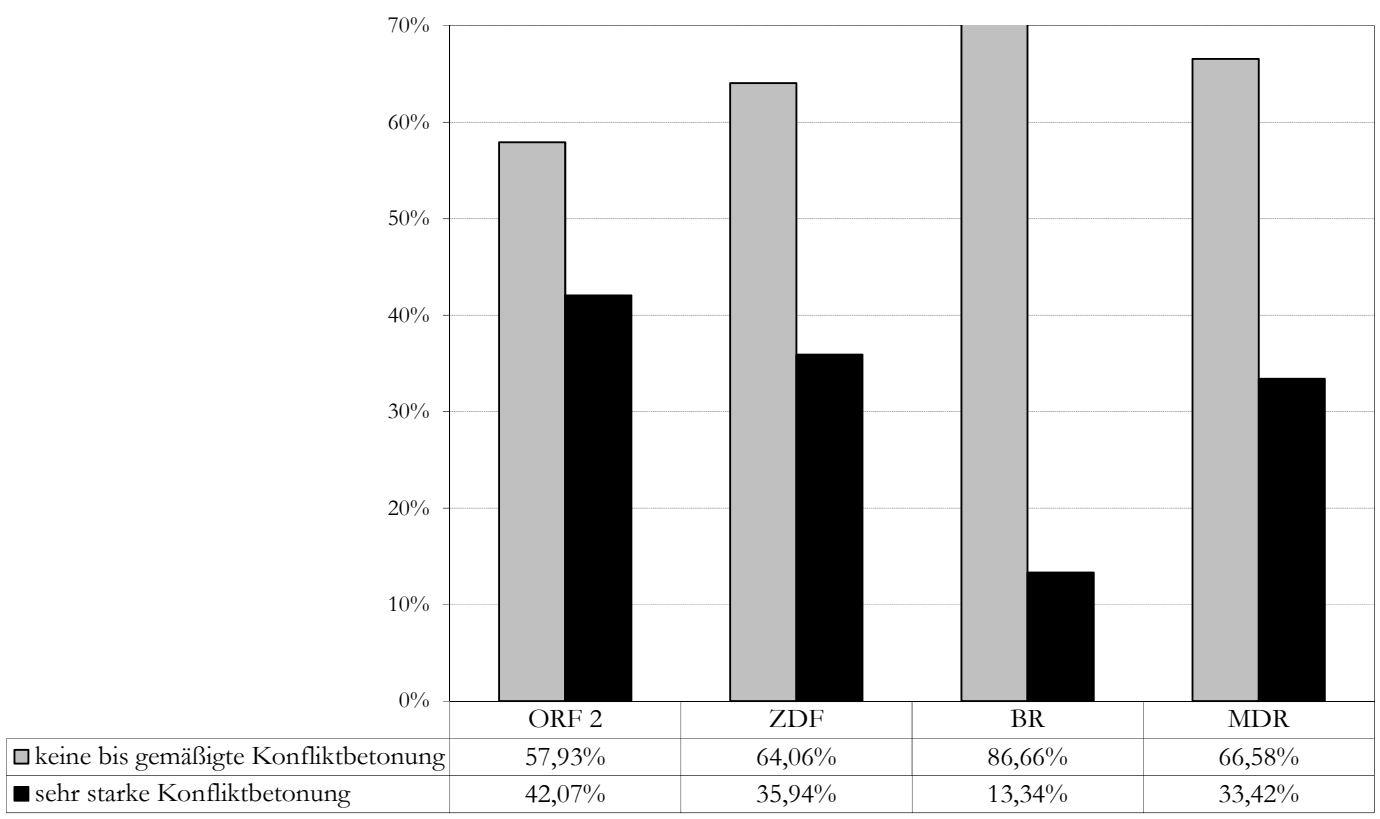


Abbildung 50: Konfliktbetonung der Berichterstattung ohne Thema Politik. Anteile der unterschiedlich kontroversen Magazinbeiträge am Gesamtumfang aller nicht politischen Magazinbeiträge

Basis: Umfang aller Magazinbeiträge ohne solche mit Thema Politik in hh:mm:ss - ORF 2: 18:11:09, ZDF: 25:44:55, BR: 20:56:42, MDR: 30:16:03

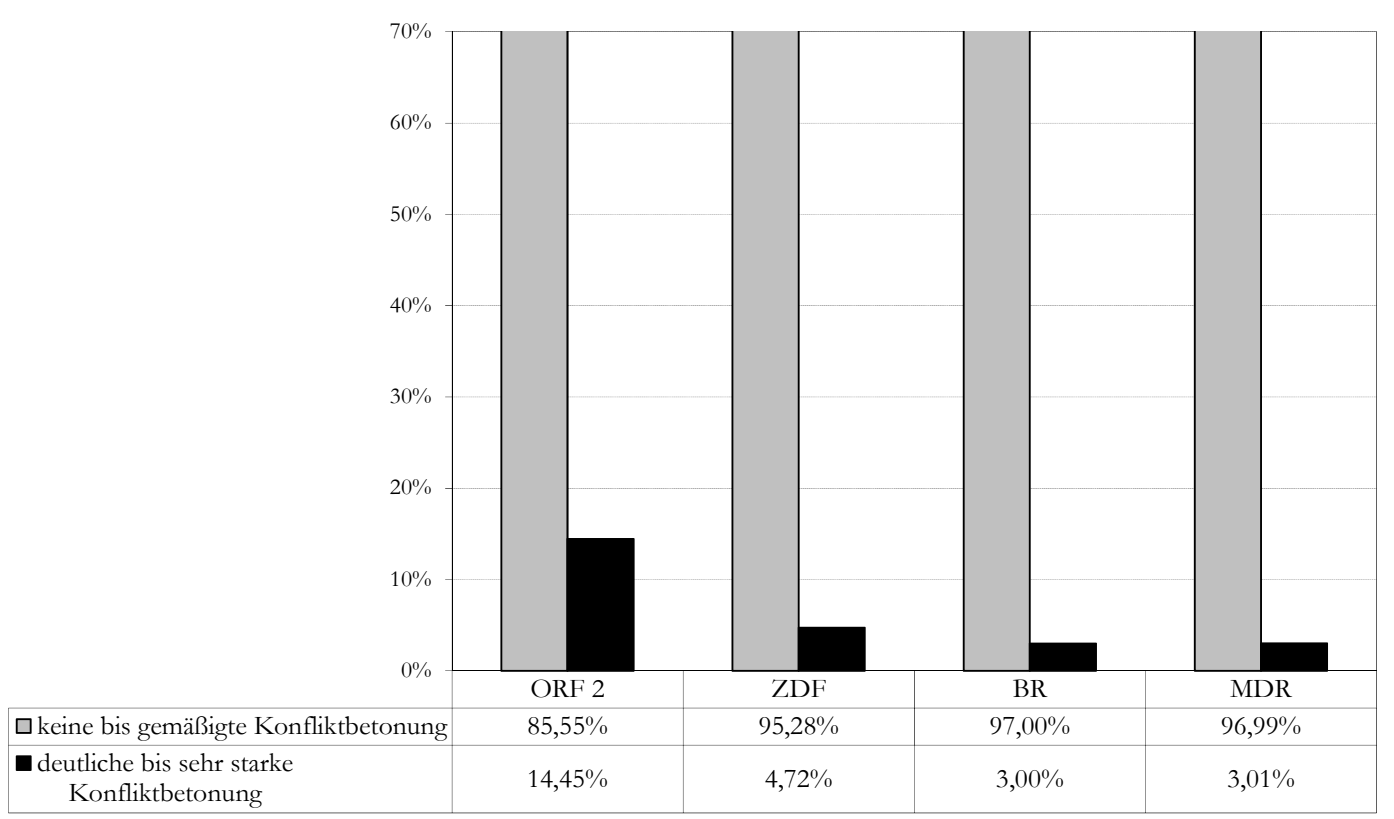

Das Thema „Politik“ wird in den untersuchten Programmen unterschiedlich kontrovers behandelt (vgl. Abbildung 49). Die deutlichste Betonung bestehender politischer Meinungsverschiedenheiten findet sich im ORF 2. Den zweithöchsten Wert weist hier das ZDF auf. Zwar ist auch im MDR der Anteil konfliktbetonender politischer Berichterstattung mit 33 Prozent relativ hoch, kann aber auf Grund des insgesamt marginalen Umfangs, den das Thema im MDR-Programm einnimmt, nicht als aussagekräftig angesehen werden. Auffällig ist dagegen der sehr geringe Anteil kontroverser Politikberichterstattung im BR. Das spricht dafür, dass in Regionalprogrammen Politik grundsätzlich als weniger konfliktbeladen erscheint. Auf Grund des zu geringen Umfangs des Themas im MDR lässt sich das hier aber nicht eindeutig belegen. ${ }^{278}$

Themen, die nicht politischer Natur sind, werden in allen untersuchten Sendern deutlich weniger häufig als kontrovers dargestellt (vgl. Abbildung 50). Der Widerstreit verschiedener Meinungen spielt hier lediglich im ORF 2 eine nennenswerte Rolle. Das spricht dafür, dass hier auch gesellschaftlich relevante Themen außerhalb der Politik in ihrer ganzen Bandbreite dargestellt werden. Dass dies in den anderen Sendern nicht der Fall ist, kann aber letztlich auch am jeweils spezifischen Themenprofil der Sender liegen (vgl. Abschnitt 8.2.4, S 226ff.).

\footnotetext{
${ }^{278}$ Die Unterschiede in der Politikdarstellung werden unten (S. 229) noch einmal aufgegriffen, daher wird an dieser Stelle auf eine weitergehende Einordnung verzichtet.
} 


\subsubsection{Ergebnis journalistische Qualität der Magazinbeiträge}

Hypothese H11 wird angenommen. Der Umfang der auf Ereignisse Bezug nehmenden Berichterstattung ist auch bei Regionalprogrammen höher als jener der ereignislosen Berichterstattung. Insofern wird hier der journalistischen Grundfunktion der Information über tatsächliches Geschehen durchaus nachgekommen. Dennoch ist der Anteil ereignisloser Berichterstattung sehr hoch, und zwar bei beiden untersuchten Regionalprogrammen. Dafür mag ein Grund sein, dass in theoretisch gleicher Sendedauer über ein relativ kleines Gebiet berichtet werden muss (zumal, wenn man Auslandsberichterstattung nicht als Domäne regionaler Sender sieht). Das Programm muss also ,irgendwie gefüllt werden“. Als Erklärung taugt diese Argumentation aber nicht, wenn man bedenkt, dass Österreich nur unwesentlich größer als Bayern ist und weniger Einwohnerinnen und Einwohner hat. Noch prekärer erscheinen die ereignislosen Berichte, wenn man die Unterschiede in der Gebietsabdeckung in Betracht zieht (siehe Abschnitt 8.2.1). Trotz höherer Berücksichtigung des eigenen Sendegebiets ist der Ereignisbezug im MDR-Programm ebenso niedrig wie im BR, dessen Berichterstattung das Bundesland Bayern nicht im selben Maße „abbildet“. Gleichzeitig ist der Ereignisbezug der Berichterstattung in ORF 2 und $Z D F$ trotz niedrigerer „Abdeckungsraten“ deutlich höher.

Hypothese H12 wird abgelehnt. Die relativen Entropiewerte für die Themenverteilung liegen in beiden Regionalprogrammen unter denen der nationalen Programme oder sind bei Betrachtung aggregierter Themenkategorien höchstens gleich hoch. Dass das Themenspektrum im Regionalprogramm höher wäre, ist daher nicht bestätigt. Vor allem aber sind die Unterschiede zwischen regionalen und nationalen Programmen zu gering, um einen systematischen Unterschied anzunehmen.

Hypothese H13 wird abgelehnt. Eine Dichotomie zwischen den untersuchten regionalen und nationalen Programmen hinsichtlich der Vielfalt von Darstellungsformen besteht nicht. Geringere Vielfalt ist also kein Merkmal des Regionalfernsehens, ebenso wie sich nationale Programme nicht per se durch mehr Vielfalt in der Darbietung ihrer Inhalte auszeichnen.

Hypothese H14 wird angenommen. Regionale Zentren werden in der Berichterstattung der Regionalprogramme umfangreich berücksichtigt. Gleichwohl bedeutet die Konzentration auf Zentren im Umkehrschluss keine Nichtberücksichtigung ländlicher Regionen. Da in regionalen Zentren mehr Menschen wohnen als auf dem Lande, hat das auch eine nachvollziehbare Berechtigung, solange die Konzentration nicht überhandnimmt. Festzuhalten bleibt daher auch, dass sich eine Berichterstattung in die regionale Breite (siehe Hypothese H6b, bzw. Abschnitt 8.2.1.2) und eine Hervorhebung zentraler Orte nicht ausschließen.

Hypothese H15 wird abgelehnt. Weder anhand der Anteile der meinungsbetonten Formen an der Berichterstattung noch an deren absolutem Umfang lässt sich ein systematischer Unterschied zwischen den nationalen und regionalen Programmen ausmachen.

Hypothese H16a wird angenommen. Beide nationalen Programme liegen sowohl anteilsmäßig als auch in absoluten Zahlen deutlich vor den regionalen Programmen, wenn es um die Häufigkeit der Konfliktbetonung geht. Betrachtet man die absoluten Zahlen, wird aber auch deut- 
lich, dass im ORF 2 außerhalb der Nachrichtenmagazine mehr als doppelt so häufig auf widerstreitende Interessen hingewiesen wird wie im $Z D F$ - trotz insgesamt geringerer Magazingesamtsendezeit. $^{279}$

Hypothese H16b wird angenommen. In den untersuchten Regionalprogrammen haben konfliktbetonende Beiträge einen jeweils ähnlich geringen Anteil an der Berichterstattung.

\subsubsection{Der Nachbarstaat in der Berichterstattung}

\subsubsection{Internationale Raumbezüge in ORF 2 und ZDF}

Im Rahmen der Frage F8 interessiert das Verhältnis zwischen Deutschland und Österreich bzw. wie es im Umfang der Berichterstattung zum Ausdruck kommt. Hintergrund ist hier vor allem der Aspekt des Next-Door-Giant-Effekts (vgl. S. 128). Dieser legt nahe, dass Deutschland in der österreichischen Berichterstattung eine herausragende Rolle spielt, umgekehrt aber Österreich nicht in der deutschen. Daneben ist auch das Verhältnis von Inlands- zu Auslandsberichterstattung überhaupt von Interesse.

In den Magazinen des $O R F 2$ ebenso wie im $Z D F$ macht die Inlandsberichterstattung über 70 Prozent der Berichterstattung aus, wobei der Anteil im ZDF etwas höher als im ORF 2 ausfällt (vgl. Abbildung 51 und Abbildung 53). Gemessen am Gesamtumfang der redaktionellen Magazinbestandteile wird Deutschland im ORF 2 mit knapp zwei Prozent berücksichtigt. Das ist relativ viel, wenn man bedenkt, dass auf den gesamten Rest Europas weniger als drei Prozent der Berichterstattung entfallen. Die herausragende Rolle Deutschlands in der österreichischen Auslandsberichterstattung zeigt sich auch daran, dass aus keinem anderen Nachbarstaat des Alpenlands vergleichbar umfangreich berichtet wird (vgl. Abbildung 52). Allerdings ist der Deutschlandanteil der Berichterstattung nicht von so überragendem Umfang wie Ergebnisse anderer Studien es zuvor haben vermuten lassen (etwa Hagen 1998: 147 280). Die Zahlen zu den anderen Ländern sind insgesamt relativ niedrig. Dass Nachbarn stärker als andere Staaten berücksichtigt würden, lässt sich für den ORF 2 jedenfalls nicht bestätigen. Das trifft auch nicht auf historisch eng mit Österreich verbundene Nationen wie Ungarn zu. Von hier wird zwar in knapp zwei Prozent der Auslandsberichterstattung berichtet, auf Grund des absolut jedoch geringen Umfangs ist das kein ausreichender Indikator für eine besondere Herausge-

\footnotetext{
${ }^{279}$ Dauer konfliktbetonender Beiträge aller Magazine: ORF 2: 5:30:42, ZDF: 4:02:31; OHNE Nachrichtenmagazine: $O R F$ 2: 5:16:02, ZDF: 2:32:33.

280 In der bei Hagen referierten „Foreign-News-Studie“ wird u. a. die Anzahl der Beiträge mit Bezug zu Deutschland in der führenden Nachrichtensendung dargelegt. Im Falle Österreichs wurde dafür die „Zeit im Bild 1“ des ORF ausgewertet. Dort bezogen sich 16,1 Prozent der Beiträge auf Deutschland. Reine Nachrichtensendungen wurden in der hier vorliegenden Studie nicht ausgewertet, allerdings lassen sich die Daten für das Nachrichtenmagazin „ZiB 2“ zum Vergleich heranziehen. Auch hier zeigen die ermittelten Werte keine Ähnlichkeit zu den Ergebnissen der „Foreign-News-Studie“. Weder auf Ebene der Anzahl von Beiträgen (Anteil 3,8 Prozent) noch hinsichtlich der Sendezeit (2,5 Prozent), hat die Berichterstattung aus Deutschland einen auch nur annähernd ähnlich hohen Wert.
} 
hobenheit. Dass Europa im österreichischen Programm relativ knapp berücksichtigt wird, ist insgesamt allerdings überraschend. Es lässt sich aber nicht ausschließen, dass dies an der Nachrichtenlage des Untersuchungszeitraums liegt. Der Schwerpunkt liegt auf dem nicht europäischen Ausland.

Abbildung 51: ORF 2 - Verteilung der Ereignisorte der Berichterstattung auf In- und Ausland Basis: alle Magazinbeiträge in hh:mm:ss = 24:58:37

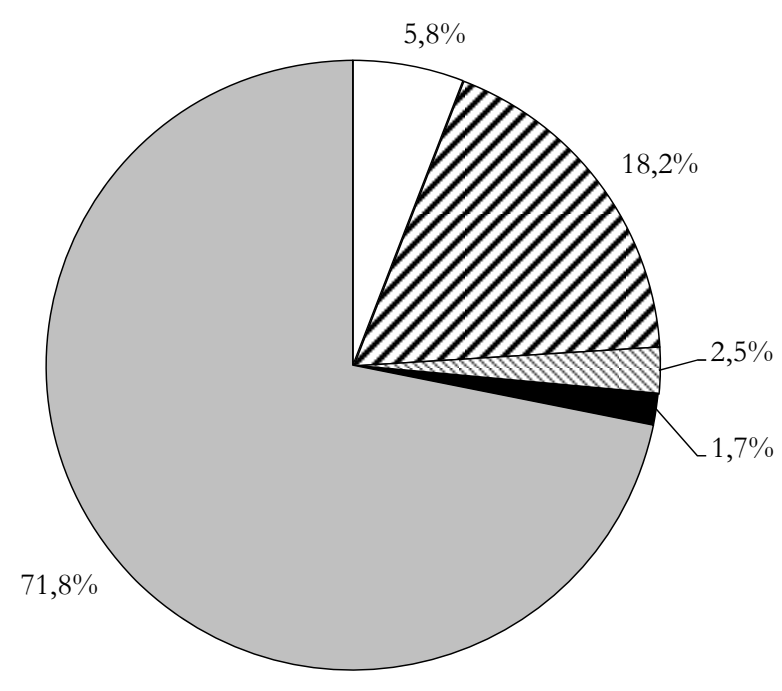

$\square$ ohne Raumbezug/

keine Zuordnung

a International außerhalb

Europas

\& Europa

- Deutschland

$\square$ Österreich 
Abbildung 52: ORF 2 - Verteilung der Ereignisorte der Auslandsberichterstattung

Basis: alle verortbaren Magazinbeiträge außerhalb Österreichs in hh:mm:ss $=$ 05:34:17

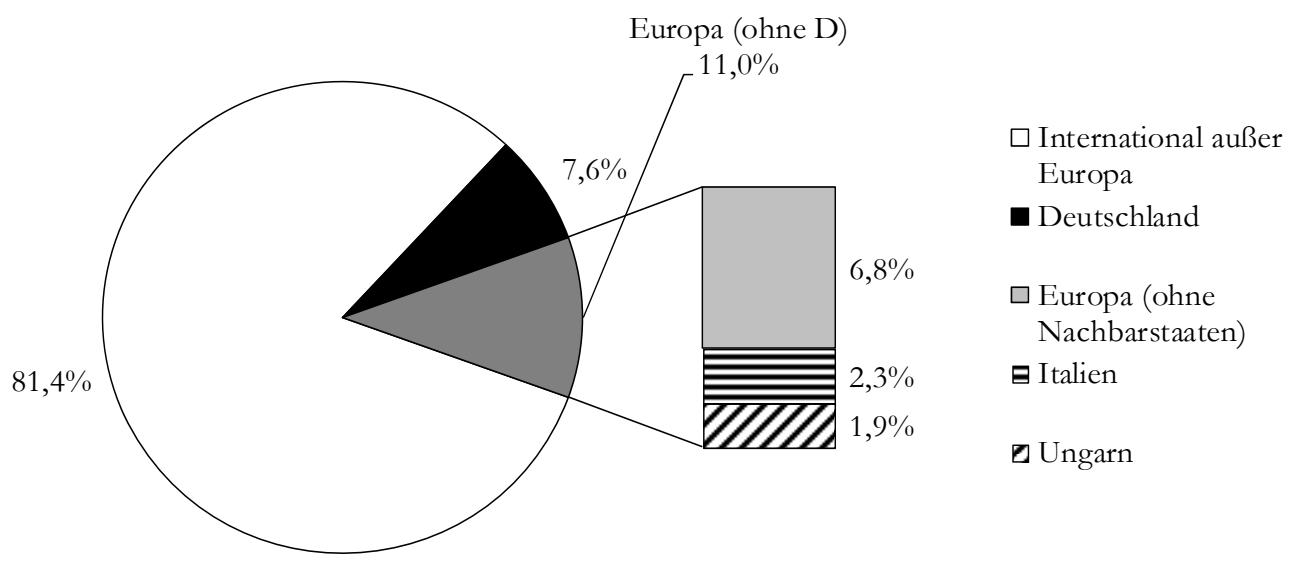

Im ZDF spielt - wie erwartet - Österreich keine vergleichbar große Rolle wie umgekehrt Deutschland im ORF 2. Weniger als ein Prozent der Berichterstattung bezieht sich auf den südlichen Nachbarn. Allerdings ist die Auslandsberichterstattung hier insgesamt weniger umfangreich (vgl. Abbildung 53). Schwerpunkt ist das nicht europäische Ausland. Im ZDF ist jedoch der Gesamtanteil der Berichterstattung über den eigenen Kontinent hinaus weniger umfangreich als im österreichischen Programm. Dementsprechend entfällt über ein Drittel auf Europa und hierbei werden auch mehr Nachbarländer berücksichtigt (vgl. Abbildung 54). Die Verteilung auf unmittelbar angrenzende Staaten und andere europäische Nationen ist dabei ungefähr hälftig aufgeteilt. Insofern lässt sich keine generelle Bevorzugung dieser näher gelegenen Länder belegen. 
Abbildung 53: ZDF - Verteilung der Ereignisorte der Berichterstattung auf In- und Ausland Basis: alle Magazinbeiträge in hh:mm:ss $=33: 36: 49$

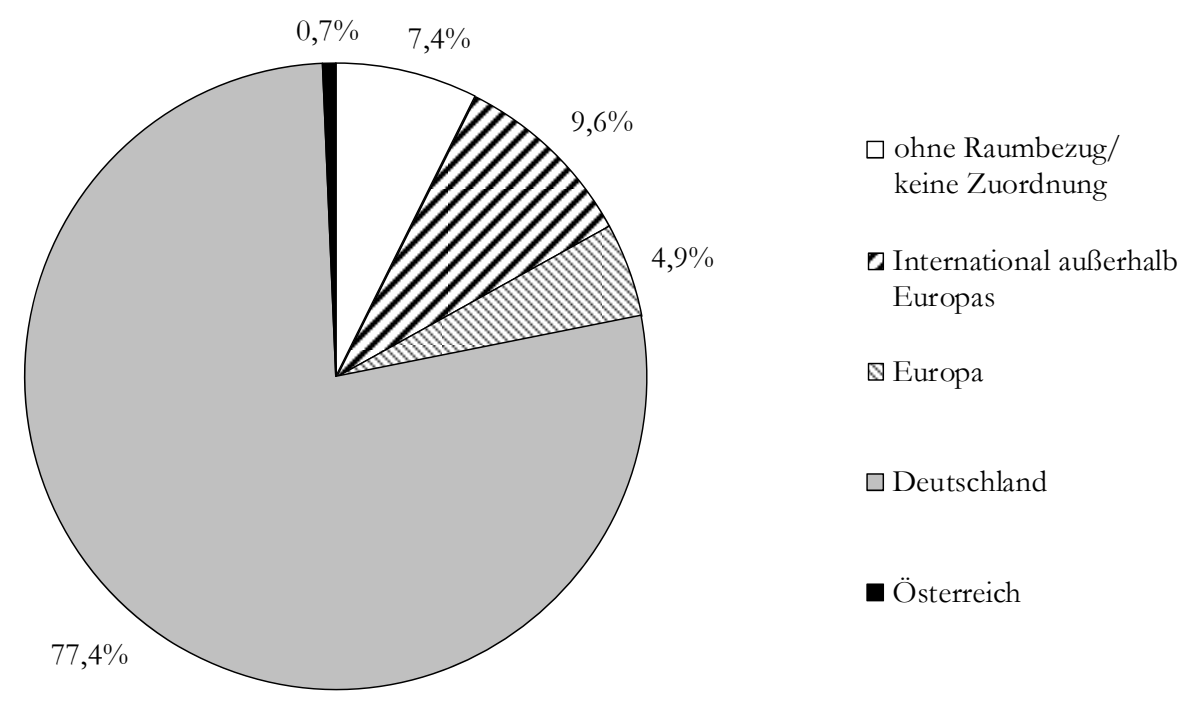

Zusammengenommen bestätigen sich die Annahmen über den Umfang der Auslandsberichterstattung nur zum Teil. Das Verhältnis von In- und Auslandsberichterstattung in den beiden Nationalprogrammen ist recht ähnlich. Im österreichischen Programm ist der Anteil von Informationen aus dem Ausland etwas höher als im ZDF. Hierfür mag die unterschiedliche Größe der beiden Staaten ein Grund sein. Allerdings ist die Differenz nicht so groß, als dass sich darin grundlegende Charakteristika ablesen ließen, wie etwa eine allgemein internationalere Ausrichtung des österreichischen Journalismus. 
Abbildung 54: ZDF - Verteilung der Ereignisorte der Auslandsberichterstattung

Basis: alle verortbaren Magazinbeiträge außerhalb Deutschlands in hh:mm:ss = 05:06:16, ohne Beschriftung: Luxemburg und Polen jeweils 0,1\%

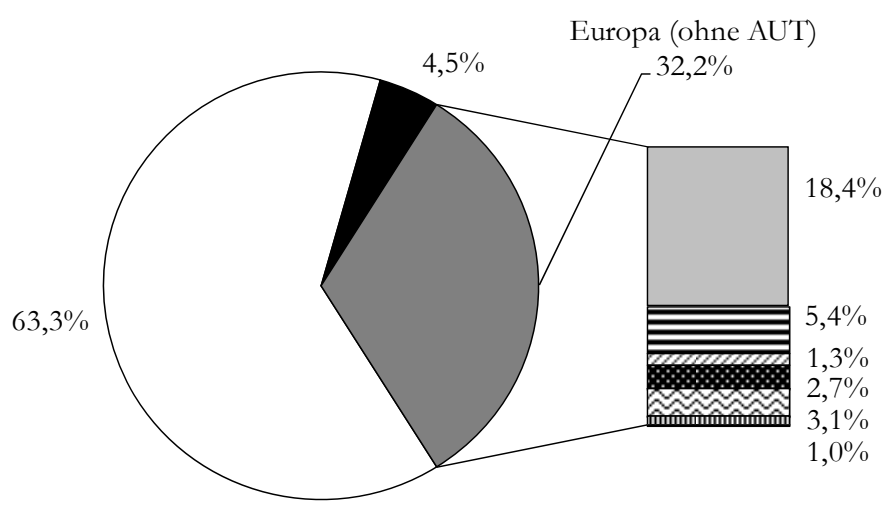

$\square$ International außer

Europa

- Österreich

$\square$ Europa (ohne

Nachbarstaaten)

EBelgien

๒ Dänemark

Frankreich

$\mathbb{0}$ Luxemburg

曰 Niederlande

$\square$ Polen

III Schweiz

\subsubsection{Internationale Raumbezüge in BR und MDR}

Im $B R$ und $M D R$ hat die Auslandsberichterstattung insgesamt einen deutlich geringeren Umfang als im $Z D F$ und ORF 2. Gerade einmal sechs Prozent in den Magazinen des bayerischen und nur neun Prozent des mitteldeutschen Programms haben ausländische Themen zum Gegenstand (vgl. Abbildung 55 und Abbildung 57). In absoluten Zahlen sind das 1 Stunde 36 Minuten im BR und 2 Stunden 56 Minuten im MDR (im Vergleich zu fünfeinhalb bzw. fünf Stunden im ORF 2 und $Z D F)$. Entsprechend sind die Verteilungen auf die verschiedenen Länder nur sehr eingeschränkt aussagekräftig. Der Vollständigkeit halber seien sie aber ebenfalls erwähnt.

Im $B R$ wird überwiegend aus dem europäischen Ausland berichtet, wobei Österreich einen Spitzenplatz einnimmt. Aus Österreich wird im nahezu gleichen Umfang berichtet wie aus dem restlichen Europa. Ansonsten haben lediglich die Niederlande noch einen erwähnenswerten Stellenwert bei der Berichterstattung aus den Nachbarländern Deutschlands. ${ }^{281}$

Im MDR kommt Österreich nicht in erwähnenswertem Umfang vor, wie auch sonst keine Schwerpunktbildung hinsichtlich der Nachbarländer Deutschlands erkennbar ist. Es dominiert

281 Wobei die Niederlande nicht an Bayern angrenzen, hier also keine Auswirkung von geographischer Nähe zugrunde liegen dürfte. Zudem ist der absolute Umfang zu gering, um die Zahlen valide zu interpretieren. 
vielmehr die Berichterstattung aus dem nicht europäischen Ausland sowie aus nicht angrenzenden Staaten innerhalb Europas.

Abbildung 55: BR - Verteilung der Ereignisorte der Berichterstattung auf In- und Ausland Basis: alle Magazinbeiträge in hh:mm:ss $=25: 54: 25$

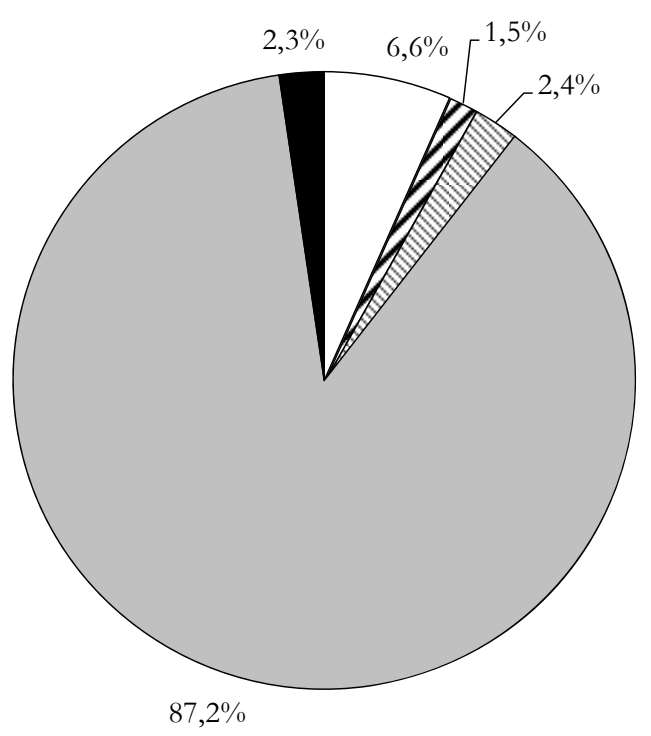

$\square$ ohne Raumbezug/ keine Zuordnung

\ International außerhalb Europas

E Europa

$\square$ Deutschland

- Österreich 
Abbildung 56: BR - Verteilung der Ereignisorte der Auslandsberichterstattung

Basis: alle verortbaren Magazinbeiträge außerhalb Deutschlands in hh:mm:ss = 01:36:24; ohne Beschriftung: Frankreich und Luxemburg jeweils 0,3\%

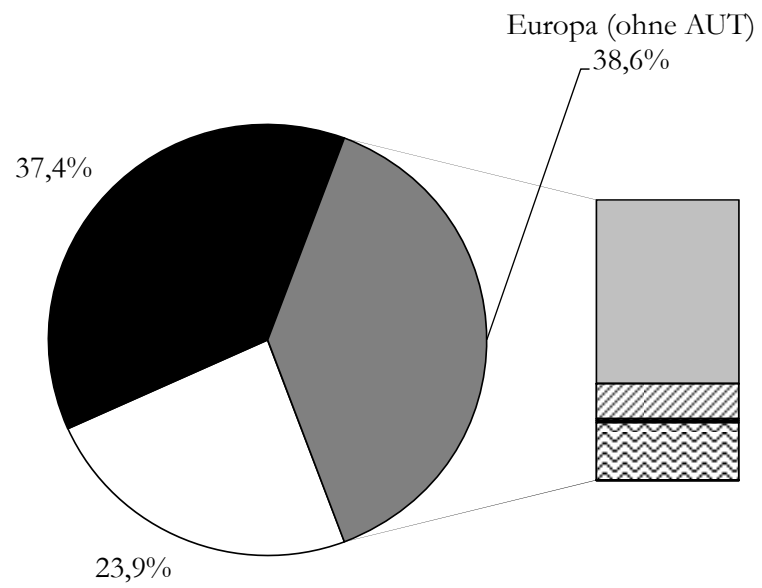

$\square$ International außer

Europa

- Österreich

$\square$ Europa (ohne

Nachbarstaaten)

$25,3 \%$

๒ Dänemark

$4,8 \%$

Frankreich

$7,9 \%$

mLuxemburg

$\square$ Niederlande

Abbildung 57: MDR - Verteilung der Ereignisorte der Berichterstattung auf In- und Ausland Basis: alle Magazinbeiträge in hh:mm:ss = 32:01:19

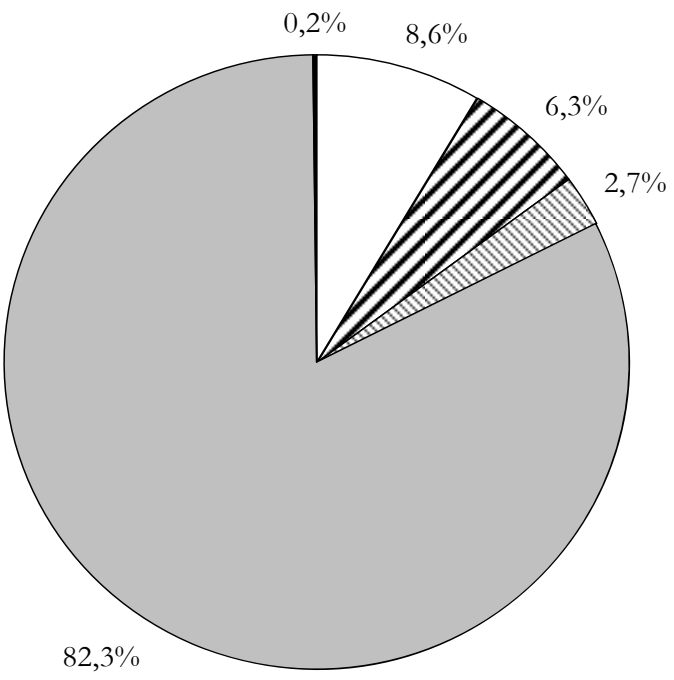

$\square$ ohne Raumbezug/

keine Zuordnung

ZInternational außerhalb

Europas

$₫$ Europa

$\square$ Deutschland

- Österreich 
Abbildung 58: MDR - Verteilung der Ereignisorte der Auslandsberichterstattung

Basis: alle verortbaren Magazinbeiträge außerhalb Deutschlands in hh:mm:ss = 02:56:21

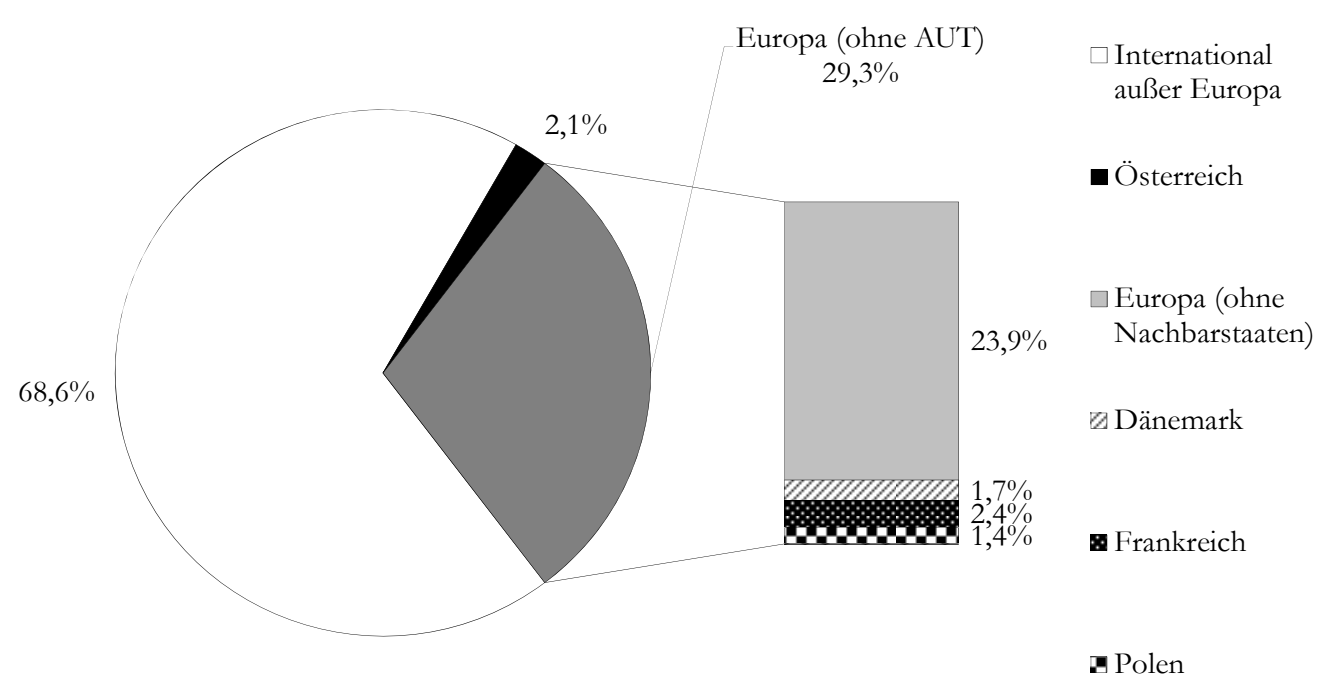

Im Bereich der Auslandsberichterstattung unterscheiden sich nationales und regionales Programm tatsächlich relativ deutlich. Dieser Unterschied ist hauptsächlich bezüglich des Anteils von Informationen aus dem Ausland erkennbar. Insofern kann hier den regionalen Programmen eine Komplementärfunktion zugeschrieben werden. Das erscheint auch unter Berücksichtigung ihres Status im deutschen Fernsehsystem als nachvollziehbar und auch gerechtfertigt.

\subsubsection{Themen der Berichterstattung aus dem Nachbarland}

Neben dem Umgang der Berichterstattung über den Nachbarn sind auch die Themen, die hier berücksichtigt werden, von besonderer Bedeutung. Hieraus ergibt sich schließlich in besonderem Maße das Bild, das von Deutschland gezeichnet wird bzw. von Österreich. Es sei aber noch mal daran erinnert, dass dieses Bild nicht nur gezeichnet wird, sondern durch prädisponierende Einstellungen auf Kommunikatorseite genauso gut schon bestehen kann. 
Abbildung 59: ORF 2 - Themengebiete der Berichterstattung aus Deutschland nach Sendezeitanteilen

Basis: Magazinbeiträge mit Ereignisort in Deutschland in hh:mm:ss $=$ 00:25:19

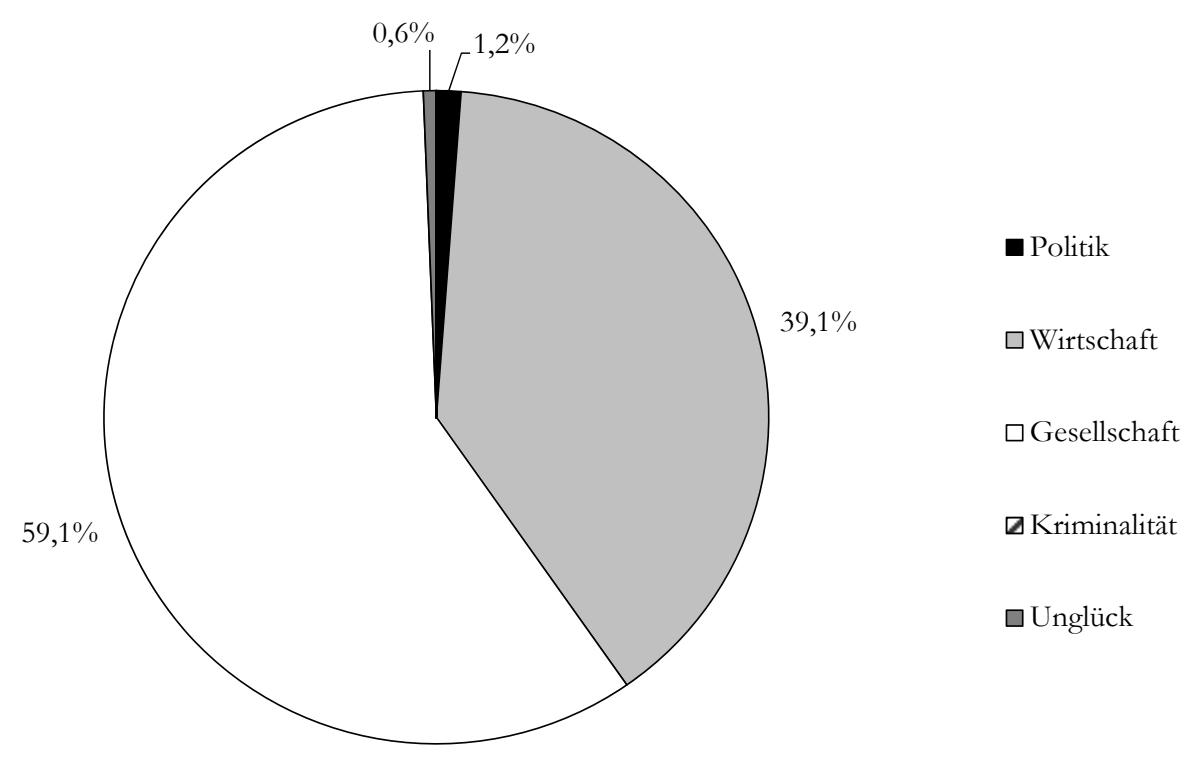

Abbildung 60: ZDF - Themengebiete der Berichterstattung aus Österreich nach Sendezeitanteilen

Basis: Magazinbeiträge mit Ereignisort in Österreich in hh:mm:ss $=$ 00:13:51

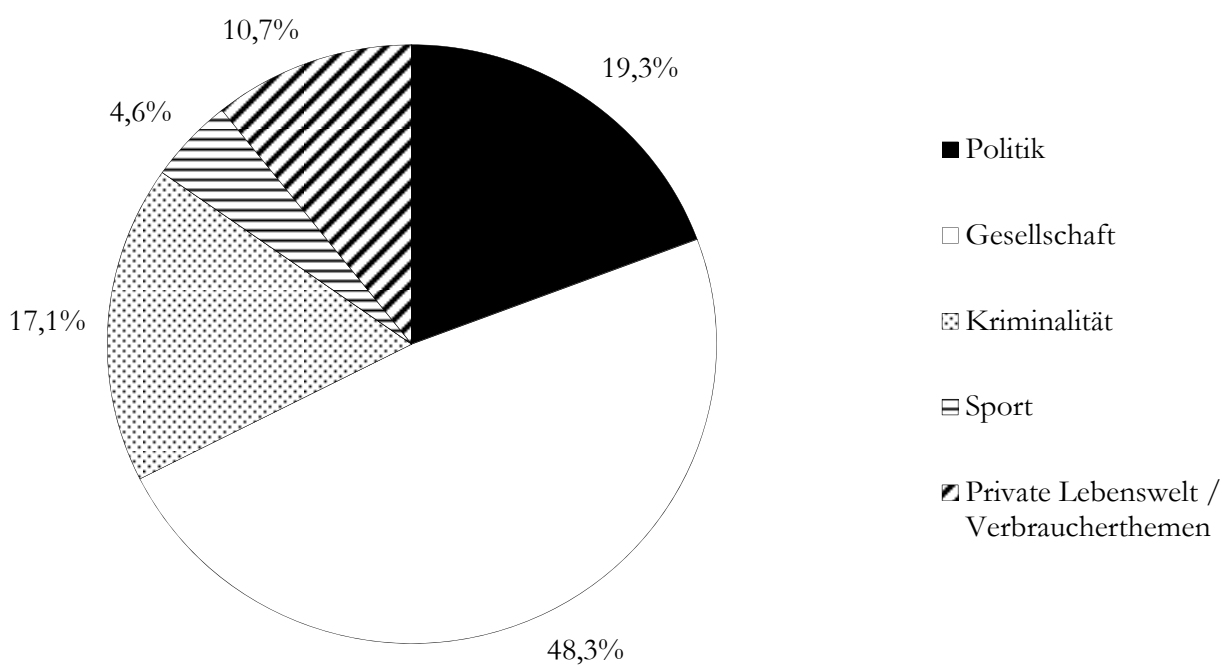


Das Themenspektrum der Deutschlandberichterstattung im österreichischen Fernsehen ist wenig ausdifferenziert. Es gibt zwei dominierende Themenbereiche (Wirtschaft und Gesellschaft, vgl. Abbildung 59). Darüber hinaus wird in marginalem Umfang über Politik sowie aus dem Human Touch Bereich (hier: Unglück) berichtet. Das legt allerdings die Vermutung nahe, dass dieses Spektrum stark von der Nachrichtenlage abhängt und weniger ein dauerhaftes Beachten bestimmter Themengebiete aus Deutschland stattfindet. Zudem ist der absolute Umfang relativ gering (25 Minuten), so dass sich die Aufteilung bei einer größeren (längeren) Stichprobe durchaus verändern könnte.

Etwas ausdifferenzierter (bei absolut deutlich geringerem Umfang: 14 Minuten) erscheint das Themenspektrum in der Österreichberichterstattung des ZDF (vgl. Abbildung 60). Auch hier wird hauptsächlich über gesellschaftliche Themen berichtet, daneben spielen aber auch Politik, Kriminalität sowie Themen der privaten Lebenswelt eine Rolle. Sport kommt im geringen Umfang ebenfalls vor.

Dass diese Zahlen allerdings vorsichtig zu handhaben sind, zeigt das Themenspektrum der Österreichberichterstattung im BR, wo - trotz deutlich größerem absoluten Umfang (36 Minuten) - eine deutlich schmalere Bandbreite von Themen geboten wird. Hier bilden Sport und Historisches (die beide sonst eher randständig vorkommen) neben gesellschaftlichen Themen die Schwerpunkte. Im MDR kommt Österreich mit einem absoluten Umfang von dreieinhalb Minuten in nur marginalem Umfang vor. ${ }^{282}$

${ }^{282}$ Dabei handelt es sich um einen Bericht aus dem Bereich Kriminalität. 
Abbildung 61: BR - Themengebiete der Berichterstattung aus Österreich nach Sendezeitanteilen

Basis: Magazinbeiträge mit Ereignisort in Österreich in hh:mm:ss $=$ 00:36:06

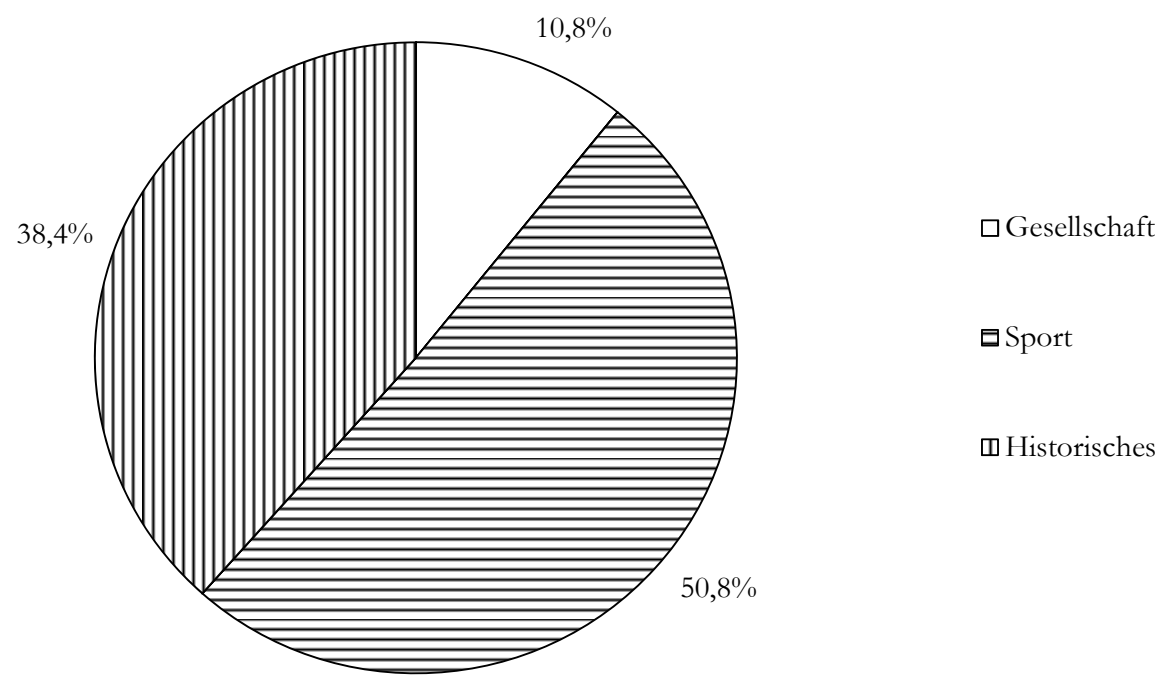

\subsubsection{Ergebnis Nachbarstaaten}

Die Vermutung, dass in Österreich besonders viel aus und über Deutschland berichtet würde, bestätigt sich anhand der Magazinsendungen, wenn auch nicht in einem solchen Umfang, dass man den Next-Door-Giant-Effekt darin zweifelsfrei als bestätigt ansehen könnte. Der Anteil der Deutschlandberichterstattung ist umfangreicher als über jedes andere einzelne europäische Ausland. Umgekehrt findet Österreich im ZDF nur wenig Beachtung. Allerdings ist Österreich relativ prominent in der Berichterstattung des Bayerischen Rundfunks vertreten, zumal es in größerem Umfang als Deutschland im Programm des ORF 2 vorkommt. Insofern ist davon auszugehen, dass auf Grund der Stichprobengröße die Aussagekraft der Daten zu dem Wechselverhältnis beider Staaten bzw. dessen Ausdrucks im Fernsehprogramm zu gering ist.

\subsubsection{Themen der Berichterstattung}

Bei der Auswertung vorkommender Themengebiete soll wiederum das Spektrum einmal unter Berücksichtigung aller Magazine und einmal ohne die Nachrichtenmagazine stattfinden. Der Grund ist - wie oben bereits erwähnt - dass es im MDR diese Sendeform nicht gibt.

In ORF 2 und ZDF stellen Beiträge aus den Themenbereichen Gesellschaft und Politik die größten Anteile (vgl. Abbildung 62). Dabei speist sich der hohe Anteil im ZDF vor allem aus 
dem täglichen Nachrichtenmagazin „heute journal“. Lässt man dieses bei der Auswertung weg, machen politische Themen nur noch den drittgrößten Anteil hinter Gesellschaft und Themen der privaten Lebenswelt/Verbraucherthemen aus. Im ORF 2 macht der Themenbereich Kunst und Kultur sowohl mit als auch ohne Berücksichtigung der Nachrichtenmagazine rund zehn Prozent aus (vgl. Abbildung 63). Das ist gegenüber allen anderen untersuchten Sendern der höchste Wert. Im ZDF sind dagegen die Human Touch Bereiche Kriminalität und Unglück umfangreicher als im ORF 2. Dasselbe gilt für Wirtschaftsthemen und den Sport. Insgesamt unterscheiden sich die behandelten Themen in beiden nationalen Sendern nicht besonders deutlich, lassen aber doch unterschiedliche Schwerpunktsetzungen erkennen.

Abbildung 62: Anteil der Themengebiete an untersuchter Sendezeit in Magazinen

Basis: alle Magazinbeiträge in hh:mm:ss - ORF 2: 25:02:33, ZDF: 33:36:49, BR: 25:54:25, MDR: 32:31:20

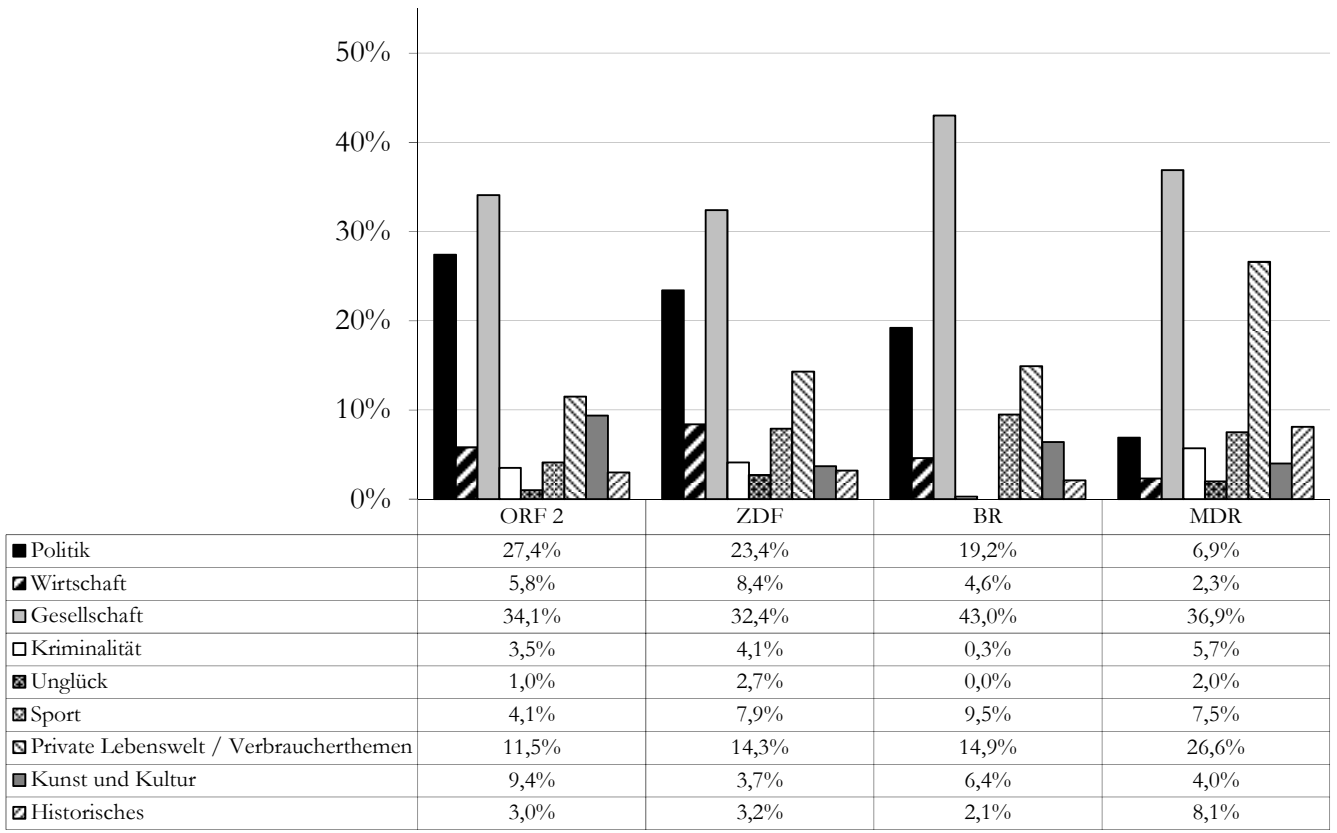


Abbildung 63: Anteil der Themengebiete an untersuchter Sendezeit in Magazinen OHNE Nachrichtenmagazine

Basis: Magazinbeiträge außerhalb von Nachrichtenmagazinen in hh:mm:ss - ORF 2: 21:47:55, ZDF: 23:35:57, BR: 24:26:44, MDR: 32:31:20

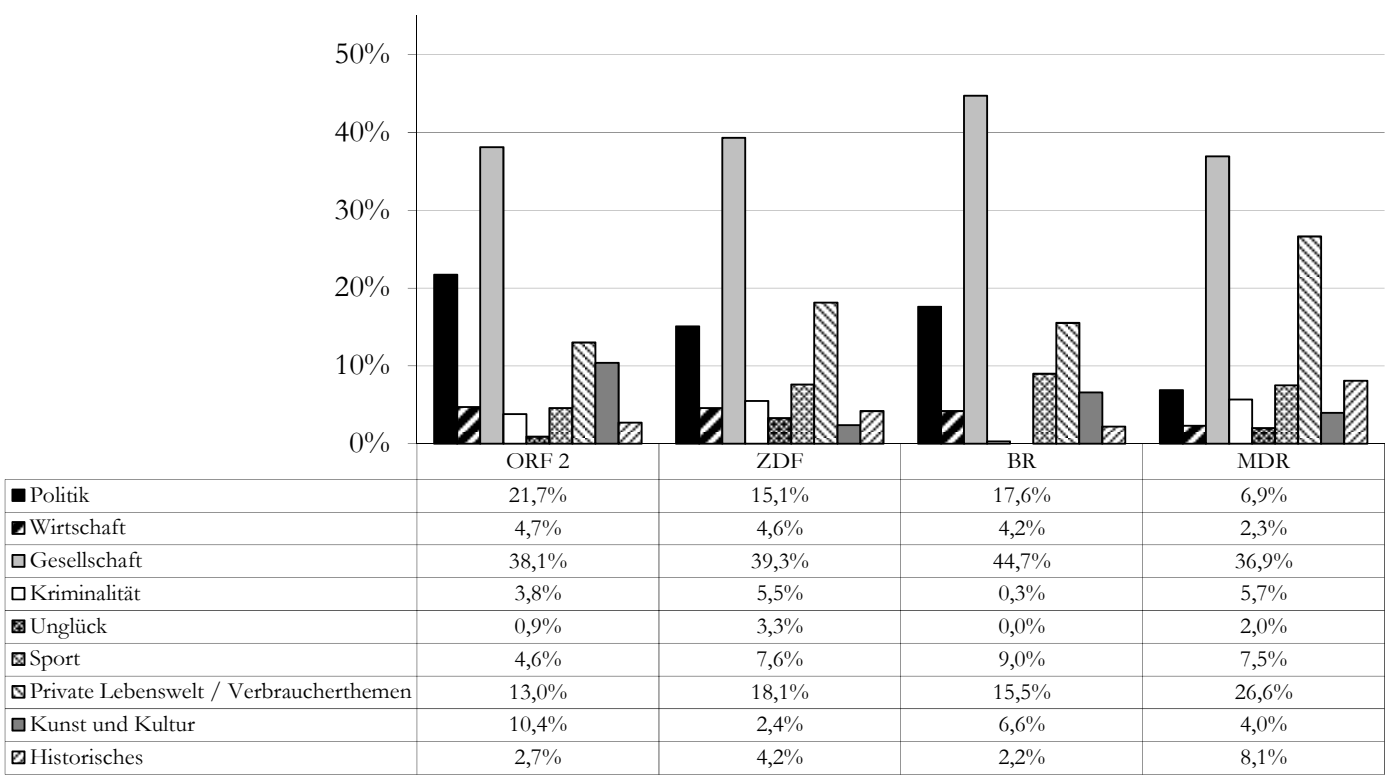

Im MDR spielt Politik nur eine untergeordnete Rolle. Das zeigt sich etwa daran, dass sie nur sieben Prozent der Berichterstattung ausmacht. Es wird aber vor allem im Vergleich mit den anderen untersuchten Sendern deutlich. Selbst ohne Berücksichtigung der Nachrichtenmagazine (also zu Gunsten des MDR) ist der Anteil politischer Themen bei keinem anderen untersuchten Programm so niedrig. ${ }^{283}$ Dagegen wird im MDR viel häufiger über Verbraucherthemen und solche der privaten Lebenswelt berichtet. Auf niedrigerem Niveau trifft das auch auf historische Themen zu.

Politikberichterstattung gehört zu den klassischen Kernressorts des Journalismus überhaupt (vgl. Wolff/Palm 2006: 217). Deshalb stellen sich wegen der unterschiedlich hohen Politikanteile in den untersuchten Sendern, Fragen an deren Journalismusverständnis - nicht zuletzt vor dem Hintergrund der von Teichert festgestellten Defizite des Regional- und Lokaljournalismus (vgl. S. 129).

Wie sich aus den Ergebnissen zur formalen Zusammensetzung der einzlenen Programme ergibt, können die hier untersuchten Dritten (wegen der hohen Anteile von Wiederholungen sowie älterer fiktionaler Sendungen) nur als Komplementärprogramme zum nationalen Programm angesehen werden (vgl. S. 153). Das könnte die von Teichert gemachten Vorhaltungen

283 Das trifft auch auf die absoluten Zahlen zu: MDR: 2 Stunden 15 Minuten, BR: 4 Stunden 17 Minuten, ZDF: 3 Stunden 34 Minuten, ORF 2: 4 Stunden 38 Minuten Politikberichterstattung in Magazinbeiträgen. 
relativieren, dass die journalistische Leistung der Regionalprogramme defizitär wäre. Normative Anforderungen, die an regionales Fernsehen gestellt werden, wären per se geringer, wenn sie keine Vollprogramme darstellten (vgl. hierzu S. 153, Fn. 247). Jedoch können geringere Ansprüche sich keineswegs auf Kriterien journalistischer Sorgfaltspflicht und ähnliches beziehen. Hinsichtlich solcher Aspekte wie Themenbandbreite und Vielfalt der Darstellungsformen würde jedoch ein Qualitätsmaßstab, der an Standards nationaler Programme orientiert ist, die besonderen Rahmenbedingungen regionaler Berichterstattung missachten.

Das ändert indes nichts an einigen Befunden zur inhaltlich-journalistischen Qualität, die immerhin als problematisch zu bewerten sind. Das betrifft zum einen den marginalen Umfang von Politikberichterstattung im MDR. Dieser ist so gering, dass er noch nicht einmal damit erklärt werden kann, die Berichterstattung habe nur eine Komplementärfunktion. In der gesamten untersuchten Woche machen innerhalb der Magazinsendungen politische Themen aus dem Sendegebiet gerade einmal 20 Minuten Sendezeit aus. Selbst wenn man davon ausgeht, dass in den Nachrichtensendungen dieses Defizit teilweise kompensiert wird, ist das zu wenig. In Nachrichtensendungen steht die reine Fakteninformation im Vordergrund. Eine Mitwirkung an der politischen Meinungsbildung durch Hintergrundinformationen und umfassende Abbildung verschiedener Meinungen wird hier also kaum stattfinden. Zum Vergleich: Im Bayerischen Rundfunk beträgt der Umfang regionaler politischer Themen selbst unter Abzug der Nachrichtenmagazine 2 Stunden 45 Minuten.

Allerdings ist trotz des höheren Umfangs die Politikberichterstattung im BR nicht grundsätzlich davon auszugehen, dass es sich um gut gemachte politische Berichterstattung handelt. Das zeigt insbesondere der geringe Grad der Betonung politischer Konflikte. Da nicht davon auszugehen ist, dass Politik in Bayern grundsätzlich weniger umstritten und von weniger verschiedenen Interessen geleitet ist als im Rest der Republik, ist das immerhin ein Indikator für eher unkritischen Verlautbarungsjournalismus. Der Befund bedeutet allerdings nicht zwangsläufig, dass im BR nur wenige politische Richtungen und Interessen vorgestellt werden. Es ist durchaus möglich, dass diese in jeweils gesonderten Berichten, Meldungen, Nachrichtenfilmen behandelt werden. Wie sie aber jeweils miteinander in Konflikt stehen können, das wird gerade nicht gesagt und gezeigt. Diese Leistung wird also weitgehend an die Zuschauer und Zuschauerinnen delegiert.

In beiden Regionalprogrammen spielen gesellschaftliche Themen die wichtigste Rolle. Ansonsten unterscheiden sich beide zum Teil beträchtlich. Während Kriminalität und Unglück im BR faktisch keine Rolle spielen, machen sie im MDR zusammen fast acht Prozent aus.

Der BR weist von allen untersuchten Sendern den größten Sportanteil auf. Der Anteil der Wirtschaftsberichterstattung bewegt sich auf dem Niveau der beiden nationalen Sender und liegt damit höher als im MDR.

Insgesamt sind die Unterschiede im Themenspektrum der regionalen Sender deutlich größer als die Unterschiede zwischen den beiden nationalen Programmen. Insofern lässt sich auch hier keine eindeutige Dichotomie beider Typen belegen, die in der Struktur der Inhalte zum Ausdruck käme. Im Ergebnis zu Frage F10 bedeutet das also ein klares Nein. 
Neben den grob zusammengefassten Themengebieten sind auch die weniger abstrahierten Themen der Berichterstattung von Interesse. Auf Grund des stark ausdifferenzierten Katalogs in der Analyse codierter Themen wäre eine Gesamtdarstellung hier zu unübersichtlich. Daher soll lediglich eine Rangliste mit den zehn am umfangreichsten behandelten Themen pro Sender betrachtet werden.

Tabelle 6: ORF 2 - Rangliste der zehn am umfangreichsten behandelten Themen

\begin{tabular}{l|r|r} 
Thema & $\begin{array}{l}\text { Zeitlicher Umfang absolut } \\
\text { (in hh:mm:ss) }\end{array}$ & $\begin{array}{l}\text { Anteil an gesamter } \\
\text { Berichterstattung in } \\
\text { Magazinen }\end{array}$ \\
\hline Internationale Politik & $2: 31: 58$ & $10,11 \%$ \\
\hline Prominente Personen & $1: 45: 33$ & $7,02 \%$ \\
\hline Wirtschaftspolitik & $1: 08: 57$ & $4,59 \%$ \\
\hline Kirche u. Religion überkonfessionell & $1: 08: 53$ & $4,58 \%$ \\
\hline Normalpersonen in Konflikt mit & $0: 44: 36$ & $2,97 \%$ \\
\hline übergeordneten Institutionen & $0: 39: 24$ & $2,62 \%$ \\
\hline Religion: Katholische Kirche & $0: 35: 59$ & $2,39 \%$ \\
\hline Parteipolitik & $0: 34: 00$ & $2,26 \%$ \\
\hline Internationale Krisen, Bedrohungen, Terrorismus & $0: 30: 58$ & $2,06 \%$ \\
\hline Finanzen, Versicherungen (Beratung) & $0: 29: 17$ & $1,95 \%$
\end{tabular}

Tabelle 7: ZDF - Rangliste der zehn am umfangreichsten behandelten Themen

\begin{tabular}{l|r|r} 
Thema & $\begin{array}{l}\text { Zeitlicher Umfang absolut } \\
\text { (in hh:mm:ss) }\end{array}$ & $\begin{array}{l}\text { Anteil an gesamter } \\
\text { Berichterstattung in } \\
\text { Magazinen }\end{array}$ \\
\hline Prominente Personen & $3: 39: 59$ & $10,91 \%$ \\
\hline Internationale Politik & $2: 32: 59$ & $7,58 \%$ \\
\hline Fußball & $1: 51: 29$ & $5,53 \%$ \\
\hline Ernährung & $1: 04: 31$ & $3,20 \%$ \\
\hline Alltagshandeln nicht prominenter Normalpersonen & $0: 56: 51$ & $2,82 \%$ \\
\hline Wirtschaftspolitik & $0: 54: 59$ & $2,73 \%$ \\
\hline Human Touch (allgemein, unprominent) & $0: 46: 02$ & $2,28 \%$ \\
\hline Börse & $0: 38: 51$ & $1,93 \%$ \\
\hline Verkehrsunfälle & $0: 37: 35$ & $1,86 \%$ \\
\hline Naturwissenschaften & $0: 37: 21$ & $1,85 \%$
\end{tabular}


Tabelle 8: BR - Rangliste der zehn am umfangreichsten behandelten Themen

\begin{tabular}{l|r|r} 
Thema & $\begin{array}{l}\text { Zeitlicher Umfang absolut } \\
\text { (in hh:mm:ss) }\end{array}$ & $\begin{array}{l}\text { Anteil an gesamter } \\
\text { Berichterstattung in } \\
\text { Magazinen }\end{array}$ \\
\hline Brauchtum/Tradition & $1: 47: 47$ & $6,93 \%$ \\
\hline Ernährung & $1: 18: 47$ & $5,07 \%$ \\
\hline Medien/Journalismus & $1: 17: 17$ & $4,97 \%$ \\
\hline Normalpersonen in außergewöhnlichen Situationen & $1: 15: 58$ & $4,89 \%$ \\
\hline Politik: Wahlen & $1: 10: 58$ & $4,57 \%$ \\
\hline Fußball & $1: 05: 48$ & $4,23 \%$ \\
\hline Naturwissenschaften & $1: 05: 19$ & $4,20 \%$ \\
\hline Natur/Umwelt/Wetterphänomene & $1: 01: 35$ & $3,96 \%$ \\
\hline Wirtschaftspolitik & $0: 51: 27$ & $3,31 \%$ \\
\hline Parteipolitik & $0: 46: 57$ & $3,02 \%$
\end{tabular}

Tabelle 9: MDR - Rangliste der zehn am umfangreichsten behandelten Themen

\begin{tabular}{l|r|r} 
Thema & $\begin{array}{l}\text { Zeitlicher Umfang absolut } \\
\text { (in hh:mm:ss) }\end{array}$ & $\begin{array}{l}\text { Anteil an gesamter } \\
\text { Berichterstattung in } \\
\text { Magazinen }\end{array}$ \\
\hline Prominente Personen & $3: 45: 39$ & $11,56 \%$ \\
\hline Fußball & $2: 05: 02$ & $6,41 \%$ \\
\hline Normalbürger in außergewöhnlichen Situationen & $2: 02: 47$ & $6,29 \%$ \\
\hline Brauchtum/Tradition & $1: 16: 05$ & $3,90 \%$ \\
\hline Ernährung & $1: 08: 09$ & $3,49 \%$ \\
\hline Wohnen, Haushalt & $0: 58: 11$ & $2,98 \%$ \\
\hline Mode/Stil/ Etikette & $0: 58: 02$ & $2,97 \%$ \\
\hline Natur, Umwelt, Wetterphänomene & $0: 53: 01$ & $2,72 \%$ \\
\hline Alltagshandeln nicht prominenter Normalpersonen & $0: 52: 03$ & $2,67 \%$ \\
\hline Drittes Reich & $0: 50: 24$ & $2,58 \%$
\end{tabular}

In den nationalen Programmen sind internationale Politik sowie prominente Personen die beiden wichtigsten Themen der Berichterstattung (in jeweils umgekehrter Reihenfolge, vgl. Tabelle 6 und Tabelle 7). Im ZDF spielen daneben die Ernährung (etwa in Form von Hinweisen zu gesundem Essen u. ä.) sowie der Fußball eine große Rolle. Im ORF 2 findet sich Fußball nicht unter den Top Ten Themen. Stattdessen sind hier die Wirtschaftspolitik sowie religiöse (aber überkonfessionelle) Themen von herausgehobener Bedeutung. Vier der zehn häufigsten Themen im ORF 2 entstammen dem Politikfeld, im ZDF nur zwei.

In den regionalen Programmen spielt Politik eine geringere Rolle. Im BR kommt sie (wie im $Z D F)$ nur zweimal in den Top Ten Themen vor, im MDR gar nicht. Im MDR fällt auf, dass 
prominente Personen das am stärksten beachtete Thema sind, Fußball das zweitstärkste. Daneben spielen Themen der privaten Lebenswelt sowie Beratung eine wichtige Rolle (Ernährung, Wohnen und Haushalt, Mode). Das Thema Brauchtum und Tradition ist im BR das wichtigste Thema. Danach spielen (in jeweils vergleichbarem Umfang) Ernährung, Medien und außergewöhnliche Leistungen von nicht prominenten Personen bzw. besondere Ereignisse in deren Leben eine wichtige Rolle. Im Vergleich aller vier Sender enthält die Top-TenThemenliste im ORF 2 den höchsten Anteil an „hard news“, die des MDR den geringsten Anteil.

Im Fall des BR erscheint die besonders häufige Behandlung von Brauchtum und Tradition in Magazinbeiträgen wie eine Bestätigung stereotyper Vorstellungen, die man sich - wenn nicht von Bayern selbst, so doch - vom Bayerischen Rundfunk gemacht hat. Ergänzt wird dieses Bild durch das an zweiter Stelle stehende Thema Ernährung - ein Thema, das durchaus regionalidentifikatorische Implikationen enthalten kann (vgl. Thomas 2003b: 296). Nun darf ein solcher Befund selbstverständlich nicht überbewertet werden, gerade weil es in der Natur von Stereotypen liegt, dass sie durch bloßes Vorkommen entsprechender Erscheinungsformen als zutreffend erscheinen - unabhängig von Umfang oder Anzahl des Auftretens. Hier aber ist Brauchtum und Tradition das häufigste aller behandelten Themen im BR (und das auch mit einem gewissen Abstand zu den nachfolgenden Themen der Rangliste). Das spricht immerhin dafür, dass es sich nicht nur um einen Gesellschaftsaspekt handelt, der (von außen) als wichtig wahrgenommenen wird, sondern dass diese Wichtigkeit sich innerhalb des Repräsentationsraums Fernsehen manifestiert und damit gesellschaftlich real wird.

Interessant ist aber auch, dass Brauchtum und Tradition überhaupt nur im regionalen Fernsehen in nennenswertem Umfang thematisiert werden. ${ }^{284}$ Das mag daran liegen, dass es sich dabei sehr oft um regional-kulturelle Erscheinungen handelt, die auf nationaler Ebene wenig relevant sind. Das schließt nicht aus, dass anlässlich größerer Ereignisse auch regionalen Traditionen im nationalen Programm Beachtung geschenkt wird (Oktoberfest, Kölner Karneval, u. ä.). Ein wie auch immer geartetes Brauchtum und seine Pflege spielt aber im nationalen Fernsehprogramm keine herausragende Rolle, was bedeutet, dass sich nationale Identität auf dieser Ebene nicht anhand von Brauchtum und Tradition manifestiert. Hierfür mag auch ausschlaggebend sein, dass auf nationaler Ebene der „kleinste gemeinsame Nenner“ gefunden werden muss, Traditionen aber häufig stark regional konnotiert sind. Im nationalen Programm wären Berichte über norddeutsche Traditionen wie die „Kohl-und-Pinkel-Fahrt“ oder das „Boßeln“ ebenso wie süddeutsche Brauchtümer wie „Schuhplatteln“ oder „Schiibefüüer“ lediglich als Kuriosa interessant. Allerdings sind Traditionen, die auf nationaler Ebene angesiedelt sind, möglicherweise so grundlegender Natur, dass sie gar nicht mehr als Brauchtumspflege wahrgenommen werden - insbesondere, wenn sie über die eigene Nation hinausreichen, wie etwa das Weihnachts- oder Osterfest (die jedoch in verschiedenen Nationen durchaus unterschiedlich begangen werden). Auch hier erscheint die Region also manifester als die Nation.

${ }^{284}$ Im ORF 2 liegt das Thema in der Rangfolge auf Platz 12 und macht 1,83 Prozent der Magazinbeiträge aus. Im ZDF erreicht es mit 0,83 Prozent nur Platz 34. 


\subsubsection{Themenbereich Kultur}

Der Themenbereich Kultur wird von den vier untersuchten Programmen in unterschiedlichem Ausmaß behandelt (vgl. Tabelle 10). Bis zu vier Prozent der Berichterstattung innerhalb von Magazinen entfallen hierauf im $Z D F$ und $M D R$, im $B R$ mit über sechs Prozent etwas mehr. Im ORF 2 spielt die Kultur dagegen mit neun Prozent eine herausgehobene Rolle - das bestätigt auch die absolute Sendedauer zu diesem Thema.

Die Bedeutung der Ergebisse zur Kulturberichterstattung im ORF 2 sollte nicht überbewertet werden. Hier spiegelt sich nicht zwangsläufig eine besondere Bedeutung für die österreichische Identität wider. Vielmehr dürften programmstrukturelle Gründe hierfür verantwortlich sein: Der ORF 2 ist, im Gegensatz zum ersten österreichischen Programm, stärker als Informationsprogramm konzipiert. Das heißt, dass Kulturinformationen ohnehin nur hier ihren Platz finden können. Gleichzeitig ist das österreichische öffentlich-rechtliche Fernsehangebot weniger ausdifferenziert als das deutsche, wo es mittlerweile mehrere vor allem der Kultur gewidmete Spartenkanäle gibt. ${ }^{285}$

Tabelle 10: Kulturberichterstattung, Gesamtumfang, Anteil „Hochkultur“

Basis: alle Magazinbeiträge

\begin{tabular}{l|r|r|r|r} 
& \multicolumn{1}{|c|}{ ORF 2 } & \multicolumn{1}{c|}{ ZDF } & \multicolumn{1}{c}{ BR } & MDR \\
\hline Absoluter Umfang der Kulturthemen (in hh:mm:ss) & $2: 21: 14$ & $1: 13: 38$ & $1: 40: 04$ & $1: 17: 26$ \\
\hline $\begin{array}{l}\text { Anteil der Kulturthemen an gesamter Berichterstattung } \\
\text { in Magazinen }\end{array}$ & $9,4 \%$ & $3,7 \%$ & $6,4 \%$ & $4,0 \%$ \\
\hline Davon „Hochkultur“ & $48,4 \%$ & $40,2 \%$ & $48,2 \%$ & $35,1 \%$ \\
\hline Sonstige Kulturthemen & $51,6 \%$ & $59,8 \%$ & $51,8 \%$ & $64,9 \%$
\end{tabular}

\subsubsection{1 „Hochkultur“}

Der Bereich „Hochkultur“ ${ }^{286}$ wird unterschiedlich stark beachtet. Im ORF 2 und BR macht er jeweils 48 Prozent der Kulturberichterstattung aus, im ZDF 40 und im MDR 35 Prozent. Der Anteil der Hochkulturberichterstattung am Gesamtprogramm ist im ORF 2 deutlich höher, weil bereits die absolute Sendezeit zu kulturellen Themen deutlich höher ausfällt. Die absolute Sendezeit zur Hochkultur liegt in der Untersuchungswoche bei 1 Stunde 8 Minuten und damit mehr als doppelt so hoch wie im ZDF und MDR und auch 20 Minuten mehr als im BR.

\subsection{Klassische Musik}

Bezüglich der Berichterstattung über Themen der klassischen Musik zeigt sich ein ganz anderes als das vermutete Bild. Gleichzeitig ist der Befund aber wenig aussagekräftig, weil die hier-

\footnotetext{
285 ZDF-Theaterkanal, EinsFestival, arte, Phoenix.

286 Siehe hierzu Definition S. 134, also im engeren Sinne sogenannte E-Musik, sowie Theater, Literatur und Kunstausstellungen.
} 
auf entfallende Sendezeit in allen Fällen zu gering ist, um belastbare Aussagen zu treffen (vgl. Tabelle 21 im Anhang, S. 323). Im ORF 2 entfällt nur etwas über ein Prozent der Kulturberichterstattung auf die klassische Musik, im ZDF knapp sechs Prozent und im MDR gut sieben Prozent, während im BR gar nicht hierüber berichtet wird. In allen Fällen bewegt sich der absolute Umfang aber etwa im Bereich der Dauer eines einzelnen Filmberichts. Es kann also lediglich die Aussage getroffen werden, dass klassische Musik in keinem der Sender einen Schwerpunkt der Berichterstattung bildet.

\subsection{Funktionen der Kulturberichterstattung}

Kulturberichterstattung kann auf neue Filme, Theaterinszenierungen oder Ausstellungen und Bücher hinweisen. Damit entspräche sie vor allem dem von Teichert bemängelten „Terminjournalismus“ (1982: 25, vgl. S. 129). Sie kann aber auch Kritik üben und damit über die reine Serviceleistung des Veranstaltungshinweises hinausgehen. Dann erfüllt sie die normative Aufgabe der Mitwirkung an der Meinungsbildung. Die Frage danach, welche Funktion die Kulturberichterstattung hauptsächlich ausfüllt, lässt sich in einer formalen sowie inhaltlichen Betrachtung beantworten. Formal kann dafür auf die journalistische Darstellungsform abgestellt werden.

Tabelle 11: Kulturberichterstattung, zeitliche Anteile der einzelnen Darstellungsformen Basis: Magazinbeiträge mit Thema Kultur in hh:mm:ss - ORF 2: 02:21:14, ZDF: 01:13:38, BR: 01:40:04, MDR: 01:17:26

\begin{tabular}{|c|c|c|c|c|}
\hline Darstellungsform & ORF 2 & ZDF & BR & MDR \\
\hline Moderation & $0,22 \%$ & $0,0 \%$ & $1,53 \%$ & $1,56 \%$ \\
\hline Sprechermeldung & $0,0 \%$ & $0,80 \%$ & $0,0 \%$ & $0,0 \%$ \\
\hline Nachrichtenfilm & $0,0 \%$ & $9,71 \%$ & $0,17 \%$ & $2,71 \%$ \\
\hline Filmbericht & $62,26 \%$ & $72,15 \%$ & $29,13 \%$ & $60,35 \%$ \\
\hline Korrespondentenbericht & $0,0 \%$ & $0,0 \%$ & $3,79 \%$ & $0,0 \%$ \\
\hline Interview/Gesprächsrunde & $4,89 \%$ & $0,0 \%$ & $26,31 \%$ & $0,0 \%$ \\
\hline Kritik/Rezension/Besprechung & $26,39 \%$ & $17,34 \%$ & $33,68 \%$ & $22,76 \%$ \\
\hline Reportage & $4,58 \%$ & $0,0 \%$ & $0,0 \%$ & $0,0 \%$ \\
\hline Service-/Hinweisform & $1,66 \%$ & $0,0 \%$ & $1,60 \%$ & $10,33 \%$ \\
\hline Sonstige Form & $0,0 \%$ & $0,0 \%$ & $3,78 \%$ & $2,28 \%$ \\
\hline Gesamt & $100,00 \%$ & $100,00 \%$ & $100,00 \%$ & $100,00 \%$ \\
\hline
\end{tabular}

Tabelle 11 zeigt, dass auf formaler Ebene der Filmbericht die dominierende Form ist, jedoch auch auf ausgewiesene Rezensionen relativ hohe Anteile entfallen. Es zeigt sich auch, dass die Vermutung einer Dominanz rein hinweisender Kulturberichterstattung im Regionalprogramm zwar zutrifft, was aber auch für die nationalen Programme zutrifft. Zudem sind Kritiken bzw. Rezensionen durchaus nicht selten, so dass es verfehlt wäre, in der Kulturberichterstattung reine Terminmitteilungen erkennen zu wollen. 
Dies wird auch deutlich, wenn man die Funktionen der Beiträge in der Kulturberichterstattung ansieht (vgl. Tabelle 12). Hier machen reine Serviceleistungen im Sinne von Veranstaltungshinweisen und ähnlichem nur einen kleinen Teil aus. Es fällt allerdings auf, dass sie in den regionalen Programmen häufiger vorkommen als in den nationalen. Das überrascht nicht. Veranstaltungshinweise etwa zu Theateraufführungen oder Kunstausstellungen sind vor allem im regionalen Kontext sinnvoll und wichtig, da hier die Wahrscheinlichkeit der tatsächlichen Erreichbarkeit auf Grund räumlicher Nähe für den Zuschauer oder die Zuschauerin höher ist. Der bloße Hinweis auf eine Zauberflötenaufführung in Hamburg hat für Münchner und Münchnerinnen wenig praktische Relevanz. Als Leipzigerin oder Leipziger kann man aber eine Ausstellungseröffnung in Dresden sehr wohl auch spontan und kurzfristig besuchen. Den höchsten Serviceanteil im Bereich Kultur bietet der $M D R .{ }^{287} \mathrm{Im} B R$ ist dagegen die Kritikfunktion in der Kulturberichterstattung am höchsten ausgeprägt. Im MDR ist der Anteil von Kritik immerhin höher als im ZDF. Insofern ist zwar die Dominanz hinweisender Formen wie in Hypothese H19 angenommen - gegeben, dies ist aber keine Besonderheit des Regionalprogramms.

Tabelle 12: Funktion von Beiträgen in der Kulturberichterstattung und ihr Anteil an der Sendezeit

Basis: Magazinbeiträge mit Thema Kultur in hh:mm:ss - ORF 2: 02:21:14, ZDF: 01:13:38, BR: 01:40:04, MDR: 01:17:26

\begin{tabular}{l|r|r|r|r} 
Funktion der Beiträge & \multicolumn{1}{c|}{ ORF 2 } & \multicolumn{1}{c|}{ ZDF } & \multicolumn{1}{c}{ BR } & \multicolumn{1}{c}{ MDR } \\
\hline Service & $3,61 \%$ & $0,00 \%$ & $5,20 \%$ & $11,64 \%$ \\
\hline Informationsfunktion & $70,00 \%$ & $78,61 \%$ & $59,99 \%$ & $63,31 \%$ \\
\hline Kritikfunktion & $\mathbf{2 6 , 3 9 \%}$ & $\mathbf{2 1 , 3 9 \%}$ & $\mathbf{3 3 , 6 8} \%$ & $\mathbf{2 2 , 7 6 \%}$ \\
\hline Beratungsfunktion & $0,00 \%$ & $0,00 \%$ & $1,13 \%$ & $0,00 \%$ \\
\hline Bildungsfunktion & $0,00 \%$ & $0,00 \%$ & $0,00 \%$ & $0,00 \%$ \\
\hline Trifft nicht zu & $0,00 \%$ & $0,00 \%$ & $0,00 \%$ & $2,28 \%$ \\
\hline Gesamt & $\mathbf{1 0 0 , 0 0 \%}$ & $\mathbf{1 0 0 , 0 0 \%}$ & $\mathbf{1 0 0 , 0 0 \%}$ & $\mathbf{1 0 0 , 0 0 \%}$
\end{tabular}

\subsection{Kulturpolitik}

Kulturpolitik ist im Untersuchungszeitraum praktisch kein Thema der Berichterstattung gewesen. Sie kam überhaupt nur im $Z D F$ und $B R$ in marginalem Umfang vor (ZDF: 9 Minuten bzw. 0,4 Prozent der redaktionellen Magazinbestandteile, BR: 4 Minuten bzw. 0,3 Prozent). Damit ist zunächst der Befund gegenteilig zur hypothetischen Annahme (H20). Die Datenbasis ist aber so gering, dass hierzu keine Aussage getroffen werden kann, außer der, dass Kulturpolitik weder im nationalen noch im regionalen Programm überhaupt eine wichtige Rolle spielt.

287 Das korrespondiert im Übrigen mit dem hohen Anteil an Verbraucherthemen im MDR. Das spricht für ein (jedenfalls auch vorhandenes) Journalismusverständnis im Sinne einer nützlichen Dienstleistung. 


\subsubsection{Sportberichterstattung}

Das Thema „Sport“ wird in allen untersuchten Sendern in beachtlichem, wenn auch unterschiedlich hohem Umfang behandelt. Im ORF 2 ist der Anteil mit vier Prozent der gesamten Berichterstattung am geringsten, im BR mit fast zehn Prozent am höchsten (vgl. Tabelle 13). Der absolute Umfang ist - abgesehen von ORF 2 mit etwas über einer Stunde - mit jeweils etwa zweieinhalb Stunden vergleichbar hoch.

Tabelle 13: Umfang und Anteil der Sportberichterstattung an allen Magazinbeiträgen

\begin{tabular}{|c|c|c|c|c|c|c|c|c|}
\hline & \multicolumn{2}{|c|}{ ORF 2} & \multicolumn{2}{|c|}{ ZDF } & \multicolumn{2}{|c|}{ BR } & \multicolumn{2}{|c|}{ MDR } \\
\hline $\begin{array}{l}\text { umfang der } \\
\text { Magazinbei- } \\
\text { träge }\end{array}$ & $25: 02: 33$ & $100,00 \%$ & $33: 36: 49$ & $100,00 \%$ & $25: 54: 25$ & $100,00 \%$ & $32: 31: 20$ & $100,00 \%$ \\
\hline $\begin{array}{l}\text { Davon } \\
\text { Sport }\end{array}$ & 1:02:20 & $4,10 \%$ & $2: 38: 23$ & $7,90 \%$ & $2: 27: 00$ & $9,50 \%$ & $2: 27: 16$ & $7,50 \%$ \\
\hline
\end{tabular}

\subsection{Fußball}

Vom Fußball - als der Sportart Nummer eins in Deutschland - wurde hypothetisch erwartet, dass sich der hohe Stellenwert im Umfang der Berichterstattung widerspiegelt. Das ist auch der Fall. In allen drei deutschen Sendern ist dies die Sportart mit dem höchsten Anteil an der Berichterstattung (vgl. Tabelle 14). Besonders hoch fällt dieser Anteil im ZDF und MDR aus, mit 70 bzw. 85 Prozent der Sportberichterstattung. Im BR sind es immerhin noch 45 Prozent. Der ORF 2 berichtet stattdessen am häufigsten über Doping im Sport. Darüber wurde in den deutschen Programmen während des Untersuchungszeitraums gar nicht berichtet. Vordergründig reiht sich dieser Befund in das Image vom skandalbehafteten Österreich ein (vgl. S. 59). Das darf aber nicht darüber hinwegtäuschen, dass dies vor allem dem Dopingfall Bernhard Kohl geschuldet ist, der bei Nachkontrollen zur Tour de France 2008 positiv getestet worden war, was im Oktober (kurze Zeit vor der hier erhobenen Woche) bekannt wurde. Insofern ist hier wohl eher die tatsächliche Nachrichtenlage als das Image ausschlaggebend. Interessant ist allerdings, dass der zeitgleiche deutsche Dopingfall Stefan Schumachers - einem Teamkollegen Kohls - im deutschen Fernsehen sich nicht gleichermaßen niederschlug. ${ }^{288}$

\subsection{Ski alpin}

In Österreich - so wurde vermutet - genießt der alpine Skisport einen besonders hohen Stellenwert. Daraus wurde eine herausgehobene Stellung in der Berichterstattung gefolgert. Der Anteil dieses Wintersports liegt aber im ORF 2 bei nur elf Prozent (knapp sieben Minuten).

\footnotetext{
${ }^{288}$ Tatsächlich schlägt er sich gar nicht nieder. Eine mögliche Erklärung könnte darin liegen, dass in Deutschland bereits einige Jahre zuvor eine Neubewertung des Radsports stattgefunden hatte, nachdem das systematische Doping im Radteam „Telekom“ bzw. „T-Mobile“ bekannt geworden war. Davon waren vor allem prominente Radsportler (Ullrich, Zabel) betroffen. In Österreich dagegen war Kohl selbst erst im Jahr 2008 in den Rang der obersten Sportprominenz aufgestiegen, da er bei der Tour de France - als erster Österreicher - das Bergtrikot gewonnen hatte. Insofern war die Skandalwirkung hier wahrscheinlich größer.
} 
Das ist der vierte Rang innerhalb der Sportberichterstattung bzw. der zweite von allen vorkommenden Sportarten. Deutlich umfangreicher wird Alpinskifahren dagegen im BR behandelt (22 Minuten bzw. 15 Prozent).

Tabelle 14: Sportberichterstattung: Anteil der einzelnen Sportarten nach Sendedauer

\begin{tabular}{|c|c|c|c|c|c|c|c|c|}
\hline Sportart & \multicolumn{2}{|c|}{ ORF 2} & \multicolumn{2}{|c|}{ ZDF } & \multicolumn{2}{|c|}{ BR } & \multicolumn{2}{|c|}{ MDR } \\
\hline Fußball & $0: 14: 21$ & $23,0 \%$ & $1: 51: 29$ & $70,4 \%$ & $1: 05: 47$ & $44,7 \%$ & 2:05:01 & $84,9 \%$ \\
\hline Handball & 0:00:00 & $0,0 \%$ & 0:00:00 & $0,0 \%$ & $0: 02: 21$ & $1,6 \%$ & $0: 01: 26$ & $1,0 \%$ \\
\hline Basketball & $0: 01: 28$ & $2,4 \%$ & 0:00:58 & $0,6 \%$ & 0:00:00 & $0,0 \%$ & $0: 01: 47$ & $1,2 \%$ \\
\hline $\begin{array}{l}\text { Volleyball/Beach- } \\
\text { volleyball }\end{array}$ & 0:00:00 & $0,0 \%$ & 0:00:00 & $0,0 \%$ & 0:00:00 & $0,0 \%$ & $0: 03: 40$ & $2,5 \%$ \\
\hline Tischtennis & 0:00:00 & $0,0 \%$ & 0:00:38 & $0,4 \%$ & 0:00:00 & $0,0 \%$ & 0:00:00 & $0,0 \%$ \\
\hline Golf & $0: 00: 45$ & $1,2 \%$ & 0:00:00 & $0,0 \%$ & 0:00:00 & $0,0 \%$ & 0:00:00 & $0,0 \%$ \\
\hline Ski alpin & $0: 06: 53$ & $11,0 \%$ & 0:00:00 & $0,0 \%$ & $0: 21: 58$ & $14,9 \%$ & 0:00:00 & $0,0 \%$ \\
\hline Ski nordisch & $0: 00: 41$ & $1,1 \%$ & 0:00:00 & $0,0 \%$ & 0:00:00 & $0,0 \%$ & 0:00:00 & $0,0 \%$ \\
\hline Biathlon & 0:00:00 & $0,0 \%$ & $0: 02: 35$ & $1,6 \%$ & 0:00:00 & $0,0 \%$ & $0: 00: 52$ & $0,6 \%$ \\
\hline Eishockey & 0:01:48 & $2,9 \%$ & $0: 04: 17$ & $2,7 \%$ & 0:05:07 & $3,5 \%$ & 0:03:27 & $2,3 \%$ \\
\hline Eisschnelllauf & 0:00:00 & $0,0 \%$ & $0: 00: 16$ & $0,2 \%$ & 0:00:00 & $0,0 \%$ & 0:00:00 & $0,0 \%$ \\
\hline Eiskunstlauf & 0:00:00 & $0,0 \%$ & 0:00:00 & $0,0 \%$ & 0:00:00 & $0,0 \%$ & $0: 00: 17$ & $0,2 \%$ \\
\hline $\begin{array}{l}\text { Schwimmen/Turm- } \\
\text { springen }\end{array}$ & 0:01:04 & $1,7 \%$ & 0:00:00 & $0,0 \%$ & 0:00:00 & $0,0 \%$ & $0: 02: 50$ & $1,9 \%$ \\
\hline Sonst. Wassersport & 0:00:00 & $0,0 \%$ & 0:00:00 & $0,0 \%$ & 0:03:01 & $2,1 \%$ & 0:00:00 & $0,0 \%$ \\
\hline Formel 1 & $0: 06: 38$ & $10,6 \%$ & 0:08:28 & $5,3 \%$ & $0: 04: 07$ & $2,8 \%$ & 0:00:00 & $0,0 \%$ \\
\hline $\begin{array}{l}\text { Sonst. Automobilren- } \\
\text { nen }\end{array}$ & $0: 00: 40$ & $1,1 \%$ & $0: 03: 10$ & $2,0 \%$ & $0: 02: 12$ & $1,5 \%$ & $0: 00: 24$ & $0,3 \%$ \\
\hline Sonst. Motorsport & 0:00:00 & $0,0 \%$ & 0:00:00 & $0,0 \%$ & $0: 08: 41$ & $5,9 \%$ & 0:00:00 & $0,0 \%$ \\
\hline Marathonlauf & 0:00:00 & $0,0 \%$ & $0: 00: 41$ & $0,4 \%$ & 0:00:00 & $0,0 \%$ & $0: 00: 51$ & $0,5 \%$ \\
\hline Boxen & 0:00:00 & $0,0 \%$ & $0: 12: 47$ & $8,1 \%$ & 0:00:00 & $0,0 \%$ & $0: 00: 31$ & $0,4 \%$ \\
\hline Ringen & 0:00:00 & $0,0 \%$ & 0:00:00 & $0,0 \%$ & $0: 02: 25$ & $1,6 \%$ & 0:00:00 & $0,0 \%$ \\
\hline Sonst. Kampfsport & 0:00:00 & $0,0 \%$ & 0:02:01 & $1,3 \%$ & $0: 05: 15$ & $3,6 \%$ & 0:00:00 & $0,0 \%$ \\
\hline Radsport & 0:00:38 & $1,0 \%$ & 0:00:00 & $0,0 \%$ & $0: 01: 30$ & $1,0 \%$ & 0:00:00 & $0,0 \%$ \\
\hline Triathlon & 0:00:00 & $0,0 \%$ & 0:00:00 & $0,0 \%$ & 0:03:01 & $2,1 \%$ & 0:00:00 & $0,0 \%$ \\
\hline Olympia gesamt & 0:00:00 & $0,0 \%$ & 0:00:00 & $0,0 \%$ & 0:00:00 & $0,0 \%$ & 0:00:28 & $0,3 \%$ \\
\hline
\end{tabular}




\begin{tabular}{l|r|r|r|r|r|r|r|r} 
Sportart & \multicolumn{2}{|c|}{ ORF 2 } & \multicolumn{2}{c|}{ ZDF } & \multicolumn{2}{c}{ BR } & \multicolumn{2}{c}{ MDR } \\
\hline Sportpolitik & $0: 09: 47$ & $15,7 \%$ & $0: 00: 00$ & $0,0 \%$ & $0: 01: 41$ & $1,1 \%$ & $0: 00: 00$ & $0,0 \%$ \\
\hline Doping & $0: 16: 08$ & $25,9 \%$ & $0: 00: 00$ & $0,0 \%$ & $0: 00: 00$ & $0,0 \%$ & $0: 00: 00$ & $0,0 \%$ \\
\hline $\begin{array}{l}\text { Sportvermarktung/ } \\
\text { Sportrechte }\end{array}$ & $0: 00: 00$ & $0,0 \%$ & $0: 00: 00$ & $0,0 \%$ & $0: 01: 20$ & $0,9 \%$ & $0: 00: 00$ & $0,0 \%$ \\
\hline $\begin{array}{l}\text { Breitensport } \\
\text { Sonst. Sport }\end{array}$ & $0: 00: 00$ & $0,0 \%$ & $0: 05: 01$ & $3,2 \%$ & $0: 10: 41$ & $7,3 \%$ & $0: 04: 14$ & $2,9 \%$ \\
\hline Gesamt & $0: 01: 28$ & $2,4 \%$ & $0: 06: 02$ & $3,8 \%$ & $0: 07: 53$ & $5,4 \%$ & $0: 01: 27$ & $1,0 \%$ \\
\hline
\end{tabular}

\subsection{Fußballigen}

Die hypothetischen Annahmen über die Berichterstattung aus den verschiedenen Spielklassen bestätigen sich. In den beiden nationalen Programmen wird am umfangreichsten über die jeweils höchste nationale Spielklasse berichtet. Den zweithöchsten Anteil macht jeweils die Berichterstattung über Fußballnationalmannschaften aus. Ein ganz anderes Bild ist in den Regionalprogrammen erkennbar. Im BR wird vor allem aus der Zweiten Bundesliga berichtet sowie auch umfangreich aus der ersten. Im MDR vor allem aus der Dritten und Vierten Liga. Darin kommt die Fokussierung auf die jeweils regionalen Vereine zum Ausdruck bzw. deren momentane Spielklassen.

Tabelle 15: Verteilung der Fußballberichterstattung auf die verschiedenen Ligen

\begin{tabular}{l|r|r|r|r} 
& \multicolumn{1}{c|}{ ORF 2} & \multicolumn{1}{c|}{ ZDF } & \multicolumn{1}{c}{ BR } & \multicolumn{1}{c}{ MDR } \\
\hline $\begin{array}{l}\text { 1. Bundesliga (D)/,tipp 3-Bundesliga powered by T- } \\
\text { Mobile” (Ö) }\end{array}$ & $\mathbf{5 9 , 2} \%$ & $\mathbf{6 6 , 0} \%$ & $29,8 \%$ & $5,0 \%$ \\
\hline 2. Bundesliga (D)/,ADEG Erste Liga“ (Ö) & $0,0 \%$ & $2,1 \%$ & $\mathbf{5 4 , 8} \%$ & $0,0 \%$ \\
\hline 3. Liga (D)/Regionalliga (Ö) & $0,0 \%$ & $11,5 \%$ & $0,6 \%$ & $\mathbf{5 7 , 8} \%$ \\
\hline Regionalliga (D)/Landesligen (Ö) & $0,0 \%$ & $0,0 \%$ & $0,0 \%$ & $25,1 \%$ \\
\hline Oberliga (D) & $0,0 \%$ & $0,0 \%$ & $0,0 \%$ & $3,1 \%$ \\
\hline Verbands- o. Landesliga & $0,0 \%$ & $0,0 \%$ & $5,9 \%$ & $1,0 \%$ \\
\hline Internationaler Vereinsfußball & $0,0 \%$ & $8,6 \%$ & $0,0 \%$ & $0,3 \%$ \\
\hline Nationalmannschaften & $24,7 \%$ & $11,8 \%$ & $7,1 \%$ & $5,0 \%$ \\
\hline Fußball außerhalb von Ligen & $16,1 \%$ & $0,0 \%$ & $1,8 \%$ & $2,7 \%$ \\
\hline Trifft nicht zu & $0,0 \%$ & $0,0 \%$ & $0,0 \%$ & $0,0 \%$ \\
\hline Gesamt & $100,0 \%$ & $100,0 \%$ & $100,0 \%$ & $100,0 \%$
\end{tabular}




\subsection{Breitensport}

Über Breitensport wird nur in den deutschen untersuchten Programmen berichtet (vgl. Tabelle 14). Im ORF 2 kommt er gar nicht vor. Im ZDF und MDR bewegt sich der Anteil bei um die drei Prozent der Sportberichterstattung, im BR liegt er bei sieben Prozent. Breitensport ist demnach kein exklusives Thema der Regionalsender. Er spielt erwartungsgemäß eine nur geringe Rolle.

In der Sport- und insbesondere der Fußballberichterstattung zeigt sich, dass die Regionalprogramminhalte komplementär zu überregionalen Medienangeboten sind. Es wird verstärkt über jene Ligen und Spielklassen berichtet, die auf nationaler Ebene weniger Beachtung finden als der nationale Wettbewerb der ersten Bundesliga. So wird im BR am umfangreichsten über die Zweite Fußballbundesliga berichtet, im MDR über die Dritte und Vierte Liga. Das ist im Falle des BR insofern beachtlich, als dass es zum Zeitpunkt der Untersuchung zwei Vereine im Bundesland gab, die in der Ersten Liga spielten. Das kann so verstanden werden, dass auf subnationaler Ebene die innerregionale Vielfalt eine größere Rolle spielt als eine möglicherweise kohäsionsstiftende Identifizierung mit einzelnen Vereinen, die eine Region als Ganzes nach außen vertreten könnten. Das liegt sicher nicht zuletzt an den fußballspezifischen Fankulturen, denen die Identifikation mit einem besonderen Verein näher ist als mit einer Region. ${ }^{289}$ Im Fall Bayerns heißt das nämlich beispielsweise, dass eine verstärkte Berichterstattung nur über den FC Bayern München oder den 1. FC Nürnberg als überregionale Aushängeschilder gerade keine nach innen integrierende Wirkung haben kann. Es spielt aber selbstverständlich auch die schlichte äußerliche Tatsache eine Rolle, in welcher Spielklasse die heimischen Vereine agieren. Da im nationalen Programm aber Erstligafußball eindeutig dominiert, ist die regionale Berichterstattung in jedem Fall als ergänzend zu betrachten und fügt sich damit auch inhaltlich in die Organisationsstruktur des Rundfunks ein.

\subsubsection{Themenbereich Religion}

Das Thema „Religion“ ist als Indikator regional bedingter Unterschiede besonders geeignet, weil es eng mit der jeweiligen historischen Entwicklung von Regionen aber auch Nationen verbunden ist. Insbesondere was die Unterschiede auf regionaler Ebene betrifft, bestätigt sich das in den Ergebnissen.

${ }^{289}$ Das kann man etwa an den Fans der beiden Münchner Vereine 1860 München und FC Bayern sehen. 
Abbildung 64: ORF 2 - Thema Religion in Magazinsendungen: Verteilung der Berichterstattung auf die Glaubensrichtungen und Konfessionen

Basis: Dauer aller Beiträge mit Thema Religion in hh:mm:ss = 01:53:41

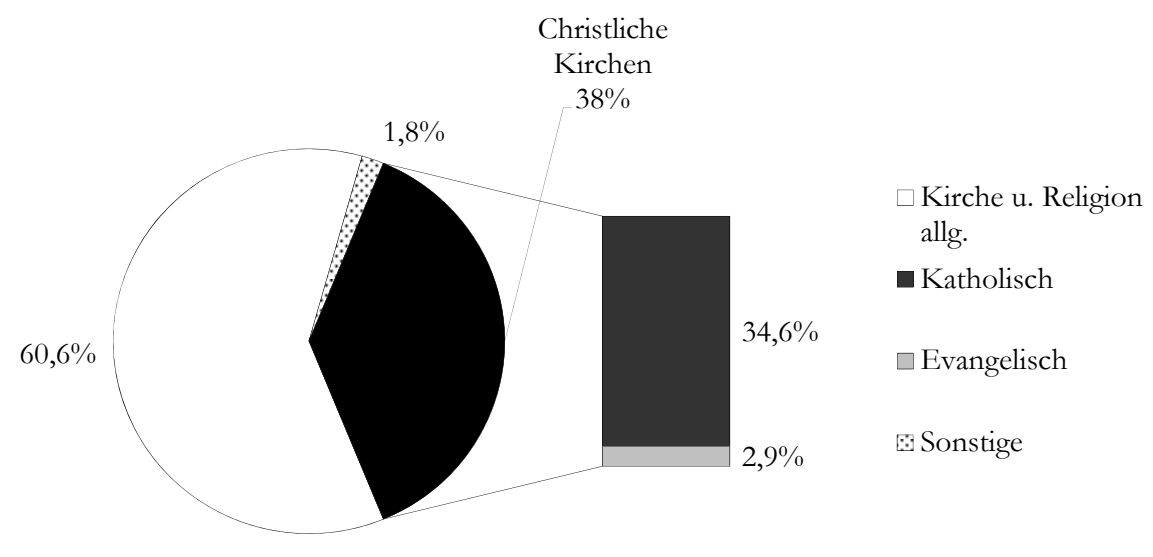

Abbildung 65: ZDF - Thema Religion in Magazinsendungen: Verteilung der Berichterstattung auf die Glaubensrichtungen und Konfessionen

Basis: Dauer aller Beiträge mit Thema Religion in hh:mm:ss $=$ 00:17:05

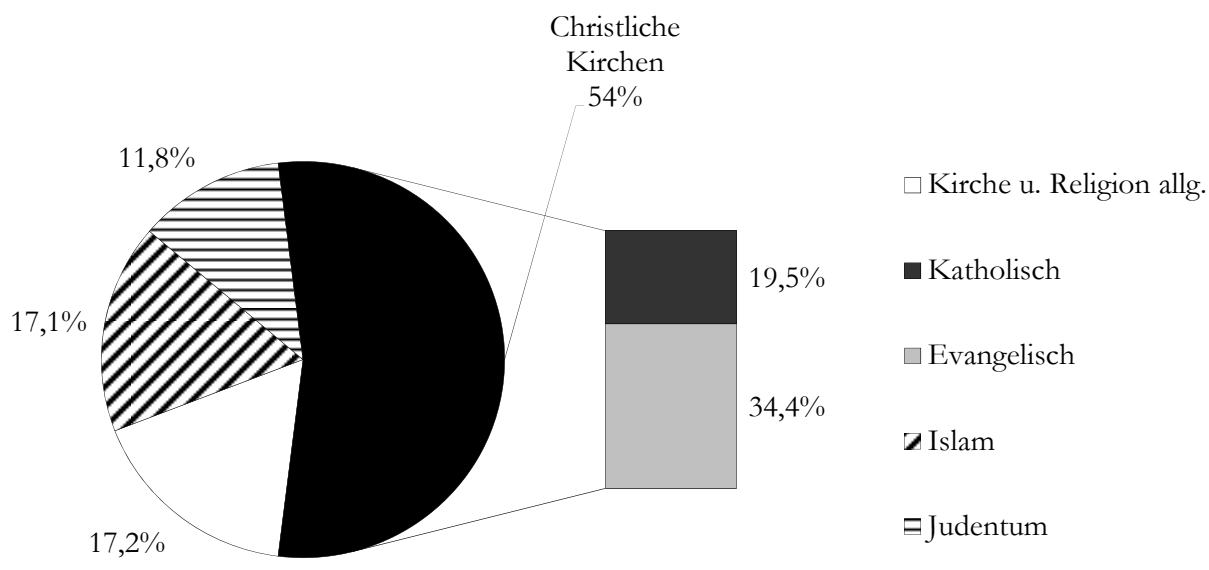


Abbildung 66: BR - Thema Religion in Magazinsendungen: Verteilung der Berichterstattung auf die Glaubensrichtungen und Konfessionen

Basis: Dauer aller Beiträge mit Thema Religion in hh:mm:ss = 00:36:12

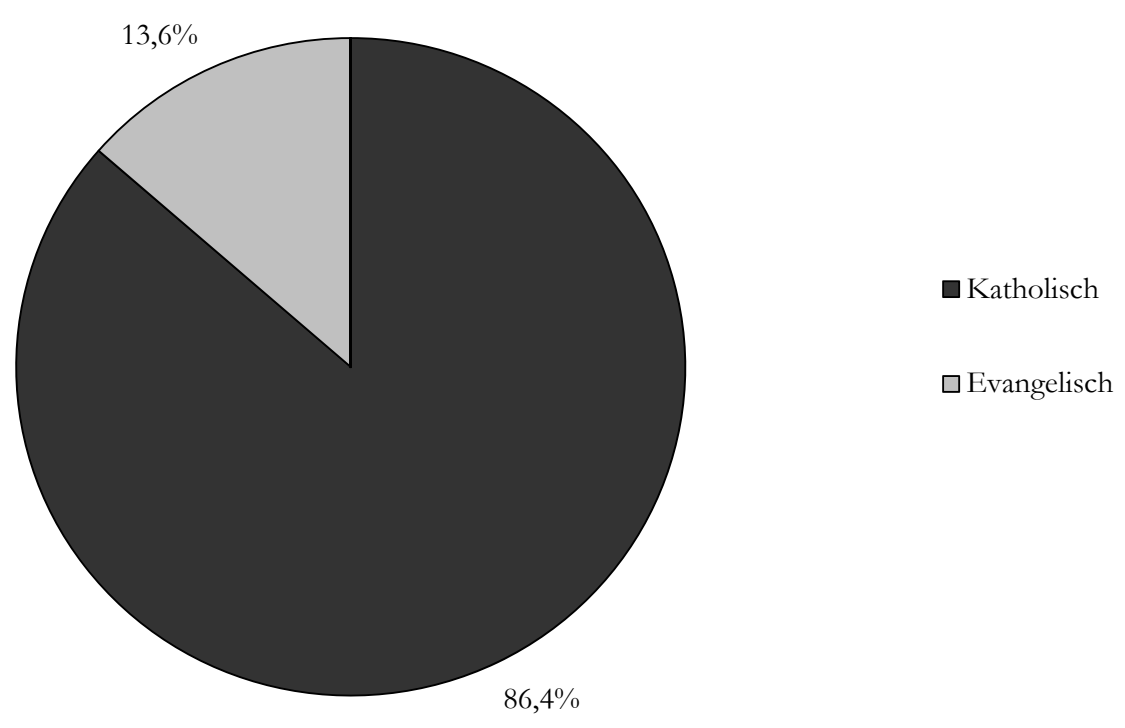

Im ORF 2 machen in Magazinbeiträgen religiöse Belange insgesamt 1 Sunde 54 Minuten aus. Davon sind 60 Prozent nicht auf einen bestimmten Glauben oder eine bestimmte Konfession bezogen, aber 38 Prozent auf die christlichen Kirchen (vgl. Abbildung 64). Hier dominiert dann die katholische Kirche, der in der Alpenrepublik ja auch die meisten Einwohnerinnen und Einwohner formal angehören.

Im ZDF ist das Bild deutlich differenzierter (vgl. Abbildung 65). Hier machen Themen der christlichen Kirchen den Hauptanteil der Themen mit religiösem Bezug aus, wovon etwas mehr Sendezeit auf die evangelische Kirche entfällt. Auf den Islam entfallen 17 Prozent, auf den jüdischen Glauben zwölf Prozent der Sendezeit zum Thema Religion. Mit insgesamt 17 Minuten macht die Religion aber nur einen geringen Teil aller Magazinthemen aus.

In Magazinen des BR kommt nur die christliche Religion vor. In den diesbezüglichen Beiträgen dominiert mit 86 Prozent Sendezeitanteil ganz eindeutig die katholische Konfession (vgl. Abbildung 66).

In Magazinen des MDR kommen religiöse Themen nur in marginalem Umfang vor. Die vier Minuten, in denen während der Untersuchungswoche über Kirche berichtet wird, beziehen sich auf die evangelische Konfession. 


\subsubsection{Thema Religion auf Sendungsebene}

Abweichend von der Behandlung ausgewählter Themen der Berichterstattung soll zum Thema Religion ergänzend ein Blick auf die Themenstruktur auf Sendungsebene geworfen werden. Der Grund hierfür ist, dass die Auswertung der Daten ergab, dass sich außerhalb von Magazinen eine nicht unbeachtliche Zahl von Sendungen (gemessen am Umfang) diesem Thema widmete. Die daraus gewonnenen Daten ergeben ein etwas differenzierteres Bild.

Abbildung 67: ORF 2 - Thema Religion auf Sendungsebene, Verteilung der Sendezeit auf die Glaubensrichtungen und Konfessionen

Basis: Dauer aller monothematischen Sendungen mit Thema Religion in hh:mm:ss $=$ 02:06:00

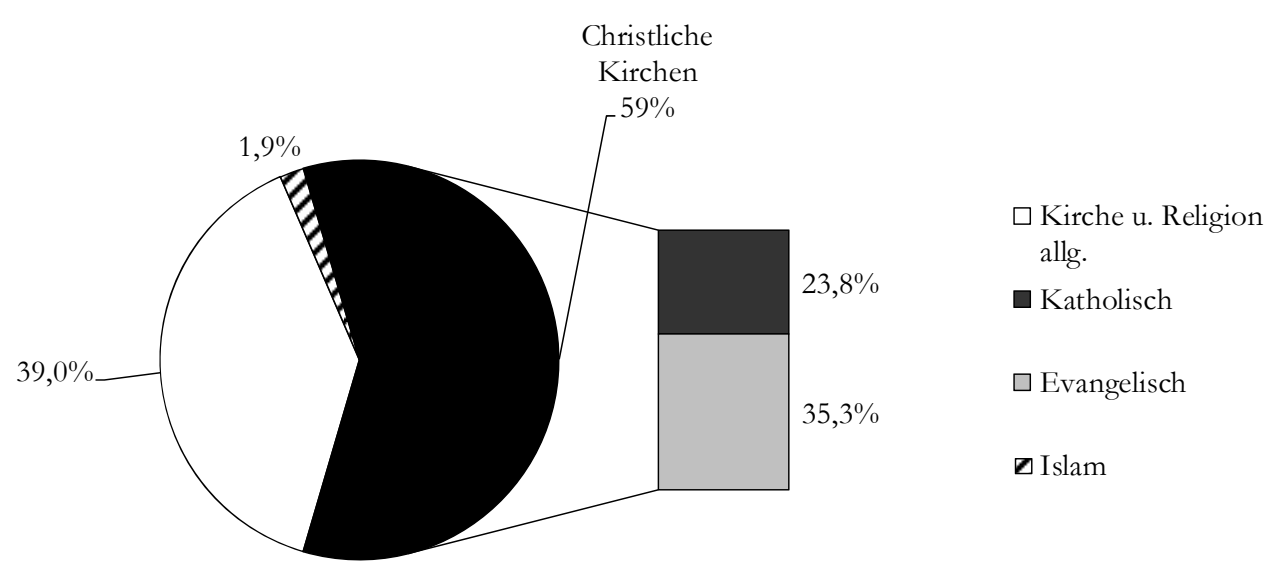


Abbildung 68: ZDF - Thema Religion auf Sendungsebene, Verteilung der Sendezeit auf die Glaubensrichtungen und Konfessionen.

Basis: Dauer aller monothematischen Sendungen mit Thema Religion in hh:mm:ss = 01:20:54

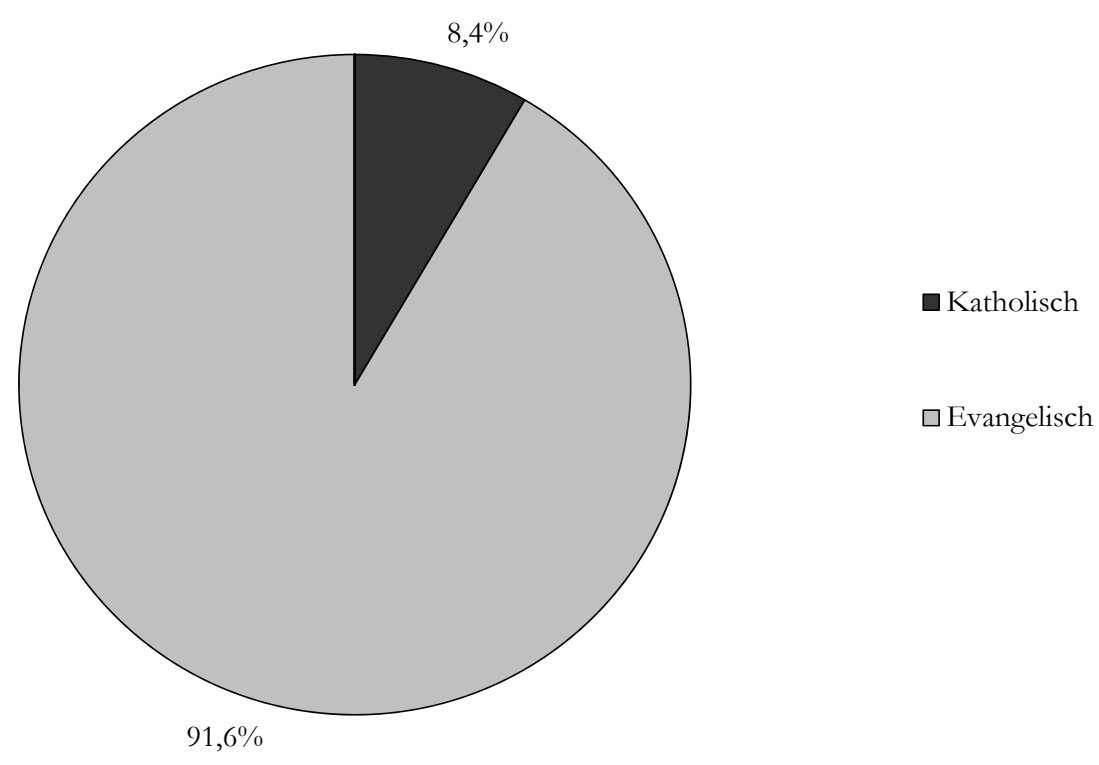

Abbildung 69: BR - Thema Religion auf Sendungsebene, Verteilung der Sendezeit auf die Glaubensrichtungen und Konfessionen

Basis: Dauer aller monothematischen Sendungen mit Thema Religion in hh:mm:ss = 04:32:13

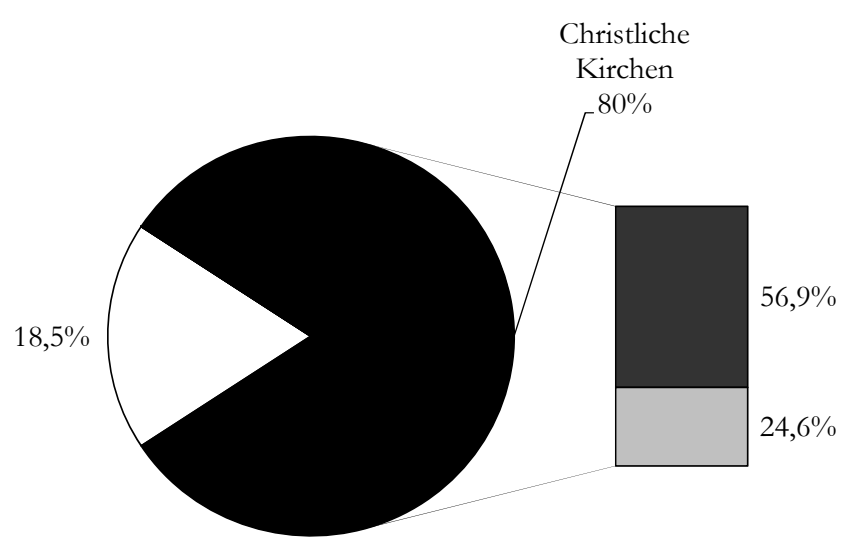

$\square$ Kirche u. Religion

allg.

$\square$ Katholisch

$\square$ Evangelisch 
Abbildung 70: MDR - Thema Religion auf Sendungsebene, Verteilung der Sendezeit auf die Glaubensrichtungen und Konfessionen

Basis: Dauer aller monothematischen Sendungen mit Thema Religion in hh:mm:ss = 01:34:21

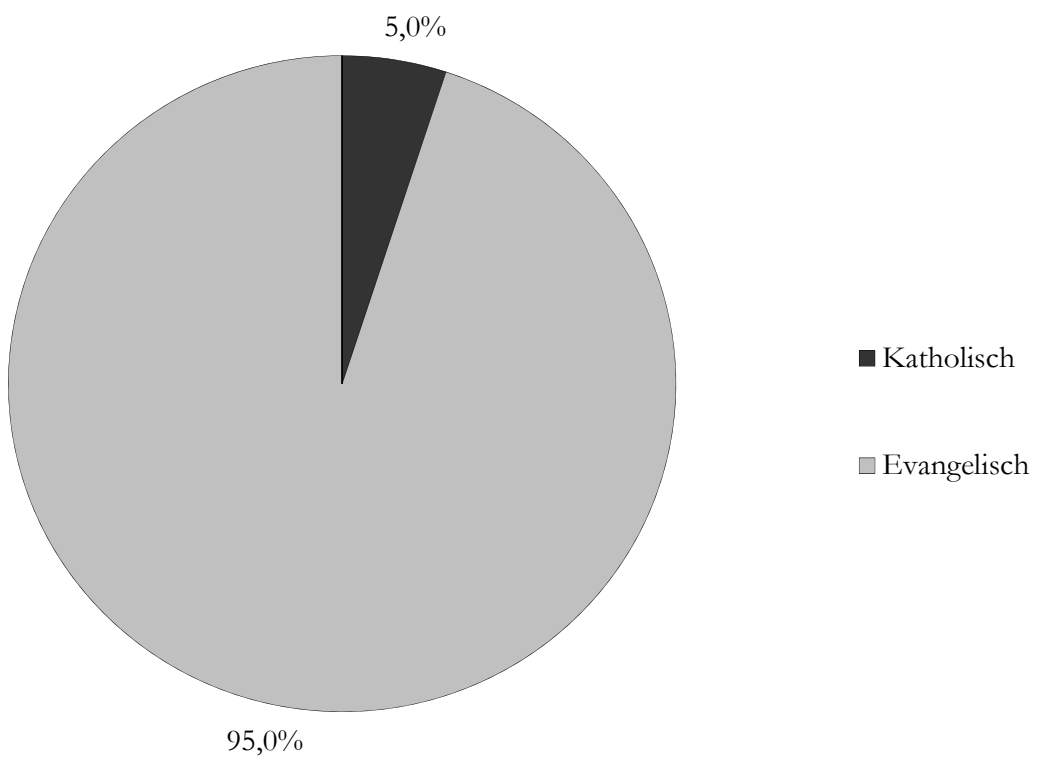

Im ORF 2 weicht das Bild der Religionsberichterstattung auf Sendungsebene (vgl. Abbildung 67) etwas vom Bild, das sich aus den Magazinen ergibt, ab. Die christliche Religion dominiert hier die Berichterstattung, wobei auf die evangelische Konfession etwas mehr Sendezeit entfällt. Das erklärt sich jedoch aus der Übertragung eines evangelischen Gottesdienstes innerhalb der Untersuchungswoche. ${ }^{290}$ Solche religiösen Riten dauern per se lange an, was sich dann in der Sendezeit niederschlägt.

Im $Z D F$ wird dagegen auf Sendungsebene innerhalb der Untersuchungswoche nur den christlichen Kirchen Sendezeit eingeräumt (vgl. Abbildung 68). Davon entfällt mit 92 Prozent der größte Anteil auf die evangelische Kirche. Auch hier wurde innerhalb der Untersuchungswoche ein Gottesdienst übertragen. ${ }^{291}$

Im Bayerischen Rundfunk bestätigt die Auswertung auf Sendungsebene im Großen und Ganzen den Eindruck der Auswertung der Magazinbeiträge. Das Bild differenziert sich lediglich etwas aus (vgl. Abbildung 69). Die meisten Sendungen zu religiösen Themen beschäftigen sich mit der katholischen Konfession - hier allerdings, obwohl in der Untersuchungswoche auch ein evangelischer Gottesdienst übertragen wird. Bei über viereinhalb Stunden Sendezeit, die im $B R$ überhaupt auf Sendungen zu Religion und Kirche entfallen, wirkt sich das aber weniger

\footnotetext{
${ }^{290}$ Hier: Gottesdienst zum Reformationstag.

${ }^{291}$ Hier: Einführungsgottesdienst der EKD-Synode.
} 
stark im Ergebnis aus als bei den anderen Sendern, wo jeweils deutlich weniger als halb so viel absolute Sendezeit auf religiöse Themen verwandt wird. ${ }^{292}$

Sendungen zu Glaubensthemen werden im MDR erwartungsgemäß von der evangelischen Kirche dominiert (vgl. Abbildung 70). Außerhalb der Magazinsendungen kommt das Thema Religion im MDR auch in etwas größerem Gesamtumfang vor, als im ZDF. Das relativiert den Befund, dass in Magazinen religiöse Themen fast gar nicht vorkommen.

Bei der Behandlung religiöser Themen zeigen sich zum Teil beträchtliche Unterschiede zwischen den untersuchten Programmen. In den beiden nationalen Programmen zeigt sich eine stärkere Ausdifferenzierung des thematisch relevanten Angebots in die verschiedenen Glaubensrichtungen, das heißt, hier kommen nicht nur die christlichen Kirchen vor, sondern zum Beispiel auch der Islam. ${ }^{293}$ Die Regionalsender beschränken sich ganz auf die dominierende Glaubensrichtung ihres Sendegebiets. Insgesamt die meiste Sendezeit (Magazinbeiträge und Sendungen zusammengenommen) widmet der BR den religiösen Themen. Im Mitteldeutschen Rundfunk spielt die Religion lediglich auf Sendungsebene eine Rolle. ${ }^{294}$ Dass in Magazinen so gut wie gar nicht hierüber berichtet wird, enthebt die Religion in gewisser Hinsicht der im MDR gezeigten alltäglichen Erfahrungswelt. Aspekte des Glaubens sind nicht Gegenstand mehr oder weniger aktueller journalistischer Berichterstattung, sondern werden auf extra dafür eingerichtete Sendeplätze verwiesen. Zuschauer und Zuschauerinnen, die nicht gezielt entsprechende Sendungen einschalten, werden auch nicht mit religiösen Themen konfrontiert. Das dürfte auch der Erfahrungswelt des Großteils des MDR-Publikums entsprechen - immerhin gehören zwei Drittel der Mitteldeutschen keiner Religion an. Die mutmaßlich geringe Relevanz von Glauben im Alltag findet also ihre Entsprechung im Fernsehprogramm. Ganz umgekehrt verhält es sich dagegen im Bayerischen Rundfunk, wo allein viereinhalb Stunden monothematischer Sendungen auf den Bereich Religion entfallen. Daneben kommen kirchliche Themen in insgesamt 15 Magazinbeiträgen, in fünf verschiedenen Magazinsendungen vor. Die auch im bayerischen Alltag erfahrbare Relevanz und herausgehobene Stellung der Kirche (fast 60 Prozent der Bayern sind römisch-katholisch) ist also auch im Fernsehen präsent bzw. wird hier repräsentiert. In den nationalen Programmen ist das Bild ein anderes: Im ORF 2 spielt Religion sowohl auf Sendungs- als auch auf Magazinebene eine wichtige Rolle (wobei sich allen zwei Magazinsendungen - „kreuz und quer“, „Orientierung“ - explizit als Ressortmagazine auf Glaubensfragen beziehen). Im ZDF sind zwar in Magazinsendungen religiöse Aspekte eingestreut vorhanden (insgesamt zehn Beiträge in sechs verschiedenen Magazinsendungen), aber sowohl absolut als auch anteilig gesehen deutlich weniger umfangreich als im ORF 2. Allerdings ist hier die Bandbreite vorkommender Religionen größer. Insofern entspricht auch

292 ORF 2: 2 Stunden, ZDF: 1 Stunde 20 Minuten, MDR: eineinhalb Stunden.

${ }^{293} \mathrm{Im} Z \mathrm{ZDF}$ ist die Vielfalt dabei die vergleichsweise größte, denn im ORF 2 kommen auf Magazinebene lediglich 2 Prozent sonstige Religionen und auf Sendungsebene lediglich der Islam im Umfang von 2 Prozent Sendezeitanteil vor. Im ZDF hingegen kommen nicht-christliche Religionen auf Magazinebene zusammen auf ein Viertel der religionsbezogenen Berichterstattung.

${ }^{294}$ Wobei die meiste Sendezeit auf Sendungen über Martin Luthers Leben und Wirken entfielen, also auch einen historischen Bezug aufwiesen (weshalb im Gang der Auswertung nur die Hälfte der Sendezeit dem Thema Religion zugeschlagen wurde). Grund hierfür war die Eröffnung der Ausstellung „Fundsache Luther“ in Halle. Diese Eröffnung fiel mit dem Reformationstag zusammen. 
auf nationaler Ebene der Unterschied der Darstellung von Glauben und Religion den Unterschieden der Länder: Während in Deutschland immerhin ein Viertel der Einwohnerinnen und Einwohner gar keiner Religion angehören, trifft das nur auf zwölf Prozent der Österreicher und Österreicherinnen zu. Gleichzeitig ist die römisch-katholische Kirche in Österreich die dominierende Glaubensrichtung, während die Deutschen etwa gleich auf evangelische und katholische Kirche verteilt sind (vgl. S. 46, 54, 71 u. 75).

\subsubsection{Themenbereich Wirtschaft}

Der Themenbereich „Wirtschaft“ kann sowohl aus gesamtgesellschaftlicher als auch aus einer auf die Privatwirtschaft beschränkten Perspektive betrachtet werden. Hier wird die gesamtgesellschaftliche gewählt. Das bedeutet konkret, dass wirtschaftspolitische Themen in der Auswertung auch berücksichtigt werden. Dieses Vorgehen rechtfertigt sich anhand der Befunde, macht doch innerhalb dieses Themenkomplexes Wirtschaftspolitik in allen untersuchten Sendern, außer dem MDR, den größten Anteil aus. Zudem sind nur geringe Verschiebungen festzustellen, was die Anteile der drei Wirtschaftssektoren an der Berichterstattung betrifft, je nachdem ob die Wirtschaftspolitik einbezogen oder weggelassen wird. ${ }^{295}$

\subsection{Thematische Aspekte der Wirtschaftsberichterstattung}

Im ORF 2 beträgt der Gesamtumfang der Wirtschaftsberichterstattung in den Magazinen etwas über zweieinhalb Stunden. Davon entfallen auf die Wirtschaftspolitik 44 Prozent. Berichterstattung über wirtschaftliche Krisen, Konkurse oder Insolvenzen macht 19 Prozent aus und allgemeine Informationen über Aktivitäten einzelner Unternehmen 13 Prozent. Im ZDF ist die Wirtschaftsberichterstattung mit über vier Stunden im Untersuchungszeitraum deutlich umfangreicher. Hiervon entfallen 23 Prozent auf Wirtschaftspolitik, 16 Prozent auf Informationen von der Börse und zwölf Prozent der Sendezeit gehen auf wirtschaftliche Krisenerscheinungen ein. ${ }^{296} \mathrm{Im}$ BR wurde das Thema Wirtschaft in Magazinbeiträgen insgesamt gut zwei Stunden innerhalb der untersuchten Woche behandelt. Auch hier ist Wirtschaftspolitik das wichtigste Thema und macht 41 Prozent aus, während auf allgemeine Unternehmensaktivitäten 14 Prozent der Zeit entfallen. Im BR machen Krisen und Konkurse allerdings nur acht Prozent aus und sind damit eher am Rande präsent. Ganz anders im MDR: Hier wird zwar insgesamt weniger als eine Stunde (52 Minuten) ${ }^{297}$ über Wirtschaftsthemen berichtet, davon entfallen aber 20 Prozent auf Krisen, Konkurse und Insolvenzen. Die allgemeine wirtschaftli-

\footnotetext{
295 Der Vollständigkeit halber sind die Grafiken zur Verteilung der Wirtschaftsthemen ohne Wirtschaftspolitik im Anhang aufgeführt (S. 320 - 322, Abbildung 87 - Abbildung 90).

${ }^{296}$ Der hohe Anteil von Börsenmeldungen erklärt sich aus dem Schwerpunkt, den dieses Thema im täglichen Nachrichtenmagazin ,heute journal“ hat. Ohne dieses Magazin ist der Anteil nur bei 4 Prozent, wobei allerdings auch der Gesamtumfang der Wirtschaftsberichterstattung ohne Nachrichtenmagazine bei nur etwas über eineinhalb Stunden liegt.

${ }^{297}$ Das liegt auch dann deutlich unter den Zahlen der anderen Sender, wenn bei diesen die Nachrichtenmagazine nicht berücksichtigt werden.
} 
che Konjunktur wird in 18 Prozent, die Wirtschaftspolitik in 15 Prozent der auf Wirtschaft entfallenden Sendezeit behandelt.

\subsection{Berichterstattung über die einzelnen Wirtschaftssektoren}

Im ORF 2 und $B R$ sind die Beiträge zum Thema „Wirtschaft“ in ihrer Mehrzahl nicht eindeutig einem Wirtschaftsbereich zuzuordnen (vgl. Abbildung 71 undAbbildung 73). Im ZDF ist dies zur Hälfte der Fall (vgl. Abbildung 72). Im MDR betrifft das nur 39 Prozent der für wirtschaftliche Themen aufgewendeten Sendezeit (vgl. Abbildung 74). Die übrigen Beiträge ließen sich unabhängig vom konkret darin behandelten Aspekt einem der drei Wirtschaftssektoren zuordnen.

\section{Abbildung 71: ORF 2 - Wirtschaftsberichterstattung, Anteile der einzelnen Wirtschaftssektoren an der Sendezeit \\ Basis: Magazinbeiträge mit Thema Wirtschaft in hh:mm:ss $=02: 36: 49$}

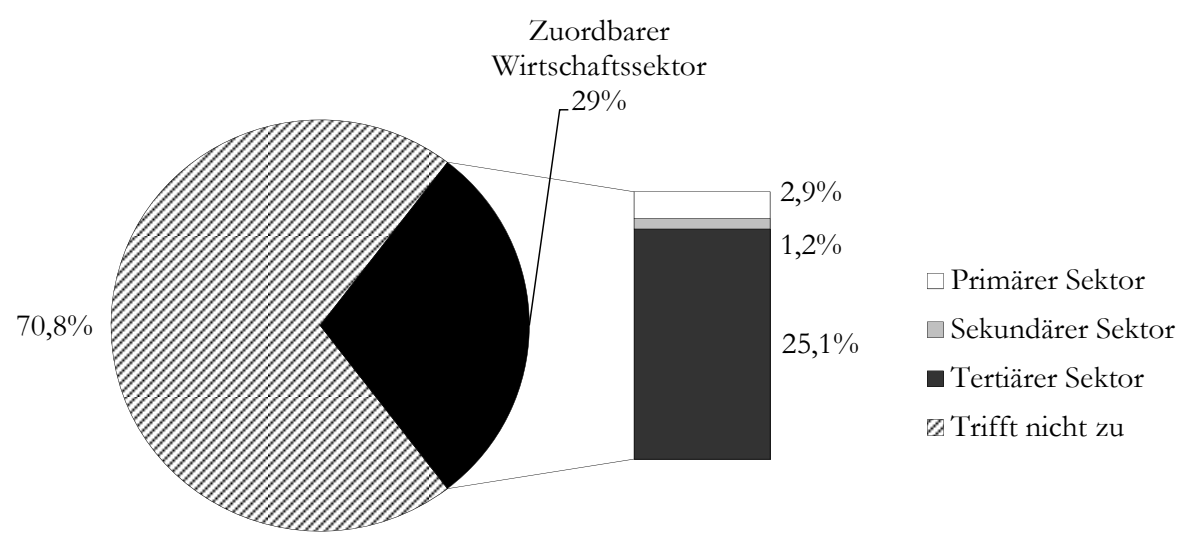


Abbildung 72: ZDF - Wirtschaftsberichterstattung, Anteile der einzelnen Wirtschaftssektoren an der Sendezeit

Basis: Magazinbeiträge mit Thema Wirtschaft in hh:mm:ss = 04:02:55

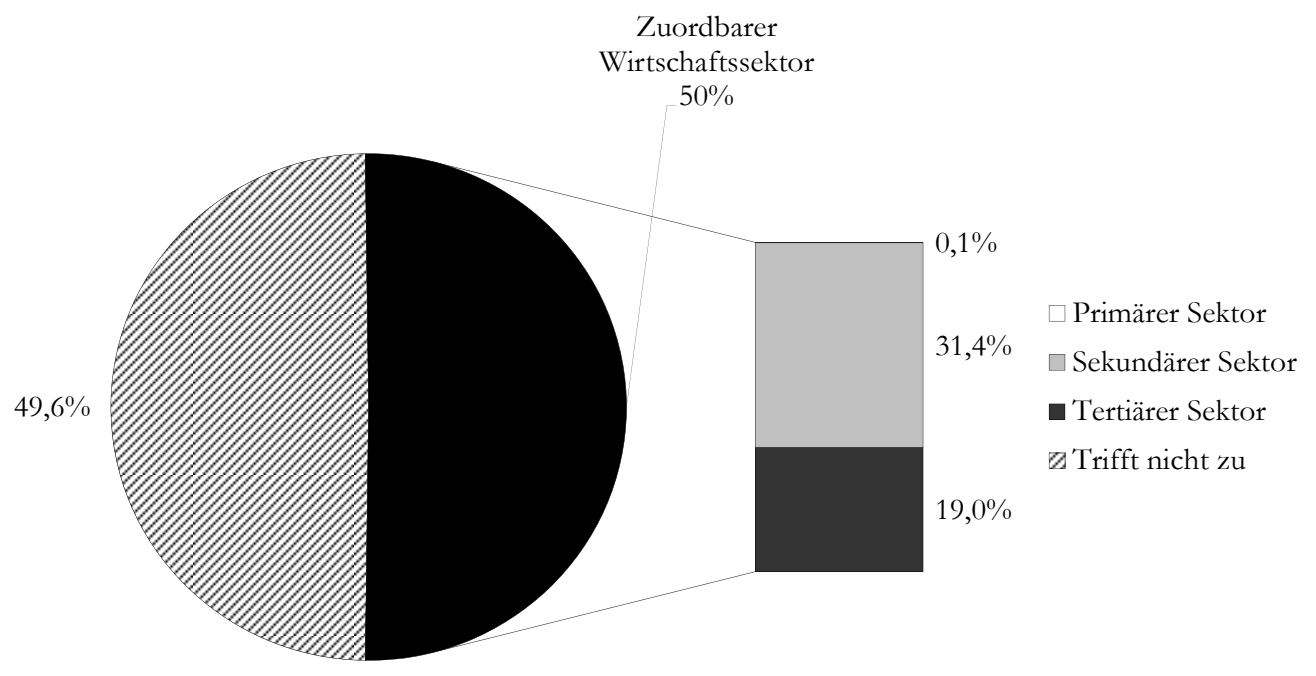

Abbildung 73: BR - Wirtschaftsberichterstattung, Anteile der einzelnen Wirtschaftssektoren an der Sendezeit

Basis: Magazinbeiträge mit Thema Wirtschaft in hh:mm:ss $=02: 04: 49$

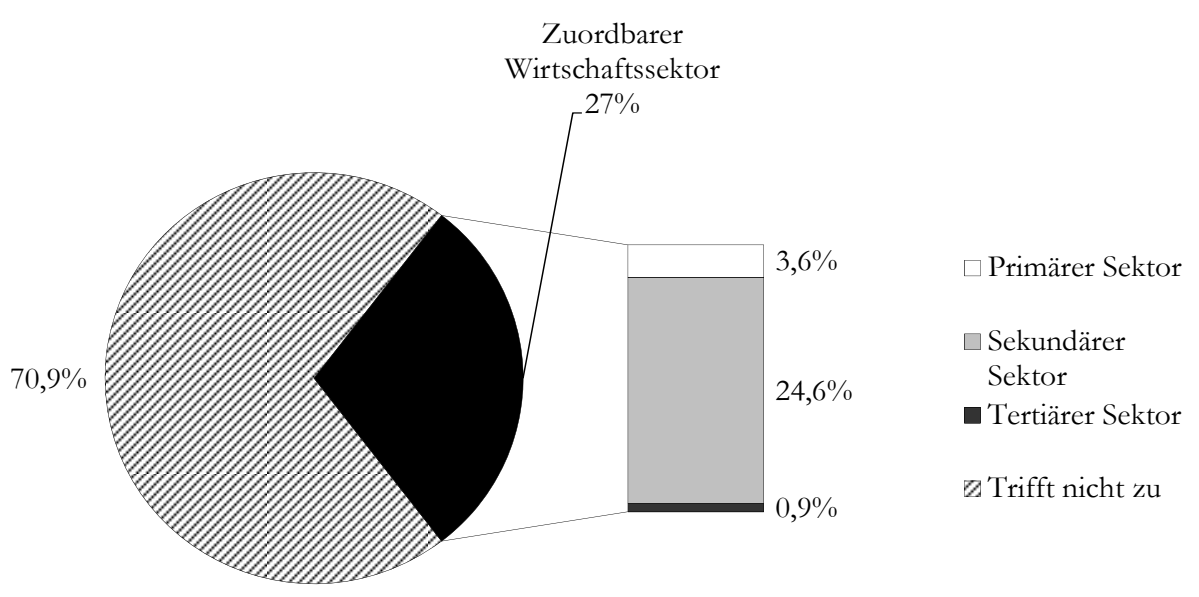


Abbildung 74: MDR - Wirtschaftsberichterstattung, Anteile der einzelnen Wirtschaftssektoren an der Sendezeit

Basis: Magazinbeiträge mit Thema Wirtschaft in hh:mm:ss = 00:52:57

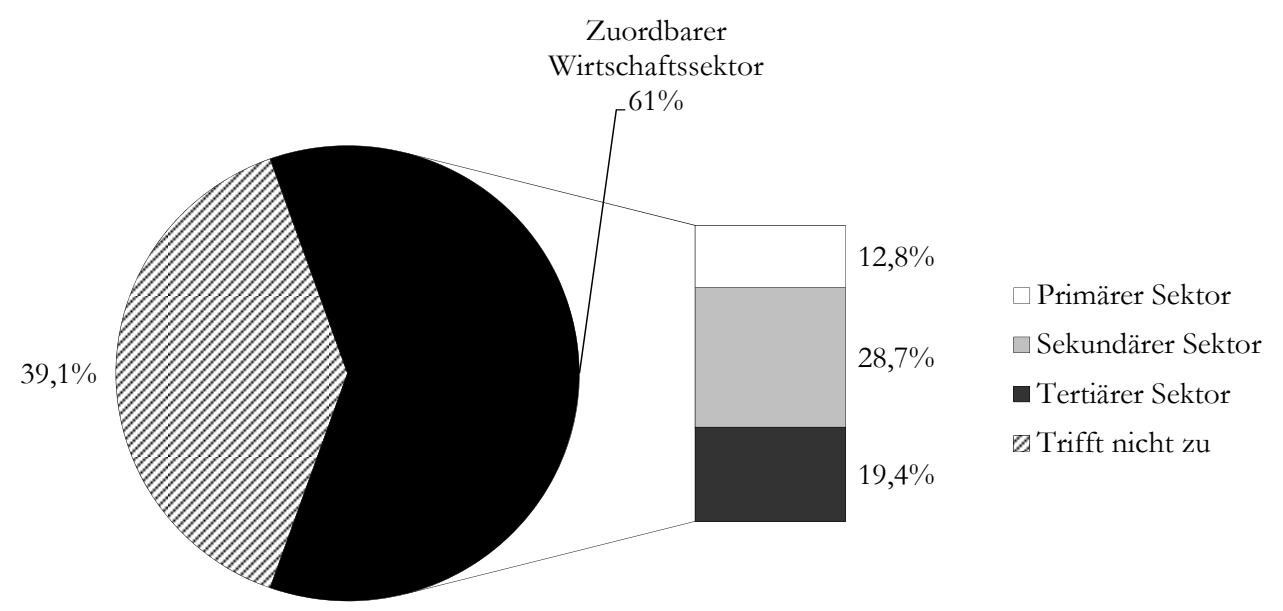

Im ORF 2 wird vor allem der tertiäre Wirtschaftssektor berücksichtigt. Ein Viertel der gesamten Wirtschaftsberichterstattung bezieht sich hierauf bzw. 86 Prozent der eindeutig einem Sektor zuordbaren Beiträge. Der industrielle Sektor spielt mit einem Prozent die geringste Rolle. Sogar auf den Primärsektor entfällt mit fast drei Prozent mehr Sendezeit.

Im ZDF spielt dagegen der primäre Sektor keine Rolle und der Hauptanteil entfällt auf den industriellen Bereich (31 Prozent). Der Dienstleistungssektor macht mit 19 Prozent ebenfalls einen beachtlichen Teil der Wirtschaftsberichterstattung aus.

Der Bayerische Rundfunk legt den Fokus auf den sekundären Sektor. Der primäre Sektor wird in vier Prozent der Sendezeit für Wirtschaftsthemen behandelt. Dagegen spielt der tertiäre Sektor fast keine Rolle.

Im MDR lässt sich zwischen den drei Wirtschaftssektoren ein deutlich ausgewogeneres Bild erkennen - trotz der insgesamt nur wenig umfangreichen Wirtschaftsberichterstattung. Auf den Primärsektor entfallen 13 Prozent der Sendezeit zu Wirtschaftsthemen, auf den industriellen Sektor 29 Prozent und 19 Prozent auf den Dienstleistungssektor.

In keinem der drei Sender lässt sich anhand der Anteile der Wirtschaftssektoren an der Berichterstattung eine Ähnlichkeit mit der Verteilung der Erwerbstätigen in den entsprechenden Ländern und Regionen auf die verschiedenen Wirtschaftsbereiche feststellen. Insofern zeigt sich hier aus Publikumssicht kein Bild, das sich mit der selbst erfahrbaren Wirklichkeit deckt. 
Aus Sicht der Kultivierungshypothese (vgl. S. 3) könnte deshalb argumentiert werden, dass das Fernsehinformationsangebot eine Fehleinschätzung der Größe und Relevanz der verschiedenen Wirtschaftsbereiche in Teilen des Publikums induziert. Es muss hier aber nicht zwangsläufig eine Verzerrung der Realität erkannt werden, schon weil der Fernsehberichterstattung keine Abbildungslogik zugrunde liegt. Und es ist zu bedenken, dass es auch keinen eindeutig richtigen Maßstab für die Einschätzung der Wichtigkeit der Wirtschaftsbereiche gibt. Diese muss nämlich nicht zwangsläufig an der Zahl der Erwerbstätigen ablesbar sein, sondern kann zum Beispiel auch auf dem Anteil am Bruttoinlandsprodukt (BIP) basieren. ${ }^{298}$ Allerdings sind auch das nur Konventionen, die ihrerseits Realitätskonstruktionen sind. Festgestellt werden kann hier insofern nur, dass das Wirtschaftsbild, das in den untersuchten Sendern (hinsichtlich der Anteile der Wirtschaftssektoren) gezeigt wird, sich zu keiner der genannten externen Konstruktionen konsistent verhält. Nicht zuletzt kann auch die reine äußere Nachrichtenlage für die Zusammensetzung der Berichterstattung verantwortlich sein. Insofern wären nur dann belastbare Aussagen über eine „Wirklichkeitsverzerrung“ möglich, wenn die Stichprobe repräsentativ für ein Kalenderjahr wäre, auf dem auch eine Berechnung der BIP-Anteile beruht.

Die deutliche Diskrepanz zwischen dem Medienbild der Wirtschaft und dem Bild, das durch Statistiken zur Bedeutung der Wirtschaft (und ihrer Teilbereiche) erzeugt wird, ist aber insbesondere hinsichtlich der nationalen Identität Deutschlands interessant. Wie oben dargelegt (vgl. S. 51) ist insbesondere mit Deutschland das Bild der „Wirtschaftsnation“ verbunden. Woraus sich dieser ökonomische Vorzug allerdings zusammensetzt, bleibt dem Fernsehpublikum weitgehend verborgen. Erstens lässt sich nicht behaupten, dass die Wirtschaft im Fernsehen ein besonders wichtiges Thema wäre (wenn auch im ZDF umfangreicher vertreten als in den anderen Programmen). Zweitens weicht das gezeichnete Bild auch noch deutlich von der tatsächlichen Bedeutung einzelner Wirtschaftsbereiche ab. ${ }^{299}$ Insofern erscheint die „Wirtschaftsnation" Deutschland als ein inkonsistentes Konstrukt.

\subsubsection{Themenbereich Geschichte}

Historische Themen sind in Magazinen der vier untersuchten Sender in sehr unterschiedlichem Ausmaß vorhanden. Im MDR macht die Geschichte mit 2 Stunden 38 Minuten acht Prozent aller Magazinbeiträge aus, im ZDF bezieht sich gut eine Stunde bzw. drei Prozent auf Historisches. Im ORF 2, wo der Umfang insgesamt etwas geringer ist, beziehen sich ebenfalls drei Prozent der hier berücksichtigten Sendezeit auf historische Themen, das sind absolut ge-

\footnotetext{
${ }^{298}$ Für Deutschland beispielsweise haben die verschiedenen Wirtschaftssektoren folgende Anteile am BIP von 2008: primärer Sektor: 0,9 Prozent, sekundärer Sektor: 29,6 Prozent, tertiärer Sektor: 69,5 Prozent

(vgl. Statistisches Bundesamt 2010). In Österreich: primärer Sektor: 1,7 Prozent, sekundärer Sektor: 30,3 Prozent, tertiärer Sektor: 68 Prozent (vgl. Statistik Austria 2010).

${ }^{299}$ Hierbei ist jedoch zu bedenken, dass sowohl Erwerbstätigenzahlen als auch Anteile am Bruttoinlandsprodukt auch nur konventionalisierte Beschreibungsverfahren sind. Ob es überhaupt einen objektiven Maßstab für die Bedeutung einer nationalen Wirtschaft oder ihrer Teilbereiche gibt, ist letztlich ein erkenntnistheoretisches Problem. Hier kann es nur darum gehen, ob verschiedene Formen der Wirklichkeitskonstruktion sich zueinander konsistent verhalten. Und das ist hier nicht der Fall.
} 
sehen 45 Minuten. Im Bayerischen Rundfunk bedeuten die ca. 30 Minuten historischer Themen einen Anteil von etwa zwei Prozent.

Diese Zahlen zeigen bereits, dass - jedenfalls innerhalb von Magazinsendungen - historische Themen eher randständig sind. Anders sieht das - zumindest für die deutschen Sender - auf Sendungsebene aus. ${ }^{300}$ Analog zum Thema „Religion“ soll hier ebenfalls ergänzend zu den Magazininhalten ein Blick auf Sendungsebene die Auswertung ergänzen.

\subsection{Anteile der am umfangreichsten berücksichtigten historischen The- men in Magazinen 301}

In den Magazinen des ORF 2 werden vor allem Themen des 20. Jahrhunderts behandelt, namentlich die Diskussion um das Atomkraftwerk Zwentendorf (das auf Grund einer Volksabstimmung im Jahr 1978 nach seiner Fertigstellung nicht in Betrieb gehen durfte) sowie USPräsidenten der Vergangenheit und ihre politischen Leistungen. Das macht 41 Prozent der historischen Themen aus. Auf Rang zwei folgen Beiträge, die sich mit der k.u.k.-Monarchie beschäftigen (27 Prozent). Jeweils um die zehn Prozent der Sendezeit zu historischen Themen entfallen auf Prähistorisches sowie den ersten Weltkrieg. Insgesamt sind diese Befunde allerdings auf Grund des insgesamt geringen Umfangs wenig aussagekräftig.

Das ZDF beschäftigt sich innerhalb der historischen Themen vor allem (zu über 50 Prozent) mit dem Dritten Reich. Zusätzlich entfallen auf die eng damit in Verbindung stehende Nachkriegszeit noch 16 Prozent der geschichtlichen Magazinbeiträge. Die Weimarer Republik, die ebenfalls in enger zeitlicher Nähe zur Zeit des Nationalsozialismus steht, wird in fünf Prozent der Beiträge behandelt. Damit entfallen drei der fünf sendezeitstärksten historischen Themen auf die Zeit zwischen ca. 1920 und 1950. ${ }^{302}$

Die Prominenz dieses historischen Zeitraums im ZDF erscheint in gewisser Weise paradox: Einerseits herrscht ein offenkundig großes Interesse (wie der Erfolg entsprechender Sendungen nahelegt), andererseits ist dieses Interesse möglicherweise einem allgemeinen historischen Interesse geschuldet, das nicht als Auseinandersetzung mit der eigenen Geschichte zu verstehen ist. Denn wie bereits erwähnt (vgl. S. 52) spielen die historischen Begriffe von Krieg, Holocaust und Nationalsozialismus in der deutschen Selbstwahrnehmung eine deutlich geringere Rolle als in der Sicht von außen auf Deutschland.

Von den 30 Minuten Sendezeit zu geschichtlichen Themen in Magazinen des BR entfallen 14 Minuten und damit ca. 43 Prozent auf Themen der prähistorischen Zeit. 17 Prozent entfallen auf allgemeine Themen des 20. Jahrhunderts, zehn Prozent auf das 18. Jahrhundert und eben-

\footnotetext{
300 Absolut gesehen beträgt der Umfang monothematischer auf Geschichte bezogener Sendungen im BR 2 Stunden, im ZDF eineinhalb Stunden und im MDR sechseinhalb Stunden.

${ }^{301}$ Eine Tabelle mit den genauen Anteilen und Umfängen der historischen Themen in Magazinen findet sich im Anhang (Tabelle 22, S. 324).

302 Auf historische Themen des 20. Jahrhunderts, die ohne Bezug auf genauer zu umschreibende historische Eckdaten bleiben, beziehen sich 19 Prozent, auf Themen aus dem 19. Jahrhundert 3 Prozent.
} 
falls zehn Prozent auf das Mittelalter. Das Königreich Bayern kommt in Magazinbeiträgen gar nicht vor.

Im $M D R$ wird ähnlich dem $Z D F$ vor allem das Dritte Reich thematisiert, wenn es um Geschichte geht. Hierauf entfallen 32 Prozent der Magazinbeiträge mit historischem Bezug. Daneben machen Informationen über das 19. Jahrhundert 13 Prozent und über das 18. Jahrhundert sieben Prozent der hier analysierten Sendezeit aus. ${ }^{303}$ Die DDR wird innerhalb der untersuchten Woche in keinem Beitrag als historisches Thema behandelt.

\subsection{Alleinstehende Sendungen zu historischen Themen in BR und MDR}

Die Betrachtung einzelner Dokumentationen zu historischen Themen wird hier auf die beiden Regionalprogramme beschränkt. Der Grund dafür ist, dass solche alleinstehenden Sendungen im ORF 2 und ZDF in wesentlichem Umfang nur je zweimal innerhalb der untersuchten Woche vorkommen und damit keine verwertbaren Aussagen erbracht werden können. ${ }^{304}$

Im MDR machen historische Themen 24 Prozent der monothematischen Informationssendungen (also hauptsächlich Dokumentationen) aus. Damit ist die Geschichte ganz eindeutig ein Schwerpunkt im Senderprofil des MDR. Im BR macht dieser Themenbereich dagegen mit etwas über zwei Stunden nur fünf Prozent der monothematischen Sendungen aus.

Im BR beschäftigt sich ein Drittel der hier betrachteten Sendungen mit dem Königreich Bayern. 23 Prozent der Sendezeit entfallen auf die Betrachtung des Mittelalters und jeweils etwa 20 Minuten auf das Deutsche Kaiserreich sowie die Antike. Diese Befunde deuten zwar in die auch in der Hypothese $\mathrm{H} 24 \mathrm{~d}^{305}$ vermutete Richtung, sind jedoch nur vorsichtig zu bewerten, da auf Grund des kurzen Untersuchungszeitraums die zugrunde liegenden Daten wenig umfangreich sind, wenn Einzelaspekte herausgegriffen werden.

Im MDR ist die Datenbasis umfangreicher, da im Programm insgesamt deutlich mehr Geschichte behandelt wird. Jeweils 24 Prozent entfallen auf Dokumentationen über die Zeit des Dritten Reichs sowie die DDR. 16 Prozent der Geschichtssendungen behandeln die Reformationszeit und jeweils elf Prozent entfallen auf das 17. Jahrhundert und die Antike. Die Behandlung der DDR ist unter allen hier untersuchten Sendern ein singuläres Phänomen. Dieser Teil deutscher Geschichte wird weder in Magazinen noch in Einzelsendungen der anderen untersuchten Sender thematisiert. Insofern ist der Befund, dass auch in MDR-Magazinen - entgegen der hypothetischen Vermutung - die DDR kein Thema ist, zu relativieren.

\footnotetext{
303 An zweiter Stelle der historischen Themen rangieren unspezifische Themen der zweiten Hälfte des 20. Jahrhunderts. Davon entfällt der Hauptanteil auf einen Beitrag über den US-amerikanischen Feuerwehrmann Red Adair. Dieser Beitrag ist die Wiederholung einer ursprünglich eigenständig im Ersten Programm der $A R D$ ausgestrahlten Dokumentation. Die Wiederholung lief hier aber im Rahmen der Sendung „Lexi-TV“. In dieser Sendung werden fast ausschließlich Wiederholungen von Beiträgen anderer $A R D$-Magazine oder ganzer Dokumentationen ausgestrahlt. Diese sind teilweise einige Jahre alt.

${ }^{304}$ Zumal im ORF 2 diese Sendungen insgesamt nur 15 Minuten umfassen. Im ZDF sind es eineinhalb Stunden, die aber zu 90 Prozent auf eine Sendung entfallen, die sich mit dem Mittelalter beschäftigt.

${ }^{305}$ Diese bezieht sich aber nur auf Magazininhalte.
} 
Die Wichtigkeit der Geschichte, sowohl für die nationale als auch regionale Identität, spiegelt sich im Programm der hier untersuchten Sender nur teilweise wider. Insbesondere ist die (theoretisch angenommene) Wichtigkeit nicht am bloßen Umfang innerhalb der Programminhalte abzulesen. Wo aber auf die jeweilige Landesgeschichte Bezug genommen wird, geschieht dies sehr wohl mit dem Hauptaugenmerk auf jene historischen Epochen, die oben (vgl. S. 138) den theoretischen Annahmen folgend - als herausragend benannt werden konnten. Allerdings nicht innerhalb von Magazinsendungen, sondern eher auf Ebene alleinstehender Dokumentationen. Die untersuchten Fernsehinhalte verhalten sich in diesem Kontext also konsistent zu den Konstruktionsmechanismen nationaler und regionaler Identität.

\subsubsection{Ergebnisse Themen der Berichterstattung}

Hypothese H17 wird angenommen. Sowohl anteilsmäßig als auch und vor allem hinsichtlich der absoluten Sendezeit, die für Hochkultur aufgewendet wird, nimmt der ORF 2 die führende Position unter allen untersuchten Programmen ein.

Hypothese H18 wird abgelehnt. Weder ist der Anteil der Berichterstattung über klassische Musik im ORF 2 höher als in den anderen Sendern noch sind die Umfänge der hierauf entfallenden Sendezeit in allen Programmen groß genug, um valide Aussagen treffen zu können.

Hypothese H19 wird abgelehnt. Obwohl hinweisende und „bloß“ informierende Berichterstattung häufiger ist als Formen der Kritik es sind, liegt darin keine Besonderheit des Regionalprogramms, zumal Kritik hier sogar häufiger stattfindet als im nationalen Programm.

Hypothese H20 wird abgelehnt. Kulturpolitik kommt im nationalen und regionalen Programm gleichermaßen so gut wie gar nicht vor.

Hypothese H21 a wird angenommen. Fußball ist die dominierende Sportart nicht nur im ZDF, sondern in allen untersuchten Sendern. Lediglich im ORF 2 wird häufiger über Doping im Sport berichtet. Das ist aber sportartunspezifisch.

Hypothese H21b wird abgelehnt. In der Themenrangfolge innerhalb der Sportberichterstattung rangiert alpiner Skisport im ORF 2 nur auf Rang vier. Damit ist er zudem nur die am zweithäufigsten beachtete Sportart in diesem Sender. Eine Dominanz besteht hier also nicht, auch wenn diese Sportart eine wichtige Rolle spielt.

Hypothese H21c wird angenommen. Im MDR dominiert Berichterstattung über Fußball auf Dritt- und Regionalligaebene.

Hypothese H21d wird angenommen. Im BR wird vor allem über den Fußball in der Ersten und Zweiten Bundesliga berichtet.

Hypothese H22 wird abgelehnt. Breitensport kommt sowohl im nationalen $(Z D F)$ als auch regionalen Programm vor. 
Hypothese $\mathrm{H} 23 \mathrm{a}$ wird angenommen. Die katholische Konfession ist in Magazinbeiträgen des $B R$ eindeutig die am häufigsten vorkommende Glaubensrichtung. Das trifft darüber hinaus auch auf monothematische Sendungen zu religiösen Themen zu.

Hypothese H23b wird angenommen. Das Thema Religion spielt in Magazinbeiträgen im Mitteldeutschen Rundfunk keine Rolle. Es gibt jedoch Einzelsendungen, die sich religiösen Belangen widmen.

Hypothese H23c wird abgelehnt. Zwar sind die Unterschiede zwischen Sendezeitanteilen für Themen der evangelischen und der katholischen Kirche absolut gesehen gering. Der Gesamtumfang ist aber nicht groß genug, um hierzu eine verlässliche Aussage zu treffen. Zudem widerspricht auch der Befund auf Sendungsebene der hypothetischen Annahme.

Hypothese H23d wird abgelehnt. Die katholische Konfession dominiert zwar die Berichterstattung über die christlichen Kirchen. Allgemein-religiöse Themen machen jedoch den Hauptanteil der Beiträge zu Aspekten des Glaubens aus.

Hypothese H24a wird abgelehnt. Die DDR wird in Magazinen des MDR als historisches Thema nicht behandelt. Allerdings setzen sich monothematische Sendungen sehr wohl mit dem einstigen sozialistischen Staat auseinander.

Hypothese H24b wird angenommen. Die Zeit der nationalsozialistischen Herrschaft spielt in Magazinen des $Z D F$ von allen historischen Themen die größte Rolle. Dieser Eindruck bestätigt sich noch dadurch, dass auch die unmittelbar vor- und nachher gelegenen Perioden der deutschen Geschichte thematisiert werden.

Hypothese H24c wird abgelehnt. Die k.u.k.-Monarchie ist nicht das häufigste der historischen Themen im ORF 2. Zudem spielen geschichtliche Betrachtungen insgesamt eine so untergeordnete Rolle, dass die diesbezüglichen Befunde nicht aussagekräftig sind.

Hypothese H24d wird abgelehnt. Das Königreich Bayern ist in Magazinsendungen des BR gar kein Thema. Allerdings wird es im Rahmen von alleinstehenden Dokumentationssendungen behandelt.

\subsubsection{Zu Wort kommende Akteurinnen und Akteure der Berichter- stattung}

\subsubsection{Umgebung}

Die Umgebung, in der Akteure und Akteurinnen gezeigt werden, bestimmt deren Wahrnehmung mit. Beispielsweise verleiht das Interview am Arbeitsplatz Seriosität und Kompetenz (vgl. Wegener 2001: 185). Darüber hinaus kann die Umgebung aber auch Identität stiften. Normalbürger und Normalbürgerinnen, die in ihrer Wohnung gezeigt werden, haben mögli- 
cherweise eine ähnlich eingerichtete Wohnung wie manche Zuschauerin oder mancher Zuschauer. Polizistinnen und Polizisten, die in der Fußgängerzone patrouillieren, lassen die Innenstadt, in der ältere Zuschauerinnen und Zuschauer vielleicht schon länger nicht mehr waren, als halbwegs sicheren Ort erscheinen. Überhaupt wird erst durch die gezeigte Umgebung das Bild scheinbar vollständig. Soll also das Fernsehen dem Publikum eine gemeinsame Vorstellung des geteilten Lebensraums, der Region oder eben der Nation vermitteln, so wäre dafür die künstliche Umgebung des Fernsehstudios eher hinderlich, Außenaufnahmen dagegen nicht. ${ }^{306}$

Tabelle 16: Umgebung der in Magazinbeiträgen zu Wort kommenden Akteure in Beiträgen mit Bezugsraum im Sendegebiet

\begin{tabular}{|c|c|c|c|c|c|c|c|c|}
\hline \multirow[b]{2}{*}{ Umgebung } & \multicolumn{2}{|c|}{ ORF 2} & \multicolumn{2}{|c|}{ ZDF } & \multicolumn{2}{|c|}{ BR } & \multicolumn{2}{|c|}{ MDR } \\
\hline & Anzahl & Anteil & Anzahl & Anteil & Anzahl & Anteil & Anzahl & Anteil \\
\hline Studio & 47 & $7,79 \%$ & 104 & $10,57 \%$ & 61 & $9,78 \%$ & 110 & $16,77 \%$ \\
\hline $\begin{array}{l}\text { Berufliche Umge- } \\
\text { bung/Arbeitsplatz }\end{array}$ & 100 & $16,58 \%$ & 187 & $19,00 \%$ & 72 & $11,54 \%$ & 161 & $24,54 \%$ \\
\hline $\begin{array}{l}\text { Semi-öffentliche } \\
\text { Umgebung }\end{array}$ & 90 & $14,93 \%$ & 218 & $22,15 \%$ & 102 & $16,35 \%$ & 80 & $12,20 \%$ \\
\hline $\begin{array}{l}\text { Öffentliche Um- } \\
\text { gebung }\end{array}$ & 331 & $54,89 \%$ & 383 & $38,92 \%$ & 362 & $58,01 \%$ & 178 & $27,13 \%$ \\
\hline Private Umgebung & 34 & $5,64 \%$ & 74 & $7,52 \%$ & 23 & $3,69 \%$ & 53 & $8,08 \%$ \\
\hline Natur/Landschaft & 0 & $0,00 \%$ & 1 & $0,10 \%$ & 0 & $0,00 \%$ & 50 & $7,62 \%$ \\
\hline $\begin{array}{l}\text { Sonstige Umge- } \\
\text { bung/nicht identi- } \\
\text { fizierbar }\end{array}$ & 1 & $0,17 \%$ & 17 & $1,73 \%$ & 4 & $0,64 \%$ & 24 & $3,66 \%$ \\
\hline Gesamt & 603 & $100,00 \%$ & 984 & $100,00 \%$ & 624 & $100,00 \%$ & 656 & $100,00 \%$ \\
\hline
\end{tabular}

Die Zusammensetzung der Umgebung, in denen die Zu-Wort-Kommenden in den verschiedenen Sendern präsentiert werden, ist sehr unterschiedlich (vgl. Tabelle 16). Während im ORF 2 und $B R$ jeweils über die Hälfte der O-Töne in öffentlicher Umgebung, also auf StraBen, Plätzen, Parks und ähnlichem eingefangen wurden, trifft dies im ZDF in 39 Prozent der Fälle zu, im MDR in nur 27 Prozent. Dagegen wird im MDR besonders häufig die berufliche Umgebung als Ort der Darstellung gewählt. Das ist im BR nur zu zwölf Prozent die gezeigte Umgebung, im ZDF zu 19 Prozent und zu 17 Prozent im ORF 2. Der hohe Anteil beruflicher Umgebung, in der Personen im MDR gezeigt werden, ist vor dem Hintergrund der hohen

306 Wobei hier nur auf den Kontext von Informationssendungen abgezielt wird. Die Studioumgebung der „Lindenstraße“ vermittelt auch eine Vorstellung von Wohn- und Lebensräumen in München, steht aber in Köln. 
Arbeitslosigkeit in weiten Teilen des Sendegebiets besonders interessant - zumal dieses Problem dort als besonders prekär empfunden wird ${ }^{307}$.

Daneben ist im MDR auch das Studio ein gern gewählter Hintergrund. In den anderen Sendern ist das seltener der Fall. Ebenfalls in den Ergebnissen zum MDR fällt auf, dass dies der einzige Sender ist, in dem die freie Natur als Ort der Berichterstattung eine wesentliche Rolle spielt. Halb-öffentliche Hintergründe spielen in allen Sendern zusätzlich zu öffentlichen Umgebungen eine große Rolle. Es handelt sich dabei um Orte, die im Wesentlichen zwischen beruflicher und öffentlicher Umgebung anzusiedeln sind, also etwa Krankenhäuser (wenn nicht Arzt oder Ärztin, sondern Patientin oder Patient interviewt wird), Gerichtsgebäude und ähnlichem. Die private Umgebung spielt im BR eine untergeordnete Rolle, was so ähnlich auch im ORF 2 zu beobachten ist. Im ZDF und MDR werden jeweils ca. acht Prozent der ZuWort-Kommenden in ihrer häuslichen Umgebung gezeigt.

Es lassen sich zwischen den Sendern durchaus einige Differenzen ausmachen, die sich aber nicht entlang der Unterscheidung von nationalen und regionalen Programmen bewegen. In allen Sendern ist aber die Öffentlichkeit der wichtigste Ort der Präsentation von Akteurinnen und Akteuren. Insofern dürfte eine hohe Wiedererkennbarkeit des Sendegebiets für viele $\mathrm{Zu}$ schauer möglich sein. Das bezieht sich selbstverständlich nicht nur auf solche öffentlichen Plätze, die auf Grund ihres Charakters als Sehenswürdigkeit von selbst einen hohen Wiedererkennungswert haben. Vielmehr spiegelt sich die Eigenart von Regionen ja zum Beispiel auch in Architekturen wider. ${ }^{308}$

\subsubsection{Dialekt}

Hinsichtlich der Dialektverwendung unterscheiden sich die vier untersuchten Sender zum Teil beträchtlich. Es lässt sich allerdings nicht an der Vermutung festhalten, dass diese Unterschiede sich aus der Klassifizierung als nationales oder regionales Programm ergäben. Vielmehr wird im ORF 2 am häufigsten ein zumindest leichter Dialekt gesprochen (vgl. Abbildung 75), während im ZDF am häufigsten Hochdeutsch zu hören ist (vgl. Abbildung 76). Hierbei ist jedoch zu bedenken, dass sich das in Deutschland und Österreich gesprochene Deutsch möglicherweise grundsätzlich unterscheiden. Nimmt man etwa die Aussprache von Nachrichtensprecherinnen oder -sprechern als Ausgangspunkt, so dürfte deutschen Hörerinnen und Hörern in der Regel ein Unterschied zwischen österreichischen und deutschen Nachrichten auf-

307 „In beiden Teilen Deutschlands nimmt die Arbeitslosigkeit als größtes Problem eine zentrale Stellung ein. Dabei ist die Besorgnis in den neuen Bundesländern mit $73 \%$ größer als in den alten mit $64 \%$. Die Bürger im Osten zeigen sich seit der Wiedervereinigung stets beunruhigter über die Arbeitsmarktsituation als die Bürger im Westen“ (Lades/Frank 2010: 3).

Es bleibt allerdings der bloßen Spekulation vorbehalten, über Zusammenhänge zwischen der Diskrepanz von Darstellung und Wahrnehmung nachzudenken. Zumal dann auch - ebenso spekulativ - in Betracht zu ziehen wäre, inwiefern das Selbstbild der Einwohnerinnen und Einwohner Mitteldeutschlands eventuell (DDR-) sozialisationsbedingt ohnehin stärker an die Berufstätigkeit gebunden ist als im Bundesdurchschnitt.

${ }^{308}$ Das muss nicht zwangsläufig das Fachwerkhaus oder das reetgedeckte Dach sein. Auch Reihenhaussiedlungen, die in ganz Deutschland nur marginal unterschiedlich aussehen, können die Wahrnehmung der eigenen Umgebung mit der im Fernsehen konsistent machen. 
fallen. Entsprechend müsste ein Index entwickelt werden, der die Stärke des Dialekts jeweils von einem Nachrichtensprecher als Beispiel für Standardsprache ausgehend einordnet. Damit könnte dann die jeweilige Abweichung von diesem Standard gemessen werden und mutmaßlich andere Ergebnisse hinsichtlich des Unterschieds zwischen nationalen und regionalen Sendern erbringen. Damit würde aber andererseits ein tatsächlich bestehender Unterschied zwischen Österreich und Deutschland verwischt werden. Insofern können die Befunde vielmehr als Ausdruck sprachlicher Besonderheiten in Österreich gelesen werden.

Hinsichtlich des ZDF ist anzumerken, dass fast ein Viertel der Zu-Wort-Kommenden weder hochdeutsch noch Dialekt spricht. Das sind in der übergroßen Mehrheit fremdsprachige Personen und daher Ausdruck des hohen Anteils an Auslandsberichterstattung im ZDF.

Abbildung 75: ORF 2 - Dialektverwendung der zu Wort kommenden Personen

Basis: alle untersuchten Personen in allen Magazinbeiträgen $=603$ Personen

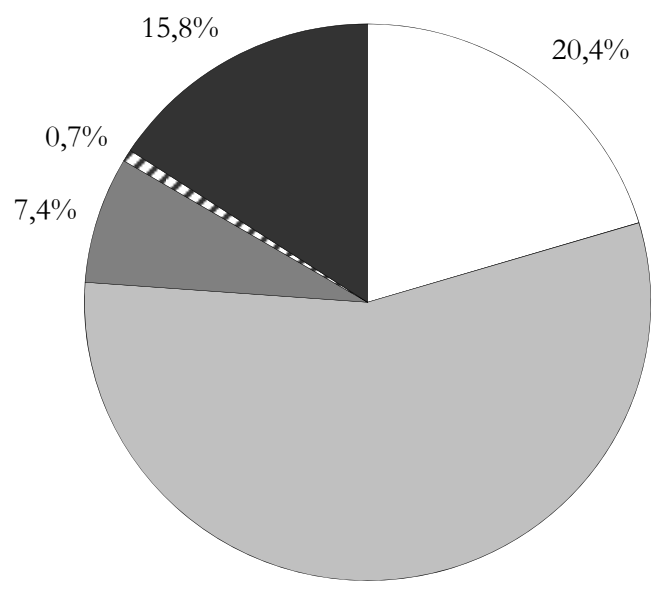

$55,8 \%$ $\square$ Hochdeutsch

$\square$ Leichte dialektische Einfärbung

$\square$ Starker Dialekt

\Sehr stark/Regionalsprache

- Trifft nicht zufremdsprachig/Gebärdensprache/ sonst. 
Abbildung 76: ZDF - Dialektverwendung der zu Wort kommenden Personen

Basis: alle untersuchten Personen in allen Magazinbeiträgen $=984$ Personen

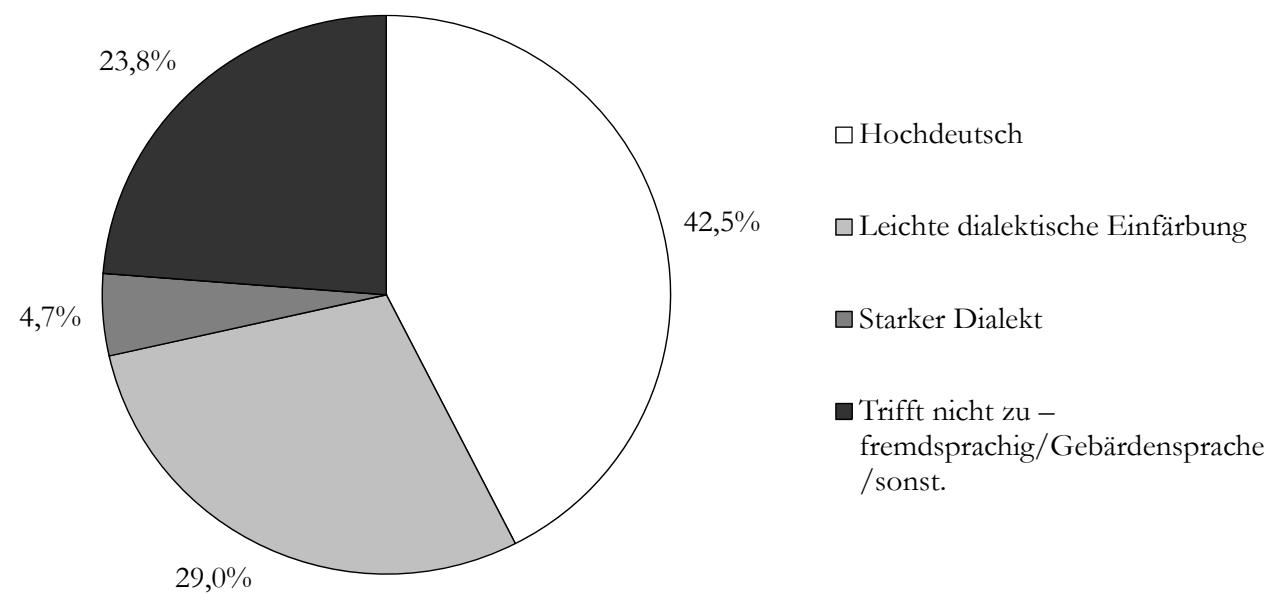

Auch die beiden regionalen Sender unterscheiden sich hinsichtlich des vorkommenden Dialekts und seiner Ausprägung (vgl. Abbildung 77 und Abbildung 78). In beiden Sendern spricht ca. ein Drittel der Zu-Wort-Kommenden hochdeutsch. Allerdings kommen im MDR deutlich häufiger Sprecherinnen und Sprecher mit starkem Dialekt vor als im BR. Hier ist dagegen ein leichter Dialekt viel häufiger zu hören. Insgesamt ist in beiden Regionalprogrammen aber Dialekt häufiger zu hören als Hochdeutsch. Sehr starker Dialekt bzw. Regionalsprache ist in allen Sendern am seltensten zu hören. Immerhin für die Regionalprogramme ist das ein überraschender Befund. Hier hätte man erwarten können, dass der regionalen Verwurzelung auch dadurch Raum gegeben wird, dass sprachliche Eigenheiten, die vielleicht sogar singulärer $\mathrm{Na}$ tur sind (im Sinne einer subregionalen Begrenztheit), gepflegt werden. Möglicherweise schlagen hier redaktionelle Entscheidungen durch, die insgesamt zu einer Einebnung von Dialekt im Fernsehen führen können. Menschen, deren Sprache nur durch Untertitelung für die Mehrzahl der Zuschauerinnen und Zuschauer verständlich wird, werden wegen dieses Mehraufwands eventuell bewusst nicht gezeigt.

Interessant ist auch der Unterschied in der Verwendung starken Dialekts bei MDR und BR. Während in dem ostdeutschen Sender über ein Viertel der zu Wort kommenden Personen einen starken regionalen Zungenschlag pflegt, trifft dies beim Sender aus dem Freistaat bei weniger als 14 Prozent der Fälle zu. Hierfür ist auch nicht - wie man vielleicht vermuten könnte - die unterschiedliche Zusammensetzung der Personen verantwortlich, die sich vor 
der Kamera äußern. ${ }^{309}$ Der Unterschied wird aber sogar stärker, wenn man nur die „unorganisierten Privatpersonen" - also solche ohne Fernsehsprecherfahrungen - betrachtet. Im BR sprechen davon nur 19 Prozent „starken Dialekt“, im MDR sind es 40 Prozent. Eine leichte Dialekteinfärbung ist im BR bei fast der Hälfte (49 Prozent) der Normalpersonen zu hören, aber nur bei 28 Prozent derer im MDR (vgl. Tabelle 23 im Anhang, S. 325). Es handelt sich also um einen tatsächlich systematischen Unterschied zwischen den beiden Regionalprogrammen, über dessen Zustandekommen mit den vorliegenden Daten aber keine Aussagen gemacht werden können. ${ }^{310}$

Abbildung 77: BR - Dialektverwendung der zu Wort kommenden Personen

Basis: alle untersuchten Personen in allen Magazinbeiträgen $=624$ Personen

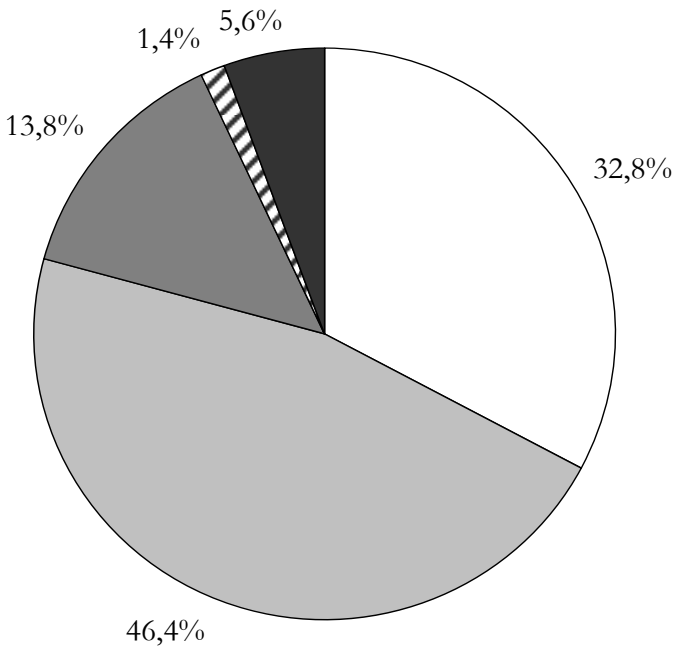

\author{
$\square$ Hochdeutsch \\ $\square$ Leichte dialektische \\ Einfärbung \\ $\square$ Starker Dialekt \\ चSehr stark/Regionalsprache \\ Trifft nicht zu - \\ fremdsprachig/ \\ Gebärdensprache/sonst.
}

\footnotetext{
${ }^{309}$ Insbesondere der Unterschied bei der Anzahl der Politiker könnte hier relevant sein (siehe S. 260)

${ }^{310}$ Es sind verschiedene Möglichkeiten denkbar. Es kann sich um redaktionelle Glättungen handeln. Diese wären dann im BR stärker als im MDR. Es kann sich auch um reziproke Effekte handeln, dergestalt, dass sich Menschen vor der Kamera bemühen, ein allgemein verständliches Deutsch zu sprechen. Warum dies im BR dann stärker durchschlägt als im MDR ist eine ebenfalls interessante - aber hier nicht zu beantwortende - Frage. Es könnte zum Beispiel mit der regionalspezifischen Verbundenheit der Personen zu dem Sender zusammenhängen. Das hieße, dass gegenüber einer Kamera des $M D R$, eine Dialekt sprechende Person in dem stärkeren Bewusstsein spräche, dass es sich um ein regionales Programm handelte, in dessen Sendegebiet man ihre Aussprache größtenteils verstehen werde. Auch wenn diese Gedanken spekulativer Natur sind, verweisen sie auf Fragen, die im erweiterten Gegenstandsbereich der vorliegenden Arbeit liegen. Gerade für die regionale Identität eines Regionalprogramms ist es von Belang, wie es wahrgenommen wird. Sobald es nur noch als ein Programm unter vielen erscheint und auch so genutzt wird, büßt es an Existenzberechtigung ein.
} 
Abbildung 78: MDR - Dialektverwendung der zu Wort kommenden Personen

Basis: alle untersuchten Personen in allen Magazinbeiträgen $=656$ Personen

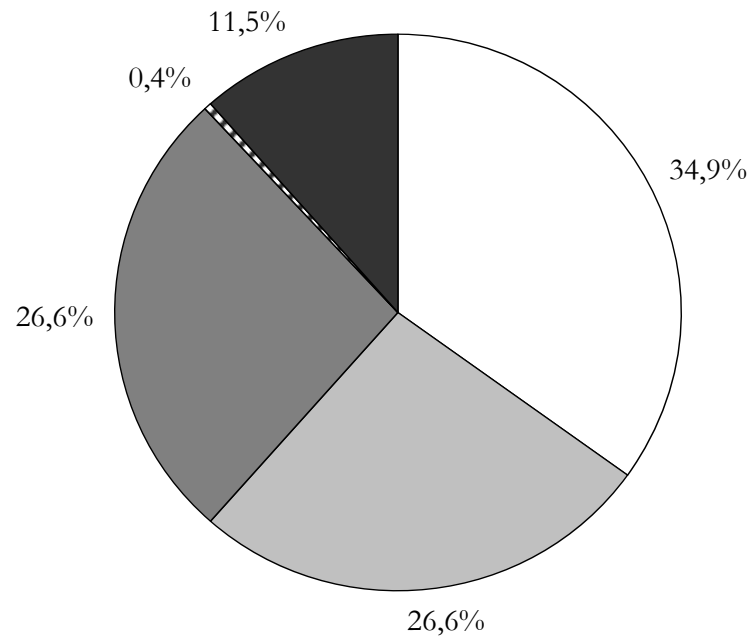

$\square$ Hochdeutsch

$\square$ Leichte dialektische Einfärbung

$\square$ Starker Dialekt

Sehr stark/Regionalsprache

Trifft nicht zu -

fremdsprachig/Gebärdensprache/ sonst.

\subsubsection{Bandbreite der gezeigten Akteurinnen und Akteure}

Die vor der Kamera Zu-Wort-Kommenden lassen sich verschiedenen Personengruppen zuordnen. In der Gegenüberstellung zeigt sich, welche gesellschaftlichen Gruppen im Fernsehen besonders häufig eine Plattform finden und welche nicht. Auch hier erfolgt die Darstellung einmal unter Berücksichtigung der Nachrichtenmagazine und einmal ohne, um auch die Befunde des MDR, in dem es diese Sendungsform nicht gibt, mit den anderen Sendern vergleichen zu können.

Tabelle 17: Zu Wort kommende Akteurinnen und Akteure nach Gruppenzuordnung Basis: alle untersuchten Personen in allen Magazinbeiträgen

\begin{tabular}{|c|c|c|c|c|c|c|c|c|}
\hline \multirow[b]{2}{*}{ Bereich/Gruppe } & \multicolumn{2}{|c|}{ ORF 2} & \multicolumn{2}{|c|}{ ZDF } & \multicolumn{2}{|c|}{ BR } & \multicolumn{2}{|c|}{ MDR } \\
\hline & Anzahl & Anteil & Anzahl & Anteil & Anzahl & Anteil & Anzahl & Anteil \\
\hline Politik & 86 & $11,93 \%$ & 117 & $9,24 \%$ & 98 & $13,39 \%$ & 27 & $2,82 \%$ \\
\hline Justiz & 17 & $2,36 \%$ & 49 & $3,87 \%$ & 4 & $0,55 \%$ & 28 & $2,93 \%$ \\
\hline $\begin{array}{l}\text { Polizei/Zoll/ } \\
\text { Ordnungsamt/ } \\
\text { Feuerwehr/ } \\
\text { Rettung }\end{array}$ & 20 & $2,77 \%$ & 60 & $4,74 \%$ & 5 & $0,68 \%$ & 62 & $6,49 \%$ \\
\hline Armee/Militär & 0 & $0,00 \%$ & 3 & $0,24 \%$ & 0 & $0,00 \%$ & 2 & $0,21 \%$ \\
\hline $\begin{array}{l}\text { Gewerkschaften/ } \\
\text { Arbeitnehmer- } \\
\text { vertretung }\end{array}$ & 4 & $0,55 \%$ & 10 & $0,79 \%$ & 2 & $0,27 \%$ & 3 & $0,31 \%$ \\
\hline
\end{tabular}




\begin{tabular}{|c|c|c|c|c|c|c|c|c|}
\hline \multirow[b]{2}{*}{ Bereich/Gruppe } & \multicolumn{2}{|c|}{ ORF 2} & \multicolumn{2}{|c|}{ ZDF } & \multicolumn{2}{|c|}{ BR } & \multicolumn{2}{|c|}{ MDR } \\
\hline & Anzahl & Anteil & Anzahl & Anteil & Anzahl & Anteil & Anzahl & Anteil \\
\hline $\begin{array}{l}\text { Sonstige Grup- } \\
\text { pen/Organisatione } \\
\text { n politisch/ } \\
\text { sozial engagierter } \\
\text { Privatpersonen }\end{array}$ & 13 & $1,80 \%$ & 19 & $1,50 \%$ & 17 & $2,32 \%$ & 9 & $0,94 \%$ \\
\hline $\begin{array}{l}\text { Wirtschaft/In- } \\
\text { dustrie/Arbeit- } \\
\text { gebervertretung/ } \\
\text { Dienstleistung - } \\
\text { institutionalisierte } \\
\text { Gruppenver- } \\
\text { tretung }\end{array}$ & 4 & $0,55 \%$ & 53 & $4,19 \%$ & 3 & $0,41 \%$ & 9 & $0,94 \%$ \\
\hline $\begin{array}{l}\text { Öffentlicher } \\
\text { Dienst }\end{array}$ & 12 & $1,66 \%$ & 8 & $0,63 \%$ & 7 & $0,96 \%$ & 29 & $3,03 \%$ \\
\hline $\begin{array}{l}\text { Privatwirtschaftli- } \\
\text { che Funktion- } \\
\text { sperson }\end{array}$ & 106 & $14,70 \%$ & 114 & $9,00 \%$ & 89 & $12,16 \%$ & 141 & $14,75 \%$ \\
\hline Journalismus & 36 & $4,99 \%$ & 32 & $2,53 \%$ & 14 & $1,91 \%$ & 19 & $1,99 \%$ \\
\hline Bildungswesen & 0 & $0,00 \%$ & 3 & $0,24 \%$ & 12 & $1,64 \%$ & 4 & $0,42 \%$ \\
\hline $\begin{array}{l}\text { Religiöse Funkti- } \\
\text { onsträger }\end{array}$ & 12 & $1,66 \%$ & 7 & $0,55 \%$ & 14 & $1,91 \%$ & 5 & $0,52 \%$ \\
\hline $\begin{array}{l}\text { Wissenschaft/ } \\
\text { Forschung }\end{array}$ & 29 & $4,02 \%$ & 48 & $3,79 \%$ & 56 & $7,65 \%$ & 42 & $4,39 \%$ \\
\hline Ärzte/Mediziner & 15 & $2,08 \%$ & 32 & $2,53 \%$ & 3 & $0,41 \%$ & 31 & $3,24 \%$ \\
\hline $\begin{array}{l}\text { Humanitäre Orga- } \\
\text { nisation/ } \\
\text { Naturschutz }\end{array}$ & 3 & $0,42 \%$ & 7 & $0,55 \%$ & 3 & $0,41 \%$ & 1 & $0,10 \%$ \\
\hline Show-Business & 76 & $10,54 \%$ & 114 & $9,00 \%$ & 25 & $3,42 \%$ & 81 & $8,47 \%$ \\
\hline $\begin{array}{l}\text { Königshäu- } \\
\text { ser/Adel }\end{array}$ & 5 & $0,69 \%$ & 6 & $0,47 \%$ & 1 & $0,14 \%$ & 4 & $0,42 \%$ \\
\hline $\begin{array}{l}\text { Sonstige Interes- } \\
\text { senverbände }\end{array}$ & 4 & $0,55 \%$ & 25 & $1,97 \%$ & 7 & $0,96 \%$ & 31 & $3,24 \%$ \\
\hline $\begin{array}{l}\text { Coaching/Thera- } \\
\text { pie/Lebenshilfe }\end{array}$ & 3 & $0,42 \%$ & 2 & $0,16 \%$ & 1 & $0,14 \%$ & 10 & $1,05 \%$ \\
\hline Sport & 48 & $6,66 \%$ & 82 & $6,48 \%$ & 70 & $9,56 \%$ & 54 & $5,65 \%$ \\
\hline $\begin{array}{l}\text { Nicht organisierte } \\
\text { Privatperson }\end{array}$ & 167 & $23,16 \%$ & 451 & $35,62 \%$ & 253 & $34,56 \%$ & 332 & $34,73 \%$ \\
\hline $\begin{array}{l}\text { Kunst/Kultur/ } \\
\text { Literatur }\end{array}$ & 55 & $7,63 \%$ & 20 & $1,58 \%$ & 43 & $5,87 \%$ & 13 & $1,36 \%$ \\
\hline $\begin{array}{l}\text { Kulturelle Organi- } \\
\text { sationen }\end{array}$ & 0 & $0,00 \%$ & 1 & $0,08 \%$ & 1 & $0,14 \%$ & 9 & $0,94 \%$ \\
\hline Sonstige & 6 & $0,83 \%$ & 3 & $0,24 \%$ & 4 & $0,55 \%$ & 10 & $1,05 \%$ \\
\hline Gesamt & 721 & $100,00 \%$ & 1266 & $100,00 \%$ & 732 & $100,00 \%$ & 956 & $100,00 \%$ \\
\hline
\end{tabular}


Tabelle 18: Zu Wort kommende Akteurinnen und Akteure nach Gruppenzuordnung

Basis: alle untersuchten Personen in allen Magazinbeiträgen ohne Nachrichtenmagazine

\begin{tabular}{|c|c|c|c|c|c|c|c|c|}
\hline \multirow[b]{2}{*}{ Bereich/Gruppe } & \multicolumn{2}{|c|}{ ORF 2} & \multicolumn{2}{|c|}{ ZDF } & \multicolumn{2}{|c|}{ BR } & \multicolumn{2}{|c|}{ MDR } \\
\hline & Anzahl & Anteil & Anzahl & Anteil & Anzahl & Anteil & Anzahl & Anteil \\
\hline Politik & 47 & $7,40 \%$ & 32 & $4,02 \%$ & 77 & $11,41 \%$ & 27 & $2,82 \%$ \\
\hline Justiz & 16 & $2,52 \%$ & 46 & $5,78 \%$ & 4 & $0,59 \%$ & 28 & $2,93 \%$ \\
\hline $\begin{array}{l}\text { Polizei/Zoll/ } \\
\text { Ordnungsamt/ } \\
\text { Feuerwehr/ } \\
\text { Rettung }\end{array}$ & 19 & $2,99 \%$ & 54 & $6,78 \%$ & 5 & $0,74 \%$ & 62 & $6,49 \%$ \\
\hline Armee/Militär & 0 & $0,00 \%$ & 0 & $0,00 \%$ & 0 & $0,00 \%$ & 2 & $0,21 \%$ \\
\hline $\begin{array}{l}\text { Gewerkschaften/ } \\
\text { Arbeitnehmer- } \\
\text { vertretung }\end{array}$ & 3 & $0,47 \%$ & 1 & $0,13 \%$ & 1 & $0,15 \%$ & 3 & $0,31 \%$ \\
\hline $\begin{array}{l}\text { Sonstige Grup- } \\
\text { pen/Organisatione } \\
\text { n politisch/ } \\
\text { sozial engagierter } \\
\text { Privatpersonen }\end{array}$ & 12 & $1,89 \%$ & 18 & $2,26 \%$ & 16 & $2,37 \%$ & 9 & $0,94 \%$ \\
\hline $\begin{array}{l}\text { Wirtschaft/In- } \\
\text { dustrie/Arbeit- } \\
\text { gebervertretung/ } \\
\text { Dienstleistung- } \\
\text { institutionalisierte } \\
\text { Gruppenver- } \\
\text { tretung }\end{array}$ & 4 & $0,63 \%$ & 15 & $1,88 \%$ & 1 & $0,15 \%$ & 9 & $0,94 \%$ \\
\hline $\begin{array}{l}\text { Öffentlicher } \\
\text { Dienst }\end{array}$ & 12 & $1,89 \%$ & 4 & $0,50 \%$ & 7 & $1,04 \%$ & 29 & $3,03 \%$ \\
\hline $\begin{array}{l}\text { Privatwirtschaftli- } \\
\text { che Funktion- } \\
\text { sperson }\end{array}$ & 96 & $15,12 \%$ & 67 & $8,42 \%$ & 84 & $12,44 \%$ & 141 & $14,75 \%$ \\
\hline Journalismus & 35 & $5,51 \%$ & 24 & $3,02 \%$ & 10 & $1,48 \%$ & 19 & $1,99 \%$ \\
\hline Bildungswesen & 0 & $0,00 \%$ & 2 & $0,25 \%$ & 12 & $1,78 \%$ & 4 & $0,42 \%$ \\
\hline $\begin{array}{l}\text { Religiöse Funkti- } \\
\text { onsträger }\end{array}$ & 12 & $1,89 \%$ & 2 & $0,25 \%$ & 12 & $1,78 \%$ & 5 & $0,52 \%$ \\
\hline $\begin{array}{l}\text { Wissenschaft/ } \\
\text { Forschung }\end{array}$ & 26 & $4,09 \%$ & 18 & $2,26 \%$ & 54 & $8,00 \%$ & 42 & $4,39 \%$ \\
\hline Ärzte/Mediziner & 15 & $2,36 \%$ & 26 & $3,27 \%$ & 3 & $0,44 \%$ & 31 & $3,24 \%$ \\
\hline $\begin{array}{l}\text { Humanitäre Orga- } \\
\text { nisation/ } \\
\text { Naturschutz }\end{array}$ & 3 & $0,47 \%$ & 3 & $0,38 \%$ & 3 & $0,44 \%$ & 1 & $0,10 \%$ \\
\hline Show-Business & 72 & $11,34 \%$ & 87 & $10,93 \%$ & 25 & $3,70 \%$ & 81 & $8,47 \%$ \\
\hline $\begin{array}{l}\text { Königshäu- } \\
\text { ser/Adel }\end{array}$ & 4 & $0,63 \%$ & 6 & $0,75 \%$ & 1 & $0,15 \%$ & 4 & $0,42 \%$ \\
\hline $\begin{array}{l}\text { Sonstige Interes- } \\
\text { senverbände }\end{array}$ & 3 & $0,47 \%$ & 13 & $1,63 \%$ & 5 & $0,74 \%$ & 31 & $3,24 \%$ \\
\hline $\begin{array}{l}\text { Coaching/Thera- } \\
\text { pie/Lebenshilfe }\end{array}$ & 3 & $0,47 \%$ & 2 & $0,25 \%$ & 1 & $0,15 \%$ & 10 & $1,05 \%$ \\
\hline Sport & 47 & $7,40 \%$ & 54 & $6,78 \%$ & 62 & $9,19 \%$ & 54 & $5,65 \%$ \\
\hline $\begin{array}{l}\text { Nicht organisierte } \\
\text { Privatperson }\end{array}$ & 146 & $22,99 \%$ & 305 & $38,32 \%$ & 247 & $36,59 \%$ & 332 & $34,73 \%$ \\
\hline
\end{tabular}




\begin{tabular}{l|r|c|r|r|r|r|r|r} 
& \multicolumn{2}{|c|}{ ORF 2 } & \multicolumn{2}{c|}{ ZDF } & \multicolumn{2}{c|}{ BR } & \multicolumn{2}{c}{ MDR } \\
\hline Bereich/Gruppe & Anzahl & Anteil & Anzahl & Anteil & Anzahl & Anteil & Anzahl & Anteil \\
\hline $\begin{array}{l}\text { Kunst/Kultur/ } \\
\text { Literatur }\end{array}$ & 54 & $8,50 \%$ & 15 & $1,88 \%$ & 41 & $6,07 \%$ & 13 & $1,36 \%$ \\
\hline $\begin{array}{l}\text { Kulturelle Organi- } \\
\text { sationen }\end{array}$ & 0 & $0,00 \%$ & 0 & $0,00 \%$ & 1 & $0,15 \%$ & 9 & $0,94 \%$ \\
\hline Sonstige & 6 & $0,94 \%$ & 2 & $0,25 \%$ & 3 & $0,44 \%$ & 10 & $1,05 \%$ \\
\hline Gesamt & $\mathbf{6 3 5}$ & $\mathbf{1 0 0 , 0 0 \%}$ & $\mathbf{7 9 6}$ & $\mathbf{1 0 0 , 0 0 \%}$ & $\mathbf{6 7 5}$ & $\mathbf{1 0 0 , 0 0 \%}$ & $\mathbf{9 5 6}$ & $\mathbf{1 0 0 , 0 0 \%}$
\end{tabular}

Sowohl mit als auch ohne die Akteurinnen und Akteure in Nachrichtenmagazinen sind nichtorganisierte Privatpersonen in allen untersuchten Sendern die am häufigsten zu Wort kommende Personengruppe. Selbstverständlich handelt es sich dabei streng genommen um keine Gruppe von Personen, sondern vielmehr um Individuen ohne Funktionszuweisung. Im ORF 2 ist die Dominanz der Normalbürgerinnen und -bürger weniger stark ausgeprägt als in den deutschen Sendern. In letzteren machen Privatpersonen jeweils ca. ein Drittel der zu Wort kommenden Personen aus, im ORF 2 ist es weniger als ein Viertel (vgl. Tabelle 17 und Tabelle 18).

Was den Anteil von Politikern und Politikerinnen betrifft, so zeigt sich, dass diese - jedenfalls in den nationalen Programmen - hauptsächlich in Nachrichtenmagazinen vorkommen. Wird diese Sendungsform weggelassen, so reduziert sich ihr Anteil beträchtlich, was sich auch in der Rangfolge niederschlägt. Anders verhält es sich im Bayerischen Rundfunk. Lässt man hier das Nachrichtenmagazin außen vor, so wechseln in der Rangfolge die Politikerinnen und Politiker lediglich den Platz mit den privatwirtschaftlichen Funktionspersonen und sind dann die Personengruppe, die am dritthäufigsten zu Wort kommt. Im MDR, wo schon das Thema „Politik“ eine nur untergeordnete Rolle spielt, kommen auch entsprechend wenige Personen dieses Berufsstandes vor - sie machen hier weniger als drei Prozent aus.

Im ORF 2 und ZDF liegt der Anteil von Politikerinnen und Politikern bei zwölf bzw. neun Prozent (in allen Magazinen). Damit bilden sie nicht die größte Personengruppe, sondern die zweitgrößte (ZDF) bzw. drittgrößte (ORF 2). Ebenfalls häufig sind privatwirtschaftliche Funktionspersonen $^{311}$ vor der Kamera zu sehen und zu hören, wobei deren häufiges Vorkommen sowohl in als auch außerhalb von Nachrichtenmagazinen auffällt.

Im MDR fallen der hohe Anteil von Personen aus dem Show-Business sowie die Präsenz der öffentlichen Sicherheitsorgane auf. Das weist auf eine ausgeprägte Berücksichtigung von $\mathrm{Hu}-$ mantouch- und Softnews-Berichterstattung hin. ${ }^{312}$

Um festzustellen, wie gleichmäßig die zu Wort kommenden Personen auf die verschiedenen Personengruppen verteilt sind, wird auch hier wieder auf das Maß der relativen Entropie zu-

\footnotetext{
${ }^{311}$ Damit sind Personen gemeint, die in ihrer Funktion, die sie am Arbeitsplatz erfüllen, zu Wort kommen, sofern sie in der privaten Wirtschaft arbeiten.

312 Tatsächlich ist Berichterstattung über Prominente das häufigste Thema im MDR, dazu kommt die - von allen hier untersuchten Sendern - mit 6 Prozent umfangreichste Berichterstattung über Kriminalität
} 
rückgegriffen. Dies wird ebenfalls für die Gesamtheit aller Magazine sowie unter Weglassen der Nachrichtenmagazine berechnet. Auf Grund der Dominanz der Privatpersonen - die streng genommen keine gesellschaftliche Gruppe darstellen - wird das Verteilungsmaß daneben auch noch ohne deren Berücksichtigung ausgewiesen (Abbildung 79 - Abbildung 81).

Abbildung 79: Vergleich relative Entropie der zu Wort kommenden Personen nach Gruppen Basis: alle untersuchten Personen in allen Magazinbeiträgen

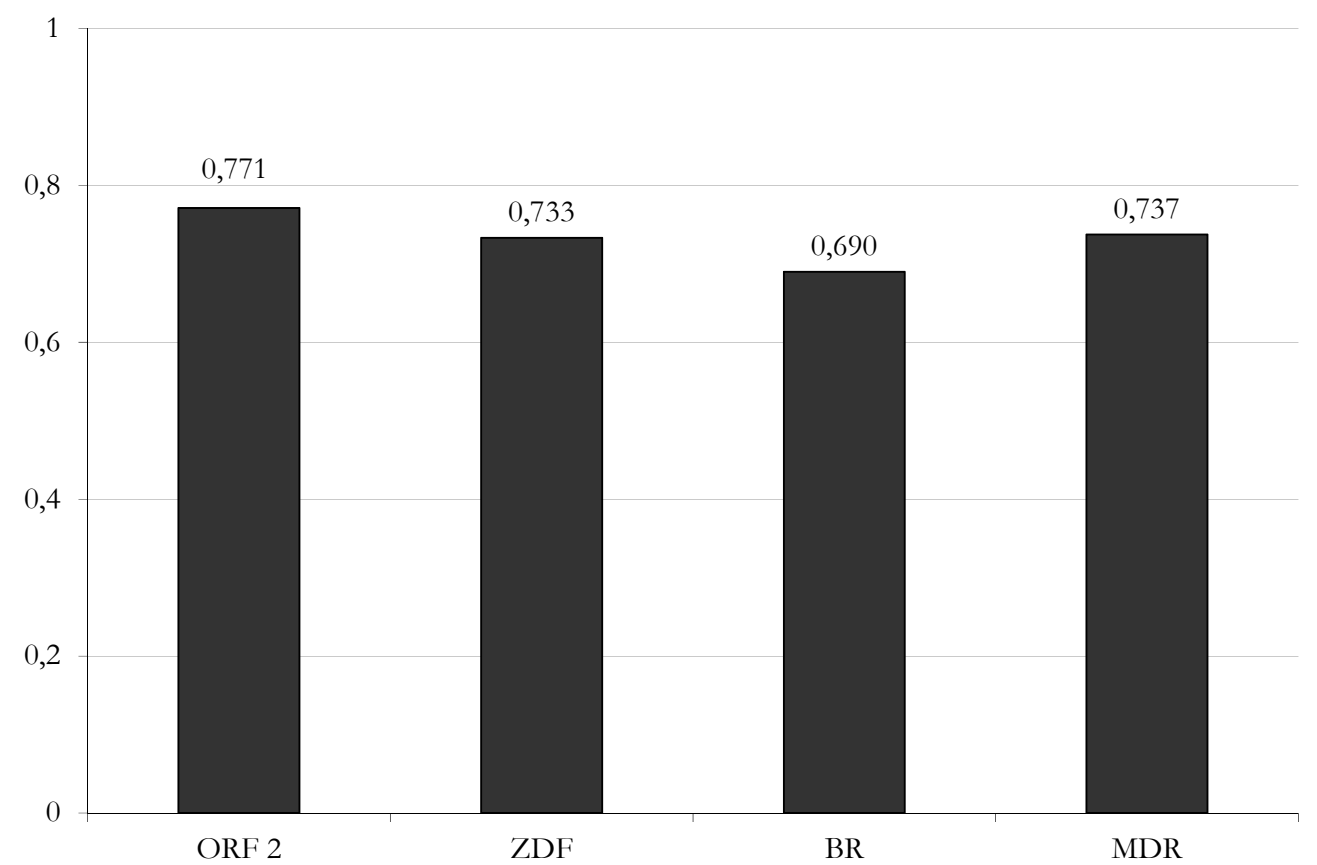


Abbildung 80: Vergleich relative Entropie der zu Wort kommenden Personen nach Gruppen Basis: alle untersuchten Personen in allen Magazinbeiträgen ohne Nachrichtenmagazine

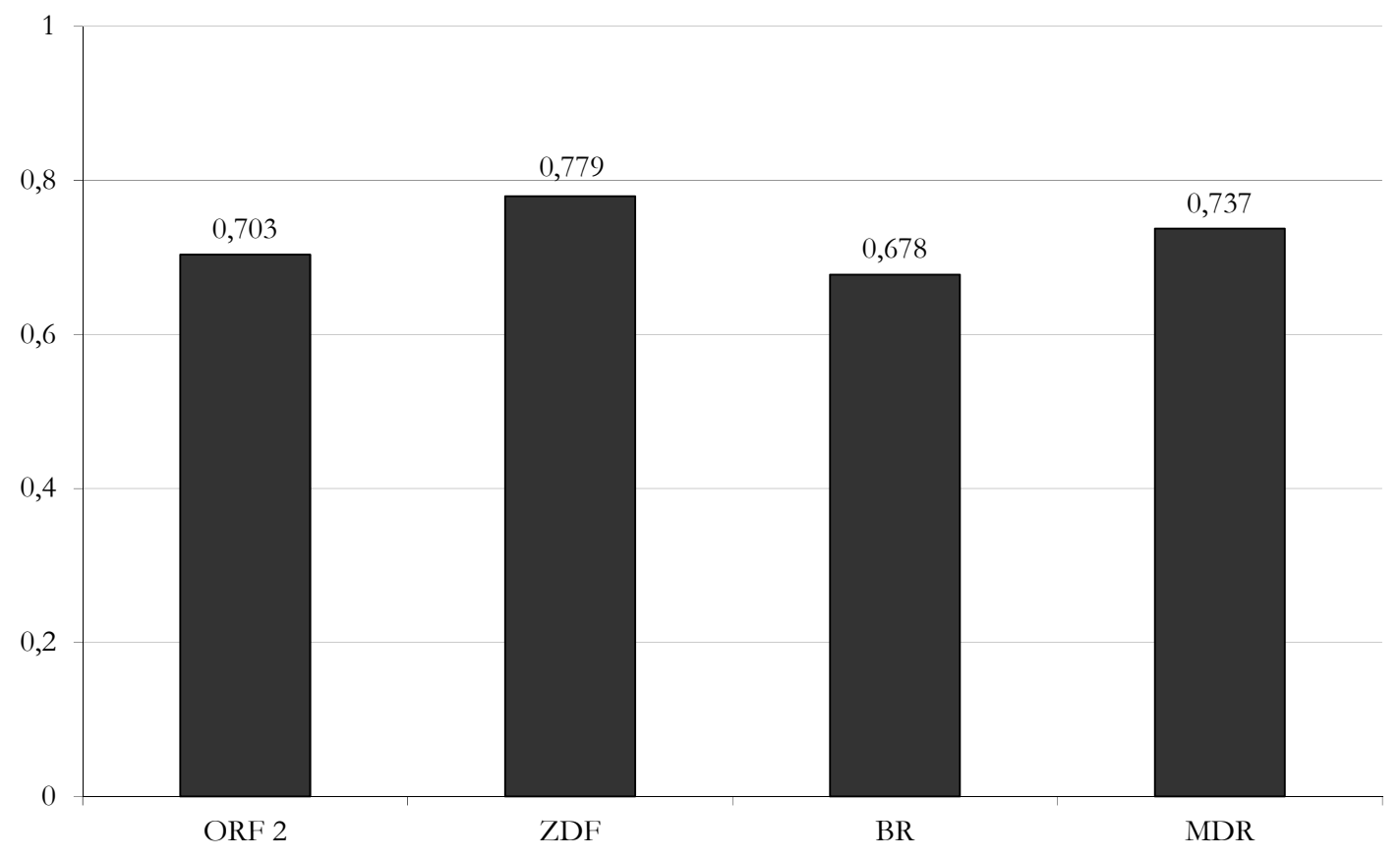

Abbildung 81: Vergleich relative Entropie der zu Wort kommenden Personen nach Gruppen Basis: alle untersuchten Personen außer Privatpersonen in allen Magazinbeiträgen

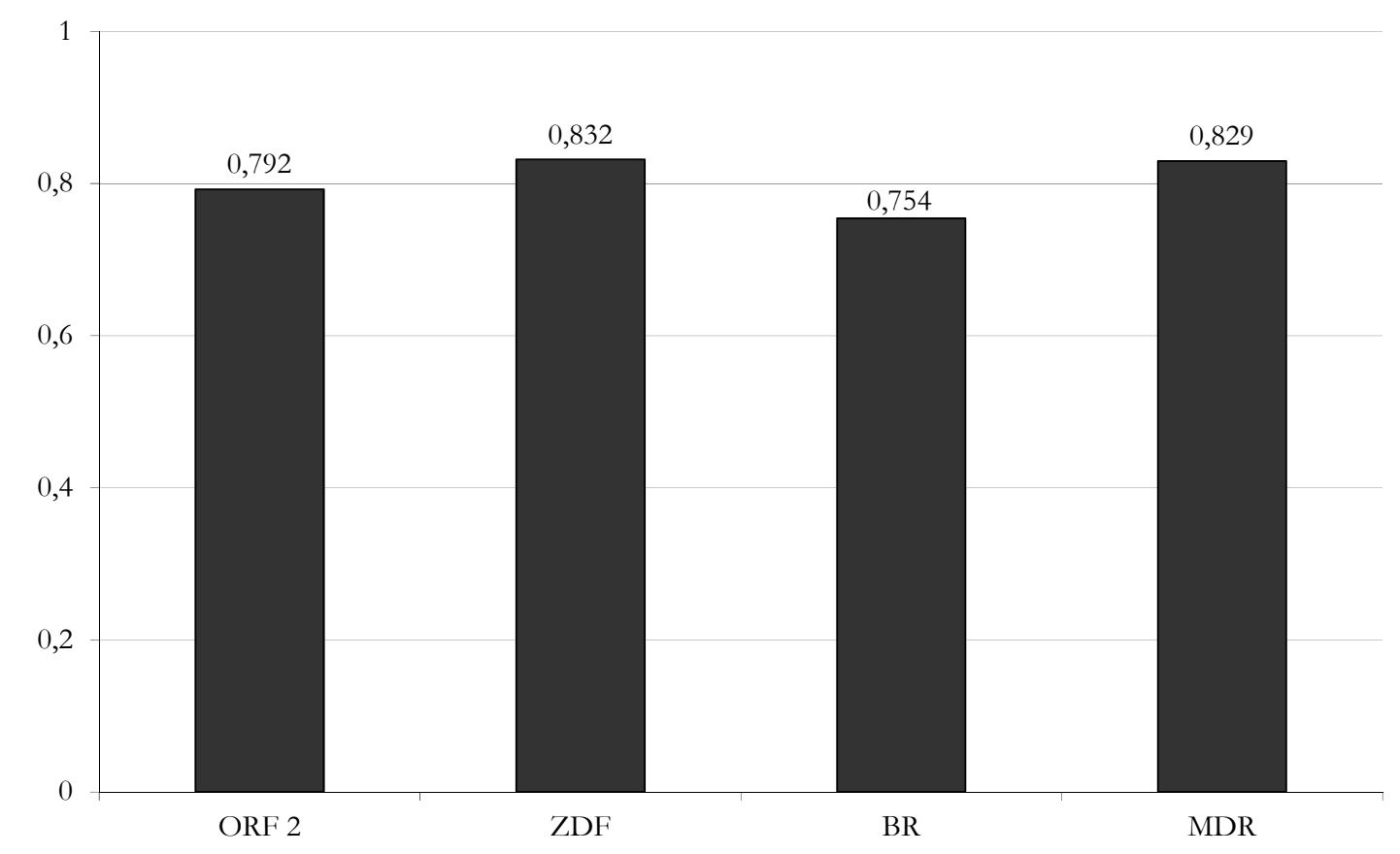


Was die Verteilung der Personen auf die verschiedenen Akteursgruppen betrifft, so zeigt sich, dass diese in den Regionalprogrammen nicht gleichmäßiger ist als in den nationalen. Der hohe Anteil von Privatpersonen macht sich bei allen Sendern bemerkbar: Werden sie weggelassen, steigt das Maß für die Gleichverteilung durchgängig deutlich an. Interessant ist auch, dass dieses Maß für das ZDF höher ausfällt, wenn die Nachrichtenmagazine nicht berücksichtigt werden. Das spricht dafür, dass bestimmte Personengruppen im „,heute-journal“ besonders häufig vorkommen. Das ist tatsächlich der Fall und betrifft die Gruppe der Politikerinnen und Politiker. Der Effekt ist im ORF 2 genau umgekehrt, was dafür spricht, dass die Akteursbandbreite in der „ZiB 2“ größer und ausgewogener ist als im sonstigen Programm. Die geringste Ausgewogenheit weist in allen Fällen der Bayerische Rundfunk auf, wogegen der MDR durchgängig den zweithöchsten Entropiewert aufweist.

Weder was die Anteile verschiedener Personengruppen noch was die Verteilung im Programm betrifft, lassen sich strukturelle Unterschiede zwischen nationalen und regionalen Sendern ausmachen. Insofern zeigt sich auch hier, dass eher das individuelle Senderprofil ausschlaggebend für die Inhalte ist. Das relativiert sich aber dadurch, dass in allen Sendern vor allem einheimische Durchschnittsbürgerinnen und -bürger vor der Kamera zu Wort kommen. Gerade in den Regionalprogrammen (wo diese auch für den hohen Anteil an Dialekt verantwortlich sind) birgt dies ein hohes Identifikationspotenzial.

\subsubsection{Politische Hierarchie}

Politik findet auf verschiedenen Hierarchieebenen statt, die sich insbesondere über die Größe des Raums, auf die sich die politische Macht erstreckt, unterscheiden lässt. So stehen Bürgermeisterinnen und Bürgermeister in der Hierarchie niedriger als Bundesministerinnen und Bundesminister. Allerdings sind die Entscheidungen, die auf lokaler Ebene getroffen werden, für Einwohnerinnen und Einwohner des entsprechenden Orts im Einzelfall von größerer Relevanz als Vorgänge in der internationalen Politik. 
Abbildung 82: Einordnung der zu Wort kommenden Politikerinnen und Politiker nach Hierarchieebene

Basis: alle Personen aus Bereich „Politik“ in allen Magazinbeiträgen: ORF 2: 86, ZDF: 117, BR:98, MDR: 27

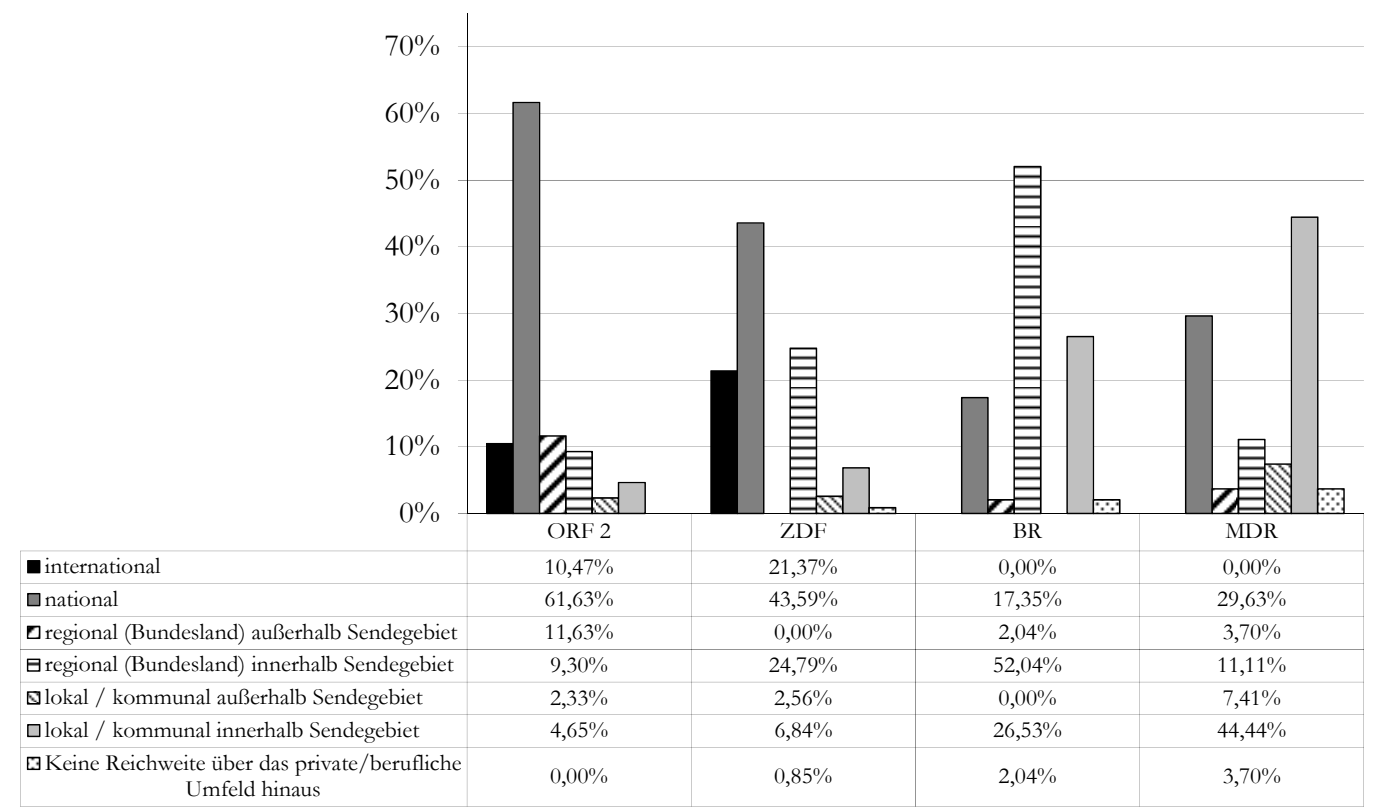

Die an unterschiedliche Hierarchien geknüpfte politische Macht spiegelt sich in der Zusammensetzung des in den Programmen zu Wort kommenden politischen Personals recht klar wider (vgl. Abbildung 82). In ORF 2 und $Z D F$ kommen vor allem Mandatsträgerinnen und -träger der nationalen Ebene zu Wort. Im $B R$ sind es vor allem Landespolitikerinnen und -politiker, während im MDR der größte Teil lokal Verantwortliche sind. Allerdings ist im ZDF die landespolitische Ebene häufiger vertreten als im MDR. Hier wird also die föderale Struktur der Bundesrepublik berücksichtigt. Im ORF 2 fällt zusätzlich auf, dass hier auch Landespolitikerinnen und -politiker von außerhalb Österreichs in beachtenswertem Umfang zu Wort kommen. Das ist im ZDF gar nicht der Fall. Darin spiegelt sich der gegenüber dem ZDF etwas höhere Anteil der Auslandsberichterstattung im ORF 2 wider.

Die Zahlen des MDR sind allerdings wenig aussagekräftig, da hier im Verlauf der untersuchten Woche insgesamt nur 27 Politikerinnen und Politiker zu Wort kamen. So spiegelt sich auch in der Anzahl der entsprechenden Personen die geringe Bedeutung wider, die im Programm des MDR der Politik eingeräumt wird. Dass es dann auch noch das in der politischen Hierarchie am niedrigsten stehende Personal ist, das am häufigsten vor die Kamera tritt, komplettiert dieses Bild in gewisser Hinsicht. In allen anderen Sendern bildet dagegen das Sendegebiet die entscheidende Referenzgröße für den Einflussbereich der zu Wort kommenden Politikerinnen und Politiker. Das ist immerhin ein Indikator dafür, dass sich die mit dem Sendegebiet verbundene publizistische Funktion in der Berichterstattung niederschlägt. Das Regionalprogramm erscheint hier als komplementär zum nationalen Programm, in dem hauptsächlich die für das regionale Geschehen relevante Politik Gegenstand der Berichterstattung ist. 


\subsubsection{Ergebnisse Akteure}

Hypothese H25 wird abgelehnt. Zwar wird in beiden Regionalprogrammen häufiger Dialekt als hochdeutsch gesprochen, das trifft aber auch auf das nationale Programm des ORF 2 zu. Insofern ist die Häufigkeit, mit der Dialekt zu hören ist, jedenfalls im Vergleich der hier untersuchten Sender, keine exklusive Besonderheit des Regionalprogramms.

Hypothese H26a wird abgelehnt. Politikerinnen und Politiker sind in keinem der untersuchten Programme die größte vorkommende Gruppe. Zudem liegen sie auch unter Weglassung der Privatpersonen zumindest im ORF 2 nicht an erster Stelle. Außerhalb der Nachrichtenmagazine spielen sie darüber hinaus (außer im BR) eine deutlich untergeordnete Rolle.

Hypothese H26b wird abgelehnt. Die Verteilung der Personen auf die verschiedenen gesellschaftlichen Gruppen ist im Regionalprogramm nicht gleichmäßiger als in den nationalen Programmen. Im BR ist die Verteilung sogar unterdurchschnittlich gleichmäßig.

Hypothese H27 wird angenommen. Die Mehrzahl der zu Wort kommenden Politikerinnen und Politiker ist in der politischen Hierarchie unterhalb der nationalen Ebene angesiedelt. 


\section{Fazit}

Im folgenden Abschnitt werden die Ergebnisse der empirischen Untersuchung kurz zusammengefasst. Anschließend wird deren Bedeutung vor dem Hintergrund der theoretischen Überlegungen zur sozialen Bedeutung des Fernsehens für nationale und regionale Identitäten erörtert. Abschließend wird ein Ausblick darauf gegeben, was sich aus der vorliegenden Studie für die mögliche weitere Forschung in diesem Feld ergibt.

\subsection{Zusammenfassung der empirischen Befunde}

Insgesamt betrachtet zeigen die Ergebnisse der vorliegenden Untersuchung, dass die untersuchten Programme sich in ihren Inhalten nicht in einer Weise unterscheiden, die eindeutig auf ihren Charakter als nationales oder regionales Programm zurückzuführen ist. Vielmehr weisen alle vier Sender individuelle Profile auf, die gleichwohl Eigenarten enthalten, die auf die jeweils einschlägige Region oder Nation verweisen. ${ }^{313}$

Auf programmstruktureller Ebene sind die festgestellten Unterschiede vor allem Differenzen der Anteile von Information, Unterhaltung und Werbung. Deutliche Unterschiede sind auch bei den Programmanteilen von Eigenprogramm, Wiederholungen und Programmübernahmen zu verzeichnen. Das erklärt sich zum Großteil aus der inhaltlichen Ausrichtung der Programme und verweist nicht zwangsläufig auf deren Sendegebiet. Jedoch sollte nicht übersehen werden, dass sich zum Beispiel im hohen Umfang des Informationsprogramms der Dritten Programme jedenfalls zum Teil auch bundesdeutsche Fernsehgeschichte niederschlägt: Von ihrem Ursprung her waren die Regionalprogramme als Bildungsfernsehen konzipiert, was sich schließlich dahingehend weiterentwickelt hat, dass diese Sender insbesondere ein komplementäres (regionales) Informationsangebot anbieten. Das hat sich schließlich im Fernsehsystem derart verfestigt, dass diese Grundausrichtung auch solche Sender betrifft, die nach der deutschen Einheit auf Sendung gingen und nicht aus derselben Tradition kommen. Dass ein Fern-

\footnotetext{
${ }^{313}$ Hinsichtlich der oben aufgeworfenen Frage, ob der ORF 2 seine ihm gesetzlich zugewiesene Aufgabe der Förderung von nationaler und regionaler Identität erfüllt (vgl. S. 113), lässt sich folgendes konstatieren: Die österreichische Identität kommt im Programm sehr wohl zum Ausdruck, insofern der ORF 2 relativ eindeutig als österreichisches Programm erkennbar ist. Das zeigt sich an den Raumbezügen der Berichterstattung und in der Behandlung bestimmter Themen. Einschränkend sind aber die großen Einflüsse des Nachbarn Deutschland zu erwähnen - diese wirken sich insbesondere bei den Raumbezügen des fiktionalen Programms aus. Da diese Nähe aber letztlich Teil der österreichischen Identität sein dürfte, muss das nicht zwangsläufig negativ gewertet werden. Das gilt umso mehr, als hiervon vor allem die fiktionalen Inhalte betroffen sind, das Informationsprogramm aber weniger als erwartet. Was die regionale Identität der Bundesländer betrifft, so können hier keine verlässlichen Aussagen gemacht werden, da hierfür wahrscheinlich vor allem die hier nicht untersuchten Regionalfenster verantwortlich sind.
} 
sehprogramm schon auf struktureller Ebene als ein Regionalsender identifiziert werden kann, ist also durch die regionale Ausdifferenzierung des Fernsehmarktes mitbedingt. Diese (regionale) Identitifizierbarkeit bezieht sich aber lediglich auf das „Regionalsendersein“ “314 selbst, nicht auf die spezifische Region. Die Struktur des Fernsehsystems ist aber keinesfalls der alleinige Grund dafür. Das wird leicht nachvollziehbar, wenn man bedenkt, dass auch zwischen Sparten- und Vollprogrammen formale Unterschiede bestehen, die sich inhaltlich auswirken. Regionalprogramme sind zwar keine (thematisch ausgerichteten) Spartenprogramme. Sie sind aber auch nicht zwangsläufig als Vollprogramme im Sinne des Rundfunkstaatsvertrags anzusehen (vgl. S. 153, Fn. 247).

Im Rahmen des Unterhaltungsangebots zeigen sich auf inhaltlicher Ebene dagegen relativ deutliche Unterschiede zwischen den einzelnen Programmen, die sich tatsächlich auf deren Sendegebiet beziehen. Das betrifft zum einen die Herkunft von Filmen und Serien. Zum anderen betrifft es die Schauplätze von Handlungen. Bezüglich der Herkunft lässt sich eine Präferenz für Produktionen des eigenen Landes feststellen. ${ }^{315}$ Diese Bevorzugung findet allerdings - im Fall des ORF 2 - ihre Grenzen im Umfang des Outputs der heimischen Film- und Fernsehindustrie. Im österreichischen Fernsehen führt das zu einem sehr hohen Anteil deutscher Produktionen, was aber durchaus als eine Eigenart Österreichs angesehen werden kann. Gerade weil der österreichische Fernsehmarkt insgesamt recht klein ist, wirkt sich die Nähe zum sehr großen deutschen Fernsehmarkt aus. Das liegt vor allem an der geteilten Landessprache, denn sonst spräche nichts dagegen, dass etwa viele italienische Filme gezeigt würden. Das ist aber nicht der Fall.

Auf der Inhaltsseite fiktionaler Sendungen sind in den deutschen Programmen deutliche Präferenzen für Filme und Serien mit Schauplätzen im Sendegebiet zu erkennen. Die relative Mehrheit der gezeigten Handlungsorte im BR liegt in Bayern, im MDR in Mitteldeutschland, im ZDF in Deutschland. ${ }^{316}$ Im ORF 2 hingegen wirkt sich die große Menge nicht österreichischer Produktionen aus: Hier spielen sich nur rund 17 Prozent der Handlungen in der eigenen Heimat ab - gegenüber fast zwei Dritteln deutscher Schauplätze. ${ }^{317}$ So lässt sich festhalten, dass sich die jeweils heimatliche Region bzw. Nation ${ }^{318}$ im fiktionalen Programm deutlich manifestiert, wenn dem nicht gravierende äußere Bedingungen entgegenstehen. ${ }^{319}$

\footnotetext{
${ }^{314}$ Im Sinne von: anders als ein nationales Programm.

315 Das betrifft auch bei den Regionalprogrammen die Nation, da die Produktionsländer von Film- und Fernsehproduktionen nur auf nationalstaatlicher Ebene zugeordnet werden können.

316 Wobei dies die beiden vorgenannten Regionen umschließt, die aber beide im ZDF-Programm nicht ,,̈̈berrepräsentiert" sind. Das spricht für eine insgesamt ausgewogene Verteilung der Handlungsorte.

317 Wobei man immerhin im darin enthaltenen großen Anteil der bayerischen Alpenregion eine dem nationalen Selbstverständnis entsprechende Landschaftspräferenz erkennen mag - „Land der Berge ... “ beginnt die österreichische Nationalhymne.

318 Mit der auch im Folgenden geltenden Einschränkung, dass - wie umfassend dargelegt wurde - die Nation sich weniger territorial definieren lässt, als das für die Region der Fall ist.

${ }^{319}$ Wobei sich im Fall des ORF 2 in diesen äußeren Bedingungen (Struktur der heimischen Film- und Fernsehindustrie) ihrerseits Eigenarten Österreichs manifestieren (Staatsgröße, Nähe zu Deutschland, deutsche Landessprache).
} 
Als eines der Kernstücke der vorliegenden Untersuchung von Magazininhalten ist die Erhebung der journalistischen Beachtung von Themen in den verschiedenen Landkreisen der Sendegebiete anzusehen. Hierin manifestiert sich am deutlichsten der territoriale Bezug zum Staatsgebiet der Nation bzw. zur Region. Die dokumentierten Ergebnisse zeigen unterschiedlich deutliche Tendenzen in Richtung der hypothetischen Annahmen. Die Regionalprogramme berücksichtigen die einzelnen Teile ihrer Sendegebiete weitgehend mit redaktionellen Inhalten. Unterschiede im Grad der Beachtung der Vielzahl von Landkreisen scheinen sich dabei aus den jeweils unterschiedlichen Zuschnitten der Region (in territorialer Hinsicht) zu ergeben. Ein weiterer Einfluss kann in der zugrunde liegenden regionalen Identität erkannt werden, sofern diese sich inhaltlich in besonderem Maße auf bestimmte Orte und Gebiete bezieht. Im Fall Bayerns zeigt sich das in der bevorzugten Berichterstattung aus dem altbayerischen und schwäbischen Kernland im Vergleich zu Franken sowie in der starken Konzentration der Berichterstattung auf die Hauptstadt München. Im MDR ist die Abdeckung des Sendegebiets dagegen beinahe vollständig. Da Mitteldeutschland keine (Gesamt-)Hauptstadt hat, fehlt es im MDR an einer entsprechenden Konzentration der Berichterstattung darauf. Diese ist dagegen für den Senderstandort Leipzig festzustellen (der zudem sehr mittig im Sendegebiet platziert ist), allerdings in deutlich geringerem Ausmaß als dies bezüglich der Hauptstädte in den anderen Sendern der Fall ist. Insofern zeigt sich auf der regionalen Seite, dass das Ausmaß der Berichterstattung aus den Landkreisen des Sendegebiets mit Bedingungen der Region und der regionalen Identität korrespondiert. Historisch oder symbolisch wichtige Regionen kommen in der Berichterstattung häufiger vor (im BR). Spielen solche Orte für das regionale Selbstverständnis keine herausragende Rolle, lassen sich solche Beobachtungen nicht machen (im $M D R$ ). Es ist dabei nicht auszuschließen, dass die Historizität des regionalen Konstrukts, auf das sich das Sendegebiet bezieht, einen wichtigen Einfluss darstellt. Im Fall Bayerns folgen die Landesgrenzen weitgehend dem historischen Königreich Bayern. Eine solche geschichtliche Grundlage fehlt dem Sendegebiet des MDR in seiner Gesamtheit.

Anders stellt sich die Gebietsabdeckung der beiden nationalen Programme dar - wenngleich ihrerseits noch unterschiedlicher als im MDR und BR. Die Berichterstattung des ORF 2 geht deutlich mehr in die Fläche als dies im ZDF der Fall ist. Das heißt, das durch die Berichterstattung „erzeugte“ Territorium des ORF 2 ist dem tatsächlichen Staatsgebiet Österreichs relativ ähnlich. Vom ZDF lässt sich das nicht behaupten - hier ergibt sich lediglich ein „Flickenteppich“ aus einzelnen deutschen Landkreisen. Allerdings sind die staatlichen Territorien von sehr unterschiedlichem Ausmaß. Im ZDF fehlt es schlicht an der praktischen Möglichkeit, aus der Mehrzahl der Kreise zu berichten, dafür sind es zu viele (439). Die Anzahl der österreichischen Landkreise (121) entspricht dagegen eher der Bayerns (96). Daneben ist die Konzentration auf die Hauptstadt Wien im ORF 2 deutlich ausgeprägter als dies im ZDF mit Berlin der Fall ist. Auch das korrespondiert mit äußeren Bedingungen: In Österreich leben ca. 20 Prozent der Gesamtbevölkerung in der Hauptstadt, in Deutschland nur vier Prozent. Darüber hinaus ist die historische Tradition des Hauptstadtstatus Wiens eine deutlich längere als die Berlins: Die Donaumetropole wurde bereits 1556 Sitz des Kaisers des „Heiligen römischen Reichs deutscher Nation“. Berlin wurde hingegen erst 1701 Hauptstadt Preußens. Insofern spiegelt sich der territoriale Zuschnitt der beiden Staaten in den beiden Nationalprogrammen 
wider. Da die zugrunde liegenden Strukturen sich aber unterscheiden, sehen diese „Spiegelbilder“ jeweils unterschiedlich aus und müssen als individuell angesehen werden.

Ebenfalls sehr individuelle Verteilungen zeigen sich bezüglich der Tragweiten der berichteten Themen in den vier Sendern. Ähnlichkeiten zwischen nationalen Sendern auf der einen und regionalen Sendern auf der anderen Seite zeigen sich hier nur bezüglich der Auslandsberichterstattung. Diese spielt in den nationalen Programmen eine deutlich größere Rolle als in den Regionalsendern. Umgekehrt ist aber die nach innen (also auf das eigene Sendegebiet) gerichtete Berichterstattung ganz unterschiedlich verteilt. ORF 2 und ZDF ähneln sich hier: 70 bzw. 76 Prozent der Berichterstattung beziehen sich auf Themen aus Österreich bzw. Deutschland. Im Regionalfernsehen sieht das anders aus: Während sich im BR 57 Prozent der Berichterstattung auf bayerische Themen beziehen, wird im MDR nur zu unter einem Drittel aus Mitteldeutschland berichtet. In absoluten Zahlen jedoch bietet der MDR mehr Informationen aus dem Sendegebiet. Das heißt, das deutliche Mehrangebot von Magazinsendungen im MDR gegenüber dem $B R$ führt dazu, dass im MDR neben den regionalen Informationen aus Mitteldeutschland insgesamt auch mehr überregionale Themen berichtet werden. Ein Plus an Magazinsendungen bedeutet also nicht zwangsläufig einen „,regionalen Mehrwert“. 320

Die Qualität der Berichterstattung in den untersuchten Programmen unterscheidet sich nicht systematisch. Es gibt allerdings einige problematisch zu nennende Befunde für die Regionalsender: Im MDR mangelt es grundsätzlich an Politikberichterstattung, im BR dagegen erscheint Politik als weitgehend konfliktfreies Geschehen. Aber daraus allein lässt sich keine geringere Qualität des regionalen Journalismus ableiten. Weder hinsichtlich der Themenvielfalt noch der Vielfalt der Darstellungsformen und auch nicht in Bezug auf meinungsbetonte Berichterstattung sind die Unterschiede groß genug, um derartige Annahmen zu bestätigen. Insofern lassen sich entsprechende Befunde aus Untersuchungen zu regionalem Journalismus (insb. Teichert 1982, Schilling 1998) nicht bestätigen.

In den Ergebnissen zur Herkunft fiktionaler Sendungen wurde bereits deutlich, dass das österreichische Programm stark vom deutschen Film- und Fernsehmarkt beeinflusst wird. In der Magazinberichterstattung wurde ebenfalls untersucht, wie sich das Verhältnis der beiden Staaten niederschlägt. Dass Österreich in den Magazinen des ZDF kaum eine Rolle spielt, hat sich dabei bestätigt. Umgekehrt wird im ORF 2 relativ umfangreich aus Deutschland berichtet. Keinem anderen Nachbarstaat wird hier ähnlich viel Beachtung geschenkt. Insofern bestätigt sich die Kernthese des Next-Door-Giant-Effekts, dass der große Nachbarstaat in der Nachrichtengebung des kleinen Nachbarn eine größere Rolle spielt als umgekehrt. Allerdings ist der Anteil der Deutschlandberichterstattung viel geringer ausgefallen als erwartet. Insofern lassen sich auch hier Ergebnisse anderer Studien nicht belegen (vor allem aus der „Foreign-NewsStudie“, siehe Hagen 1998). Die Berichterstattung aus Deutschland bezieht sich im ORF 2 zumeist auf gesellschaftliche Themen und Wirtschaft. Politik spielt dagegen kaum eine Rolle.

\footnotetext{
${ }^{320} \mathrm{Da}$ der Informationsanteil aber in beiden Regionalprogrammen ähnlich hoch ist, stellt sich die Frage, ob die Informationen, die im BR statt in Magazinsendungen in alleinstehenden Sendeformen gegeben werden, diesen „regionalen Mehrwert“ enthalten. Diese Frage muss hier aber offen bleiben, da der Regionalbezug für diese Sendeformen nicht erhoben wurde.
} 
In allen Sendern außer dem BR ist das nicht europäische Ausland in der Auslandsberichterstattung am häufigsten vertreten. Auch das ist vor dem Hintergrund der mittlerweile vielfältigen innereuropäischen institutionellen Bindungen ein überraschendes Ergebnis - insbesondere für die beiden nationalen Sender. Es scheint eher die äußere Nachrichtenlage zu sein, die den Umfang der Auslandsberichterstattung bestimmt, als es die latent bestehenden Bezüge zu den europäischen Nachbarn sind. Insofern sprechen die Ergebnisse nicht dafür, dass für das aktuell im Fernsehen erfahrbare Bild der eigenen Nation besondere historische Verbindungen zu Nachbarstaaten (etwa Österreich und Ungarn) eine besondere Rolle spielen. Für neuere Entwicklungen (etwa im Prozess der europäischen Einigung) trifft das aber ebenso wenig zu.

Die Themenagenda der einzelnen Sender weist ebenfalls eher individuelle Strukturen auf als solche, die sich aus dem Unterschied von Regionalprogramm und nationalem Fernsehen erklären ließen. ORF 2 und $Z D F$ sind sich hier in mancher Hinsicht ähnlicher als es für BR und MDR der Fall ist. Das liegt vor allem daran, dass die thematische Zusammensetzung des MDR sich sehr stark von den anderen Sendern unterscheidet. Betrachtet man zum Beispiel die Bereiche Politik, Wirtschaft und Gesellschaft, so sind diese in ihrer Rangfolge (auch im Vergleich zu den anderen Themenbereichen) im ORF 2, ZDF und BR gleich. Im MDR ist lediglich der Anteil und Rang der gesellschaftlichen Themen vergleichbar mit den Werten der anderen Programme. Bei der Rangliste der zehn häufigsten Themen sind in den beiden nationalen Programmen die ersten beiden Plätze in jeweils umgekehrter Reihung mit ,internationaler Politik“ und ,prominenten Personen“ besetzt. Dabei ist auch der Abstand der beiden Top-Themen zu den nachfolgenden Rangplätzen vergleichbar groß. Allerdings sind in den zehn häufigsten Themen der Regionalsender mehr Übereinstimmungen zu finden als in den nationalen Programmen (jedoch nur hinsichtlich des Vorkommens, nicht in der Rangfolge). Diese heterogenen Befunde weisen in Verbindung mit den Ergebnissen zur Themenvielfalt auch wieder darauf hin, dass sich inhaltlich keine systematischen Unterschiede zwischen regionalem und nationalem Fernsehen ausmachen lassen. Die Unterschiede sind vielmehr individuell. Allerdings sind innerhalb einzelner Themenbereiche Unterschiede auszumachen, die wiederum auf das jeweilige Sendegebiet und seine Eigenarten verweisen. Da dies aber bereits in den Bereich der Interpretation verweist, müssen diese Befunde vorsichtig behandelt werden. So zeigt sich zum Beispiel, dass Brauchtum und Tradition eine herausgehobene Rolle in der Berichterstattung des Bayerischen Rundfunks spielen. Das korrespondiert mit stereotypen Vorstellungen über dieses Bundesland.

Im Themenbereich Sport lässt sich insbesondere hinsichtlich der Fußballberichterstattung feststellen, dass die regionalen Programme eine Komplementärfunktion zur überregionalen Berichterstattung haben. In den Dritten wird vor allem über jenes Spielgeschehen berichtet, das sich unterhalb der ersten Bundesliga befindet. Die meiste Aufmerksamkeit wird jeweils der höchsten Spielklasse (unterhalb der ersten Liga) zuteil, in der Vereine aus der eigenen Region vertreten sind (im Untersuchungszeitraum war das in Bayern die zweite Bundesliga, in Mitteldeutschland jedoch die 3. Liga, da keine mitteldeutschen Vereine in der 2. Bundesliga spielten).

Relativ eindeutige Ergebnisse sind im Themengebiet Religion zu verzeichnen. Hier spiegeln sich vor allem die regional und national recht unterschiedlichen Einflusssphären der beiden 
christlichen Kirchen wider, was seinerseits vor allem historisch bedingt ist. In Magazinen des ORF 2 wird dementsprechend vor allem über die katholische Kirche berichtet, während im ZDF beide Konfessionen gleichmäßiger verteilt sind. Im Bayerischen Rundfunk dominierten erwartungsgemäß katholische Aspekte die religiösen Themen, während im MDR die Religion insgesamt keine Rolle spielte. Allerdings ließen sich diese Befunde zum Teil durch Ergebnisse, die zusätzlich auf Sendungsebene gewonnen wurden, relativieren. Im Lichte dieser Gegenüberstellung erscheint der Themenbereich insgesamt etwas ausdifferenzierter als in Magazinsendungen allein. ${ }^{321}$

Dass Fernsehinhalte nicht vornehmlich der Abbildung gesellschaftlicher Realität dienen, zeigt sich sehr deutlich in der Wirtschaftsberichterstattung. Wenn sich die hierzu gemachten Befunde in einer größeren Stichprobe erhärten lassen, entspricht die Verteilung der Berichterstattung in den einzelnen Sendern in keinem Fall den Leistungen, die von den einzelnen Wirtschaftssektoren für die Gesamtwirtschaft erbracht werden (gemessen am Bruttoinlandsprodukt). Sie entspricht auch nicht der Verteilung der Arbeitskräfte in den einzelnen Branchen. ${ }^{322}$ Dass Fernsehinhalte und Außenwelt nicht deckungsgleich sind, erscheint zunächst banal und nur das Gegenteil wäre überraschend gewesen. Zu bedenken ist aber, dass auch Konzepte wie die Einteilung in Wirtschaftssektoren und die Berechnung ihrer Bedeutung für eine Gesellschaft nur Konstruktionen sind, die das Bild der Welt mitformen. Das gilt umso mehr, als es sich bei der Perspektive ihrer Generierung um eine Sicht handelt, die normalerweise im Alltag keine Rolle spielt, also der persönlichen Lebenswelt gleichsam enthoben ist. Insofern wäre es durchaus interessant, wenn die Mechanismen der Erzeugung sozialer Wirklichkeit keine deckungsgleichen Bilder von Aspekten der Gesellschaft erzeugten (wofür die hier gemachten Befunde zu sprechen scheinen), die gemeinhin als relevant angesehen werden. Für den Bereich der Wirtschaft wäre das deshalb von Bedeutung, weil Deutschland auf internationaler Ebene zum Kreise der führenden Wirtschaftsnationen gezählt wird. Gleichzeitig wird Deutschland sowohl von den Deutschen selbst als auch von außerhalb mit wirtschaftlichen Errungenschaften assoziiert (vgl. S. 51). Es ist also anzunehmen, dass die wirtschaftliche Potenz eine wichtige Rolle für die nationale Identität Deutschlands spielt. Wenn das so ist, sind allerdings die Grundlagen, auf denen diese Wirtschaftskraft beruht, für die durchschnittlichen Fernsehzuschauer und -zuschauerinnen möglicherweise kaum erkennbar, da die Wirtschaftsberichterstattung eine untergeordnete Rolle spielt.

Von herausragender Bedeutung für die sozialen Konstrukte regionaler und nationaler Identität wurde in den theoretischen Überlegungen die Geschichte einer Region bzw. Nation erkannt. Diese Wichtigkeit schlägt sich in den Fernsehprogrammen nicht in besonders großem Aus-

\footnotetext{
321 Wobei die Daten auf Sendungsebene vorsichtig behandelt werden müssen, da sich hier der kurze Untersuchungszeitraum auf die Ergebnisse auswirkt. Monothematische Sendungen zum Thema „Religion“ sind nicht selten Übertragungen von Gottesdiensten, die üblicherweise im wöchentlichen Rhythmus sonntags stattfinden. Hier wechseln die Programmverantwortlichen zwischen den beiden Konfessionen ab, da gleichzeitig nur ein Gottesdienst ausgestrahlt werden kann.

322 Es muss aber darauf hingewiesen werden, dass Bruttoinlandsprodukt und Arbeitskräfteverteilung normalerweise über ganzjährige Zeiträume hinweg erhoben werden. Deshalb ist der Vergleich nur unter der Annahme zulässig, dass in einer größeren Stichprobe - oder sogar in einer ganzjährigen Erhebung - die Verteilung der Berichterstattung auf die Wirtschaftssektoren ähnlich ausfällt.
} 
maß nieder. Das ist jedoch wenig überraschend, da die Domäne des Journalismus vor allem die aktuelle Berichterstattung ist. Gleichwohl wurden sowohl in den Magazinsendungen als auch in alleinstehenden dokumentarischen Sendungen zahlreiche Beispiele für die Behandlung historischer Zusammenhänge gefunden. Am umfangreichsten war das im MDR mit über zweieinhalb Stunden der Fall sowie im ZDF mit gut einer Stunde. Das liegt unter anderem daran, dass in diesen beiden Programmen historisch unterrichtende Magazine zum fixen Senderepertoire gehören, was im $O R F 2$ und $B R$ während des Untersuchungszeitraums nicht der Fall war. Sowohl im $Z D F$ als auch im $M D R$ ist die historische Betrachtung des Dritten Reichs das häufigste Geschichtsthema. Dieser - für die deutsche Geschichte prägende Zeitraum - ist also keineswegs die Domäne nationalen Programms. Betrachtet man zusätzlich die Behandlung historischer Themen in alleinstehenden Sendungen, so zeigt sich zumindest für die Regionalsender, dass hier die relative Mehrheit der Sendezeit auf jene historischen Epochen entfällt, die für die dem Sendegebiet zugrunde liegende Region von besonderer historischer Bedeutung sind. Im BR ist das die Epoche des Königreichs Bayern, im MDR-Fernsehen die DDR-Zeit. Das spricht auch auf Inhaltsseite für eine komplementäre Funktion des regionalen TV-Angebots: Die historischen Themen beschränken sich zwar keineswegs auf jene Aspekte der Geschichte mit besonderer regionaler Bedeutung, aber die Regionalsender behandeln diese Themen deutlich prominenter als andere Programme.

Hinsichtlich der Akteurinnen und Akteure, die in der Berichterstattung zu Wort kommen, konnten einige Unterschiede festgestellt werden, die sich (jedenfalls zum Teil) auf die Regionalität bzw. Nationalität des Programms zurückführen lassen. Das betrifft insbesondere die Verwendung von Dialekt. Auch hier verläuft die Unterscheidungslinie aber nicht zwischen regionalen und nationalen Sendern, sondern die „Sprechprofile“ erscheinen durchaus individuell. Lediglich die Verwendung „starken Dialekts“ ist in den beiden Regionalprogrammen häufiger zu beobachten als in den nationalen. Am wenigsten hochdeutsch wird dagegen im ORF 2 gesprochen. Hier dürften sich aber die Besonderheiten Österreichs als Sprachregion niederschlagen, die insgesamt zum bairischen Sprachraum gehört (vgl. Glück 2000: 153). Das $Z D F$, wo dagegen am häufigsten hochdeutsch gesprochen wird, integriert alle deutschen Hauptsprachräume, was die Verwendung von Standardsprache nahelegt. Wobei in der Untersuchungsperspektive, die instrumentbedingt in dieser Arbeit eingenommen wird, offen bleibt, ob es sich hierbei um redaktionelle Einflüsse (Auswahl der O-Töne) oder tatsächliche Unterschiede im Sprechverhalten der zu Wort kommenden Personen handelt. In jedem Fall wird aber im Ergebnis das ZDF-Publikum häufiger mit Standardsprache als mit Dialekt konfrontiert. Hinsichtlich der Anteile verschiedener zu Wort kommender Personengruppen sind ebenfalls eher individuelle Profile zu erkennen. Deutliche Unterschiede zeigen sich aber im Bereich der politischen Hierarchieebene, der sich Politikerinnen und Politiker zuordnen lassen, die in den Magazinsendungen vorkommen. Hier dominieren in den nationalen Programmen die Volksvertreterinnen und -vertreter auf bundesweiter Ebene, während im BR und MDR solche aus dem regionalen und lokalen Kontext häufiger vorkommen. Auch daran wird die Komplementärfunktion der Dritten Programme innerhalb des öffentlich-rechtlichen Fernsehmarktes in Deutschland noch einmal deutlich. 


\subsection{Schlussfolgerungen}

Was bedeuten nun diese vielfältigen, teilweise disparaten und in ihrer Tragweite recht unterschiedlichen Ergebnisse für den theoretischen Rahmen, der in Kapitel 4 skizziert wurde? Zunächst einmal ist festzuhalten, dass weder die Nation noch die Region die maßgebliche Einflussgröße für die Ausbildung individueller Programminhalte und -strukturen ist. Das bedeutet auch, dass die Einteilung in nationales und regionales Fernsehprogramm über den inhaltlichen Zuschnitt der Programmangebote nur begrenzt aussagekräftig ist. Insbesondere der Charakter des ZDF als Vollprogramm im Sinne des Rundfunkstaatsvertrags dürfte die inhaltliche Ausprägung deutlicher bestimmen als es das bloße Sendegebiet tut. Das gilt unter den besonderen Bedingungen des österreichischen Rundfunksystems in ähnlicher Weise auch für den ORF 2. Gleichzeitig sind die Dritten Programme ${ }^{323}$ mehr als nur „regionalisierte Spartenprogramme“.

Für die Bedeutung des Fernsehens in dem Prozessen nationaler und regionaler Identitätsbildung ergeben sich somit folgende Schlussfolgerungen: Das Fernsehsystem selbst ist in seiner Organisationsstruktur zum Teil auf Region und Nation bezogen. Aus dieser Voraussetzung entstehen unterschiedliche Arten der inhaltlichen Ausfüllung regionaler und nationaler „Programmanforderungen“. Hier wirken sich insbesondere rechtliche und organisatorische Bedingungen des Fernsehsystems aus.

Auf regionaler Ebene dagegen, wo die Programmangebote bisher jeweils konkurrenzlos sind, kommt die Regionalität der TV-Sender deutlicher zum Vorschein und zwar in vielen inhaltlichen Aspekten. Die stärkste Dimension der regionalen Programmidentität ist dabei der Raumbezug - dieser lässt sich sowohl im Informations- als auch Unterhaltungsprogramm deutlich nachweisen. Auch das „Identifikationsobjekt“ regionaler Dialekte ist im Regionalprogramm deutlich präsent. Dass es sich aber dabei um eine genuine Besonderheit dieser Programmform handelt, ließ sich - dem Untersuchungsdesign geschuldet - nicht eindeutig nachweisen. Darüber hinaus lassen sich in der inhaltlichen Ausgestaltung des regionalen Programms solche Aspekte gut nachweisen, die mehr oder weniger eindeutig den Charakter einer Region (mit-)bestimmen. Das sind zum Beispiel historische oder religiös-konfessionelle Bezüge. Dabei handelt es sich aber - etwa im Gegensatz zu tagesaktueller politischer Berichterstattung - um relativ stabile kulturelle Kategorien. Dass diese dann im regionalen Programm recht deutlich zum Vorschein kommen, ist aber teilweise auch eine Auswirkung der Organisationsstruktur des Fernsehens: Der zeitlich recht hohe Informationsanteil ${ }^{324}$ in den Dritten Programmen schafft erst die Möglichkeit, diese Aspekte zu thematisieren.

In der mehrfach festgestellten komplementären Ausrichtung des inhaltlichen Angebots der Regionalsender zeigt sich aber, dass die Region keine „kleine Nation“ ist, sondern sich ihrem Wesen nach auf die größere Einheit der Nation bezieht. Insofern wird von Regionalprogram-

\footnotetext{
${ }^{323}$ Die möglicherweise nicht vorbehaltlos als Vollprogramme angesehen werden können (vgl. S. 153, Fn. 247)

${ }^{324}$ Der folgt seinerseits auch wieder dem - historisch gewachsenen - Programmangebotsverständnis.
} 
men keine Unvereinbarkeit von Nation und Region behauptet oder gefördert. Das deckt sich mit Weichharts Annahmen zum Einfluss der Maßstabsebene auf Rollenanforderungen symbolischer regionaler Gemeinschaften (siehe S. 62). Da das Fernsehangebot auf den unterschiedlichen Maßstabsebenen von Nation und Region komplementär erscheint, wirkt es an deren gesellschaftlicher Hierarchisierung mit. Gleichzeitig ist diese Ebenenunterscheidung bereits durch den jeweiligen gesellschaftlich und historisch ausgehandelten Status vorgegeben - darauf basiert schließlich unter anderem die Stellung der unterschiedlichen TV-Sender im Fernsehsystem.

Als einer der Hauptunterschiede zwischen Nation und Region wurde der Grad ihrer Bindung an einen physischen Raum herausgestellt. Daraus folgen unterschiedliche Bedeutungen der Programmangebote hinsichtlich der von ihnen repräsentierten Raumvorstellungen. Einerseits sollen sie bestehenden Kulturräumen folgen, andererseits eigene Kommunikationsräume konstituieren (vgl. S. 84). Die individuell durch die Berichterstattung geschaffenen Gebiete weisen im Regionalprogramm Merkmale genau dieser beiden Pole auf. So wird zum Beispiel im BR gerade aus dem historisch bedeutsamen altbayerischen Raum deutlich umfangreicher berichtet als aus dem übrigen Land. Das Sendegebiet des BR ist dabei deckungsgleich mit dem Bundesland Bayern, das seinerseits weitestgehend auf den historischen Grenzen des Königreichs Bayern beruht. Anders verhält es sich dagegen beim MDR. Dieser konstituiert als Sendeanstalt erst einen Kommunikationsraum. Historisch-kulturelle Grundlagen Mitteldeutschlands sind nur latent vorhanden. Der so geschaffene Kommunikationsraum wird im Programm des MDR beinahe vollständig und sehr gleichmäßig ,abgebildet“. Insofern scheint es sich tatsächlich um einen Beleg dafür zu handeln, dass hier der Rundfunk einen eigenen Kommunikationsraum konstituiert. Dieser basiert allerdings vollständig auf politisch festgelegten Verwaltungseinheiten und die Konstitutionsleistung beschränkt sich somit darauf, die drei hier zusammengefassten Bundesländer unter einer medialen Klammer zu vereinigen - was jedenfalls inhaltlich auch gut gelingt. In beiden Fällen aber handelt es sich um eine kommunikative Bestätigung der Regionen - und damit auch der entsprechenden Annahmen Ronnebergers (vgl. S. 84). Fraglich bleibt allerdings, ob heutige Funktionsräume zum Ausgangspunkt regionaler Identitäten werden können (vgl. S. 29). Im BR schlagen vornehmlich frühere Bedeutungsräume in der Programmrealität durch, im MDR jedoch nicht. ${ }^{325}$

Anders sieht das aber im Bereich der Nation aus. So wie sich dieses soziale Konstrukt weniger stark auf einen zugrunde liegenden Raum bezieht, so wird dieser durch die TVBerichterstattung im ZDF auch weniger ausgefüllt - Ereignisorte der Berichterstattung sind nur punktuell über Deutschland verteilt. Der ORF 2 lässt sich in eine derart dichotomisierende Betrachtung allerdings kaum sinnvoll einordnen: Zwar wird nicht aus ganz Österreich so flächendeckend berichtet wie in den deutschen Regionalprogrammen, eine nur punktuelle Berichterstattung wie im $Z D F$ lässt sich aber ebenfalls nicht feststellen. Insofern lassen die Ergebnisse nicht darauf schließen, dass eine Kohärenz von theoretischem Konstrukt Nation und seiner kommunikativen Ausformung im Fernsehprogramm besteht. Das gilt umso mehr, als

325 Wobei hinsichtlich einer „,mitteldeutschen Identität“ letztlich nur eine Untersuchung auf Publikums- bzw. Bevölkerungsseite Antwort geben kann, ob diese auch auf personaler Seite salient sein kann. 
dass im österreichischen Sender deutliche Einflüsse von äußeren Bedingungen, die mit der Größe und Lage der Alpenrepublik zusammenhängen, feststellbar sind. Hinsichtlich der Repräsentation von Raumvorstellungen in den unterschiedlichen TV-Programmen sind die Ergebnisse also uneinheitlich. Gleichwohl wird in allen vier untersuchten Programmen in verschiedenen inhaltlichen Aspekten deutlich, für welches Verbreitungsgebiet sie die kommunikative Klammer bilden, sei es in fiktionalen oder informierenden Programmangeboten. Man kann also sehr wohl sagen, dass jeder der hier untersuchten Fernsehsender eine mehr oder weniger stark ausgeprägte nationale oder regionale Identität aufweist. Die Inhalte sind nicht austauschbar oder beliebig, sondern auf das jeweilige Sendegebiet bezogen.

Unter Rückbezug auf die Frage nach Offen- und Geschlossenheit der Konzepte Nation und Region heißt das insgesamt auch, dass die Nation im Fernsehprogramm als offener erscheint als die Region. Das liegt an der geringeren Bindung an das geografische Territorium des Nationalstaates. Das Publikum wird durch die Berichterstattung, die gerade nicht regional fokussiert ist, jederzeit gleichermaßen „eingeladen“, sich „gemeint zu fühlen“ und zwar auch dann, wenn nicht aus der eigenen lokalen oder regionalen Alltagsumwelt berichtet wird. ${ }^{326}$ Der Nationalstaat als Ganzes ist häufiger der „Bezugsraum“ der Berichterstattung der nationalen Programme, als es das einzelne (gesamte) Bundesland in den Regionalprogrammen ist. Das heißt, dass die Relevanz für alle (räumlich verteilten) Teile des Publikums gleich groß erscheint. ${ }^{327}$ In den Regionalprogrammen ist weitgehend nur für das Publikum im Sendegebiet der Fall. Die Berichterstattung ist deutlich auf die Region und ihre kleineren Dimensionen hin ausgerichtet. Das Programm ist deshalb auch ohne das Wissen, für welche Region die Berichterstattung gedacht ist, als spezifisch regional (also bayerisch oder mitteldeutsch) erkennbar (Handlungsorte von fiktionalen Inhalten, Ereignisorte der Berichterstattung, Dialekt). Damit erscheint es auch „geschlossen“. Das auswärtige Publikum kann sich hier zwar über das Geschehen im Sendegebiet informieren, ist aber dann ausgeschlossen, wenn es um die Relevanz der Berichterstattung für den eigenen Alltag geht. Hinzu kommt, dass im BR Brauchtum und Tradition den wichtigsten Gegenstand der Berichterstattung darstellen. So wird der „geschlossene“ Eindruck verstärkt, weil die spezifische Region von außen betrachtet zusätzlich als traditional codiert (vgl. S. 15) erscheint - damit wird auf durch Sozialisierung erworbene Kompetenzen verwiesen. Diese Kompetenzen wirken nach außen ausschließend, weil sie nicht durch das Fernsehen allein erworben werden können, nach innen wirken sie einschließend, weil die Bedeutsamkeit im regionalen Kontext verstärkt wird, wenn die Traditionen auch in der öffentlichen Kommunikation präsent sind.

Vor diesem Hintergrund können so auch die eigentlich thematischen Bestandteile des Programmangebots als Repräsentationen von Wissensstrukturen, die sich auf die Region und die Nation beziehen, gelesen werden. Dabei zeigt sich aber, dass diese keinesfalls als komplettes und konsistentes Bild verstanden werden können. Das ergibt sich schon aus der Vielzahl äu-

\footnotetext{
326 Wobei vom österreichischen Publikum teilweise größere „Abstraktionsleistungen“ abverlangt werden, weil ein so großer Anteil v. a. deutscher Produktionen gezeigt wird.

327 Das bedeutet selbstverständlich nicht, dass ein nationales Programm auch Angehörige anderer Nationen (etwa Nachbarstaaten) einlädt, sich als Teil der Nation zu sehen, sondern das diese „Einladung“ nach innen, hier aber an alle, gerichtet ist.
} 
Berer Einflüsse, welche die Zusammenstellung der Programminhalte und der Berichterstattung beeinflussen. Innerhalb des derart aufgespannten Kommunikationsraums sind die Möglichkeiten zur Information über die verschiedenen gesellschaftlichen Subsysteme allerdings ganz unterschiedlich verteilt. In den Magazinen aller vier untersuchten Sender sind nicht-organisierte Privatleute die Personengruppe, die am häufigsten zu Wort kommt. Das bedeutet aber selbstverständlich nicht einen herrschaftsfreien Diskurs um die Gültigkeit gesellschaftlich geteilter Werte und Normen. Die vermittelte Koorientierung wird aber dennoch ermöglicht und durch die Bedingungen des jeweiligen Programms in einen Kontext gestellt, der eben regional sein kann oder national. Gerade auf regionaler Ebene kommt den einzelnen TV-Sendern eine besonders ausgeprägte Machtstellung zu, da diese in der Größenordnung und für das jeweilige Sendegebiet singulär sind. ${ }^{328}$ Auch das fügt sich in die begrifflichen Grundlagen, denen zu Folge - überspitzt formuliert - die Region ein manifestes Konstrukt ist, die Nation aber „nur“ ein latentes. Während für regionale Programme bereits in den rechtlichen Grundlagen das zu versorgende Sendegebiet unter Verweis auf die Grenzen der jeweiligen Bundesländer benannt ist, gibt es solche expliziten Regeln für nationale Programme nicht. Die gesellschaftliche Gültigkeit der Unterscheidung von Nation und Region spiegelt sich damit bereits in der Organisationsstruktur des Fernsehens wider und wirkt sich programminhaltlich aus.

\footnotetext{
${ }^{328}$ Subregionale TV-Sender konkurrieren (zumal auf Grund ihrer Organisationsform) auf anderer Ebene. Lokale Tageszeitungen sind als Presseerzeugnisse mit kleiner zugeschnittenem Verbreitungsgebiet schon auf Grund der Tatsache, dass es sich um ein anderes Medium handelt, wohl als nachrangig zu den Regionalsendern zu betrachten.
} 


\subsection{Ausblick}

Aus der Vielzahl heterogener und teilweise disparater Befunde der vorliegenden Studie ergeben sich neue sowie offen gebliebene Fragen. Diese fordern zu weiterer Forschung auf. Vor dem Hintergrund der hier erbrachten Ergebnisse lassen sich weitere Befunde zum Thema hinsichtlich ihrer Relevanz klar einordnen. Zum Beispiel wären aus rein quantitativer Sicht Zweifel angebracht, wenn der Politikberichterstattung in Magazinen des MDR Tendenz vorgeworfen würde. Da diese Berichterstattung insgesamt so wenig umfangreich ist, dürfte sich eine Tendenz der Aussagen in aggregierten Daten zum einen kaum vermeiden lassen. Zum anderen wäre es fraglich, welche Wirkung auf die politische Meinungsbildung von derart marginaler Berichterstattung ausgehen sollte. Allerdings sind es gerade die hier vorgelegten Befunde zur Politikberichterstattung in den beiden untersuchten Regionalsendern, die Anlass für weitere Untersuchungen geben - insbesondere vor dem Hintergrund der konstatierten Machtstellung des regionalen Fernsehens. Denkbar wären hier vor allem Untersuchungen des Einflusses von Politikdarstellung auf regionale politische Entscheidungsprozesse (Landtagswahlen) oder überhaupt zur Relevanzeinschätzung regionaler Politik. Nimmt man dabei die in dieser Arbeit zugrunde gelegte Repräsentationsfunktion des Fernsehens ernst, wäre dabei auch zu fragen, welchen Stellenwert Politik im sozialen Zusammenleben überhaupt hat.

Insgesamt sprechen die vorliegenden Ergebnisse dafür, dass Unterschiede der Berichterstattung zwischen nationalem und regionalem Fernsehen vor allem individuell sind. Insofern erscheint es sinnvoll, nicht generalisierend zwischen den Kategorien „national“ und „regional“ zu unterscheiden, sondern konkret auf spezifische Regionalsender Bezug zu nehmen. Da somit die Tragweite möglicher Aussagen eingeschränkt wird, dürfte es sich anbieten, insbesondere Einzelthemen und ihre unterschiedliche Behandlung aufzugreifen.

Somit erscheinen vor allem Analysen unterschiedlichen Framings (zum Framingansatz vgl. Scheufele 1999, Scheufele 2003) in bestimmten Regionalsendern und nationalen Programmen von Interesse. Damit könnten schließlich auch die Angebots- und Rezipientenseite integriert werden. Das ist sinnvoll, weil sich gezeigt hat, dass sich auf Ebene des Gesamtinhalts von Fernsehprogrammen sehr heterogene Einzelbefunde ergeben. Auf der Sub-Ebene einzelner (möglicherweise regional und national unterschiedlich „geframter") Themen, dürften sich deren Auswirkungen auf ihre Einschätzung durch die Rezipienten tatsächlich messbar machen lassen. Vor dem Hintergrund der hier erbrachten Ergebnisse dürfte es aber nicht um allgemein „regionale Frames“ gehen, sondern um jeweils spezifisch-regionale Einordnungen. Es stellt sich also eher die Frage nach einer genuin bayerischen oder auch mitteldeutschen (usw.) Einordnung von Themen.

Innerhalb der beiden Regionalprogramme wurden Unterschiede in der Beachtung bestimmter subregionaler Räume festgestellt. Insbesondere im MDR zeigte sich, dass die Berichterstattung sehr gleichmäßig über das Sendegebiet verteilt ist. Dies scheint unter anderem darauf zu verweisen, dass innerhalb des Drei-Länder-Verbundes keine kulturhistorisch herausragenden 
Regionen die Identität Mitteldeutschlands maßgeblich bestimmen. Auch ließ sich - im Gegensatz zu Bayern - keine Konzentration auf die Landeshauptstädte feststellen. Insofern wären die Regionalfenster des MDR ein interessantes Forschungsobjekt. Da sich die drei mitteldeutschen Bundesländer in ihren geschichtlichen Bezügen unterscheiden, könnten sich hier andere Strukturen auf der subregionalen Ebene zeigen. Ähnliches gilt denn auch für die subregionalen Sendefenster im Bayerischen Rundfunk. Hier wäre zu fragen, ob zum Beispiel innerhalb der fränkischen Sendungen eine starke Konzentration auf Nürnberg stattfindet und ob sich im südbayerischen Fensterprogramm die Konzentration auf München verschärft oder eine „flächige“ Berichterstattung die Konzentration des Gesamtprogramms abmildert.

Im Rahmen der vorliegenden Arbeit wurde gezeigt, dass sich bestimmte Merkmale von Regionen im Programm wiederfinden. Neben dem expliziten Raumbezug betraf dies vor allem inhaltliche Aspekte historischer, kultureller und auch religiös-konfessioneller Art. Da einer der Hauptunterschiede zwischen nationalem und regionalem Programm im Anteil des Informationsangebots liegt - das hier hauptsächlich untersucht wurde -, liegt es nah, solche Unterschiede auch im fiktionalen Unterhaltungsangebot zu untersuchen. Vorliegend konnte immerhin bereits gezeigt werden, dass auch diese Inhalte deutliche Unterschiede hinsichtlich ihrer Raumbezüge (Handlungsorte) aufweisen. Das legt nahe, dass in den Filmen und Serien auch latente Unterschiede relevant sein können - sei es in der Anlage der Figuren, sei es in den Konflikten, die dort ausgetragen werden.

Medieninhalte sind - ebenso wie sie auch ein Produkt der Umstände sind, in denen sie hergestellt werden - vor allem Ergebnis der Arbeit von Journalistinnen und Journalisten, Redakteuren und Redakteurinnen. Hier wurde davon ausgegangen, dass diese Personen in ihren sozialen Beziehungen auch Teil der gesellschaftlichen Strukturen von Region und Nation sind. Es stellt sich aber auch die Frage, inwiefern gerade die regionale Ausgestaltung des Programms auch Folge bewusster Auswahlprozesse auf Kommunikatorseite ist. Werden zum Beispiel die vor der Kamera zu Wort kommenden Personen bevorzugt dann in den Berichten belassen, wenn sie einen deutlichen Dialekt sprechen? Werden umgekehrt Personen, die eine auswärtige Mundart pflegen, bewusst zu Gunsten eines regionalen Anstrichs der Berichterstattung nicht gezeigt? Entsprechende Untersuchungen zu den Auswahlkriterien der Kommunikatoren können hierüber Aufschluss geben und die hier erbrachten Befunde sinnvoll ergänzen.

Der nachgewiesene Einfluss des Nachbarn Deutschland auf das österreichische Fernsehprogramm dürfte auch über den Next-Door-Giant-Effekt hinaus von Interesse sein. Das betrifft zum Beispiel den hohen Anteil deutscher Film- und Fernsehproduktionen. Die bereits in der Einleitung zitierte Studie von Trepte untersuchte den Einfluss der Nationalität von Rezipienten auf deren Auswahlverhalten bezüglich unterhaltender Inhalte (Trepte 2004, siehe auch S. 4). Im österreichischen Fernsehen wirft das die Frage auf, ob sich nicht nur hinsichtlich der Wahl amerikanischer, sondern eben auch deutscher Serien und Filme Unterschiede zur Zu- 
wendung zu heimischen Produktionen ausmachen lassen. Hier könnte zusätzlich interessieren, inwiefern Co-Produktionen ${ }^{329}$ des ORF mit deutschen Filmproduzenten das Bild beeinflussen.

$\mathrm{Zu}$ fragen bleibt außerdem nach den Unterschieden zwischen öffentlich-rechtlichen und privaten Programmen. Eine diesbezügliche Untersuchung würde aber auf subnationaler Ebene weitere Unterscheidungskategorien erfordern. Insbesondere das Fehlen regionaler (landesweiter) Fernsehprogramme auf privater Seite erfordert die Untersuchung lokaler Programmangebote. Diese sind stark ausdifferenziert und häufig auch als Spartenprogramme ausgelegt. Zu fragen wäre, inwiefern sich so etwas wie „lokale Identität“ in solchen Sendern widerspiegeln kann.

Eine umfassende Aufarbeitung des Themas nationaler und regionaler Identität als Einflussvariable auf Struktur und Funktion des Fernsehens bedarf also noch einiger weiterer Forschung. Insbesondere die Eruierung einzelner Themen und Diskurse erscheint hier als fruchtbares Betätigungsfeld. Diese (möglicherweise qualitativ zu bewerkstelligende) Forschung ist aber auf die Makroperspektive von gesamtsystematisierenden Untersuchungen angewiesen, um sinnvolle Einschätzungen der Relevanz einzelner Themen vornehmen zu können. Das gilt insbesondere vor dem Hintergrund des weithin regional ausdifferenzierten Fernsehsystems in Deutschland. Hierin steckt nicht zuletzt auch rundfunkpolitische Brisanz: Es stellt sich die Frage, ob die - häufig unter finanziellem Druck - immer wieder geforderte Zusammenlegung einzelner Rundfunkanstalten sich inhaltlich rechtfertigen lässt, wenn die genuin regionale Berichterstattung staatsvertraglich oder gesetzlich geregeltes Ziel der Rundfunkordnung ist.

${ }^{329}$ Co-Produktionen wurden in dieser Studie nicht gesondert erhoben. Insofern basiert die Einschätzung, dass diese im ORF 2 relativ häufig vorkamen, auf einem subjektiven Eindruck nach der Programmcodierung. 


\section{Literaturverzeichnis}

Ahbe, Thomas, 2004: Die Konstruktion der Ostdeutschen. Diskursive Spannungen, Stereotype und Identitäten seit 1989. In: Aus Politik und Zeitgeschichte (41/42), S. 12-22.

ALM, 2005: Gemeinsame Richtlinie der Landesmedienanstalten zur Sicherung der Meinungsvielfalt durch regionale Fenster in Fernsehvollprogrammen nach \$25 RStV (Fernsehfensterrichtlinie). 06.07.2005.

Alsleben, Brigitte; Wermke, Matthias, 2007: Das Herkunftswörterbuch. Etymologie der deutschen Sprache; auf der Grundlage der neuen amtlichen Rechtschreibregeln Bd. 7. Mannheim: Dudenverlag.

Altes, Bärbel, 2003: \5a. In: Hahn, Werner/Altes, Bärbel (Hrsg.), Beck'scher Kommentar zum Rundfunkrecht. [Rundfunkstaatsvertrag, Rundfunkgebührenstaatsvertrag, Rundfunkfinanzierungsstaatsvertrag, Jugendmedienschutzstaatsvertrag]. München: C.H. Beck, S. 262325.

Anderson, Benedict, 2005: Die Erfindung der Nation. Zur Karriere eines folgenreichen Konzepts. 2., um ein Nachwort von Thomas Mergel erweiterte Auflage der Neuausgabe 1996. Frankfurt/Main: Campus-Verlag.

ARD (Hrsg.), 2007: ARD Jahrbuch 07. Hamburg: Hans-Bredow-Institut.

Avenarius, Hermann, 1997: Die Rechtsordnung der Bundesrepublik Deutschland. Eine Einführung. 2., neubearb. Aufl. Bonn: Bundeszentrale für Politische Bildung.

Bausinger, Hermann, 2006: Wann ist deutsch? Zu den Funktionen des Typisierens. In: Brehm, Thomas/Wambsgan₹, Ingrid (Hrsg.), Was ist deutsch? Fragen zum Selbstverständnis einer grübelnden Nation ; Germanisches Nationalmuseum, Nürnberg, in Kooperation mit dem Kunst- und Kulturpädagogischen Zentrum der Museen in Nürnberg (KPZ), 2. Juni bis 3. Oktober 2006 ; [Ausstellung „Was Ist Deutsch?‘]. Nürnberg: Verlag des Germanischen Nationalmuseums, S. 22-31.

BDZV, 2004: Neuer Eigentümer für „Vogtland-Anzeiger“. 16. September 2004 (Pressemitteilung) (Online: http://www.bdzv.de/bdzv_intern+M54d95ce1554.html; Abruf 14.5.2010).

Beal, Joan C., 2006: Language and region. London: Routledge.

Beck, Klaus, 2006: Gatekeeper. In: Bentele, Günter/Brosius, Hans-Bernd/Jarren, Otfried (Hrsg.), Lexikon Kommunikations- und Medienwissenschaft. Wiesbaden: VS Verlag für Sozialwissenschaften, S. 79-80.

Bergmann, Rolf/Stricker, Stefanie/Götr, Ursula, 2005: Einführung in die deutsche Sprachwissenschaft. 4. Heidelberg: Winter.

Bernhard, Uli, 2008: Wie unterhaltsam ist Politik? Eine Analyse der Politikberichterstattung in regionalen Tageszeitungen. Saarbrücken: VDM Verlag Dr. Müller.

$B L M$, 2007: Private Rundfunkangebote und Telemedien in Bayern (Online abrufbar unter: http://www.blm.de/apps/documentbase/data/de/anbieterliste_05.2007.pdf; Abruf 2.7.2007).

Blotevogel, Hans H., 2000: Zur Konjunktur der Regionsdiskurse. In: Informationen zur Raumentwicklung (9/10), S. 491-506.

Blotevogel, Hans H./Heinritz, Günter/Popp, Herbert, 1989: „Regionalbewusstsein“. Zum Stand der Diskussion um einen Stein des Anstoßes. In: Geographische Zeitschrift (1) 77, S. 65-88.

Blotevogel, Hans H., 1996: Auf dem Wege zu einer ,Theorie der Regionalität':. Die Region als Forschungsobjekt der Geographie. In: Brunn, Gerhard (Hrsg.), Region und Regionsbildung in Europa. Konzeptionen der Forschung und empirische Befunde ; wissenschaftliche Konferenz, Siegen, 10. - 11. Oktober 1995. Baden-Baden: Nomos, S. 44-68. 
Blumer, Herbert, 1973: Der methodologische Standort des Symbolischen Interaktionismus. In: Arbeitsgruppe Bielefelder Soziologen (Hrsg.), Alltagswissen, Interaktion und gesellschaftliche Wirklichkeit. Symbolischer Interaktionismus und Ethnomethodologie. Reinbek bei Hamburg: Rowohlt, S. 80-101.

Bonfadelli, Heinz, 2005a: Medienwirkungsforschung. In: Bonfadelli, Hein₹/Jarren, Otfried/Siegert, Gabriele (Hrsg.), Einführung in die Publizistikwissenschaft. Bern: Haupt, S. 337-379.

Bonfadelli, Hein₹, 2005b: Was ist öffentliche Kommunikation? Grundbegriffe und Modelle. In: Bonfadelli, Heinz/Jarren, Otfried/Siegert, Gabriele (Hrsg.), Einführung in die Publizistikwissenschaft. Bern: Haupt, S. 73-102.

Bornewasser, Manfred/Wakenhut, Roland, 1999: Nationale und regionale Identität:. Zur Konstruktion von Nationalbewußtsein und sozialer Identität. In: Bornewasser, Manfred (Hrsg.), Ethnisches und nationales Bewußtsein. Zwischen Globalisierung und Regionalisierung ; [Beiträge zum 4. Kolloquium der deutsch-italienischen Forschungsgruppe FIMO vom 30. September bis 2. Oktober 1997 Banz]. Frankfurt am Main: Lang, S. 41-64.

Bosl, Karl, 1980: Bayerische Geschichte. Im Text ungekürzte Ausg. München: dtv.

BR, 2007: Programmschema Bayerisches Fernsehen | Wir über uns | BR (Online abrufbar unter: http://www.br-online.de/br-intern/artikel/div/programmschema-bfs/index.xml; Abruf 4.7.2007).

Brockhaus, F. A., 1906: Brockhaus' Kleines Konversations-Lexikon. Mit 1000 Textabbildungen, 63 Bildertafeln, darunter 15 bunte, 221 Karten ud Nebenkarten, sowie 34 Textbeilagen. Leipzig: F. A. Brockhaus.

Brosius, Hans-Bernd, 2003: Medienwirkungen. In: Bentele, Günter/Brosius, Hans-Bernd/Jarren, Otfried (Hrsg.), Öffentliche Kommunikation. Handbuch Kommunikations- und Medienwissenschaft. Wiesbaden: Westdeutscher Verlag, S. 128-148.

Bruns, Thomas/Marcinkowski, Frank, 1996: Konvergenz Revisited. Neue Befunde zu einer älteren Diskussion. In: Rundfunk und Fernsehen (4) 44, S. 461-478.

Bucher, Hans-Jürgen (Hrsg.), 2003: Qualität im Journalismus: Grundlagen, Dimensionen, Praxismodelle.

Bundesregierung des Bundesstaates Österreich, 1934: Kundmachung der Bundesregierung vom 1. Mai 1934, womit die Verfassung 1934 verlautbart wird. In: Bundesgesetzblatt für den Bundesstaat Österreich (1) 1, S. 1-32.

Bundeszentrale für Politische Bildung (Hrsg.), 2008: Datenreport 2008. Ein Sozialbericht für die Bundesrepublik Deutschland. Bonn: Bundeszentrale für Politische Bildung.

Butt, Lydia, 2005: Zur Konstruktion von Deutschsein in der publizistischen Kontroverse zur ,Leitkultur' 2004. In: Thiele, Martina/Scharf, Wilfried (Hrsg.), Konkurrenz der Wirklichkeiten. Wilfried Scharf zum 60. Geburtstag. Göttingen, Göttingen: Universitäts-Verlag Göttingen; Niedersächsische Staats- und Universitätsbibliothek, S. 151-188.

BVerfG, 1961: 1. Fernsehurteil. In: Entscheidungen des Bundesverfassungsgerichts 12, S. 205264.

$B V \operatorname{erfG}, 1971:$ 2. Rundfunkurteil - „Mehrwertsteuer“. In: Entscheidungen des Bundesverfassungsgerichts 31, S. 314-357.

$B V \operatorname{erfG}$, 1986: 4. Rundfunkentscheidung (Niedersachsen-Urteil). In: Entscheidungen des Bundesverfassungsgerichts 73, S. 118-205.

$B V \operatorname{erfG}, 1987:$ 5. Rundfunkentscheidung (Baden-Württemberg). In: Entscheidungen des Bundesverfassungsgerichts 74, S. 297-357.

Chaffee, Steven H., 1972: The Interpersonal Context of Mass Media Communication. In: Kline, F. G./Tichenor, Phillip J. (Hrsg.), Current perspectives in mass communication research. Beverly Hills, Calif.: Sage Publications, Ltd., S. 95-120.

Christmann, Gabriela B., 2003: ,Die stolze Residenz'. Dresden-Videos und Dresdner Identität. In: Winter, Carsten/Thomas, Tanja/Hepp, Andreas (Hrsg.), Medienidentitäten. Identität im Kontext von Globalisierung und Medienkultur. Köln: Halem, S. 153-170. 
Cicero-Media GmbH, 2009: Frankenpost. Die Geschichte der Frankenpost (Online abrufbar unter: http://www.frankenpost.de/verlag/wir/art799,647512; Abruf 14.5.2010).

Coover, Gail E./Godbold, Linda C., 1998: Convergence Between Racial and Political Identities. In: Communication Research (6) 25, S. 669-688.

Costa, Paul T./McCrae, Robert R., 1992: Normal personality assessment in clinical practice: The NEO Personality Inventory. In: Psychological Assessment (1) 4, S. 5-13.

Dehm, Ursula, 1984a: Fernsehunterhaltung. Zeitvertreib, Flucht oder Zwang? Eine sozialpsychologische Studie zum Fernseh-Erleben. Mainz: v. Hase \& Koehler.

Dehm, Ursula, 1984b: Fernsehunterhaltung aus der Sicht der Zuschauer. In: Media Perspektiven (8), S. 630-643.

Diekmann, Andreas, 2010: Empirische Sozialforschung. Grundlagen, Methoden, Anwendungen. vollst. überarb. und erw. Neuausg. 2007, 4. Aufl., [21. Aufl. der Gesamtausg.]. Reinbek bei Hamburg: Rowohlt-Taschenbuch-Verlag.

Drosdowski, Günther; Müller, Wolfgang; Scholze-Stubenrecht, Werner; Wermke, Matthias, 2007: Duden - das Fremdwörterbuch. Auf der Grundlage der neuen amtlichen Rechtschreibregeln 9., aktualisierte Aufl. Mannheim: Dudenverlag.

EGMR, 1993: Art. 10 MRK - Rundfunkmonopol (Art. 50 MRK, Art.1 Abs. 2 BVG über die Sicherung der Unabhängigkeit des Rundfunks). In: Österreichische Juristen-Zeitung (1) 49, S. 32-34.

EGMR, 2000: Art. 10 MRK - Privatfernsehen (BVG-Rundfunk, RFG, RRG). In: Österreichische Juristen-Zeitung 56, S. 156-158.

Engel, Christian, 1993: Regionen in der EG. Rechtliche Vielfalt und integrationspolitische Rollensuche ; Gutachten im Auftrag der Staats- und Senatskanzleien der Länder. Bonn: Europa-Union-Verlag.

Estel, Bernd, 2002: Nation und nationale Identität. Versuch einer Rekonstruktion / Zugl.: Tübingen, Univ., Habil.-Schr., 1996. Wiesbaden: Westdeutscher Verlag.

Europäische Kommission (Hrsg.), 2007: Eurostat Jahrbuch der Regionen 2007: Luxemburg: Amt für amtliche Veröffentlichungen der Europäischen Gemeinschaften.

Europarat; Europäisches Parlament, 2003: Verordnung (EG) Nr. 1059/2003 des Europäischen Parlaments und des Rates vom 26. Mai 2003 über die Schaffung einer gemeinsamen Klassifikation der Gebietseinheiten für die Statistik (NUTS). In: Amtsblatt der Europäischen Union (L 154), S. 1-41.

Felgenhauer, Tilo, 2007: Geographie als Argument. Eine Untersuchung regionalisierender Begründungspraxis am Beispiel „Mitteldeutschland". Stuttgart: Steiner.

Felgenhauer, Tilo/Schlottmann, Antje, 2007: Schreiben - Senden - Schauen? Medienmacht und Medienohnmacht im Prozess der symbolischen Regionalisierung. In: Social Geography (1) 2, S. 77-83.

Flamm, Leo, 1993: Westfalen und der Westdeutsche Rundfunk. Eine rundfunkhistorische Studie zur Regionalisierung. Köln, Berlin: Kohlhammer-Grote.

Frank, Ronald, 2006: Das Image der Deutschen in Deutschland und Europa: Selbstbild und Fremdbild. Eine empirische Untersuchung. In: Brehm, Thomas/Wambsganæ, Ingrid (Hrsg.), Was ist deutsch? Fragen zum Selbstverständnis einer grübelnden Nation ; Germanisches Nationalmuseum, Nürnberg, in Kooperation mit dem Kunst- und Kulturpädagogischen Zentrum der Museen in Nürnberg (KPZ), 2. Juni bis 3. Oktober 2006 ; [Ausstellung „Was Ist Deutsch?']. Nürnberg: Verlag des Germanischen Nationalmuseums, S. 214-235.

Friedrich, Walter, 2001: Ist der Rechtsextremismus im Osten ein Erziehungsprodukt der autoritäten DDR? In: Aus Politik und Zeitgeschichte (46), S. 16-23.

Früh, Werner, 2007: Inhaltsanalyse. Theorie und Praxis. 6., überarbeitete Auflage. Konstanz: UVK.

Früh, Werner/Hasebrink, Uwe, 1999: Ostdeutschland im Fernsehen. München: KoPäd. 
Fuchs, Gerbard, 1999: Die Macht der Bilder. Fernsehen in Bayern (1954 - 1999). In: Hamm, Margot (Hrsg.), Der Ton - das Bild. Die Bayern und ihr Rundfunk 1924 - 1949 - 1999 ; Begleitbuch zur Ausstellung des Hauses der Bayerischen Geschichte und des Bayerischen Runfunks, 13. April bis 4. Juli 1999, Funkhaus München ; 22. Juli bis 17. Oktober 1999, Museum für Post und Kommunikation, Nürnberg. Augsburg: Haus der Bayerischen Geschichte, S. 92-101.

Fürst, Dietrich, 1995: Region/Regionalismus. In: Noblen, Dieter/Schultze, Rainer-Olaf(Hrsg.), Politische Theorien. München: C.H. Beck, S. 539-543.

Galtung, Johan/Ruge, Mari H., 1965: The Structure of Foreign News. In: Journal of Peace Research (1) 2, S. 64-91.

Gerbner, George, 2000: Die Kultivierungsperspektive. Medienwirkungen im Zeitalter von Monopolisierung und Globalisierung. In: Schorr, Angela (Hrsg.), Publikums- und Wirkungsforschung. Ein Reader. Wiesbaden: Westdeutscher Verlag, S. 101-121.

Gerbner, George/Gross, Larry/Morgan, Michael/Signorelli, Nancy/Jackson-Beeck, Marylin, 1979: The Demonstration of Power. Violence Profile No. 10. In: Journal of Communication 29, S. 177-196.

Giesen, Bernhard (Hrsg.), 1996: Nationale und kulturelle Identität. Frankfurt am Main: Suhrkamp.

Giesen, Bernhard, 1999a: Identität und Versachlichung. Unterschiedliche Theorieperspektiven auf kollektive Identität. In: Willems, Herbert/Habn, Alois (Hrsg.), Identität und Moderne. Frankfurt am Main: Suhrkamp, S. 389-402.

Giesen, Bernhard, 1999b: Kollektive Identität. Frankfurt am Main: Suhrkamp.

Glück, Helmut (Hrsg.), 2000: Metzler-Lexikon Sprache. Stuttgart: Metzler.

Gockerell, Nina, 1974: Das Bayernbild in der literarischen und „wissenschaftlichen“ Wertung durch fünf Jahrhunderte. Volkskundliche Überlegungen über die Konstanten und Varianten des Auto- und Heterostereotyps eines deutschen Stammes. München: Wölfle.

Götr, Maya, 2003: Identität durch Seifenblasen? Die Bedeutung von Daily Soaps für Kinder und Jugendliche. In: Winter, Carsten/Thomas, Tanja/Hepp, Andreas (Hrsg.), Medienidentitäten. Identität im Kontext von Globalisierung und Medienkultur. Köln: Halem, S. 264-281.

Gries, Rainer, 2005: Mythen des Anfangs. In: Aus Politik und Zeitgeschichte (18/19), S. 12-18.

Gruber, Thomas, 1999: 50 Jahre Bayerischer Rundfunk. Von einem zu fünf Hörfunkprogrammen (1949 - 1999). In: Hamm, Margot (Hrsg.), Der Ton - das Bild. Die Bayern und ihr Rundfunk 1924 - 1949 - 1999 ; Begleitbuch zur Ausstellung des Hauses der Bayerischen Geschichte und des Bayerischen Runfunks, 13. April bis 4. Juli 1999, Funkhaus München ; 22. Juli bis 17. Oktober 1999, Museum für Post und Kommunikation, Nürnberg. Augsburg: Haus der Bayerischen Geschichte, S. 71-82.

Hagen, Lutz M., 1995: Informationsqualität von Nachrichten. Meßmethoden und ihre Anwendung auf die Dienste von Nachrichtenagenturen. Opladen: Westdeutscher Verlag.

Hagen, Lutz M., 1998: Die Beachtung Deutschlands in ausländischen Medien als Funktion des Nachrichtenfaktors Nähe. Eine Analyse von Zeitungs- und Fernsehnachrichten. In: Publizistik (3) 43, S. 141-157.

Hagen, Lutz M., 2006: Nachrichtenfaktoren. In: Bentele, Günter/Brosius, Hans-Bernd/Jarren, Otfried (Hrsg.), Lexikon Kommunikations- und Medienwissenschaft. Wiesbaden: VS Verlag für Sozialwissenschaften, S. 196-197.

Hanitzsch, Thomas, 2004: Integration oder Koorientierung? Risiken funktionaler Differenzierung und Journalismustheorie. In: Löffelholz, Martin (Hrsg.), Theorien des Journalismus. Ein diskursives Handbuch. Wiesbaden: VS Verlag für Sozialwissenschaften, S. 217-232.

Hartmann, Peter C., 1989: Bayerns Weg in die Gegenwart. Vom Stammesherzogtum zum Freistaat heute. Regensburg: Pustet.

Hartstein, Reinhard/Ring, Wolf-Dieter/Kreile, Johannes/Dörr, Dieter/Stettner, Rupert, 1995: Rundfunkstaatsvertrag. Kommentar zum Staatsvertrag der Länder zur Neuordnung des Rundfunkwesens. 2. Aufl. München: Rehm. 
Hasselbring, Bettina, 1999: „Hier ist die Deutsche Stunde in Bayern“. Die Anfänge des Rundfunks (1924 - 1934). In: Hamm, Margot (Hrsg.), Der Ton - das Bild. Die Bayern und ihr Rundfunk 1924 - 1949 - 1999 ; Begleitbuch zur Ausstellung des Hauses der Bayerischen Geschichte und des Bayerischen Rundfunks, 13. April bis 4. Juli 1999, Funkhaus München; 22. Juli bis 17. Oktober 1999, Museum für Post und Kommunikation, Nürnberg. Augsburg: Haus der Bayerischen Geschichte, S. 51-58.

Heise, Ulla (Hrsg.), 1994: Süße muß der Coffee sein! Drei Jahrhunderte europäische Kaffeekultur und die Kaffeesachsen. Begleitbuch zur Ausstellung, 28.4. - 12.6.1994, Stadtgeschichtliches Museum Leipzig im Alten Rathaus. Leipzig.

Hepp, Andreas/Thomas, Tanja/Winter, Carsten, 2003: Medienidentitäten. Eine Hinführung zu den Diskussionen. In: Winter, Carsten/Thomas, Tanja/Hepp, Andreas (Hrsg.), Medienidentitäten. Identität im Kontext von Globalisierung und Medienkultur. Köln: Halem, S. 7-26.

Hickethier, Knut (Hrsg.), 1992: Fernsehen. Wahrnehmungswelt, Programminstitution und Marktkonkurrenz. Frankfurt am Main, Berlin: Lang.

Hickethier, Knut, 1993: Dispositiv Fernsehen, Programm und Programmstrukturen in der Bundesrepublik Deutschland. In: Hickethier, Knut (Hrsg.), Institution, Technik und Programm Rahmenaspekte der Programmgeschichte des Fernsehens. München: Fink, S. 171-243.

Hickethier, Knut/Hoff, Peter, 1998: Geschichte des deutschen Fernsehens. Stuttgart: Metzler.

Hobsbawm, Eric J./Rennert, Udo, 2005: Nationen und Nationalismus. Mythos und Realität seit 1780. Bonn: Bundeszentrale für Politische Bildung.

Hock, Sonja, 2005: Engagement für die Region. Initiativen der Regionalbewegung in der Region Nürnberg ; Ziele, Strategien und Kooperationsmöglichkeiten ; mit 18 Tabellen. Erlangen: Selbstverlag der Fränkischen Geographischen Gesellschaft.

Hoffmann, Jochen, 1998: Glossar. In: Sarcinelli, Ulrich (Hrsg.), Politikvermittlung und Demokratie in der Mediengesellschaft. Beiträge zur politischen Kommunikationskultur. Bonn: Bundeszentrale für Politische Bildung, S. 431-439.

Höfig, Willi, 1973: Der deutsche Heimatfilm. 1947 - 1960. Stuttgart: Enke.

Hörnig, Edgar/Klima, Rolf, 1988: Identität. In: Fuchs, Werner (Hrsg.), Lexikon zur Soziologie. Ungekürzte Sonderausgabe. Opladen: Westdeutscher Verlag, S. 327.

Ible, Holger, 2008: Die Tour de France in den deutschen Medien. Strukturen, Themen und Beispiele der Berichterstattung in Fernsehen und Presse. Saarbrücken: VDM Verlag Dr. Müller.

Jandura, Grit/Jandura, Olaf/Kublmann, Christoph, 2005: Stichprobenziehung in der Inhaltsanalyse. Gegen den Mythos der künstlichen Woche. In: Gehrau, Volker (Hrsg.), Auswahlverfahren in der Kommunikationswissenschaft. Köln: Halem, S. 71-116.

Jarren, Otfried, 2008: Massenmedien als Intermediäre. Zur anhaltenden Relevanz der Massenmedien für die öffentliche Kommunikation. In: Medien- \& Kommunikationswissenschaft (4) 56, S. 329-346.

John, Jürgen, 2001 a: Die politisch-administrative Geschichtslandschaft „Mitteldeutschland". In: John, Jürgen (Hrsg.), „Mitteldeutschland“. Begriff - Geschichte - Konstrukt. Rudolstadt: Hain-Verlag, S. 229-255.

John, Jürgen, 2001b: Gestalt und Wandel der „Mitteldeutschland“-Bilder. In: John, Jürgen (Hrsg.), „Mitteldeutschland“. Begriff - Geschichte - Konstrukt. Rudolstadt: Hain-Verlag, S. 17-68.

John, Jürgen, 2001c: Vorwort. In: John, Jürgen (Hrsg.), „Mitteldeutschland“. Begriff - Geschichte - Konstrukt. Rudolstadt: Hain-Verlag, S. 11-14.

Kaiser, Wolf, 1998a: Rundfunk. In: Ben₹, Wolfgang/Graml, Hermann/Weiß, Hermann (Hrsg.), Enzyklopädie des Nationalsozialismus. Stuttgart: Klett-Cotta, S. 707-708.

Kaiser, Wolf, 1998b: Volksempfänger. In: Ben₹, Wolfgang/Graml, Hermann/Weiß, Hermann (Hrsg.), Enzyklopädie des Nationalsozialismus. Stuttgart: Klett-Cotta, S. 786.

Kambara, Naoyuki, 1992: Study of the Diversity Indices Used for Programming Analysis. In: Studies of Broadcasting 28, S. 195-206. 
Kant, Immanuel, 1968: Die Metaphysik der Sitten. In: Weischedel, Wilhelm (Hrsg.), Werke in zwölf Bänden. Frankfurt am Main: Suhrkamp, S. 307-632.

Köck, Christoph, 1998: Das kulturelle Erbe und die Erfindung des Regionalen. In: Lut\%, Ronald (Hrsg.), Die Region der Kultur. Münster: LIT, S. 195-210.

Kobler-Koch, Beate, 1998: Regionen als Handlungseinheiten in der europäischen Politik. In: Krämer, Raimund (Hrsg.), Regionen in der Europäischen Union. Beiträge zur Debatte. Berlin: Berliner Debatte Wissenschafts-Verlag, S. 45-74.

König, Werner/Paul, Hans-Joachim, 2004: dtv-Atlas Deutsche Sprache. Orig.-Ausg., 14., durchges. und aktualisierte Aufl. München: dtv.

Kops, Manfred, 1977: Auswahlverfahren in der Inhaltsanalyse. Meisenheim am Glan: Anton Hain.

Kors, Johannes/Grigoleit, Dagmar/Freund, Cornelia, 2007: ALM Jahrbuch 2006. Landesmedienanstalten und privater Rundfunk in Deutschland. Berlin: Vistas.

Köster, Ingo, 2008: Fernsehkultur. Kulturelle und ökonomische Einflüsse auf institutionelle Strukturen im westeuropäischen Fernsehen. Münster, Westf: LIT.

Kraus, Andreas, 1983: Geschichte Bayerns. Von den Anfängen bis zur Gegenwart. München: C.H. Beck.

Kröber, Martin, 2003: \6 RStV. In: Habn, Werner/Altes, Bärbel (Hrsg.), Beck'scher Kommentar zum Rundfunkrecht. [Rundfunkstaatsvertrag, Rundfunkgebührenstaatsvertrag, Rundfunkfinanzierungsstaatsvertrag, Jugendmedienschutzstaatsvertrag]. München: C.H. Beck, S. 1111.

Krüger, Udo M., 2001: Zur medienpolitischen Instrumentalisierung der Konvergenzthese von Heribert Schatz. In: Schatz, Heribert/Abromeit, Heidrun/Nieland, Jörg-Uwe/Schierl, Thomas (Hrsg.), Politik, Medien, Technik. Festschrift für Heribert Schatz. Wiesbaden: Westdeutscher Verlag, S. 187-206.

Krïger, Udo M./Zapf-Schramm, Thomas, 2000: ARD 3 - Regionalität und Alltagsorientierung. Programmanalyse der Dritten Programme 1997 - 1999. In: Media Perspektiven (12), S. 534-549.

Krüger, Udo M./Zapf-Schramm, Thomas, 2007: Sparten, Sendungsformen und Inhalte im deutschen Fernsehangebot 2006. Programmanalyse von ARD/Das Erste, ZDF, RTL, SAT.1 und ProSieben. In: Media Perspektiven (4), S. 166-186.

Krüger, Udo M./Zapf-Schramm, Thomas, 2008: Sparten, Sendungsformen und Inhalte im deutschen Fernsehangebot 2007. Programmanalyse von ARD/Das Erste, ZDF, RTL, SAT.1 und ProSieben. In: Media Perspektiven (4), S. 166-189.

Krüger, Udo M./Zapf-Schramm, Thomas, 2009: Politikthematisierung und Alltagskultivierung im Infoangebot. Programmanalyse 2008 von ARD/Das Erste, ZDF, RTL, Sat.1 und ProSieben. In: Media Perspektiven (4), S. 201-222.

Lades, Sandra/Frank, Ronald, 2010: Die Deutschen machen sich die meisten Sorgen - Arbeitslosigkeit größte Herausforderung für Europa. Ergebnisse der Studie „Challenges of Europe 2010" des GfK Vereins. Nürnberg.

Langer, Josef, 1999: Last in, First out? Austria's Place in the Transformation of National Identity. In: Kriesi, Hanspeter/Armingeon, Klaus/Siegrist, Hannes/Wimmer, Andreas (Hrsg.), Nation and national identity. The European experience in perspective. Chur: Rüegger, S. 153-173.

Lilli, Waldemar/Diebl, Michael, 1999: Regionale Identität in der Kurpfalz und in Südhessen. Untersuchungen zur Raumwahrnehmung, Raumbindung und Bewahrung regionaler Identität. In: Bornewasser, Manfred (Hrsg.), Ethnisches und nationales Bewußtsein. Zwischen Globalisierung und Regionalisierung ; [Beiträge zum 4. Kolloquium der deutschitalienischen Forschungsgruppe FIMO ... vom 30. September bis 2. Oktober 1997 ... Banz]. Frankfurt am Main: Lang, S. 101-121.

Löffler, Heinrich, 2003: Dialektologie. Tübingen: Narr. 
Lünenborg, Margreth, 2006a: Fensterprogramm. In: Bentele, Günter/Brosius, Hans-Bernd/Jarren, Otfried (Hrsg.), Lexikon Kommunikations- und Medienwissenschaft. Wiesbaden: VS Verlag für Sozialwissenschaften, S. 63.

Lünenborg, Margreth, 2006b: Magazin. In: Bentele, Günter/Brosius, Hans-Bernd/Jarren, Otfried (Hrsg.), Lexikon Kommunikations- und Medienwissenschaft. Wiesbaden: VS Verlag für Sozialwissenschaften, S. 157.

Lünenborg, Margreth, 2006c: Regionalprogramm. In: Bentele, Günter/Brosius, Hans-Bernd/Jarren, Otfried (Hrsg.), Lexikon Kommunikations- und Medienwissenschaft. Wiesbaden: VS Verlag für Sozialwissenschaften, S. 244.

Lutr, Ronald, 1998: Kultur und Region. In: Lutr, Ronald (Hrsg.), Die Region der Kultur. Münster: LIT, S. 221-234.

Maletzke, Gerhard, 1963: Psychologie der Massenkommunikation. Theorie und Systematik. Hamburg: Hans-Bredow-Institut.

Maletzke, Gerhard, 1998: Kommunikationswissenschaft im Überblick. Grundlagen, Probleme, Perspektiven. Opladen: Westdeutscher Verlag.

Markuse, Eric, 2006: Medienmarketing. Markenbildung am Beispiel des MDR. In: Altendorfer, Otto/Hilmer, Ludwig (Hrsg.), Medienmanagement. Band 3 Medienbetriebswirtschaftslehre Marketing. Wiesbaden: VS Verlag für Sozialwissenschaften, S. 341-358.

Marschik, Matthias/Dorer, Johanna, 2003: Manichäische Impressionen. Aktuelle MedienIdentitäten am Beispiel Österreichs. In: Winter, Carsten/Thomas, Tanja/Hepp, Andreas (Hrsg.), Medienidentitäten. Identität im Kontext von Globalisierung und Medienkultur. Köln: Halem, S. 120-135.

Martinek, Günter, 1990: Das Selbstbild der Österreicher. Eine Studie zur verbalen und nonverbalen Imagemessung. Wien: Service-Fachverlag.

Märø, Peter, 2008: Zur Geschichte Bayerns. In: Künzel, Werner/Rellecke, Werner (Hrsg.), Geschichte der deutschen Länder. Entwicklungen und Traditionen vom Mittelalter bis zur Gegenwart. Bonn: Bundeszentrale für Politische Bildung, S. 59-98.

Mathes, Rainer/Donsbach, Wolfgang, 2002: Rundfunk. In: Noelle-Neumann, Elisabeth (Hrsg.), Das Fischer Lexikon Publizistik, Massenkommunikation. Frankfurt am Main: Fischer Taschenbuch Verlag, S. 546-596.

Matter, Max, 1998: Schwierigkeiten mit der "Region". Gedanken zu Begriffsinhalt und umfang, zu Alltags- und Wissenschaftssprache. In: Lut₹, Ronald (Hrsg.), Die Region der Kultur. Münster: LIT, S. 31-48.

Maurer, Torsten, 2009: Fernsehen - als Quelle politischer Information überschätzt? Eine Bestandsaufnahme des Angebotes und der Nutzung des „politischen Leitmediums“. In: Marcinkowski, Frank. Pfetsch, Barbara (Hrsg.), Politik in der Mediendemokratie. Wiesbaden: VS Verlag für Sozialwissenschaften, S. 129-150.

Maurer, Torsten/Fretwurst, Benjamin/Weiß, Hans-Jürgen, 2009: Programmprofile. Wie sich Fernsehprogramme voneinander abgrenzen und wie sie sich gleichen. In: $A L M$ (Hrsg.), Fernsehen in Deutschland. ALM Programmbericht 2008. Berlin: Vistas, S. 41-61.

McCombs, Maxwell, 2000: Agenda Setting. Zusammenhänge zwischen Massenmedien und Weltbild. In: Schorr, Angela (Hrsg.), Publikums- und Wirkungsforschung. Ein Reader. Wiesbaden: Westdeutscher Verlag, S. 123-136.

Mcdonald, Daniel G./Dimmick, John, 2003: The Conceptualization and Measurement of Diversity. In: Communication Research (1) 30, S. 60-79.

MDR, 2007: Fühlen Sie sich wie zu Hause: Fernsehen für die Region (Online abrufbar unter: http:/ /www.mdr.de/unternehmen/standorte-programme/178534.html; Abruf 31.7.2007).

Mead, George H., 2005 [1934]: Geist, Identität und Gesellschaft. Aus der Sicht des Sozialbehaviorismus. [Nachdr.]. Frankfurt am Main: Suhrkamp.

Meister, Ulla, 1984: Integration eines Kommunikationsraumes. Chancen und Grenzen einer Regionalzeitung für die Gestaltung eines gemeinsamen Bewußtseins. Dissertation; Universität Nürnberg-Erlangen. Nürnberg: Verlag der Nürnberger Forschungsvereinigung. 
Merten, Klaus, 1983: Inhaltsanalyse. Einführung in Theorie, Methode und Praxis. Opladen: Westdeutscher Verlag.

Merten, Klaus, 2007: Einführung in die Kommunikationswissenschaft. Grundlagen der Kommunikationswissenschaft. 3. Münster: LIT.

Morass, Michael, 1994: Regionale Interessen auf dem Weg in die Europäische Union. Strukturelle Entwicklung und Perspektiven der Interessenvermittlung österreichischer und deutscher Landesakteure im Rahmen der Europäischen Integration. Wien: Braumüller.

Moser, Dietz-Rüdiger, 1999: Vorurteile. Bayern über Preußen und Preußen über Bayern. In: Erichsen, Johannes/Brockhoff, Evamaria (Hrsg.), Bayern \& Preußen \& Bayerns Preußen. Schlaglichter auf eine historische Beziehung: [Katalog zur Ausstellung in der Bayerischen Vertretung, Berlin, 13. Mai bis 20. Juni 1999 und zur Bayerischen Landesausstellung auf der Plassenburg, Kulmbach, 8. Juli bis 10. Oktober 1999]. Augsburg: Haus der Bayerischen Geschichte, S. 100-120.

Mübler, Kurt, 2005: Sozialisation, Konfliktwahrnehmung und regionale Identifikation. In: Fach, Wolfgang (Hrsg.), Region und Vision regionalpolitische Leitbilder im Vergleich. Leipzig: Leipziger Universitäts-Verlag, S. 193-206.

Mübler, Kurt/Opp, Karl-Dieter, 2006: Region - Nation - Europa. Die Dynamik regionaler und überregionaler Identifikation. Wiesbaden: VS Verlag für Sozialwissenschaften.

Mübler, Kurt/Opp, Karl-Dieter/Skrobanek, Jan/Werner, Christian, 2004: Region und Nation. Zu den Ursachen und Wirkungen regionaler und überregionaler Identifikation. Wiesbaden: VS Verlag für Sozialwissenschaften.

Müller, Helmut M., 2002: Schlaglichter der deutschen Geschichte. Lizenzausg. Bonn: Bundeszentrale für Politische Bildung.

Mummendey, Amélie/Otten, Sabine, 2002: Theorien intergruppalen Verhaltens. In: Frey, Dieter/Irle, Martin (Hrsg.), Gruppen-, Interaktions- und Lerntheorien. Bern: Huber, S. 95-119.

Muricant, Ariel, 2005: Österreich ist anders. In: Der Standard vom 4.5 2005.

Nationalversammlung, 1920: Bundes-Verfassungsgesetz. 5.10.1920. In: Staatsgesetzblatt für die Republik Österreich, S. 1791-1809.

Newcomb, Theodore M., 1953: An approach to the study of communicative acts. In: Psychological Review (6) 60, S. 393-404.

Niederstätter, Alois, 2007: Geschichte Österreichs. Stuttgart: Kohlhammer.

Nitschke, Peter, 1996: Was heißt regionale Identität im heutigen Europa? In: Brunn, Gerhard (Hrsg.), Region und Regionsbildung in Europa. Konzeptionen der Forschung und empirische Befunde ; wissenschaftliche Konferenz, Siegen, 10. - 11. Oktober 1995. BadenBaden: Nomos, S. 285-299.

Noblen, Dieter/Scbultze, Rainer-Olaf/Schüttemeyer, Suzanne S. (Hrsg.), 1998: Politische Begriffe: C.H. Beck.

Pfau, Hagen/Lieberwirth, Steffen, 2000: Mitteldeutscher Rundfunk - Radio-Geschichte(n). Altenburg: Kamprad.

Plake, Klaus, 2004: Handbuch Fernsehforschung. Befunde und Perspektiven. Lehrbuch. Wiesbaden: VS Verlag für Sozialwissenschaften.

Prin₹, Friedrich, 1997: Die Geschichte Bayerns. Mit 8 Farbtafeln und 71 Abbildungen. München: Piper.

Rager, Günther, 1994: Dimensionen der Qualität. Weg aus den alseitig offenen Richter-Skalen? In: Bentele, Günter (Hrsg.), Publizistik in der Gesellschaft. Festschrift für Manfred Rühl. Konstanz: Universitätsverlag Konstanz, S. 189-209.

Reitre, Helmut (Hrsg.), 2007: Media Perspektiven Basisdaten. Daten zur Mediensituation in Deutschland 2007. Frankfurt am Main.

Renan, Ernest/Ritter, Henning/Euchner, Walter, 1996 [1882]: Was ist eine Nation? Rede am 11. März 1882 an der Sorbonne. Hamburg: Europäische Verlags-Anstalt.

Richardson, John D., 2005: Switching Social Identities. In: Communication Research (4) 32, S. 503-528. 
Riescher, Gisela, 1998: Nation. In: Noblen, Dieter/Schultæe, Rainer-Olaf/Scbüttemeyer, Suzanne S. (Hrsg.), Politische Begriffe: C.H. Beck, S. 406-407.

Robinson, Gertrude J., 1973: 25 Jahre "Gatekeeper"-Forschung. Eine kritische Rückschau und Bewertung. In: Aufermann, Jörg/Bohrmann, Hans/Sülz̨er, Rolf (Hrsg.), Gesellschaftliche Kommunikation und Information. Frankfurt (am Main): Athenäum-Fischer-TaschenbuchVerlag, S. 344-355.

Roembeld, Lutr/Roembeld, Regine/Rojahn, Gerd, 1987: Der Begriff „Region“ im Spannungsfeld zwischen Regionalwissenschaft und Regionalpolitik. Versuch der Problematisierung eines ambivalenten Begriffs. In: Duwe, Kurt (Hrsg.), Regionalismus in Europa. Beitr. über kulturelle u. sozio-ökonom. Hintergründe d. polit. Regionalismus. Frankfurt am Main: Lang, S. 72-86.

Rohe, Karl, 1996: Die Region als Forschungsgegenstand in der Politikwissenschaft. In: Brunn, Gerhard (Hrsg.), Region und Regionsbildung in Europa. Konzeptionen der Forschung und empirische Befunde ; wissenschaftliche Konferenz, Siegen, 10. - 11. Oktober 1995. Baden-Baden: Nomos, S. 100-111.

Ronneberger, Fran₹, 1990: Wandel von Raumvorstellungen durch Medienkommunikation. In: Publizistik 35, S. 257-266.

Rosenberg, Milton J./Hovland, Charles I., 1960: Cognitive, affective, and behavioral components of attitudes. In: Rosenberg, Milton J. (Hrsg.), Attitude organization and change : an analysis of consistency among attitude components. New Haven, Conn: Yale University Press, S. 1-14.

Rössler, Patrick, 2005: Inhaltsanalyse. Konstanz: UVK.

Rossmann, Constanze, 2006: Kultivierungshypothese. In: Bentele, Günter/Brosius, HansBernd/Jarren, Otfried (Hrsg.), Lexikon Kommunikations- und Medienwissenschaft. Wiesbaden: VS Verlag für Sozialwissenschaften, S. 145-146.

Rüble, Angela, 2003: Sportprofile deutscher Fernsehsender 2002. Das Sportangebot im deutschen Free-TV. In: Media Perspektiven (5), S. 216-230.

Rutz, Werner, 2001: Mitteldeutschland in den Konzepten zur Neugliederung der Bundesrepublik nach 1990. In: John, Jürgen (Hrsg.), „Mitteldeutschland“. Begriff - Geschichte - Konstrukt. Rudolstadt: Hain-Verlag, S. 449-463.

Salomon, Gavriel, 1984: Television is "easy" and print is "tough": The differential investment of mental effort in learning as a function of perceptions and attributions. In: Journal of Educational Psychology (4) 76, S. 647-658.

Scharf, Wilfried, 1981: Objektivität und Ausgewogenheit. Bedingungen für die Integrationsfunktion des Fernsehens. In: Publizistik (2) 26, S. 202-223.

Schat, Heribert, 1994: Rundfunkentwicklung im dualen System: die „Konvergenzhypothese“. In: Jarren, Otfried (Hrsg.), Politische Kommunikation in Hörfunk und Fernsehen. Opladen: Leske + Budrich, S. 67-79.

Schenk, Birgit, 1987: Die Struktur des Internationalen Nachrichtenflusses. Analyse der empirischen Studien. In: Rundfunk und Fernsehen 35, S. 36-54.

Schenk, Michael, 2002: Medienwirkungsforschung. 2., vollst. überarb. Aufl. Tübingen: Mohr Siebeck.

Scheufele, Bertram, 2003: Frames - Framing - Framing-Effekte. Theoretische und methodische Grundlegung des Framing-Ansatzes sowie empirische Befunde zur Nachrichtenproduktion. Wiesbaden: Westdeutscher Verlag.

Scheufele, Dietram A., 1999: Framing as a theory of media effects. In: The Journal of Communication (1) 49, S. 103-122.

Schilling, Heinz, 1998: Region zwischen Konstruktion, Interpretation und Manipulation. oder: Cuius definitio, eius regio als mediales Konzept. In: Lutz, Ronald (Hrsg.), Die Region der Kultur. Münster: LIT, S. 49-62. 
Schönfelder, Günther, 2001: Mitteldeutschland aus geographischer Sicht. Versuch einer Deutung. In: John, Jürgen (Hrsg.), „Mitteldeutschland“. Begriff - Geschichte - Konstrukt. Rudolstadt: Hain-Verlag, S. 161-179.

Schul, Winfried, 2003: Globalisierung und Diversifizierung der Massenmedien in ihrer Bedeutung für die kulturelle Identität (Online abrufbar unter: http:/ / www.orient.unierlangen.de/kultur/papers/schulz.htm; Abruf 17.4.2009).

Schulz, Wolfgang, 2008: § 2 RStV. In: Hahn, Werner/Altes, Bärbel (Hrsg.), Beck'scher Kommentar zum Rundfunkrecht. Rundfunkstaatsvertrag Rundfunkgebührenstaatsvertrag Rundfunkfinanzierungsstaatsvertrag Jugendmedienschutzstaatsvertrag. München: C.H. Beck, S. 5867.

Schwarzkopf, Dietrich, 1978: Verlust der Integrationsfunktion würde Verlust der Legitimation bedeuten. In: Funk-Korrespondenz (11-12), S. 2.

Schwotzer, Bertil/Weiß, Hans-Jürgen, 2009: Nach wie vor „Leitmedium“. Fernsehen in Deutschland 2007/2008. In: ALM (Hrsg.), Fernsehen in Deutschland. ALM Programmbericht 2008. Berlin: Vistas, S. 16-33.

Siegrist, Hannes, 2001: Region, Regionalisierung und Regionalismus in Mitteldeutschland aus europäischer Perspektive. In: John, Jürgen (Hrsg.), „Mitteldeutschland“. Begriff - Geschichte - Konstrukt. Rudolstadt: Hain-Verlag, S. 91-108.

Simon, Erik/Kloppenburg, Gerbard/Schütz, Michael, 2009: Regionale Interessen und Heimatverständnis. Ergebnisse einer qualitativen und quantitativen Studie in Nordrhein-Westfalen. In: Media Perspektiven (2) 39, S. 60-67.

Stadtgeschichtliches Museum Leiprig, 2008: Kaffeekantate und Kaffeeklatsch (Online abrufbar unter: http://www.stadtgeschichtliches-museumleipzig.de/coffebaum/coffebaum_start.htm; Abruf 2.3.2009).

Stark, Birgit, 2008: Die Vielfalt der Messung „der Vielfalt“. Überlegungen zur methodischen Umsetzung des Vielfaltskonzepts. In: Matthes, Jörg/Wirth, Werner/Daschmann, Gregor/Fahr, Andreas (Hrsg.), Die Brücke zwischen Theorie und Empirie. Operationalisierung, Messung und Validierung in der Kommunikationswissenschaft. Köln: Halem, S. 196-216.

Statistike Austria (Hrsg.), 2007: Österreich. Zahlen, Daten, Fakten. Wien.

Statistik Austria (Hrsg.), 2008: Statistisches Jahrbuch Österreichs 2009. Wien.

Statistik Austria, 2009: STATISTIK AUSTRIA - Statistiken (Online abrufbar unter: http://www.statistik.at/; Abruf 20.1.2009).

Statistik. Austria, 2010: Jahresdaten. Bruttoinlandsprodukt nach Wirtschaftssektoren, laufende Preise (Online abrufbar unter:

http://www.statistik.at/web_de/statistiken/volkswirtschaftliche_gesamtrechnungen/brutt oinlandsprodukt_und_hauptaggregate/jahresdaten/019715.html; Abruf 26.8.2010).

Statistisches Bundesamt, 2010: Inlandsproduktsberechnung. Bruttowertschöpfung nach Wirtschaftsbereichen (Online abrufbar unter:

http://www.destatis.de/jetspeed/portal/cms/Sites/destatis/Internet/DE/Content/Statis ti-

ken/VolkswirtschaftlicheGesamtrechnungen/Inlandsprodukt/Tabellen/Content75/BWS nachBereichen,templateId=renderPrint.psml; Abruf 26.8.2010).

Steinmaurer, Thomas, 2002: Konzentriert und verflochten. Österreichs Mediensystem im Überblick. Innsbruck: Studien-Verlag.

Steinmets, Rüdiger, 1999: Initiativen und Durchsetzung privat-kommerziellen Rundfunks. In: Wilke, Jürgen (Hrsg.), Mediengeschichte der Bundesrepublik Deutschland. Bonn: Bundeszentrale für Politische Bildung, S. 166-191.

Stierstorfer, Klaus, 2003: Einleitung. In: Stierstorfer, Klaus (Hrsg.), Deutschlandbilder. Im Spiegel anderer Nationen ; Literatur - Presse - Film - Funk - Fernsehen. Reinbek bei Hamburg: Rowohlt-Taschenbuch-Verlag, S. 7-17.

Stoll, Ulrike, 2001: Bayern - ein Land ohne Identitätsprobleme? In: Geschichte im Westen 16, S. 20-37. 
Stuiber, Heinz-Werner, 1979: Kommunikationsräume der lokal informierenden Tagespresse. Pressestatistische Typenbildung und raumstruktuelle Analyse. Nürnberg: Verlag der Nürnberger Forschungsvereinigung.

Tajfel, Henri, 1982: Gruppenkonflikt und Vorurteil. Entstehung und Funktion sozialer Stereotypen. Bern: Huber.

Tajfel, Henry/Turner, John, 1979: An Integrative Theory of Intergroup Conflict. In: Austin, William G./Worchel, Stephen (Hrsg.), The social psychology of intergroup relations. Monterey, Calif.: Brooks/Cole, S. 33-53.

Teichert, Will, 1982: Die Region als publizistische Aufgabe. Ursachen, Fallstudien, Befunde. Hamburg: Hans-Bredow-Institut.

Thiele, Martina, 2005: Österreich im „Spiegel“, Deutschland im „profil“. Die Berichterstattung der Nachrichtenmagazine über ihren Nachbarn. In: Thiele, Martina/ Scharf, Wilfried (Hrsg.), Konkurrenz der Wirklichkeiten. Wilfried Scharf zum 60. Geburtstag. Göttingen, Göttingen: Universitäts-Verlag Göttingen; Niedersächsische Staats- und Universitätsbibliothek, S. 189-216.

Thomas, Tanja, 2003a: „,sie wird ja nicht ausgebürgert, die deutsche Currywurst". Talkshows, nationale Identitätsangebote und methodische Überlegungen zu ihrer Analyse. In: Winter, Carsten/Thomas, Tanja/Hepp, Andreas (Hrsg.), Medienidentitäten. Identität im Kontext von Globalisierung und Medienkultur. Köln: Halem, S. 184-205.

Thomas, Tanja, 2003b: Deutsch-Stunden. Zur Konstruktion nationaler Identität im Fernsehtalk. Frankfurt/Main: Campus-Verlag.

TNS Infratest MediaResearch, 2007: Funkanalyse Bayern (Online abrufbar unter: http://funkanalyse.tns-infratest.com/2007/2_tv/2bayerng/6MA.pdf; Abruf 4.7.2007).

Trebbe, Joachim, 2005: Stichprobenkonzepte der kontinuierlichen Fernsehprogrammforschung in Deutschland. Forschungslogische Probleme und forschungspraktische Lösungen. In: Gehrau, Volker (Hrsg.), Auswahlverfahren in der Kommunikationswissenschaft. Köln: Halem, S. 117-137.

Trebbe, Joachim, 2010: Programmkonkurrenz in der Prime Time - Revisited 2009. In: ALM (Hrsg.), ALM Jahrbuch 2009. Landesmedienanstalten und privater Rundfunk in Deutschland. Berlin: Vistas, S. 45-59.

Trepte, Sabine, 2004: Soziale Identität und Medienwahl. Eine binationale Studie zum Einfluss von Gender-Identität und nationaler Identität auf die Selektion unterhaltender Medieninhalte. In: Medien- \& Kommunikationswissenschaft (2) 52, S. 230-247.

Trepte, Sabine, 2008: Cultural proximity in TV entertainment. An eight-country study on the relationship of nationality and the evaluation of U.S. prime-time-fiction. In: Communications: The European journal of communication research (1) 33, S. 1-25.

Tributsch, Svila/Ulram, Peter A., 2004: Kleine Nation mit Eigenschaften. Über das Verhältnis der Österreicher zu sich selbst und zu ihren Nachbarn. Wien: Molden.

Unger, Torsten/Lieberwirth, Steffen, 2002: Vom Kofferstudio zum Mediencenter. Die Geschichte des Rundfunks in Thüringen 1925 - 2000. Altenburg: Kamprad.

Uzarewicz, Charlotte/Uzarewicz, Michael, 1998: Kollektive Identität und Tod. Zur Bedeutung ethnischer und nationaler Konstruktionen / Charlotte Uzarewicz; Michael Uzarewicz. Zugl.: Göttingen, Univ., Diss., 1997. Frankfurt a. Main [u.a.]: Lang.

Vocelka, Karl, 2000: Geschichte Österreichs. Kultur - Gesellschaft - Politik. Graz: Styria. Volpers, Helmut, 2005: Regionale Informationen. Wie attraktiv ist die Region? GEP; AGI; LMK; LFK; LPR. Frankfurt am Main: Gemeinschaftswerk der Evangelischen Publizistik gGmbH (GEP); Adolf Grimme Institut (AGI).

Volpers, Helmut/Bernhard, Uli/Schnier, Detlef, 2008: Public Relations und werbliche Erscheinungsformen im Fernsehen. Eine Typologisierung persuasiver Kommunikationsangebote des Fernsehens. Berlin: Vistas. 
Volpers, Helmut/Salwiczek, Christian/Schnier, Detlef, 2000: Regionalfenster im Programm von RTL und SAT.1. Eine vergleichende Inhaltsanalyse von Programmangeboten und journalistischer Qualität ; eine Studie im Auftrag der Bayerischen Landeszentrale für Neue Medien (BLM) ... Opladen: Leske + Budrich.

Vowe, Gerhard, 2006: Infotainment. In: Bentele, Günter/Brosius, Hans-Bernd/Jarren, Otfried (Hrsg.), Lexikon Kommunikations- und Medienwissenschaft. Wiesbaden: VS Verlag für Sozialwissenschaften, S. 100.

Wanta, Wayne/Golan, Guy/Lee, Cheolhan, 2004: Agenda Setting and International News. Media Influence on Public Perceptions of Foreign Nations. In: Journalism \& Mass Communication Quarterl (2) 81, S. 364-377.

Wegener, Claudia, 2001: Informationsvermittlung im Zeitalter der Unterhaltung. Eine Langzeitanalyse politischer Fernsehmagazine. Wiesbaden: Westdeutscher Verlag.

Weichbart, Peter, 1990: Raumbezogene Identität. Bausteine zu einer Theorie räumlich-sozialer Kognition und Identifikation. Stuttgart: Steiner.

Weichbart, Peter, 1996: Die Region - Chimäre, Artefakt oder Strukturprinzip sozialer Systeme. In: Brunn, Gerhard (Hrsg.), Region und Regionsbildung in Europa. Konzeptionen der Forschung und empirische Befunde ; wissenschaftliche Konferenz, Siegen, 10. - 11. Oktober 1995. Baden-Baden: Nomos, S. 25-43.

Weiß, Hans-Jürgen, 2008: Konzeption, Methode und Basisdaten der ALM-Studie 2006/2007. In: ALM (Hrsg.), Fernsehen in Deutschland 2007. Programmforschung und Programmdiskurs. Berlin: Vistas, S. 211-263.

Weiß, Hans-Jürgen, 2009: Konzeption, Methode und Basisdaten der ALM-Studie 2007/2008. In: $A L M$ (Hrsg.), Fernsehen in Deutschland. ALM Programmbericht 2008. Berlin: Vistas, S. 201-257.

Weiß, Hans-Jürgen/Trebbe, Joachim, 2001: Mediennutzung und Integration der türkischen Bevölkerung in Deutschland. Ergebnisse einer Umfrage des Presse- und Informationsamtes der Bundesregierung. Potsdam.

Weiß, Hans-Jürgen; Trebbe, Joachim, 2006: ALM-Fernsehprogrammanalyse. Stichprobenbericht Herbst 2006 (Online abrufbar unter: http://www.alm.de/fileadmin/Medienforschung/Programmbericht2006/Herbst_2006/St ichprobenbericht_He2006_Druckversion.pdf; Abruf 24.7.2007).

Weiß, Hans-Jürgen; Trebbe, Joachim, 2008: ALM-Fernsehprogrammanalyse. Stichprobenbericht Herbst 2008 (Online abrufbar unter: http://www.alm.de/fileadmin/Medienforschung/Programmbericht2008/Herbst_2008/D aten/Druckversion_2008_II.pdf; Abruf 4.8.2010).

Wesche, Ilka/Reizenbüchler, Heike/Schwachulla, Wolfram (Hrsg.), 2004: Brockhaus-Wissen 2004. 4 CD-ROMs mit ca.100.000 Stichwörtern, rund 60.000 Artikeln, über 4.100 Bildern. Hamburg; Mannheim: Die Zeit; F. A. Brockhaus.

Westley, Bruce/MacLean, Malcolm, 1957: A Conceptual Model for Communication Research. In: Journalism Quarterly 34, S. 31-38.

Wilke, Jürgen, 2002: Pressegeschichte. In: Noelle-Neumann, Elisabeth (Hrsg.), Das Fischer Lexikon Publizistik, Massenkommunikation. Frankfurt am Main: Fischer Taschenbuch Verlag, S. 460-492.

Willey, Malcolm M., 1926: The Country Newspaper. A study of socialization and newspaper content. Chapel Hill, London: The University of North Carolina Press.

Winter, Carsten/Thomas, Tanja/Hepp, Andreas (Hrsg.), 2003: Medienidentitäten. Identität im Kontext von Globalisierung und Medienkultur. Köln: Halem.

Woelke, Jens, 2007: TV-Programmanalyse. Fernsehvollprogramme in Österreich 2006. Wien: Rundfunk und Telekom Regulierungs-GmbH (RTR-GmbH).

Woelke, Jens, 2008a: Fernsehen in Österreich. Basisdaten und Programmprofile der Fernsehvollprogramme ORF1, ORF2 und ATV. In: Steininger, Christian/Woelke, Jens (Hrsg.), Fernsehen in Österreich 2008. Konstanz: UVK, S. 13-63. 
Woelke, Jens, 2008b: TV-Programmanalyse Fernsehvollprogramme in Österreich. Programmbericht Frühjahr 2007. Wien: Rundfunk und Telekom Regulierungs-GmbH (RTR-GmbH).

Woelke, Jens, 2010: TV-Programmanalyse Fernsehvollprogramme in Österreich. Bericht zur

Frühjahrsstichprobe 2009. Wien: Rundfunk und Telekom Regulierungs-GmbH (RTR$\mathrm{GmbH})$.

Wolf, Gabriele, 2005a: Bayern stereotyp. Über aktuelle Identifikationen mit einer Region in Europa. In: Bayerisches Jahrbuch für Volkskunde, S. 129-135.

Wolf, Karl H. (., 2005b: Der Brockhaus in Text und Bild 2005. Das Lexikon in der PC-

Bibliothek; Mehr als 122000 Artikel mit 195000 Stichwörten. 3.0. Mannheim: Bibliographisches Institut \& F. A. Brockhaus.

Wolff, Volker/Palm, Carla, 2006: Politik-Ressort. In: Bentele, Günter/Brosius, Hans-Bernd/Jarren, Otfried (Hrsg.), Lexikon Kommunikations- und Medienwissenschaft. Wiesbaden: VS Verlag für Sozialwissenschaften, S. 217.

Wolling, Jens, 2005: Normalzeit vs. Spezialzeit. Besondere Ereignisse als Problem der Stichprobenziehung bei Inhaltsanalysen von Medienangeboten. In: Gehrau, Volker (Hrsg.), Auswahlverfahren in der Kommunikationswissenschaft. Köln: Halem, S. 138-157.

Zöllner, Erich, 1990: Geschichte Österreichs. Von den Anfängen bis zur Gegenwart. 8. Aufl. Wien: Verlag für Geschichte und Politik.

Zubayr, Camille/Gerhard, Heinz, 2009: Tendenzen im Zuschauerverhalten. Fernsehgewohnheiten und Fernsehreichweiten im Jahr 2008. In: Media Perspektiven (3), S. 98-112.

Zubayr, Camille/Gerhard, Heinz, 2010: Tendenzen im Zuschauerverhalten. Fernsehgewohnheiten und Fernsehreichweiten im Jahr 2009. In: Media Perspektiven (3), S. 106-118.

Zwahr, Annette (Hrsg.), 1999: Meyers großes Taschenlexikon. In 25 Bänden. Mannheim: BI-

Taschenbuchverlag. 


\section{Anhang}

\subsection{Codebuch}

\section{Erhebungstechnische Variablen}

Wenn hinter der Kategorie keine besonderen Anweisungen stehen, erfolgt die weitere Vercodung bei der jeweils folgenden Variablen. Ansonsten bei der mit Pfeil angewiesenen Variablen. Vertikale Linien über mehrere Kategorien gelten als Klammer (nächste Variable für die weitere Vercodung für die ,geklammerten“ Variablen ist dieselbe). „Ende“ bedeutet, dass keine weiteren Variablen zu bedienen sind außer V 48 und gegebenenfalls V 47.

\section{1 Datensatz-Nr.}

Wird automatisch erstellt.

$\begin{array}{ll}\text { V } 2 \text { Programm } \\ 11 & \text { ORF 2 } \\ 12 & Z D F \\ 21 & \text { BR-Fernsehen } \\ 22 & \text { MDR-Fernsehen }\end{array}$

\section{3 Sendedatum}

TT.MM.JJJJ

$\begin{array}{ll}\text { V } & \text { Wochentag } \\ 1 & \text { Montag } \\ 2 & \text { Dienstag } \\ 3 & \text { Mittwoch } \\ 4 & \text { Donnerstag } \\ 5 & \text { Freitag } \\ 6 & \text { Samstag } \\ 7 & \text { Sonntag }\end{array}$

V 5 UE-Anfang

Std:Min:Sek

\section{6 UE-Ende}

Std:Min:Sek

\section{7 UE-Dauer}

Std:Min:Sek

[wird automatisch berechnet]

\section{8 Sendungsname \\ Texteingabe}

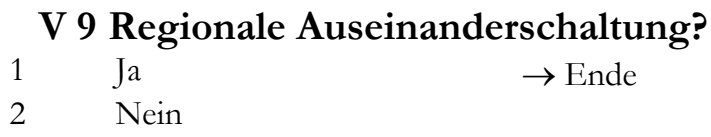

\section{10 Ausstrahlung}

1 Erstsendung

2 Wiederholung kurzfristig - Sendung wurde vor max. 72 Stunden schon einmal ausgestrahlt.

3 Wiederholung langfristig Sendung wurde in längerem Zeitabstand (über 72 Stunden) schon einmal ausgestrahlt. Hierbei kommt es nicht mehr auf den zuerst ausstrahlenden Sender an. (Ein zwei Jahre alter „Tatort", der bisher nur im Ersten Programm lief, nun aber etwa erstmals im BR ausgestrablt wird, gilt als Wiederholung).

4 Übernahme direkt (zeitgleich) Sendung wird zur selben Zeit in mind. einem weiteren Sender ausgestrahlt und ist nicht vom in V2 identifizierten Sender produziert.

5 Übernahme kurzfristig zeitversetzt Erstsendung in erstausstrahlendem und produzierendem Programm erfolgte vor max. 48 Stunden.

6 Übernahme langfristig zeitversetzt Erstsendung in erstausstrahlendem Programm erfolgte vor mehr als 48 Stunden, aber innerhalb einer Woche. (sonst: Wdh.).

9 Problemfall, nicht bestimmbar

\section{Untersuchungseinheit Sendung}

\section{11 Programmfläche}

1 Werbung
Gekennzeichnete Werbespots, en
bloc inklusive optisch-akustischer Trenner. Sponsorhinweis Hinweise auf wirtschaftliche Partner oder Präsentatoren einer nachfolgenden oder vorangegangenen Sendung.

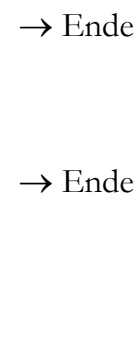


3

Trailer/Programmhinweis

Clip, der auf nachfolgendes oder späteres Programm hinweist.

4

Fiktionale Sendung

Sendung, die eine fiktive (oder fiktionalisiert aufbereitete) Hand-

lung darbietet.

$5 \quad$ Nicht fiktionale Sendung

Sendung, die reales Geschehen

wiedergibt.

9 Sonstiges

\section{12 Fiktionale Sendeform}

1 Spielfilm

Aus inszenierten, gespielten Szenen zusammengesetzter Film, mit einer durchgehenden fiktiven und abgeschlossenen Handlung (auch mehrteilige Filme bis 5-teilig).

2 TV-Serie

Inhaltlich, thematisch und formal zusammengehörende Folge von Sendungen mit inszeniertem szenischen Handlungsablauf.

3 Theater-/Opernmitschnitt Auf Bühne und vor Publikum aufgeführtes (musik-)theatralisches Werk. Zeichentrick/Animation Gezeichnete oder animierte Filme oder Serien, auch Puppentrick.

$9 \quad$ Sonstige

\section{Raumbezug fiktionaler Sendun-}

\section{13 Nationalität Protagonist}

Nationalität der (fiktionalen) Hauptperson

Eingabe Staat (kein Adjektiv)

trifft nicht zu/nicht erkennbar $=9999$

\section{14 Geschehensort}

Ort bzw. Territorium, wo der Hauptteil der gezeigten Handlung spielt.

USA/Nordamerika

Australien

Mittel-/Südamerika

Afrika

Naher Osten

Asien

Westeuropa

Osteuropa

19 Sonstige außerhalb Deutschlands oder Österreichs

21 Deutschland allg. (keine der anderen deutschen Regionen)

22 Österreich allg. (keine der anderen Regionen in Österreich)

23 Ostdeutschland (ostdt. Bundesland außerhalb Mitteldeutschlands)

24 Mitteldeutschland (Sachsen, S.-Anhalt oder Thüringen)

25 Bayern allg. (ohne Gebirgsregionen)

26 Bayerische Gebirgsregionen
Österreichische Alpenregionen

28 Sonst. Alpenregionen außerhalb Österreichs oder Deutschlands

Sonstige

\section{15 Charakterisierung Geschehensort}

1 Großstadtmilieu $\rightarrow$ V 16

Kleinstadtmilieu $\rightarrow \mathrm{V} 16$

3 Ländliches/bäuerliches Mi- $\rightarrow$ V 16

lieu

Natur $\rightarrow$ V 16

$9 \quad$ Sonstige/trifft nicht zu $\rightarrow$ V 16

\section{16 Geschehenszeit $\rightarrow$ V 21}

Jahreszahl vierstellig (eventuell geschätzt Jahrzehnt)

trifft nicht zu (Science Fiction; Fantasy; Mär(hen) $=9999$

\section{17 Nichtfiktionale Sendungsformen}

1 Unterhaltung $\rightarrow \mathrm{V} 21$

Quizshows, Musiksendungen,

„Abendunterhaltung“ u. ä.

2 Nachrichten $\rightarrow$ Ende

3 Reportage/Dokumentation $\rightarrow$ V 18

Alleinstehende ausführliche Be-

handlung eines Themas mit journalistischen Mitteln mit Informa-

tionscharakter.

$4 \quad$ Übertragung $\rightarrow \mathrm{V} 18$

Live-Übertragung von Ereignissen

(aber nicht: TV-Sender eigene

Veranstaltungen)

5 Politische Talkshow/Politisches $\rightarrow$ V 18

Interview alleingestellt

Gesprächsrunden/Interviews zu

vornehmlich politischen Themen.

6 Wetterbericht alleingestellt $\rightarrow$ Ende

7 Magazin $\rightarrow$ V 23

Sendung, die mehrere redaktionel-

le Beiträge enthält, die innerhalb einer formalen und inhaltlichen

Klammer (Gestaltung und Mode-

ration) präsentiert werden.

9 Sonstige

$\rightarrow \mathrm{V} 18$

\section{18 Thema der Sendung}

Vercodung nach Themenliste

V 19 Weiteres Thema der Sendung

Vercodung nach Themenliste

\section{20 Thema der Sendung offen formuliert}

Stichwortartige Erfassung des Themas

\section{21 Produktionsland}

Eingabe Ländername

Bei internationalen Co-Produktionen ist immer das für die Studie erhebliche (D, Ö) vorzuziehen. Da in der Regel auch nicht von tatsächlicher 
„Gleichrangigkeit“" mehrerer Produktionsländer ausgegangen werden muss, ist immer das „höchstrangige“ zu benennen (das ergibt sich aus einer Gewichtung der Herkunft der Mehrzahl der Schauspieler, des Regisseurs und der Produzenten).

\section{22 Produktionsjahr}

Jahreszahl vierstellig Ende

\section{Untersuchungseinheit Magazinbei- trag}

\section{23 Magazintyp}

11 Politisches Magazin

Magazin, das sich vornehmlich Themen der Politik widmet (es kommt dabei nicht auf die Einzelausgabe des Magazins an).

12 Nachrichtenmagazin Tagesaktuell, über reine Meldungen und Nachrichtenfilme hinausgehende Formen, Moderation statt nur Sprecherin/Sprecher.

13 Wirtschaftsmagazin

Magazin, das sich vornehmlich Themen der Wirtschaft widmet.

\section{Kulturmagazin}

Magazin, das sich vornehmlich Themen der Kultur widmet.

15 Wissenschaftsmagazin Themen aus dem Bereich der Wissenschaft, Wissensvermittlung.

16 Ratgebermagazin Verbraucherthemen, hauptsächlich beratschlagende und hinweisende Funktion.

17 Boulevardmagazin Human-Touch-Themen, Prominente und Show-Business.

18 Sportmagazin

21 Regionalmagazin

Magazin, das sich der Berichterstattung aus einer bestimmten Region widmet, ohne thematische Einschränkung.

31 Gemischtes Magazin

Magazin, das ohne thematische oder räumliche Einschränkung aus vielfältigen Lebensbereichen berichtet.

41 Spezielles Zielgruppenmagazin: Frauen Magazin, das sich explizit an Frauen richtet.

42 Spezielles Zielgruppenmagazin: Behinderte

(analog zu 41)

43 Spezielles Zielgruppenmagazin: Homosexuelle (analog zu 41)

44 Spezielles Zielgruppenmagazin: Kinder (analog zu 41)
Spezielles Zielgruppenmagazin: Sonsti-

ge

(analog zu 41, wenn keine der festgelegten Gruppen 41-42) (Erklärung im Bemerkungsfeld!)

99 Sonstiges Ressortmagazin Thematisch eingegrenztes Magazin, zu einem nicht unter 11 bis 18 fallenden Ressort.

(Erklärung im Bemerkungsfeld).

\section{24 Magazinbestandteile}

1 Selbstrefenzielle Programmfläche $\rightarrow$

Trailer, Teaser, Vorspann,

Abspann, Gewinnspiele u. ä.

2 Sponsorhinweis

Hinweis auf Sponsor einer $\overrightarrow{\text { Ende }}$

Rubrik innerhalb des Maga-

zins.

3 Beitrag

Redaktionell aufbereitete

Formen zur Vermittlung von

Informationen zu Themen.

\section{25 Reihenfolge}

Position innerhalb der Sendung durch fortlaufende Nummerierung

\section{26 Gekennzeichnete Wiederholung?}

Beitrag ist insgesamt eine Wiederholung bzw. Wiederverwertung aus anderer Sendung und als solche gekennzeichnet

1 Ja

$2 \quad$ Nein

\section{27 Darstellungsform}

\section{Moderation}

Alleinstehende Moderation, die nicht explizit auf einen Beitrag Bezug nimmt. Muss einen ,informativen Mehrwert“ aufweisen - reine Hinweise auf nächste Sendung u. ä. reichen nicht aus.

12 Sprechermeldung (inkl. kurzem Statement und/oder Bildmaterial)

Von SprecherIn (auch: ModeratorIn) verlesene Meldung (Tatsachen-/ Ereignismitteilung).

13 Nachrichtenfilm

Meldung in Filmform, meist Agenturmaterial. Ohne Hintergrundinformation, reine Tatsachenmitteilung.

14 Filmbericht Über reine Tatsachenmitteilung hinausgehender Filmbeitrag, inkl. O-Töne.

15 Korrespondentenbericht Wie 14, aber mit explizitem Hinweis auf Korrespondenten/Korrespondentin der/die berichtet und Mitteilung seiner/ihrer persönlichen Einschätzung des Berichteten (meist im Bild zu sehen).

16 Interview/Gesprächsrunde 
Befragung/Gespräch externer (nicht normalerweise an Sendung beteiligt) Personen, ohne Einbettung in Filmbeitrag.

17 Übertragung

Live-Übertragung eines Ereignisses (etwa

Pressekonferenz).

18 Ironisierende Form

Filmbeitrag, der durch Kommentar, Zusammenschnitt oder andere Gestaltungsmittel das in den Blick genommene Geschehen ironisch/satirisch kommentiert.

21 Kritik/Rezension/Besprechung Einschätzung und Bewertung kultureller Erzeugnisse oder Aufführungen. Meinungsbetont.

22 Reportage Persönlich gefärbter Tatsachenbericht. Die Persönliche Komponente kommt durch Auswahl des Ereignisses und „Miterleben“ zum Ausdruck. Länger als 15.

31 Service-/Hinweisform

Nicht rezensierende Hinweise auf aktuelle Veranstaltungen, Veröffentlichungen u. ä. meist im kulturellen oder gesellschaftlichen Bereich.

Bei kurzen VTs aus verschiedenen Kulturbereichen (U/ E) sind diese als Einzelbeiträge zu vercoden. - Grund: Hinweisende ggü. kritischer Form bei Kulturberichterstattung.

99 Sonstige Form

\section{V27.1 Funktion}

1 Servicefunktion

Hinweisfunktion, Terminmitteilungen (hptsl. Wetterberichte, Lottozahlen und Veranstaltungstipps).

2 Informationsfunktion

Tatsachenvermittlung steht im Vordergrund.

3 Kritikfunktion

Einordnung und Bewertung von Sachverhalten mit expliziter Kundgabe subjektiver Meinung von RedakteurIn.

4 Beratungsfunktion

Explizite Beratung verbunden mit Handlungsanweisung (hptsl. Verbraucherthemen).

5 Bildungsfunktion

Implizite oder explizite Wissensvermittlung, über reine Tatsacheninformation hinaus.

9 Sonstige

Keine gemäß 1 - 5 zuordbare Funktion.

\section{28 Thema des Beitrags}

Vercodung nach Themenliste

\section{29 Weiteres Thema des Beitrags}

Vercodung nach Themenliste

\section{30 Thema des Beitrags offen formuliert} Textfeld, stichwortartige Erfassung des Themas

\section{31 Wirtschaftssektor}

$\mathrm{Zu}$ erfassen für Beiträge mit V27.1 und/oder V $29=119$ bis 121 oder 200er-Bereich. Alle anderen erhalten hier den Code $9=$ trifft nicht zu. Welchem Wirtschaftssektor sind die berichteten wirtschaftlichen Themen zuzuordnen?

Primärer Wirtschaftssektor

Sekundärer Wirtschaftssektor

Tertiärer Wirtschaftssektor

Trifft nicht zu

\section{32 Fußball-Liga}

Nur zu erfassen für Beiträge mit V27.1 und/oder $\mathrm{V} 29=601$

In welcher Liga bzw. ähnlicher Organisationsform spielt sich das berichtete Fußballgeschehen $a b$ ?

1 1. Bundesliga (D)/ tipp 3-Bundesliga powered by T-Mobile (官)

2 2. Bundesliga (D)/ADEG Erste Liga (Ö)

3 3. Liga (D)/Regionalliga (Ö)

4 Regionalliga (D)/Landesligen (Ö)

5 Oberliga (D)

6 Verbands- o. Landesliga

7 Internationaler Vereinsfußball

8 Nationalmannschaften

9 Fußball außerhalb von Ligen (etwa: Benefizspiele o. ä.) aber abgrenzen von Breitensport

\section{33 Aktualität}

Wann geschahen die berichteten Sachverhalte? Bezogen auf Zeitpunkt der Ausstrahlung.

Tagesaktuell (gestern/heute/morgen) Wochenaktuell (max. 7 Tage Abstand) 14-Tages-Abstand

Monatsaktuell

Nicht aktuell

\section{34 Geschehensdauer}

Welche Zeitspanne umfassen die berichteten Sachverhalte?

1 Punktuelles Ereignis - Geschehen, dessen Anfang und Ende klar abgrenzbar innerbalb von 2 3 Stunden liegt (etwa: Mord, Explosion, Unfall).

2 Tagesereignis - Geschehen, dessen Anfang und Ende klar abgrenzbar innerhalb eines Tages liegt (Tagung, Kongress, Verhandlung).

3 Mehrtägiges Ereignis - Geschehen, das sich im Verlauf einer Woche abspielt.

$4 \quad$ Langzeitgeschehen, Daueraktualität

\section{35 Ereignisraum}

Wo findet das Ereignis faktisch statt? 


\section{36 Verortung Ereignisraum} Bundesland

Max. drei Bundesländer je Staat (D/Ö), in Reihenfolge des Auftauchens im Beitrag.

V36.1

\section{Verortung Ereignis- raum Bundesland in Deutschland}

V36.1.1 Textfeld Bundesland 1

V36.1.2 Textfeld Bundesland 2

V36.1.3 Textfeld Bundesland 3

\section{V36.2 Verortung Ereignis-} raum Bundesland in Österreich

V36.2.1 Textfeld Bundesland 1

V36.2.2 Textfeld Bundesland 2

V36.2.3 Textfeld Bundesland 3

\section{37 Verortung Ereignisraum Ort}

Max. sechs je Staat (D/Ö). In Reihenfolge des Auftauchens im Beitrag. Zuordnung zu Gemeindekennziffern erfolgt edv-mäßig.

\section{V37.1 Verortung Ereignis- raum Ort in Deutsch- land}

V37.1.1 Textfeld Ortsangabe 1 V37.1.2 Textfeld Ortsangabe 2 V37.1.3 Textfeld Ortsangabe 3 V37.1.4 Textfeld Ortsangabe 4 V37.1.5 Textfeld Ortsangabe 5 V37.1.6 Textfeld Ortsangabe 6

\section{V37.2 Verortung Ereignisraum Ort in Österreich}

V37.2.1 Textfeld Ortsangabe 1

V37.2.2 Textfeld Ortsangabe 2

V37.2.3 Textfeld Ortsangabe 3

V37.2.4 Textfeld Ortsangabe 4

V37.2.5 Textfeld Ortsangabe 5

V37.2.6 Textfeld Ortsangabe 6

\section{38 Bezugsraum}

Auf welchen Raum/Ort beziehen sich die Auswirkungen des Ereignisses?
10

20

40
39 Verortung Bezugsraum Bundesland Max. drei Bundesländer je Staat (D/Ö), in Reihenfolge des Auftauchens im Beitrag.

\section{V39.1 Verortung Bezugsraum} Bundesland in Deutschland

V39.1.1 Textfeld Bundesland 1

V39.1.2 Textfeld Bundesland 2

V39.1.3 Textfeld Bundesland 3

\section{V39.2 Verortung Bezugsraum Bundesland in Österreich}

V39.2.1 Textfeld Bundesland 1

V39.2.2 Textfeld Bundesland 2

V39.2.3 Textfeld Bundesland 3

\section{40 Verortung Bezugsraum Ort}

Max. sechs je Staat (D/Ö). In Reihenfolge des Auftauchens im Beitrag. Zuordnung zu Gemeindekennziffern erfolgt edv-mäßig.

\section{V40.1 Verortung Bezugsraum Ort in Deutschland}

V40.1.1 Textfeld Ortsangabe 1 V40.1.2 Textfeld Ortsangabe 2 
V40.1.3 Textfeld Ortsangabe 3

V40.1.4 Textfeld Ortsangabe 4

V40.1.5 Textfeld Ortsangabe 5

V40.1.6 Textfeld Ortsangabe 6

V40.2 Verortung Bezugsraum Ort in Österreich

V40.2.1 Textfeld Ortsangabe 1

V40.2.2 Textfeld Ortsangabe 2

V40.2.3 Textfeld Ortsangabe 3

V40.2.4 Textfeld Ortsangabe 4

V40.2.5 Textfeld Ortsangabe 5

V40.2.6 Textfeld Ortsangabe 6

\section{41 Regionalität}

Thema stellt eine regional-kulturelle

Besonderheit/Singularität dar

In dieser Ausprägung finden keine Ereignisse dieser Art und Bedeutung auBerhalb des Berichtsraumes statt. (Bsp.: Münchner Oktoberfest). Sehr strikt zu handhabende Kategorie.

2 Thema des Beitrags ist im Kern regionalspezifisch.

Sachverhalt findet an genannten Orten statt und ist keine bloße Auswirkung von Ereignissen anderswo.

3 Universelles Thema, das aber hinsichtlich regionalspezifischer Auswirkungen dargestellt wird (Bsp.: Bundesweite Arbeitslosenzablenverkündung unter Hinweis auf entsprechende Entwicklung in einer Region).

4 Thema ist universell, wird aber durch zahlreiche Bezüge regionalisiert.

(Bsp.: Verspätungen bei Deutscher Bahn, Bericht mit Bildern des örtlichen Babnhofs, Befragung von Passanten ebendort).

5 Thema ist universell und wird lediglich durch den Akteur regionalisiert (durch explizite Benennung von Menschen und ihrem Bezug zum Ort, aus dem berichtet wird, andere Regionalbezüge als die Herkunft oder Wohnort bestehen dabei aber nicht).

6 Thema ist nicht regional Thema steht in keinem direkten inhaltlichen Zusammenhang zu einer bestimmten Region/ Ort.

9 Problemfall

\section{42 Ereignisbezug}

Rekurriert der Bericht auf tatsächlich stattgefundenes Geschehen?

$1 \quad$ Eindeutig vorhandener Bezug Über ein tatsächliches Ereignis, dass von alltäglichen Routinen abweicht, wird berichtet.

2 Geringer/uneindeutiger Ereignisbezug Ausgangsereignis wird zum Anlass einer dieses Ereignis selbst nicht oder nur sehr entfernt betreffenden Berichterstattung genommen. (Bsp.: Anlass: Statistik über Migräne als Volkskerankheit Nr. 1 ist Ausgangsereignis, berichtet wird dann nicht von der Vorstellung der Studie, sondern vom Alltag einer Migränestation im städtischen Krankenhaus. - Ohne das „Ausgangsereignis" fiele der Beitrag in die Kategorie „kein Ereignis").

3 Selbstinszeniertes Ereignis

Der berichtende Sender veranstaltet/inszeniert ein Geschehen um darüber zu berichten. Oder: Eigene Berichterstattungsinhalte werden über die ursprüngliche Berichterstattung hinaus thematisiert. (Bsp.: TED-Ergebnisse zur Publikumsmeinung zu einem Thema).

$4 \quad$ Kein Ereignis

Dem Beitrag liegt kein Geschehen zugrunde. Es handelt sich um Alltagsbeobachtungen, Routinen o. ä., die in der gezeigten Form auch an jedem anderen Tag so stattfinden, wenn auch mglw. mit anderen (nicht prominenten) Personen.

$9 \quad$ Problemfall

\section{43 Personalisierung}

Wie stark werden die Sachverhalte auf Personen bezogen?

$1 \quad$ Keine Personalisierung

Personen, Namen und Titel werden nicht genannt, rein sachliche Tatsachenbeschreibung.

$2 \quad$ Geringe Personalisierung Personen werden zwar genannt, sind aber für das Geschehen ohne Bedeutung. Kern der Berichterstattung sind sachliche Vorgänge, abstrakte Tatsachen.

$3 \quad$ Mittlere Personalisierung Im Mittelpunkt des Geschehens stehen etwa gleichrangig Personen und unpersönliche Sachverhalte. Die Äußerung einer bzw. die Auseinandersetzung zwischen einigen wenigen namentlich genannten Personen dreht sich um abstrakte Vorgänge.

$4 \quad$ Starke Personalisierung

Das Geschehen dreht sich primär um eine oder wenige namentlich genannte oder genau bezeichnete Personen.

\section{44 Konfliktbetonung}

Wie stark werden im Sachverhalt liegende Konflikte, bzw. Konflikte die damit in Verbindung stehen, betont?

$1 \quad$ Keine Konfliktbetonung In der Darstellung des Themas/Ereignisses kommt kein Widerstreit von Interessen zum Ausdruck.

$2 \quad$ Geringe Konfliktbetonung Dem geschilderten Sachverhalt entgegenstehende Interessen werden lediglich erwähnt, ohne dass Gründe oder Inhalte der gegenteiligen Position verdeutlicht werden.

3 Gemäßigte Konfliktbetonung Dem Thema/Ereignis werden gegenteilige oder widersprechende Aussagen anderer Personen (als dem Hauptakteur des Ereignisses/des Themas) gegenübergestellt. Diese 
Kontrastierung verbleibt aber noch auf der Ebene der „umfassenden“ Information.

4 Deutliche Konfliktbetonung

Mind. zwei Personen mit widerstreitender Interessenlage/Ansicht kommen zu Wort. Im Vordergrund der Statementsauswahl stehen die inhaltlichen Widersprüche und nicht etwaige Gemeinsamkeiten.

$5 \quad$ Sehr starke Konfliktbetonung

Mind. zwei Personen mit widerstreitender Interessenlage/Ansicht kommen zu Wort. Streitpunkte werden verdeutlicht. Die Stärke des Konflikts wird dadurch betont, dass der Hauptakteur (Ereignisträger) den anderen Interessen auch seinerseits ,,antwortet“.

\section{Untersuchungseinheit zu Wort kommende Person}

\section{45 Akteurinnen und Akteure}

Anzahl - wenn $0 \rightarrow$ Ende

Gesamtanzahl eintragen, auch wenn mehr als vier. Die weitere Erfassung erfolgt nur für die ersten vier Akteurinnen bzw. Akteure (in Reihenfolge des Auftretens).

\section{V45.1 AkteurIn 1}

\section{V45.1.1 Geschlecht}

Männlich

Weiblich

Nicht zu entscheiden

\section{V45.1.2 Altersgruppe}

Kinder $(0-13)$

Jugendliche $(14-18)$

Heranwachsende (bis unter 20)

Erwachsene I: 20 - 39

Erwachsene II: 40 - 60

Senioren über 60

Nicht zuordbar

\section{V45.1.3 Personen-Orts-}

\section{Bezug}

Welche Bedeutungsreichweite hat die Person? Ausschlaggebend immer die im Vordergrund stehende Funktion im Bericht. Bsp.: Wenn Landesministerpräsident gleichzeitig Bundesvorsitzender einer Partei ist, ist vom Kontext her zu bestimmen, in welcher Funktion er hier vorkommt: Geht es um Landeshaushaltsentscheidungen, dann „Führungselite Länderebene"; geht es um Kanzlerkandidatur, dann Bundesebene.

International

National

Westdeutschland gesamt

Ostdeutschland gesamt

Regional (Bundesland) außerhalb Sendegebiet Regional (Bundesland) innerhalb Sendegebiet Lokal/kommunal außerhalb Sendegebiet Lokal/kommunal innerhalb Sendegebiet Keine Reichweite über das private/berufliche
Umfeld hinaus

\section{V45.1.4 Bereich}

In welchem Tätigkeitsbereich agiert die Person? Maßgeblich ist immer die im Bericht maßgebliche Funktion.

Politik

Justiz

Poli-

zei/Zoll/Ordnungsamt/Feuer wehr / Rettung

13 Armee/Militär

14 Gewerkschaften/Arbeitnehmervertretung

19 Sonstige Gruppen/Organisationen politisch/sozial engagierter Privatpersonen (Bürgerinitiativen, Hochschulgruppen $u$. ̈̈.)

21 Wirt-

schaft/Industrie/Arbeitgeberv ertretung/Dienstleistung institutionalisierte Gruppenvertretung. Nicht für Einzelfirma sprechend (-> dann: privatwirtschaftliche Funktionsperson).

Öffentlicher Dienst Bsp.: Arbeitsberater, der in einem Beitrag über einen Arbeitslosen dessen Berufsperspektiven einschätzen soll.

Privatwirtschaftliche Funktionsperson - Bsp.: Vermieter in eines Normalbürgers, dem bei Problem mit Vermieter geholfen werden soll.

Journalismus

Bildungswesen

Religiöse Funktionsträger

Wissenschaft/Forschung

Ärzte/Mediziner/Heilpraktiker u.ä.

36 Humanitäre Organisation/Naturschutz

37 Show-Business

38 Königshäuser/Adel

39 Sonstige Interessenverbände

$40 \quad$ Coaching/Therapie/ Lebenshilfe (sofern nicht medizinisch indiriert)

$60 \quad$ Sport

70 Nicht-organisierte Privatperson

81 Kunst/Kultur/Literatur

82 Kulturelle Organisationen

99 Sonstige

\section{V45.1.5 Politische Partei}

Welcher Partei gehört die Person an (wenn genannt oder offensichtlich/allgemein bekannt)?

Eingabe der Partei [fortlaufend ergänzte Liste] 
V45.1.6

Art der Äuße-

rung

1 Statement

Gezielt von JournalistIn eingeholte Stellungnahme; umfasst max. eine Frage mit Antwort und eine Nachfrage die sich auf die vorhergehende Antwort bezieht.

Statement im Rahmen einer Straßenumfrage Wie 1, jedoch werden innerhalb des Beitrags nacheinander viele Statements von PassantIn- 9 nen eingeholt und zusammen präsentiert.

Redeausschnitt

Adressat ist nicht JournalistIn sondern ein allg.

Publikum; Aussage bezieht sich auf keine von JournalistIn des Beitrags gestellte Frage Interview

Fragen von JournalistIn werden mitgesendet, mind. zwei Fragen.

Sonstige

\section{V45.1.7}

Anonymisie-

rung

AkteurIn ist durch technische oder gestalterische Mittel anonymisiert

2 AkteurIn ist nicht anonymisiert

\section{V45.1.8 Präsentations-}

\section{kontext}

In welchem Umfeld wird der Akteur bzw. die Akteurin präsentiert?

1 Studio

2 Berufliche Umge-

bung/Arbeitsplatz

3 Semi-öffentliche Umgebung

4 Öffentliche Umgebung - öff. Plätre, Straßen, Gebäude

$5 \quad$ Private Umgebung

6 Natur/Landschaft - außerbalb private Umgebung

9 Sonstige Umgebung/nicht identifizierbar

V45.1.9

Berufliche

\section{Umgebung: Wirtschafts- sektor}

Welchem Wirtschaftssektor gehört die gezeigte berufliche Umgebung an? Nur in Bezug auf den AkteurIn, d. h. Arbeitsplatz der Akteurin/des Akteurs selbst.

1 Primärer Sektor

2 Sekundärer Sektor

(n)

\section{Tertiärer Sektor}

\section{V45.1.10 Dialektausprägung}

Wie stark spricht die Akteurin bzw. der Akteur Dialekt?

Hochdeutsch

Leichte dialektische Einfär-

bung

Starker Dialekt

Sehr stark/Regionalsprache

Trifft nicht zu - fremdspra-

chig/

Gebärdensprache/sonst.

\section{V45.1.11 Räumliche Kohärenz}

Ist der gesprochene Dialekt aus der Region, aus der berichtet wird?

Dialekt der Region aus der berichtet wird

Dialekt einer anderen Region

Nicht zu entscheiden

\section{V45.2 AkteurIn 2}

V45.3 AkteurIn 3

$\begin{array}{ll}\text { V45.4 } & \text { analog zu Akteur } 1 \\ & \text { AkteurIn } 4 \\ \text { analog zu Akteur } 1\end{array}$

\section{46 Vercodungsprobleme}

V46.1 Art des Problems

Vercodung allgemein

Zuordnung Gemeindekennziffer

3 Aufzeichnung (technische Störung im Untersuchungsmaterial u. ä.)

9

Sonstige

\section{V46.2 Notiz zum Verco- dungsproblem}

Textfeld, genaue Beschreibung des Problems

\section{47 Bemerkungen}

Textfeld, Anmerkungen zu besonderen Beobachtungen im Material.

\section{48 Coder}

Name 
Themenliste (V18, V19, V28, V29)

\begin{tabular}{|c|c|c|}
\hline Code & Bezeichnung & Erläuterung (Welche Themen fallen in diese Kategorie?) \\
\hline \multicolumn{3}{|r|}{ 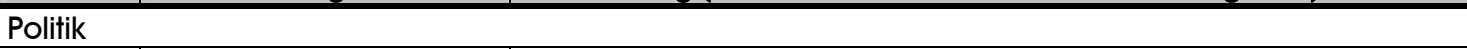 } \\
\hline 101 & Parteien & Politische Vorgänge innerhalb und zwischen politischen Parteien \\
\hline 102 & Wahlen & $\begin{array}{l}\text { Politische Vorgänge, die in direktem Zusammenhang mit einer be- } \\
\text { vorstehenden oder kurz zurückliegenden Wahl stehen. Dazu zählen } \\
\text { nicht nur die Stimmabgabe der Wahlberechtigten, sondern auch } \\
\text { innerparlamentarische Wahlvorgänge, wie die Abstimmung über eine } \\
\text { Ministerpräsidentin oder einen Ministerpräsidenten oder eine Parla- } \\
\text { mentspräsidentin oder einen Parlamentspräsidenten. }\end{array}$ \\
\hline 103 & $\begin{array}{l}\text { Politische Affären, } \\
\text { Untersuchungsaus- } \\
\text { schüsse }\end{array}$ & $\begin{array}{l}\text { Politische Vorgänge, deren Korrektheit offen angezweifelt oder un- } \\
\text { tersucht wird: auch private Umstände, die das Bild einer politisch } \\
\text { tätigen Person negativ beeinflussen können. }\end{array}$ \\
\hline 104 & Justiz, Kriminalität & $\begin{array}{l}\text { Justiz und Kriminalität als Gegenstand politischen Handelns. Bsp.: } \\
\text { Kriminalstatistik, wird vorgestellt, Gesetzesreformen. }\end{array}$ \\
\hline 105 & $\begin{array}{l}\text { Verfassungsgerichtsbar- } \\
\text { keit, staatsrechtliche } \\
\text { Verfahren u. Entschei- } \\
\text { dungen }\end{array}$ & $\begin{array}{l}\text { Höchstrichterliche Prozesse und Entscheidungen, die staatliches } \\
\text { Handeln zum Gegenstand haben. }\end{array}$ \\
\hline 106 & $\begin{array}{l}\text { Polizei, staatliche Ge- } \\
\text { waltausübung }\end{array}$ & $\begin{array}{l}\text { Polizeiliches Handeln als Gegenstand politischer Entscheidungspro- } \\
\text { zesse. Bsp.: Überwachungsbefugnis öffentlicher Räume, personelle Ausstattung } \\
\text { der Polizei. }\end{array}$ \\
\hline 107 & Innere Sicherheit & $\begin{array}{l}\text { Sicherheitspolitik, die sich auf innerstaatliche Vorgänge bezieht. Ins- } \\
\text { besondere Gefahrenabwehr. }\end{array}$ \\
\hline 108 & Asyl, Zuwanderung & $\begin{array}{l}\text { Politische Prozesse, die Zuwanderung und Asyl zum Gegenstand } \\
\text { haben. }\end{array}$ \\
\hline 109 & $\begin{array}{l}\text { Verteidigung, Militär } \\
\text { (allg.) }\end{array}$ & $\begin{array}{l}\text { Allgemeine Verteidigungspolitische Prozesse. Bsp.: Abschaffung der } \\
\text { Wehrpflicht. }\end{array}$ \\
\hline 110 & $\begin{array}{l}\text { Militärische. Konflikte, } \\
\text { Krieg }\end{array}$ & $\begin{array}{l}\text { Militärisches Handeln unter Beteiligung der Bundeswehr/des Bun- } \\
\text { desheeres. }\end{array}$ \\
\hline 111 & $\begin{array}{l}\text { Krisen, Bedrohungen, } \\
\text { Terrorismus }\end{array}$ & $\begin{array}{l}\text { Terroristische Aktivitäten und sicherheitspolitische Krisen, die eine } \\
\text { Bedrohung darstellen. Nur bei unmittelbarer Betroffenheit Deutsch- } \\
\text { lands/ } \\
\text { Österreichs. Bsp.: Anschlagspläne auf deutsche oder österreichische Institutionen } \\
\text { etc. }\end{array}$ \\
\hline 112 & Humanitäre Hilfe & $\begin{array}{l}\text { Technische, finanzielle oder logistische operative Hilfen in Krisensi- } \\
\text { tuationen. }\end{array}$ \\
\hline 113 & Entwicklungshilfe & $\begin{array}{l}\text { Unterstützung von Entwicklungsländern durch finanzielle oder Sach- } \\
\text { leistungen zur wirtschaftlichen Entwicklung. }\end{array}$ \\
\hline 114 & $\begin{array}{l}\text { Sozialpolitik, Sozialhilfe, } \\
\text { Renten, sozialer Wohn- } \\
\text { bau }\end{array}$ & $\begin{array}{l}\text { Politisches Handeln, das die Unterstützung wirtschaftlich weniger } \\
\text { leistungsfähiger gesellschaftlicher Gruppen zum Gegenstand hat } \\
\text { sowie Rentenpolitik (staatliche Altersvorsorgeleistungen). }\end{array}$ \\
\hline 115 & $\begin{array}{l}\text { Familien-, Jugend-, } \\
\text { Kinderpolitik, Ehe }\end{array}$ & $\begin{array}{l}\text { Politische Vorgänge im Bereich der Tätigkeitsbereiche des Bundes- } \\
\text { ministeriums für Familie, Senioren, Frauen und Jugend bzw. des } \\
\text { Bundesministeriums für Gesundheit, Familie und Jugend. Auch Op- } \\
\text { positionspolitik in diesen Sachgebieten. }\end{array}$ \\
\hline 116 & Gesundheitswesen & $\begin{array}{l}\text { Politische Prozesse, die die Gesundheitsversorgung und deren Finan- } \\
\text { zierung zum Gegenstand haben. }\end{array}$ \\
\hline 117 & $\begin{array}{l}\text { Bildungs-, Wissen- } \\
\text { schaftspolitik }\end{array}$ & $\begin{array}{l}\text { Politische Vorgänge, die auf Bildung (Vorschule, allgemeinbildende } \\
\text { Schulen, Hochschulen, duale Ausbildung) und Wissenschaft Einfluss } \\
\text { nehmen. }\end{array}$ \\
\hline 118 & Kulturpolitik & $\begin{array}{l}\text { Kultur als Gegenstand politischen Handelns (etwa: Subventionen } \\
\text { von Bühnen, Finanzierung von Museumsbauten, Filmförderung). }\end{array}$ \\
\hline 119 & Wirtschaftspolitik & $\begin{array}{l}\text { Politisches Handeln, das die wirtschaftliche Entwicklung explizit } \\
\text { beeinflussen soll. Dafür muss erkennbar sein, dass die handelnden } \\
\text { staatlichen Institutionen/Personen sich von der politischen Maß- } \\
\text { nahme eine konkrete Wirkung auf die Wirtschaft versprechen. All- } \\
\text { gemeine Nebeneffekte politischen Handelns reichen dafür nicht aus } \\
\text { (etwa Bürokratieabbau). }\end{array}$ \\
\hline 120 & Gewerkschaft & $\begin{array}{l}\text { Politisches Handeln von Gewerkschaften (etwa Vorstandswahlen) } \\
\text { analog zum Code „Parteien“. Auch explizite Teilnahme von Gewerk- }\end{array}$ \\
\hline
\end{tabular}




\begin{tabular}{|c|c|c|}
\hline Code & Bezeichnung & Erläuterung (Welche Themen fallen in diese Kategorie?) \\
\hline & & schaften an politischen Diskussionen. \\
\hline 121 & Tarifpolitik, Streik & Tarifpolitische Entscheidungen und Prozesse. \\
\hline 122 & Arbeitslosigkeit & $\begin{array}{l}\text { Vor allem Entwicklung der Zahlen und Arbeitsmarktsituation. Geht } \\
\text { es aber um Versorgung (Hartz IV), dann Sozialpolitik! Im Zweifelsfall } \\
\text { über Mehrfachcodierung lösen. Auch politische Maßnahmen, die sich } \\
\text { explizit auf das Problem der Arbeitslosigkeit beziehen. }\end{array}$ \\
\hline 123 & $\begin{array}{l}\text { Arbeitsbedingungen, } \\
\text { soziale Situation }\end{array}$ & $\begin{array}{l}\text { Gesellschaftspolitische Auseinandersetzungen um Arbeitsbedingun- } \\
\text { gen und soziale Situation (etwa: Mindestlohnforderungen, Aufsto- } \\
\text { ckung geringer Gehälter, Diskussion um bedingungsloses Grundein- } \\
\text { kommen). }\end{array}$ \\
\hline 124 & $\begin{array}{l}\text { Haushalt, Finanzen, } \\
\text { Steuern }\end{array}$ & $\begin{array}{l}\text { Politisches Handeln, das den Staatshaushalt, die Staatsfinanzen sowie } \\
\text { die Steuereinnahmen und -erhebung zum Gegenstand hat. Nur genu- } \\
\text { in politischer Bezug, keine allgemein gehaltenen Klagen über Steuer- } \\
\text { last. }\end{array}$ \\
\hline 125 & Verwaltungsakte & $\begin{array}{l}\text { Routinehandeln politischer Institutionen, „Tagesgeschäft“. Nicht } \\
\text { kontrovers. }\end{array}$ \\
\hline 126 & Umwelt, Klimaschutz & $\begin{array}{l}\text { Umweltpolitische Aktivitäten staatlicher oder parteipolitischer Insti- } \\
\text { tutionen. Politisches Handeln, das den Umwelt- und Klimaschutz } \\
\text { befördern soll. }\end{array}$ \\
\hline 127 & Verkehr & Verkehrspolitische Prozesse und Entscheidungen. \\
\hline 128 & Rechtsextremismus & $\begin{array}{l}\text { Als Gegenstand politischen Handelns; rechtsextremistisch motivierte } \\
\text { Straftaten Einzelner: Kriminalität. }\end{array}$ \\
\hline 129 & $\begin{array}{l}\text { Sonstige innenpolitische } \\
\text { Themen }\end{array}$ & Innenpolitische Vorgänge, die in keine andere Kategorie passen. \\
\hline \multicolumn{3}{|c|}{ Außen - Außenpolitisches Handeln Deutschlands bzw. Österreichs. } \\
\hline 131 & EU-Politik & $\begin{array}{l}\text { Politische Vorgänge auf Ebene der Europäischen Union. EU- } \\
\text { Gremien müssen involviert oder Gegenstand dieser Vorgänge sein. }\end{array}$ \\
\hline 132 & $\begin{array}{l}\text { UN/NATO } \\
\text { /supranationale Organi- } \\
\text { sationen }\end{array}$ & $\begin{array}{l}\text { Politische Vorgänge innerhalb übernationaler Organisationen, sofern } \\
\text { Deutschland oder Österreich mitwirkt. (Ohne Beteiligung: 139). }\end{array}$ \\
\hline 133 & $\begin{array}{l}\text { Diplomatische Bezie- } \\
\text { hungen zu anderen } \\
\text { Staaten }\end{array}$ & $\begin{array}{l}\text { Außenpolitische Kontakte zu anderen Staaten, unabhängig von deren } \\
\text { Bündniszugehörigkeit (bilaterale Verhandlungen zwischen Frankreich } \\
\text { und Österreich fallen also hierunter und nicht unter 131, sofern nicht } \\
\text { ein expliziter Bezug zur EU-Politik herausgestellt wird). }\end{array}$ \\
\hline 139 & $\begin{array}{l}\text { Sonstige Außenpoliti- } \\
\text { sche Themen }\end{array}$ & Außenpolitische Vorgänge, die in keine andere Kategorie passen. \\
\hline 140 & Internationale Politik & $\begin{array}{l}\text { Politische Vorgänge außerhalb Deutschlands oder Österreichs. Re- } \\
\text { gelmäßig im Fall „,klassischer Auslandsberichterstattung““. Bsp.: Wablen } \\
\text { in Südafrika. }\end{array}$ \\
\hline 141 & $\begin{array}{l}\text { Krisen, Bedrohungen, } \\
\text { Terror (international) }\end{array}$ & $\begin{array}{l}\text { Terroristische Aktivitäten und sicherheitspolitische Krisen, die eine } \\
\text { Bedrohung darstellen, aber nicht Deutschland oder Österreich betref- } \\
\text { fen. Bsp.: Bombenanschlag im Irak. }\end{array}$ \\
\hline 142 & Krieg & Militärische Auseinandersetzungen zwischen Staaten. \\
\hline 199 & $\begin{array}{l}\text { Sonstige politische } \\
\text { Themen }\end{array}$ & Politische Vorgänge, die in keine andere Kategorie passen. \\
\hline \multicolumn{3}{|c|}{ Wirtschaft } \\
\hline \multicolumn{3}{|c|}{ Gesamtwirtschaft (Makroperspektive) - Makroperspektive aber ohne explizit staatlich/politische Bezüge } \\
\hline 211 & $\begin{array}{l}\text { Wirtschaftslage, Kon- } \\
\text { junktur }\end{array}$ & $\begin{array}{l}\text { Gesamtwirtschaftliche Lageeinschätzungen, konjunkturelle Entwick- } \\
\text { lungen. Auch retrospektiv und prognostisch, wenn Bezug zur Ge- } \\
\text { genwart besteht. }\end{array}$ \\
\hline 212 & Preisentwicklung & $\begin{array}{l}\text { Entwicklung von Preisen. Auch Einkaufspreise (etwa Rohölmarkt), } \\
\text { nicht nur Verbraucherpreise. }\end{array}$ \\
\hline 213 & Branchenentwicklung & Wirtschaftliche Lage und Prognose einer einzelnen Branche. \\
\hline 219 & $\begin{array}{l}\text { Sonstige gesamtwirt- } \\
\text { schaftliche Themen }\end{array}$ & Themen der Gesamtwirtschaft, die in keine andere Kategorie passen. \\
\hline \multicolumn{3}{|c|}{ Privatwirtschaft } \\
\hline 221 & Börse & Geschehen an Wertpapiermärkten, Kursentwicklungen u. ä. \\
\hline 222 & $\begin{array}{l}\text { Unternehmensbilanzen } \\
\text { und -berichte }\end{array}$ & $\begin{array}{l}\text { Berichte einzelner Unternehmen über ihre wirtschaftliche Entwick- } \\
\text { lung. }\end{array}$ \\
\hline 223 & $\begin{array}{l}\text { Unternehmensaktivitä- } \\
\text { ten }\end{array}$ & $\begin{array}{l}\text { Geschäftliche Tätigkeiten einzelner Wirtschaftsunternehmen, die } \\
\text { hauptsächlich deren alltäglichen Betrieb umfassen und keine ereignis- }\end{array}$ \\
\hline
\end{tabular}




\begin{tabular}{|c|c|c|}
\hline Code & Bezeichnung & Erläuterung (Welche Themen fallen in diese Kategorie?) \\
\hline & & $\begin{array}{l}\text { bezogene Besonderheit im Sinne einer groben Abweichung vom } \\
\text { üblichen Handeln im Unternehmen darstellen. }\end{array}$ \\
\hline 224 & $\begin{array}{l}\text { Krisen, Konkurse, In- } \\
\text { solvenzen }\end{array}$ & $\begin{array}{l}\text { Finanzielle Schwierigkeiten einzelner Unternehmen, die deren Fort- } \\
\text { bestand oder die sonst üblichen unternehmerischen Aktivitäten auf } \\
\text { Dauer oder vorübergehend gefährden. }\end{array}$ \\
\hline 225 & Messen, Ausstellungen & $\begin{array}{l}\text { Zeitlich begrenzte, meist periodisch wiederkehrende Waren- oder } \\
\text { Dienstleistungsschau. }\end{array}$ \\
\hline 229 & $\begin{array}{l}\text { Sonstige Privatwirt- } \\
\text { schaftsthemen }\end{array}$ & $\begin{array}{l}\text { Themen, die sich auf einzelne private Wirtschaftsunternehmen be- } \\
\text { ziehen und in keine der anderen Kategorien passen. }\end{array}$ \\
\hline 299 & $\begin{array}{l}\text { Sonstige Wirtschafts- } \\
\text { themen }\end{array}$ & $\begin{array}{l}\text { Themen, die sich auf wirtschaftliche Zusammenhänge und Ereignisse } \\
\text { beziehen und in keine andere Kategorie passen. }\end{array}$ \\
\hline \multicolumn{3}{|c|}{ Gesellschaft } \\
\hline 301 & Medien/Journalismus & $\begin{array}{l}\text { Gegenstand der Berichterstattung sind Massenmedien oder Journa- } \\
\text { lismus selbst. Bsp.: Herausgabe eines neuen Nachrichtenmagazins beginnt; } \\
\text { immer mehr festangestellte Journalistinnen und Journalisten werden durch Freie } \\
\text { ersetzt. }\end{array}$ \\
\hline 302 & Bildungswesen & $\begin{array}{l}\text { Vorgänge, die das Bildungswesen und seine Organisation betreffen, } \\
\text { sofern kein genuin politischer Bezug hergestellt wird. }\end{array}$ \\
\hline 303 & $\begin{array}{l}\text { Brauch- } \\
\text { tum/Tradition/Regione } \\
\mathrm{n}\end{array}$ & $\begin{array}{l}\text { Vorstellung und/oder Erläuterung und Darstellung von Brauchtü- } \\
\text { mern und Traditionen und deren Pflege sowie kulturelle Besonder- } \\
\text { heiten einzelner (Sub-)Regionen. }\end{array}$ \\
\hline 304 & Alltagskultur & $\begin{array}{l}\text { Alltägliche und nicht außergewöhnliche Erscheinungen kultureller } \\
\text { Art nur aus in Makroperspektive u. nicht personalisiert (sonst: } 362 \text { ). }\end{array}$ \\
\hline 310 & Kirche u. Religion & $\begin{array}{l}\text { Allgemein religiöse Themen ohne eindeutige konfessionelle Zuord- } \\
\text { nung. Bsp.: Gottesglaube im Alltag; religiöser Hintergrund des Weibnachtsfes- } \\
\text { tes: }\end{array}$ \\
\hline 311 & Katholisch & $\begin{array}{l}\text { Religiöse Themen, die die Ausübung des Glaubens innerhalb der } \\
\text { katholischen Kirche zum Gegenstand haben sowie innerkirchliche } \\
\text { Vorgänge. } \\
\text { Bsp.: Hinweis auf besonderen Gottesdienst; Bischofsweihe. }\end{array}$ \\
\hline 312 & Evangelisch & $\begin{array}{l}\text { Religiöse Themen, die die Ausübung des Glaubens innerhalb der } \\
\text { katholischen Kirche zum Gegenstand haben sowie innerkirchliche } \\
\text { Vorgänge. } \\
\text { Bsp.: Hinweis auf besonderen Gottesdienst; Amtseinführung eines Bischofs oder } \\
\text { einer Bischöfin. }\end{array}$ \\
\hline 313 & Islam & $\begin{array}{l}\text { Religiöse Themen, die die Ausübung des Glaubens innerhalb der } \\
\text { islamischen Religionsgemeinschaften zum Gegenstand haben sowie } \\
\text { entsprechende organisationsimmanente Vorgänge. }\end{array}$ \\
\hline 314 & Judentum & $\begin{array}{l}\text { Religiöse Themen, die die Ausübung des Glaubens innerhalb der } \\
\text { jüdischen Religionsgemeinschaft zum Gegenstand haben sowie ent- } \\
\text { sprechende organisationsimmanente Vorgänge. }\end{array}$ \\
\hline 315 & Sekten & $\begin{array}{l}\text { Vorgänge in und um religiöse und weltanschauliche Sekten, sofern } \\
\text { die entsprechenden Organisationen oder Gemeinschaften als solche } \\
\text { bezeichnet werden oder eindeutig als solche bekannt sind. }\end{array}$ \\
\hline \multicolumn{3}{|c|}{ Wissenschaft/Technik/Forschung } \\
\hline 321 & Naturwissenschaften & $\begin{array}{l}\text { Forschung, Entwicklungen und Ergebnisse sowie deren Diskussion } \\
\text { im Bereich der Naturwissenschaften. }\end{array}$ \\
\hline 322 & $\begin{array}{l}\text { Geistes- und Sozialwis- } \\
\text { senschaften }\end{array}$ & $\begin{array}{l}\text { Forschung, Entwicklungen und Ergebnisse sowie deren Diskussion } \\
\text { im Bereich der Geistes- und Sozialwissenschaften. }\end{array}$ \\
\hline 323 & $\begin{array}{l}\text { Computertechnologie, } \\
\text { Informatik }\end{array}$ & $\begin{array}{l}\text { Forschung, Entwicklungen und Ergebnisse sowie deren Diskussion } \\
\text { im Bereich der Computertechnologie, Informatik. }\end{array}$ \\
\hline 324 & $\begin{array}{l}\text { Ingenieurs- und Tech- } \\
\text { nikwissenschaften }\end{array}$ & $\begin{array}{l}\text { Forschung, Entwicklungen und Ergebnisse sowie deren Diskussion } \\
\text { im Bereich der Ingenieurs- und Technikwissenschaften. }\end{array}$ \\
\hline 325 & $\begin{array}{l}\text { Medizin wenn nicht als } \\
\text { Gesundheitsthema }\end{array}$ & $\begin{array}{l}\text { Forschung, Entwicklungen und Ergebnisse sowie deren Diskussion } \\
\text { im Bereich der medizinischen - d. h. auf Krankheitsheilung und - } \\
\text { vorsorge gerichteten - Forschung. }\end{array}$ \\
\hline 326 & $\begin{array}{l}\text { Psychologie, Hirnfor- } \\
\text { schung u. ä. }\end{array}$ & $\begin{array}{l}\text { Forschung, Entwicklungen und Ergebnisse sowie deren Diskussion } \\
\text { im Bereich der Psychologie und Hirnforschung. }\end{array}$ \\
\hline
\end{tabular}

Gerichtsverfahren außerhalb Strafverfolgung und Staatsrecht 


\begin{tabular}{|c|c|c|}
\hline Code & Bezeichnung & Erläuterung (Welche Themen fallen in diese Kategorie?) \\
\hline 331 & $\begin{array}{l}\text { Arbeitsrecht, Sozialge- } \\
\text { richtsbarkeit }\end{array}$ & $\begin{array}{l}\text { Verfahren und Entscheidungen, die die Rechtsgebiete Arbeitsrecht } \\
\text { und/ } \\
\text { oder Sozialrecht betreffen. }\end{array}$ \\
\hline 332 & Verwaltungsrecht & $\begin{array}{l}\text { Verfahren und Entscheidungen, die das Rechtsgebiet des Verwal- } \\
\text { tungsrechts betreffen. }\end{array}$ \\
\hline 333 & Bürgerliches Recht & Verfahren und Entscheidungen im Zivilrecht. \\
\hline 339 & $\begin{array}{l}\text { Sonstige Gerichtsver- } \\
\text { fahren }\end{array}$ & $\begin{array}{l}\text { Gerichtsverfahren, die nicht die Strafverfolgung oder staatsrechtliche } \\
\text { Fragen betreffen und in keine andere Kategorie passen. }\end{array}$ \\
\hline 340 & Soziales & $\begin{array}{l}\text { Residualkategorie für Themen sozialen Engagements, die nicht in die } \\
\text { Kategorien } 341 \text { bis } 344 \text { passen. }\end{array}$ \\
\hline 341 & $\begin{array}{l}\text { Umwelt- und Natur- } \\
\text { schutz }\end{array}$ & $\begin{array}{l}\text { Gesellschaftliches Engagement im Bereich des Umwelt- und Natur- } \\
\text { schutzes ohne expliziten Politikbezug. }\end{array}$ \\
\hline 342 & $\begin{array}{l}\text { Soziales Engagement } \\
\text { (innen) }\end{array}$ & $\begin{array}{l}\text { Vorgänge und Ereignisse, die die Unterstützung Hilfsbedürftiger im } \\
\text { Inland durch die Gesellschaft als Solidargemeinschaft betreffen, aber } \\
\text { keinen politischen Bezug haben. Bsp.: Eröffnung einer neuen Suppenkü̈he } \\
\text { für Obdachlose. }\end{array}$ \\
\hline 343 & $\begin{array}{l}\text { Soziales Engagement } \\
\text { (außen) }\end{array}$ & $\begin{array}{l}\text { Vorgänge und Ereignisse, die die Unterstützung Hilfsbedürftiger im } \\
\text { Ausland betreffen, aber keinen politischen Bezug haben. Bsp.: DRK } \\
\text { betreibt AIDS-Präventionskampagnen in Mosambik. }\end{array}$ \\
\hline 344 & Gleichberechtigung & $\begin{array}{l}\text { Gesellschaftliches Engagement für die Gleichberechtigung der Ge- } \\
\text { schlechter oder Thematisierung der weiterhin bestehenden Notwen- } \\
\text { digkeit diesbezüglich tätig zu werden. }\end{array}$ \\
\hline 345 & Verkehr & $\begin{array}{l}\text { Vorgänge rund um Verkehrs- und Mobilitätsfragen, sofern kein poli- } \\
\text { tischer Bezug. Bsp.: neue U-Babnlinie nimmt Betrieb auf; Fährverkehr wird } \\
\text { witterungsbedingt eingestellt. }\end{array}$ \\
\hline 351 & NS-Aufarbeitung & $\begin{array}{l}\text { Thematisierung der gesellschaftlichen Auseinandersetzung mit der } \\
\text { nationalsozialistischen Vergangenheit Deutschlands oder Österreichs. } \\
\text { Bsp.: Streit um Grass' SS-Mitgliedschaft: } \\
\text { Aber nicht bei historischer Darstellung vergangenen Geschehens. }\end{array}$ \\
\hline 352 & DDR-Aufarbeitung & $\begin{array}{l}\text { Thematisierung der gesellschaftlichen Auseinandersetzung mit der } \\
\text { DDR-Vergangenheit. Bsp.: Diskussion um Schließung der Stasi- } \\
\text { Unterlagenbehörde. } \\
\text { Aber nicht bei historischer Darstellung vergangenen Geschehens. }\end{array}$ \\
\hline 360 & Human Touch & $\begin{array}{l}\text { Auf bloße Unterhaltung zielende Berichterstattung, ohne dass die } \\
\text { inhaltliche Substanz über den Unterhaltungscharakter hinausgeht und } \\
\text { die nicht in die Kategorien } 361 \text { - } 366 \text { passt. }\end{array}$ \\
\hline 361 & Prominenz & $\begin{array}{l}\text { Auftritte, Handeln, Äußerungen und Aktivitäten prominenter Perso- } \\
\text { nen, sofern deren Beteiligung oder Persönlichkeit der Anlass der } \\
\text { Berichterstattung ist. }\end{array}$ \\
\hline \multicolumn{3}{|c|}{ Persönliches (nicht prominent) } \\
\hline 362 & Alltagshandeln & $\begin{array}{l}\text { Alltägliche Vorgänge im Leben von nichtprominenten Personen, die } \\
\text { nicht außergewöhnlich sind. Bsp.: berufliches Alltagshandeln wird darge- } \\
\text { stellt. }\end{array}$ \\
\hline 363 & $\begin{array}{l}\text { Normalpersonen in } \\
\text { außergewöhnlichen } \\
\text { Situationen }\end{array}$ & $\begin{array}{l}\text { Ungewöhnliche, vom Alltag der Durchschnittsbevölkerung deutlich } \\
\text { abweichende Ereignisse oder Vorgänge im Leben nichtprominenter } \\
\text { Personen. Bsp.: Vierlingsgeburt; Auftritt eines Rechenkünstlers in „Wetten, } \\
\text { dass ...?". }\end{array}$ \\
\hline 364 & $\begin{array}{l}\text { Normalbürger in Kon- } \\
\text { flikt mit übergeordneten } \\
\text { Institutionen }\end{array}$ & $\begin{array}{l}\text { Nicht prominente Personen, die einen Konflikt mit Institutionen } \\
\text { austragen, wie etwa Behörden, Vermieter u. ä. Aber anzugrenzen von } \\
\text { Rechtsstreits, dann evtl. } 331-339 .\end{array}$ \\
\hline 365 & $\begin{array}{l}\text { Tierstories (,,ver- } \\
\text { menschlicht") }\end{array}$ & $\begin{array}{l}\text { Ungewöhnliche, kuriose oder überraschende Begebenheiten mit } \\
\text { individuellen Tieren oder allägliche Vorgänge rund um besonders } \\
\text { bekannte individuelle Tiere. Bsp.: artistisch begabter Panda im Wittenberger } \\
\text { Zoo macht auf Kommando Purzelbäume; Eisbär Knut im Berliner Zoo frisst } \\
\text { gern Fisch. }\end{array}$ \\
\hline 366 & $\begin{array}{l}\text { Kurioses, Ungewöhnli- } \\
\text { ches (unpersönlich) }\end{array}$ & $\begin{array}{l}\text { Kuriose, ungewöhnliche oder überraschende aber nicht personalisier- } \\
\text { te Begebenheiten. Bsp.: Äpfel eines einzelnen Apfelbaums in der Mebrzabl } \\
\text { heraförmig. }\end{array}$ \\
\hline 371 & $\begin{array}{l}\text { Partnerschaft/ } \\
\text { Liebesbeziehungen/Ehe } \\
\text { (persönlich) }\end{array}$ & $\begin{array}{l}\text { Personalisierte, d. h. auf individualisierbare Personen bezogene Be- } \\
\text { richterstattung über Themen von Partnerschaft, Liebe und Ehe. Aber } \\
\text { keine allgemein gehaltene Beratung. Bsp.: nicht prominentes Paar hat }\end{array}$ \\
\hline
\end{tabular}




\begin{tabular}{|c|c|c|}
\hline Code & Bezeichnung & Erläuterung (Welche Themen fallen in diese Kategorie?) \\
\hline & & Beqiehungskerise überwunden. \\
\hline 372 & $\begin{array}{l}\text { Erotik/Sexualität/ } \\
\text { Intimes (persönlich) }\end{array}$ & $\begin{array}{l}\text { Personalisierte, } \mathrm{d} \text {. h. auf individualisierbare Personen bezogene Be- } \\
\text { richterstattung über Erotik, Sexualität und Intimes. Bsp.: nicht prominen- } \\
\text { tes Ehepaar besucht regelmäßig Saunaclubs. }\end{array}$ \\
\hline 380 & $\begin{array}{l}\text { Natur, Umwelt, Wet- } \\
\text { terphänomene }\end{array}$ & $\begin{array}{l}\text { Vorgänge in der Natur und Umwelt sowie Auftreten von Witte- } \\
\text { rungsbesonderheiten ohne individuelle Betroffenheit von Personen. }\end{array}$ \\
\hline \multicolumn{3}{|c|}{ Kriminalität } \\
\hline \multicolumn{3}{|c|}{ Tat } \\
\hline 401 & Tötungsdelikte & $\begin{array}{l}\text { Taten, bei denen jemand ums Leben kam. Ausnahme: Verkehrsde- } \\
\text { likt, wenn nicht mindestens eine Verletzungsabsicht hervorgehoben } \\
\text { wird. }\end{array}$ \\
\hline 402 & Körperliche Gewalttat & $\begin{array}{l}\text { Körperverletzungsdelikte, bei denen die Gewaltausübung gegen eine } \\
\text { Person im Vordergrund steht und die nicht die Gewaltanwendung } \\
\text { das Mittel zu einem anderen Zweck (etwa einer Wegnahme) ist. }\end{array}$ \\
\hline 403 & Sexualdelikte & Delikt gegen die sexuelle Selbstbestimmung. \\
\hline 404 & $\begin{array}{l}\text { Vandalismus, Brandstif- } \\
\text { tung }\end{array}$ & $\begin{array}{l}\text { Gewalt gegen Sachen, die deren substanzielle Integrität beeinträchtigt } \\
\text { und diese Beeinträchtigung selbst zum Zweck hatte. }\end{array}$ \\
\hline 405 & $\begin{array}{l}\text { Organisierte Kriminali- } \\
\text { tät }\end{array}$ & $\begin{array}{l}\text { Kriminelle Vorgänge, die organisationsmäßig betrieben werden und } \\
\text { das auch in der Berichterstattung thematisiert wird. }\end{array}$ \\
\hline 406 & $\begin{array}{l}\text { Individuelle Eigen- } \\
\text { tumsdelikte }\end{array}$ & $\begin{array}{l}\text { Delikte, die einen Vermögensschaden beim Opfer zur Folge einer } \\
\text { Vermögensmehrung des Täters oder der Täterin haben (Betrug, } \\
\text { Diebstahl u. ä.). Opfer aber individuell als Abgrenzung zur Wirt- } \\
\text { schaftskriminalität. }\end{array}$ \\
\hline 407 & Wirtschaftskriminalität & $\begin{array}{l}\text { Eigentumsdelikte, die sich nicht gegen einzelne Personen sondern } \\
\text { gegen Unternehmen oder Institutionen richten. Auch kriminelle } \\
\text { Handlungen zwischen Unternehmen (Produktpiraterie, Wirtschafts- } \\
\text { spionage). }\end{array}$ \\
\hline 408 & Umweltkriminalität & $\begin{array}{l}\text { Strafbare Handlungen, die eine Schädigung der Umwelt zum Gegens- } \\
\text { tand haben. }\end{array}$ \\
\hline 409 & Verkehrsdelikte & $\begin{array}{l}\text { Straftaten und Ordnungswidrigkeiten im Straßenverkehr. Auch: } \\
\text { Trunkenheitsfahrten ohne Schadenseintritt. }\end{array}$ \\
\hline 410 & $\begin{array}{l}\text { Rechtsextremistisch } \\
\text { motivierte Straftaten }\end{array}$ & $\begin{array}{l}\text { Nur wenn diese Motivation explizit erwähnt wird. Immer in Mehr- } \\
\text { fachvercodung genauer zu spezifizieren (Tötung, Körperverletzung } \\
\text { etc.) }\end{array}$ \\
\hline 419 & Sonstige Straftaten & Straftaten, die in keine andere Kategorie passen. \\
\hline \multicolumn{3}{|c|}{ Gerichtsverhandlung } \\
\hline 421 & Tötungsdelikte & \multirow{10}{*}{$\begin{array}{l}\text { Wie unter entsprechender Kategorie von } 401-410 \text {, aber nicht die } \\
\text { Tat selbst ist Anlass der Berichterstattung, sondern ein darauf bezo- } \\
\text { genes gerichtliches oder staatsanwaltschaftliches Vorgehen. }\end{array}$} \\
\hline 422 & Körperliche Gewalttat & \\
\hline 423 & Sexualdelikte & \\
\hline 424 & $\begin{array}{l}\text { Vandalismus, Brandstif- } \\
\text { tung }\end{array}$ & \\
\hline 425 & $\begin{array}{l}\text { Organisierte Kriminali- } \\
\text { tät }\end{array}$ & \\
\hline 426 & $\begin{array}{l}\text { Individuelle Eigen- } \\
\text { tumsdelikte - Betrug, } \\
\text { Diebstahl; Opfer aber } \\
\text { individuell, keine Wirt- } \\
\text { schaftskriminalität }\end{array}$ & \\
\hline 427 & Wirtschaftskriminalität & \\
\hline 428 & Umweltkriminalität & \\
\hline 429 & Verkehrsdelikte & \\
\hline 430 & $\begin{array}{l}\text { Rechtsextremistisch } \\
\text { motivierte Straftaten }\end{array}$ & \\
\hline 431 & NS-Verbrechen & $\begin{array}{l}\text { Gerichtsverhandlung, deren Gegenstand ein nationalsozialistisches } \\
\text { Verbrechen oder Kriegsverbrechen aus der Zeit zwischen } 1933 \text { und } \\
1945 \text { ist. }\end{array}$ \\
\hline 439 & Sonstige Straftaten & $\begin{array}{l}\text { Wie } 419 \text { aber nicht Tat, sondern gerichtliches oder staatsanwalt- } \\
\text { schaftliches Vorgehen ist Berichterstattungsanlass. }\end{array}$ \\
\hline \multicolumn{3}{|c|}{ Sonstige Kriminalität } \\
\hline 440 & Suizid & Selbsttötung eines Menschen. \\
\hline 450 & Amoklauf & Plötzliche, willkürliche, unprovozierte, möglicherweise aber vorher \\
\hline
\end{tabular}




\begin{tabular}{|c|c|c|}
\hline Code & Bezeichnung & Erläuterung (Welche Themen fallen in diese Kategorie?) \\
\hline & & $\begin{array}{l}\text { geplante Gewaltattacke einzelner oder weniger Personen in psychi- } \\
\text { scher Ausnahmesituation gegen eine andere Mehrzahl von Personen, } \\
\text { die nicht geplant und gezielt als Opfer ausgewählt wurden, mögli- } \\
\text { cherweise aber einer abgrenzbaren Gruppe möglicher Opfer angehö- } \\
\text { ren. }\end{array}$ \\
\hline 460 & Kriminalitätsprävention & $\begin{array}{l}\text { Getroffene Maßnahmen, die Kriminalität verhindern sollen, wenn } \\
\text { Berichterstattung keinen Beratungscharakter hat (dann: 742). }\end{array}$ \\
\hline 499 & Sonstige & $\begin{array}{l}\text { Sonstige kriminelle Handlungen, die in keine andere Kategorie pas- } \\
\text { sen. }\end{array}$ \\
\hline \multicolumn{3}{|r|}{ ( } \\
\hline 501 & Verkehrsunfall & $\begin{array}{l}\text { Wenn nicht als strafbare Handlung charakterisiert, regelmäßig dann } \\
\text { der Fall, wenn Opfer und Schaden im Vordergrund stehen. }\end{array}$ \\
\hline 502 & Flugzeugabsturz & Unfall eines Luftfahrzeuges. \\
\hline 503 & Bahnunfall & $\begin{array}{l}\text { Unfall eines Schienenfahrzeugs, etwa Entgleisungen u. ä. Bei Unfäl- } \\
\text { len an Bahnübergängen mit Autobeteiligung: Verkehrsunfall. }\end{array}$ \\
\hline 504 & $\begin{array}{l}\text { Schiffshavarie, - } \\
\text { untergang }\end{array}$ & $\begin{array}{l}\text { Notfälle technischer Art an Wasserverkehrsfahrzeugen sowie Notla- } \\
\text { gen, Strandungen, Untergänge solcher. }\end{array}$ \\
\hline 505 & Naturkatastrophen & $\begin{array}{l}\text { Durch Vorgänge in der Natur (endogen oder tektonisch, gravitato- } \\
\text { risch, klimatisch) ausgelöste Schädigungen größeren Ausmaßes. }\end{array}$ \\
\hline 506 & Explosionen, Brände & $\begin{array}{l}\text { Durch Sprengstoffe, Gasentzündungen oder ähnliches verursachte } \\
\text { Zerstörung von Sachen sowie Feuerschäden (auch noch andauernd). }\end{array}$ \\
\hline 507 & Grubenunglück & $\begin{array}{l}\text { Unfall im Bergbaubetrieb, in dem dich die latenten Risiken des über- } \\
\text { oder untertägigen Rohstoffabbaubetriebs manifestieren (Einsturz u. } \\
\text { ä.). }\end{array}$ \\
\hline 508 & $\begin{array}{l}\text { Unfall im Haus- } \\
\text { halt/Arbeitsplatz }\end{array}$ & $\begin{array}{l}\text { Körperliche Schädigung durch Tätigkeiten in der Haushaltsführung } \\
\text { oder am Arbeitsplatz. }\end{array}$ \\
\hline 510 & Störfall Kernkraft & $\begin{array}{l}\text { Technische Zwischenfälle, Beschädigung oder Zerstörung von Kern- } \\
\text { kraftwerken. }\end{array}$ \\
\hline 599 & Sonstige & Unglücksfälle, die in keine der anderen Kategorien passen. \\
\hline \multicolumn{3}{|r|}{20} \\
\hline 601 & Fußball & \\
\hline 602 & Tennis & \\
\hline 603 & Handball & \\
\hline 604 & Basketball & \\
\hline 605 & $\begin{array}{l}\text { Volley- } \\
\text { ball/Beachvolleyball }\end{array}$ & \\
\hline 607 & Feldhockey & \\
\hline 608 & Tischtennis & \\
\hline 609 & American Football & \\
\hline 610 & Baseball & \\
\hline 611 & Rugby & \\
\hline 612 & Golf & \\
\hline 619 & Sonstige Ballsportarten & Ballsportarten, die nicht unter $601-612$ aufgeführt sind. \\
\hline \multicolumn{3}{|c|}{ Wintersport } \\
\hline 621 & Ski alpin & \\
\hline 622 & Ski nordisch & \\
\hline 623 & Skispringen & \\
\hline 624 & Biathlon & \\
\hline 625 & Eishockey & \\
\hline 626 & Eisschnelllauf & \\
\hline 627 & Eiskunstlauf & \\
\hline 628 & Bob/Rodeln & \\
\hline 629 & Sonst. Wintersportarten & $\begin{array}{l}\text { Wintersportarten (in Grundform auf Schnee und Eis als Umweltbe- } \\
\text { dingung angewiesen), die nicht in } 621-628 \text { aufgeführt sind. }\end{array}$ \\
\hline
\end{tabular}




\begin{tabular}{|c|c|c|}
\hline Code & Bezeichnung & Erläuterung (Welche Themen fallen in diese Kategorie?) \\
\hline \multicolumn{3}{|c|}{ Wassersport } \\
\hline 631 & $\begin{array}{l}\text { Schwimmen/ } \\
\text { Turmspringen }\end{array}$ & \\
\hline 632 & Rudern & \\
\hline 633 & Segeln & \\
\hline 634 & Wasserski & \\
\hline 639 & Sonst. Wassersport & $\begin{array}{l}\text { In oder auf Wasser ausgeführte Sportarten, die nicht unter } 631 \text { - } 634 \\
\text { aufgeführt sind. }\end{array}$ \\
\hline \multicolumn{3}{|r|}{ 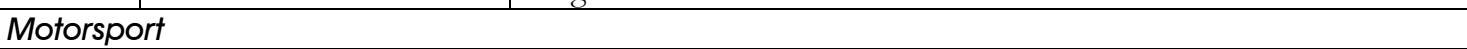 } \\
\hline 641 & Formel 1 & \\
\hline 642 & sonst. Automobilrennen & \\
\hline 643 & Motoradrennsport & \\
\hline 649 & Sonst. Motorsport & $\begin{array}{l}\text { Sportarten, die mittels motorisierter Fortbewegungsmittel ausgeführt } \\
\text { werden und nicht unter } 641-643 \text { aufgeführt sind. }\end{array}$ \\
\hline \multicolumn{3}{|c|}{ Leichtathletik } \\
\hline 651 & Marathon & \\
\hline 652 & $\begin{array}{l}\text { Laufsport } \\
\text { (außer Marathon) }\end{array}$ & \\
\hline 653 & $\begin{array}{l}\text { Sprungsportarten } \\
\text { (Hoch-, Weit-, Drei-, } \\
\text { Stabhoch-) }\end{array}$ & \\
\hline 654 & $\begin{array}{l}\text { Wurfsport (Speer, Dis- } \\
\text { kus, Kugelstoßen etc.) }\end{array}$ & \\
\hline 655 & Zehnkampf & \\
\hline 659 & sonst. Leichtathletik & $\begin{array}{l}\text { Disziplinen der Leichtathletik, die nicht unter } 651 \text { - } 655 \text { aufgeführt } \\
\text { sind. }\end{array}$ \\
\hline \multicolumn{3}{|r|}{ ( } \\
\hline 661 & Boxen & \\
\hline 662 & Ringen & \\
\hline 663 & Fechten & \\
\hline 669 & Sonstiger Kampfsport & $\begin{array}{l}\text { Sonstige Sportart, in der die direkte körperliche oder mittels Hilfs- } \\
\text { mitteln auf den Körper des Kontrahenten zielende Auseinanderset- } \\
\text { zung zweier Kontrahenten Gegenstand des Wettkampfes ist und die } \\
\text { nicht unter } 661-663 \text { aufgeführt ist. }\end{array}$ \\
\hline 670 & Radsport & \\
\hline 671 & Triathlon & \\
\hline 672 & Turnen & \\
\hline 673 & Reitsport & \\
\hline 674 & $\begin{array}{l}\text { Kraft- } \\
\text { sport/Gewichtheben }\end{array}$ & \\
\hline 675 & Billard & \\
\hline 680 & Olympia gesamt & $\begin{array}{l}\text { Nicht auf einzelne Disziplinen, sondern den Veranstaltungsrahmen } \\
\text { olympischer Spiele bezogene Berichterstattung. }\end{array}$ \\
\hline 682 & Sportpolitik & $\begin{array}{l}\text { Auf den Sport und seine Organisationsformen bezogene politische } \\
\text { Vorgänge sowohl des politischen Systems (Parteien, gewählte Volks- } \\
\text { vertreter u. ä.) als auch der Sportorganisationen (etwa: BDR oder } \\
\text { NOK) - außer wenn sich dieses Handeln auf Doping bezieht (dann: } \\
685) \text {. }\end{array}$ \\
\hline 685 & Doping & $\begin{array}{l}\text { Berichterstattung über Sportbetrug mittels unerlaubter medizinischer } \\
\text { Präparate oder Methoden. }\end{array}$ \\
\hline 686 & $\begin{array}{l}\text { Sportvermarktung/ } \\
\text { Sportrechte }\end{array}$ & $\begin{array}{l}\text { Berichterstattung über die (werbliche) Vermarktung von Sportarten, } \\
\text { Sportereignissen oder einzelner Sportler sowie Vorgänge rund um } \\
\text { Sportrechtehandel (Ausstrahlungsrechte). }\end{array}$ \\
\hline 688 & Breitensport & $\begin{array}{l}\text { Sportausübung durch Normalbürgerinnen und Normalbürger zum } \\
\text { Zwecke der Freizeitgestaltung, wenn nicht Gesundheitsaspekt im } \\
\text { Vordergrund steht. }\end{array}$ \\
\hline 699 & Sonstiger Sport & $\begin{array}{l}\text { Berichterstattung, die körperliche Betätigung zum Gegenstand hat, } \\
\text { ohne dass der Gesundheitsaspekt im Vordergrund steht. }\end{array}$ \\
\hline
\end{tabular}


\begin{tabular}{l|l} 
Code & Bezeichnung
\end{tabular}

Erläuterung (Welche Themen fallen in diese Kategorie?)

Private Lebenswelt/Service/Verbraucher

Gesundheit

\begin{tabular}{|c|c|c|}
\hline 701 & Ernährung & $\begin{array}{l}\text { Essen und Trinken, Ernährungsgewohnheiten, Nahrungserzeugung, } \\
\text { Rezepte. }\end{array}$ \\
\hline 702 & Krankheiten & $\begin{array}{l}\text { Krankheitsbilder und darauf bezogene Diagnose-, Therapie- } \\
\text { und/oder Präventionsformen. Aber nicht allgemeine Gesunderhal- } \\
\text { tung. }\end{array}$ \\
\hline 703 & $\begin{array}{l}\text { Drogen, Alkohol, Niko- } \\
\text { tin }\end{array}$ & $\begin{array}{l}\text { Berichterstattung, die die Gefahren von Drogen-, Alkohol- oder } \\
\text { Nikotinkonsum (Rauchen) zum Gegenstand hat. Wenn - in Bezug } \\
\text { auf illegale Rauschmittel - nicht als Kriminalität behandelt. }\end{array}$ \\
\hline 704 & $\begin{array}{l}\text { Ero- } \\
\text { tik/Sexualität/Partnerbe } \\
\text { ziehungen (unpersön- } \\
\text { lich) }\end{array}$ & $\begin{array}{l}\text { Sexualleben und -praktiken sowie deren Bedeutung, Störung oder } \\
\text { deren Auswirkungen auf die Lebensqualität sowie zwischenmenschli- } \\
\text { che Beziehungen, Formen partnerschaftlichen Zusammenlebens - } \\
\text { nur wenn nicht personalisiert, also nicht als Individualsituation be- } \\
\text { handelt Bsp.: Sexualität im Alter; Erektile Dysfunktion. }\end{array}$ \\
\hline 705 & Psychologie & $\begin{array}{l}\text { Geistig-seelische Gesundheit und ihre Erhaltung sowie Therapie bei } \\
\text { psychischen Krankheiten. }\end{array}$ \\
\hline 706 & $\begin{array}{l}\text { Sport/Fitness als Ge- } \\
\text { sundheitsvorsorge und } \\
\text { allgemeine Prävention. }\end{array}$ & Gesundheitserhalt und -vorsorge durch körperliche Betätigung. \\
\hline 709 & $\begin{array}{l}\text { Sonstige Gesundheits- } \\
\text { themen }\end{array}$ & $\begin{array}{l}\text { Themen aus dem Bereich der Gesundheitserhaltung und Vorsorge, } \\
\text { die in keine andere Kategorie passen. }\end{array}$ \\
\hline
\end{tabular}

Alltag

\begin{tabular}{|c|c|c|}
\hline 710 & Auto, Verkehr & $\begin{array}{l}\text { Autokauf, -wartung, -pflege, Verhalten im Autoverkehr und Unfall- } \\
\text { prävention. Auch: Autotests und -bewertung. Aber keine Verkehrs- } \\
\text { rechtsfragen ( } 741 \text { oder 409, 429). }\end{array}$ \\
\hline 720 & Reisen & Reiseplanung, -buchung, -durchführung, Vorstellung von Reisezielen. \\
\hline 730 & Wohnen, Haushalt & $\begin{array}{l}\text { Wohnungs- oder Hauseinrichtung, -pflege, -ausstattung. (aber keine } \\
\text { Mietrechts und Finanzierungsfragen - dann } 743 \text { oder 741). }\end{array}$ \\
\hline 741 & Rechtsberatung & $\begin{array}{l}\text { Allgemeine oder individuelle Beratung in Rechtsfragen, Aufklärung } \\
\text { über rechtliche Situation und eventuell Erfolgsaussichten bei Gericht } \\
\text { in bestimmten Fallkonstellationen. Auch Gerichtsurteile mit zivil- } \\
\text { rechtlicher Signalwirkung. Bsp.: OLG-Urteil über Renovierungspflichten von } \\
\text { Mietern. }\end{array}$ \\
\hline 742 & $\begin{array}{l}\text { Beratung Kriminalitäts- } \\
\text { prävention }\end{array}$ & $\begin{array}{l}\text { Individuelle Möglichkeiten, sich davor zu schützen, Opfer einer } \\
\text { Straftat zu werden (keine gesamtgesellschaftlichen Kriminalitätsprä- } \\
\text { ventionsbemühungen - } 460 \text { oder 104). }\end{array}$ \\
\hline 743 & $\begin{array}{l}\text { Finanzen, Versicherun- } \\
\text { gen (Beratung) }\end{array}$ & $\begin{array}{l}\text { Formen von Finanzanlage und privater Versicherungen, Chancen, } \\
\text { Risiken und Nutzen. Auf Endverbraucher bezogen. }\end{array}$ \\
\hline 751 & Haustiere & $\begin{array}{l}\text { Aufzucht, Pflege und Leben mit Haustieren, nicht individualisiert in } \\
\text { Human-Touch-Aufbereitung sondern mit vordergründigem Bera- } \\
\text { tungscharakter. }\end{array}$ \\
\hline 752 & Garten & Gartenpflege, -anlage, -unterhaltung und -gestaltung. \\
\hline 753 & Mode/Stil/Etikette & $\begin{array}{l}\text { Kleidung, Trends und Entwicklungen, Stoffe, Formen, Farben von } \\
\text { Kleidungsstücken. Fragen quasi-normhafter Umgangsformen im } \\
\text { Kontakt mit anderen Menschen. Bsp.: Herbstmode setzt vor allem auf } \\
\text { Brauntöne; Worauf ist bei Geschäftsessen zu achten? }\end{array}$ \\
\hline 754 & Kinder/Familie & $\begin{array}{l}\text { Erziehungsfragen, familiäres Zusammenleben, Organisation des } \\
\text { familiären Alltags. }\end{array}$ \\
\hline 759 & Sonstige Freizeitthemen & Freizeitgestaltung allgemein, in keine andere Kategorie passend. \\
\hline \multicolumn{3}{|c|}{ Service } \\
\hline 780 & Wetter & $\begin{array}{l}\text { Selbstständiger Wetterbericht (selbstständig heißt im Rahmen einer } \\
\text { Magazinsendung: einzelner Beitrag, der die aktuelle Wettervorhersage } \\
\text { zum Gegenstand hat; auf Sendungsebene: die Sendung ist der Wet- } \\
\text { terbericht und nicht in eine andere Sendung eingebettet). }\end{array}$ \\
\hline 799 & Sonstiges & $\begin{array}{l}\text { Sonstiges Thema der privaten Lebenswelt und Verbraucherthemen, } \\
\text { das nicht die Freizeitgestaltung betrifft (759) und in keine andere } \\
\text { Kategorie passt. }\end{array}$ \\
\hline
\end{tabular}


Kunst, Kultur - Als Abgrenzung zwischen klassischer Moderne und Zeitgenossenschaft gilt Ende des 2. WK. Literatur

\begin{tabular}{l|l|l}
\hline 811 & Klassische Literatur & Belletristik von vor 1880. \\
\hline 812 & Klassische Moderne & Belletristik der Zeit von 1870 bis 1945. \\
\hline 813 & $\begin{array}{l}\text { Zeitgenössische Litera- } \\
\text { tur }\end{array}$ & Belletristik seit 1945. \\
\hline 815 & Sachbuch & Nicht fiktionale Literatur. \\
\hline Oper, Operette & $\begin{array}{l}\text { Musikdramatisches Werk, entstanden vor 1880 (nicht auf aktuelle } \\
\text { Aufführung bezogen). }\end{array}$ \\
\hline 821 & Klassische & $\begin{array}{l}\text { Musikdramatisches Werk, entstanden nach } 1880 \text { und vor 1945 1880 } \\
\text { (nicht auf aktuelle Aufführung bezogen). }\end{array}$ \\
\hline 822 & Moderne & $\begin{array}{l}\text { Musikdramatisches Werk, entstanden nach 1945 (nicht auf aktuelle } \\
\text { Aufführung bezogen). }\end{array}$ \\
\hline \multicolumn{2}{l}{ Konzertmusik } \\
\hline
\end{tabular}

\begin{tabular}{l|l|l}
\hline \multicolumn{2}{l|}{ Konzertmusik } & $\begin{array}{l}\text { Musikalisches Werk von vor } 1880 \text { (nicht auf aktuelle Aufführung } \\
\text { oder Aufnahme bezogen). }\end{array}$ \\
\hline 831 & Klassisch & $\begin{array}{l}\text { Musikalisches Werk von nach 1880 und vor 1945 (nicht auf aktuelle } \\
\text { Aufführung oder Aufnahme bezogen). }\end{array}$ \\
\hline 832 & Moderne & $\begin{array}{l}\text { Musikalisches Werk nach 1945 entstanden (nicht auf aktuelle Auffüh- } \\
\text { rung oder Aufnahme bezogen). }\end{array}$ \\
\hline 840 & Zeitgenössisch & $\begin{array}{l}\text { Künstlerischer Bühnentanz zu Musikbegleitung, wobei sich die Auf- } \\
\text { führung auf die Musik und den Tanz beschränkt, also nicht etwa Teil } \\
\text { einer Opernaufführung ist. (Wird Ballettmusik konzertant zur Auf- } \\
\text { führung gebracht, dann 831 - 833). }\end{array}$ \\
\hline Theater & Klassische & $\begin{array}{l}\text { Sprechtheaterstück von vor 1880 (nicht auf aktuelle Aufführung } \\
\text { bezogen). }\end{array}$ \\
\hline 851 & Modern & $\begin{array}{l}\text { Sprechtheaterstück aus der Zeit von 1880 bis 1945 (nicht auf aktuelle } \\
\text { Aufführung bezogen). }\end{array}$ \\
\hline 853 & Zeitgenössisch & $\begin{array}{l}\text { Sprechtheaterstück von nach 1945 (nicht auf aktuelle Aufführung } \\
\text { bezogen). }\end{array}$ \\
\hline
\end{tabular}

\begin{tabular}{|c|c|c|}
\hline \multicolumn{3}{|c|}{ Bildende Kunst } \\
\hline 861 & Klassisch & $\begin{array}{l}\text { Werke und/oder deren Ausstellung aus dem Bereich der Bildhauerei, } \\
\text { Malerei und Grafik von vor } 1880 \text { (nicht auf aktuelle Ausstellung } \\
\text { bezogen). }\end{array}$ \\
\hline 862 & Modern & $\begin{array}{l}\text { Werke und/oder deren Ausstellung aus dem Bereich der Bildhauerei, } \\
\text { Malerei und Grafik die zwischen } 1880 \text { und } 1945 \text { entstanden sind. }\end{array}$ \\
\hline 863 & Zeitgenössisch & $\begin{array}{l}\text { Werke und/oder deren Ausstellung aus dem Bereich der Bildhauerei, } \\
\text { Malerei und Grafik die nach } 1945 \text { entstanden sind. }\end{array}$ \\
\hline 864 & Fotografie & $\begin{array}{l}\text { Künstlerische Fotografie und deren Ausstellung oder Verbreitung in } \\
\text { Bildbänden. }\end{array}$ \\
\hline 865 & Architektur & $\begin{array}{l}\text { Bauwerke, die mit einem künstlerischen Anspruch gestaltet sind } \\
\text { sowie Aspekte dieser Gestaltung. }\end{array}$ \\
\hline \multicolumn{3}{|l|}{ Film } \\
\hline 871 & „Klassiker““ & $\begin{array}{l}\text { Nicht aktuelle Filme, denen eine filmhistorische Bedeutung zu- } \\
\text { kommt. Diese resultiert entweder aus ihrer individuellen Gestaltung, } \\
\text { der Bedeutung des Regisseurs im Kontext seines Lebenswerkes oder } \\
\text { dem Auftritt eines oder mehrerer Schauspielerinnen und Schauspieler } \\
\text { im Kontext deren Lebenswerks. }\end{array}$ \\
\hline 872 & Aktuell & $\begin{array}{l}\text { Aktuelle Kino- oder Fernsehfilme. Der Aktualitätsaspekt ergibt sich } \\
\text { aus der entweder kurz bevorstehenden oder nur kurz zurückliegen- } \\
\text { den erstmaligen Ausstrahlung oder Kinovorführung in Deutschland, } \\
\text { Österreich oder einem anderen Land (Berichtsanlass kann also so- } \\
\text { wohl die „Weltpremiere“ sein oder ein zeitlich später liegender Kino- } \\
\text { start in Deutschland oder Österreich). }\end{array}$ \\
\hline 881 & Popmusik & Populäre Unterhaltungsmusik. \\
\hline 882 & Werbung & $\begin{array}{l}\text { Wenn nicht als Wirtschaftsthema sondern etwa Auszeichnung für } \\
\text { Werbespots bzw. Dreharbeiten an Werbespots etc. }\end{array}$ \\
\hline 899 & Sonstiges & $\begin{array}{l}\text { Themen der Kunst und Kultur (Darbietung, Ausübung, Diskussion) } \\
\text { die in sonst keine Kategorie passen. }\end{array}$ \\
\hline
\end{tabular}


\begin{tabular}{l|l} 
Code & Bezeichnung \\
\hline
\end{tabular}

Erläuterung (Welche Themen fallen in diese Kategorie?)

Geschichte (Historie) - Abgegrenzt von Vergangenheitsaufarbeitung. Hier nur Darstellung historischer Ereignisse. Dass diese der Aufarbeitung auch dienen, steht im Hintergrund, wenn es nicht um die tatsächliche aktuelle Auseinandersetzung mit der Vergangenheit geht.

\begin{tabular}{|c|c|c|}
\hline 901 & Prähistorisch & $\begin{array}{l}\text { Alle erdgeschichtlichen Epochen vor der Entstehung von Zivilisatio- } \\
\text { nen. }\end{array}$ \\
\hline 902 & Antike & $\begin{array}{l}\text { Vorgänge, Ereignisse und Zusammenhänge in Zivilisationen des } \\
\text { Altertums im Mittelmeerraum. }\end{array}$ \\
\hline 903 & Mittelalter & $\begin{array}{l}\text { Vorgänge, Ereignisse und Zusammenhänge im Europa des 6. bis } 15 . \\
\text { Jahrhunderts. }\end{array}$ \\
\hline 904 & Reformationszeit & $\begin{array}{l}\text { Vorgänge und Ereignisse in Europa in zeitlichem Zusammenhang } \\
\text { mit den Kirchenreformationen zwischen } 1517 \text { und } 1648 .\end{array}$ \\
\hline 905 & 17. Jahrhundert & \multirow{3}{*}{ Wenn nicht 904, $911-914}$. \\
\hline 906 & 18. Jahrhundert & \\
\hline 910 & 19. Jahrhundert & \\
\hline 911 & Vormärz & $\begin{array}{l}\text { Vorgänge, Zusammenhänge und Ereignisse in Europa in der Zeit } \\
\text { zwischen Wiener Kongress (1815) und (einschließlich) Märzrevoluti- } \\
\text { on } 1848 .\end{array}$ \\
\hline 912 & Deutsches Kaiserreich & $\begin{array}{l}\text { Vorgänge und Ereignisse im deutschen Kaiserreich von } 1871 \text { bis } \\
1914 \text { und im Zusammenhang mit seiner Gründung. Werden Ent- } \\
\text { wicklungen dargestellt, die explizit einen Zusammenhang zum ersten } \\
\text { Weltkrieg herstellen (Ursachen u. ä.) dann: 621, eventuell auch Dop- } \\
\text { pelvercodung. }\end{array}$ \\
\hline 913 & Königreich Bayern & Vorgänge und Ereignisse im Königreich Bayern ab 1806 bis 1871. \\
\hline 914 & k.u.k.-Monarchie & $\begin{array}{l}\text { Vorgänge und Ereignisse in der habsburgischen Doppelmonarchie } \\
1848 \text { bis } 1914 \text { (beginnend also nicht mit dem österreichisch- } \\
\text { ungarischen Ausgleich, sondern schon 1848, wegen des Beginns der } \\
\text { Regentschaft Franz Joseph I.). Werden Entwicklungen dargestellt, die } \\
\text { explizit einen Zusammenhang zum ersten Weltkrieg herstellen (Ursa- } \\
\text { chen u. ä.) dann: 621, eventuell auch Doppelvercodung. }\end{array}$ \\
\hline 920 & 20. Jahrhundert & $\begin{array}{l}\text { Ereignisse und Vorgänge im 20. Jahrhundert, die nicht in direktem } \\
\text { Zusammenhang mit solchen Begebenheiten stehen, die in eine der } \\
\text { anderen Kategorien dieser Zeitspanne passen. }\end{array}$ \\
\hline 921 & 1. Weltkrieg & $\begin{array}{l}\text { Ereignisse innerhalb und in direktem Zusammenhang mit dem } 1 . \\
\text { Weltkrieg. }\end{array}$ \\
\hline 922 & Weimarer Republik (D) & Deutsches Reich in der demokratischen Phase von 1918 bis 1933. \\
\hline 923 & Ständestaat $(\ddot{O})$ & $\begin{array}{l}\text { Zeit des Austrofaschismus: Ereignisse und Vorgänge in Österreich } \\
\text { zwischen } 1934 \text { und } 1938 .\end{array}$ \\
\hline 933 & Drittes Reich & $\begin{array}{l}\text { Ereignisse und Vorgänge in Deutschland zwischen } 1933 \text { und } 1945 . \\
\text { Hierzu zählt auch die systematische Vernichtung der Juden durch die } \\
\text { Nationalsozialisten. Stehen Kriegshandlungen und deren Folgen im } \\
\text { Vordergrund: } 934 \text {. }\end{array}$ \\
\hline 934 & 2. Weltkrieg & $\begin{array}{l}\text { Ereignisse innerhalb und in direktem Zusammenhang mit dem } 1 . \\
\text { Weltkrieg. }\end{array}$ \\
\hline 941 & Nachkriegszeit & $\begin{array}{l}1945 \text { bis } 1949 \text { (unmittelbare Nachkriegszeit, Besatzungszeit bis zum } \\
\text { Inkrafttreten des Grundgesetzes bzw. der Verfassung der DDR). }\end{array}$ \\
\hline 950 & $\begin{array}{l}\text { Adenauer-Ära, Wirt- } \\
\text { schaftswunder }\end{array}$ & Zeit der Regierungen Adenauer, Erhard, Kiesinger. \\
\hline 961 & $1968 \mathrm{er}$ & Zeit der Studentenunruhen und ihrer politischen Auswirkungen. \\
\hline 962 & Brandt- ̈̈ra & $\begin{array}{l}\text { Zeit der Regierung Willy Brandts, sofern nicht unter } 961 \text { fallende } \\
\text { Ereignisse im Vordergrund stehen. }\end{array}$ \\
\hline 963 & Deutscher Herbst & $\begin{array}{l}\text { Zeit des RAF-Terrorismus } 1977 / 78 \text { und darüber hinaus, sofern in- } \\
\text { haltlich eine eindeutige Verbindung zu den terroristischen Aktivitäten } \\
\text { der RAF hergestellt wird. }\end{array}$ \\
\hline 964 & Helmut-Schmidt-Ära & $\begin{array}{l}\text { Zeit der Regierung Willy Brandts, sofern nicht unter } 964 \text { fallende } \\
\text { Ereignisse im Vordergrund stehen. }\end{array}$ \\
\hline 970 & Helmut Kohl & $\begin{array}{l}\text { Regierungszeit Helmut Kohls ohne Bezug zur deutschen Wiederver- } \\
\text { einigung. }\end{array}$ \\
\hline 971 & Deutsche Einheit & $\begin{array}{l}\text { Ereignisse und Vorgänge im direkten Zusammenhang mit der Verei- } \\
\text { nigung von BRD und DDR. Vor allem darauf zielendes politisches } \\
\text { Handeln. }\end{array}$ \\
\hline 980 & DDR & Ereignisse und Vorgänge in der DDR, sofern sie inhaltlich nicht in \\
\hline
\end{tabular}




\begin{tabular}{l|l|l} 
Code & Bezeichnung & Erläuterung Welche Themen fallen in diese Kategorie?) \\
\hline 981 & Ulbricht & $\begin{array}{l}\text { die Nähe der friedlichen Revolution und der deutschen Vereinigung } \\
\text { gestellt werden und nicht explizit das Regierungshandeln Walter } \\
\text { Ulbrichts und Erich Honeckers betreffen. }\end{array}$ \\
\hline 982 & Honecker & $\begin{array}{l}\text { Regierungszeit Walter Ulbrichts, sofern dessen politisches Handeln } \\
\text { thematisiert wird (also nicht nur zeitlich gesehen). }\end{array}$ \\
\hline 983 & Wende & $\begin{array}{l}\text { Regierungszeit Erich Honeckers, sofern dessen politisches Handeln } \\
\text { thematisiert wird (also nicht nur zeitlich gesehen). }\end{array}$ \\
\hline 999 & $\begin{array}{l}\text { Sonstige historische } \\
\text { Themen }\end{array}$ & $\begin{array}{l}\text { Ereignisse, Vorgänge und Zusammenhänge rund um den politischen } \\
\text { Umsturz in der DDR, beginnend mit den Kommunalwahlen 1989 } \\
\text { und den öffentlich gemachten Zweifeln an deren Ergebnissen durch } \\
\text { die Oppositionsbewegung. }\end{array}$ \\
\hline $\begin{array}{l}\text { Historische Vorgänge, Ereignisse und Zusammenhänge, die in keine } \\
\text { andere Kategorie passen. }\end{array}$
\end{tabular}

\subsection{Reliabilitätswerte}

Die hier dargestellten Reliabilitätswerte sind die Werte aus allen über die Dauer der Vercodung stattgefundenen Kontrollerhebungen zur Messung der Intracoderreliabilität. Es handelt sich also nicht um Durchschnittswerte. Vielmehr wurden alle Untersuchungseinheiten der jeweiligen regulären Erstcodierungen, die zur Kontrolle zufällig ausgewählt wurden, den entsprechenden Kontrollcodierungen gegenübergestellt.

Tabelle 19: Intracoderreliabilitätswerte aller Variablen der Inhaltsanalyse

\begin{tabular}{|c|c|c|}
\hline Variable & Beschreibung & Holsti-Koeffizient \\
\hline \multicolumn{3}{|c|}{ Technische Variablen } \\
\hline V1 & Datensatz-Nr. & Automatisch generiert \\
\hline V2 & Programm & 1 \\
\hline V3 & Sendedatum & 1 \\
\hline V4 & Wochentag & 1 \\
\hline V5 & UE-Anfang & entfällt \\
\hline V6 & UE-Ende & entfällt \\
\hline V7 & UE-Dauer 330 & .888 \\
\hline V8 & Sendungsname & 1 \\
\hline V9 & Regionale Auseinanderschaltung & 1 \\
\hline V10 & Ausstrahlung & 1 \\
\hline \multicolumn{3}{|c|}{ Variablen Sendungsebene } \\
\hline V11 & Programmfläche & 1 \\
\hline V12 & Fiktionale Sendeform & 1 \\
\hline V13 & Nationalität Protagonist & 1 \\
\hline V14 & Geschehensort & 1 \\
\hline V15 & Charakterisierung Geschehensort & 1 \\
\hline V16 & Geschehenszeit & 1 \\
\hline V17 & Nicht fiktionale Sendungsformen & .974 \\
\hline V18 & Thema der Sendung & .909 \\
\hline V19 & Weiteres Thema der Sendung & .875 \\
\hline
\end{tabular}

330 Abweichungen von bis zu drei Sekunden gelten als Übereinstimmung. Diese Abweichungstoleranz ergibt sich aus der definierten Mindestdauer für eine Untersuchungseinheit. 


\begin{tabular}{|c|c|c|}
\hline Variable & Beschreibung & Holsti-Koeffizient \\
\hline V20 & Thema der Sendung offen formuliert & entfällt 331 \\
\hline V21 & Produktionsland & 1 \\
\hline V22 & Produktionsjahr & 1 \\
\hline \multicolumn{3}{|c|}{ Variablen Magazinebene } \\
\hline V23 & Magazintyp & .835 \\
\hline V24 & Magazinbestandteil & .988 \\
\hline V25 & Reihenfolge & Automatisch generiert \\
\hline V26 & Gekennzeichnete Wiederholung & 1 \\
\hline V27 & Darstellungsform & .984 \\
\hline V27.1 & Funktion & .984 \\
\hline V28 & Thema des Beitrags & .911 \\
\hline V29 & Weiteres Thema des Beitrags & .75 \\
\hline V30 & Thema des Beitrags offen formuliert & entfällt \\
\hline V31 & Wirtschaftssektor & .9 \\
\hline V32 & Fußball-Liga & .9 \\
\hline V33 & Aktualität & .962 \\
\hline V34 & Geschehensdauer & .919 \\
\hline V35 & Ereignisraum & .984 \\
\hline$V 36$ & Verortung Ereignisraum Bundesland & \\
\hline V36.1 & $\begin{array}{l}\text { Verortung Ereignisraum Bundesland in Deutsch- } \\
\text { land } 332\end{array}$ & .998 \\
\hline V36.2 & $\begin{array}{l}\text { Verortung Ereignisraum Bundesland in Öster- } \\
\text { reich } 333\end{array}$ & 1 \\
\hline$V 37$ & Verortung Ereignisraum Ort & \\
\hline V37.1 & Verortung Ereignisraum Ort in Deutschland 334 & .969 \\
\hline V37.2 & Verortung Ereignisraum Ort in Österreich ${ }^{335}$ & .916 \\
\hline V38 & Bezugsraum & 1 \\
\hline V39 & Verortung Bezugsraum Bundesland & \\
\hline V39.1 & $\begin{array}{l}\text { Verortung Bezugsraum Bundesland in Deutsch- } \\
\text { land }{ }^{336}\end{array}$ & 1 \\
\hline V39.2 & $\begin{array}{l}\text { Verortung Bezugsraum Bundesland in Öster- } \\
\text { reich }^{337}\end{array}$ & 1 \\
\hline$V 40$ & Verortung Bezugsraum Ort & \\
\hline V40.1 & Verortung Bezugsraum Ort in Deutschland 338 & .971 \\
\hline $\bar{V} 40.2$ & Verortung Bezugsraum Ort in Österreich 339 & .914 \\
\hline V41 & Regionalität & .935 \\
\hline V42 & Ereignisbezug & .919 \\
\hline V43 & Personalisierung & .887 \\
\hline V44 & Konfliktbetonung & .919 \\
\hline
\end{tabular}

331 Offene Formulierungen wurden nicht auf Reliabilität getestet. Sie fließen nicht in die Auswertung ein, sondern dienen der internen Zuordnung. Zudem konnte der Codierer auf eine sich selbst ergänzende Liste bereits bestehender Formulierungen zurückgreifen, was eine Übereinstimmungsprüfung obsolet macht.

332 Zusammengefasst aus V36.1.1 - V36.1.3.

333 Zusammengefasst aus V36.2.1 - V26.2.3.

334 Zusammengefasst aus V36.1.1 - V36.1.6.

335 Zusammengefasst aus V36.2.1 - V36.2.6.

336 Zusammengefasst aus V39.1.1 - V39.1.3.

337 Zusammengefasst aus V39.2.1 - V39.2.3.

338 Zusammengefasst aus V40.1.1 - V40.1.6.

339 Zusammengefasst aus V40.2.1 - V40.2.6. 


\begin{tabular}{l|l|r} 
Variable & Beschreibung & Holsti-Koeffizient \\
\hline Akteursvariablen & \\
\hline V45 & Anzahl der Akteurinnen und Akteure in UE & .968 \\
\hline V45.1 & Geschlecht & .995 \\
\hline V45.2 & Altersgruppe & .943 \\
\hline V45.3 & Personen-Orts-Bezug & .913 \\
\hline V45.4 & Bereich & .886 \\
\hline V45.5 & Politische Partei & .997 \\
\hline V45.6 & Art der Äußerung & .953 \\
\hline V45.7 & Anonymisierung & .997 \\
\hline V45.8 & Präsentationskontext & .893 \\
\hline V45.9 & Berufliche Umgebung: Wirtschaftssektor & .941 \\
\hline V45.10 & Dialektausprägung & .931 \\
\hline V45.11 & Räumliche Kohärenz & .928
\end{tabular}

${ }^{340}$ Die hier ausgewiesenen Reliabilitätskoeffizienten basieren auf der Zusammenfassung der Vercodung der jeweiligen Kategorien für alle Akteurinnen und Akteure (mit Ausnahme von V45, die eine reine Zählung aller vorkommenden Personen darstellt). 


\subsection{Zusätzliche Abbildungen}

Im Folgenden finden sich Abbildungen, auf die in der Auswertung nur am Rande Bezug genommen wird. Zu Gunsten einer besseren Übersichtlichkeit des Textteils werden sie deshalb hier im Anhang wiedergegeben.

Programmleistung im Informationsprogramm

Abbildung 83: Programmleistung im Informationsprogramm der einzelnen Sender .

Basis: Programm ohne Werbung, Sponsoring, selbstreferenzielle Flächen und Regionalfenster in hh:mm:ss ORF2: 55:27:23, ZDF: 56:19:07, BR: 70:44:19, MDR: 66:22:04

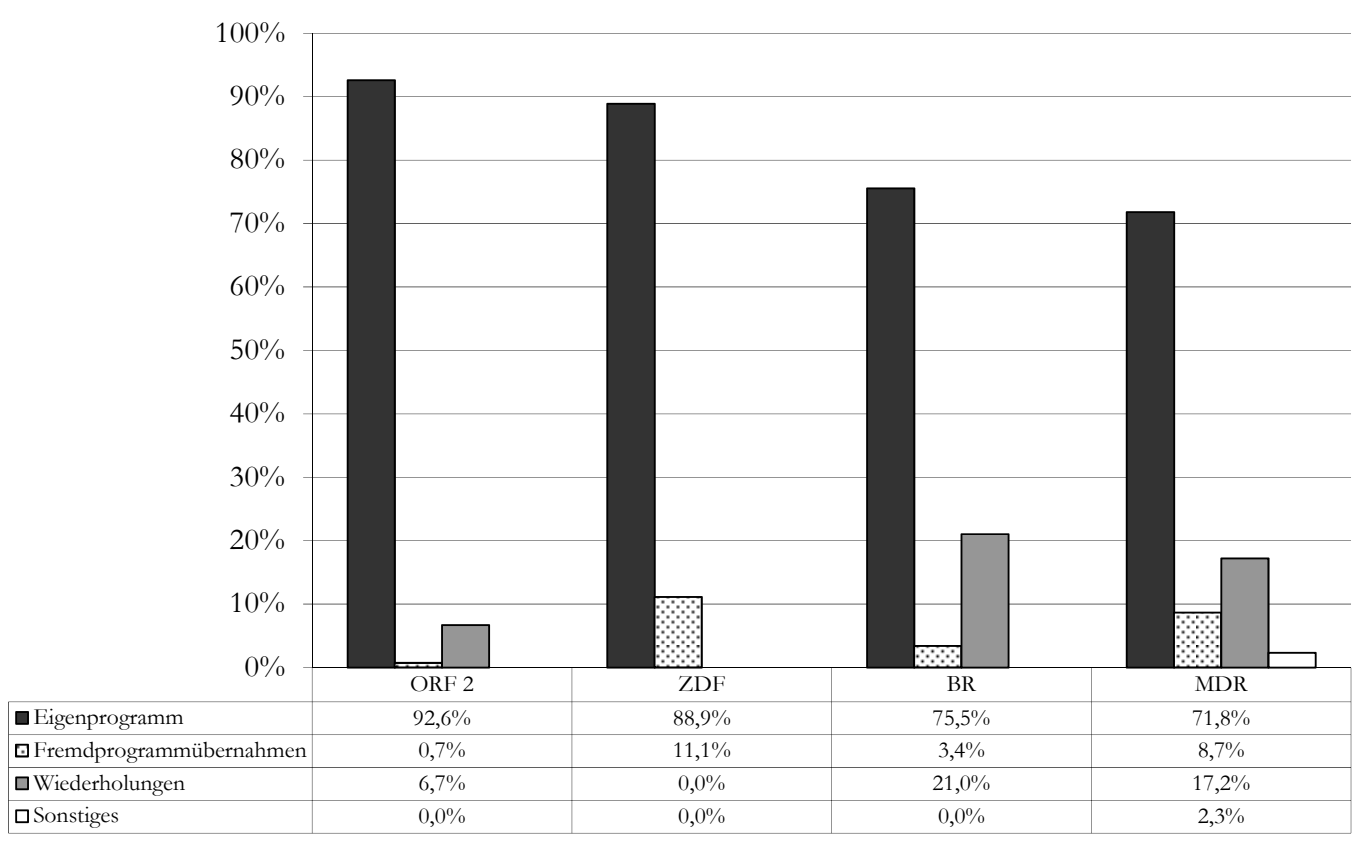


Detaillierter Ereignisbezug der Berichterstattung

\section{Abbildung 84: Detaillierter Ereignisbezug der Berichterstattung}

Basis: alle Magazinbeiträge in hh:mm:ss - ORF 2: 25:02:33, ZDF: 33:36:49, BR: 25:54:25, MDR: 32:31:20

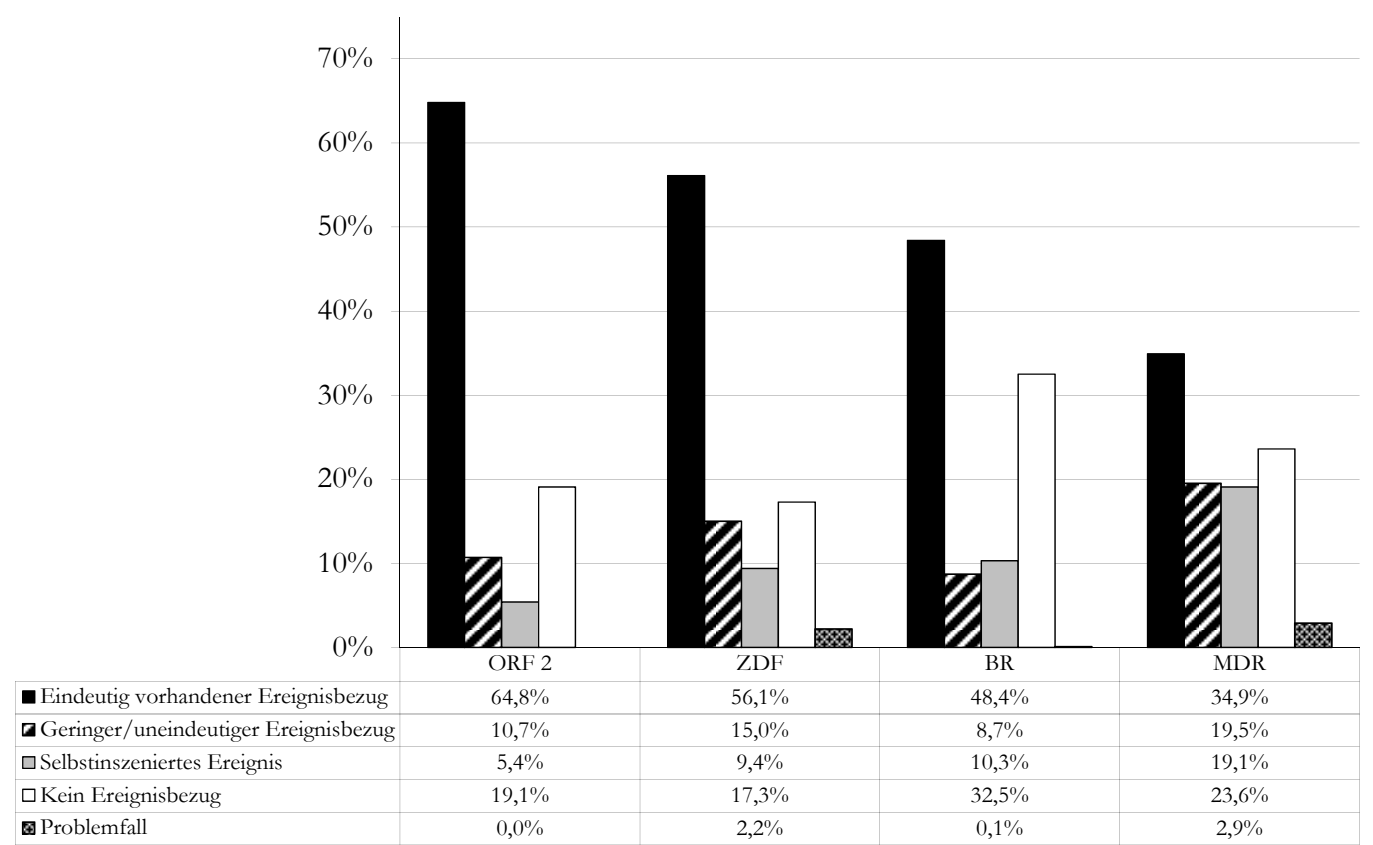


Entropiewerte der Themenverteilung ohne Berücksichtigung von Nachrichtenmagazinen

Abbildung 85: Vergleich relative Entropie der Themenverteilung in allen Magazinen außer Nachrichtenmagazine der untersuchten Sender auf Ebene aller möglichen Themen

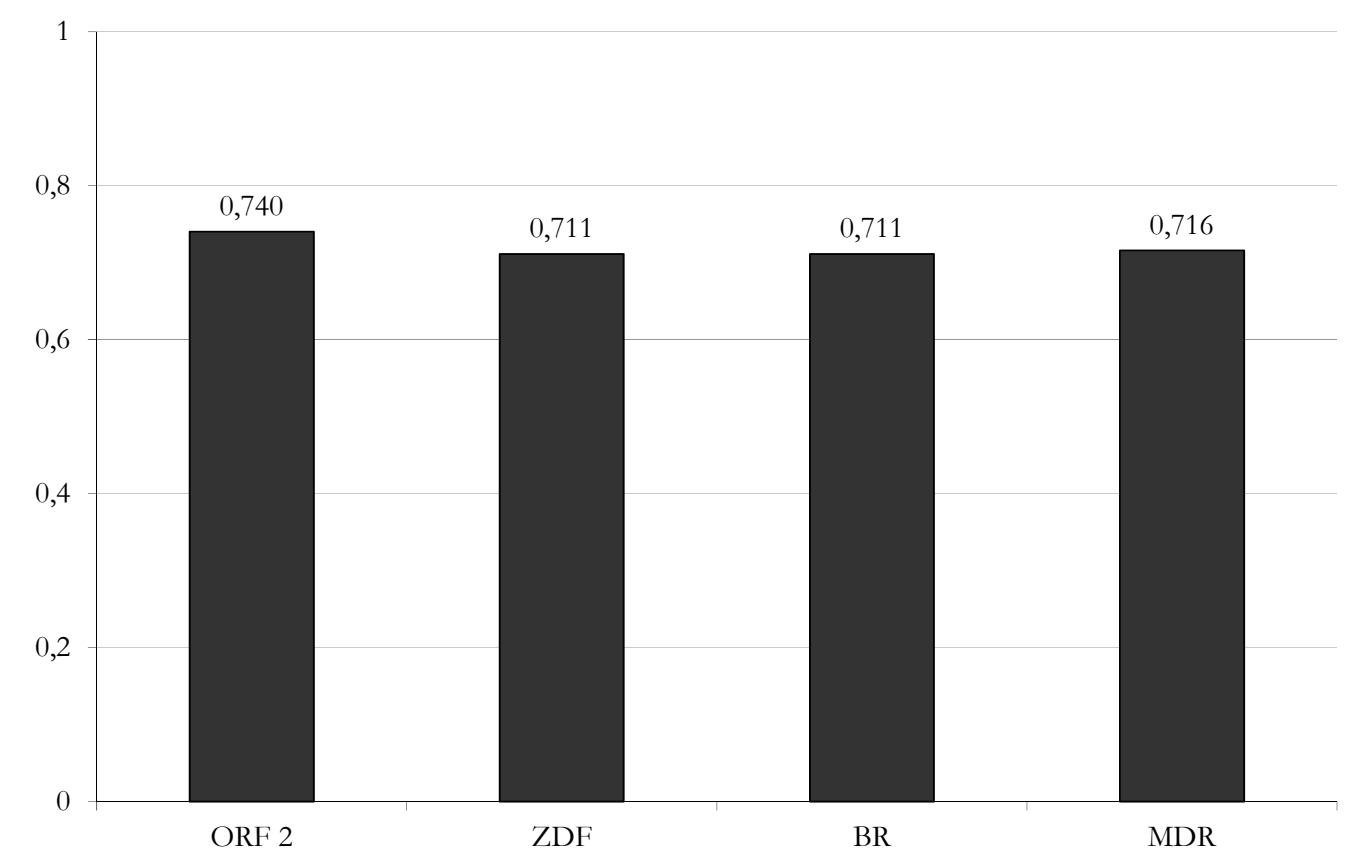

Abbildung 86: Vergleich relative Entropie der Themenverteilung in allen Magazinen außer Nachrichtenmagazinen der untersuchten Sender auf Ebene aggregierter Themenbereiche

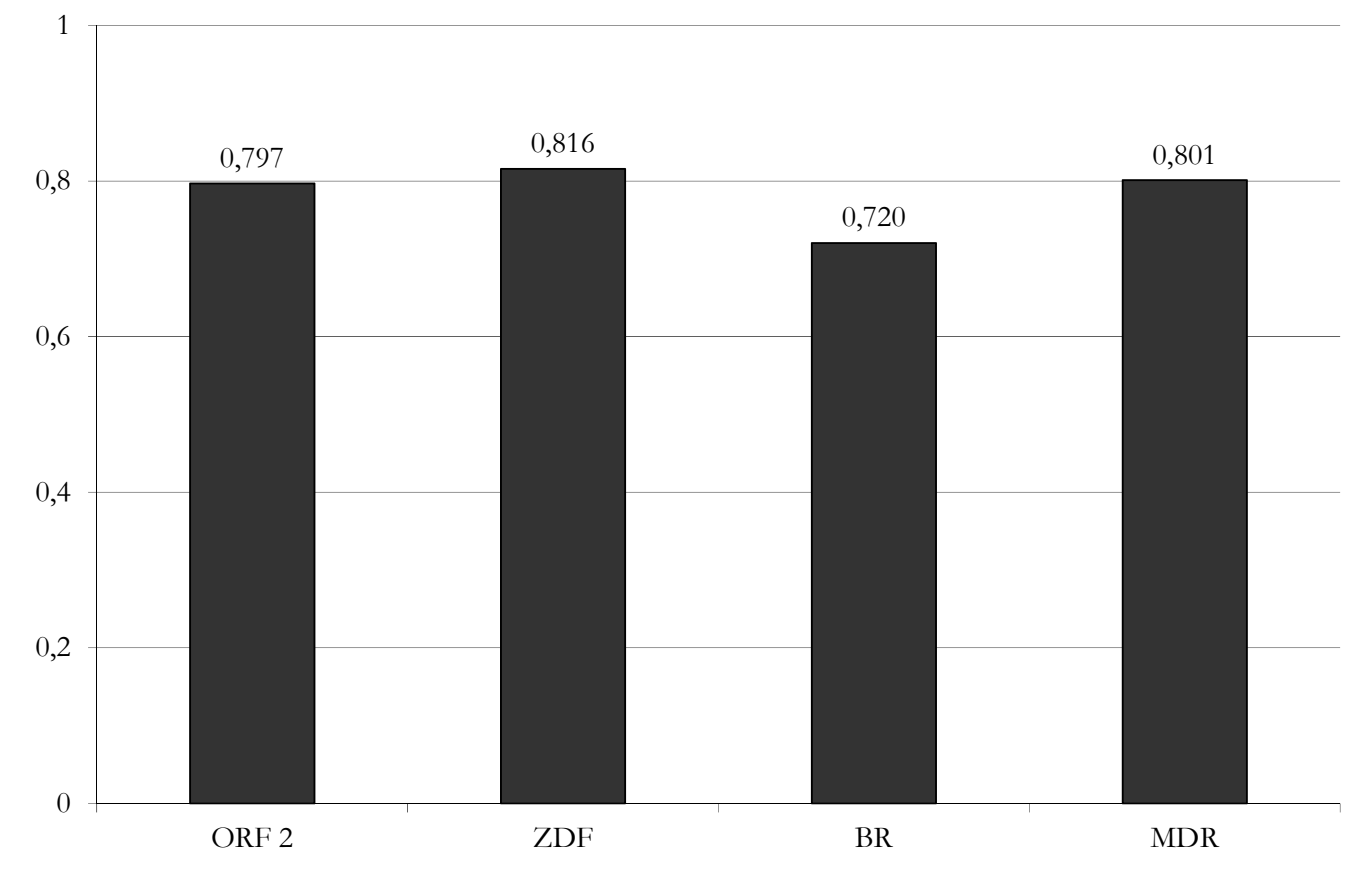


Verteilung der Wirtschaftsberichterstattung auf Wirtschaftssektoren ohne Berücksichtigung von Wirtschaftspolitikberichterstattung

Abbildung 87: ORF 2 - Wirtschaftsberichterstattung ohne Wirtschaftspolitik, Anteile der einzelnen Wirtschaftssektoren an der Sendezeit

Basis: Magazinbeiträge mit Thema Wirtschaft in hh:mm:ss $=$ 02:00:38

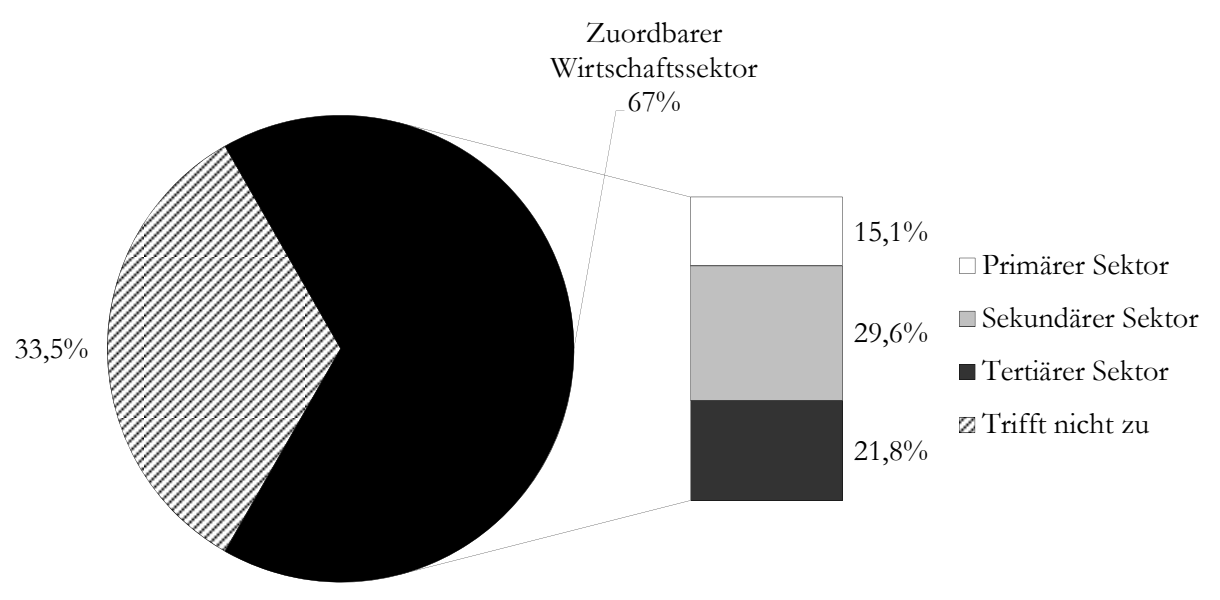


Abbildung 88: ZDF - Wirtschaftsberichterstattung ohne Wirtschaftspolitik, Anteile der einzelnen Wirtschaftssektoren an der Sendezeit

Basis: Magazinbeiträge mit Thema Wirtschaft in hh:mm:ss = 04:13:41

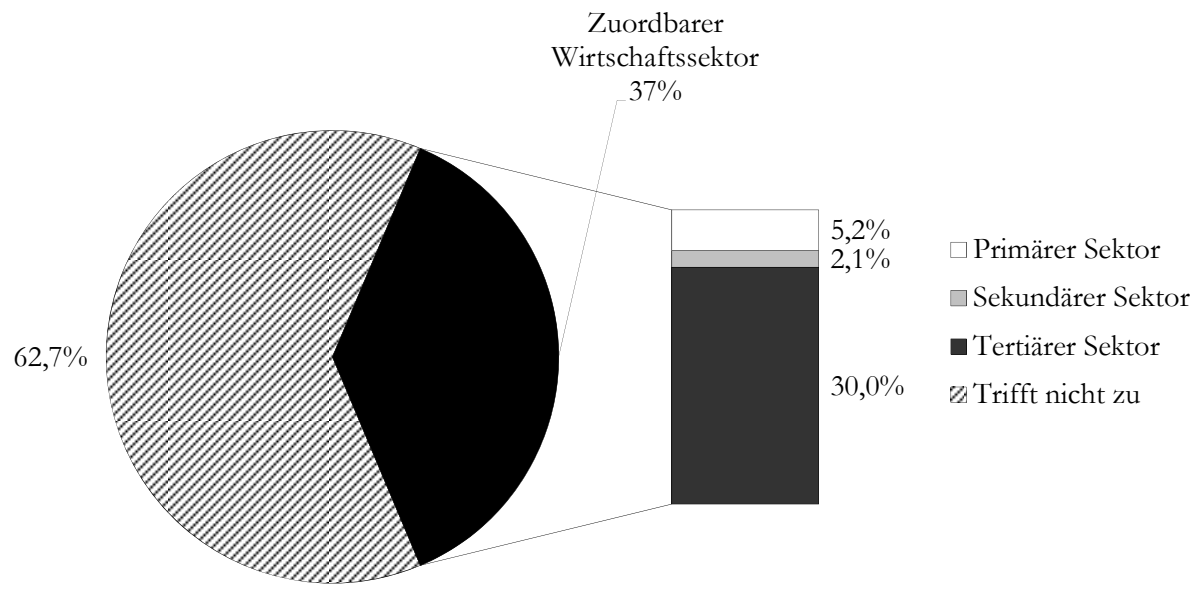

Abbildung 89: BR - Wirtschaftsberichterstattung ohne Wirtschaftspolitik, Anteile der einzelnen Wirtschaftssektoren an der Sendezeit

Basis: Magazinbeiträge mit Thema Wirtschaft in hh:mm:ss = 01:38:19

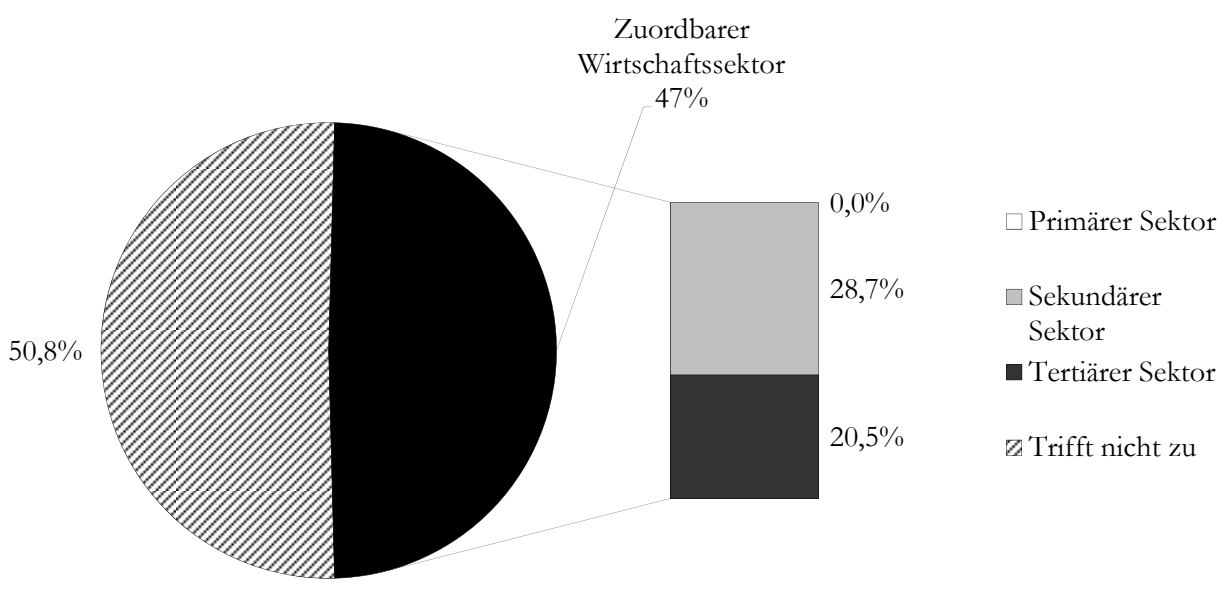


Abbildung 90: MDR - Wirtschaftsberichterstattung ohne Wirtschaftspolitik, Anteile der einzelnen Wirtschaftssektoren an der Sendezeit

Basis: Magazinbeiträge mit Thema Wirtschaft in hh:mm:ss $=01: 14: 48$

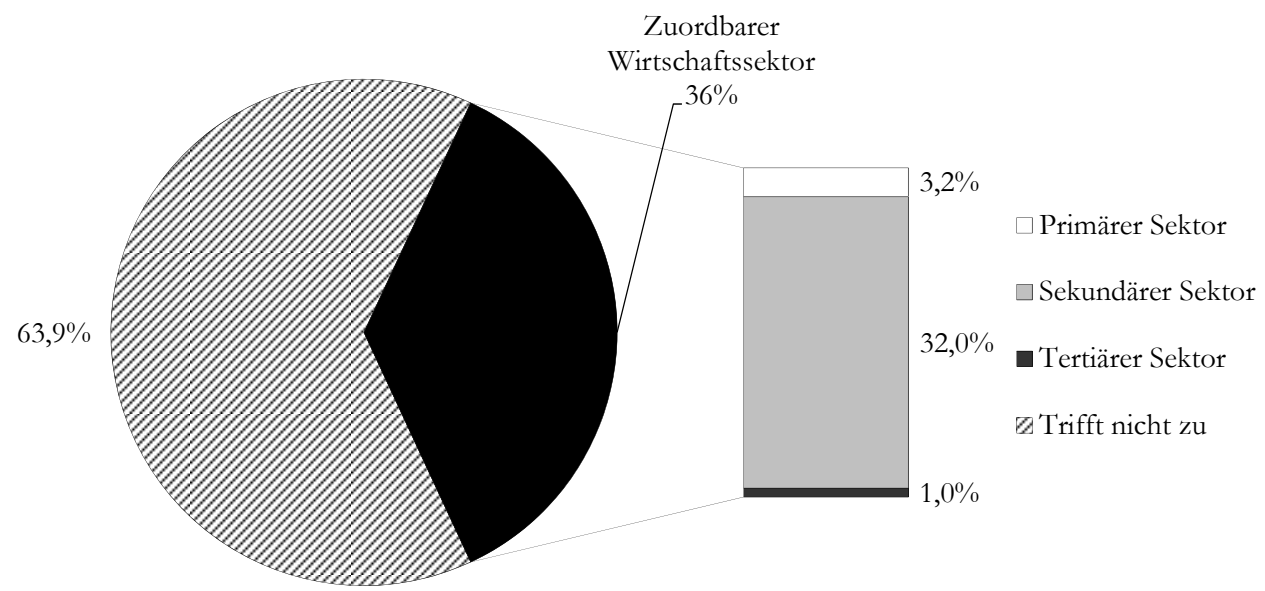

\subsection{Zusätzliche Tabellen}

Im Folgenden finden sich Tabellen, auf die in der Auswertung nur am Rande Bezug genommen wird bzw. die auf Grund ihrer Größe den Textfluss zu sehr gestört hätten.

Tabelle 20: Ereignisbezug der Regionalberichterstattung

Basis: Magazinbeiträge mit im Kern regionaler Berichterstattung

\begin{tabular}{l|c|c|c|c|c|c|c|c} 
& \multicolumn{2}{|c|}{ ORF 2 } & \multicolumn{2}{c|}{ ZDF } & \multicolumn{2}{c}{ BR } \\
\hline & $\begin{array}{c}\text { Umfang } \\
\text { (hh:mm:ss) }\end{array}$ & Anteil & $\begin{array}{c}\text { Umfang } \\
\text { (hh:mm:ss) }\end{array}$ & Anteil & $\begin{array}{c}\text { Umfang } \\
\text { (hh:mm:ss) }\end{array}$ & Anteil & $\begin{array}{c}\text { Umfang } \\
\text { (hh:mm:ss) }\end{array}$ & Anteil \\
\hline $\begin{array}{l}\text { Ereignis- } \\
\text { bezug } \\
\text { vorhanden }\end{array}$ & $05: 49: 07$ & $79,87 \%$ & $08: 31: 58$ & $80,93 \%$ & $09: 18: 05$ & $71,09 \%$ & $09: 20: 36$ & $72,15 \%$ \\
\hline $\begin{array}{l}\text { Kein Er- } \\
\text { eignis- } \\
\text { bezug } \\
\text { vorhanden }\end{array}$ & $01: 27: 59$ & $20,13 \%$ & $02: 00: 37$ & $19,07 \%$ & $03: 46: 56$ & $28,91 \%$ & $03: 36: 26$ & $27,85 \%$ \\
\hline $\begin{array}{l}\text { Sonstige/ } \\
\text { unent- } \\
\text { scheidbar }\end{array}$ & $00: 00: 00$ & $0,00 \%$ & $00: 00: 00$ & $0,00 \%$ & $00: 00: 00$ & $0,00 \%$ & $00: 00: 00$ & $0,00 \%$ \\
\hline $\begin{array}{l}\text { Gesamt } \\
\mathbf{n e n a m}\end{array}$ & $\mathbf{0 7 : 1 7 : 0 6}$ & $\mathbf{1 0 0 , 0 0 \%}$ & $\mathbf{1 0 : 3 2 : 3 5}$ & $\mathbf{1 0 0 , 0 0 \%}$ & $\mathbf{1 3 : 0 5 : 0 1}$ & $\mathbf{1 0 0 , 0 0 \%}$ & $\mathbf{1 2 : 5 7 : 0 2}$ & $\mathbf{1 0 0 , 0 0 \%}$
\end{tabular}


Tabelle 21: Kulturberichterstattung in Magazinen, Umfang und Anteile

\begin{tabular}{|c|c|c|c|c|c|c|c|c|}
\hline . & \multicolumn{2}{|c|}{ ORF 2} & \multicolumn{2}{|c|}{ ZDF } & \multicolumn{2}{|c|}{ BR } & \multicolumn{2}{|c|}{ MDR } \\
\hline Thema & $\begin{array}{l}\text { Umfang } \\
\text { (hh:mm:ss) }\end{array}$ & Anteil & $\begin{array}{l}\text { Umfang } \\
\text { (hh:mm:ss) }\end{array}$ & Anteil & $\begin{array}{c}\text { Umfang } \\
\text { (hh:mm:ss) }\end{array}$ & Anteil & $\begin{array}{l}\text { Umfang } \\
\text { (hh:mm:ss) }\end{array}$ & Anteil \\
\hline $\begin{array}{l}\text { Literatur } \\
\text { allgemein }\end{array}$ & 0:00:00 & $0,00 \%$ & 0:00:00 & $0,00 \%$ & 0:02:20 & $2,33 \%$ & 0:00:00 & $0,00 \%$ \\
\hline $\begin{array}{l}\text { Literatur } \\
\text { klassisch }\end{array}$ & 0:00:00 & $0,00 \%$ & 0:00:00 & $0,00 \%$ & 0:00:00 & $0,00 \%$ & 0:00:00 & $0,00 \%$ \\
\hline $\begin{array}{l}\text { Literatur } \\
\text { klassische } \\
\text { Moderne }\end{array}$ & 0:00:00 & $0,00 \%$ & 0:00:00 & $0,00 \%$ & 0:00:00 & $0,00 \%$ & 0:00:00 & $0,00 \%$ \\
\hline $\begin{array}{l}\text { Literatur } \\
\text { zeit- } \\
\text { genössisch }\end{array}$ & $0: 10: 52$ & $7,69 \%$ & 0:06:55 & $9,39 \%$ & $0: 11: 19$ & $11,32 \%$ & 0:00:00 & $0,00 \%$ \\
\hline Sachbuch & 0:08:21 & $5,92 \%$ & 0:01:20 & $1,82 \%$ & 0:05:35 & $5,58 \%$ & $0: 01: 22$ & $1,77 \%$ \\
\hline $\begin{array}{l}\text { Oper/ } \\
\text { Operette } \\
\text { klassisch }\end{array}$ & 0:01:39 & $1,17 \%$ & 0:00:00 & $0,00 \%$ & 0:00:00 & $0,00 \%$ & $0: 05: 22$ & $6,93 \%$ \\
\hline $\begin{array}{l}\text { Oper/ } \\
\text { Operette } \\
\text { moderne }\end{array}$ & 0:00:00 & $0,00 \%$ & 0:00:00 & $0,00 \%$ & 0:00:00 & $0,00 \%$ & 0:00:00 & $0,00 \%$ \\
\hline $\begin{array}{l}\text { Oper/ } \\
\text { Operette } \\
\text { zeit- } \\
\text { genössisch }\end{array}$ & 0:00:00 & $0,00 \%$ & 0:00:00 & $0,00 \%$ & 0:00:00 & $0,00 \%$ & 0:00:00 & $0,00 \%$ \\
\hline $\begin{array}{l}\text { Konzert- } \\
\text { musik } \\
\text { klassisch }\end{array}$ & 0:00:00 & $0,00 \%$ & 0:01:17 & $1,74 \%$ & 0:00:00 & $0,00 \%$ & $0: 00: 25$ & $0,54 \%$ \\
\hline $\begin{array}{l}\text { Konzert- } \\
\text { musik } \\
\text { Moderne }\end{array}$ & 0:00:00 & $0,00 \%$ & 0:00:00 & $0,00 \%$ & 0:00:00 & $0,00 \%$ & 0:00:00 & $0,00 \%$ \\
\hline $\begin{array}{l}\text { Konzert- } \\
\text { musik } \\
\text { zeitgenös- } \\
\text { sisch } \\
\end{array}$ & 0:00:00 & $0,00 \%$ & 0:00:00 & $0,00 \%$ & 0:00:00 & $0,00 \%$ & 0:00:00 & $0,00 \%$ \\
\hline Ballett & 0:00:00 & $0,00 \%$ & 0:02:59 & $4,05 \%$ & 0:00:00 & $0,00 \%$ & 0:00:00 & $0,00 \%$ \\
\hline $\begin{array}{l}\text { Theater } \\
\text { klassisch }\end{array}$ & 0:00:00 & $0,00 \%$ & 0:00:00 & $0,00 \%$ & 0:00:00 & $0,00 \%$ & 0:00:00 & $0,00 \%$ \\
\hline $\begin{array}{l}\text { Theater } \\
\text { modern }\end{array}$ & 0:03:39 & $2,58 \%$ & 0:00:00 & $0,00 \%$ & $0: 00: 00$ & $0,00 \%$ & 0:00:00 & $0,00 \%$ \\
\hline $\begin{array}{l}\text { Theater } \\
\text { zeitgenös- } \\
\text { sisch }\end{array}$ & $0: 17: 39$ & $12,49 \%$ & 0:00:00 & $0,00 \%$ & 0:01:56 & $1,93 \%$ & 0:00:00 & $0,00 \%$ \\
\hline $\begin{array}{l}\text { Bildende } \\
\text { Kunst } \\
\text { klassisch }\end{array}$ & 0:00:00 & $0,00 \%$ & 0:01:26 & $1,95 \%$ & 0:00:00 & $0,00 \%$ & 0:01:30 & $1,95 \%$ \\
\hline $\begin{array}{l}\text { Bildende } \\
\text { Kunst } \\
\text { modern }\end{array}$ & 0:02:50 & $2,01 \%$ & 0:07:58 & $10,81 \%$ & $0: 12: 52$ & $12,85 \%$ & 0:00:00 & $0,00 \%$ \\
\hline $\begin{array}{l}\text { Bildende } \\
\text { Kunst } \\
\text { zeitgenös- } \\
\text { sisch } \\
\end{array}$ & $0: 20: 04$ & $14,21 \%$ & 0:08:22 & $11,36 \%$ & 0:02:06 & $2,10 \%$ & 0:00:00 & $0,00 \%$ \\
\hline Fotografie & $0: 08: 56$ & $6,33 \%$ & 0:00:40 & $0,91 \%$ & 0:03:50 & $3,83 \%$ & $0: 19: 52$ & $25,66 \%$ \\
\hline Architektur & 0:02:46 & $1,96 \%$ & 0:00:00 & $0,00 \%$ & $0: 13: 52$ & $13,86 \%$ & 0:00:00 & $0,00 \%$ \\
\hline $\begin{array}{l}\text { Film „,Klas- } \\
\text { siker“ }\end{array}$ & 0:00:00 & $0,00 \%$ & 0:01:13 & $1,65 \%$ & 0:00:00 & $0,00 \%$ & 0:00:00 & $0,00 \%$ \\
\hline Film aktuell & $0: 28: 13$ & $19,97 \%$ & $0: 28: 22$ & $38,52 \%$ & $0: 27: 15$ & $27,24 \%$ & 0:21:01 & $27,14 \%$ \\
\hline Popmusik & $0: 16: 24$ & $11,61 \%$ & $0: 11: 02$ & $14,98 \%$ & $0: 17: 23$ & $17,37 \%$ & 0:04:35 & $5,91 \%$ \\
\hline Werbung & 0:00:00 & $0,00 \%$ & 0:00:00 & $0,00 \%$ & 0:00:00 & $0,00 \%$ & 0:00:00 & $0,00 \%$ \\
\hline Webkultur & 0:00:00 & $0,00 \%$ & 0:00:00 & $0,00 \%$ & 0:00:00 & $0,00 \%$ & $0: 10: 03$ & $12,98 \%$ \\
\hline Sonstiges & $0: 19: 51$ & $14,06 \%$ & 0:02:04 & $2,81 \%$ & $0: 01: 36$ & $1,60 \%$ & $0: 13: 16$ & $17,13 \%$ \\
\hline Gesamt & $2: 21: 14$ & $100,00 \%$ & 1:13:38 & $100,00 \%$ & 1:40:04 & $100,00 \%$ & $1: 17: 26$ & $100,00 \%$ \\
\hline Hochkultur & $1: 08: 25$ & $48,44 \%$ & $0: 29: 37$ & $40,21 \%$ & $0: 48: 15$ & $48,21 \%$ & $0: 27: 09$ & $35,07 \%$ \\
\hline
\end{tabular}




\begin{tabular}{l|r|r|r|r|r|r|r|r} 
& \multicolumn{2}{|c|}{ ORF 2 } & \multicolumn{2}{c|}{ ZDF } & \multicolumn{2}{c|}{ BR } & \multicolumn{2}{c}{ MDR } \\
\hline \multicolumn{1}{c|}{ Thema } & $\begin{array}{c}\text { Umfang } \\
\text { (hh:mm:ss) }\end{array}$ & Anteil & $\begin{array}{c}\text { Umfang } \\
\text { (hh:mm:ss) }\end{array}$ & Anteil & $\begin{array}{c}\text { Umfang } \\
\text { (hh:mm:ss) }\end{array}$ & Anteil & $\begin{array}{c}\text { Umfang } \\
\text { (hh:mm:ss) }\end{array}$ & Anteil \\
\hline $\begin{array}{l}\text { Sonstige } \\
\text { Kultur }\end{array}$ & $1: 12: 49$ & $51,56 \%$ & $0: 44: 01$ & $59,79 \%$ & $0: 51: 49$ & $51,79 \%$ & $0: 50: 17$ & $64,93 \%$ \\
\hline $\begin{array}{l}\text { Klassische } \\
\text { Musik }\end{array}$ & $0: 01: 39$ & $1,17 \%$ & $0: 04: 16$ & $5,79 \%$ & $0: 00: 00$ & $0,00 \%$ & $0: 05: 47$ & $7,47 \%$
\end{tabular}

Tabelle 22: Historische Themen in der Magazinberichterstattung, Umfang und Anteile

\begin{tabular}{|c|c|c|c|c|c|c|c|c|}
\hline \multirow[b]{2}{*}{ Thema } & \multicolumn{2}{|c|}{ ORF 2} & \multicolumn{2}{|c|}{ ZDF } & \multicolumn{2}{|c|}{ BR } & \multicolumn{2}{|c|}{ MDR } \\
\hline & $\begin{array}{l}\text { Umfang } \\
\text { (hh:mm:ss) }\end{array}$ & Anteil & $\begin{array}{l}\text { Umfang } \\
\text { (hh:mm:s } \\
\text { s) }\end{array}$ & Anteil & $\begin{array}{l}\text { Umfang } \\
\text { (hh:mm:ss) }\end{array}$ & Anteil & $\begin{array}{l}\text { Umfang } \\
\text { (hh:mm:ss) }\end{array}$ & Anteil \\
\hline Prähistorisch & 0:04:34 & $10,12 \%$ & 0:00:00 & $0,00 \%$ & $0: 13: 52$ & $43,49 \%$ & 0:08:12 & $5,19 \%$ \\
\hline Antike & 0:00:00 & $0,00 \%$ & 0:00:00 & $0,00 \%$ & $0: 02: 32$ & $7,95 \%$ & $0: 01: 19$ & $0,83 \%$ \\
\hline Mittelalter & 0:00:00 & $0,00 \%$ & 0:01:08 & $1,75 \%$ & 0:03:06 & $9,72 \%$ & $0: 03: 19$ & $2,10 \%$ \\
\hline $\begin{array}{l}\text { Refomrati- } \\
\text { onszeit }\end{array}$ & 0:00:00 & $0,00 \%$ & $0: 01: 34$ & $2,43 \%$ & 0:00:00 & $0,00 \%$ & 0:08:06 & $5,13 \%$ \\
\hline $\begin{array}{l}\text { 17. Jahr- } \\
\text { hundert }\end{array}$ & $0: 03: 21$ & $7,42 \%$ & 0:00:00 & $0,00 \%$ & 0:00:00 & $0,00 \%$ & $0: 06: 10$ & $3,90 \%$ \\
\hline $\begin{array}{l}\text { 18. Jahr- } \\
\text { hundert }\end{array}$ & 0:00:00 & $0,00 \%$ & 0:00:00 & $0,00 \%$ & 0:03:11 & $9,98 \%$ & $0: 12: 12$ & $7,72 \%$ \\
\hline $\begin{array}{l}\text { 19. Jahr- } \\
\text { hundert }\end{array}$ & 0:00:00 & $0,00 \%$ & 0:02:01 & $3,12 \%$ & 0:00:00 & $0,00 \%$ & $0: 21: 03$ & $13,32 \%$ \\
\hline Vormärz & 0:00:00 & $0,00 \%$ & 0:00:00 & $0,00 \%$ & 0:00:00 & $0,00 \%$ & 0:00:00 & $0,00 \%$ \\
\hline $\begin{array}{l}\text { Deutsches } \\
\text { Kaiserreich }\end{array}$ & 0:00:00 & $0,00 \%$ & 0:00:00 & $0,00 \%$ & 0:00:00 & $0,00 \%$ & 0:00:00 & $0,00 \%$ \\
\hline $\begin{array}{l}\text { Königreich } \\
\text { Bayern }\end{array}$ & 0:00:00 & $0,00 \%$ & 0:00:00 & $0,00 \%$ & 0:00:00 & $0,00 \%$ & 0:00:00 & $0,00 \%$ \\
\hline $\begin{array}{l}\text { k.u.k.- } \\
\text { Monarchie }\end{array}$ & $0: 12: 11$ & $26,99 \%$ & 0:00:00 & $0,00 \%$ & 0:00:00 & $0,00 \%$ & 0:00:00 & $0,00 \%$ \\
\hline $\begin{array}{l}\text { 20. Jahr- } \\
\text { hundert }\end{array}$ & $0: 18: 32$ & $41,06 \%$ & $0: 12: 28$ & $19,30 \%$ & $0: 05: 25$ & $16,99 \%$ & 0:03:39 & $2,31 \%$ \\
\hline 1. WK & $0: 04: 11$ & $9,27 \%$ & 0:00:00 & $0,00 \%$ & 0:00:00 & $0,00 \%$ & 0:00:00 & $0,00 \%$ \\
\hline $\begin{array}{l}\text { Weimarer } \\
\text { Republik (D) }\end{array}$ & 0:00:00 & $0,00 \%$ & 0:03:24 & $5,26 \%$ & 0:00:00 & $0,00 \%$ & 0:00:00 & $0,00 \%$ \\
\hline $\begin{array}{l}\text { Ständestaat } \\
(\ddot{O})\end{array}$ & 0:00:00 & $0,00 \%$ & 0:00:00 & $0,00 \%$ & 0:00:00 & $0,00 \%$ & 0:00:00 & $0,00 \%$ \\
\hline Drittes Reich & 0:00:00 & $0,00 \%$ & $0: 32: 24$ & $50,17 \%$ & 0:00:00 & $0,00 \%$ & $0: 50: 24$ & $31,89 \%$ \\
\hline 2. WK & 0:00:00 & $0,00 \%$ & 0:00:00 & $0,00 \%$ & 0:00:00 & $0,00 \%$ & $0: 02: 42$ & $1,71 \%$ \\
\hline $\begin{array}{l}\text { Nachkriegs- } \\
\text { zeit (unmitt.) }\end{array}$ & $0: 02: 19$ & $5,13 \%$ & $0: 10: 25$ & $16,13 \%$ & $0: 01: 18$ & $4,08 \%$ & 0:00:00 & $0,00 \%$ \\
\hline $\begin{array}{l}\text { Adenauer- } \\
\text { Ära, Wirt- } \\
\text { schaftswunder }\end{array}$ & 0:00:00 & $0,00 \%$ & 0:00:00 & $0,00 \%$ & $0: 01: 48$ & $5,65 \%$ & 0:01:29 & $0,94 \%$ \\
\hline $1968 \mathrm{er}$ & 0:00:00 & $0,00 \%$ & 0:00:00 & $0,00 \%$ & $0: 00: 00$ & $0,00 \%$ & 0:00:00 & $0,00 \%$ \\
\hline Brandt-Ära & 0:00:00 & $0,00 \%$ & 0:00:00 & $0,00 \%$ & $0: 00: 41$ & $2,14 \%$ & $0: 01: 36$ & $1,01 \%$ \\
\hline $\begin{array}{l}\text { Deutscher } \\
\text { Herbst }\end{array}$ & 0:00:00 & $0,00 \%$ & 0:00:00 & $0,00 \%$ & 0:00:00 & $0,00 \%$ & 0:00:00 & $0,00 \%$ \\
\hline $\begin{array}{l}\text { Helmut- } \\
\text { Schmidt-Ära }\end{array}$ & 0:00:00 & $0,00 \%$ & 0:00:00 & $0,00 \%$ & 0:00:00 & $0,00 \%$ & 0:00:00 & $0,00 \%$ \\
\hline Helmut Kohl & 0:00:00 & $0,00 \%$ & 0:00:00 & $0,00 \%$ & 0:00:00 & $0,00 \%$ & 0:00:00 & $0,00 \%$ \\
\hline $\begin{array}{l}\text { Deutsche } \\
\text { Einheit }\end{array}$ & 0:00:00 & $0,00 \%$ & 0:00:00 & $0,00 \%$ & 0:00:00 & $0,00 \%$ & 0:00:00 & $0,00 \%$ \\
\hline DDR & 0:00:00 & $0,00 \%$ & 0:00:00 & $0,00 \%$ & $0: 00: 00$ & $0,00 \%$ & 0:00:00 & $0,00 \%$ \\
\hline Ulbricht & 0:00:00 & $0,00 \%$ & 0:00:00 & $0,00 \%$ & 0:00:00 & $0,00 \%$ & 0:00:00 & $0,00 \%$ \\
\hline Honecker & 0:00:00 & $0,00 \%$ & 0:00:00 & $0,00 \%$ & 0:00:00 & $0,00 \%$ & 0:00:00 & $0,00 \%$ \\
\hline Wende & 0:00:00 & $0,00 \%$ & 0:00:00 & $0,00 \%$ & 0:00:00 & $0,00 \%$ & 0:00:00 & $0,00 \%$ \\
\hline $\begin{array}{l}\text { Sonstige } \\
\text { historische } \\
\text { Themen }\end{array}$ & 0:00:00 & $0,00 \%$ & 0:01:11 & $1,83 \%$ & 0:00:00 & $0,00 \%$ & $0: 37: 51$ & $23,95 \%$ \\
\hline Gesamt & $0: 45: 08$ & $100,00 \%$ & 1:04:35 & $100,00 \%$ & $0: 31: 53$ & $100,00 \%$ & $2: 38: 02$ & $100,00 \%$ \\
\hline
\end{tabular}


Tabelle 23: Dialektausprägung bei nicht organisierten Privatpersonen

\begin{tabular}{|c|c|c|c|c|c|c|c|c|}
\hline & \multicolumn{2}{|c|}{ ORF 2} & \multicolumn{2}{|c|}{ ZDF } & \multicolumn{2}{|c|}{ BR } & \multicolumn{2}{|c|}{ MDR } \\
\hline & Anzahl & Anteil & Anzahl & Anteil & Anzahl & Anteil & Anzahl & Anteil \\
\hline Hochdeutsch & 17 & $10,20 \%$ & 148 & $32,80 \%$ & 63 & $24,90 \%$ & 69 & $20,80 \%$ \\
\hline $\begin{array}{l}\text { Leichte dialektische } \\
\text { Einfärbung }\end{array}$ & 81 & $48,50 \%$ & 159 & $35,30 \%$ & 124 & $49,00 \%$ & 93 & $28,00 \%$ \\
\hline Starker Dialekt & 30 & $18,00 \%$ & 33 & $7,30 \%$ & 47 & $18,60 \%$ & 131 & $39,50 \%$ \\
\hline $\begin{array}{l}\text { Sehr stark/ } \\
\text { Regionalsprache }\end{array}$ & 5 & $3,00 \%$ & 0 & $0,00 \%$ & 4 & $1,60 \%$ & 1 & $0,30 \%$ \\
\hline $\begin{array}{l}\text { Trifft nicht zu - } \\
\text { fremdsprachig/ } \\
\text { Gebärdensprache/ } \\
\text { sonst. }\end{array}$ & 34 & $20,40 \%$ & 111 & $24,60 \%$ & 15 & $5,90 \%$ & 38 & $11,40 \%$ \\
\hline Gesamt & 167 & $100,00 \%$ & 451 & $100,00 \%$ & 253 & $100,00 \%$ & 332 & $100,00 \%$ \\
\hline
\end{tabular}

